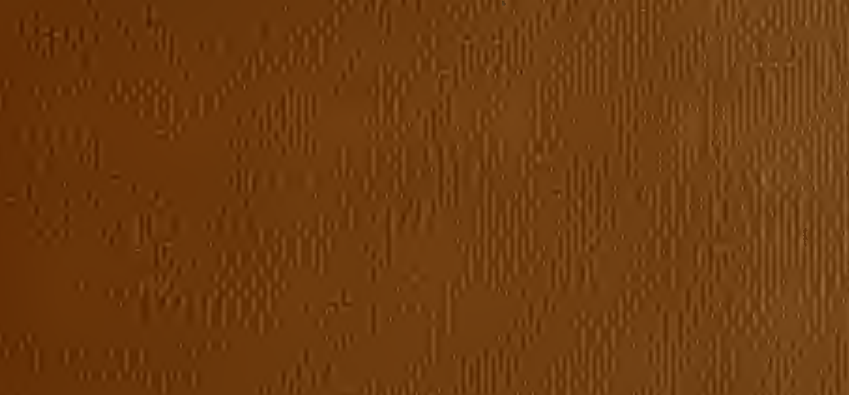


AtEx. Atentix.

丝ibraty of the itlusem

$\mathrm{OF}$

\section{COMPARATIVE ZOÖLOGY,}

AT HARTARA COLLBGE, CAJIBRIDGR, IISS.

Jounved by private substription, in 1st;1.

Doposited by ALEX. AGASSIZ.

Aprel 24, 1903 




\section{UNTERSTCHUNGEN}

äber das

\section{SEHORGAN DER ARTHROPODEN,}

insbesondere der

SPINNEN, INSECTEN UND CRUSTACEEN.

Ton

Dr. II. Grenacher,

Professor der Zuologie unl vergleitismilen Anatomie an der Universitait zu Rostock.

Heransgegeben mit Unterstützng der Böniglich Prenssischen Academie der Wissenschaften in Berlin.

Mit 11 lithographirten, zum Theil colorirten Tafeln.

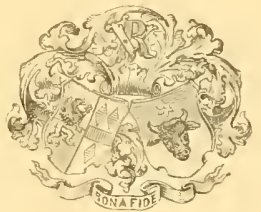

Göttingen.

Verlag von Vandenhoeck \& Ruprecht. 1879. 
$\hat{n}$ 


\section{HERRN}

\section{CARL THEODOR ERNST VON SIEBOLD,}

PROFESSOR IN MÜNCHEN.

VOLL VEREHRUNG ZUGEEIGNET

VOM VERFASSER. 



\section{Vorwort.}

Hiermit übergebe ich eine Reihe ron Untersuchmgen über das Arthroporlenange, deren Beginn bis in das Jahr 1874 zurückreicht, der Deffentlichkeit, und hoffe, damit einen nicht ganz werthlosen Beitrag zur Kemntniss dieses so eigenartig rielgestaltigen Organs sowohl hinsichtlich seines Baues, als anch einiger Seiten seiner Wirkungsweise geliefert zu haben. Schon zweimal habe ich äber die meines Erachtens wichtigsten Resultate Bericht erstattet. Zuerst erschien eine nur ganz kurze Notiz in den "Göttinger Nachrichten" rom Jalue 1874 (Nr. 26); damn ein etwas ansführlicherer, nit einigen Mbbildmogen ausgestatteter Aufsatz als Beilageheft für den Monat Nai zu dem fünfehnten Jahrgang der ,Klinischen Monatsblätter für Augenheilkunde" (1877).

Die Veranlassung, mich auf dies Gebiet zu begeben, lag in dem Umstande, dass mir schon bei einer frühern Gelegenheit, bei der Entwickelnngsgeschichte des Cephalopodenanges (Ztschft. f. wiss. Zool. Vol. XXIT. 1874) Gerlanken ïlser die Möglichkeit eines imnigeren morphologischen Zusammenhanges der Retinaelenente der rerschiedenen grösseren Thierabtheilungen anfgetancht waren, die gerade an den bisher darin so spröden Arthopodenangen zu priffen in mehr als einer Beziehnng Reiz hatte. Wie die Fragestellung etwa lantete, und wie die Antwort der Frwartung entsprechend ausfiel, mag aus dem letzten Abschnitt ersehen werden; wie aber der ursprünglich kaum in's Auge gefasste Nebengewim, nämlich eine nene Basis für die morphologische Vergleichung zwischen Stemma und Facettenauge, sowie eine hoffentlich stichhaltige Beantwortmng der noch immer offenen Frage ïber den Sehrorgang in letzteren, den Ausgangspunkt mehr in den Hintergrund treten liess, daron zeugt die ganze Disposition der Arbeit.

Eine Monographie des Arthropodenanges will das Buch nicht sein; für diesen anspruchsvollen Titel sind die Lücken zu gross. Abgesehen davon, dass die Angen der Myriapoden 
wegen Mangels an geeignetem Material sowohl, als anch wegen der nur nühsam zn bewältigenden technischen Schwierigkeiten, ferner die der Schmetterlingsraupen und anderer Larvenformen vorlïnfig ansser Betracht gelassen sind, bleiben anch sonst noch recht fühlbare Lücken, die andere, unter günstigeren famistischen Bedingungen lebende Forscher im Laufe der Zeit vielleicht ausfïllen werlen. - Auch die msprünglich beabsichtigte Entwickelungsgeschichte des Anges musste noch zurückgestellt werden, um die Horrschaft über das Material nicht zu verlieren, und wenigstens vorlïufig zn einem Abschlnss zn kommen. Reichlich bemessenes persönliches Missgeschick mancher Art, das mir die letzten Jahre trübte, hat ohnehin wegen der dadurch verursachten oft längeren Unterbrechungen der Arbeit rlie Veröffentlichung der vorliegenden Studien über Gebülr rerzögert, und überdies der formalen Darstellung stellenweise Spuren aufgeprägt, die völlig zu beseitigen ich leider nicht meln im Stande war.

OJjwoll ich durch die Terhältnisse mich ansser Stand gesetzt sah, die frühere Literatur vollständig und läckenlos zu berücksichtigen, glaube ich mich doch dem Torwurf, Wichtiges und Wesentliches übersehen zu haben, nicht ausgesetzt. Auf einige neuere, erst nach Abschluss des Manuscriptes oder währenr des Druckes nir zu Gesicht gekommene Arbeiten darf ich wohl lier mit cin paar Worten eingehen. Der Controverse mit O. Schmidt über die bedingte oder umbedingte Geltung der Mäller'schen Theorie habe ich, da ich den betreffenden Abschnitt meines Buches unverändert zu lassen meine Gründe hatte, in einem Nachtrag (pag. 168) Rechnumg getragen, kann sie also hier übergelıen. - Die Arbeit von Chatin: "Recherches pour servir a l'histoire du bâtonnet optique chez les crustacés et les vers" (Ann. sc. nat. VI. Sér. Zool. Vol. V. 1877, Vol. VII. 1878) ist, soweit sie die Crustaceenaugen angeht, denen die zweite Hälfte gewidmet ist, in der ganzen principiellen Anffassung ron der meinigen so diametral verschieden, dass ich hiex keine Kritik daran üben will. - Zn nemnen habe ich noch die Arbeit von Berger: "Entersuchungen über den Bau des Gehims und der Retina der Arthropoden" (Arb. Zool. Inst. Wien. heransgegeben von Clans, Bd. I, Heft 2), der die Simme der Retimulae des Facettenanges als eime von den fünf Schichten seiner "Retina auffasst, von denen aber meiner Ansicht nach vier zum Ganglion opticum gelören; eudlich A. Forel's "Beitrag zur Kemntniss der Simnesempfindungen der Insecten" (Mittheil. d. Mïnchener Entomol. Vereins f. 1878), eine von einem sehr kemntnissreichen Entomologen ansgehende, auf eigene Versuche und Beobachtungen basirte Zustimmung zu der von mir vertretenen Theorie vom musivischen Sehen, die ich mit besonderer Genugthumng begrüsse.

Die in die Darstellung aufgenommenen Beobachtungen über die Angen einiger Copepoden verdanken ilure Entstehmng einem Aufenthalte in der Zoologischen Station zu Neapel, der sich anch durch die daselbst so reichlich gebotene Gelegenheit. Sehorgane einer Reihe anderer Thier- 
formen genaner kennen zu lernen, für den dem letzten Abschnitt dieser Arbeit zu Grunde gelegten Gedlankengang als fruchtbringend erwiesen hat.

Die Abbildungen der Tafeln sind sämmtlich ron mir nach der Natur gezeichnet, die Melnzahl derselben unter Zuhülfenahme der Camera lncida. Da die Wiedergabe mit dem Pinsel an-geführter Tuschezeichnungen durch Gravirung und Tondruck an gewisse Schranken gebunden, nurl Manches deshall, nur annähermugsweise zu erreichen ist, so bin ich nm so mehr rerpflichtet, dem Kïnstler, der sich dieser schwierigen Anfgabe mit solcher Sorgfalt und solchem Erfolge miterzog, wie es Herr Funke gethan hat. meine volle Anerkennmg öffentlich auszusprechen.

Hinsichtlich der änssern Eintheilung der Arbeit habe ich blos zu bemerken, dass die dem Ganzen rolansgeschickte historisch-kritische Cebersicht keineswegs blos die Aufgabe hat, das successive Anwachsen unverer Kenntnisse und die Wandelungen der Torstellungen rom Arthropodenange vorzuführen. sondern in noch höherm Grade bezweckt, einige für die spätere Beantwortung funclamentale Begriffe an der Hand der frühern Lösungssersuche festzustellen. Dazu gab namentlich die Besprechung ron J. Mïller's Behandlung der Frage Teranlassung, und man wird gut thun, dieses Umstandes bei der Lectüre des 2. Abschnittes des 2. Theils eingedenk zu bleiben. - Die Angabe der den Abbihkungen zu Grunde liegenden Vergrösserungen, sowie die Messmngen sind, un den Text nicht zn unterbrechen, in die Figurenerkłärmng verwiesen.

Endlich bleibt wir noch übrigg, dankbar der Unterstützung und Hülfe zu gedenken, der ich mich theils bei meinen Untersuchungen, theils bei der Drucklegung neines Buches zu erfreuen hatte.

In erster Limie sei es nir gestattet, meinen ehrfurchtsvollsten Dank auszusprechen dem erhabenen Kanzler unserer Landesuniversitït. Sr. Kgl. Hoheit den Grossherzog Friedrich Franz ron Mecklenburg-Schwerin, Dessen fürstliche Nunificenz mir den Aufenthalt in Neapel. so fruchtbar an wiscenschaftlichen Erfaln'mgen, so reich an Anregmig aller Art, allein ermöglicht lat.

Dass die Früchte meiner langen und mühsamen Arbeit nicht nur als selbständiges Werk, sondem anch in riner Ausstattming erscheinen komnten, die den Vergleich mit analogen Trerken in keiner Weise zn schenen brancht, dafür bringe ich meinen ehrerbietigsten Dank dar der Akademie der Wissenschaften zu Berlin, die mit rühnenswerthester Liberalität eine namhafte Sumne zur Bestreitung eines Theiles der nicht geringen Herstellungskosten bewilligt hat. Möge das Buch dieser Unterstützung sich würdig erweisen! 
Ebensowenig darf ich die vielfache Förderung merwähnt lassen, welche mir in der Zoologischen Station zu Neapel sowohl von Seiten des durch die Gründung derselben um die Wissenschaft so hochverdienten Herrn Dr. A. Dohrn, als anch seiner Assistenten, besonders des Herm Dr. H. Eisig, zu Theil geworten ist.

Schliesslich ist es mir noch eine angenehme Pflicht. anch der Verlagshandlung für die Opferbereitwilligkeit, die zu bethätigen sie trotz der von der Berliner Akademie gewährten Subrention noch Gelegenheit genug fand, hier meine danklare Anerkennumg anszusprechen.

Rostock, Ende November 1878.

H. Grenacher. 


\title{
Historisch-kritische Tebersicht
}

\author{
seit Joh. Miiller's:
}

\section{„Zur vergleichenden Physiologie des Gesichtssinnes.“}

„Non quis, serl quid!"

Ich begime meine I'ebersicht der Leistungen anf mserm Gebiete mit Jols. Müller's berühmten Buche: "Zur vergleichenden Physiologie des Gesichtssinnes 1), "als dessen "Glanzpunkt" Inan namentlich in nenerer Zeit den das Sehen der Spimen, Insecten unr Krebse behandehrlen Abschnitt zu bezeichmen sich gewöhnt hat. Weiter in der Zeit zuriickzngreifen, finde ich für meinen Zweck keine Veraulassung; jenes Buch bezeichnet den Beginn einer neuen Periorle, und erst in dieser erheben sich die Fragen, nit deren Lösmg sich die vorliegenden Intersuchungen zu befassen haben.

Der Schwerpunkt der ausführlichen Darstellung doh. M̈̈ller's in dem genamnten Werke (pag. 305-390) beruht nicht sowohl in seinen eigenen ansgedehnten anatomischen Untersnchungen ïber den Bau namentlich des zusammengesetzten Auges — so weit sie auch die seiner Torgänger überragen -, als viehmelı auf semer vieldiscutirten und, wie mir scheint, nicht immer in ihrer ganzen Tragweite erfassten, selbst oft missverstandenen "Theorie des nu si vischen Sehens" rermittelst jenes Organes. So ansführlich diese behandelt ist, so kurz ist anf der andern Seite die Beziehung des einfachen zun zusanmengesetzten Luge in morphologischen Sinne erörtert, was im Tergleich zn dem Unfang der unständlich bespochenen Relationen der Angen nach allen Seiten lin und zn allen Organen jetzt etwas frappiren kann. Die Stelle (1. c. pag. 388) lautet in characteristischer Kïrze folgendermassen: „Der Uebergang der einfachen Augen in zusammengesetzte ist in den zu einem scheinbar zusammengesetzten Ange gehäuften einzehnen körnigen Angen der Assehn und Polyporlen nicht zn verkemen." Das Wahre und Richtige dieser Ansicht zugestanden, so fehlt es doch nicht an Schwierigkeiten, die sich aus der Mïller'schen $\Lambda_{n-}$ schammgsweise bei weiterer Verfolgmng dieser Vergleichnng in ihren Consequenzen nothwendig rrgeben müssen. Wir wollen hier der Entwickelnng folgen, wie sie ms M ̈̈ller selbst gegeben hat.

Der erste Abschnitt handelt: "Von den beiden in der Natur möglichen Arten des Sehorgans."

Wenn die Sonderung des von verschiedeneu Theilen des zu sehenden Objectes ausgehenden Lichtes auf den zor Lichtempfiudung bestimmten Theilen als Grundbedingnng für das deutliche

1) Leipzig, 1826 .

Grenacher, Untersuchungen äber das Sehorgan der Arthropoden. 
Sehen festgehalten werden muss, so giebt es, wie Miiller in musterhaft klarer Weise ansfïlnt, theoretisch zwei Möghichkeiten, dieser Bedingung zu entsprechen. Die erste derselben, von selır grosser Verlreitung in der Reihe der Thiere. erreicht diesen Effect durch Einschaltung sphärisch gekrümmter, linsenartig wirkender Nedien vor der conearen Retina, auf welcher durch jene die von den Punkten a, b, c, d . . des Objectes ansgehenden Lichtstrahlen durch Brechung in . . . d, c, b, a gesammelt mul ron den entsprechend vertheiten Endorganen percipirt werden. - Die andre Möglichkeit, von M ̈̈ller (l. c. pag. 313) aprioristisch erfasst, bedarf zu rer Sonderung der discreten Lichtstrahlen keiner sammelnden Medien. „Es ist begreiflich, dass ant einer Fläche anch ein Bild entstehen künne, indem dasjenige Licht. welches senkrecht anf die empfindende Fläche einfällt, an dieser Stelle nn allein zugelassen wird, alles andere Licht aber, welches von demselben Punkte ansgeht und unter andern Winkeln in näheren mol fermeren Kíreisen anf die empfindende Fläche fallen kann, intercipirt wird. Wenn nun auf dieser Netzhant von jedem Punkte des Objectes nur das senkrecht einfallende Licht sich darstellt, wie dies immer bewirkt werden mag. so muss das Bikl des Gegenstandes zwar undentlich. aber doch in den natïrlichen Verhältnissen der Rämmlichkeit verwirklicht werden. Anch wird eingesehen, dass eine solehe Netzhant nicht in gerarler Ebene ausgebreitet sein dürfe, als welche nämlich nm von den wenigsten und kleinsten Gegenstänrlen senkrechte Lichtstrahlen aufnehnen könnte; dass die empfindende Fläche eimes Sehorgans dieser zweiten Art nothwendig kugelig sein müsse, so dass die Radien des Kngel auch denjenigen Theilen der änsseren Gegenstände entsprechen. welche in der Richtmng jener Radien liegen“ (I. c. pag. 311). „Es kïme nm anf ein Organ an, welches, vor der kngeligen Netzhaut gelegen, diese Sonderung [der Lichtstrahlen] genan luewirken könnte" (l. e. pag. 312).

Die M̈̈glichkeit, dass in der lier wörtlich nach Mï ll e r angefiilurten Weise ein dentlich sehendes Ange sollte existiren können, lässt sich wohl nicht anzweifeh und ist meines Wissens auch nie angezweifelt worlen; wie richtig seine allgemeine Anffassmng des Sehrorganges war, ist noch in msern Tagen, nachdem das Tertrauen auf das Torkommen eines solchen Sehorganes in der Natur schon bedentend untergraben war, noch liervorgehoben worden durch Antoritäten auf diesem Gebiete, wie Helmholtzid) und Dn Bois-Reymon $\mathrm{L}^{2}$ ).

Anders aber gestaltet sich die Frage bei einer Prüfung nach der wirklichen Realisirung eines nach diesem Principe construirten Auges. Die erste Art des Anges, nit lichtbrechenten Sammellinsen, erkannte Mïller in den sogen. pinfachen Augen der Spinnen. Scorpionen mat Insecten, bei welchen die einzelnen Bestandtheile, ihrer Function entsprechend, eine wesentlich analoge Form mol Anordnung anfweisen, wie es ron den Angen der Virbelthiere, Ceplaloporlen ete. schon längst bekannt war; die andere aber — und rlarin liegt der Schwerpmkt der anatomischen. Untersuchungen II ïller's - wollto er verwirklicht finden in den zusammengevetzten Augen der Insecten nnd Krebse. Wir mïssen hier auf $M$ üller's Kemntuisse rom Ban dieser Organe etwas näher eingehen.

Das stark kngelig vorspringende, meist in anserordentlich zahlreiche. gewölbte Facetten getleilte, zusammengesetzte Ange ent-juch. was scinen imnern lian anbelangt, in zwei Punken

1) Helmholtz, Physiologische Optik, pag. 3.

2) D n Fo is - R e y mond, Gedächtnissrede auf Joh. Müller (Abłullgn. d. Berl. Acal.), 1860, pag. 41 res Sieparat-Abur. (n- Freilich sind in neuerer Zeit, namentlich auf Grund der Beobachtungen ron Gottsche, Zweifel an der Riehtigkeit der Lehre vom musivischen Sehen erholen worden. Immer würde es eine sehr feine Leistung bleiben, die das tiefste Eindringen in die Bedingungen des Sinnes verräth, eine Art angegeben zn haben, wie die bildende Natur, wenn es ihr anders beliebt hätte, auch wohl noch hätte ein deutlich sehendes Ange schaflen können. - -) 
röllig den Anforterungen. die man an dasselbe stelten muste, um in ilun eine Realisirung jener zweiten theoretisch als möglich erkannten Angenform zu selıen; und für einen dritten wesentlichen Punkt rerstand es Müller, die Wahrseheinhehkeit so gross zu machen, dass es eines vollen Vierteljahrhunderts bedurte, lis durh einseitige Betonmo einer Beobachtung, dif mur durch diese Einseitigkeit eine liedeutung rhalten konnte, es gelang, das bisher allgemeine Vertranen anf den Scharfhlick Miiller's zu erschütterm.

Einer zucrst zu stellenden Anforderung für jene Theorie genügte das zusammengesetzte Ange durch die leicht zu verificirende Krngelgestalt der Retina. die ronrex gegen die facettirte ('ornea so rortritt, dass ihre imere begrenzung der letzteren ungetïlr parallel bleibt. Ebenso war es nicht schwierig zu erkemen, dass die percipirenden Einheiten der Retina, die pigmentirten Endigungen des Sehueren, vou Eintritt deselben in das Ange an radiär anseinanderstrahlen, Inn je eine sich einer Facette zn nähern. Dass man diese pignentirten lasern als einfache, weiter nicht differenzirte Nervenfasern auffasste, und ohne besondere buligmng als ohne Weiteres zur Lidhtperception für qualificirt hielt, lag im danaligen Zustande der hiologischen l)isciplinen mod ihrer technischen 1liilfsunittel. - Nan bleiht noch der dritte Factor. "das Organ, das, ror der Netzhant gelegen. dis Sonderung des Lichtes genan hewirken kïmnte" - und diecen erkannte Nïller in den durhsichtigen, zwischen Cornea und Sehnervenchdigmg gelegenen, von einer Pigmentscheide an ihrer Mantelflïche muluillten, nmnerisch den Corneafacotten entsprechenden lirystallkegeln ${ }^{1}$ ).

Olne uns lice auf eine Geschichte dieser so vielfach besprochenen, so mannigfaltig gedeuteten sonderharen Organe einlassen zu können. mag es genügen, darauf hinzuweisen. dass Müller der Erste war, der auf das allgemoine Torkommen derselben im zusammengesetzten Auge hinwies (1. c. pag. 345 11. 362 ); freilich musste er einige dahre später, nach ementen Untersnchungen ${ }^{2}$ ), diese Allgemeinheit des Torkonmens wieder etwas einschünken, ohne doch im Wesentlichen seine Ansichten üher ilne berlentung für das Sehen zn ändern.

Diese Bedeutung fasst I ̈̈ller in folgenden Sïtzen zusammen: . Wem einer bestimmten Stelle der Netzlıant anch nur Licht rom einer bestimmten Stelle des Oljectes zukommen kann, allen andern Theilen der Netzhant dieses hesondere Licht ansgeschlossen wird, so ist dadurch ein Bild gegeben. Dies geschieht in den zusanmengesctzten Augen der lnserten und Kirebse durch die zwischen den Fasem des Sehnerven und den Facetten der Hornhant gelegenen, mit beiden ducls ihre Extremititen verbundenen, an ihren seitlichen Wänden mit Pigment bekleideten, durchschtigen Kegel. Jeder dieser mm eine convexe Nervemmasse peripherisch gestellten Kegel lässt nur dasjenige Licht zu der Taser des Sehnerven, nit welcher er an seiner Spitze verbunden ist. was umnittelbar durch die Achse des Kegels einfiilt. Alles andrue von demselben Punkte ausgehende, anf die Hornhant selief auffallende Licht wird nicht die untere Extremitiit des Kegels erreichen und deshalb nicht zu Perception von andern Fasem des Sehnerven kommen; es wird, schief einfallend, von den mit Pigment bekleideten Wänden der nur in der Axe durchsichtigen liegel absorbirt werden" (1. c. pag. 363,364 ).

Die einzehen, fast iiberall melır orler weniger convexen Facetten der Cornea werden natürlich, ihrer Krömmung und Lichtlprechungsfähigkeit gemïiss, anf die durchtretenden Lichtstrahlen ihren entsprechenden Finfluss ansïben. Auch $M$ üller erwog den Gedanken, oh sie, mo wit ihnen die Kegel. nicht dazu bestimnt sein künnten, ein dioptrisches Bild behufs der

1) oder ,durchsichtigen Kegeln des Glaskörpers.", wie M üller sie nennt.

2) Meckel's Archir, 1829, pag. 53 u. anlere Stellen. 
Perception zn entwerfen, aber nur, um ihn entschieden von der Hand zu weisen. Er sagt: „Die Convexitiit der einzelnen Facctten der Cornea wird das in der Richtung der Achse einfallende Licht als brechendes Medimu ler Achse selbst zulenken und in der Tiefe des Auges zu grösserer Einigung bringen. So mag es kommen, dass das den ganzen Kegel durchlenchtende Licht in der Spitze desselben, wo es die Sehfaser afficirt, punktförmig rereinigt wird, wodnrch die Bestimmtheit des bildes selr gehobeu werden nuss. Die von der änssern convexen Fï̈che der Cornea bedingte Brecling ist aber nicht so gross, dass es zur Entstehmg besonderer kleiner Bilder von jeder Facette aus kommen könnte. Nichts kömnte eine dentliche Gesichtsrorstellung so seln aufleben. als eben dies; den wenn in der Vereinignngsweite der Facetten als linsenlafter Nedien Bilder entständen, so würden alle diese nothwendig eine Uukelıung erleiden. Nicht das ganze Gesichtsfeld würde rerkehrt sein, sondern die relative Lage der Bilder aller einzehnen Facetten gegen einander verkehrt and widernatiirlich. Wie also die Facetten in den zusammengesetzten Angen der Insecten olt genug fast ganz ihre Convexitit verlieren, so ist ihrer vordern convexen Fläche keine andere Wirkung beizmmessen, als das uach den Gesetzen der Beleuchtung divergirend in jeden durchsichtigen Kegel einfallende Licht nach der punktförnigen Extrenität desselben hin zu vereinigen" (l. c. pag. 367).

Fügen wir noch den Satz hinzu: „Die Insecten sehen weder nach dioptrischen, noch nach katoptrischen Gesetzen, sonderu blos dmch eine nähere Bestinumug der Belenchtung* (1. c. pag. 363), so labeu wir die Stellen, auf welche es wesentlich zur Beurtleilung der Stellung Mäller's in dieser schwierigen Frage ankommt, der Hauptsache nach beisammen, und können uns nun einer näheru Prüfung der gesammten Theorie zuwenden. -

Bei näherer Teberlegung der Frage über den Modus des Sehens vermittelst des zusammengesetzten Auges ergiebt sich leicht, dass dieselbe trotz ihrer im Wesentlichen physiologischen Natur anch schon einer Lösung anf dem Wege einer genanen anatonischen Untersnchung fïhig ist. Ich will nicht so weit gehen zu behaupten, dass die Lösnng nur ansschliesslich auf diesem Wege möglich sei; aber es ist sicher nicht zu viel gesagt, wemn wir die genane hemntuiss des anatomischen Banes der fraglichen Organe als eine unerlïssliche Toranssetznng anch der rein physiologischen Behandlung ansehen. Eine nähere Betrachtung der Bedingungen, wer welchen die sog. Theorie des musivischen Sehens zu Recht bestehen kann, dürfte geeignet sein, jeden Zweifel darüber zи heben.

Schon rorhin wurde der Anforderungen gedacht, die an ein durch Isolation sehendes Auge gestellt werlen müssen. Dass das Hauptgewicht nicht anf die nach anssen convexe Gestalt der percipirenden Schicht zu legen ist, so lange man über die Bedentmg der einzehnen sie zusannensetzenden Elemente nicht jeden Zweifel ansznschliessen in Stande ist, liegt anf der Hand. Dem gesetzt, die einzelnen sogenannten Sehnervenfasern — ich habe, da es für den mmittelbar vorliegenden Zweck noch völlig gleichgültig ist, vorlünfig noch diesen Ansdruck hier beibehalten erwiesen sich bei weiter eindringender Intersuchung doch nicht als so einfach, sonderu als ebeisoviele selbständige Retinae. so würde eine andere Deutung des Seluvorganges von der zufällig convex-kngeligen Anordnung derselben zu einem Gesammtange in keiner Weise bertilht werden. Die Totalfom ist also blus unter gewissen Voransetzmgen, die erst noch zu prüfen sind, Berlingming.

Schon grössere Wichtigkeit, aber auch noch nicht fundauentaler Natur. hat die Function der einzeluen convexen Cornealinsen mit den ihneu dicht anliegenden kirystallkegeln zu beanspruchen. Lässt sich der Nachweis führen, dass durch die ersteren, nnd mbehindert durch die zweiten. mgekehte und verkleinerte Abbilder vor deuselben gelegener Objecte entworfen werden, so ist wenigstens der Gedanke an eine durch Linsenwirkung vermittelte Perception nach Analogie 
der einfachen Arthopoden- und der Wirbelthierangen nicht einfach alowweisen, sondern vardient cine nähere Prïfung. Diese Prüfung wirl aber nothwendig anf den dritten Factor gerichtet seiu ın̈̈ssen, von welchen die beiden ersten bezïglich ilırer Bedentung völlig abhïngrg sind, nämlich auf die Beschaffenleit, besonders aber anf die Anzahi der zn jeder Corneafacettr gelörigen percipirenden Elemente.

Es int klar, dass zn Perception eines wenn anclı nur kleinen Selufeldes, von welchem ans discrete Lichtstrahlen anf das Einzelange fallen, anch wieder discrete Perceptionsorgane nöthig sinct; und die Sehschärfe ist, ceteris paribus, ungefähr proportional der Zahl dieser Elemente, clie sich bei gleichem Sehfeld in die Arbeit der Perception der anzehnen ron letzteren ansgesandten Lichtstrahlen theilen. Ist num an der Stelle, wo die Lichtstrahlen sich zmm lible rereinigen, mu ein einziges solches Organ rorhumlen, so kann ron einer Perception des gauzen Bihles in seinen nach der Natur der Ausgangspmkte vershiedenen Lichtqualitäten, und mag dasselbe anch durch die optische Tollkommenheit der brechenden Merlien noch so rollkommen projieirt werden, ummöglich die Reele sein. Das betreffende Endorgan wird, wenn nur ein Theil des Bildchens auf dasselbe fïllt, nur auf rlenjenigen Lichtreiz entsprechend reagiren, dem es in der gegebenen Zeiteinheit ansgesetzt ist; die andern Theile des Bildchens werten olne jeden Effect auf dasselhe bleiben. Ist aber das Perceptionselement gross oder das Bildchen klein genug, dass das letztere in semer ganzen flächenhaften Anslehmmg anf das erstere fallen kamn, so kam die Erregung nur eine genischte sein, die den Character der an nuisten hervortretenden Lichtrqualität des Bildchens trägt. Das betreffende Endorgan wird eben unter allen Umständen nur einen einzigen Reiz zu len centralen Organen leiten, und bei ausserordentlich grosser Anlı̈ufimg solcher Einzelaugen mit vollkommenem Linsenapparat, aher ruthentärer, nur ans cinem cinzigen Perceptionselement bestehenden Retina, mol unter der Toraussetzung der" ratliären Anordnung derselben in der beschiebenen Wreise wirl der Antheil eines Einzelauges an der Gesamntwahrnehmmg functionell derselle sein, wie bei der Perceptimseinheit des dioptrischen Anges. Damit ist aber eingestanden, dass für diese Fïlle es keine andere Erklärmug anser der 'Theorie vom musivischen Sehen giebt. Nir ist die geringe Betonung der fundamentalen Bedeutung, welche gerade die Einheit der Percrptionsorgan hinter den hirystallkegehn bean-

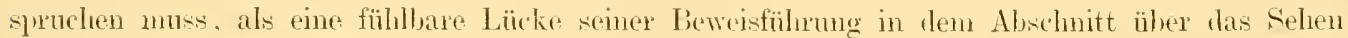
der lnecten ete, den Nïller somst so meisterhaft und rielseitig durehdacht und behandelt. hat, anfgefallen. Hätte er diesen Punkt in semer vollen Bedentung lervorgehoben, so wïrde m" sich rielleicht nicht so schroff abweluend gegen den Gedanken, die Corneafacetten könnten trotz der Krystallkegel Bililer projiciren, ansgesprochen haben. wobei er den optischen Gosetzen zuwider diese Fühigkeit ihnen überhapt nicht zuerkennen wollte. Er scheint ïberhanpt darin eine Gefahır für seine Theorie erblickt zu laben, wie ich dies anch ans dem Eifer erkennen nöchte, mit welchem er anf die Lnverträglichkeit der Unkehrung der Einzelbestandtheile des Gesinmtsehfeldes hinwejst (s. oben). Nun haben die Spinnen 6-8 einfache, unzweifelhaft bildunkehrende dioptrische Sammelangen; gewisse Wasserkafferlarven deren 12; die Augen der () niscoisle en mo Polypoden, die Mïller nur als Agregate ron ebensolchen einfachen Augen ansieht, deren 20-40 jederseits - für diese muss doch dersolbe Einwand seine volle Berechtignng haben, wenn auch die Ziffern lange nicht an die bei len Facetten der Insecten und Krebse gezählten heramreichen. In Princije ist die Schwierigkeit bei diesen letztgenamten Angen der Assehn und Tansendfüsse nicht in den gleichen Maasse geringer für unsere Torstellung, in welchem die Zahl der Compronenten des Auges linter derjenigen bei ïcliten Facettenaugen zmü̈ckbleibt. Tielleicht hätte $M$ üller diese Schwierigkeit für msern Intellect überlaupt nicht 
so sehr betonen dïrten; er wärde wohl anch kam so grossen Nachdrnck daranf gelegt haben, wemn er nicht geglanbt liäte, larbuch seine Theorie vor Einwentungen sicherstellen zn kïnnen. Die anatmuischen Voranssetzungen, die der von ihm vertretenen Lehe von den identischen Netzhantstellen bein Inge des Menschen zn Grunde liegen, sind unserm Terntiunduiss fast ebenso mzngäinglich. wie die in jenem Falle sich aufirä̈ngenden.

Auf das Sehen der (Oniscoidren nud Polypoden kam äbrigens Mäller in einer nun drei lahre jüngeren Arbeit1) zuriock, in welcler er spine eigenen Intersuchmgen über den

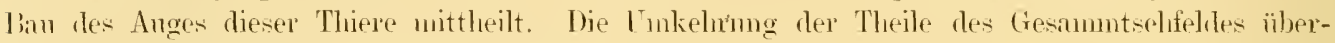
geht er nut Stillschweigen; seine Vorte sind: „Das Sehen dieser Thiere kann numöglich scharf sein nud ïber die nächsten Tngebnngen hinanseichen. Dem von fernen Gegenstïnlen müssen die verschiedenen Strahlen alle rinfachen Angen zngleich belenchten, worluch alle sperification des Bildes anfgehoben wird. Nur Gegenstände, welche ganz diclit vor den Augen sind. kïmnen bei diesm Bane unterschieden werden, idden jerles einzehe Ange damn meln von bestimnten entsprechenden Stellen des ganz nahen objectes belenchtet wird. Daher dieser Pan der Angen

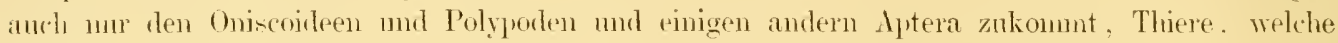
theils in dor Erete. theils muter Steinen, theils selbst als Schnarotzer der Fische laben."

Die anscheinende hoconsequenz. die 11 ïller hermit beging, crklärt sich ïbrigens ans seinen anatonimclien Befunden, die ihn veranlassten, in den Angen dieser Thiere statt desen, was sie wirklich sind. nänlich zusanmengerotzte Angen (- ich rede hier aber nur ron den 0 niscoideen und Verwanden. die Myia forlen lasse ich in Ermangehng eigener algeschlosener

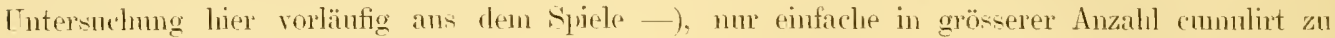
erthicken. Zwei Beobachtmesirrthïmer, die sich zufüllig gerade in die Hände arbsiteten, veranlassten dlipe Parallelisirmug.

Der erste lrothum beruhte anf der mogenaten Kenntniss des Banes der einfachen Angen, ïher welche M̈̈ller sowohl wir seine Vorlinfer mu Zeitgenosen gehoten. Der andere wnrde bei der bobachtung der vermeintlich aggregirten einfachen Angen der Oniscoideen ete. begangen.

Die Comea des einfachen Anges sollte ausen conrex, nach imm aher concar sein, mol in ihrer Höhlung eine biconvexe bis splbïriche Line tragen. Hinter dieser glanbte Mäller einen durchichtigen, hiconvexen Glaskïrper zn finden, ant welchen dam die flïchenhafte, nach vorn ebenfalls ansgehiohlte Anshreitung des sehnerven folgte, mugeben ron riner jigmentirten Chorioirlea, die vor dem (rlaskïrper emen Diaphragna-artigen Ring, eine Iris bildete.

Der lier begangene Irrthun, die Annahne einer von der Cornea getrennten Linse. rowie rines dahinter gelegenen bic onvaxen Glaskïpers, wrde and in der Untersuchmg des Anges der Assoln nicht vermierlen. und larauf lin hatte natürlich die vorgenommene Parallelisirung der

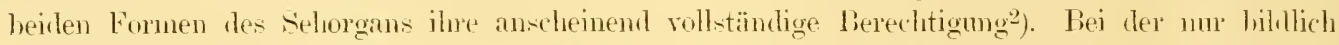
zu fassenten Ausdruksweise des "Lebergangs" des einfachen Anges durch das agglomerirte in das znsannengesetzte machte anch die für das letztgenamnte von der Theorie geforderte, durch die Beobarbing wengstens nicht abgelehnte Einheit des percipirenden Nervenendes linter denn "Glaskïrper" gegenïber der ebenfalls postulirten Meluheit derselben bei den ersteren nicht in dem Maase ilıen stïrenden Ë̈nflus geltend, wie sie es leute thun wïrde.

1) J. 11 ïller, Fortgesetzte anutomische Untersuchungen ülor den Bau der Augen bei den Insecten und Crustaceen. Meckel's Archiv, Juhrgang 1829 , pag. 43.

2) Vgl. dariilser lerner: If iiller, Teber den Bau der Augen bei Argulus foliaceus in Tiedeman n und Treviraus, Zeitschrift für Physiologie Be. IV. 1831. pag. 97-105. 


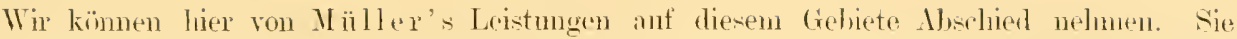
sind die grösten. trotz einzelner Jnvollkommenheiten in sich an meisten logich grolixderten, welche rie Geschichte mseres Thenas anfanweisen hat. Er ist zwar noch mehrfach genöthigt gewesen, für thes geistige Lieblingskind semer Jugend Lanzen zu brechen, wie wir noch sehen werden; in kurem An-zuge hat er sie nur noch in seinem "Lehlumch der Physiologie" als Ganzes behandelt, wo anch. heilänfig benerkt, meines Wissens zmn ersten Male die Ausdrüicke „mosaikartig" und "mmsivisch," als Evitheta für diese Art der Perception zur Anwendung konmen (l. e. Bd. Il. pag. 279).

Wir wollen mu den Schicksalen der Theorie in Lanfe der Zeit zn folgen vorsuchen.

Den ersten Zweifel an ihrer Riclitigkeit erhob R. Wagner ${ }^{1}$ ) anf Grund einer vereinzelten Beohachtung. Er glanbte nümlich die von ihm geselıene Seheide nm die Krystallkegel für die walıe Anbreitung des Selmerven, also für eine ärlite multiple Retina, halten zı dö̈rfu, womit allerdings das Loos der Theorie besiegelt gewesen wäre. Indessen rerlief dieser Angriff, wohl anch durch IÏ̈ller's²) Entgegmung entkräftet. ohne becondere Wirknng zu änssern. zienlich resultatlos.

Baht daranf erschienen die Untersuchmgen ron A. Brants ${ }^{3}$ ). die allerdings nu die morphologische Vergleichmg des einfachen mul des znsamnengesetzten Anges zn corrigiren lrestrebt waren. Die Intersnchmoen hahen Anspruch darauf, hier genannt zu werden. einmal, weil sie Veranlassmg für J. Müller gegehen haben, die Anatomie des Arachnoilenanges durch noch-

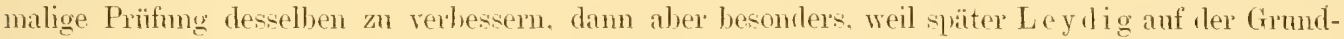
lage der Brants'schen Resultate seine so allgenein acceptirte Ansicht über den morphologischen /usammenhang beider Formen des Sehorgans antbaute.

Brants wollte in dem rinfirchen Auge (zunächst der Arachoiden) eine Lrt von Bimleglied zwischen dem Ange der Vertebraten und den zusammengesetzten Arthropolenange erkemen; er vergleicht das spinnenange mit den letzteren als (ianzes, will also von einer Gleichwertligkeit deselben mit einer Inzahl einfacher Angen hichts wisen. Er verbesserte die Beschreibung If ïller's äber den vermeintlich biconvexen Gilaskïper, indem er seine wahn Gestalt, vorn concar, hinten convex, orkannte: ankerdem 'ntrleckte er in rer hinter dem cilaskörpor gelegenen pigmentirten Nasse faserige, radiär gelagerte Röhnen mu rergleicht dime nit den Krystallkegehn res Facettonanges.

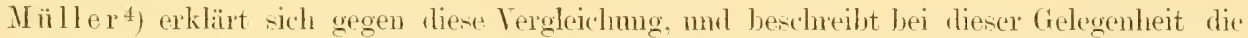
Structur des Glaskïrpers als , ans pflanzenartigen Zellgewebe, mit zum Theil länglichen Zellen, deren Längache in der Rirhtung der Raulien des Glaskörpers liegt bestehend, nud erklärt ferner. dass die Linse mit der Cornea verwachen ist.

Anch äher die bekannte, in mancher Beziehung recht verdienstliche Arbeit von Will5) künnen wir kurz hinweggehen, da sie auf die ms hier beschäftigenden Ham,fragen sich nur sehr wenig einlässt. Will drückt sich über den Modns res Sehens mit einem rorsichtigen skepticis-

1) R. W a gner, Einige Bemerkungen ïber den Ban der zusammengesetzten Augen der Insecten, in W i eg m a n n's Areh. f. Naturgeseh. Jahrg. I. 183j. Bd. 1. pag. 372.

2) Areh. f. Anat. ete. 1835. pag. 613.

3) in: Tyjjlschrift voor Nat.-Gesch. en Physiol. Tom. V. 1. 2; unl Bull. Sc. phys, und nat. en Neerl. (ron mir nicht eingesehen); ferner in: Amales des sciences nat. Tum. 9. 1838 pag. 308-313; Frorieps Nene Nutizen etc. 1838 . Bd. VI. pag. 289-294.

$\left.{ }^{4}\right)$ Vgl. Arch, f. Anat. und Physiol. 1838. Jahresbericht pag. CXXXVII.

5) Will, Beitrïge zur Anatonie der zusammengesetzten Angen mit facettirter Hornhaut. Leipzir 1810. 
mus ans, schliest sich aber muerkenubar näher an P. Hagner, dessen Schüler er war, an, als an J. M̈̈̈ler. Er sieht in zusammengesetzten Ange nur ein Aggregat von einfachen, denen (r) einen complicirteren Ban zuschreil,t als seine Vorgänger. Sie sollen nämlich „eine Hornhant, eine Pupille, cinen Humor aquens, eine wahseheinlich mit einer feinen Kapsel umgebene Linse (Krystallkege]), einen Glaskörper, einen Sehnerrenfaden, eine Retina und endlich eine Choroidea " (l. c. lag. 30) enthalten. Was Will als Retina bezeichnet, ist dasselbe, wie rlas, was fioulier R. Wagner für eine solche amsmach; bessere Gründe als dieser hat Will auch niclıt für eine solche Behanptung zu liefern rermocht. - Das Haupitgewicht der Will'schen Intersuchungen berulıt auf dem Nachweis des solı ansgedehnten Torkommens der Krystallkegel, das besonders durch sie zu einem verfrühten ansnahmslosen gestempelt wurde; femer verdient noch lierrorgeboben zu werden, dass er der Erste war, der auf die Differenzirung des . Nervenfadens", an welchen or bei zahlreichen Arthopoden eine „imnere Röhre" und eine „änssere Scheide" beabaclitete, aufmerksam gemacht liat.

Ein besonderes Verhängniss für die M ̈̈ller'sche Theorie rom musivischen Sehen beschwor die kleine Abhandhung rom Gottsche: "Beitrag zur Anatomie mol Phỵiologie des Anges der Fliegen und Krebsel) heranf. In diesen Anfsatze rerüfentlichte Gottsche nicht nur Beobachtungen über die Anatomie des zusammengesetzten Anges, sondern ep schildert auch einen ron ilm angestellten Tersuch, der his in die neueste Zeit hinein als ein mwiderlegliches Argument gegen die thatsächliche Richtigkeit der M̈̈ller'schen Theorie hat gelten mï̈sen. Wir haben es hier rorzugsweise mit dem Versuhe und den ans ihm gezogenen Consequenzen zu thum.

Schon mehrfach war die Peobachitung gemacht worden, dass, wemn man die facettirte Hornhant eines Insectes rein prïparirt unter das Mikroskop legt, mol den Focus resselben um eine gewise Gröse oberhall, einstellt, ein mehr oder weniger dentliches Bild rles Diaphragmas. des Fensters, ror dem das Mikroskop anfgestellt ist, orler rines zwischen Spiegel mol Ohjecttisch gelattenen Gegenstandes zum Vorschein kommt; mngekelnt, wenn das Mikroskop ein cinfaches, anfrecht, wem es ein zusammengenetztes, also selhst bildumkehrendes ist. Znerst hat schon Leenwenhoek in den Areana naturae die hetreffenden Sütze sind nenerdings ron Fr. Boll in seiner weiter unten noch anznfïlnenden Arbeit wieder reproducirt worden) diese Beob-

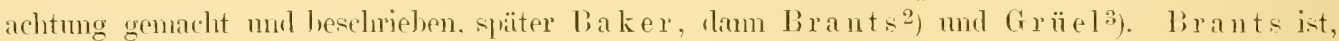
wie J. N ïller und Fr. Boll erwïhnen. der Erste gewren, der anf die Unverembarkeit dieser Thatsache nit der $\mathrm{M}$ iiller'schen Theorie hingewiesen hat, obschon er in seiner frïluern, oben erwïhnten Arbeit nur bezïglich der morphologichen Anffasmo der Arthopodenaugen als Gegner Ml̈̈ller's aufgetreten war.

Diese Borbachtung der Entstehmg eines mogekehrten Bildchens wurle num ron Got sc he

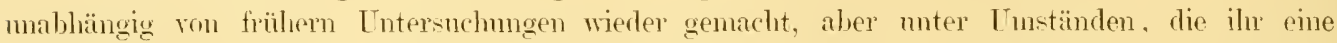
weit gröscere Tragweite beizulegen geeignet waren. als jene älteren sie besassen. Diese nümlich, angestellt an der gereingten Cornea, demonstrinten nur, was eines Beweises gar nicht erst hedurfte. nämlich die focale Vereinigung der durch eine Linse gehenden Lichtstrahlen zu einem mugckehten. rerkleinerten Bilde des lichtausendenden Objectes. Nun liegen aber beim lebenden Thier linter diesen Facettenlinsen die Krystallkegel mol ob diese eine solehe Bilderzengmg zu-

1) in: $M$ ïller's Areh. f. Anat. u. Plysiologie 1852 pag. 483-492. (Briefl. Mittleilung an Jol. M ii 11 e r.)

${ }^{2}$ ) in: Tijdschrift roor natul. Geschiedenis en Plyssiologie. Brl. X. 1843. (Citirt nach Boll, mir nicht zugiinglich.)

3) Poggendorf"'s Annalen 18t4. Tol. LXI. rag. 220-222. 
liessen, oder ob sie vielleicht nur einem Büschel diffusen Lichtes den Durchtritt gestatteten, diese Alternative war nicht so leicht a priori zu entscheiden, wie für rlie Facetten allein; ansserdem boten für eine analytische Behandlung des Problems die Kegel in sofern keine Handhabe, als ihre wechsehnde Form geometrisch wenig fassbar, ferner ilue geringe Grösce und ihre oft so anssorordentliche Teränderlichkeit unter dem Einfluss der rerschiedenen Nethorlen auch Annüherungsmessmngen schwer zngünglich war.

Das Gottsche'sche Exporiment schien nun den muiderleglichen Beweis zn liefern, rlass ein Bildehen trotz der Krystallkegel hinter diesen erzengt wird. Er stellte seinen Versnch an Fliegen an. md beschreibt Müller das dabei beobachtete Verfahren ganz ausführlich. wofür ich anf seine Darstellung selbst verweise (1. c. pag. 489).

Nun werle ich später allerdings zu zeigen haben, dass bei Gottsche's Tersuch rlie Krystallkegel höchst wahrscheinlich gänzlich anser Spiel sind, dem sie sind hier so dünnflïssig, dass schon ihr Nachweis mit grossen Schwierigkeiten zn kämpfen hat, und sicher ist mir wenigstens, dass bei semem in Glycerin aufbewalnten Demonstrationspräparat das Bilchen lediglich den Facetten zuzuschreiben ist, und eine Nodification desselben durch die Krystallkegel deshalk hier ausgeschlossen werden muss. weil sie ausgelanfen mol durch die Zusatzflïsigkeit ersetzt sind. Dies ist aber für unsem Zweck hier gleichgültig, denn, wenn idh dies schon hier anführen darf, der Tersuch gelingt anch bei andern Inspeten mit selır resistenten Kegeln ganz gut (ich habe ilm bei Nachtsclmetterlingen wiedlerdolt), wenn die Kegel nu vorher von Pigment befreit worden simb.

Non sind aber die Consequenzen wichtig, die Gottsche aus seinem Experimente zieht. Er ritirt wörtlich einen längern Anszug ans Bergunnn und Lenckart, (Anat.-physiol. Uebersicht des Thimeichs - die, beilinfig bemerkt, eine treffliche Darstellung der Theorie rom musivischen Selıeu geliefert, mol dahei namentlich die Einheit rles percipirenden Elementes linter dem Krystallkegel als Postulat fü dieselbe betont haben -), und fülurt damn fort (1. c. 491): "Wer den fadenförmigen Theil, welcher ron der hintem Flïche des Krystallkörpers im Fliegenange in seiner lockern Scheide nach der Aushreitung rler Nervi optici zu hinlïuft, für eine Selmervenfaser ansieht, rler kam diese Sü̈ze (nämlich von Bergunann und Leuckart) nicht nnterschreiben, weil dieser von mir angegebene Versncl, total dem wirlerspricht, un in rliesem Falle befinden sich fast alle dentschen Physiologen."

Aus dem ganzen Zusammenhang geht hier unzweifelhaft hervor, dass Gottsche die wörtlich citirten Stellen aus Bergmann und Lenckart ganz falsch anfgefasst hat. Diese nänlich behaupten mit Mïller um die anfrechte Stcllung des dmeh das Gesammtange vernittelten Bilıles. da sie das Einzelange für die Bildpereption für untanglich, und nur zur Perception des einfachen, aus seiner directen Vurdüngerung herstammenden Lichtreizes qualificirt halten; Grottsche aber bezieht dies irrigerweise anf die Einzelfacette, für welche Lenckart nur ans der schon ron Mïller formulirten psychologischen Schwierigkeit die Tnmöglichkeit, dass sie ein ganzes Partialbild des Gesammisehfeldes als nmgokehrtes Bilı percipire, demonstrirt hatte. Das Einzige, was an der von frottsche reprorlucirten Stelle des genannten Buches allenfalls zu Einwenilungen Veranlassung geben kimn, wäre folgenter Passus: „— wäre nun bei den Arthoporlen das Sehen auf dieselbe Weise vernittelt, wie bei den Wirbelthieren, entstïnle anch bei ihmen linter den einzehen brechenden Körpern nach den Gesetzen der Dioptrik ein mmgekehrtes Bilıl der änssem Gegenstände, damn wäre eine reutliche Gesichtsvorstellung ganz ummöglich" - demn lier ist dem Nortlante nach der Schwerpmikt auf den secundären Torgang der Projection des Billes gelegt, statt auf die Perception, was übrigens gleich darauf wieder in's richtige Terhältniss gebracht wird.

Uebrigens scheint Gottsche anch wenig geneigt, als percipirende Endorgane dasselbe Grenacher, Tutersuchungen über das Sehorgan der Arthropoden. 
anzusehen, was frühere Forscher dafür erklärt latten. Wenigstens ist seine "Retina" etwas ganz anderes, und wir rechnen sie jetzt überhaupt nicht melı zu den eigentlichen Angentheilen, sondern eher zn dem Ganglion opticum, dessen Ausstrahlung gegen die hintere Angengrenze, die dureh eine siebartig durchbohrte Chitinlamelle bezeichnet ist, sie bildet. Seine Zweifel gegen dic ältere Auffassung sucht er noch zu stützen durch den Hinweis auf älmliche Bedenken, die Milne Edwardsi) früher ausgesprochen hatte. Nor andentend bespricht er die muthmassliche Function jener von dem Hinterende der Krystallkegel zwr vermeintlichen Retina ziehenden Fürlen; el hält es nämlich nicht für mmöglich, dass das ganze projicirte Bildchen durch einen solchen Faden zur Retima geleitet werde — also etwa, wie eine Depesche durch einen Telegraphendraht! - um dort erst zur Perception zu kommen. Es ist wohl völlig überflüssig, sowohl über diese Vorstellung, als anch über andere in jenem Aufsatz enthaltene Dinge, z. B. das von ilm angenommene Doppelsehen durch das Einzelange bei einer gewissen Objectristanz, - das schon durch Claparède (s. unt.) eine nähere Belenchtung erfahren hat - noch viele Worte zu verhieren.

Wie leicht zu ersehen, ist der wirkliche Gewim, den die Wissenschaft aus der Arbeit Gottsche's zog, em sehr geringer für die Hauptfragen, und doch bezeichmet sie emen für die Mïller'sche Theorie rerhängnissrollen Wendepunkt in der Geschichte des Problems. Trotz aller' Missverständnisse und schiefen Auffassungen, die in jenen par Seiten enthalten sind, erhol, sich das ominöse Bildchen hinter den Krystallkegeh gegen das so überzeugend aufgeführte Gebäude Nü̈ller's, und brachte es nach und nach zı Falle.

Die bald darauf reröffentlichte Arbeit von $Z$ enker ${ }^{2}$ ), welche sich ebenfalls auf unser Thema einlïsst. stellt sich zwar auch auf die Seite der Gegner der Theorie rom musivischen Sehen, ohne jedoch schon durch das Gottsche'sche Experment in nachweisbarer Weise beeinfusst zu sein. Sem Gedankengang ist ein wesentlich verschiedener, und wir wollen versuchen, ilm in kuzen Zügen zu skizziren.

Zenker geht von einfachen Auge aus, auf das er durch seine speciellen Studien ïber Ostracoden and Copepoden gekommen war. Scine Auffassung dieses Organs weicht, namentlich was die lichtbrechenden Theile desselben anbelangt, ron der bisher üblichen ab, umd er führt eine Tergleichmg mit dem Wirbelthierange durch, die jetzt freilich nicht mehr aufrecht zu balten ist, aber für die damalige Zeit manche irrige Anschamung berichtigte. - Die lichtbrechenden Nedien theilt er ein in exogene und endogene; unter den crsteren versteht er die Comea in den verschiedenen Formen ihues Auftretens (glatt, linsenartig verdickt etc.), unter den letzteren Glaskörper und Krrystallkegel. Ueber die Betheiligung dieser beiden Categorieen an der Bilderzengung spricht er sich (1. c. pag. 29) folgendermassen aus: "Vergleichen wir die Augen mit glatter Homhant (Ostracoden etc.) denen mit optisch mitwirkender Homhaut (Isopoden. Nyriapoden, Arachniden), so tritt uns der bemerkenswerthe Gegensatz entgegen, dass in diesen der eigentlich lichtbrechende Körper ein exogenes Gebilde (Linse), in jenen ein endogenes (Glaskürper) ist; dass in diesen der Glaskörper zur Terminderung. in jenen zur Erzeugung der Convergenz der Lichtstrahlen bestimmt ist." — — "Dasselbe, was wir hier bei den einfachen Angen finden, gilt num auch für die zusammengesetzten. Anch in ihnen findet sich der Unterschied, dass bald die exogenen, bald die endogenen Angentheile die Convergenz der Strahlen bewirken." _ _ _Bei den Asseln und Decapoden — liegt die Ursache der Convergenz in der Hornhaut, welche in der Mitte dicker ist, als am Rande. Dasselbe findet bei

1) H. II ine Edwards, Histoire naturelle des Crustacés. Tol. I. 1831. pag. 119, wo von den ,filamens vilrés gèlatineux" hinter den Kirystallkegeln die Rede ist.

2) Zenker, Monographie der Ostracoden. in: Arch. f. Naturgesch. 20. Jahrg. Bd. 1. pag. 1-87. 1854. 
Insecten statt, z. B. bei Dytiscus, wo die Hornhaut innerhalb jeder Facette eine Wölbung von $160^{\circ}$ macht. Der dahinter liegende Glaskürper, rler sogenannte lichtbrechende Körper (Krystallkegel), dient nur dazu, die Convergenz der Strahlen bis zn seiner Spitze zn rerzögern." etc. (1. c. pag. 30.)

Seine Ansichten über das Sehen nit dem znsammengesetzten Ange fasst er in folgenden Sätzen zusammen (l. c. pag. 31): .Ein zusammengesetztes Ange ist - nur als eine Aggregation einfacher Angen zn betrachten, die sich, veränderten Verhältuissen genäiss, umgebildet haben; ein specifischer anatomischer Unterschied besteht nicht. Auch muss deshalb die Art mod Weise des Sehens dieselbe sein. Die moekehrten Bilder in den benachbarten parallel gerichteten $n u b e w e g l i c h e n$ einfachen Randangen des Scorpions können nur darlurch reremigt werden, dass der Ort des gesehenen Gegenstandes in der Richtung des einfallenden Lichtstrahls nach aussen projicirt wird, und dass da, wo für je zwei Augen die Projectionsrichtungen sich krenzen, der Körper selbst geselren wird. Es ist lier gleichgüiltig, ol, diese Bilder ans 2 oder 3,4 und mehr Angen projicirt werden; die Kremungsstelle wirr immer mur der Gegenstand selhst sein kömnen. Durch die zahlreichen Ocellen des zusammengesetzten Anges wirl also eine ebenso klare Anschaumg erreicht werden, wie in jeden zwei gleichgerichteten mberveglichen einfachen Angen." — "Es wäre kam denkbar, dass die Insecten mit iluren Nebenangen momgekehrte, nit ihren zusammengesetzten Angen dagegen anfrechte Bilder sehen sollten. Es darf ans dem Vorgange des Sehens mit heweglichen Angen kein Schluss gezogen werden für die Theorie der mubeweglichen." (1. c. prag. 32.)

Die hier im Ansznge mitgetheilte Anffassung des Sehvorganges bein zusammengesetzten Ange ist sicher eine eigenartige, originelle, aber, wie sich bei näherer Leberlegrmg bald ergibt, nichts weniger als befriedignnde. Die ganze Beweisfülumg zmm Beispiel stützt sich anf Voranssetzungen, die theils mgenügend begründet, theils gerarlezu unrichtig sind. Unter die ersteren gehört die Anmalme ron der morphologischen Uebereinstimmung des einfachen Anges mit dem Einzelange des facettirten; hier ist weder für den Krystallkegel, noch für die Retina die Auskunft. eine genïgende, rund selbst wenn man zuzugeben geneigt ist, dass das Facettenange als eine Aggregation ron einfachen, den reränderten Umstïnden gemïis umgebildeten Angen (s. ob.) anfgefasst werden kann, so frïgt sich doch wieder, ob diese veränderten Uustände anf die Art und Weise des Sehens nicht anch von sehr wesentlichen Einflusse sein kömnen.

Unter die thatsïhlich unichtigen Toranssetzmgen aber reche ich, dass Zenker mit den Einzelangen des Facettenanges, deren Axen doch notorisch divergirend anf einer lingelfläche angeordnet sind, so operirt, als ob sie parallel gerichtet wïreu.

Es liesse sich leicht Schnitt für Schritt zeigen, dass das ganze System dadurch hinfällig wird. Genan genommen ist anch ,larin keme emste Widerlegung der Müller'schen Theorie versucht, inden dieselbe gar nicht berührt wird; keine einzige der Prämissen, die zu jener Theorie geführt haben, ist einer nïhern Prüfung nnterworfen worden. Es ist deshalb auch überflïssig, alle rlie sich ergebenden Einwände hier besonders anfzuzählen und zu widerlegen.

Eine ganz andere, weit hervorragendere Stellung nelmen die Arbeiten Leydig's1) über das Arthropodenange ein, seit Joh. Mïller bis auf unsere Tage rie ansgedehntesten mor sorgsamsten in der ganzen Reihe der einschlagenden Publicationen. Leydig hat sowohl das einfache

1) F r. Le y di g, Zum feineren Bau der Arthropoten. M ï l l e r' 's Areh. f. Anat. u. Physiol. 1855. pag. 106-414. Lehrbuch der Histologie 1857. pag. 249-262. - Das Ange der Gliederthiere etc. Tiibingen, 1864. - Tafeln zur rergleichenden Anatomie. Tübingen 1864: aussertem zalılreiche Einzelarbeiten. 
wie das znsammengesetzte Ange einer grossen Anzahl ron Arthroporlen sehr eingehend geprüft, und eine ganze Summe neter Entrleckungen ron grïsserer oder geringerer Bedentming dem spröden Materiale alozugewinnen verstanden.

Die aus so ansgedehnten Erfahrungen erlangte Uebersicht über die sämmtlichen Erscheinmosformen des Sehorgans hat, obschon zunächst dem morphologischen Verstänhuisse dienstbar, natürlich nicht verfehlen künnen. den Antor anch hinsichtlich der Frage über die Art mol Weise des Sehens Partei ergreifen zu lassen. Um seinen Standpunkt würdigen und besprechen zn können, nüssen wir nothwendig schon hier anf das Fundanent an Thatsachen eingehen. welches demselben zu Grunde liegt.

Leydig räunte mit den bisher allgemein gelregten Vorstellungen äber die Berlentung rler euzzelnen hinter der Linse gelegenen Weichtheile der beiderlei Angenformen gründlich anf. und setzte eine völlig nene Auffassungsweise an deren Stelle, die sich grossentheils lis hente in der Wissenschaft erhalten hat. Mit welchem Rechte. mag hier noch merörtert bleiben, da ich später noch ansfïhrlich genug daranf zurückzukommen labe.

Un mit dens Facettenange zu beginnen, so erimnern wir uns, dass ron den bisherigen Forschern seit J. Müller alle in dem Krystallkegel lediglich einen optischen, dem Perceptionsapparat vorgelagerten. demselben semer Natur nach aber fremden Apparat, bestimmt, auf das durchtretende Licht in einem oder dem andern Sinne zu wirken, erblickt haben. Nicht so Leydig. Für ihn ist der Krystallkegel ein nervöser, percipirender Theil des Auges, ein Differenzirungsproduct der "Nerrenfaser" der älteren Autoren. an den sich nach hinten ein weiteres derartiges Gebilde, der "Nervenstal,", anschliesst, die continuirlich mit einander zusammenhïngen, und eine physiologische Einheit bilden, die ihrerseits verglichen wird mit dem Perceptionselement des Wirbelthieranges. Der Krystallkegel, das peripherische Ende der .Nervenfaser", lat nur eine abweichende, durchsichtige Beschaffenheit angenommen. Die grosse Schwierigkeit, eine scharfe Grenze zwischen dem Hinterende des Krystallkegels, besonders dessen Umlüllung, und dem dilinter gelegenen Abschnitt nachzuweisen - eine Schwierigkeit, die sich bisweilen bis zur Unmöglichkeit steigert — veranlasste diese von der bisherigen so völlig abweichende Deutung. die Leydig selbst dann noch anfrecht erhielt, als er die imige Verwachsmg des Krystallkegels mit der Corneafacette bei Elater noctilucus, Telephorus etc. entdeckte. - Besonders verfolgte Leydig den Ban des "Nerrenstabes" mehr in's Einzelne. Er nimut an demselben eine bindegewebige, den eigentlichen, in frischem Znstande meist rosaroth gefïrbten und hä̈fig zart quergestreiften "Nervenstab" umgebende Hülle an, in welcher anch selı zarte pigmentirte Muskehn rerlaufen, deren Contraction er direct beobachtete, md deren Function besonders in der Verengerung eines irisartigen Pigmentringes um das Hinterende des Krrystallkegels bestehen soll.

Ebenso abweichend ron den bisherigen ist seine Interpretation der Untersuchungsresnltate des einfichen Anges. Die durchsichtige Schicht radiür zum Lunsencentrum gestellter Zellen im Spimnenange, die bisher als "Glaskörper" anch nur eine secundïre physiologische Rolle gespielt latte, erhielt durch Leydig auch eine wesentlich andere Dentung.

Nach seinen Untersuchnngen endigen dieselben nach linten zu nicht scharf und eben abgeschnitten, wie die frühern Beobachter angegeben hatten. sondern hängen durch eine Art von bipolarer Ganglionzelle mit einem dahinter gelegenen stabfömnigen Gebilde zusammen, das in seinem Innem wieder analoge Differenzirungen zeigt, wie der "Nervenstab" in Facettenange. Den erstgenamten Elementen spricht er den Besitz ron Kemen ab, und bezeichnet sie wegen ilner Zerfliesslichkeit nnd ihres Anssehens als "Gallertkolben". die er morphologisch und physiologisch mit den Krystallkegehn des Facettenanges in die gleiche Reihe stellt. Denselben Ban 
beschreibt ex anch von den einfachen Angen der Insecten, wo die Theile die gleielie Anortumng zu einander zeigen.

Die Schlüsse, welehe Leydig in Bezug anf die morphologischen Relationen zwischen den beiden Angenformen zieht, zeigen viele Anklïnge an die selon obeu bei $\Lambda$. Brants besprochenen, ınd sind, die Richtigkeit der Pränissen vorangesetzt, nieht anzufechten. Wenn der einzehe "Nervenstab" nit seinem etwas anders entwickelten Torlerende, dem Krystallkegel, einem einzelnen, analog complicirten Stabelentent des einfachen Anges morphologisch gleichwerthig zu setzen ist, so ist gegen die Folgerung, dass anch die Summimng der einzehen verglichenen Factoren, das zusammengesetzte Muge anf der einen, das einfache anf der andern Scite, norphologisch einander gleichwerthig zi achten seien, wohl kaum etwas einzuvenrlen. So sieht denn Leydig consequenter Weice das Facettenange nicht als ein Aggregat eunfacher, dicht zusammengerückter Angen an, sondern als eine „organische Finheit, ein Einzelange", und berïlnt sich in dieser Beziehmg nit $\mathrm{A}$. Brants (s. ob.), wobei die Unterschiede, die freilich linsichtlich der Dentung der einzehen Angentheile zwischen Beiden obwalten, für das Gesammtresultat ohne Belang bleiben.

Soweit wäre die Sache in der Ordnung. Nun musste aber Leyrlig loch auth eine Ansnalme zulassen, die ganz direct auf den entgegengesetzten Modus der Augenbildumg limfülnte, also auf die Entstehung eines zusammengesetzten Anges duch Cumulation ron einfachen; und, was an meisten zu denken giebt, bei Thicren, deren systematische Stellung eine solche Ansnahmeposition a priori nicht vermuthen liess. An einem exotischen Bockkäter nämlich hat Leydig eine Angenbildung beobachtet, die er auf eine Anluäufmg von Emzelaugen zmöckfühnen zu müssen glanbt. Damit wird aber nothwendig dem Zweifel an der Richtigkeit der einen oder der andern Dentung Zulassmg gestattet, demn es wäie doch wohl ziemlich beispiellos, dass in ein und derselben Ordnung, wie hier die ler Käfer, dasselbe Organ ̈̈usserlich röllig den gleichen Eindruck bei den verschiedensten Pepräisentanten nachen, ferner derselben Function dienen, nud doch hier nach diesem, dort aber nach einem ihuchans rerschiedenen Typus gebant erscheinen sollte. Aber man unss doch die Möglichkeit zngeben, so sehr sonst das paradoxe Terhalten den ans den gesammen Erfalnungen gewomenen Regehn widerspricht.

Ander's aber ist es mit den Folgermgen bestellt, welche Leydig für die Frage nach den Morns des Sehens vernittelst des Facettenauges aus seinen Untersuchnngen zog. Nach der Art, wie ex die Elenente rles zusammengesetzten Anges bezüglich ihrer functionellen Bedeutung bestimmte, hätte nnan das Recht zu erwarten, dass er ein Vorfechter für die Müller'sche Theorie sein müsste, deun (r) lat ja gerade den Beweis geliefert, der bisher noch ausstand, nämlich von der Emheit des percipirenden Elementes linter je einer Facette, und damit jene Theorie zn einer mabweisbaren genacht. Dem älunliches lat schon Claparède in seiner gleich zn erwähnenden Arbeit richtig leransgefunden und ausgesprochen. Leydig aber stellt sich auf Seiten der Gegner Mïller's; anfïnglich änssert er sich mu sehr zurückhaltend und vorsichtig, lässt aber doch zwischen den Zeilen durchblicken, dass er die Müller'sche Theorie als gefallen und unhaltbar ansehe; in semer späteren Arbeit aber, die nach jener Abhandlung ron Claparède erschien, rerwaht er sir.h entschieden gegen jene Folgenng. Einen Vorschlag aber, den CIaparède, dessen Emwendungen gegen die Leydig'sche Auffassung sich anf die angefühnte beschränken, in rermittehdem Sime macht, adoptirt Leydig, nämlich in dem Krystallkegel lichtbrechende mo lichtempfindende Elemente zngleich zu sehen. Sonst aber ist er der Ansicht, dass das herufene Bilikhen hinter der Cornea , schon allein genügt, die Müller'sche Theorie rom musivischen Sehen als mhaltbar aufzugeben". Der Schwierigkeit, die grosse Anzahl der den einzehen Facetten 
entsprechenden Bildchen für eine einheitliche Wahrnehmung zu verwerthen, sucht Leydig anf eine selur aigentlüuliche, wohl kaum als physiologisch haltbar zu bezeichnende Weise zu entgehen. Er denkt sich nämlich, die Einzelbildchen könnten auf der Bahn zum Nervencentrun lim gewissermassen in ein einziges grosses Bild zusammenfliessen, und zieht dafür die Art der Nervenansbreitung. wornach „keineswegs je ein Nervenstab einer einzigen Nervenfaser entspricht, sondern die Nervenstübe bündelweise zu einer Faser gehören, und diese wieder rückwärts, also zun Gehirn lin, sich abermals zu Stammfasern vereinigen", leran, welches Verlalten er unit einer zusammengesetzten Dolde vergleicht.

Fs ist, wie ich glaube, wohl nicht nothwendig. diesen Darlegmngen besonders und ausdrïcklich entgegenzutreten, da sie so weit von allen wissenschaftlich festgestellten Thatsachen der physiologischen Optik abweichen, als möglich. nnd zur Erkliirung einer Erscheinung eine Anzahl von merklärlichen Anmahmen einfülıren. Wir werten ohnehin noch auf diesen Torstellungskreis stossen bei der Besprechung von Claparède's Stellung zu der Frage.

Der morphologischen Deutung der Krystallkegel, wie sie Leydig aufstellte, kan GegenJa ur1) zu Hülfe, der an den Augen eines nicht nüher bestimmten Krebses ans der Familie der Hyperiden, die völlig pigmentfrei waren, die Beobachtung machte, dass die Krystalliegel mit ihren lang ausgezogenen spitzen Enden sich bis an das Gehirn fortsetzten, und dort ohne Dazwischentreten besonderer Eleniente direct an Centralorgan endigten. Dieser Fund hat wohl auch die Auffassungsweise dieses Autors, die er bisher in seinen Compendien der vergleichenden Anatomie rertrat. mit befestigen lielfen.

Die schon flüchtig erwälnnten Intersuchungen von Claparède ${ }^{2}$ ) fördern. was das Thatsächliche anbetrifft, vor Allem das bisher unangebante Gebiet der Entwickelungsgeschichte des zusammengesetzten Anges (dlas einfacle hat er nicht berücksichtigt), und eine Reihe von interessanten Beobachtungen war die Fruchit daron. Da aber diese Untersuchungen selbst keinen Antheil an seinem Standpunkt bezüglich der uns hier rorwiegend beschäftigenden Ilanptfragen haben, so können wir sie rorläufig ans dem Spiele lassen.

Die eigentlich morphologische Seite der Frage wird ron Claparède nur gestreift; es ist in erster Linie hervorzuheben, dass el entrchieden der Vergleichung des Arthroporlenauges und seiner Theile mit den Wirbelthierange und seinen Constituentien. wie wir sie bei Leydig finden. entgegentritt. Ueber die Tergleichung der beiden Augenformen der Arthropoden unter sich äussert er sich so umbestimunt, dass sich kein sicheres Urtheil über seine Ansicht gewinnen lïsst; indessen sclieint es mir, als ob er darin seinem Vorgänger Leydig folge.

Viel ausführlicher rerbreitet er sich über den Mechanismus des Sehens. Auch er gehört zu den Gegnem der Mïller'schen Theorie. aber seine Gründe sind ganz andere, als die seiner Torgïnger; man merkt ihm sehr deutlich die Ueberwindmg an. die es ihn kostet, der Ley ilig'schen Auffassung Concessionen zu machen, er betont, wie schon oben angeführt, dass sie in dieser Form anf die Mïller'sche Theorie fülıre (l. c. prag. 207), und macht. zwischen Scylla und Charybdis, einen Vermittelungsvorschlag, der bei Lichte besehen erst recht unamelmbar erscheinen muss.

Sein Widerstand gegen die Theorie rom musivischen Sehen stiitzt sich weniger auf das

1) Gegen banr. Zur Kenntniss der Krystallstäbchen iu Krustenthierauge. in: Mïller's Areh. f. Anat. u. I'hysiol. 1858. p. 82-84.

$\left.{ }^{2}\right)$ E. Claparede, Zur Morphologie der zusammengesetzten Augen bei den Arthropoden. in: Ztschft. f. wiss. Zool. Bd. X. 1860. pag. 191-211. 
berufene Leenwenhoek'sche Bildchen, als darauf, dass gewisse Consequenzen jener Theorie durch Erfahrungsthatsachen widerlegt werden sollen. Jene Consequenzen bestelsen darin, dass nach jener Theorie die Schärfe des Unterscheidnngsvermögens nothwendig proportional der Anzahl der Facetten sein muss. Dies ist nicht wohl zn bestreiten; aber hüren wir ihn weiter. Er fülurt aus Will's Arbeit Zälllnngen ron Facetten an; die kleine Käfergattung Morllella soll über 25.000, eine Ameise hingegen nur 50 haben. . Welcher Abstand in der schärfe des Unterscheidmgsrernögens", fährt er fort, „müsste nicht nach Müller's Theorie diese beiden Insecten von eineinander tremen! Man darf ja dreist behanpten, dass nach dieser Theorie ein Insect, welches wie slie Ameise nur 50 Facetten an ler Hornhant besitzt, für wirkliche Bilder vö̈lig blind ist. Es kömnte wohl Helligkeit von Dunkelheit unterscheiden, doch keine Gegenstïnde, keine Lmrisse wahmehmen. Dies genügt. um Müller's scharfsimige Lehre zu Borlen zu shlagen, dem wir wissen, dass viele Insecten ein feines Unterscheidungsvermögen selbst in bedentender Entfernung besitzen. Schon aus grosser Ferne stemert eine Biene geradlinig auf die Oeffinung des Bienenkorbes los, and es rlarf wohl angenommen werden, dass der Gesichtssimn ihr Hauptführer dabei ist" - und dann berechnet er ans fler ungeführen Facettenzahl (ca. 4000), class sie schon in einer Entfernung von b Fuss das Flugloch nicht mehr erkennen künne, da ja nach der Müller'schen Theorie das Bild mehrere Facetten eimehmen müsse, um noch wahnohmbar zu sein.

Iachen wir hier emen Angenblick Halt, bevor wir seme Ideen weiter rerfolgen, um die hier angewandte Art des Schliescens etwas näher zu belenchten. In der wörtlich citirten Stelle (rgl. 1. e. pag. 208) ist der Gedankengang doch nur der: es giebt Insecten, die mit zahlreichen Facetten ausgertistet anf weite Distanzen scharf unterscheiden; andere, wie die Ameise, besitzen nur sehr spärliche Facetten — folglich ist die Mïller'sche Theorie falsch. Wie Claparède so molücklich argumentiren komnte, ist mir mbegreiflich. Freilich wäre es für die Müller'sche Theorie ein ganz bedenkliches Ding, wenn ıler Nachweis geführt werden künnte, dass die Ameise, trotz ihrer geringen Anzahl von Facetten ${ }^{1}$ ), auch nnter die Insecten mit scharfem Unterscheidungsremögen, and besonders in die Ferne, gelıörte. Aber diesen Nachweis, den man doch eigentlich erwarten müsste, hat Claparède nicht geführt, und er dürfte ihn, anch wem er es rersucht hïtte, doch etwas schwierig geworden sein; dem Jeder, der diese Thiere je in Leben beobachtet hat, wird diesen langsamen, immer mit ihren Fühlern manipnlirenden Geschüpfen nach all den empirischen Anhaltspunkten, dwe wir in solchen Fällen zur Anwendung bringen kömen, ein mu seln wenig entwickeltes Sehvernögen zuschreiben, ebenso aber den blitzschnellen, gewandten Mordellen ein selrr hoch ansgebildetes, mo damit stehen die Zahlenverhïltnisse der Facetten in keinerlei Widerspruch. Hätte Claparède seine Anfmerksamkeit etwas mehr der Insectenclase zugewandt, so würde er gefurlen haben, dass jene ersterwähnte Consequenz der Müllerschen Theorie, die er zur Bekämpfung der letzteren aufbieten zn können glaubt, durchweg ihre Bestaitigung findet.

Was aber ferner die so ummotivirt in die rermeintliche Beweisführung eingefülnte Biene anbelangt, so ist es lloch wohl sehr fraglich, ob sie nothwendig gerade las Flugloch ihres Stockes aus grossen Entfernungen sehen muss, mu wieder dahin zo gelangen. Darf man einen Thier, dessen Psyche so mnerhältnissmässig hoch entwickelt ist, nicht anch zutrauen, dass schon der Korb, oder das Bienenhaus, selbst dessen Ungebung, bei der Rückkehr zum Wegweiser

1) Ieh möehte hier beilüufig erwähnen, dass ich übrigens bei Formica r u fa ca, j00 Facetten gezïhlt habe; in dem Oval der Cornea stehen einige 20 in der grössten Breite, einige 30 in der grössten Lünge; fïir unsern Zweck ist das aber nebensächlich. 
dienen kann? Ind könnten hier nicht auch ausserdem Dinge uns gänzlich unbekannter Natur ihre Rolle spielen, wie z. F. bei den Brieftauben, deren Orientirungstermögen roch sicher nicht anf einen in's Tnglaubliche rerfeinerten Gesichtssinn zurückgeführt werden kamn? Ich führe dies an, weil ich einmal irgendwo gelesen habe, llass im fernen Westen Nord-Amerikas die Honigsammler die Stöcke wilder Bienen auf meilenweits Distanzen aus den gerarlen Flughalmen zweier ilmen zngehörigen Bienen peilen sollen - muss aher freilich die Richtigkeit dès Factums dahingestellt sein lassen.

Kelnen wir aber nach dieser Abschweifung wieder zn der weiteren Entwickelmng zurïck, die Claparède giebt.

Nachdem er ans der Thatsache, dass für die zusammengesetzten Angen die Selıschürfe in die Ferne rasch abnimmt, den Widerspruch mit der gewöhnlichen Ammahne. dass sie für das Fernsehen, die Ocellen aber für das Sehen in der Nähe bestimnt seien, betont lat, stellt Claparède die, wie er glaubt, nothwendige Amuhme auf (1. c. pag. 209), ,dass jerle einzelne nervöse Abtheilung les Arthropodenanges mehrere discrete Eindräcke gleichzeitig leiten kam, und dass das Selifeld jerles zusammengesetzten Auges musirisch aus den den einzehnen Angenabtheilungen entsprechenden Bildchen zusammengesetzt ist." Die psychologische Schwierigkeit der Perception so vieler unter sich rerkehrter Einzelbildchen macht ihn wenig Sorge, indem er auf die zuweilen in grösserer Anzahl sich fintlenten Ocellen linweist, für welche dieselbe auch Geltung haben mïsste. Die Function jedes Theilanges als rollstïndiges Organ berlingt aber vieder dioptrische Medien zur Bilderzengung, und da nach seiner Ansicht die Cornea nur in seltenen Fällen himreichend gewölht ist, so muss der Krystallkegel aushelfen. Da nun Claparède anser Stande ist, ler Leydig'schen Auffassung des Krystallkegels. so sehr er sich anch gegen dieselbe strïuben mag, eine bescere entgegenznstellen, so wirft er die Frage auf, ob nicht der Krystallkegel lichtbrechend und percipirend zu gleicher Zeit sei, und stiitzt rliese Termuthung noch rlureh die Krystallkegel der Hyperiden, wie Gegenhaur sehon gethan. - Claparède sieht sich also veranlasst, eine Hypothese zn Hülfe zu rufen, die eigens ad loc geschaffen ist, und für welche ans der gesamnten Summe der Kenntnisce der Bedingungen des Seliens, wie sie aus andem Intersuchungen gewonnen wrde, keine Stïtze geholt werden kann. Er sieht in dem Krystallkegel. ausser spiner Linsennatur, auch noch eine metaplysische Retina. wenn ich mich so ausdrücken dart, deren einzehne der Elementarwahruelmung dienende Theile anch nicht eimnal andentungsweise unsern optischen Hülfsmitteln zngänglich sind.

Nicht minteressant ist daneben die Art, wie er Leydig nachweist, dass er .. an die Mïller"sche Theorie gebunden" sei (1. c. pag. 207). Nimmt Leydig die nervösen Abtheilungen des Facettenanges als Analoga der Stäbchen des Vertebratenanges, „der einfachsten Gebilde, in welchen die Lichtwellen einen gesonterten specifischen Bewegungsorgang einleiten können", so wïrden sie ein dem Schachbrett vergleichbares Mosaik für das Licht enuffindlicher Punkte darstellen, das Bilr der Anssenwelt demgemäss in ebenso viele Stücke zerlegt werden, ron rlenen jerles als gänzlich homogener Theil zur Perception gelangte: jerle nervöse Augenabtheilung rermag nur einen, niemals aber mehrere gesonderte Lichteindrücke zugleich zu leiten." Das (iesammtbild im Ange wird demnach ein anfrechtes. nicht mogekehrtes sein, wie es ja die Müller'sche Theorie erfordert. - - Nïhne aber Leydig auch an, rlie einzelnen nervösen Abtheilungen vermögen mehrere verschiedene Einzelempfindungen zugleich, d. h. zusammengesetzte Bilder, zu leiten. so wïrde democh die Theorie zn Reeht bestehen, denn die Cornealinsen der Facetten wïren in den meisten Fïllen ansser Stande, ein Bilılchen zu liefern, wegen zu schwacher Krümmung, und jene Leitmosfilligkeit würle nur eine virtnelle sein. Fehlt also eine weitere linsenartig 
wirkende Vorrichtung, so lässt sich die Anerkennung der Müller'schen Theorie auch dadurch nicht rermeiden.

Ich habe mich absichtlich bei der Besprechung ron Claparède's Arbeit so lange anfgehalten, weil sie so ansserordentlich instructiv zeigt, wie tief die Frage nach dem Verlassen der II ̈̈ller'schen Theorie verfahren war. Die ansgezeichneten anatomischen Untersuchungen von Leydig lagen ror; ihr Urheber glaubte sie gegen die Theorie benutzen zu kömen, und Claparède weist ihm nach, dass sie im Gegentheil schnurstracks darauf hinführen. Da er aber selbst der Theorie nicht vorurtheilsfrei gegeniibersteht, so bringt er daran ein kleines Correctiv an, das aber in seinen Consequenzen bedenklich ist, und glaubt sich so aus dem Dilemma zu ziehen. Und dabei darf man nicht rergessen, dass Claparède hinter keinem seiner Vorgänger an Scharfsinn zurückbleibt, an Kemntniss der physiologischen Optik und ilırer Methoden sie aber sämmtlich ïbertrifft!

Einen wieder ander's motivirten Versuch, das Problem zu lösen, verdanken wir Ruete ${ }^{1}$ ).

Ruete's Forschung lag die morphologische Seite der Frage ferner als die physiologische, und er begnügt sich, trotzdem er sich sonst sehr an Leydig anschliesst, wegen des Leeuwenhoek'schen Bildchens das Facettenauge für ein Aggregat ron einfachen Augen anzusehen.

Bezüglich des Sehrorganges im Facettenange glaubt er sich in gewisser Weise im Anschlusse an die Iüller'sche Theorie zu befinden, aber bei nälıerer Prüfung ergiebt sich doch, dass er in wesentlichem Gegensatz dazu steht. Wïhrend Müller dem nervösen Apparat der einzelnen Facette das Termögen der Perception eines Bildchens, das ja nach ihm anch nicht zu Stande kommen soll. abspricht, und nur die axial einfallenden Strahlen wirksam sein lässt, sagt Ruete (l. c. pag. 17.): „Der Hauptunterschied der hier zu erörternden Ansicht von der J. Müller's liegt darin, dass nicht nur ein einziger Punkt eines Objectes Lichtstrahlen durch einen einzigen Hornhantkegel schickt, sondern viele zugleich durch mehrere liegel, so dass ein und dasselbe Nervenstïbchen auch zugleich von mehreren Punkten des Objectes afficirt wird. Jedes getroffene Nervenstäbchen erhält daher ein vollständiges Bild eines kleinen nahen Objectes, orler ein Stück des Bildes eines grösseren Objectes, und dieses Stück wird einen un so grösseren Theil des Objectes repräsentiren, je melır das Object rom Ange entfernt liegt. Jedes einzelne Stück des Bildes wird num anf das entsprechende Stïck des Objectes bezogen (projicirt) und somit ist also das Totalbild, d. I. dasjenige, welches zum Bewnsstsein gelangt, ein ans vielen einzelnen Bildstïcken mosaikartig zusammengesetztes."

Unter Hornhantkegehn versteht Ruete aber nicht die Krystallkegel, die er mit Leydig als Perceptionsorgane auffasst, sondern die Facettenantheile der Cornea, die er richtiger als Hornhautpyramiden bezeichnen wïrde. Auf Seite 19 seiner Abhandhung giebt or anch eine schematische Figur, die seine Darstellung rersinnlichen soll.

Ich glaube mir die Mühle sparen zu dürfen, den detaillirten Nachweis zu führen, dass auch diese rermittehde Auffassung Ruete's in keiner Weise die Zweifel zu beseitigen rermag, die sich digegen erheben müssen. Sie gipfelt in letzter Instanz wieder auf der Amnahme, dass der vermeintlich nervöse Krystallkegel Bilder zu percipiren im Stande sei, und Puete sucht in der Viertheiligkeit desselben ein Argument dafür.

Die in der genannten Arbeit noch ausserdem enthaltenen Bestimmungen optischer Constanten als nicht in den Kreis mserer Betrachtıng gehörig ïbergehend, wenden wir uns zu dem

1) Ruete, Ueber die Einheit des Princips im Bau der Augen bei den rerschiedenen Thierchassen und besonders über das Sehen der Insecten mit polyedrischen Augen. Gratulationsschrift der med. Fac. zu Leipzig zu C. G. C a ru s 50jähr. Doctorjubiläum. 1861 .

Grenacher, Untersuchungen über das Sehorgan der Arthropoden. 
fast gleichzeitig von einem andern Ophthalmologen veröffentlichten Versuch, dem Problem eine bessere Seite abzugewinnen.

Dor $\left.{ }^{1}\right)$ sieht die Müller'sche Theorie für so gründlich beseitigt an, dass er sich der Mühe überhoben glaubt, gegen sie zu polemisiren. Vorwiegend hält er sich an die Leydig'sche Darstellung, die übrigens anch nicht seinen Beifall findet. Wie Ruete hat er sich auch vielfach mit der Bestimmmig optischer Constanten beschäftigt und ich darf für den Modus der Gewinnung derselben sowohl, wie auch für die numerischen Resnltate mich mit dem Hinweis auf das Original begnïgen. - Da nach seinen Untersuchungen die Bildprojection immer am Hinterende rer Krystallkegel zu Stande kommt, und nicht, wie man nach Leyrig wohl eher erwarten müsste, am rordern, der Corneafacette zngewandten, so ist für Dor diese Thatsache himreichend, über die Annahme einer nerrösen Natur des Krystallkegels den Stab zu brechen. Als eigentliche Retina will er die conische Hülle um den Krystallkegel angesehen wissen, nnd nur eben diese conische Form derselben, die einer Bildprojection anf dieselbe wenig gïnstig ist, erregt sein Bedenken, das aber durch den Hinweis anf die auch nicht inmer rein sphärische Gestalt der Retina des Menschen beseitigt wird. Anch die Unzahl von umgekehrten Bildchen kann seine Ueberzengung nicht in's Wanken bringen. - Dor schliesst sich, wie man darans ersieht, hierin an die viel ältere Ansicht ron R. Wagner (s. ob.) an, die ihm, wie es scheint, nicht bekannt geworden war.

Eine ganz andere Stellung als die bisher besprochenen Arbeiten nehmen die Untersuchungen von Max Schultze ${ }^{2}$ ) ein, die ein neues Licht auf das noch immer so dunkle Problem zu werfen bestimmt schienen. Obschon die Untersuchungen von ganz anderen, rein histologischen Gesichtspmkten ansgegangen sind, und demmach der Schwerpunkt derselben anderswo gesucht werden mnss, so komnte doch die nähere Berührmg mit dem Gegenstand nicht verfehlen, einen Forscher wie M. Schultze zu einem Versuch der Klärung der noch immer so rerworrenen Frage herauszufordern.

M. Schultze gerieth an das Problem in Folge seiner bekannten Untersuchungen über den Ban der Retina der Wirbelthiere und Molhusken. Es war ihm gelumgen, dort eine eigenthümliche Plättchenstructur rler Netzhantstäbchen anfzufinden, deren ausgedehnte Verbreitung dem Gedanken Ramn gab, in ihr rielleicht eine fundamentale Bedingung füi die Lmwandlung der lebendigen Kraft der Lichtstrahlen in specifische Nervenerregung zu erkennen; wie demn bekanntlich Zenker nmmittelbar darauf das Resultat vorläufig in eine Art von Perceptionstheorie zusammenzufassen versucht hat. Um num anch die Arthropoden auf das eventuelle Vorkommen dieser Plättchenstructur zu jü̈fen, mtemalm Schultze jene Arbeit; denn es musste jedenfalls znr Feststellung der principiellen Bedentung jenes Banes von grösster Bedeutung sein, wemn Augen von sonst ganz verschiedener Architectur sich darin gleich verhielten.

Anch nach N. Schultze ist die Theorie vom musivischen Sehen als yphysikalisch mhaltbar" zu verwerfen. Ebenso bestimmt aber tritt er anch den Ansichten Leydig's über die Lichtempfindungsfühigkeit des Krrystallkegels, sowie den unmittelbaren Zusammenhang desselben mit dem dahinter gelegenen "Nerrenstab" oder "Schstab“, wie er den unbestritten nerrösen Theil zu nemen vorschlïgt, entgegen. Für ihn ist der Krystallkegel ein rein dioptrischer Apparat, bestimmt, bei der Erzengung des Bildchens mitzuwirken. Es konnte einem Forscher wie

1) H. Dor, De la vision chez les Arthropodes, in: Bibliothèque unirerselle (Arch. d. sciences phys. et natur.) 1861. Decemberheft mit 1 Tafel.

2) M. Sehultze, Untersuehungen über die zusammengesetzten Augen der Krebse und Insecten. Bonn 1868. Fol. mit 2 Taf. (Vorläutige Mitth. im Arch. f. mikr. Anat. III. 1S67. pag. 404.) 
II. Schultze nicht entgehen, dass die bisher vorhandenen, so ausserordentlich schwankenden und unsicheren Kenntnisse über die Nervenendigung im Facettenange nicht entfernt limreichen, einer einigermassen haltbaren Torstellung rom Wesen des Sehrorganges eine sichere Grundlage zu bieten, und dass deshalb ror Allem der Erforschung des Thatsächlichen noch eine löchst bedentsame Aufgabe blieb. Verlässt man die Theorie Müller's, so ist die notluwendige Consequenz das Postulat einer Retina, also einer Vielleit ron percipirenden Endorganen, die der Mannigfaltigkeit der gleichzeitig durch das projicirte Bild gegebenen Reize gerecht werden kann.

Was nun diese Seite seiner Untersuchungen anbelangt, so kann man nicht behaupten, dass das Glück II. Schultze hierin eben so günstig gewesen wäre, wie nach der andern Richtung hin, nämlich dem Nachweis des allgemeinen Vorkommens der Plättchenstructur anch in Typus der Arthropoden. Der "Sehstab" liess sich nicht so ohne weiteres als Retina interpretiren. wenigstens fehlte noch sehr riel für die postulirte Vollkommenheit desselben, indem M. Schultze zwar eine Zerfällung desselben in vier, höchstens in acht, wie er glaubte, Segmente erkannte, was aber für die Anwendung jener Bezeichnung noch nicht ausreicht. Eine weitere Zerfüllung in feine Füserchen, die ja allerdings von grosser Bedentung luätte sein müssen, war aber nur hypothetisch, und es fehlte jerler Anlaltspunkt aus Beobachtungen dafür. Nun sollte aber eine andere Beobachtung dafür eintreten. Bei einer Reihe von lnsecten tritt der Nerv scheinbar einfach an das hintere Ende des Trystallkegels, bei andern aber glaubte M. Schultze ein Zerfallen desselben in äusserst feine, oft recht zahlieiche Nervenfärchen beobachtet zu haben, die sich entweder an das hintere, etwas flache Ende des Krystallkegels (Fliegen) oder becherfürmig um die Spitze rlesselben (Mistkïfex und Nachtschmetterlinge) legen. Hierin war für ihn die Lösmg des Räthsels enthalten: Das zusammengesetzte inge entspricht einem Aggregat von einfachen, ron denen jedes mit einer aus zahlreichen feinen Nervenenden bestehenden, in der Nïhe des hintern Endes der Krystallkegel gelegenen Retina versehen ist. Nach rorn lin soll sie sich weit weniger ansdehnen, als frihere Forscher, die analoge Ansichten geäussert haben, annahmen.

Es ist hier nicht der Ort, über die thatsächlichen Grundlagen, ihre Richtigkeit oder Unrichtigkeit, mich auszusprechen. Dies mag bei der Darlegung meiner eigenen Untersuchungsresultate geschehen. Aber auch olme Scrupel nach dieser Seite him zu haben, kann man doch nicht behaupten. dass durch die Art und W'eise der Darstellung, wie sie M. Schultze giebt, alle Bedenken zom Schweigen gebracht worden wären. Ein misslicher Umstand muss es schon genannt werden, dass es diesem in allen Feinheiten der modernen mikroskopischen Techik so ausgezeichnet beranderten Forscher nur in einzehen wenigen Fïllen unter den selur zahlreichen, die er einer Prüfung unterwarf, gelungen ist, jene Zertheilung in feinste Fibrillen anfzufinden, und ex ausserdem genöthigt wax, bei den andern das Vorkommen zu negiren. Wir laben in solchen Fundamentalfragen alles Recht, Gesetzmässigkeit zu erwarten, nnd wenn schon vereinzelte Ausnalmmen störent gewesen wären, so wird die Sache doch höchst bedenklich, wenn die zur Erklärung herangezogenen Beobachtungen selbst nur selu rereinzelte unter einer erdrückenden Majorität ron dagegen sprechenden bleiben.

Nun erhebt sich ansserdem eine zweite Frage nach der Natur des "Sehstabes", dessen Rolle durch den Schultze'schen Fund jener feinsten Nervenfäden eine räthsellıafte wird. Er zeigt jene besprochene Plätchenstructur, die rosenrothe Färbung in frischem Zustand, er ist quellbar und höchst vergänglich, stark lichtbrechend - kurz, es rereinigen sich in ilm eime Summe von Eigenschaften, welche in den Sehorganen ron Nirbelthieren und Mollusken den Retinastäbchen zukommen. Nun stehen diese anerkanntermassen mit der Umwandlung der Lichtbewegung in 
Nervenerregung in imnigstem Zusammenhang — so verschieden auch die Rolle sein mag, die man ihnen dabei zutheilt —, sollte dies nun hier nicht der Fall sein? Durch seine erste Dentmg ist M. Schultze gezwungen, dies zu verneinen, denn, um aus einer ganzen Reihe ron Gründen blos den einen anzuführen, bei denjenigen Augen, wo er am deutlichsten die feinsten Fibrillen erkamnte (bei Nistkïfern und Nachtschmetterlingen), liegen diese "Sehstäbe" sehr weit ron der Stelle ab, wo jene Fibrillen sich ansbreiten, wo auch das Bildchen entstehen nü̈sste, und sind mit denselben durch je einen langen Faden rerbunden, der wohl in seiner Axe ein Strahlenbüschel durchtreten lassen wird, durch den aber das an seinem Vorderende entstehende Bildchen gleiten zu lassen eine physikalische Absurditït wäre. - Die "Sehstäbe“ können also keine Analoga der Retinastäbchen andrer Thiere sein, sie sind hier keine Endorgane der Sehnerven, und jenen Fibrillen kommen ihrerseits wieder keine Endorgane zu, wenigstens keine wahrnehmbaren, und dies ist auch wieder ein Widerspruch gegen die Erfahrung.

Das Thema liesse sich noch weit ansspinnen, das Gesagte mag aber genügen, um darzuthun, dass auch die Untersuchungen MI. Schultze's noch zu vielen Einwendungen Raum geben, um als abschliessende betrachtet werden zu können.

Dies erhellt in sehr characteristischer Weise aus dem Unstand, dass II. Schultze's Schüler, Fr. Boll11), ans dessen Untersuchmgen Consequenzen folgerte, die geradezu auf den diametral entgegengesetzten Standpunkt, nämlich auf den der Müller'schen Theorie, hinführten. Boll ist anscheinend dem Gegenstand nicht durch eigene Lntersuchungen nïher getreten, sondern durch eine auf anderm Gebiete der physiologischen Optik gemachte Erfahrung veranlasst worden, demselben seine Aufmerksamkeit zuzuwenden, und fusst dabei fast durchgängig auf den Resultaten II. Schultze's.

Boll ist der Erste, der mit Sicherheit und Klarheit das Leeuwenhoek'sche Bildchen auf seinen wahren Werth und seine richtige Bedentmg zurückführt — als nothwendige Consequenz der sphïrischen Krümmmg der vor den Nervenendigmen gelegenen Nedien, womit aber keineswegs auch der Zwang gegeben sei, demselben in der bisher üblichen Weise eine herrorragende physiologische Bedentung zuzuschreiben, d. h. anzunehmen, dass es als solches anch percipirt werden müsse. Er erörtert die Schwierigkeiten, welche sich dieser Anffassmng entgegenstellen, etwa wie folgt.

In erster Linie glaubt er den ron MI. Schultze beschriebenen melrfachen Nerrenendigungen hinter dem Krystallkegel sowohl die morplologische als physiologische Bedeutung einer Retina absprechen zu müssen, denn eimmal fehlt ihnen das den Reiz localisirende Pigment (ein Einwand, dem er selbst nur geringes Gewicht beilegt), damn aber sind sie zu sparsam, um den Namen einer Retina zu verdienen, der nicht blos eine Mehrheit, sondem eine grosse Anzahl von Nervenenden involvire. Dann weist er auf das häufig so sehr verschmälerte Hinterende der Krystallkegel hin, wodurch blos eine sehr kleine centrale Partie des Bildchens ron einer etwa dort rorhandenen Retina percipirt werden kömnte; und endlich macht er die Seltenheit des Vorkommens, wie ich es rorhin bei der Besprechung ron Schultze's Arbeit gethan, sehr entschieden geltend als Argument gegen ihre Bedentung, während der viel weiter rerbreitete, einfache und nicht fibrilläre Sehstab eher als Norm aufgefasst zu werden verdiene.

Eine fernere Quelle für Terlegenheiten, die nicht anatomischer, sondern physiologischer Natur ist, erkennt er im Nangel der Accomodation, da olne eine solche die Trenmung gleichzeitig entworfener Bilder von nahen und fernen Gegenständen nicht möglich ist.

1) F r. Boll, Beiträge zur physiologischen Optik. in: Arch. f. Anat. u. Physiol. 1871. pag. 530. 
Endlich spielt bei Boll auch die psychologische Schwierigkeit eine grosse Rolle, da die Eimrichtung des Centralorgans eines Insectes, das eme Unzahl von unter sich ungleichen, verstïmmelten und unvollstïndigen Bildchen zu einer einzigen Wahrnelmumg combiniren soll, unser Vorstellungsvermögen weit überschreitet.

So hält vor dem Urtheil des Verfassers keines der Argumente gegen die Müller'sche Theorie Stand, md er entscheidet sich — seit dem Gottsche'schen Versuch als erster — für dieselbe.

Die Vorstellmgen, die Boll sich ïber die morphologischen Bezielumgen des einfachen Anges zum zusammengesetzten gebildet hat, sind in seiner Arbeit nur so kurz und aphoristisch angedentet, dass man sie gewissermassen zwischen den Zeilen herauslesen muss. Er scheint einer Vergleichung des einfachen Anges mit dem facettirten, resp. der Auffassung des letzteren als eines Aggregates von ersteren nicht gerade geneigt zu sein, olme aber anch sich Leydig's Auffassmg zuzuwenden. Freilich sagt er nur: "Wenn man die zusammengesetzten Augen physiologisch nicht meln als eine Aggregation einfacher Augen betrachten kann, so ergiebt sich daraus rlie Nothwendigkeit, auch die rergleichend-anatomische Auffassung derselben, wie sie bisher in der Wissenschaft üblich war, einer Revision zu unterziehen" - er wendet sich damn aber melır gegen die vielfach, namentlich bestimmt ron Leydig, in Anwendung gelurachte Tergleichung mit dem Wirbelthierange.

Endlich hat vor Kurzem Lenckart1) in einer allgemeinen Uebersicht über die Formen des Sehorganes in der Thierreihe sich über unsern Gegenstand ausgesprochen. Anch er hält fest an der Müller'schen Theorie, und ist trotzden keineswegs geneigt, deslralb anf die morphologische Zurückführung des einfachen und des zusamnengesetzten Auges auf einander Verzicht zu leisten. Er sagt wörtlich: „- Da anch die typischen Formen der einfachen und zusammengesetzten Augen bei den Arthopoden mancherlei Eigenthünlichkeiten mit einander gemein haben, liegt die Annahme nahe, dass beide anf dem Wege einer divergirenden Weiterentwickelmmg aus einer indifferenten Urform hervorgegangen seien. Es heisst indessen den Werth morphologischer Beziehungen überschätzen, wenn man aus den her hervorgehobenen Thatsachen in nenerer Zeit mehrfach den Schluss gezogen hat, dass beiderlei Angen num auch in Bezug auf den optischen Vorgang des Sehens eimander gleich ständen, und „, die Müller'sche Theorie rom musirischen Sehen als unhaltbar aufzugeben sei (Leydig)." "

Die Richtigkeit dieses Standpunktes zu erweisen ist die Anfgabe der vorliegenden Arbeit, deren wichtigste Resultate zuerst im Jahre $187 t$ veröffentlicht wurden ${ }^{2}$ ).

Wir haben hier schon eme stattliche Reihe ron Arbeiten über das so eng umschriebene Gebiet Revue passiren lassen, und dabei ganz abgeselıen ron allen rein descriptiv-histologischen, die kemen eigenen Standpunkt restreten; man kann wohl sagen: quot capita, tot sententiae. Wenn trotz der besten md klangrollsten Namen, deren Träger sich melr oder weniger eingehend mit dem Arthropodenauge beschäftigten, doch das Gefühl der absoluten Unsicherheit jeder Dentung im morphologischen wie im physiologischen Simne nicht ferngehalten werden komnte, so wird man nicht mit Unrecht einen wesentlichen Grund des wohl kaum im Ernste zu lüugnenden Misslingens in der grossen Schwierigkeit der Lntersuchmg selbst rermuthen. Eigene Erfahrungen haben mich darüber genïgend belehrt, und ich will deshalb die von niir angewandten Methoden, die seln einfach sind, in Küuze darlegen.

1) R. Le uckart, Organologie des Auges. in: Graefe und Saemisch, Handbueh der gesammten Augcnheilkunde, Bd. II. 1. Abth. pag. 290 n. ff.

2) Ueber die später erschienene werthvolle Arbeit ron Exner s, unt. 


\section{Bemerkingen ïber Methode und Technik.}

Dass es keine Panacee für die Untersuchung des Arthropodenanges giebt, die sich ein für allemal empfehlen liesse, das habe ich im Terlaufe meiner eigenen Untersuchungen nur zu selur crfahren. Da die meisten und wichtigsten Resultate wenigstens hinsichtlich der hier zu beantwortenden Hauptfragen sich nu durch gut geführte Schnitte gewimnen lassen, so galt es vor Allew, zweckmässige Erhärtungsmittel in Anwendung zı bringen, und trotz der Menge von hiefür empfohlenen und anch für andere Zwecke äusserst brauchbaren Substanzen kann ich doch kaum ein besonders geeignetes liervorheben.

Da nir mehr auf die topographischen Beziehungen der das Ange bildenden Elemente zu einander ankan, als auf den feinsten histologischen Ban derselben namentlich in frischem Zustande, so habe ich nur relativ selten die Untersuchung der lebenden Gewebe rorgenommen. Sie ist fast immer eine sehr schwierige. weil, ganz abgesehen von der eminenten Veränderlichkeit aller Weichtheile, das Pigment, das diesen nicht oberflïchlich anhaftet, sondern in sie eingebettet ist, einer genameren Einsicht in ihren Ban mgemein hinderlich ist, oder sie selbst ganz unmöglich macht. Eine Entfïrbung in frischem Zustande, olme die zarten Gewebe zu zerstören, ist aber nach den mir bekaunten Nethoden nicht möglich, da alle dazı verwandten Sulsstanzen stark einwirken, und namentlich frischen Geweben rerderłblich sind, wälnend sie bei vorsichtiger Anwendung an gehärteten Präparaten weit weniger Veränderungen in Gefolge haben.

Wie aus der spïteren anatomischen Schilderung hervorgeht, habe ich Sclmitte beim einfachen wie beim zusammengesetzten Ange sowohl parallel der Augenaxe, als auch senkrecht rlarauf, gemacht, und ich verdanke namentlich der Anwendung der letzteren Schnittrichtung auf das Facettenange eine Reihe der wichtigsten Resultate.

Ton Erhïrtungsmitteln halıe ich Chromsäme und ilre verschiedenen Salze rersucht, aber die dadurch bewirkte grobe Granulirung erweist sich meist als ein schwer zu ïberwindendes Hinderniss. Ferner habe ich nit der von M. Schultze und von Steinlin empfohlenen Oxalsüme in wässeriger und alkoholischer Lösung experimentirt; in einzelnen Fällen erhielt ich ganz brauchbare, in andern wieder völhg unbrauchbare Resultate. Anch mit Pikrinsäure ging es mir nicht besser. Nur die von Ḱleinenberg angegebene Mischung von Pikrin- und Schwefelsäıre, deren Anwendıng aus dem Anlang zu der ron Kleinenberg übersetzten Entwickelungsgeschichte von Foster und Balfour ersehen werden kam, und deren Bekanntschaft ich in der Zoologischen Station in Neajel im Winter 1875/76 machte, scheint nach den allerdings nur sparsamen Tersuchen, die ich vor Krurzem noch mit ihr anstellte, wenigstens für manche Fälle gute Dienste zu leisten, obschon sie nicht jene rorzüglichen Eigenschaften zu entwickeln scheint, die ich für pelagische Thiere besonders an ilır schätzen lernte. Wo im lntegunente Kalk 
vorkommt, also bei den meisten Crustaceen, ist sie freilich unbrauchbar, da die KohlensïurcEntwickelung die noch weichen Gewebe aus ihrer Lage bringt und selbst zerstört.

Für die einfachen Angen habe ich zuweilen gute Erfolge mit emem mir ron meinem Collegen. Herm Prof. Merkel, empfohlenen Gemenge von Chromsäure und Platinchlorid (von jedem $1 / 4 \%$ in aq. dest.) gebabt. Aber die Verschiedenheit der Wirkung anf rerseliedene Augen zeigte sich gerade hier recht auffallend. Während ich z. B. das Ange ron Phalanginm ganz trefflich damit studiren konnte, ebenso diejenigen der Acilius-Larren, ergab die Anwendung auf die Angen von Epeira und andere Spinnen, ebenso auf das Facettenange, ganz und gar negative Resultate.

Dass ich auch die ron M. Schultze gerade für diesen Zweck so selır gerïhmte Osmiumsäure vielfach erprobte, rersteht sich von selber. Ich kann aber nicht behaupten, dass ich für die von mir angestrebten Zwecke besondere Lrsache hätte, sie zu empfehlen. Sie bewährt zwar ihre Eigenschaft, den Geweben bis zu emem gewissen Grade den Character der frischen zu erhalten, anch hier, wie sie demn anch an ehesten sich eignet, die Plättchenstructur des Sehstabes zn conserviren. Dazu kommen aber ein paar unangenehme Eigenschaften. Zunächst ist der am meisten zu bekümpfende Gegner das dichte, dunkle Pigment, und wenn die Osminmsïure diesem nicht nur eine weitere Terdunkelung um etliche Schattirungen hinzufügt, sondern auch die Löslichkeit des Pigmentes so bellentend verringert, dass man die Lösungsmittel weit lïnger und in concentriterer Form, als die Gewebe vertragen können, in Anwendung bringen muss. so ist das ein bedenklicher Tehelstand. Ausserdem werden durch die Osmiunsüure manche natürlich sehr wesentliche Differenzen in der Lichtbrechnngsfïhigkeit ausgeglichen, so class stark brechende Theile, wie die Stäbchen, von sonst schwach lichthrechenden, wie das zugehörige Protoplasma der Zelle, sich nur schwierig tremnen lassen; auch die interstitielle (Blut-) Flüssigkeit gerinnt in ähnlicher Weise, und stürt oft sehr. Endlich verden die Gewebe des Auges sehr spröde und brüchig, und es hält sehr schwer, gute Schnitte ron ihnen zu gewinnen.

Alles in Allem habe ich weitaus am meisten Weingeist in rerschiedenen Concentrationsgraden angewandt, obschon natürlich anch dieser seine sehr bedenklichen Seiten hat. Besonders nützlich halse ich ihn beim Facettenange sowoll der Insecten als der Krelse gefunden, während ich beim einfachen Auge mich allerdings lieber nach andern Substanzen mmsah. lch kann auch lier für seine Anwendung kein Universalrecept geben: das eine Mal leistet $70 \%$ iger bessere Dienste, das andere Mal $90 \%$ iger oder absoluter etc. etc.

Die durch Weingeist herrorgebrachte Gerinnung ist in Ganzen eine ziemlich gleichmässige, mod es finden nicht leicht bedeutende Schrumpfumgen dabei statt, wenn man vorsichtig verfahren ist. Die hyalinen Stäbchen bleiben fast immer nach Alkoholeinwirkung klar und durchsichtig, verlieren aber natürlich Fürbung, Qnerstreifung (wenigstens bei Insectenangen), und, was ich als das Störendste empfunden habe, häufig einen Theil ihres in frischem Zustande so bedentenden Lichtbrechungsvermögens, so dass die Schwierigkeiten, sie in ihrer Zusamunensetzung zu studiren, oft sehr bedeutend sind. Dies habe ich sowohl bei einfachen als bei zusammengesetzten Augen beobachtet, und manche Lücke in meinen Untersuchnugen rübrt daron her', dass ich kein anderes passendes Surrogat auffinden konnte. Auch der Nachweis der Zellkerne, von dem, besonders bei Spinnenaugen, oft viel abhängt, ist nach Weingeisterhärtung und darauf folgender Entfürbung häufig sehr erschwert, was als ein Uebelstand bezeichnet werden muss.

Nicht minder wichtig als die Wahl der Erhärtungsflüssigkeit für den gegebenen Fall ist die Entfärbung, da die Fälle, wo das Pigment ganz fehlt, oder doch nur so wenig entwickelt ist, dass man mbehindert durch dasselbe sich über die Form und die gegenseitigen Lagerungs- 
verhältnisse der Angenelemente orientiren kann, zu den seltenen Ausnalmmen gehören. An eine mechanische Entfernung desselben (etwa durch Alpinsehn) ist nicht zu denken, denn es ist, ausser in eigenen Pigmentzellen, fast immer in reichlichen Quantitäten anch in den essentiellen Bestandtheilen der percipirenden Schicht, zwar nicht in den Stïbchen, wohl aber in den zugehörigen Zellen, aufgespeichert. Man muss ihm deshalh anf anderm Wege beizukommen suchen, und allen Löstugsmitteln klebt der Uebelstand an, dass ihre zerstörende Wirkung sich nicht auf den Farbstoff allein beschünkt, sondern mehr oder weniger fühlbar anch den Träger desselben angreift, den man conserviren möchte. Ich habe znerst mit Kalilange, selten mit Chlorwasser, dann aber zu allermeist mit der von Gottsche zuerst, siäter ron M. Schultze empfohlenen Salpetersïmre gearbeitet. Aetzkali löst zwar das Pigment sehr rasch, aber fast ebenso rasch folgt ihm alles Uebrige, bis anf die chitinisirten Theile, nach; nu die bekannte Moleschott'schen Kalilange, sofern sie als einzige Zusatzflüssigkeit benutzt wird, lässt Zeit genug, ein Präparat eingehend zu studieren. Chlorwasser wirkt sehr langsam, greift aber zu stark die Theile an, die man zu erhalten wünscht; es hält sich ansserdem schlecht, und ist den Mikroskopen gefälırlich. Dagegen leistet die Salpetersäure bei gehöriger Vorsicht recht gute Dienste, und ich kann sie nur empfehlen.

Gottsche wandte concentrirte, M. Schultze $25 \%$ ige Salpetersäture an; letzterer setzte frische Angen ilırer Einwirkung aus. Ich habe nur Schnitte damit behandelt, die schon in rerdïnntem Glycerin unter dem Deckglas lagen, da die Einwirknng derselben auf frisclre Gewebe viel zn intensiv ist, und sie in ihrem Zusammenhange zerstört. Ich fand, dass man am besten thut, sie recht langsam einwirken zu lassen, indem man dem Präparat am Rande des Deckglases ein Tröpfchen 20-25\% iger Süme zufügt, so dass die Beimengung allmälig erfolgen kamn, was man ja immer durch rorsichtiges Lüften des Deckglases unterstützen mag, wenn es zu lange danern sollte. Der Begimn der Entfärbung zeigt sich durch das Auftreten eines braunrothen oder purpumen Hofes nm den Schmitt an, was seine Ursache darin hat, dass das Pigment zuerst gelöst, und dann erst zerstört wird. - Wirkt die Sämre zu stark ein, so vird das Präparat zu durchsichtig, krümelig und zerbrechlich, wnd es treten im Innem Gasblasen anf, die wegen der Zerreissung der morschen Weichtheile das Präparat unbranchbar machen. Man thut gut, wälurend der Entfïrbung das Präparat ab und zu zu durchmustern, denn manche Structureigenthümlichkeiten zeigen sich besonders deutlich gerade während dieses Processes.

Vie schon bemerkt, stösst nach Einwirkung ron Alkohol und darauf folgender ron Salpetersämre der Nachweis der Zellkerne oft auf grosse Schwierigkeiten, die nicht so bedentend sind, renn als Erhärtungsmittel Chromsäure und ihre Salze, Oxalsäure oder dergl. zur Verwendung gekommen sind. Ist der Nachweis der Kerne unerlässlich, wie beim Spimnenauge, so hat man im ersteren Falle viele Nühe, ein entfärbtes Präparat soweit wieder von der sich zähe eimmistenden Salpetersäure zu befreien, dass die bekannten Tinctionsmittel für Kíerne (Carmin, Haemotoxylin etc.) mit Erfolg in Anwendung gebracht werden kömmen; es gehört oft langanhaltendes Auswaschen mit Wasser und Alkohol dazu, und doch ist der Erfolg nicht immer sicher, und Zeit und Niühe verloren. Häufig habe ich nun bem Spinnenange ein Verfahren angewandt, das ebenso einfach als sicher zum Ziele führt. Nan färbt nämlich einfach mit dem in Lösung z̈bergefülurten Pigmente selbst, indem man nur eime minimale Spur von Salpetersäure hinzufïgt, und dam das Präparat sich selber überlässt. Die Lösung mnss aber so langsam erfolgen, dass erst nach 12-24 Stumden der Hof 1 m den Sclmitt auftritt. Das Pigment wirkt hier wie ein ron aussen eingefülnrter Farbstoff; es rerschwindet ron jenen Stellen, wo es sich rorher befand, um sich ganz in den Kernen niederzuschlagen, wobei die andern Gewebstheile 
nur umbedentend daran participiren. Dnrch diese Methorle der Translocation des Farbstoffes erhält man zwar keine brillanten Bilıer, wohl aber solche, die an Klarheit nnd Schärfe Nichts zu wünschen üJrig lassen, um so weniger, als anch die Gewebe wegen der schwachen Einwirkmng der Sïure selır gut erhalten bleiben ${ }^{1}$ ). - Da durch die nachherige Behandlung der Präparate das Pigment nicht wieder ausgezogen wird, so sind sie anch einschlnssfülnig.

Ich bin absichtlich ïber die ron mir angewandten Methoden etwas ansführlicher geworden. als es sonst der Fall zu sein pflegt. Einmal, run zn zeigen, dass ich meine Resnltate keinen besonders nnd rmgewölmlich günstigen Zufüllen verdanke; dann aber, un die Nittel und Wege znr Erklärung der Entstelınng etwaiger Irrtlïmer, deren Quelle ja so häufig die in Anwendung gebrachte Technik zı sein pflegt, an die Hand zı geben. Dass es möglich ist, Besseres an die Stelle der hier heschriebenen Methorlen setzen zn können, bezweifele ich selbstrerständlich an wenigsten.

1) Eine ähnliche Erfahrung (Lüsung des Pigmentes — durch Essigsäure - und Tinetion benachbarter Theile durch dasselbe) hat schion Leydig (Ange der Gliederthiere, pag. 41) mitgetheilt. 


\title{
I. Untersuchungen.
}

\author{
1. Abschnitt.
}

\section{Vom Stemma.}

A. Augen ron Schwimmkïfer-Larveu.

Die räuberischen Larven von Schwimmkäfern (Dytiscus, Acilius) besitzen Angen, die nicht nur durch ihre in einzelnen Füllen sehr eigenartige und hohe Organisation, sondern anch besonders reshalb interessant sind, weil sie dentlicher als andere mir bekannt gewordene Formen des Sehorgans innerhalh des Arthropodentypus die norphologische Znsammengehörigkeit der Elemente des Auges und des Integumentes (der Hypodermis) anch noch im fertigen Organe erkemmen lassen. Die Augen der Larven beider genamnten Gattungen rerhalten sich in dieser Hinsicht übereinstimmend, so gross sonst anch die Unterschiede sein mügen.

Ich habe meine Untersuchungen an jüngeren sowohl wie an reifen Larven angestellt, aber den ersteren schliesslich den Torzng gegeben. Bei den älteren leistet nämlich die zwar nicht sehr dicke, aber harte und sprödte Cuticula dem Messer beim Schneiden grossen Widerstand, und die absplitternden, sich vor dem Messer herschiebenden Fragmente derselben zerstören ur zu leicht die Weichtheile. Zum Hïrten bediente ich mich anfangs des Weingeistes, gab später aber dem Platinchlorid-Chromsäure-Gemenge den Vorzng. Nach so erhaltenen Präparaten sind einige der Figuren gezeichnet.

1. Augen der Dytiscuslarven. Die Larven der Gattung Dytiscus besitzen jederseits 6 im Kreise angeordnete Angen, von denen die beiden obersten sich duch ihre langgezogene Form von den mehr kreisrunden anderen muterscheiten. In Fig. 1 Taf. 1 habe ich einen Schnitt durch eines der runden Angen einer noch jüngeren, etwa 3 cn langen Larre abgebililet; die Larve gehört höchst wahrscheinlich zur Untergattung Cybister.

Hinter der dïnnen, bräunlich tingirten und wit kleinen schuppenartigen Wärzchen besetzten Cuticula (Ct. Fig. 1) hiegen die namentlich bei jüngern Larveu noch recht ansehnlichen Zellen der Hypodermis $\left(H_{p}\right.$. $)$ als senkrecht gegen jene gestellte Prismen. Sie sind farlolos, und an ihrem imeren Ende, welches wieder durch eine dünne, stellenweise kerntragende Cuticula $(c t$.) begrenzt ist, mit grossen ovalen mul sehr deutlichen Kernen rersehen. Die Linse ist eine farblose, biconvexe Verdickung der Cuticula (L.); ilne relative Wölbung bleibt hier noch beträchtlich hinter der zurück, welche sie bei grösseren Larven erreicht.

Die der Linsenperipherie genäherten Hypodermiszellen richten sich zunächst schief, so rlass ihre äussem Enden rom Auge abgewandt erscheinen, md ihre Innenenden ziehen sich spitz ans, wodurch sie an Längenansdehnung gewinnen. Die Keme aber rïcken dabei nach rorn, bis in 
die Mitte der Zelle und darüber hinaus. Noch weiter gegen die Linse zu richten sich nun die Zellen mit ihren äussern Enden gegen diese hin, indem sie sich von der ganzen Peripherie her gegen die Augenaxe zusammenmeigen; zugleich tritt Pigment in ihnen auf ( $\mathrm{Pg}$.), welches aber in dem der Zeiclmung zu Grunde liegenden Präjarat zerstört war und nur durch den etwas dunklem Ton der dasselbe führenden Zellen angedentet wurde. Die bis nahe an die Linsenperipherie herantretenden Zellen sind ihrer ganzen Länge nach pigmentirt; auf sie folgen solche, die sich an die innere Oberfläche der Linse anlegen, daun weitere, welche die Linse selbst nicht mehr erreichen. sondern in der Axe des Anges mit entsprechenden von der andern Seite herkommenden zusammentreffen. Bei den beiden zuletat genannten rücken die Kerne successive wieder an das Hinterende der Zellen, und die Pigmentirmg erstreckt sich nicht mehr ïber die ganze Zelle, sondern bleibt auf die hintere Hälfte, mehr oder weniger, beschränkt, während die rordere, resp. in der Bahn der eintretenden Lichtstralılen liegende durchsichtig und klar bleibt. Dieses Zellenende verïndert sich aber unter dem Einfluss der zur Erhärtung angewandten Agentien sehr leicht, so class es Schwierigkeiten bietet, die Contouren mit Sicherheit zu bestimmen. Der Inhalt wird krünclig und rerliert oft bedeutend an Tolum, so dass nicht selten grössere Lücken im Innern rles Auges zum Torschein kommen, die sicher im lebenden Auge nicht existiren.

Auf diese Zellen, welche Glaskörper- und Pigmentzellen zugleich sind, folgt num noch weiter nach innen und hinten die Retina $\left(P t_{\text {. }}\right.$. welche den hintern, splü̈risch oder etwas conisch rorspringenden und in den Sehnerven $(\Lambda . o p$.) sich fortsetzenden Theil des Auges bildet, und wie der Nerv von del schon genannten zarten imneren Cuticula überzogen wird. Terfolgt man den inneren Contour des Schnittes, so erinnert Nichts daran, dass man auf eimmal an der Grenze zweier physiologisch so mngleichwerthiger Zellcategorieen steht; die Richtung, Dicke und das Anssehen der beiden Zellformen, wie die Lage und Grösse der Keme sind sich gleich geblieben; nur die bei näherer Untersuchung sich zu erkemnen gebenden Nervenfasern, die zu den Retinaelementen treten, machen cinen gevichtigen Unterschied.

Die Petinazellen (Fig. 2 Taf. I) reichen mit ihren vorderen, durch besondere Bildungen Stäbchen - characterisirten Enden (St.) bis ungeführ in die Nitte des Anges. wo sie an die quergelagerten, durchsichtigen Enden der sie umgebenden Zellen stossen. Sie sind spindelförmig, liegen dicht aneinander, und sind ganz mit dunkelbraunem Pigment angefüllt. Die grossen, blïschenfömigen, ovalen Kerne derselben liegen etwas linter dem grössten Querschnitt, und gleichen in jerler Beziehung vollkommen tlenen der andern Zellen des Auges.

Die Stäbchen (Taf. I Fig. 1 -3. St.) sind sehr schwierig zu untersuchen, und ich kann nicht behaupten, dass neine Beobachtungen ïber sie erschöpfend wären. Sie umgeben das cylindrisch ansgezogene Vorderende der Retinazellen als eine demselben dicht anliegende, rorn und hinten offene Röhre, wenigstens anscheinend, demn es ist mir nicht gelungen, Querschnitte davon herzustellen. und an iliesen zur Entscheilung zu gelangen, ob sie im ganzen Junfang geschlossen, orler ob die Continuität mehr orler weniger weit unterbrochen ist. In frischem Zustande sie zu untersuchen, ist wegen der Schwierigkeit, sie zu isolinen, unl ihrer wie bei allen Arthropoden ungemein starken Quellbarkeit eine undankbare Aufgabe; ich labe rlamit keine andern Resultate erreicht, als dass ich gesehen habe, dass ihnen der bekannte rosenfarbige Schimmer ebenfalls zukommat. - ln der Platmchlorid-Chromsïme-Nischung halten sie sich relativ gat; sie erscheinen flann stark lichtbrechend und glasartig durchsichtig, olme körnige Trülıng. Sie liegen palissadenartig neben einander, in gleichen Nivean, meist sich berührend; die Reilıe verlünft bald einfach gerade, ball ist sie rorn etwas concar; die seitlichen Stübchen fand ich immer der Augenaxe etwas zugeneigt. 
In Fig. 2 sind einige Retinazellen von einer reifen Larve ron Dytiscus marginalis bei stïrkerer Vergrösserung gezeichnet. Augenscheinlich ist das Verhalten rler stark lichtbrechenrlen Substanz der röhrenförmigen Stäbchen zu der ihre Ilöhlung bis vorn erfüllenden Fortsetzung des Zellenkürpers genan das gleiche, wie das einer Cuticula zu ihrer Matrix, h. h. es macht den Eindruck. als ob die Stäbchensubstanz eine Ansscheidnng des vorrleren Theiles der Retinazelle wäre. Ob dies num wirklich die Genese der Stäbchen ist, oder ob sie ihren Ursprung einer partiellen Unwandlung des Zellenkörpers verdanken, das ist eine Frage, die sich nicht so leicht mit Bestmmontheit entscheiden lassen dürfte. Für unsern Zweck ist sie aber aureh ziemlich gleichgültig; es genügt, schon hier zu constatiren, dass das Stäbchen immer seinen Ursprung einer mit ihm in imuigstem Zusammenhang stehenden Zelle verdankt, die ilnerseits wieder in eine Faser des Opticus äbergeht; dass das Stäbchen also nie eine selbständige, sondern immer erst eine secundäre, abgeleitete Bildung ist. - Wenn ich von num an die Stäbchen als Cuticularbildungen bezeiclue, so geschieht das blos der Küurze wegen, und es ist selbstrerständlich damit keineswegs eine Herabsetzung ihrer physiologischen Bedentung ausgesprochen, ebensowenig als eine Gleichstellung mit den unter der gleichen Collectivbezeichnung zusammengefassten Integunentbildnngen der Arthropoden und anderer Evertebraten.

Die hier exörterten Beziehmugen der Stäbchen zu den Zellen der Retina smol fundamental bei den Arthropoden, und, soweit sich das übersehen lässt, nicht mur bei diesen, sondern vielleicht bei allen Sehorganen in dem gesammten Thierreiche. Es mag deshalb schon hier nachdrüicklich darauf hingewiesen werden, obschon die ausführliche Erörterung einem späteren Capitel vorbehalten werden muss.

Kommen wir aber wieder auf unsere Beobachtungen zurtïck, so habe ich noch anzuführen, dass es mir zuweilen den Eindruck gemacht hat, als ob der im Innern des Stäbchenhohlrames befindliche cylindrische Fortsatz der Retinazelle sich oft noch um ein Geringes nach vorn über das Stäbchen hinaus erstreckte; es ist aber nicht leicht, darüber Sicheres auszusagen. Der Regel nach war aber das Ende so beschaffen, wie es Fig. 2 zeigt.

Wie schon angeführt, gehen die Retinazellen nach hinten, unter allmäliger Zuspitzung jenseits des Kernes, je in eine Opticnsfaser über. Das ganze Verhalten ist ein so einfaches und relativ so leicht zu übersehendes, dass schwerlich ein Zweifel dagegen sich erheben kam. Es fehlen lier - wie überall hei den Arthropoden, um das gleich voranszuschicken - durchans jene complicirten Structurverhältnisse, wie in die Nervenbahn eingeschobene Ganglionzellen etc., welche das Verständniss des Anges bei Vertebraten und Cephalopoden in morphologischer wie in physiologischer Hinsicht so sehr erschweren.

Die einzelnen Nervenfasem gehen direct mol ohne nachweisbare Grenze allmälig in den Zellenleib üher, dessen Pigmentirung sich anch auf sie eine Strecke weit ansdehnt; die Verbindnng zwischen dem Endorgan der Retinazelle und der centripetal leitenden Opticusfaser wird allein und ansschliesshich durch die Zelle rermittelt, welcher jenes erstere, das Stäbchen, seinen Ursprung verdankt.

Ich möchte num noch einige Bemerkungen über die Fig. 3 Taf. I, die einen Theil eines der länglichen Angen von einer ansgewachsenen Larve in schiefem Schnitte darstellt, hier anfügen. Die Linse ist hier ganz durch die schiefe Schnittführung in Wegfall gekommen, und mit ilır der grösste Theil der nicht percipirenden Angenzellen. Man erkennt wierter die Hypodermiselemente unter dex dicken. aussen intensiv tingirten Cuticula; in der Vitte der Wölbung sieht man solche im Querschnitt. Die dicke Retina besteht aus einer grossen Anzahl von Zellen, von denen die seitlichen sich stark nach der Nitte zusammenneigen, wobei ilıre Stäbchen tragenden Enden bei- 
nahe horizontal zu liegen kommen; die mittleren lanfen mehr gerarle gegen die Linse. Dix Stïbchen füllen hier, radiär gestellt, eine auf der vordexn Retinaseite gelegene Fmehe ans, mul sind weit zahlreicher vorhanden als bei den jüngeren Larven. wie anch die Linse mngleich schöner als bei jenen ansgebildet erscheint. Der Sehnerv ist bei einer solchen Ansicht nicht zu sehen.

Das Prïparat, das hier bei einer mässigen. ca. 120fachen Tergrösscirnng gezeichnet ist, war durch Erhärtmo in Weingeist gewonnen, mol für manche Einzelleiten nicht günstig.

Wenn wir num, besonders anf Fig. 1 finsemu, den Tersnch machen, den morphologischen Werth der einzehnen Theile des Anges zu bestimnen, so ergielt sich leicht, dass wir die simmutlichen Weichtheile des Anges als Nodificationen der Elemente einer und derselhen Zellenlage, welche zugleich die Grundlage des Integumentes ist, ansehen müssen. Alle Thatsachen weisen daranf lim, rlass sowohl die nichtpercipirenten, als anch die der Perception dienenden Zellen dieser Angen nur umgelildete Hypodemiszellen sind, die entsprechend ihrer andern Function modificirt worden sind. Die einfachen Hyporlermiszellen scheiden die allgemeine Cuticula ans; die Linse ist nur eine Cuticularbildung von besonderer Art, die demnach anch den darnnter liegenden Zellen ihre Entstehmg verdankt. Diese Zellen sind theils ganz (in der Linsenperipherie) mit Pigment erfïllt, theils nur in ihrer imneren Hälfte, wïhrend die vordere Hälfte sich durch grosse Durchlässigkeit für das Licht anseichnet. Diese beiden Formen bilden zusammen die. seitlichen Wandmgen einer hinter der Linse sich bildenden Einstülpung der Hypodermis, deren Lmmen aber durch das starke Wachsthmm der Zellen zum Verschwinden gebracht wird. Der Borlen der Einstülpung, aus ursprünglich den ïbrigen gleichwerthigen Elementen gebildet, differenzirt sich an meisten, ohne aber ans der Reihe heransutreten; ans ilm geht die Retina hervor.

Die hier geschilderte Entstehung dieser Augenform ist nun nicht direct beobachtet, aber die topographischen Beziehmoen des ganzen fertigen Organes lassen eine andere Dentung nicht zn, mud was allenfalls an Beweiskraft noch fehlt. wirt durch später noch anzuführende Erfahrungen an andern Angen ergänzt. Wir können denmach schon hier eine allgemeine Folgerung ziehen und sie, wie die oben schon gemachten, voransschicken, dass nämlich überall bei den Arthropoden das Inge mit allen seinen Weichtheilen aus einer und dersellsen Grundlage, der Hypodermis, durch entsprechende Umgestaltung mol Lmlagermo der in Mitleidenschaft gezogenen Elemente sich herrorbililet.

Ein weiteres Noment, das bei diesen und den gleich zu besprechenden Angen von Acilins sich findet, nud sie scharf den andern, nachher zu behandehnden Formen des Stemma gegenüberstellt, berulıt darauf. dass hier kein sellsständiger sog. "Glaskürper" rorkommt. Pigmentschicht und Glaskörper, deren Functionen sich diametral gegenüberstehen, gehören wenigstens insofern zusammen, als die imeren der peripherischen Zellen mit ihrem Vorderente Glaskörper, mit ihren Hinterende Pigment führend sind, wïhrend die änseren lediglich zum Ausschlusse fremden Lichtes dienen. - natürlich abgesehen von ihrex Bedentung als Matrix der Cuticula.

Was mir von früheren Untersuchungen dieser Angen bekannt geworden ist, beschränkt sich anf einige spärliche Angaben, die wir Joh. Müller ${ }^{1}$ ) und später Leydig²) rerdanken. Sonst scheint sich Niemand dafür interessirt zu haben.

J. Nüller beschreibt zunächst die Stellung der einzelnen Angen zu einander; ihre Linsen sind nach ihm linter der entsprechend gewölbten Hornhant gelegen. klein und krystallhell. bei

1) J. Mïllex in: Meckel's Archiv für Physiologie 1829. pag. 39.

2) Leydig. Das Auge der Gliederthiere. Tübingen 1864. pag. 37. - Tafeln zur verglcichenden Anatomie. Tat: VI. Fig. 4. 
den rmalen kugelig, bei den länglichen Angen walzenförmig. Nach innen von den Linsen folgt noch je eine schware Krugel, die bei den länglichen Angen seitlich comprimirt ist. Gegen die Linse zu zeigen diese Kingeln Grübchen, denen das schwarze Pigment fehlt, und Müller vermuthet, dass hier noch ,eine dritte Mlaterie orler Glaskörper innerhalb der becherförmigen Retinarorlanden ist".

Wenig eingehend im Tergleich mit seinen sonstigen Untersuchungen über das Arthropodenauge ist die Beschreibung, welche Leydig von diesen Auge entwirft. Hinter der aus einer Terdickmg der Cuticula herrorgegangenen Limse ist das becherförmige ,Chorioidealpigment" gelegen, umgeben von einer hellen zelligen Zone, welche unmittelbar aus dem Sehnerven hervorgeht, und die er als "Analogon der gangliüsen Basis, ans welcher etwa bei der Ameise, bei der Biene das Chorioidealpigment rles einfachen Anges sich erhebt", anzusehen geneigt ist. Ob, wie Müller meint, ein Glaskörper, (d. h. nach Leydig's Auffassung nerröse Gallertkolben, die er bei den übrigen einfachen Angen als percipirende Organe beschreibt,) vorhanden ist, lässt er unentschieden.

Ton dieser "nerrösen Schale", welche Leydig an dem Auge der Dytiscus-Larve beschreibt, habe ich nichts gesehen; jch bin deshalb anch ansser Stande, eine Mnthmassung darüber zu äussern.

2. Angen der Larven von Acilins sulcatus. - Noch interessanter als die vorstehend beschriebenen Angen sind die der Larven von Acilius sulcatus, die ich in der ersten Hälfte des Sommers reichlich erhalten komte.

An dem ungefïln dreieckigen, rom verbreiterten, nach linten gegen das erste Thoracalsegment hin sich halsartig verschmälemden liopt. der von oben nach unten stark alygeplattet ist, fallen zwej an den Seitenrïndern gelegene tiefschwarze Stellen anf, die sich scharf von der bräunlich gelbgranen Grundfarbe der Cuticula des Kopfes absetzen. Diese Stellen sind unregelmüssig gefornt, und greifen sowohl nach oben als nach unten über. Im Bereiche dieser Flecken liegen die Angen, ron denen sich anch hier jederseits sechs vorfinden. Ungemein verschichen ist die Grössenentwickelung rieser Angen, und ebenso die Totalform anch der innerlichen Weichtheile. Anf der Oluerseite fallen zumïchst anf die grössten, von denen je zwei dicht nebeneinander gelagert jeder Kopflälfte angehören; sie ïbertreffen die ïbrigen vier ganz ansserordentlich, und verursachen mit ihren stark prominirenden Linsen ansehnliche Hervoragungen, die namentlich bei Ansichten des Kopfes im Profil sich bemerklich machen. Ausserdem befindet sich auf der Iorsalseite des Koyfes noch jederseits ein kleines Auge, das weit nach hinten gerïckt und dem Rande genïhert ist; ein weiteres, ebenfalls kleines, liegt gerade am Seitenrande und noeh weiter nach limten, umi endlich liegen noch zwei etwas ansehnlichere auf der Unterseite des Kópfes.

Ich habe sehr zahlieiche Exemplare dieser Thiere untersucht, und namentlich rlen Bau der. Hauptaugen eingehend studirt. Genau genommen verliente eigentlich jerles rlieser Augen eine besondere Beschreibung, da bei näherer Bekamntschaft mit dem Objecte man sehr bald eine Anzahl für das morphologische Verhalten zwar unwesentlicher, aber sehr constanter Eigenthümlichkeiten im Ban derselben enteckt. lch werde mich aber auf den Ban der Hauptangen und eines der beiden grösseren, der Tnterseite des Kopfes angehörenden Augen zweiten Ranges beschränken. Ich verdanke meine Resultate hauptsächlich der Anwendung der Mischung von Platinchlorid und Chromsïme; letztere allein, sowie anch ausnahmsweise die Osmimsïme. haben mir anch gute Dienste geleistet. Die Terwendung ron Alcohol kann ich liefür nicht empfehlen.

Die beiden grossen Angen, mit deren Beschreibung ich begimmen will, haben dicht hintereinander an Seitenrande des Kopfes gelegene Linsen ron ca. 0,3 mm Durchmesser bei reifen Larven. Die zugehörigen Weichtheile bilden einen eylindrischen, nach hinten sich schwach ver- 
dickenden Zapfen, der über und über von tief blanschwarzem Pigment, mol ausserden noch von einer zarten darüber hinziehenden, sich anch anf den Sehmerven ausdelmenden Cuticula bedeckt ist; sein halbkugelig abgerundetes hinteres Ende stösst fast ummittelbar anf die Cnticula der Kopfunterseite. Die Angenaxe steht nicht senkrecht zum Integument, sondem bildet damit emen Winkel von ca. $45-50^{0}$ nach hinten; dieser Neignug entsprechend ist anch die Aequatorialebene der Linse nicht in derjenigen der allgemeinen Kopfoberfläche gelegen, sondern um einen entsprechenden Winkel darüber erhohen, wodurch die Cnticnla niedrige, schiefe Höcker bildet, die oben und rom von den Linsen abgeschlossen werden. Die Axen der beiden Angen jerler Seite lanfen im Ganzen annähernd der Medianebene des Kopfes parallel nach linten und unten. so dass man, um die besonders instructiven Längsschnitte zu gewinnen, longitudinal durch den Seitemand des Kopfes schneiden muss; genan parallel sind sie damit aber nicht, da die Axe des vorderen Anges etwas nach amsen, die des hinteren aber etwas nach imen rlagegen geneigt ist. so dass das Selifeld des letzteren mehr nach rom und innen gegen das des ersteren liegt. Es gelingt deshalb anch nicht, Schnitte durch die ganze Länge von beiden zugleich zn machen.

Beide Augen sind selır vollkommen organisirt, nicht nur, was ilure Dimensionen anbelangt, (auf eine Dicke von ca. 0,3 mm eine Länge von ca, 0,72 mm bei ansgebildeten Larven,) sondem anch in Hinsicht auf den Ban ihrer durchsichtigen Merlien und iluer Netzhant; sie übertreffen hierin die Augen der nahe serwandten Dytiscus-Larven bei weitem. Die von einen solchen (hinteren) Hauptange gegebene Abbildmg Fig. 4 Taf. I ist nach einem jüngeren, nur $10-12$ mm grossen Thiere entworfen; es verhält sich, abgeselın von der mmerischen Entwickehng der Elemente, genan wie das Ange der grossen, welehes für eine hinlänglich dentliche Viedergabe dinen zu grossen Ram beanspruclit hätte.

Der Infbau des Anges ans den, rerschierlenen Functionen ent-1rechend modificirten, Hypodemiszellen ist der gleiche, wie bei den vorhm beschiebenen Angen der Dytiscus-Larven. Die dünne, feste, in der Angenregion tief schwarzbran tinginte Cuticula (Ct.) zeigt dicht stehende, nach vom gerichtete, schnpenartige Wärzchen, die nu den Linsen fehlen. Die Linse sellsst ist selı schön biconvex, mit etwas stärkerer imerer Wöllong; sie zeigt sehr dentlich concentrische grobe Schichten, namentlich nach Erhärtmo in Chromsäure enthaltenclen Flüssigkeiten, die in verschiedenem Grade die Schichten tingirt, die änssersten, ältesten am intensivsten. Ausser diesen groben, in Fig. 4 angedenteten Znwachszonen sieht man, wemn bei der Entfürbung die Salpetersänre länger einwirkt, die Linse mter Beibehaltnng ihrer Form aufquellen, und dam treten äusserst feine, dicht und contimmirlich der innern Begrenzmng parallel lanfende Linien anf, als Andeutung einer Zusammensetzung ans sehr dümen Lamellen.

Die deutlich gekernten. farblosen, polygonalen Ilypodermiszellen $\left(H_{p}\right.$.) gehen nach der Linse zu unter allmäliger Aufnahme von Pigmentkömern, Terlängerung und entsprechendem Dïmnerwerden in Pignentzellen (Pg.) über. Noch weiter gegen die Angenaxe zu zeigen die folgenden Zellen im Wesentlichen dieselben Tnwandlmgen, die ich schon oben beschieben habe, nur mit dem einzigen Unterschiede, dass lier sïmutliche Zellen, mit Ausnahme rlerjenigen der Retina, mit dej imern Oberfläche rer Linse in Contact bleiben.

Die Elemente des ,Glaskörpers", der den weiten Ranm zwischen Linse und Retina ansfuillt (Gli. Fig. 4), sind in frischem Zustande zum weitans grössten Theil ihrer Masse völlig dnrchsichtig, und die Grenzen der einzehnen Zellen gegenenander nicht zu erkemnen. Nur an ihrem der Linse abgewandten Ende, welches der Mantelfläche des Augencylinders angeliört, findet sich eine dieses Ende erfüllende Pigmentanhäufung, das in Gestalt ron zienlich grossen, mnd dam hell-, unch kleinen, dam dunkelpurpurn gefürbten Tropfen den Kern ungiebt. Die 
rordersten zu ihm zu rechnenden Zellen. welche umnittelbar auf rlie in ihrer ganzen Länge pigmentirten folgen, besclureiben, wenn man rom pignentirten Hinterende ausgeht, nur einen schwachen Bogen mit ihren durchsichtigen Theil, um zur Linse zu gelangen; bei den weiter nach hinten gelegenen wird dieser immer stïrker; die in rler halben Länge des Anges ron der Mantelfläche entspringenden knicken schon unter einem rechten Winkel nach rorn um, und die noch weiter nach hinten gegen die Netzhant hin gelegenen laufen rlex Concarität derselben parallel bis zur Angenaxe, um dann muter einem spitzen Winkel nach rom unzubiegen. So entsteht auf Lüngsschnitten ein digenthümliches Bild; in der Mitte des Anges verläuft ein von der Linse ansgehender Stamm, der sich his dicht ror die Retina erstreckt, und ams einer Unzahl sehr feiner Fäilen besteht, die in ganzen Umfang sich ron ihm loslösen, 1 m in relativ dicke Aeste, wenn ich so sagen darf, sich fortzusetzen. Bei Platinchlorid-Präparaten gerimnt dabei der Zellenimlalt. und es treten Schrumpfungen auf, die das Bild weniger elegant machen; verdümnte Osmiumsäure crhält dagegen das Anssehen der Zellen recht gut. wenn ilue Einwirkung nicht zu lange danert, und man die Präparate ror dem Schmeiden in starkem Alcohol härtet.

Fig. 5 Taf. I zeigt die Mantel-Enden einiger Glaskürperzellen, wie sie bei Tangentialschinitten erhalten werden, ron der Fläche; auch hier ist das Pigment zerstört. un die Kerne sichtbar zu machen.

Das Interessanteste des Auges ist num aber dessen Retina (Rt. Fig. 4), die eine ganz auffallende Eigenthünlichkeit der Structur besitzt. lm Ganzen ist sie halbkugelig, mit riner der Linse zugewandten flachen Anshöhlung. wnd besteht aus schlank pyramidalen, stark pigmentirten, radiär gestellten Zellen, die wieder rom je ein Stäbchen tragen, und hinten mit Opticusfasern in Zusammenhang stehen. Auffallend und meines Wissens nu hier vorkommend ist eine Spalte $\left(S_{p}\right.$.). welche die Retina ilwer ganzen Breite und fast ihrer ganzen Dirke nach durchsetzt. und sie in zwei Hälften theilt, rlie eine etwas moleiche Entwickelmg zeigen. Sowoll das rordere als das hintere Ange jerler Seite besitzt diese Eigenthünlichkeit, die den andem Angen fehlt, wenigstens nicht entfernt in dieser Weise znkommt. Die beiden mter sich gleichgrossen Retinahälften stehen an dem Hinterende der Spalte nur durch eine dïmne Brücke, die durch die darüber streichenden Fasern des Opticus gebildet wird, in Zusammenlıang. Die Spalte selbst liegt übrigens etwas geneigt zur Augenaxe, und zwar so, dass ilure Ebene sich mehr einer senkrechten auf die Cuticula rler Kopfoberfläche nähert. Da sie quer durch das Ange zieht, so erlı̈lt man bei Schnitten parallel der Medianebene Profilansichten derselben, wie in Fig. 4; um sie in ihrer ganzen Auslehnung zu übersehen, muss man Querschitte durch den Kopf, parallel dem Stirnrande desselben, machen. Bei reifen Larven beträgt ihre Tiefe $0,08-0,1 \mathrm{~mm}$.

Diese Retinaspalte wird eingefasst ron zwei Reihen colossaler Stäbchen, die dicht aneinander gelagert ihre Wandung in der ganzen Tiefe bilden (St Fig. 4). Betrachtet man diese ron der Seite, auf Querschnitten durch die Retinaspalte, so stellen sie sich als schmale, stabförmige, stark lichthrechende, völlig durchsichtige und homogene Gebilde dar, die rom ein etwas abgerundetes breiteres Ende haben. mr nach hinten in eine ziemlich feine Spitze anslaufen. Ist der Sehnitt nicht ganz senkrecht auf die Ebene der Spalte geführt, so kamn man die Nebeneinanderlagerung derselben beim Einstellen des Focus in die Tiefe gut übersehen. (Fig. 7 Taf. I.)

Betrachtet man einen entfürbten Schnitt rler Retina parallel der Ebene der Spalte, auf dem man diese in ihrer ganzen Ausdehmmg rerfolgen kann. so überzengt man sich leicht, dass sie überall, durch die ganze Ansdehnung der Petina, diese bis fast ganz an iluren hintern Rand durchsetzt, und dass die unter sich parallel gelagerten Spaltenstäbehen nach beiden Seiten hin entsprechend der Dicke der Netzhant an Länge abnehnen. Bei solchen Ansichten kann man 
leicht noch weiteren Aufschluss über den Bau dieser sonderbaren Gebilde erlualten. Stellt man anf die dem Auge näher liegende Waurl der Spalte ein, nähert sich also den Stäbchen mit dem Objectiv von ilurer der zugehörigen Retinahälfte anliegenden Rïckenseite, so glaubt man anfïnglich einfache, aber paarweise einander genäherte Stäbchen vor sich zu haben (Taf. I Fig. 6). Senkt man nun den Tubus langsam nach der Tiefe hin, so rücken die Stäbchen jedes Paares scheinbar einander näher, und verschmelzen endlich zu einem einzigen. Bei noch weiterer Tiefeneinstellnng kommen dicht darunter die Stäbchen der entgegengesetzten Wand mit ihren vorderen freien Kanten zum Vorschein, scheinbar einfach, m sich ihrerseits bei fortgesetzter Tiefeneinstellung wieder in je zwei anfznlösen. Diese successir anftretenden Bilder sind natürlich nur der optisehe Ausdruck für einen rinnenförmigen Pau der Stïbchen: sie bestehen aus zwei dünnen Lamellen, die anf ihrer dem Spaltenlumen zugewandten Seite unter einem spitzen Winkel zusammentreffen. Querschnitte zweier gegenüherliegender Stäbchen würden also etwa so anssehen $><$.

Frisch sind die Stïlwhen ansscrordentlich schwierig zu untersuchen, theils wegen iluer grossen Qnellbarkeit in andern als den natirlichen Nedien, theils wegen der Schwierigkeit, sie ans der pigmentirten Umgelung frei zu erhalten. Ich kam deshalb weiter nichts über sie anssagen, als dass sie ebenfalls, wie bei so zahlreichen Arthroporten, rosenroth gefürbt sind. Leichter wird die Untersnchung, wenn man die Thiere nur kmze Zeit, etwa 1/2 - 1 Stmude, in Weingeist geworfen hat. Jene Fïrbung ist damn allerdings verschwmiten, aber die Quellbarkeit ist beseitigt, ohne dass schon stirende Verändernngen in der Form und Durchsichtigkeit Platz gegriffen hätten. Zerzupft man damn solche Mugen, so lüst sich, wie bei dem tiefen Eindringen der Retinaspalte begreiflich, die Netzliant hesonders leicht in dieser Region, und man hat dam am eliesten Gelegenheit, diese Stäbchen in zusammenhängender Feihe zu übersehen. Ein Stück eines so erhaltenen Prïparates (etwa der vierte Theil des ganzen erhaltenen Fraginentes) zeigt Fig. 8 Taf. I. Die Stäbchen sind lier von der der Spralte zngewandten Seite lier zesehen, mo erscheinen als einfache, seitlich sich berührende, in grosser Regehnäsigkeit parallel nebeneinander verlaufende Gebilde; bei Einstellung in die Tiefe erkannte ich anch dentlich das scheinbare Anseinanderweichen in zwei getrennte Stäbchen, wie dies durch ihre Rimnenform bedingt ist. Das untere Ende derselben ist durch eine dichte Pigmentlage verdeckt, die sich in Streifen stellenweise in die Höhe zieht. Dieses Pigment exkennt nan anch auf Schnitten wie Fig. 4, namentlich vor der Entfirbung; es füllt die spalte bis zur Nitte oder darüber von unten her aus. Nach ller Entfürbung ist es oft nur schwer zn erkennen, da die noch übrig bleibenden Granulationen leicht übersehen werden können. Die vorderen Stäbchenenden ragen noch ziemlich weit darüber hinaus, und endigen scharf abgeschnitten alle im gleichen Nivean. Nach linten treten unter dem Pigmente starke, sich rasch verjüngende, protoplasmatisch aussehende Fasem hervor, welche durch selır kleine brame Körnchen und grosse gellogefürbte Pigmenttropfen, die fast wie Fett anssehen, ansgezeichnet sind. Sie sind die Anslïufer derjenigen Retinazellen, zu denen die Stäbchen als Coticularbildungen gehören, und ihre rasche Verjüngung nach unten deutet anf den Uebergang in je eine Opticusfaser hin.

Wenden wir unn noch der übrigen Retina unsere Aufmerksamkeit zu, so ist zunächst hervorzuheben, dass die beiden durch die Spalte getrennten Hälften derselben sich durch eine mngleiche Entwickelung ihrer Stïbchenlage von einander mnterscheiden. Dies gilt für beide Augen jeder Seite, in denen man je eine Hälfte mit stärker und eine andere mit geringer entwickelten Stäbchen erkemnen kann; aber die je einander hinsichtlich der Stäbchenentwickelung entsprechenden Hälten haben zn einander eine umgekehrte Lage. Das in Fig. 4 gezeichnete Auge ist, wie schon vorlin bemerkt, das hintere; es ist nun möglich, den Schmitt so zu führen, dass 
man neben dem Retinalende desselben, etwa da, wo in der Figur der Sehnerv aufhört, einen Schnitt durch die Retma des vordem Auges erhält, wobei man freilich auf Uebersicht des Glaskörpers ete. verzichten muss. In dem gezeichneten Ange ist nun die vordere Hälfte der Petina, oder wem man in Anbetracht der schiefen Stellung der Angenaxe zum Integumente lieber will, die ventrale durch den Besitz beträchtlich stärker entwickelter Stäbchen vor der hinteren oder clorsalen Hälfte ansgezeichnet; in vordern Auge aber ist die so bevorzugte Hälfte die hintere, respective dorsale. - Die Entwickelıng der Stäbchen, besonders in ler Länge, variurt selır anf beiden Hälften; darin aber kommen sie überein, dass die längsten imner der centralen, von der Retinaspalte durchsetzten Region angehören, und von da aus alhnählig nach der Peripherie abnehmen. Selbst die an meisten entwickelten Stäbchen der gewöhnlichen Categorie erreichen nicht amnähernd die Dimensionen der die Spalte anskleidenden grossen. werden viehmeln von diesen mn das drei- bis fünffache äbertroffen; mgefähr im gleichen Verhältniss stehen wieder zu ihnen die Stäbchen der gering entwickelten Retinahälfte. Gegen die Peripherie hin werden diese so niedrig. dass sie auf Figuren im Naassstab der Fig. 4 gar nicht mehr oder nur als schwer zu bemerkender. Samm wiedergegeben werden kïnnen, an welchem dam die Stäbchen selbst nicht mehr sichtbar sind. Ob übrigens die in der Abbildung wierlergegebene schräge Lage, die schupenartige Aneinanderlagerung derselben blos Kimstproduct oder in der Natur begründet ist, wage ich nicht zu entscheiden; ich fand es so hänfig, dass ich mich remulasst sah, die Zeichnung so wiederzugeben.

Die, wie schon bemerkt, radïir gestellten Zellen der Retina sind ebenfalls ron sehr verschiedener Länge, aber in beiden Hälften gleich. Die peripherischen sind die kürzesten, und verlanfen. voun Kernende an gerechet, von rom nach linten; je nähri aber dem Retinacentrum, desto meln wird ilne Richtung axial und ron hinten nach rom. Ihre Gestalt ist eine langgezogen pyranidale; hinter den Kern verschmälern sie sich plötzlich in die Opticusfaser. Sämmtliche Farern treten zu einen dicken Nervus opticus (N. op.) zusammen, dessen Verhalten an centralen Ende ich nicht verfolgt habe.

Ueber die Natur der Stäbchen Aufschlnss zu erhalten, ist mit denselben Schwierigkeiten verknüpft, die schon olıen. gelegentlich der Dytiscuslarven hervorgehoben wurden. Was zunäclıst die Stäbchen der Retinaspalte anbelangt, so sind dieselben sicher als einseitige Zellenansscheidungen anfzufasmen; die in Fig. 4 dicht neben den Hinterenden dieser Stäbchen gelegenen Kerne gehören mzweifelhaft diesen Zellen an, welche nach rom spitz anslanfend ihrer ganzen länge nach den Stäbchen anliegen. Die andern Retinazellen besitzen solche Stäbchenansscheidungen blos am vordern Ende; dass sie auch hier nur einseitig, und nicht das ganze Ende umgebend, anftreten, dafür scleinen mir die Fig. 9 A, B, C Taf. 1 zu sprechen, die nach Fragmenten gezeichmet wurden, welche beim Zerzupfen grosser Angen nach kurzer Einwirkmg von Alcohol inmer in Nenge in der Zusatzflïssigkeit hermmschrammen. Es ist nicht mmöglich, dass übrigens die unter C gezeichneten Fragmente von grosen Spaltenstïbchen sind. die doch noch der Qnellung moterlagen; wenigstens widersuricht die noch dentlich Vfömige Gestalt, mo das Verhalten der Stäbchen zun Protoplasma diesem Einwande nicht. Kamn dürfte derselbe die unter A und B dargestellten treffen, bei denen, besonder's dentlich bei B, die Stäbchensubstanz etwa löffelförning ausgehöhlt der Natıix anliegt.

Endlich wäre noch anf die continuirliche Reihenfolge der Keme von der Hypodermis an durch die sïmmtlichen in die Bildung des Sehorgans verflochtenen zelligen Elemente hindurch bis anf der anden Seite wieder in die Hypodermis hinzuweisen, gerade wie bei den Larven ron Dytiscus, und zu denselben Folgernngen berechtigend. 
Wenn man Gelegenheit gehabt hat, die Thiere lebendig zu beobachten, und dabei gesehen hat, wie ausgezeichmet sie den Nachstellungen - namentlich wemn man sich ilmen von oben nähert zu entgehen, ebenso aber ilue Bente zu fangen wissen, dam liegt der Gedanke nahe genng, in der Retinaspalte mit ihren riesigen Stäbchen eine Art von Forea centralis, eine Stelle Jesonders gesteigerter Wahnelmungsfühigkeit, zn erblicken. Dabei ist freilich die lineare Anordnumg der Stiibchen in zwei einander so nahe liegenden Reilien ein selı eigenthünliches Factum. für das (ine plansible Erklärmug zn geben ich ansser Stande bin. Leichter dürfte es sein, die ungleiche Ausbildung der beiden durch die Spalte geschiedenen Retinaluälften sich vorläufig zurechtzulegen. lis steht wohl nichts im Wege, die Entwickelnng der Stäbchen als einen anatomischen Ausdruck ler physiologischen Leistumgsfüligkeit anzusehen. Damn hätten wir wieder eine Art von Arbeitstheilmng zwischen den beiden grossen Dorsalangen der einen Seite, die schon in der Divergenz der Sehaxen beider ihre erste Andentung findet. Das vordere Ange, dessen Sehfeld mehr die nach anssen vor dem Stirntheil liegenden Gegenstïnde übersieht, wird namentlich dentlich solche percipiren. die mnterhalb der Angenaxe gelegen sind, deren Bild also anf die dorsale oder hintere Retinahälfte projicint wird; das hintere, nach rorn und etwas meln nach imnen gerichtete Ange ungekehrt die meln oberhalb der Verlïngerung der Angenaxe liegenden.

Wem wir diesen grossen Angen anf Grund ihres anatomischen Banes anch ein feines Unterscheidungstermögen zngestehen müssen, so werden wir ilmen dagegen, anf demselben Grunde fussend, ein nu beschränktes Gesichtsfeld eimräımen kömnen, da die Netzhant nur einen relativ sehr kleinen Theil der imaginären Kugelfläche bildet, deren Centrum mit dem der Linse zusammenfïllt, und deren Radius die Entfernme dieses Centrums von der Retina ist. Anf dieser Netzhaut werden wohl sehr klare Bilder änsserer Gegenstände entworfen werden, nach dem rollendet schönen Ban der Linse zu schliessen. aber nu innerhalb eines engen Rahmens. Was diesen Augen demnach zn leisten nicht möglich ist, ersetzen die vier anderen, kleineren, nach verschiedenen Richtungen hin sehenden Hülfsamgen, über welche nun noch einige Bemerkmgen am Platze sein dürften.

Eines der beilen der Banchseite angehörigen Augen, und zwar das grössere, ist auf denn Lïngssclmitte in Fig. 10 Taf. I gezeichnet, nach voransgegangener Chromsüure-Erhärtung und unvollständiger Entfürbung durch Salpetersï̈me.

Die kleinen Augen muterscheiden sich, ron den auführlich beschriebenen grossen zunächst durch die abweichende Form der Linse, die bei einigen vollständig kugelig, bei andern (Fig. 10, L.) eiförmig ist mit in die Angenaxe fallendem grösstem Durchmesser; ferner durch andere Gestaltıng des Glasköruers, dessen Fireitendurchmesser die in die Argenaxe fallende Lïngendimension um ein Anselunliches übertrifft, mn endlich durch die grosse Flïchenausbreitung der Retina. Durch alle diese Einzelfactoren erhiilt das Auge eine in der Richtung der Angenaxe etwas comprimirte sphärische Gestalt, die bis zur querovalen gesteigert werden kann.

Das dargestellte Ange ist einer fast völlig ausgewachsenen Larve entnommen. Bezr̈glich seiner Lage ist zn bemerken, dass dasselbe sich zwischen die Hinterenden (Retinae) der beiden grossen Hauptaugen emlagert, so dass man auf Sclmitten durch eines der letzteren häufig mehr oder weniger vollständig seinen Ban übersehen kann. Die Linse ist schön eifümig. mit dem spitzeren, stark rorspringenden Pol nach aussen gerichtet. In der niichsten Umgebung der Linse verdickt sich die Cuticula bedentend, und der ringförmige Ansatz der letzteren an erstere lïsst dentlich zwei Schichten erkennen, woron die änssere einfach die Fortsetzung des Integumentes bildet, das allmälig dïmner und farblos werdend olme Trennmgslinie in die vorderste. 
Linsenschicht übergeht. Die mnere Schicht bildet einen überall, auch von der Linse, scharf abgesetzten Fing, nud trägt zur Fixirung der letzteren in ihrer Lage bei.

Das Verhalten der Hypodermiszellen, iln Uebergang in pigmentirte, dann in durchsichtige Elemente des Glaskörper's ist der Hanptsache nach dasselbe, wie bisher. Erwähnenswerth mag nur sein, dass die Pigmentzellen horizontal, ja selbst mit den äusseren Enden nach limten gerichtet, gegen den Linsenumfang treten. Schon wesentlicher ist, wenigstens dem Anscheine nach, die Entwickelung nud der Terlanf der Glaskörperzelleu, verglichen mit denen der Hauptangen. Während nämlich, wie wir uns erimern, die der letzteren mit ibren nach anssen umgebogenen kemtragenden Innenenden die Nantelfäche des Anges bilden, schemen sie hier vor der Netzhant, zu der sie fast gerade verlanfen. zu endigen (Fig. 10, Gk:) Tergeblich habe ich aber zwischen Netzhant mo Linse nach Kernen gesncht; selbst nach Anwendung ron Reagentien, die solche sonst überall dentlich machen, und bei sehr starken Vergrösserungen gelang mir dies nicht. Nan könnte annelmen, dieselben seien vollständig zu Grunde gegangen, wenn nicht in der ringfömigen Pigmentzone ror der Netzhantperipherie eine Ansammlung von Kernen sich fünde, die fast zu gross ist, um allein den Pigmentzellen anzugehören. Ich möchte in der That der Annahme, dass ein Theil dieser Kerne den Glaskörperzellen zugehöre, derẹn feine, nach anssen mimgebogene Hinterenden mir entgangen sein mögen, den Vorzug gelsen vor jener erst angedenteten, sie seien zu Grunde gegangen, bin aber nicht im Stande, diese Mnthmassung sachlich zn begründen, und muss deshalb die Frage vorläufig noch offen lassen.

Die rorn halbkugelig ansgehöhlte Retina, die mit ihrem Rande der Cuticula ganz nahe rückt, besteht ans im Cranzen ziemlich gleichmïsig entwickelten Zellen (Rt. Fig. 10), denen am Vorderende die nnter sich elienfalls wenig unterschiedenen Stäbchen (St.) anfsitzen. Die Zellen sind hier relativ massiger, die Stïbchen ebenfalls dicker als bei den Scheitelangen, das Unterscheidungstermëgen demuarh wohl weniger entwickelt, was aber nach der andern Seite hin durch das grössere Gesichtsfeld compensirt wird. Der directe Uebergang der Fietmazellen in Nervenfasern konnte an andern Präparaten besser constatixt werden, als an demjenigen, das der gegebenen Figur zu Grunde lag. Die Verschmälermng der Zellen in die Fasern des Opticus geschieht anch hier dicht hinter den Zellkcmen, die leicht am hintern Rande der Retina in continnirlicher Reihe stehend erkamnt werden. - Anch die auf den Opticus sich eine Strecke weit fortsetzende Pigmentirung der Zellen ist wie bei den Hauptangen vorhanden.

In der Nitte der Retina markint sich eine Jesondere Stelle, die man als eine leichte Andentung einer Retinaspalte anseluen kam. Nan erkent dort eine kleine, aber dentliche Unterbrechung der Stïbchenlage, der anch eine ebensolche der Retmazellen entspricht; man darf sich diese letztere aber nicht so gross im Leben rorstellen, wie sie anf der Figm erscheint. da das Prüparat beim Schneiden etwas gerlrückt mol gezerrt wurde. Allerdings sind die Stälıchen an dieser Stelle kamn ron denen der andern verschieden; aber bei emem der andern Angen, wo diese Continuitätsmerforechung noch dentlicher ist, treten sie beiderseits ror den benachbarten schon auffällig durch grössere Länge mol stïrkere Dickenentwickelung herror.

Die Stïbchen $(S t$.$) sind mir anch hier nicht in der Weise klar geworden, wie ich es$ wünschte. Von der Netzhantfliche gesehen, bieten sie einen eigenthümlichen Aublick (Fig. 11 Taf. I); sie stellen nämlich keineswegs das von andem Thieren bekamte Nosaik dar, sondern bilden ein helles Naschenwerk, welches rlunkelpigmentirte Stellen einschliesst. Die Naschen smd ziemlich regelmäissig angeordnet, rundlich polygonal (4-6eckig) und jedenfalls nur durch die Annahme von Cuticnlarsämmen der Retmazellen zn erklären. Es ist mir indessen niclıt geglückt, in den hellen Stäbchen noch die Trennungslinien des Antheils je zweier benachbarten Zellen nachzuweisen, 
und so zu entscheiden, ob die Sümme geschlossenen, oder aber mehr orler weniger weit offenen Hohlcylindern entsprechen. Nach dem oben schon Angefüluten neige ich aber melı zu letzterer Annalme, für welche auch Längsschnitte wie Fig. 10 melr zu sprechen scheinen.

Der Tollstindigkeit wegen führe ich noch an, dass anch die kleinen Angen von einer feinen inneren Cuticula muhüllt werden.

Damit kamn ich diese Darstellung beschliessen. Beror ich jedoch zu andern Angenformen mich wende, möge es mir gestattet sein, noch eines eigenthünlichen Sinnesorganes dieser Larven zu gedenken, das nach Lage und Ban gewissermassen an eine Retina erinnert, der die lichtbrechenden Medien fehlen.

Betrachtet man den Kopf einer Acilinslarve son oben, so sieht man am medialen Rand des schwarzen Fleckes, innerhalb dessen die Angen stehen, moefïhr neben der Linse des lintern Hanptanges, ein mnter der Cuticula gelegenes rundliches. etwas lappig ansgebuchtetes Organ. dessen änsserer Rand theilweise von dem sich darüluer wölbenden schwarzen Flecke bedeckt wiri. Es macht ren Eindruck einer ziemlich massigen Scheibe; die Randpartie ist (an lebenden Thieren) völlig durchsichtig, und lïsst nur schwer Zellengrenzen und Kerne erkemnen. Die obere, der Cuticula anliegende Fläche ist grösstentheils ron St:̈ibchen bedeckt; die peripherischen derselben liegen schief, nach imnen nnd oben gegen eine Axe gerichtet, welche die Scheilue etwas excentrisch nach rorn durchsetzen würde; hier liegen einige Stäbchen vertical, md die andern gruppiren sich alle radiiir und mehr oder weniger geneigt um sie. Ich habe das Organ sowoll bei jungen als bei reifen Larven untersucht. aber ansser den Terschiedenheiten in dessen Grösse, und der Zahl der Stübchen (deren es nach ungefülıer Schätzung bei letzteren ca. 120-150 sein mögen), keine sonstigen Unterschiede anffinden kümen. Die Stäbchen sind farblos, stark lichtbrechend, und an ihrer Basis befindet sich in die Unterlage eingebettet spïrliches körniges schwarzviolettes Pigment. Auf Schnitten zeigt sich, dass das Organ ebenfalls nur aus modificirten Hypodemiszellen hervorgegangen ist, denn an Rande desselben werden diese allun̈ilig länger, und werden plötzlich ron diesen Simneszellen exsetzt, deren Stïbchen direct an die Cuticula stossen. Jede der langgestreckten Zellen trägt rorn ein solches Stïbchen, mol hinten geht sie in eine Nervenfaser über, die sich zusammen nahe dem ïussern Rande des Organs zn einem ziennlich ansehnlichen Nerv rereinigen. - Die Cuticnla zeigt keine weiteren Nodificationen, sie verhält sich wie an andern Stellen der Kiopfoberflïche anch.

Nir ist die Natur des fraglichen Organes, dem man die Bedeutung eines Simmesapparates kam wird rorentlualten kömnen, völig unklar geblieben. Vielleicht ist es nur die erste Anlage eines Organes, das erst in der weitern Entwickelung zur Ansbildung kommt. Wie dem auch sei, ich bin nicht in der Lage, den rorstehend Gesagten etwas Weiteres hinzufügen zn künnen, und muss urich begnügen, daranf lingewiesen zu haben.

Ich möchte hier anhangsweise noch die Beschreihnng einer Form enfacher Larvenangen himznfügen, die allerdings zu den vorigen in keinerlei Beziehnng steht, sondem eine Categorie für sich bildet. Es sind dies die einfachen Angen mit krystallkegelähnlichen Torlagermuen ror der Retina, zwischen dieser mul der Linse, wie ich sie bei einer Larve von Semblis Fab. (Sialis) anfgefunden habe.

Einen Schmitt durch eines der jerlerseits am Kopfe in der Sechszahl sich findenden Angen einer nicht näher bestimmten, in der hiesigen Gegend nicht seltenen Larve dieser Gattumg zeigt 
Fig. 12 Taf. 11. Die grosse, schön bicouvex gewöllste, aber etwas flache Cuticularlinse zeigt änsserlich eine dünne Schicht, welche die allgemeine dunklere Tingirung res Chitins der Cuticula aufweist; der grössere Theil der Linse $(L$.$) ist aber hell, und die feinen Porencanälchen der Cnticnla lören$ an ihren Rande auf.

Der Linse innerlich dicht anliegend findet sich ein eigenthümlicher Körper, wie er mir bisher aus keinem andern Arthropodenange bekannt geworden ist, wenigstens, was seine Form nnd Zusamuensetzıng anlangt. In Gesammtumiss ist er oval oder elliptisch, mit mehr orler weniger regehnüssigen, ron semer Segmentirmg herrühenden gewölbten Torsprüngen; oben und men abgeflachit, selbst etwas concar, mo mit diesen Seiten in Contact einestheils mit der Linse, anderntheils nit der Retina. Er ist stark lichtbrechend, und ziemlich resistent gegen Druck (etwa wie Wachs), und nach meinen Erfahrungen regehmässig aus acht Seguenten zusammengesetzt. Ton diesen stehen sich je drei an den längern Seiten befindliche parweise gegenüber, und ihre in der Nittellinie zusammentreffenden Enden bilken. da sie alterniren, eine rertiefte Zickzacklinie; zwei andere Segnente schliessen die beiden Enden ab (vgl. Taf. II Fig. 13 A, B). Jedes dieser Segmente hat wieder seine Wölbung für sich, durch welche die Tungrenzungslinie sowohl wie anch die Oberflächengestaltung complicirt wird, und welche auf das durchtretende Liclit ron so bedentendem Einflusse sein muss, dass wir nus das ron der Linse entworfene Bild kaum anders als stark verzerrt und rerschoben denken können. - Die Form dieses Krystallkörpers ist, wie schon angedentet, ziemlich variabel; die meisten derselben, die ich gesehen habe, glichen mehr oder weniger dem in Fig. 13 A. abgebildeten. In Fig. 13 B. labe ich einen anderen, bei dem durch leichten Druck die beiden Endsegmente ans ihrem Znsammenlang losgesprengt werden, dargestallt; las eine dieser Segmente zcigt noch eine uur ein einziges Mal beobachtete Eigenthïmlichkeit, indem es anscheinend wieder ans drei Stïcken znsammengesetzt ist.

Der ganze Krystallkörper wird ron einer feinen, nur bei starken Vergrösserungen sichtbitren Membran unschlossen, die in einem gexingen Abstand von seiner Oberfläche allen Lmissen derselben folgt. Da wir es hier unzweifelhaft mit einer Cuticularbildung von der Categorie der Krrystallkegel des facettirten Arthropodenanges zu thun laben, so dürfte die Deutung dieser MemJran als letzter Ceberrest der sonst verschwmilenen Natrix des fraglichen Körpers wohl kamm fehl gehen, und die acht Segmente werten wohl auch hier anf ebensoviele msprüngliche Zellen zuriirkznfühnen sein. (1) hier noch die Kerne der Zellen rorlanden sind, wie bei den Krystallkrgeln fast ausnahnslos, das habe ich allerdings nicht zu entscheilen remocht.

Von der Randpartie der Cuticularlinse her umgeben massenluafte. fadenförmige, ziemlich direct nach innen zieheude Pigmentzellen $(P y$.$) , deren allnäliger Uebergang in die Elemente$ Ier Hypodernis leicht zu verfolgen ist, den Krystallkörper. Hinter dem Krystallkërper und mit diesem in Berührung finden wir die ebenfalls ganz eigenthünlich gebante Retin a (Rt. Fig. 12-14). Sie brsteht ans einigen dreissig Zellen (ich zöhlte in dem in Fig. 14 gezeichneten lalle deren 33), die radiär gestellt. und in zwei Schichten, die mit flachen in einander steckenrlen llohlkegehn verglichen werden können, rertheilt sind. Diese Hohlkegel richten ihre Spitzen, denen die Stäbchenenden der Zellen entsprechen, nach rorn gegen den Krystallkürper, wïlnenı an die Bisis der mässig entwickelte Opticns lierantritt ( $N$. op. Fig. 12), 11 sich zu den Zellen zu begeben. Dem obern grüssern Zellenkranze gehörten in den erwälnten Specialfalle 21, dem untern 12 Zellen an. Die ganze Anordnung wird viel leichter ans der Combination des Durchschnittes Fig. 12, der allerdings nur eine einzige Zellenlage trifft, mit der Ansiclit ron hinten Fig. 14 verstanden, als ans einer Darstellung mit Worten. Die letaterwähnte Figur zeigt zn unterst ren ron der Linse losgelösten. in der Zeiclmung etwas zu regelmïssig ansgefallenen Krystallküruer; 
ummittelbar darauf liegt die gü̈ssere obere Zellenschicht, deren Stïbchensïnme die änssere Strahlenrosette bilden, und anf dieser wieder die klemere untere, zu der die innere Stäbchenrosette gehürt. Bci allen Zellen beider Schichten sind aber die üuseren, resp. hinteren Zollenenden, in denen die Kerne liegen (vgl. Fig. 12) nnel an welche die opticusfasem herantreten, bei der Präparation abgebrochen und verloren gegangen.

Die Retinazellen sind pyramidal gestaltet, mit der Spitze nach vorn, gegen das Centrm des Krystallkörpers, d. h. gegen die Angenaxe gerichtet, nud durch mol dureh dunkel pigmentirt. An ihrem rortern Ende tragen sie ein Stäbelıen, welcher Anshuck eigentlich hier nicht passend ist, da er doch immer eine bestimmte Form bezeichnet, welche die lier sich findenden Gebilde nicht besitzen. Sehen wir aber in Interesse der emheitlichen Bezeichnnng davon ab. Ihre Bezichungen zu den zugehörigen Retinazellen lassen sich ganz treffend bezeichnen, wenn man sagt, sie sitzen dem Torderende der letzteren etwa so auf, wie ein Fingerhut der Fingerspitze. Sie berülnen sich ganz imnig, und nur schwierig kamn man die Tremmugsflïchen als feine Linien walnnehmen. Da man sie nur in optischen Schnitte, an den seitlichen Rüindern der Zellen, erkennen kann, dagegen nicht an den dem duge zu- und abgewantten, so machen sie bei Ansichten wie Fig. 14 (St.) den Findruck eines doprelten Strahlensystems, das mm den Mittelpmnkt je dnrch einen meln oder weniger regehnäsigen Kreis oder Ellipse vereinigt wirl. Gewöhnlich laufen die Strahlen nach ansen ziemlich spitz zu, weil die hintern Rïnder der hutfürmigen Cnticularsïme sich zuschärfen. In Lebrigen kann ich blos noch hinzufügen, dass sie an erhärteten Präpraten röllig farblos nnd stark lichtbrechend sind, im frischen Zustand aber rosenroth und äusserst vergänglieh.

Ich hahe die Thiere oft nud gleichzeitig mit den Acilinslaren erhalten. mul dabei wohl beobachten kömmen, wie selur gering entwickelt im Verlü̈lniss zn letzteren ihn Sehremögen ist, wie das ja anch die Tergleichmg der Angen arschliessen läisst.

\section{B. Augen einiger Arachniden.}

Schon in dex historischen Lebersicht. welche ich meinen Unterstehungen roranstelite, sind die innerhalb der berïcksichtigten Periorle aufgetanchten Ancichten ïber den anatomischen Piau und die physiologische Leistung des Anges der Aradmiden (Spinnen. Scorpione) erwähnt, und nanentlich hervorgehoben worden, wie Leydig in seinen Arbeiten zu Resnltaten gelangte, welche llie früheren vollstïnlig vom Schamplatze verdrängten. Tch will schon hier voransschicken, dass meine eigenen Intersuchungen mich keineswegs zu einer Bestitigmng der Ansichten dieses Forschers gefühnt lıben, ich viehnehr genöthigt bin, ilmen fast in allen wesentlichen Punkten entgegenzutreten, und in mancher Hinsicht die ätere, num verlassene Anschamungsweise für zntreffender zu halten, als die seinige. Was die Anzahl der von mir untersuchten Formen anbelangt, so kamn sich dieselbe mit den von Leydig verarbeiteten nichit messen. lch habe mich auf die Gattmgen Phalangium, Epeira, Lycosa mol Salticus beschränt, anch die Gattung Dolomedes näher untersucht, aber lier nicht besonders erwïhnt. weil ich sie im Angenlau mit. Lycosa übereinstimmend fand. Vergleicht man die ans meiner folgenden Darstellung hervorgehenden Differenzen dieser par Genera bezüglich der Structur ilner Angen, so wirr man es wohl kanm für mwahrscheinlich erklïren können, dass in der grossen Anzahl der nicht berücksichtigten Gattungen anch nur der dentschen Fanna bei näherer Untersuchmg noch ebensogrosse Unterschiede zu Tage treten mögen. Andererseits wird aber, trotz aller Schwankungen in rler 
Ansfühung der einzelnen Hauptfactoren des Auges, the principielle Uebereinstimmung derselben in Ban und Lagerung wieder eine gewisse Garantie geben, dass diese nur vermutheten Oscillationen sich nicht über gewisse Cirenzen hinaus erstrecken werden, sondern noch immer eine Eimeihung in die lier zu Tage tretende Grund- oder Urform zulassen.

Um hier schon das Allgemeinste des Baues des Spinnenanges (inclus. Plıalangium) im Umrisse vorauszuschicken, mag bemerkt sein, dass auf den essten Blick die Structur zwar mit der schon bei den Wasserkiferlarven beschriehenen übereinzustimmen scheint, bei nälıerer Betrachtung sich aber lloch einige recht gewichtige Unterschiede ergeben. Wïhrend bei jenen die ganze Anordnung der Elemente auch des ausgebildeten Auges deutlich das Hervorgehen derselben aus einer allen gemeinsamen Grundlage. der Hypodermis, verrieth, deren in continuirlicher Reihe aufeinander folgende Zellen an rerschiedenen Stellen ihrer verschiedenen Leistung gemäisse Umformungen erlitton haben, ist hier diese Continuität unterbrochen. Wir finden beim Spinnenauge eine dentliche Anordnung der Weichtheile in zwei anscheinend von einander völlig unablüngige Schichten, von denen die eine. vordere, allerdings ebenso wie bei jenen Larven aus der Umformung der Hypodernis entstanden ist, aber nur Pigment und Glaskörper unfasst; die hintere dagegen, die Retina, ist gänzlich ans dem Verbande ausgeschieden, und ihre Herkunft verrïth sich nicht auf den ersten Blick aus dem anatomischen Ban, wie dort.

Eine der bemerkenswerthesten Eigenthümlichkeiten der Augen der ächten Spimen — also nit Auschluss von Phalangium - besteht nun in einem, wie es scheint, reit rerbreiteten Dimorphismus derselben. Jch verstehe darunter num freihich nicht jene schon lïngst bekannten Variationen in der äussern Form und Grösse der einzelnen Augen desselben Thieres unter sich, sondern viel tiefer liegende. besonders die Retinazellen berïhende, Verschiedenheiten, die so weit gehen können. ılass man oft glauben möchte. Augen ganz verschiedener Genera, ja selbst Familien, vor sich zu laben, welche doch thatsïchlich einem und demselben lndividum entnommen sind. Diesen Dimorphismus, der sicher anch mit einer Verschiedenheit der physiologischen Leistung der einzelnen Augenpare Hand in Hand geht, scheint vor mir noch Niemand beobachtet zu haben.

Eine fernere Eigenthümlichkeit des Auges der ächten Spimen bildet das Torkommen einer besonderen Musculatur, die schon seit lange bekannt geworden ist (zuerst durch A. Brants l. c.). Soweit meine Beohachtungen reichen. ist das Vorhandensein dieser Musculatur an eine der beiden specifisch verschiedenen Augenfornen allein geknïpft, und fehlt der anderu. Dannit soll aber keineswegs gesagt sein. dass dieser Satz nicht durch fernere Untersuchungen umgestossenwerden kann.

1. Ange von Plıalangium. - Einen Schnitt durch eines der Augen ron Phalangium habe ich in Figur 15 Taf. II wiederzugeben versucht. Diese Gattung besitzt deren bekanntlich nur zwei, die seitlich an einen ziemlich spitzen Höcker des Cephalothorax so gelegen sind, dass sie nach aussen und oben gerichtet prscheinen. Ich habe die Richtung der Nerlianebene, in der sich die Retinae beider Augen berïhren. durch einen Pfeil in meiner Figur angedentet. Es ist wohl nicht ïberflüssig, hier noch zu bemerken, dass die mit ıler Camera lucida gezeichnete Figur, lie einem Platinchlorid-Chromsüurc-Präparat entnommen ist, die Weichtheile des Auges, Glaskürper und Retina, nicht genau in ihuer natürlichen Lage wiedergiel,t, weil das Präparat etwas durch die Schnittführung vertrückt war. Die Vorderseite der Retina mïste eigentlich concentrisch mit der Hinterseite der Linse verhanfen, und der Glaskörper ılen Raum zwischen beiden in ïberall gleicher Tiefe ansfüllen.

Die dicke, aussen dunkel tingirte und mit Schïppchen-Sculptur versehene Cuticula (Ct.) zeigt deutliche Schichtung und zahlreiche feine Porencanäle; in der nälsern Umgebung der Linse 
macht sie den Eindruck, als ob sie in Prismen zerklïftet wäre. -- Die Linse ist schün und sehr stark gewölbt; ihre beilen convexen Fliichen gehören Kngeln von ungleichen Radien an, und zwar ist die änssere Wülbung Abschnitt einer grössern Kingel als die innere. - Porencanäle, wie sie Leydig (rgl. unt.) an der Linse geselien hat, sind mir nie zu Gesicht gekommen; auch die doch unzweifellaft vorhandene Schichtenstructur ist so wenig hervortretend, dass man, wenigstens bei mässigen Vergrösserıngen, nichts davon wahrnimmt.

Die unter der Cuticula des Körper's gelegenen Hypodermiszellen $\left(H_{p}\right.$.), die in der genamnten Erlü̈rtungsflïssigkeit sich allerdings stark veränderu, gehen in einiger Entfernung rom Rande der Linse in langgestreckte Pigmentzellen $(P g$.) über, die einen dichten, für Licht mdurchlässigen Ping mn das Ange bilden. Der Uebergang in die Zellen des Crlaskörpers linter der Linse geschieht ziemlich plützlich, doch ohne nachweisbare lestimmte Grenze. Nan kann an besten an der Lage der Kerne den Tebergang verfolgen, wemn durch rollständige Entfärbung die sonstigen Unterschiede ausgeglichen sind. In den Pignent führenden Zellen liegen sie nümlich ror und in der Mitte, je näher aber am Glaskörper, desto weiter rücken die Kerne nach hinten, und in den Gilaskürperzellen selbst liegen sie ganz dicht vor dem gerade abgeschnittenen Hinterende.

Der Glaskürper (G/i.) in toto bildet un die innere Linsenwölbung eine concentrische, völlig duchsichtige Lage von überall gleicher und ziemlich ansehnlicher Dicke. Die ihn bildenden Zellen sind radiär gestellte, langgestreckte, abgestutzte Pyraniden, die mit ler Basis an die Retina, mit der alogestntaten Endflïche an die Linse reiclen. In frischen Znstande sind sie stark lichtbrechend, md zwar in Innern ebensosehr wie an der Oberflïche, so dass man, wenn beim Zerzupfen melnere noch in ihrem ursprünglichen Zusammenhang neben einander liegen, die Tremmgslinien anfünglich gar nicht, sondern erst unter dem Einthnss der allerdings sebr balil auftretenden Quellung anftreten sieht. Sie bleiben auch nach der Erhärtung in verschiedenen Medien noch rclativ selı durchsichtig, aber ihre Membranen treten sehr deutlich lierror, wogegen der Inhalt sein starkes Lichtbrechungsvermögen einbüsst. Qnerschnitte duch diese Zellen zeigen dam anffallend jene Aelınlichkeit mit Pflanzengeweben, welche frühern Beobachtern, wie Müller', schon auffiel,

Die Kerne der Glaskürperzellen sind ziemlich klein, kugelig, und selur dentlich. Sie liegen, wie schon bemerkt. in retiralen Ende der Zellen. das scharf alogeschnitten, und olme eine Spur eines imnigeren Zusammenhanges mit der Retina exkannt wird. Auf Schnitten kann man immer mit vollster Sicherheit die hintere Begrenzung des Glaskürpers als eine sehr scharfe, vor den Stäbchenenden gelegene Limie nachweisen, was ich liier besonders betonen möchte, weil darin der principielle Gegensatz meiner Anffassung gegen die ron Leydig rertretene iluen Ausdruck findet.

Die hinter dem Glaskörper gelegene Retina (Rt.) besteht ebenfalls nur aus einer einzigen Zellenlage; die Elemente derselben sind stark verlïngert, in frischem Zustand mehr cylindrisch als nach der Erhärtung, wo sie duch mgleichnässige Schrmupfung ziemlich spindelföming werden. Soust ist an frischem Material kam an eine Untersuchung derselben zu denken, weil sie ron vorn bis hinten mit intensir schwarzem Pigment erfüllt sind, und selbst selır feine Sclmitte an erlü̈rtetem Nateriale zeigen ans diesem Grmde olne vorherige Entfürbung gar nichts. An ihrem vorderen Ende ist ilmen je ein Stäbchien eingelagert, und an ihren hintern Enden treten sie mit den Fasem des Opticus ( $N$. op.) in Zusammenhang. Die Kieme liegen hinter der Mitte, sind aber nicht mehr mit solcher Regehmässigkeit in Reihe und Glied gestellt, wie wir es bei den Angen der Schwimmkïferlarven kemnen gelernt haben. An Schnitten ans erhürteten Augen ist gerade die den dentlichen, runden Kern einschliessende Stelle diejenige, die das spindelförmige Anssehen der Zelle durch ihre Anftreibung verusacht. 
Die Stäbchen (St. Fig. 15, 16. Fig. 17 Taf. II) liegen im vordem Ende der Retmazellen so. dass sie noch ringsum durch einen dïmen Ueberzug derselben eingeschlossen werden. Besonder's dentlich ist noch das Protoplasma der Retinazelle in Nireau des hinteren Stäbchenendes zu erkemen, aber nach vorn wird dies allmälig dünner bis zmn Terschwinden. Soweit sich dieses Protoplasma erstreckt, geht auch das Pigment, das in ilm enthalten ist. Die Stäbchen lassen sich etwa nit einem Getreidekorn vergleichen, spindelförnig md an beiden Enden abgerundet. Sie scheinen ron einer feinen Membran umschlosen zu sein, die an Schnittpräparaten zwischen sich und dem eigentlichen Stälochenkürper noch einen geringen Zwischenram lässt. Bei Lüngsansichten zeigen die Stäbchenkörper eine sehr feine Längslinie, die nur ilnen, und nicht anch der sie überziehenden Membran angehört (Fig. 16); dieser Linie entsprechen oft leichte Einkerbungen an den abgerundeten Enden. Glückt es, Querschnitte durch die Stäbchen zu erhalten, so zeigen diese leicht (Fig. 17), dass die Längslinie der Ansdruck einer Zusammensetzung des Stïbchens ans drei gleichgrossen, der Länge nach an einander gekitteten Segmente ist. so dass man bei gelungenen Präparaten ein Mosaik von Kleeblattillnulichen Figuren erblickt. un deren jede einzehne sich zarte Contomen, als Querschnitte durch die kapselartige Nembran der Stäbchen,erkemen lassen.

Die Gestalt der Stäbchen ist nu insofern Variationen unterworfen, als die randständigen in Allgeneinen kürzer und gedrmgener, die nehr central gelegenen aber lïnger und gestreckter sind. Thre Zahl muss eine ziemlich ansehnliche sein, wie schon ans der Fig. 15, die zwar nicht ganz genan Stäbchen für Stäbchen, aber doch möglichst die richtige Tertheilung und Proportion wiedergiebt, geschlossen werden kann.

Es könnte wohl der Gedanke auftauchen, die aus drei Stäcken zusammengesetzten Stibchen wïren nicht anf eine einzige, sondem anf ebensoviele Zellen zurückzuführen, als Segnente da sint. Auch ich habe, namentlich nach meinen Beobachtungen an zusammengesetzten Auge, anfünglich diese Möglichkeit ins Auge gefisst, aber mich bald überzengt, dass der Thatbestand der oben gegebenen fchilderung entepricht.

Die beiden Sehnerven treten dicht noben einander an die Augen heran; es war mir allerdings hier nicht möglich, mit derselben sicherheit wie früher das Eintreten der einzehnen Fasem in die Retinazellen zu verfolgen, ich hege aber durchaus keinen Zweifel darüber, dass der endliche Terlauf der gleiche ist.

Yon Untersuchmgen über das Ange von Phalangium sind blos anzuführen die ron Tulk1), dessen Darstellung, sonst ganz im alten Stil gehalten, nur deswegen lier erwähnt wird. weil er zwei an die Angen tretende Muskeln beschreibt und abbililet, ron denen mir nichts zu Gesicht gekommen ist. Ich glaube, dass hier die Insertion der Mnskeln. deren es allerdings in der Nühe des Anges manche giebt, irrigerweise an das Ange verlegt rorden ist. - Leydig²) verdanken wir auch einge Notizen ïher dieses Ange, und ror Allen eine schöne Figur; er erwähnt die nitgetheilte Beobachtung Tulk's, giebt aber nicht an, ob er sie bestitigt gefunden hat, oder nicht.

Ich gehe nun über zu den ächten Spinnen. - Auf die Zahlen- mol Stellungsterhältnisse der Spimnenangen hier nïher emzngehen, liegt mu so weniger Vermulassmg ror, als jerles Handbuch der Zoologie, oder jedes systematische Terk über Spinnen über diese Dinge genügende Anskunft ertheilt. lch will hier nur noch die Bemerkung vorauschicken, dass ich auch bei den zu Grunde gelegten Arten nicht alle Augen einer eingehenden Prüfung unterwarf, sondern mich

1) A. Tulk, On the anatomy of Phalangium opilio. Ann. Mag. nat. list. 1843. Vol. XII. pag. 324, Pl. 5. Fig. 24 .

2) Fr. Leydig, Arch. f. Anat. etc. 1855. pag. 432 u. ff. Taf. zur vergl. Anat. VIII. Fig. 2. 
anf diejenigen beschrünken zu dürfen glanbte, die für die Untersuchung durch Schuitte nicht allzı unciunstig placirt waren, da ich mein Hauptziel, die Grundzüge der Architectur des spmmenanges, der Einzelforschung nicht miterordnen wollte.

2. Angen ron Epeira. - lch stelle die Angen ron Epeira roran, nicht, weil sie für die Tntersuchung gerade besonders günstig wären, sondern weil man hier am deutlichsten den Jeberblick über den eigenthümlichen Dinorphismus der Spinnenaugen, und zwar bei xichtiger Schnitführmg an ein und demselben Präparate sich verschaffen kann. Nieine Beschreibung beschrinkt sich auf die zwei Par Augen, die an obern Vorderrand des Cephalothorax, der Mittellinie sowohl als unter sich genähert, liegen; die Pandaugen sind für Schnitte reichlich klein, und liegen sehr ungünstig. - Ich beziehe mich ansschliesslich anf Epeira Diadema, da andere chenfalls untersuchte Arten (E. apoclysa, E. umbratica) genan den gleichen Ban erkemen liessen.

Der in Fig. 18 Taf. 11 gezeichnete Schnitt ist durch ein rorderes (A) und ein hinteres (B) Ange einer Seite ziemlich parallel der Merlianebene und so geführt, dass die Augen darlurch hallirt werden. Die gleich in's Auge fallenden Differenzen beider Sehorgane berühren hauptsïchlich die Retina und viel weniger Linse und Glaskörper, die moter sich in beiden so nahe übereinstimmen, dass eine Tnterscheidung nicht wohl thunlich erscheint.

Eine besondere detaillirte Beschreibmg der Linsen und der Glaskörper zu geben, kamn ich mir um so eher ersparen, als alle wesentlichen Punkte sich hier ganz übereinstimnend finden nit dem ron Plıa langinm schon Bekannten. Folgende Bemerkmgen werden genügen. Die Linsen ron Epeira zeigen eine sehr dentliche grobe Schichtung, deren continuirliche Fortsetzung in die Cnticula sehn leicht nachweisbar ist. Dazwischen treten bei stïkeren Vergrössermen noch riel feinere Zuwachsstreifen herror, die auf der Zeichmung aber ansgelassen wurden. Selı lı̈ufig, aber uicht inmer, ist mir eine ganz eigenthümliche Structur aufgefallen, nämlich cine ron der Torderfliche ansgehende, lis an die lmenfläche reichende, die Limse aber in rer Peripherie nicht rffüllende, zapfenartige Differenzirung in Imnern, die sich durch etwas andere Lichtbrechmg schwach aber deutlich genug abhol,1). Es macht fast den Eindruck, als wenn die Linse ursprünglich diese Kilpfenform liätte, und arst durch yüteren, hauptsïchlich in der Aequatorialebene arfolgenden Zuwachs in die definitive Form überginge.

Der Leberwang der Hypodermiszellen in die Pigmentzellen ( $P g . . P g^{I}$.) ist leicht zu rerfolgen, weniger kricht aber die Contimnitit der letzteren mit denen des Glaskörpers (Gki, GhI.). Die Pigmentzellen sind nïnlich lïnger ats die Zellen des letzteren, und greifen mit ilıren hinteren Enden ziemtich weit darüber hinans. Die continurliche Reihenfolge der Kerme, die in einer allerdings mamigfach geloggenen Linie liegen, rerwischt jedoch diesen anscheinenden Sprung.

Die Glaskürperzellen sind sowohl in frischem wie in erhärtetem Zustand ron gleicher Beschaffenheit, wie bei Phalangium, nur relativ kürzer. Der kleine splärische Kern, der ebenfalls dicht vor dem scharf abgeschnittenen Hinterende der Zelle liegt, kann auf Schmitten nicht wohl übersehen werden.

Eine eingehendere Beschreibumg erfortern aber die Retinae der beiden Augen.

Die Netrhaut des rordern Anges (Rt.) besteht ans sehr zahlreichen, langgestreckten, hinten etwas angeschwollenen und meist etwas gehogen rerlaufenden Zellen, die wie bei Phalanginn intensir pigmentirt sind. 1)as Pigment erstreckt sich aber nur bis an das Hinterende der stiblychen, so dass man auf feinen nicht entfirrbten Schnitten diese als eine helle Zone zwischen (rlaskörper und dem pigmentirten Theil der Retina erkemnen kamn (St., Fig. 18). Am längsten sind

1) Tyl, die Linse des vordern Auges (A) Fig. 18. 
diese Zellen im axialen Theil rler Retina; nach den Seiten hin werden sie allmälig kürzer, wobei ihre Form im Ganzen die nämliche bleibt.

Am Torderende tragen diese Zellen die Stübchen (St. Fig. 18, 19. Taf. 11). Auch diese nehmen ron der Nitte ans nach den Seiten hin an Länge, kanm aber an Breite ab. Anch hier scheinen sie, wie bei Phalanginm, nicht blos dem vordern Ende der Retinazellen anfgesetzt, sondern ron ihm umschlossen $\mathrm{zn}$ sein, wenigstens sprechen meines Erachtens die über die vordern Stäbchenenden vortretenden winzigen Kmppen, welche ich in Fig. 19 angegeben habe1), für diese Dentung, wenn anch die Limkleidung an den Seiten, zwischen den einzelnen Stäbchen, kann noch walınehmbar genannt werden kam. - Die Stäbchen erscheinen prismatisch, an beiden Enden rmndlich abgestutzt, und, nach Erhärtung in Alcolıol, von nu geringem Lichtbrechnngsrermögen. Sie werden durch eine änsserst zarte Längslinie halbirt, und ausserdem habe ich zuweilen (bei selır starken Vergrössertugen und schiefem Licht) an den Rändern eine chenfalls höchst feine, sich nicht bis zur Mitte erstreckende, Querstreifung gesehen, als Andentung einer auch hier sich findenden Plättchenstructur. Qnerstreifen und Längslinie exinnern etwa an eine seln kleine Grammatophora, das bekannte Test-Object.

lch habe zwar keine gnten Querschmitte durch diese so feinen Stäbchen anfertigen kümen, halte abex doch die Längslinie für den Ausdruck einer Znsammensetznng aus zwei Hälften. und ich darf zur Begründung dieser Ansicht wohl schon in Torans anführen, dass ich bei allen Angen ächter Spinnen diese Zusammensetzmng gefunden liabe.

Die Retinazellen tragen in ihrer hinteren kenlenförmigen Anschwellnng einen dentlichen. ziemlich grossen Zellenkern; ich habe mich genïgend, anch nach Untersuchung ron Tinctionspräparaten (mit Haematoxylin) yon dieser Lagermng überzengt, um diese mit all der Sicherheit, die eine oft und unter rerschiedenen Unständen wiederholte Beobachitung gewähren kamn, belanpten zu können (Fig. 18, K.).

Der Nertus opticus (N. op., Fig. 18) tritt als gerader, sehr ansehnlicher Stamm etwas anserhalh, der Mitte (mehr dorsal) in die Retina. Wie schon Leydig herrorlıelst, zeichnet er sich sowohl hier als bei andern Spinnen durch eine bei drthopoden seltene Dentlichkeit seiner Nervenfasern ans, die anch bei exhärteten Angen nocli anffallent klar und durchsichtig bleiben. Er verdickt sich beim Uebergang in die Retina allmälig, und seme peripherischen Fasern setzen sich direct und ohne scharfe Grenze in die herantretenden Netzhantzellen fort. Die innern Fasem desselben treten aber in das Innere der Retina ein. theilen sich dort in zwei Bündel. von denen das eine kleinere dorsalwärts, das andere grössere ventralwärts zieht, um dann nach beiden Seiten hin in einzehe Fasern auszustrahlen, die wieder zn den entsprechenden Zellenenden treten. Diese Form der Vertheilung sieht man besonders dentlich an Horizontalschnitten, bei denen die Retinazellen senkrecht anf ihre Hamptrichtung getroffen werden; solche Schnitte in Verbindmig mit der Lünge nach geführten lassen keine andere Dentung zu.

Ganz ander's geartet erscheint die Netzhant des hinteren Anges $\left(R t^{I}\right.$.), rerglichen mit der eben beschriebenen. Wälırend diese eine mehr kugelige, rom nur mässig concave, und mit dieser Höhlung den Glaskörper umfassende Masse bildet, erscheint die erstere tief becherförmig ansgehöhlt; der grossen Anzahl schlanker Zellen der vordern Retina stellen sich hier weit weniger zahlreiche, datür aber mu so gedrungenere Elemente gegenüber; und ansserdem sind sowohl die Stäbchen selbst, als ihre relative Lagermg zu den Kernen der Retinazellen, anscheinend fundamental ron einander verschieden.

1) Sie simu in Fig. 19 etwas zu clunkel ausgefallen. 
Die dicken, abgerundet prismatischen Zellen der hintern Retina zeigen, wie bei der vordern, in der Mitte die grösste Entwickelung, doch sind die Differenzen gegen die randständigen Zellen lange nicht so bedentend, wie bei jenen. Anch ist ihre Anordnung eine mehr radiüre, und sie momgreifen die Hinterflïche des Glaskörpers weit nehr nach oben lin, so dass man auf ein grüsseres Gesichtsfeld schliessen darf. (Dieses ist wenigstens auf Sagittalschnitten der Fall; bei einigen frontalen, die ich anfertigte, schien es mir, als ob nach anssen die Retina unvollständig wäre; dic benutzten Exemplare waren aber nicht besonders gut erhalten.)

Die Zellen zerfallen in drei $\Lambda$ schmitte, dic allerdings nicht seharf von einander gesondert sind, aber doch eine sehr ungleiche Ausbihlung zeigen. Das vordere, dem Glaskïrper zngekehte Drittel ist pigmentfrei und völlig durchsichtig in frischem Zustande, (ähnlich wie die Zellen des Glaskönpers), mol umschliesst den Zellenkern ( $K^{I}$. Fig. 18, 20 Taf. II). Der hintere Abschitt ist durch seinen starken Pigmentgehalt ausgezeichnet, und rerjüngt sich conisth in die zugehörige Opticusfaser. Der mittlere Theil ist duch die Einlagerung des Stäbchens (Fig. 18, 20 St $t^{I}$.) characterisirt, das, an einem nicht entfürbten Präjarate von der Seite gesehen, mit seinem vordern Ende frei aus dem umgebenden Pigmente herrorragt, ron dem der hintere Theil bedeckt ist. Die Abnahne des Pigmentes nach rom erfolgt alhnälig; dasselbe bestelit aus sehr regehüssigen gleichgrossen Kö̈nchen, die in ebenso regelmäissigen, aber oft unterbrochenen parallelen Querreihen angeordnet sind.

Ich möchte zı den Fignren 18 mnd 20 nodı anführen, dass dort die kernführenden vordern Theile der Retinazellen etwas regehn̈̈ssiger gezeichnet sind, als es meine Präparate thatsïchlich zeigen. Dieser Theil der Zelle nänlich ist äusserst zart und rergïnglich, und alle von nir erprobten Agentien reräudem denselben ziemlich stark, und durch die Gerinnmog werlen die Lmrisse weniger dentlich und regelmïssig, als ich sie wiederzugeben mir erlanbt habe.

Die Stäbchen (Fig. 18, 20, 21 St ${ }^{\text {. }}$ ) sind auch nach Einwirkmg der erhärtenden Agentien durchsichtig bleibende, stark lichtbrechende lï̈per ron im Ganzen prismatischer Form mit abgermdeten Enden. Sie liegen anscheinend in einem sie eng mselliessenden, scharf begrenzten Hohlram, der aber wohl ein Kmstproduct, entstanden durch die Tolumveringermo bei der Erhärtung, sein dürfte. An ihren seitlichen Begrenzmgen lässt sich dentlich der Einschluss derselben in Innem der Retinazelle nachweisen. Qucrstreifung labe ich an ibnen nicht mehr gesehen, wohl aber eine ebenfalls ïusserst feme Lüngslinie, deren Bedentnng aus Fig. 21 Taf. II, welche Querschitte dureh die Stïbchemregion der Petina darstellt, als Ausdruck zweihälftiger Zusammensetzung herrorgeht.

Der Nervus opticus $\left(\Lambda\right.$. op $^{I}$.) zeigt hier anch ein etwas anderes Verhalten bein Eintritt. in die Retina, als beim vordern Ange. Seine Fasern breiten sich nämlich hier becherförmig über die hintere Fläche der Retina aus, und man kamn bei guten Präparaten olne besondere Schwierigkeit den Uebergang der einzehnen Nervenfaser zur Zelle rerfolgen.

Dass beide Angen von einer feimen Cuticula (ct. Fig. 18) überzogen werden, die sich einerseits nach der Innenfliche der Hypodermis, andererseits auf den Opticus fortsetzt, mag ebenfalls nicht merwïhnt bleiben.

Endlich lıbe ich noch der dem Spinnenange eigenthümlichıen Musculatur zu gedenken, ron der ich schon oben anführte. dass sie, sureit meine eigenen, allerdings beschrünkten Erfahrungen reichen. nur ciner der beiden, durch den Bau ilırer Retina merschiedenen Augenformen zuzukommen scheme. Hier ist es das vordere Augenparr, und wir werden anch in den noch zn behandehden Beispielen sehen, dass sie sich, wenigstens an diesen, nur als ein Attribut derjenigen Angen findet, welche mit jenem don gleichen Ban haben, d. h. bei welchen die St:̈bchen endständig, und die Kerne zwischen ihmen und den eintretenden Opticusfasern gelegen sind. 
Wie schon oben angefüht, wuden die Muskeln des Spinnenanges ron A. Brants bei Mygale entdeckt. Er sagt larüber: "Was lie Nuskeln anlangt, so findet man deren zwei in der Mygale. welche von dem sogenannten os hyoblemm kommen, mnd sich an das gefässreiche Gewebe der mittlern grossen Angen begeben. So gelangten also an jedes kleine Randange Mnskelfasern. welche ihren Ursprnng won deo Kimnlarlenmnskeln nelmen." 1) Später scheinen sie anch Blanchard zn Gesicht gekommen zn sein, wie ich ans einem Citat in Milne Edwards, Leçons sur la physiologie etc. Vol. XIl. prag. 239 erselıe$^{2}$ ). der ihnen einen ringförmigen Terlauf in dem irisartigen Diaphragma. welches er ans dem Pigmentgïrtel macht, zntheilt. und ansserdem noch Mnskelbündel von dem Ange nach den benachbarten Partien des Hantskeletes gehen lässt. - Endlich hat Leydigi ${ }^{3}$ sie wohl an ansführlichsten besprochen. Er sieht in den Ringfasern mit Querstreifung einen Splnincter zur Verengermng und Erweitemng der Pupille, nnd giebt ein einfaches Terfalnen an, die rnckweisen Bewegnngen dieser Mnskeln am lebenden Thiere in ihren Wirkungen direct zu beobachten; inan macht dasselbe nümlich einfach durch Abschneiden der Beine mbeweglich, smol betrachtet dam die Augen im anfallenden Licht.

Neine eigenen Erfahrungen über diese Nuskeh, so unvollständig sie anch sind, treten nun einer solchen Dentung ihrer Function als Sphincteren entgegen, sowohl für Epeira als die folgenden Gattungen. Ich habe sie nicht z $\mathbf{m}$ Gegenstande eingehender Studien gemacht. sondem kinn. lier nur meine gelegentlichen Beoluachtnngen nittheilen. - Die Mnsculatur besteht ans einigen (6-10) dentlich quergestreiften Fasern (M. Fig. 18) die von Integmente dicht ror dem hintern Ange entspringend nach ruten und vorn treten, nm das vordere Ange schleifunfömig zu numgeben. Sie ziehen über der feinen Cnticula lin, welche das Ange einschliest. und anf Schnitten wie Fig. 18 begegnet man regehnässig den Querschnitten der Fascrn am vorlern Rande. nnd nur hier $\left(1 Y^{L}\right.$.). Ihr weiterer Terlanf ist mir nicht klar geworden. demn er ist ancl anf Transversalschmitten wegen der Massen ron umgebenden Zellen (die in der Mblilimng fast ganz weggelassen sind, um nicht $z u$ verwirren) äusserst schwierig zn verfolgen. Sicher scheint mir nur. dass, wo anch die Mnskeln mit ilıren andern Enden sich inseriren mögen. die schon hier angedentete Anordnmg ihnen rine ganz andere Function als die eines Sphincters. oder eines Apparates zur Terändermong der Accomodation zuweist. Eine jede Contraction derselben wird nothwendig eine Lageverändermng der Axe der Petina, eine Verschiebung der letzteren zur Linse. zur Folge haben müssen. nnd diese Bewegmgen haben mit denjenigen, die wir mit dem Begriffe der Accomodation verbinden, niclsts gemein. Mägen wir num den noch mbekannten Insertionspunkt der Angenmuskeln verlegen, wohin wir wollen, das Resnltat wird immer blos für die Richtnng der Verschiebmg von Belang sein, aber die Art mol Weise derselben nicht berühren. Eine Terschiebung der Retina in einer Ebene, welche senkrecht anf ler Angenaxe steht, wird aber nothwendig zur Folge haben. dass andere Regionen der Anssenwelt auf dieselbe jrojicirt werden. und, wenn man einmal durchaus vergleichen will, eher in Parallele gestellt werden kïnnen mit den durch die änssern Angenmmskeln vermittelten Drehnngen unserer eigenen Bulbi. - Die zuckenden Bewegnngen, die Leydig bei verstïmmelten Thieren an dem Immern der Angen beobachtete. bleiben natïrlich anch bei dieser veränderten Dentung derselben als Thatsachen mangefochten.

Ans den Ban nud der Zahl der Stäbchen folgern wir eme grönsere Schärfe des Sehrermögens für das vortere Ange; ans der Grösse der respectiven Kngelabelmitte der beiden Fetinac rin grösseres Selhfeld für das limtere. Dieser Torzng kann für das rordere in gewisser Teise

1) A. Brants, in: Frorieps Nenen Notizen etc. Vol. VI. 1838. pag. 294.

2) Das Wrk von Blanchard: De l'organisation dn rẻgne animal, ist mir nicht zugänglich.

3) Arch. f. Anat. und Phys. 1855. pag. 440. 
compensirt werden durch die Muskeh, durch deren Action, bei feststehender Linse, rie Retina nach eimander rerschictene Theile des Sehfeldes nercipiren kanm.

3. Augen von Lycosa. - Die bei uns in so zahlreichen Arten vorkommente Gattmeg Lycosa besitzt Augen, die wenigstens, was die vier rückenständigen anbelangt, an Grösse und Aubillung diejenigen ron Epeira weit übertreffen. Ich habe eine Reihe von leider meist nur kleineren Arten darauf untersucht. umd, wie schon frïher angefüht, die nahverwandte Gattung Dolomedes, bei allen aher den gleichen Bau getroffen.

Bei den Lycosen sind die acht Augen bekamntlich so rertheilt, dass am Vorderrande des Cephalothorax vier kleine Angen in einer Querreile stehen; in einiger Entfernung dahinter folgen zwei grössere, und eluenso in einiger Distanz hinter diesen die beirlen grössten. Die erstgenannten sind wegen ilner Klemheit sehr schwierig zu untersuchen. intlessen gelingt es doch zuweilen, Schnitte durch sie und zugleich duch ein Ange des nächsthintern Paares zu führen, die, wie Fig. 2.2 Taf. HI zeigt, eine mmittelbare Tergleichung der beiden dimorphen Augen in bequenster Weise zulassem, wie bej Epeira. Der in genannter Figu dargestellte Schnitt ist ein Seitenstück zn Fig. 18 mol die Buchstabenbezeichnmg die gleiche; A ist das vordere, gegen das limtere (B) an Grüsse weit zurückbleilsende Auge. Die Zeichmug ist nach einem mit Haematoxylin grafürbten Präparate entworfen. um in Hinsicht auf Sicherheit und Zurerläscigkeit des Hauptmomentes, die relative Lage von Stïbchen und Kern in beiden Angen. ein Uebriges zu thun.

Limsen und Glaskörper sind in beiden Angen wieder gleich gelout, aber die Grössendifferenzen sind selu ancehnlich. Characteristi-ch für die Linse ist die ungleirhe Wölhung beider Oberflächen, was besonders stark an hintem Ange zur Geltung kommt. Die imnere Wölbung bildet mehr als die Hiilfte einer Kugel von einem Rarlins, welcher beträchtlich hinter dem zuräckheibt, weleher zur vordern Wölbung gehört, und diese ist viel weniger als eine Hallsugel. Die

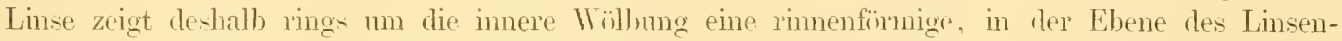
äquators verlanfende Tertiefung. Dentliche schichtumg. namentlich der imneren Partien, ist leicht zil erkennen.

Die Hyporlermis $\left(H_{\mu}\right.$.) unter der in ihren äusseren Schichten stark tingirten Cuticula ist mit einen schwarzen Piguent, das selhst nach längerer Einwirknng rler Salpetersäme nicht weicht, so fest imprïgnirt. dass man von ilnen Elementen nichts zn erkemnen remag. Besondere Pignentzellen scheinen deswegen hier gar nicht entwickelt zu sein; umnittelbar dit, wo die Hypodermis an der Basis des imnern Yorynungs der Linse aufhört. begimnen die Zellen des Glaskürpers (Gli, $G l^{I}$.). (Dieser ist, beilïufig benerkt, um im vordern Auge mrerändert gezeichnet, das hintere hat durch das Schmeilen eine, wemn auch nicht bedentencle. Zusammentrückung in der Richtumg der Angenaxe erlitten. und dadurch sind anch namentlich die mittleren Zellen des Glaskürpers flurch welliges Hin- und Herbiegen etwas rerkïrzt.) Die peripherisch gelegenen Zellen des (ilaskörpers erreichen die Retina nicht, wie bei Epeira, sondem endigen mit ihren hintern Basen in der seitlichen Nantelflïche desselben, ganz analog dem bei den grossen Augen der Acilius-Larven beschriebenen Terhalten (Fig. 4), nur dass sie nie bogenfümig verlaufen. Die am weitesten von der Angenaxe abliegenden sind sehr kurz. die nächstimneren etwas länger, und so nehmen sie stetig an Crösse zu. bis sie endlich ihr Maximum, das durch den Abstand zwischen Retina und hinterer Linsenwölbung bedingt ist, erreicht lıben. Die Ferne liegen, wie ïberall, am Hinterende, das ausserdem nit Pigment erfültt ist, und lassen sich leicht ron der Retina an den Manteltläclıen limauf rerfolgen, wo sie, ent-prechend den Zellenkürpern, an Grösse abmelmen.

Die Retina des vordern Auges (Rt.) schliesst sich in der allgemeinen Form und in der 
Art der Ausbildung ihrer Elemente an die entsprechende bei Eveira an. Sie besteht ans langgestreckten Zellen, die zusammen eine kolbenfömnige, hinten allmälig in den Sehnerven ( $\Lambda$. op.) sich rerschmilernte Masse bilden. Die Vertheilumg der Kerne ( $\boldsymbol{K}_{\text {. }}$ ) ist in der Abbildung wiedergegeben. I ie Stäbchen (St.) habe ich wegen ilıer Kkemheit mol ihres geringen Lichtbrechumgsvemöggens einer nähern Prüfung nicht miterwerfen kömen; es ist mir aber melıfach aufgefallen, dass sie nur auf die hintere Hälfte der Retina beschränkt zu sein scheinen, und in dieser an Grösse derart verschieden sind, dass sie rom hintern Rande an gegen die Mitte lin an Grösse almehmen, und etwas jenveits derselben gänzlich verschwinden.

Ganz anders erscheint die Retina des hinteren Auges (Rt ${ }^{I}$. Fig. 22, Fig. 23 Taf. Il1). Sie bildet eine sehr anselmliche Kngelschale, an deren hinten gewöllste Seite die Opticusfascrn in 8-10 starke Bündel vertheilt herantreten; jeder dieser Stïmme $\left(N\right.$. op ${ }^{I}$.) ist mgeführ ron der Stärke des Opticus, der zur Retina des vorderen Anges tritt. Sie scheint bei der Betrachtung soleher S'chitte in drei Schichten von ungleicher Dicke und Beschaffenheit zu zerfallen, was aber natürlich nu wieder in einer analogen Differenzirung der sie bildenden Zellen wie bei Epeira den Grumd lat. Dunkel mud schwer zu studiren ist die vordere, dem Glasköner genäherte Region, granulirt und längsgestreift die hintere, wïhrend in der hellen Nittelzone leicht die durchsichtigen, palissadenartig nebenemander stehenden Stïbchen erkannt werden. - Die Pignentirung der Retina erstreckt sich his an die Torderenden der Stälschen; diese sind aber selbst nicht allseitig ron Pigment mulüilt, sondern in Reihen angeordnet. die durch Pignentstreifen ron cinander getrennt werden (rgl. Fig. $23 \quad S t^{I}$.). -

Es ist nicht leicht, über den Ban der Retina und die Beziehmngen der anscheinend so versehiedenen Schichten derselben unter sich ins Klase zn kommen. Namentlich ist es schwierig, sich zu überzeugen, dass die an den Glaskürper angrenzende Lage nicht eine selbständige ist. Indessen ist es mir doch gelungen, Folgendes sicher zu stellen. Die Retinazellen, welche in ihrem Innern etwas vor der Mitte je cin Stäbchen angeschlossen tragen, verlängem sich über dieses linaus in einen alluälig sich kolbig verdickenden Fortsatz, in welchem der Zellenkern liegt. Diese Fortsïtze verlaufen wenigstens an gehïrteten Präparaten nicht gerade nach vorn. sondern sind sehr mregelmaissig durch einander gelagert und meist etwas zur Seite, gegen den freien Rand der Fetina hin, gerichtet; bald sind sie rundlich, bald durch gegenseitigen Druck eckig geworden. Die meisten stossen an die lintere Begrenzmgstlïche rles Glaskörpes, während andere diese nicht erreichen, so dass die Kerne fast durch die ganze Dicke der anscheinend scelbstïndigen Lage rertheilt sind, jerloch mit rorwiegender Concentration nach der vordern Begrenzung zn. - Zur bessern Vertentlichung babe ich in Fig. 23 Taf. 11 noch einen nicht entfïrbten, stark mit Haematoxylin tingirten Schnitt, der seitlichen Partie der Retina entnommen, wiedergegeben. Rt ${ }^{I}$. ist die mit Pignent erfüllte Retina, den lintern Theilen der Zellen, die nicht als solche erkamnt werden kïmen, ent-prechend; auch ron den Stiibchen, die ron Pigmentscheiden in Reihen gruppirt und theilweise umhïllt werten $\left(S t^{t}\right)$, ist wenig wahrmmehmen. Ans jeder Pigmenthülle aber steigt ein solcher Kolben mit tem Kírn $\left(\boldsymbol{K}^{T}\right.$.) empor gegen den Glaskürper $\left(G i^{I}\right.$.) zu, dessen scharfe imnere Abgrenzmng hinter den Zellkernen keineswegs übertrieben dargestellt ist. Diese ganze Schicht ist in frischem Zustand vollkommen durchichtig, und auch die Kerne besitzen das gleiche Lichtbrechungsvernü̈gen wie ihre ITmgebung, so lass sie dem Durchtritte des Lichtes dureh Ablenkung etc. kein Finderniss in den Weg legen.

Die Stïbchen $\left(S t^{2}\right.$.) sind regehmïsige, gleichlange Cylinder ron starker Lichtbrechung, vorn und hinten scharf und eben begrenzt, md die Enden derselben stehen mit grosser Regelmässigkeit in gleichen Nivean. Sie halten einen gewissen Abstand ron einander imne (wenigstens 
in medialen Schnitten), der seitliche Ueberzug, der dem Zellenkörper angehört, ist aber nur schwierig nachzuweisen. Nit grosser Deutlichkeit lässt sich an ihnen eine Lüngslinie erkennen, und Querschnitte, die nicht schwierig zn erhalten sind, zeigen, dass sie ans zwei Hälften bestehen. Die Stäbchenhälften erscheinen auf solchen Qnerschnitten von etwa nierenförmigem Umriss, mit der schwach concaven Seite dicht aneinander gelagert; eine besondere Abbildung derselben habe ich nicht gegeben, weil die Tebereinstimmung mit den Stäbchen von Salticns, von denen ich eine Zeiclmung beifüge, eine sehr grosse ist.

Eine eigenthünliche Anordnung zeigen die Stäbchen des hintersten Augenpares; sie mag auch dem eben besprochenen mittleren im Princip zu Grunde liegen, ist aber nicht melı so leicht herauszufinden, wie dort. Ich habe nach einem Flächensclmitt der Retina diese Tertheilung in Fig. 24 Taf. III skizzenhaft wiederzugeben versucht, dabei aber von der Darstellung der einzelnen Stäbchenquerschnitte, deren Aufeinanderfolge durch die lin- und herlaufende Linie angedentet ist, abgesehen. Die Figur bedarf wohl keines erklärenden Commentares. Es macht durchans den Eindruck, als wemn die Stäbchen ureprünglich in einer einfachen Kreislinie entstanden wären, deren Peripherie sich nach und nach. bei der numerischen Zmohme der Elemente, vielfach gegen einen Durchmesser rorgebuchtet hätte. Jis demn schliesslich daraus als Endresultat die rorliegende Vertheilmng hervorging. Zu bemerken wäre noch, dass die Stäbchen in der Reihe sich ganz innig berühren und kein Pigment sich zwischen sie einrrüngt; dasselbe ist auf den Raum zwischen den Schleifen bescluänkt.

Die Terbindung der Fasem des Opticus, oder besser der Optici, zu denen die Hinterenden der Retinazellen büschelweise convergiren, ist mir bei einer Reilıe ron Präparaten sehr klar mond anschanlich entgegengetreten. Ich komnte ganz deutlich den allmäligen Uebergang der hellen, scharfbegrenzten Faser in das allmälig anschwellende und sich mit Körnchen füllende Zellenende wahlnnehmen und nirgends cine scharfe Grenze zwischen beiden, oder ein sich einschiebendes neues listologisches Element auffinden.

Was ich endlich bei Lycosa-Angen von Muskeln gesehen habe, ist in der Figur 22 (bei M.) durch Zeichnung wiedergegeben. Auch hier machen die paar Fasem nicht den Eindruck eines Splineters.

Wenn wir die Leistung der beiden Angenformen (ich darf lier wohl noch beifügen, dass anch das hinterste Paar den Bau des mittleren zeigt) nach den anatomischen Frgebnissen beurtheilen wollen, so erscheinen die rordern Randaugen seln gering entwickelt gegenüber den beiden lintern Paren, deuen wir ebensowohl ein sehr grosses Gesichtsfeld, als, nach der grossen Zahl ron Stübchen $2 u$ schliessen, ein scharfes Unterscheidungsvermögen zuschreiben müssen. Die rorderen haben allerdings, wemn ich die Function der Muskeln anders richtig interpretire, eine gewisse Beweglichkeit für sich, die aber kaum zur Ausgleichung ansreichen dürfte. - Die, wie es allen Anschein hat, partielle Reduction der Retinastälschen auf den hintern Theil der Netzhaut dürfte wohl insofern nicht sehr sehwerwiegend sein, als die Gegenstïnde der Aussenwelt, deren Bild durch die Linse auf den Theil der Netzhant geworfen rerilen würde, anf welchem keine Stäbchen nachgewiesen werden konnten. bei nicht allzu geringer Distanz anch in den Bereich des Gesichtsfeldes des nahe gelegenen grossen Auges fallen mïssen; das kleine behen'seht nur die mehr nach rom und inten fallenden Theile der Lmgebung.

4. Angen ron Salticus. - Einer noch riel weiter gehenden Entwickelung der Angen, rerbunden mit entsprechender Ausprägung des Dimorphismus - fast könnte man sich rersucht fühlen, von Polynoryhismus zu sprechen - begegnen wir bei der artenreichen Gattung Salticus. Grenacher, Lntersuchungen üher das Sehorgan der Arthropoden. 
Ich labe meine Untersuchungen darüber an einer leider nicht nüher bestimnten Art, die ich in Spätsommer und Herbst in den Weinbergen meiner Heimath (barlisches Oberland) mir ziemlich reichlich verschaffen komnte, angestellt; keine der Beschreibungen, die ich später in dem bekamnten Werke ron Hahn und Koch nachsah, and noch weniger eine der bekanntlich herzlich mässigen Abbildungen dieser Autoren passte auf die Form. Ich halte diesen Uebelstand, das Fehlen der Artbestimmung, indessen fï den hier in's Ange zu fassenden Zweck fïr un so gleichgïltiger, als mir ein zufällig in die Hände gefallenes Exemplar von S. scenicus ganz den gleichen Angenban zeigte, und also wohl kam anzmnehmen sein wird, jene Art verhielte sich abnorm gegenüber den andem.

Die Tertheilung der Angen bei Salticns ist folgende. Am Stirnrand des Cephalothorax funden sich vier Angen, von denen das immere Paar das grösste ist (es sind vielleicht überhanpt die anch absolut grössten Angen bei Spimnen meeres Famengebiets). Diese berïhren sich in der Nedianebene mit ihren weit rorspringenden Limsen. Die seitlichen Ecken des Vorderrandes des Cephalothorax werden von einem Paar Augen eingenommen, die, obschon hinter ren mittleren um ein Beträchtliches zurïckbleibend, doch noch sehr ansehnliclı entwickelt sind. In einiger Entfermung hinter ilmen liegt ein ferneres Paar, das ich aber wegen seiner Kleinheit nicht berïcksichtigte; und endlich abermals in einer gewissen Distanz hinter diesem das letzte, das ungeführ Linsen wie das rordere ïussere Paar aufzuweisen hat. - Ich habe ron diesen Augen die drei grösseren Paare eingehender whersucht, und nicht unbeträchtliche Unterschiede zwischen ihnen gefunden; ich werde hier mit dem zweiten Paare begimen und daran die Schilderung des letzten, das in den gleichen Formenkreis gehürt, anknïpfen, und zuletzt die medialen vorderen Hauptangen besprechen.

Einen Längsschnitt durch eines der rorderen eckständigen Angen des zweiten Paares stellt Fig. 25 Taf. III dar. Die Kerne des zu Grunde gelegten Präparates sind in der frülier erwähnten Weise durch das sehr langsam, nur mit Spuren von Salpetersäure gelöste Pigment, dessen sich die Kerne bemächtigen, timgirt, wobei anch die übrigen Weichtheile einen leichten brännlichpurpumen Ton bekommen halıen.

Bei der schönen Linse $(L$. $)$ entspricht die besonders stark rortretende innere Wölbung anch wiedler einem kleineren Radius, als der der äussern ist. - Der Glaskörper (Grk.) bildet sich, wie beim entsprechenden hintern Auge ron Lycosa (Fig. 22), aus den stark pigmentirten Zellen der Hypodermis $\left(H_{p}\right.$.) herror, anscheinend ohme Temittlung besonders differenzirter Pigmentzellen. Sein Bar, namentlich das Terhalten seiner im L'mfang gelegenen Zeller, ist der gleiche wie dort; es ist nur seine starke Entwickelung in der Richtrung der Augenaxe, dagegen seine geringere Entfaltung der Dicke nach herrorzuhelsen, wodurch seine Gesammtform eine mehr conische wird. Der Mantel des Coms bis zur Retina ist mit reichlichem Pigment versehen, das in den Hinterenden der Glaskürperzellen $m$ den Kern hermm abgelagert ist; dieses ist durch Salpetersäme zerstörhar, gegen welche das der Hypodermis sich völlig unempfindlich erweist. Die Kerne der Glaskörperzellen sind gross und änsserst dentlich, nach der Linse hin nehmen sie an Entwickehng ab.

Besonders interessant ist nun die Retina (Rt.). die, als Ganzes betrachtet, umgekehrt conisch, uxl mit der Spitze in den Selmerv ( $N$. op.) übergehend erscheint. Die dem Glaskörper zugewandte Flïche berïhrt anscheinend diesen nicht ummittelbar, da die Wölbung des letzteren stärker ist, als die correspondirende Aushöhlung ihrer Vorderfläche, und so eine nach der Peripherie hin sich erweiternde spaltenförmige Lücke freibleibt, ron welcher, resp. ihrer Ausfüllumgsmasse. nachher noch die Rede sein wird. - Die Stäbchen (St.) sind immer sehr dentlich, besonders 
in ihrem rordem Theile, wo sie der Linse gegenüber scharf abgeschnitten sind; nach linten hin wird es weit schwieriger zu sagen, wie weit sie reichen, weil sie alhmälig an Lichtbrechung abnelmmen, und dafür die den Retinazellen angehörige Gramulirung ebenso allmälig einsetzt. Ebenso schwierig ist der Uebergang der langgestreckten Retinazellen in die Fasern des Opticus zu bestimmen. - Die Stäbchen sind sehr nahe an einander gerückt, namentlich in der der Augenaxe benachlbarten Region, wo sie anch eine Länge erreichen, welche die der peripherischen um das Doppelte etwa übertrifft; die Dicke derselloen ist aber nur ganz unbedentenden Schwankungen unterworfen. Die durch eine feine Längslinie angedeutete Zusammensetzung aus zwei Hälften ist bei stärkem Tergrössermugen, als die der Zeichnung, nicht leicht zu übersehen.

Lange habe ich mich rergeblich abgemüht, die Lage der zu den Retinazellen gehörenden, hier doch aller Wahrscheinlichkeit nach ebenfalls nicht fehlenden Kerne aufzufinden, und erst der Zufall fülnte mich auf die Spur, denn dort wo sie sich finden sie aufzusuchen. war mir durch meine frühem Erfahrungen noch nicht nahe gelegt. Sie haben nämlich folgende, ganz ungewölnuliche Lage. In der Region, in welcher Glaskörper und Retina zusammenstossen, zieht ringföming um das ganze Auge herum ein flacher breiter Wulst, der bei noch nicht entfürlsten Präparaten sich durch eine besonders intensive Pigmentirung bemerklich macht. Nach geschehener Entfärbung erkemut man, dass derselbe unter der aucl lier dem Auge zukommenden feinen Cuticula (ct.) gelegen ist, und fast ausschliesslich aus einer Anhüufung ganz dicht aneinandergedrängter Zellkerne besteht, die aber wegen der Blässe, die sie nach der Einwirkung der Salpetersïure amelmen, bei nicht speciell clarauf gerichteter Anfmerksamkeit leicht älersehen oder doch umrichtig gerlentet werden kïmen ( $K$. Fig. 25). Aber man sieht auch bald, dass diese Kerne zur Rutina in einer nïhem Beziehung stehen, als ihre relative Lage zu dersellsen vermuthen lässt. Jener spaltenförmige Raun nümlich zwischen Glaskörper und Retina ist erfüllt ron einer Unzahl ïusserst feiner blasser Füden ( $F$. Fig. 25), die lockenartig gekränselt im Ganzen einen centrifugalen Verlauf laben, und über deren Endpunkte bei genauer Untersnchung kein Zweifel mehr obwalten kam. Jeder dieser Fäden entspringt nämlich am Torderende eines Stïbchens, tritt damm, etwa rechtwinkelig mbiegend, nach ansen, und endigt im Umfang des Auges an einem Kern. Dabei treten diese Fäden bald nach rom (über (ten lintern Rand des (ilaskürners), bald nach hinten (ïber die peripherischen Retinatheile), soweit es eben die Breite der Kernzone erfordert; man kam olne Schwierigkeit den Verlauf derselben bis in die äussersten Theile jenes Gürtels rerfolgen. - Zwischen diesen feinen Fäden, soweit sie jene Spalte erfüllen, befinden sich ab und zu noch rundliche Lücken, anch ist hier und da (aber im Ganzen selten) ein Kern noch dazwischen nachweisbar, der, wie ich fast sagen möchte, nicht an den Ort seiner Bestimmmg gelangte. - Die Kerne werden rermuthlich nicht nit ihrer eigenen Sulstanz mit jenen Fäden zusammenhängen, aber sicher ist die Menge der allenfalls noch wn sie rorhandenen Zellsubstanz eine minimale, die sich auch nicht direct nachweisen lässt. Da aber die Kerne in eme so dichte Pigmentmasse eingebettet sind, mir aber bei meinen Untersnchumgen nie Keme vorgekommen sind, welche selbst Pigment enthalten, so dürfte das letztere wohl in der geringen jene lierne umhüllenden Menge Protoplasma eingelagert sein.

Wie ans meiner Zeichmung ersichtlich, finden sich anch im Innem der Retina noch Zellkerne. Diese haben aber sicher nichts mit den Retinazellen zn thmn, dem für diese reicht ilure Zahl lange nicht ans, und ilne in bammartig verästelte Züge vertheilte Anordnung, die ganz ansehmliche Stücke der Retina unversorgt lässt, weist auf ein der Retina als solche fremdes histologisches Element hin. walnscheinlich anf das Ange rersorgende Blutgefässe (Gf.(?) Fig. 25). 
Diese Kerme erscheinen spindelförmig, während sonst überall die der in die Bildung des Auges selbst eingchenden Zcllen kugelig oder höchstens etwas lïnglich sind.

Ich möchte noch anshrücklich lievrorheben. dass ich keine Mühe geschent habe, die Richtigkeit der hier gegebenen Sclnilderung über allen Zweifel zu erheben.

Wemn wir ms nun fragen, ob wir überhaupt in dieser Angenform eine mit emer der beiden bei Epeira und Lycosa beschiebenen vergleichbare, oder eine specifisch ron ihmen verschiedene ror uns liaben, so kann die Antwort nur bejahend für erste Frage ausfallen, und die damit in Parallele zu stellende Form wird nur die mit vor den Stäbchen gelegenen Kernen der Retinazellen sein kömen. Derselbe Theil der Retinazelle, welcher den Kern enthiilt, ist bei Epeira gerale vor dem Stïbchen gelegen; bei Lycosa dagegen schon kolbig ansgezogen, und meist etwas zur Seite gebogen. olme aber zwischen Retina unt Glaskörper herausutreten; hier aber hat sich dex vordere Zellentheil in einen langen diumen Faden rerschmächtigt, und an ihm hängt der günzlich aus der Bahn der Lichtstrahlen linansgerückte liern, wie eine Beere an ihrem Stiel.

Fig. 26 Taf. 11 zeigt noch einen etwas schiefen Querschnitt durch ein Auge dieser Art vor der Entfärbung, un die Anordnung der Stäbchen anf Querselmitten zu zeigen (St.). Da schon vorhin bei Lycosa von diesen Querschnitten die Rede war, so kamn hier einfach anf die Figur selbst verwiesen werden. - Bei einer gewissen Einstellung traten in dem ron Pigment wngebenen Pahmen des Schnittes, auf welchen die regehmäsige Mosaik der Stäbchen sich nicht erstreckte. (es lagen nur einzehne, wohl durch das Schmeiden selbst aus ihren natürlichen Zusammenhang gerissene Stälschenfragmente darin), feine radiär austrahlende Füden auf; bei tieferer Einstellung kamen darmer grosse Maschen mit Zellkemen zum Vorschein. Darnach musste dex Gedanke nahe liegen, dass der Schnitt etwa in der Ebene geführt worden sei, in rer in Fig. 25 der Pfeil verläuft, die mit $K$. bezeichnete Pigmentzone demnach wohl die Korne umschlösse. Dies verhielt sich in der That so, wie die nachträglich rorgenommene Entfïrbung ergab. Die aus der Tiefe hervortretenden Zellen aber sind nux die von hinten geschenen Endtächen der Glaskörperzołlen nebst deren grossen Kiemen. Das mit Pg. Rt. bezeichnete Pigment gehört dagegen den hinteru Theilen der Retinazellen an.

Der eigenthümliche Ban dieses Auges wiederholt sich bei dem lintersten Paar - abgesehen ron der Gesamntform des Organs, die sich ziennlich enge an das grosse Auge von Lycosa anschliesst - so genam, dass es genügen wird, wem ich auf die in Fig. 27 Taf. 11 gegebene Zeichnung eines Schnittes duch eines derselben verweise. Anch hier wude mit Sicherheit die Teberzeugung gewonnen, dass nu die peripherischen Zellenkerne als zu den Petinazellen gehörig anzusehen sind. - Die Stäbchen sind her im Ganzen gleichmässiger entwickelt.

Die sonderbarsten Angen bei Salticus, - und wohl ïberhanpt bei den Spimnen sind die am Vorderrande des Cephalothorax befindlichen, dicht neben der Medianebene gelegenen, die ich oben als erstes Paar bezeichnet habe; und zwar verdanken sie das Anffallende nicht nur ihren mächtigen Dimensionen im Verhältniss zu denen der andern Angen und zum ganzen Thier; sondern anch der abnormen Entwickehng iluer einzelnen Componenten (Fig 28 Taf. 1T.).

Die mächtigen, halbkugelig hervortretenden Linsen (L. Fig. 28) kömen mit Leichtigkeit mit blossem Auge erkannt werden, selbst an kleineren Formen; dies wird beconders erleichtert durch einen eigenthümlichen, wenigstens der von mir untersuchten Art zukommenden, lebhaften griunlichen Perhuntterschiller, der wohl auf Rechnung der Linsenstructur zu stellen ist, und nicht imern Reflexionen zngeschrieben werden kamn, weil er anch an isolirten Linsen, sowie an lïngere Zeit in Spiritus aufluewahten Thieren sich noch erhïlt. - Wie ans der Abbildung erhellt, weichen die Weichtheile selr bedentend ron der bisher mehr oder weniger herschenden Kugelform ab. 
Sie treten in Form eines langen cylindrischen Zapfens, der hinten durch die etwas angeschwollene Retina abgeschlossen wird, tief in das Innere des Cephalothorax ein. Die Länge des ganzen Anges bei Exenplaren von 7-9 mm betı̈̈gt ca. $1-1,25$ mm und darïber, also ungefüh ${ }^{1 / 7}$ der gesammten Körperlänge!

Man wird Durchschnitte der Linse nicht immer genan so geformt finden, wie die Zeichnung ilm darstelit. Ahweichmoen von dieser Form sind mir zahlreich begegnet, aber ich kam sie nicht etwa einer Variabilität derselben zuschreiben, sondern eher einer geringern Dichtigkeit der Substanz der innern Wölbung, die hierbei allein in Frage koumt, und welche durch die zur Erluärtung dienenden Agentien in nicht immer sich gleichbleibender Weise der Schrumpfung unterliegt. Für diese Dentung sprechen auch die oft recht umegelmässigen, kleinwelligen Contomren, die man ab und zu trifft. Der schön gewölbten äussern Fläche entspricht eine kleine imere, die auf der Schnittflïche eines abgestutzten Kegels, ungeben ron einer ringförmigen vertieften Delle gelegen ist. Von der ganzen innern Wülbung kamn wohl nur dieser kleine centrale Theil zur wirklichen optischen Geltung kommen, da die ilur rings mogebenden Partien durch iln'e unregehmässige Oberflïchenbeschaffenheit kaum Lichtstrahlen, die noch für den Sehact zu verwenden sind. durchtreten lassen. Die Schichtung der Linse ist meist eine ïnsserst deutliche und bis nach aussen lin nachweisbare.

Die pigmentirte Hypodermis $\left(H_{\nu}\right.$. $)$ geht unter den seitlichen Rïndern der Linse in betrïchtlich verlängerte Pigmentzellen ( $P g$.) ïber; letztere lassen sich entfärben, die erstere aber nicht. Gegen den ringsum vortretenden inneren Linsenrand hin werden diese Pigmentzellen wieder ziemlich kurz, und gehen damn über in die Zellen des Glaskörpers (Gk:).

Die sonderbure Formentwickelung des Auges ist auf den Glaskürper zurïckzufüluren. dessen Länge den Qnerdurchmesser etwa mu das Doppelte übertrifft. Seine nur im Punkte der Durchsichtigkeit ïbereinstimmenden Elemente sinu, was ich nur an dieser Augenform kemne, in zwei hinsichtlich der Form selı verschieden auftretende Gruppen zu sonderu. von denen die erste zwar die Innenflïche der Linse berührt, aber nucht bis zur Retina reicht; die andre lingegen mit letzterer in Contact stelit, aber sich nicht bis zur Linse erstreckt. Die erste Form der Glaslörlerzellen (Gh. Fig. 28) ist langgestreckt, und stösst mit dem Torderende an die Linse. das Hinterende aber liegt in der Mantelflïche des Glaskörpers, wo es einen Klumpen körnigen Pigmentes, welches den Kem verdeckt, unschliesst. Die innersten, längsten Zellen lassen durch ihre Divergenz nach hinten eiren conischen Hohlraum frei, der ansgefïllt wird ron den Glasküruerelennenten der zweiten Form (GkI. Fig. 28), die anf Lïngs- wie anf Querschnitten den Eindruck eines grosizelligen blasigen Pflanzenparenchyms machen. $O b$ sie einfich rundlich-blasige Zellen, oder vielfach durcheinandergewundene Schlänche sind. dafür habe ich ans den Schnitten keine Anhaltspmkte gewinnen kümen. Anch sie betheiligen sich an der Bildung der änssern MantelAlïche, und zwar an der des hintern Fünftels etwa, wohin die Zellen der ersten Art nicht reichen. Hier kanm man dentlich lierne, die anch stellewweise in den der Retina ummittelbar vorgelagerten Zellen zu benerken sind, wahrnehmen; ferner ebensolche Pigmentballen, wie sie den andern Zellen zukommen. In einer noch zu besprechenden trichterförmigen Grube der Vorderflïche der Retina sind diese Zellen abgeplattet mo aufeinandergeschichtet. Das Pigment fehlt natürlich vor der Fetina. In der innern Hauptmasse dieses Theils des Glaskörpers ist es mir nicht gelungen, Keme ausfindig zn machen, selbst nicht vermittelst der sonst so zuverlïssigen Tinctionsmethoden; möglich, dass sie u'sprïnglich vorhanden, später aber völlig atrophirt sind.

Auch die Structur der Petina (Rt.) zeigt wieder manches ganz Eigenthümliche. Bedauerlicherweise war es mir aber nicht nü̈glich, mir über alle Einzelheiten derselben ein völlig klares und abgermotes Bild zı verschaffen, trotz aller daranf verwandten Mühe. Wem ich aber hien: 
Lücken zngestehe, so glaube ich doch auf der andern Seite hin nicht annelmen zu dürfen, dass ich wesentliche Irrthümer in dem begangen habe, was ich hier wiedergebe.

Die Retina hat eine sehr ansehmliche Dicke, so dass sie als ein birnförmiger, nach linten in den Opticus übergehender Anlıang des Glaskörpers erscheint. Gegen diesen hin trägt sie eine ziemlich tiefe conische orler trichterfömige Grube, deren tiefste Stelle in der Augenaxe liegt und abgerundet endigt. Schnitte durch die Netzhant zeigen drei anscheinend wierler selbständige Schichten; die vorderste ist durchsichtig und pigmentfrei, rlie mittlere enthält die von intensiv gefürlbtem Pigment mmgebenen Stäbchen, wälurend in der hinteren, ebenfalls pigmentirten, eine Menge ron Zellkernen auftreten. An diese Lage treten anch die Opticusfasem. Selbstrerständlich sind alle diese Schichten nur als aus Differenzirung der einzelnen Zellen, die nur in einer Reihe vorhanden sind, hervorgegangen aufufassen.

Ueber das Terhalten der rordersten Schicht ( $F$. Fig. 28) zu der Retina bin ich nicht völlig in's Reine gekommen. Sie ist ron ziemlich ansehnlicher Dicke, ausser im Centrum, wo die Concavität der Retina am tiefsten ist, ziemlich stark lichtbrechend (an erhärteten Präparaten) und fein radiär gestreift orler gestrichelt, als ob sie ans einer grossen Anzahl sehr feiner, der Länge nach leicht mit einander verschlungenen Fäden zusammengesetzt wäre.

Die Stäbchen (St.) liegen in einer nach vorn schwach concaven Fläche, die anch unter der trichterförmigen Tertiefung olme Mlodification ihres Characters sich continuirlich linzieht. Sie sind äusserst schwierig zu umtersnchen. sowohl wegen ihrer Kleinheit, als auch wegen ihres geringen Lichtbrechungsremögens. Die randständigen sind etwas dicker als die centralen, etwa gerstenkornförmig; die in der Nitte gelegenen aber sind sehr dümn und zart, und verlängern sich sehr stark gegen den Opticus hin. Ihre Länge ist aber wegen der moleutlichen Alggrenzung nach linten nicht wohl genaner zn bestimmen. Dass sie wie die bisherigen zusaumengesetzt sind, habe ich nicht sehen können. laalte es aber für höchst wahrscheinlich.

Die hintere Schicht wiod ans den eigentlichen Zellenkürpern, zu denen die Stäbchen gehören, gebildet. Sie sind nach hinten him divergirend, und ihre Feinheit richtet sich nach derjenigen der Stäbchen. (Fig. 28.)

Die Kerne der Zellen $(\boldsymbol{K}$.) sind hinter den Stäbchen gelegen, zwischen diesen und den Opticusfasem; ich kann dies mit aller Bestimmtheit angeben, da der Nachweis derselben sowohl mit Hülfe des in Lösung übergeführten und von ihnen aufgenommenen Pigmentes, als auch duch Haematoxylinfürbung ein über jeden Einwand sicherer war. - Die peripherischen Zellen scheinen keine Stäbchen zu führen $\left(P_{i} t^{I}\right.$ ), sondern mit ihren vordem Enden direct in die erstgenamnte durchsichtige Lage ülserzugehen. Ob nm ron den diese Lage zusammensetzenden Fïden nur einer, orler, wie es mir walurscheinlicher ist, ein ganzes Bündel zu je einer einzigen Zelle gehört, bin ich zu entscheirlen ausser Stande. Sicher scheint mir blos, eimmal, dass sie keine fremden, neuen Elemente, sondern directe Ansläufer der Retinazellen sind, und zweitens, dass in ihrem Bereich keine Zellenkerne vorkommen.

Ueber den Opticus $(N$. op.) weiss ich wenig zu sagen. Er ist ziemlich ansehnlich, und seine Fasern, die sich mehrfach rerflechten und krenzen, treten becherförmig auseinander ïber die hintere Retinafläche hin, wo sie sich verlieren. - Auch hier findet sich die bekannte feine Cuticula (ct.).

Dass das Auge bezüglich der Bildung seiner Retina-Elemente mit den vordern Augen ron Epeira und Lycosa in eine Reihe gestellt werden muss, dafür branche ich blos auf die rorstehende Schilderung hinzuweisen. Nir haben in ihm eine dritte Form der Ansbildung, die dasselbe im Tergleich zu den audern Augen erreichen kann. Bei Epeira war diese Angenform 
der andern ziemlich gleich in der Ansbildung und wohl anch in der Leistungsfühigkeit; bei Lycosa dagegen der andern sehr untergeordnet; hier aber ist ihre Entwickelung eine ganz exorbitante, was noch besonders auffïllt, wenn ich hinzufüge, dass der Maassstab der Fig. 28 sich zu dem ron Figg. 25 mo 27 etwa verhält wie $2: 3$.

Das Auge hat aber anch seine Muskeh, die den andern beiden Augen fehlen; ein fernerer Beleg für die obige Vergleichnng. Ich habe sie in der Figur nicht gezeichnet; sie bilden einen. aus ziemlich zahlreichen Fasem bestehenden Plexus, der, schrïg zur Augenaxe gestellt, und von hinten nach vom streichend, einem Theil der Mantelfliche des Auges dicht anliegt. Also auch hier kein Anhaltspunkt für die der Musculatur von Leydig rindicirte Rolle.

Ans der Kleinheit der Retina und ans ihrem grossen Abstand von der Linse ergiebt sich ein sehr geringes Sehfeld für das Ange, während die Feinheit der Stäbchen namentlich in der Nitte auf ein scharfes Unterscheidungsvermögen schliessen lässt. Danit stimmt anch das Gebahren der Thiere überein, die ich sehr oft mit Tergnïgen beobachtet habe, sowohl wemn sie ihre Bente zu erhaschen, als wem sie der Verfolgung zu entrinnen suchten. Sie machen mit unglaublicher Behendigkeit immer Front gegen ihren Verfolger, indem sie sich, rückwärts concentriren", und springen dabei mit unfehlluarer Sicherheit von Blatt zu Blatt und ron Panke zu Ranke.

Meine Erfahrungen über das STinnenauge habe ich hier mitgetheilt; sie sind an nur wenigen Formen gewonnen worden, haben aber doch, wie ich glanbe. manches Interessante mod Eigentliümliche zu Tage gefördert.

Bevor ich nun dazu übergehe, meine Befunde mit denen memer Torgänger auf diesem Gebiete, namentlich Leydig's, zn vergleichen, gestatte man mir einige Bemerknugen.

Es mag auffallen, dass ich in meiner Darstellung des Tajetum der sjinnenangen mit keiner Silbe gedacht habe. Der Grund ist ein einfacher. Zunächst ging meine Absicht keineswegs dahin. Alles und Jedes, was am Spinnenauge (oder überhaupt bei den Augen des Arthropodenkreises) rorkommt, in gleicher Weise zu berticksichtigen. Da nm das Tapetum als solches nichts bietet, was für das Terständniss des einfachen Auges und seiner Beziehmuen zum zusammengesetzten ron Belang wäre, so mterliess ich eine nähere Berücksichtigung desselben, besonders anch noch - und dies ist der zweite Grund - weil die Methode der Untersnchung: dadurch eine ganz andere hätte werden müssen. Das Tapetum nämlich erhält sich nicht, wenn man Salpetersäure auf die Prïparate einwirken lässt; es geht in kürzester Zeit. ohne eine Spur zu hinterlassen, zu Grunde, und an nicht entfärbten dugen sieht man nur irisirende Flecken oder Streifen, eingebettet in dem gleichmässig tiefschwarzen Grund.

Neben dem Interesse, welches das Spinnenange in Hinsicht seines Verhaltens zum einfachen Ange der Insecten erregen muss, verlangt der Dimorphismus der Retina anch sein Recht. Auf das erstere haben wir ums hier nicht näher einzulassen, und für den letztern werden ein par Bemerkumgen genügen.

Wir müssen den Dimorphismus als eine gegebene Thatsache himnelımen, und seine physiologische Bedentung als eine ms noch total unverständliche ganz auf sich beruhen lassen. Seine Entstehmg, oder besser seine allmälige Weiterbildung aus gegebenen Anfängen in die jetzt vorliegende Form künnen wir uns zur Noth so denken, dass die Stäbchenhälften hier ursprünghich oberflüchliche Zellanflagermoen waren, wie sonst ganz allgemein. und dass diese allmälig in das Innere der Zelle eingeschlossen wmden. Welche Ursachen aber veranlassten, dass die allmälig 
nach imnen rückenden Stäbchenhälften in dem einen Auge den Kern nach vorn, in andern aber nach linten drängten, das zu erklären fehlen uns noch jegliche Mittel.

Im endlich noch die Gegensïtze, welche die von mir erhaltenen Resultate vor Allem gegenülser denen, welche Leydig seiner Zeit erhielt, zur Sprache zu bringen, mag das Folgende genïgen.

In Bezug anf die Bedentung der beiden in Spinnenange hintereinander liegenden Zellenschichten (Glaskörper und Retina) schliesse ich mich, wie leicht ersichtlich, an J. Müller und Brants an, ohne jedoch die ron letzterem gezogenen morphologischen Folgerungen muterschreiben zu können. Meine Opposition aber gegen die Darstellung Leydig's bezieht sich fast auf alle limter der Linse gelegenen Weichtheile, und ich muss, un die Contraste herrorzuheben, nïher auf jene eingehen.

Nach Leydig sind die ummittelbar hinter der Linse gelegenen Elemente, seine „Gallertkolben", keine sellständigen, nach innen oder hinten hin abgesclilossenen Zellen, sondern sie sind nur vordere differenzirte Abtheilmugen der "Nerrenstäbe", in welche sie olme scharfe Grenze übergehen; sie selbst sind kernlos, aber die Vermittelung mit dem "Nervenstab" geschieht durch cine kernführende, ganglienkugelartige Zelle. In von Pigment mnschlossenen Theile des „Nervenstabes" treten jene eigenthümlichen. so teicht durch Quellung zerstörbaren Gebilı auf, die er anch im Facettenange wiederfinilet; nnd darauf hin, und andererseits anf den rermeintlichen directen Uebergang des Krystallkegels in den Nervenstab gründet er dem anch seine morphologischen Folgermngen. Ausserdem beschreibt er noch in hintern Abschnitt des Spinnenanges ein Sehganglion. das durch Autinahme von zelligen und körnigen Elementen in die Ansbreitung des Nervus optiens zu Stande kommt, nud mit dem des zusammengesetzten Anges rerglichen wird.

Ich lrabe hier die Hanptpunkte, denen ich auf Grund eigener eingehender Lntersuchungen entgegentreten muss, liurz zusamnengestellt - mit Ausnahme seiner schon oben erörterten Darstellung der Musculatur des Spinnenanges und meiner dagegen erhobenen Einwendungen. Dass die Zellen des Glaskörpers wirkliche, unter sich und gegen die Retina hin scharf abgegrenzte Zellen sind, die ächte Kerne fülıen, wird wohl nach meinen Lntersuchungen Niemand mehr bezweifeln kümnen. Ich möchte noch besonders auf die Figuren 25 und 27 hinweisen, wo schon durch die Einschiebung der Fadenlage ein unnittelbarer Zusammenhang zwischen Glaskürper und Retina ausgeschlossen ist. Die Function dieser Zellen muss aber damn nothwendig eine andere sein, als die von Leydig smponirte lichtempfindende; die zmm „Craskörper" modificirten Hypodermiszellen scheirlen in erster Linie die Linse ab und erhalten, mnter nöglichst geringer Absorption des durch sie tretenden Lichtes, die Retina in der richtigen Focaldistanz. - Was Leydig als ,ganglienkugelartige Zelle" bezeichnet, dürfte bei Lycosa, die er als Untersuchmngsolject namhaft macht, wahrscheinlich der vor dem Stäbchen gelegene kolbenfürmige und kernfühuende Theil der Retma sein; bei dem rou ilm aber abgebildeten Ange von Salticus (Arch. f. Auat. 1855. Taf. XVI. Fig. 24; Histologie Fig. 135) gehören die Kerne sicler den Glaskörperzellen an. - Welches Ange ron Salticus aber Leydig untersucht hat, ist ans seiner Zeichmung nicht zu entscheiden; sie passt auf keines der drei Paare, die ich geprüft habe, und das winzige rierte Paar, das ich nicht beachtete, dürfte doch kam zu der in alle Lehrbücher iibergegangenen Fignr Modell gestanden haben, $n$ so weniger, als er ja sellsst diese Gattung wegen ihrer grossen Angen zu Vormtersuchungen empfiehlt. - Auch für die "Zellenschicht" der Retina, das Homologon des Ganglion opticum des Facettenanges, muss ich behanpten, dass dem Auge sellst fremde Elemente dafür herangezogen wurden; ich habe nirgends innerhall, der Cuticula Andentungen des Torhandenseins einer solchen finden kömen. Dagegen lagern sich ausserhalb 
derselben meist massenhaft Zellen an das Ange an, olme aber zu demselben engere Beziehungen zu haben; vielleicht haben diese den Irrthum reraulasst. Dass ich damit nicht einem am andern, cerebralen Ende des Nervus opticus sich findenden Ganglion opticum die Existenz absprechen will, füge ich noch ausdrücklich bei, um Missverständnisse zn remeiden.

Damit können wir das Spimenauge rerlassen und uns einer nahe rerwandten Form dieses Organs zuwenden.

\section{Einfache Angen einiger Insecten ${ }^{1}$ ).}

Ton den bei ausgebildeten lnsecten sich fusdenden einfachen Augen habe ich nu einige wenige untersuclit, und will in diesem Abschnitte meine dabei gewomenen Resultate mittheilen, die ebenfalls in einigen fundamentalen Beziehnngen ron den allgemein acceptirten Leydig's sich entfernen.

Neine Aufgabe wird sein, zu zeigen, dass der morphologische Bau des Insectenstemma soweit die Untersnchungen reichen - derselbe ist wie der des Spinuenanges, oder, genaner ausgedrückt, da wir hier ja zweierlei Formen kennen gelernt haben. wie der jener der beiden Augenformen, bei welcher die Stäbchen vor dem Kerne der Retinazelle gelegen sind. Wir haben demnach im einfachen Ange der Hexapoden alle rlie dort vorkommenden Eilemente wieder zı erwarten, und der ganze Tnterschied besteht nur in der rerschierlenen Ansbildmng, welche besonders den Glaskärper hetrifft, der wenigstens in den meisten Fïllen weit hinter dem der Spinnenangen zurïcklbleibt, und bisher eben wegen dieser geringen Entwickelung fast völlig überselıen. zum mindesten stark verkannt wurde.

Es sind bekanntlich nur wenige Insectenformen, die auch als Imagines sich mit dieser Angenfor'n allein behelfen müssen. Ton diesen habe ich nn den Flolı untersuchen können, und will mit ihm begmmen. weil er den besten Anschluss an die Spinnenangen remittelt.

1. Ange des Hundeflohes, Pulex canis. - Die Gruppe der Aphaniptera ist u. A. anch dadurch ausgezeichnet. dass bei ihren Angehörigen jederseits am Kopfe, wo sich bei den anderu Insecten die zusimunengesetzten Augen finden, nur ein einzelnes Stemma rorkommt. Das Auge ist wegen seiner Ḱleinheit seln schwer zu mtersuchen, loch ist es mir geglückt, einge Schmitte zn erlalten, die wenigstens die Grundzüge seiner Architectur, wem anch nicht die Einzelleiten, für den ummittelbar vorliegenden Zweck mit genügender Sicherheit bestimmen lassen. Ich habe einen solchen in Fig. 29 Taf. IV wiedergegeben; die Schnittläche ist senkrecht zur Längsaxe des Thieres.

Das Auge ist ringsum von einer dicken Chitinkapsel umschlossen, in welche nach roru die Linse $(L$.) eingesetzt erscheint. wïhrend nach innen nur eine relatir kleine Deffnung zum Durchtritt des Selnuerven ( $T_{\text {. op }}$.) offen bleibt. Diese Kapsel $\left(C t^{I}\right.$.) ist ron der Linse an änsserst intensiv schwarz tingirt und völlig modurchsichtig, so dass man, um Einblick in das Innere derselben zu erlalten, rorn und hinten Stücke daron abzuschneiden suchen mus; eine Entfärbung des Chitins ist nicht möglich, wenigstens nicht, olme die eingeschlossenen Weichtheile röllig zu zerstören. Die Kapsel ist etwa birnförmig, mit der Spitze nach innen und unten gerichtet.

1) Leber die Verhültnisse der Lage und der Zaht lerselben vgl. bes. : K lug, Ueher das Verhaiten der einfachen Stirn- und Scheitelangen ete. Abh. Berl. Akad. - Physik. Cl. für d. Jahr 1831 (1532) pag. 301.

Grenacher. Lntersuchungen üher das Sehorgan her Arthropoden. 
Die ans der allgememen Cuticula (Ct.) herrorgegangene Linse ist mässig und auf beiden Seiten gleich gewölbt; von schichtung ist nur sehr schwer etwas wahrzmehnen. Der vordere Rand der Chitinkapsel $m$ das Auge inserirt sich in einiger Entfernung von ihrem Lmfang an der Cuticula, setzt sich aber bis zum Aequator der Linse lin fort, und ersetzt so das fehlende vordere Pigment (rgl. Fig. 29).

Was ich ron der Beschaffenheit der Weichtheile zu erkemen vermochte, ist in der $\mathrm{Ab}$ billung niedergelegt. An die immere Linsenflüche stösst eine Schicht von ansehnlicher Dicke, nit sehr ansgeprägter radiärer Streifung, und scharfer Abgrenzung nach hinten gegen eine zweite Schicht lin. Erstere ist der Glaskürper $(G k)$, letztere die Retina (Rt.), die sich in den Nervus optiens fortsetzt. An dem Prïparat, nach welchen die Zeichnme entworfen wurde, gelang es mir nicht. Kerne in dem Glaskörper aufzufinden und so seine Bedentumg absolnt festzustellen; wohl aber habe ich an einem andem, sonst nicht so übersichtlichen, nach Anwendurg ron Haematoxylin-Fürbung längs der lintern Grenzlinie der Schicht eine dentliche Kernreihe nachzuweisen vermocht, genau also analog dem Verhalten im Spimenange.

Von der Retina kam ich nur weng mitheilen. Sie umfasst in Gestalt einer Kugelschale den Glaskörper; der dem letzteren anliegende Rand erschien in meinen Präparaten gezähnelt und stärker lichtbrechend, anch stärker grannlint als der limtere Theil, der rom Opticus ausgehende leichte Strichelung als Andentung der Ausbreitung der Favern desselben zeigte. Die abgerundet prismatisch rorspingenden Zühme sind wohl als einzige Spur der Anwesenheit von Zellen, die wohl auch Cuticularschichten als Stäbchen produciren, aufzufassen. Auch in der Retina finden sich, wie mich das oben erwähnte Haematoxylinpräinarat belehte, zahlreiche Kerne, die etwa in einem der vordem Kernieihe concentrischen Bogen angeordnet sind.

Anffallend ist mir der Mlangel an Pigment in der Retina gewesen. Ich habe die Thiere in Alcohol sowohl, wie in dem Platinchlorid-Chromsïure-Gemenge gehärtet und nach meinen sonstigen Erfahrungen zerstürt, wenigstens bei lnsecten, keine dieser Flüssigkeiten das Pigment. Ich glaube deshalb, dass es den Angen der Flöhe ïberhanpt fehit, mol dass dieser Nangel einigermaassen durch die tingirte Angenkapsel ausgeglichen wirt.

2. Stemma von Mnsca romitoria. - Leichter zu behandeln als die Angen der Flöhe sind die der Fliegen, von denen ich ein Stemma der blanen Schmeissfliege in Fig. 30 Taf. I im Durchschitte abgebildet habe.

An der stark biconvexen. gleichgewölbten Linse ist selbst bei stärkeren Vergrösserungen ron Blitterstructur nichts zu erkennen. Die Ebene des Acquators derselben ist um einen gewissen Winkel geneigt gegen die der umgebenden Cuticula, aus der sie herrorgeht; dem entsurechend steht anch die Augenaxe schräg zm letzteren, wenn auch nicht in dem Maasse, wie die Figmr es zeigt, da der Schnitt ctwas durch das Meser verschoben war; die richtige Lage der Angenaxe würde hier in die Verlängerung der Axe der Linse fallen.

Die Hyporlemis $\left(H_{p}\right.$.) zeigt nu sparsame Keme. und Zellgrenzen sind kaum nachzuweisen; sie erscheint schürfer von den in die Bildung des Auges eingehenden Elenenten abgesetzt. trotzdem diese doch auch nur ans ihr sich hervorbilden. An entfärbten Präparaten lassen sich die Pigmentzellen, welche einen Ring um die des Glaskörpers bilden, kamm mehr von letzterem tremnen. Die (taskörperzcllen zeigen schon eine relativ geringere Ausbildung (Gh.), als beim Floh, bilden aber doch noch eine deutliche Lage durchisichtiger, prismatischer Zellen mit endstïndigem Kerne.

Die inelu als halbkugelig gewölbte Retina (Rt.) besteht aus lang ausgezogenen, unter sich 
parallelen Zellen, die in der Nitte länger sind als in der Peripherie. Jede triggt an ihrem vordern Ende ein Stäbchen (St.) von etwas stïrkerem Lichtbrechungsvermögen, das rorn abgerundet, mud nach hinten scharf abgeschnitten erscheint. Die mittleren Stäbchen übertreffen ebenfalls die peripherischen um ein Ansehnliches. Die Zellenkörper sind nach hinten stark pigmentirt und enthalten ror der scharf hervortretenden Uebergangsstelle in die Opticusfasern je einen dentlichen Kern. Der Opticus (N. op.) ist ein anselmlicher, ans ziemlich blassen Fasern gebildeter Strang, der ans einer kömigen, gangliösen Misse $(G . o p$.), ans welcher anch die Optici der beiden andern Stemmata entspringen, herantritt, und ron der gleichen feinen Cuticula wie das Ange nmhïllt wird $(c t$.).

Ich bedaure, nähere Anskimft weder darüber, ob die Stïbchen dem vordern Ende der Retinazellen auf- oder eingelagert sind, geben zu kömmen, noch auch, ob sie einfach sind oder wie die Stäbchen des Spinnenanges zweihïlftige Znsammensetzmng haben.

Die in der Figur um das Ange herum gezeicheten Zellen (Fki) gehören zum Fettkörper; dazwischen verlïuft ein lst einer Trachee $(T r$.).

3. Stemmata ron Tespa communis und ron Crabro cribrarius. Die beiden genamnten Hymenopteren sind die einzigen dieser Ordnung, deren Stemmata ich einer nähern Prüfung unterwarf, und wegen ihrer Ueberenstimmung will ich sie hier gemeinsam besprechen.

Die Linsen (L. Fïg. 31, $3 \pm$ Taf. V) sind umgemein dick, und ihxe imere Hälfte, die von der änssem durch eine bei Vespa (Fig. 31) breite aber seichte, bei Crabro (Fig. 34) schmale aber tiefe Ringfurche almgesetzt ist, springt sehr bedentend ïber die innere Grenzfliche der Cuticula (Ct.) gegen die Retina lin ror. Die Schichten der Linse sind von anssen nach imen allmälig an Härte und Consistenz abnehmend, wie sowohl ibr Aussehen nach der Härtung, als ihr Terhalten beim Schneiden beweisen. Die immern Theile nämlich zeigen nach der Einwirkung ron Alcohol oder sonstigen Hïrtmgsmitteh Erscheinumgen, die sich nur durch Gerinnung und dadurch entstandene Tolmmsveränderungen erklären lassen. Bei Trespa treten in den immern Lagen gewöhnlich grössere orler klemere, spaltenartige Höhlen auf, oft ron selur unregehmïsiger Gestalt, aber im Ganzen meist der Schichtung entsprechend verlaufend. Pei Crabro aber gewälnt die imnerste Schale der Linse (Fig. $34 L^{T}$.) fast das Ansehen ron hyalinem Knorpel bei sehr schwacher Vergrössermg, weil die Lïcken ganz unregehmïssig gestaltet und rertheilt sind. Bei beilen sind die äussern Theile der Linsen klar nud fest.

Die Hypodernis $\left(H_{l}\right.$.) unter der sehr dicken, schwarzen und spröden Cuticnla ist sehr dünn und nur mit sparsamen Kernen rersehen. Die am Linsenmmfang ans ilır herrorgehenden Pigmentzellen $\left(Y_{g}\right.$.) sind langgestreckte Prismen. die sich noch eine Strecke weit über die Seitenränder der Retina hinïberziehen.

Eine anfallend geringe Entwickelung erreicht der Glaskörper (Gki), und es ist sehr leicht, ihn völlig zu äbersehen, wenn man nicht durch die Erfahrmng an andern Angen geleitet speciell daranf seme Aufmerksankeit hinlenkt; dies ist un so nothwendiger. als die Elenente desselben in allen Flüstigkeiten wenigstens. die ich benutzte (Weingeist-, Oxalsänre, Kleinenberg"sche Pikninsïnrelösmg) - sich nur sehr mïssig conserviren. Ich musste deshalb in der Zeichnung des Wespenanges Fig. 31 den Glaskörper anch etwas schematisiren, denn ich habe ihn anf Schnitten nicht so deutlich, wie ich ihn gezeichnet habe, gesehen, namentlich nicht bei so schwachen Vergrössermugen. Die Zellen werden ausserordentlich unscheinlar, ganz krümelig; ihre Contomen sind nur auf Flächenansichten, und ihre Kerne fast gar nicht olme Tinction zu erkennen. Um aber sicher zu gehen, habe ich letztere Methode bei Crabro angewandt, mo zeichne das Präparat 
wie es sich darbietet. Wälırend bei Tespa die Zellen des Glaskörpers ans der Flächenansicht reconstruirt wiedergegeben wurden, liessen sie sich bei Crabro dentlich als eine epithelartige dünne Lage, die der ron der Linse losgetrennten Retina anhaften geblieben war, erkennen, ganz besonders leicht aber ihre dichtstehenden kleinen, intensir gefürbten Kerne. - Die so geringe Entwickelung des Glaskörpers scheint in Correlation zn stehen mit der starken Entwickelung der ron ilmm ansgeschiedenen Linse; man könnte denken, die Substanz semer Zellen sei fast ganz bei dem Aufban der letzteren verbrancht worden.

Die Retina (Rt. Fig. 31, 34) bildet, wenn man von der sie ïberziehenden Ausbreitung des Selmerven $(\boldsymbol{N}$. op.) absieht, eine überall ziemlich gleichdicke, der innern Linsenoberfläche bis an die äquatoriale Furche anliegende Schale. Sie besteht ans gestreckten, prismatischen, dicht an einander gelagerten Zellen, deren Kerne, wie besonders dentlich in Fig. 34 zn ersehen, in der innern Hälfte gelegen sind. Ihre der Linse zugewandten Enden sind abgermolet (vgl. Fig. 32 Taf. T) und mit einer eigenthümlichen Stäbchenbildnng im Innern versehen (St. Fig. 32, 33), die ich besonders bei Vespa näher untersucht habe. Soriel ich aber bei Crabro, wo die Bedingungen weniger gïnstig waren, gesehen habe, sind sie hier von gleichem Ban.

Jedes Stäbchen besteht ans zwei dïmnen, stark lichtbrechenden Platten, die aneinandergelagert in das rordere Viertel der Zelle etwa eingesenkt sind. Ihre Breite entspricht der Stäbchendicke, so dass ilne Ründer, wie man anf Qnerschnitten (St. Fig. 33 Taf. I) sieht, jederseits an die Oberflïche treten. In Längsansichten kann man sie blos erkemnen, wemn man auf ilne Kanten sieht (Fig. 32 u.), in Ansichten auf ihre Flïche decken sich ilure Contomen mit denen der Zellen (Fig. 32 b.). - Wie tief sie in das Innere des Zeilenkörpers hineinragen, konnte ich mit Sicherheit nicht bestimmen, denn nach hinten werden sie weniger lichtbrechenr, und gleichzeitig nimmt die Trübung des Zellenleibes, als Leberrest des dmreh die Salpetersäme zerstörten körnigen Pigmentes, stark zu.

Die hier von mir gegebene Darstellung der Stäbchen stimmt nicht ganz überein mit derjenigen, die in nenerer Zeit Leydigl) rom Ban derselben bei der Honigbiene gegeben hat, und ich bezweifle, ol, die Differenz allein in der Terschiedenheit des Materiales sich begründen lässt. Leydig hat frisches Material benutzt, und darnach sind die Retinazellen (seine "Gallertkolben") rorn stark lichtbrechend; was nach meinen Untersnchumgen eigentliche Stäbchensubstanz, gesondert von der der Zelle ist, trennt er nicht ron ilır, und im den stark lichtbrechenden Lüngslinien, in denen ich die zwei Lamellen des Stäbchens erblicke, erkennt er nur Kanten. - Dafür hat er die Qnerstreifung dieser Gebilde beobachtet, die sich an gehärteten Angen nicht erhält.

Das Terhalten des Opticus zur Retina zeigen die Figuren 31 und 34, auf welche rerwiesen werden kamn. Die feine Cuticula. welche Ange und Nerv einschliesst, ist nur in letzterer Figur gezeichnet, zugleich mit den Kernen. welche zu ihr gehören.

4. Stemma ron Phryganea grandis. - Das Stemma von Phryganea grandis habe ich in mehr als einer Beziehnng recht wesentlich ron den bisherigen sich entfernend gefunden, bin aber, da ich nur Weingeistexemplare zur Disposition hatte, nicht in der Lage zn entscheiden, ob alle die hier anfgezählten Differenzen bei näherer Prüfung unter verschiedenen Methoden sich als beständige erweisen, oder nur der hier zur Anwendung gekommenen zur Last zu schreiben sind.

Die grosse biconvexe Linse (Fig. 35, L. Taf. V) steht mit iluer Aequatorialebene beinahe rechtwinklig auf der Cuticula des Scheitels, so dass das Auge mansardenartig hervorragt. Ihre

1) Ley dig, Auge der Gliederthiere etc. pag. 34; Taf. z. vergl. Anatomie IX, Fig. 3, 4. 
Wölbung ist schön und ebenmässig, wenn anch nicht sehr bedeutend; die Schichtung dentlich und regelmässig.

Der Glaskürper hat denselben Bau, wie bei den eben beschriebenen Angen, d. h. er überzieht als eine düme, anscheinend epitheliale Berleckung, aus kleinen, flachen, deutlich gekernten Zellen bestehend (Gk. Fig. 35), die innere Linsenoberflïche. Herrorzulieben aber ist das eigentliümliche Verhalten am Umfang der Linse, wo die Zellen ohne Interpolation von Pigmentzellen ganz direct in die gewöhnlichen Elemente der Hyporlermis sich fortsetzen. Dicht am Linsenrand sind die Zellen der Hyporlermis noch schmal. so dass die Kerne dicht neben einander gerückt erscheinen; in grösserer Entfermung aber werden letztere viel sparsamer. Um das epitheliale Verhalten des Glaskörpers recht deutlich zu zeigen, habe ich ans den Schnitten, die ich habe, einen mehr rom Rande gewählt, mol mit Haematoxylin gefürlst; er ist instructiver, als ein genau durch die Vitte geführter, weil man den Glaskörper ron der Fläche, und zugleich (am untern Rande) in Profil übersieht.

Anch die Retina (Rt.) entbelnt des Pignentes vollstïndig. Iclı glaube rlies auch schon deshalb amehmen zu dïrfen. weil die von mir ebenfalls mtersuchten und spriter zu besprechenden zusammengesetzten Augen starkes Pigment vollig malterint aufwiesen, mol kein Grumd rorliegt zu der Annahme, die Nebenangen hesïsen ein in Weingeist zerstörbares Pigment, die Hanptaugen dagegen ein resistentes. Die Anordnumg der Retinazellen, wie anch ihr Ban. stinmt auch nicht mit dem bisher Bekannten überem. Sie bilden ein nach vom. gegen die Linse zu, divergirendes Büschel nach rom kolbenförniger Zellen; ganz dicht vor den Vorderende, im dicksten Theile der Zelle. befindet sich der grosse kngelige Kern.

Stäbchen habe ich an ilmen rergeblich gesucht, und da mir bisher kein Beispiel bekamnt geworden, dass die Stäbchen lediglich unter dem Einfluss des Weingeistes spmrlos verschwinden, anch durch die Pigmentlosigkeit des Anges die Einwirkung ron Salyetersäme, die ja oft störend genng ist, überflüssig gemacht wurde, so glaube ich, dass sie ron Hause aus fellen. Selbstverständlich muss imner die Nöglichkeit offen gehalten werden, dass meine an andern Objecten gewonnenen Erfahrungen trotz aller Tebereinstimmung unter sich keine Folgerung für dieses specielle Object zulassen.

Der Nervus opticus ( $N$. op.) tritt als starker. blasser Strang, in dem dicht hinter der Retina an einer bestimmten Stelle eine starke Anläufung von Kemen sich findet, an diese heran; er entspringt ans einer grandirten, ganglionartigen Masse $(\sigma$. op.) und hat nur einen kurzen Verlauf.

Wem die hier gegebene Darstelhng anch bei Lntersuchung auf andern W'egen sich als eime zutreffencle erweisen sollte, so können wir dem Ange kaum eine besonders hoch entwickelte physiologische Leistmg zuschreiben, ja, es wird überhaupt mit Fug und Recht zu bezweifeln sein, ob dasselbe. bei dem Mangel ron Stäbchen besonder's, damn anch ron Pigment, noch als functionsfähig zu bezeichnen ist, und nicht etwa blos die Rolle eines rudimentären spielt. Indessen ist zur Zeit eine definitive Ent-cheidung darüber noch unzulässig.

Meine eigenen Erfahrungen über das einfache Insectenange sind damit abgeschlossen. Sie sind, rerglichen mit dem grossen nicht berücksichtigten Nateriale, nur dürftig zu nennen, und es lïsst sich hier wohl die gleiche Prognose wie oben für das Spimnenange stellen, nämlich, dass eingehendere Studien rorausichtlich noch manches Eigenartige zu Tage fördern dürften.

Die vorgeführten Thatsachen bedürfen keines besondern Coumentares, rm meine diesem Abschnitte vorausgeschickte Behauptung, das Stemma der lnsecten-Imagines schliesse sich ganz 
unnittelbar an das Spimnenauge an, zu rechtfertigen. Ich kann deshalb gleich zu der Vergleichmg meiner Darstellnng mit der meines Vorgïngers, Leydig, übergehen; die älteren, in der Literatur zerstrenten Angaben ïber diesen Gegenstand haben zu den meinen zu wenig Beziehung, 1 m sie zu berücksichtigen, und sind ansserdem in den Leydig'schen Schriften schon seriügend besprochen.

In der Anerkennumg der morphologischen Identitït des Spimnen- und einfachen Insectenauges stimme ich, wie gesagt, mit Leydig iiberein, wogegen sich in der Feststellung der morphologischen wie der functionellen Dignität der Elemente des Insectenstemma Differenzen herausstellen, die sich schwer rereinigen lassen.

Leydig findet in Insectenstemma dieselben „Gallertkolben“, wie im Spinnenange, und dentet sie natürlich in rlerselben Weise. In semer ersten Arbeit (Arch. etc. 185う. Taf. XVI Fig $28[c$.$] ) zeichnet er sie ron der Hornisse; später (Tafeln etc. IX Fig. 3, 4) mit besonderer$ Eleganz ron der Biene.

Ich habe num schon oben beim Spinnenange gezeigt, dass Leydig bei diesem, durch Uebersehen der bestehenden scharfen Abtrennungslinien, aus zwei Zellen verschiedener Schichten, des Glaskörper's und der Retina, eine rermeintliche Einheit gemacht hat. Diesen Fehler hat er hier, beim einfachen Insectenange, vermieden; was er hier als "Gallertkolben" bezeichnet, ist nur das Retinaelement mit dem zngehörigen Stäbchen. Die Zellenlage des Glaskörpers hat el zwar nicht ganz übersehen, wohl aber rerkamnt. Er spricht nümlich ${ }_{1}$ ) von einer die Weichtheile des Anges umhüllenden Membran (die er irrthümlich anch sich über die Torderfläche der Retina hinüberschlagen lïsst) bei der Biene und Hornise. und zeichnet Kerne darin; nach der Fig. 4 (l. c.) können diese Kerne (bei c.) nur den Zellen des Glaskürper's angehüren. Anch die von der Maulwurfsgrille mitgetheilte Beobachtung des Vorkommens, einer gewissen zelligen Zeichnung oder Sculptur" auf der Innenflïche der Linse²) glanbe ich in diesem simne deuten zu müissen.

Die "Gallertkolben" hier sind demnach keineswegs dieselben Gebilde, wie die des Spimnenanges, sondern rubriciren unmittelbar neben den Petinaelementen des letzteren nach meiner Iuffassung.

Von sonstigen. für mmsern Zrreck untergeordneten Differenzen mag hier noch erwäbnt sein, dass Leydig auch bei dieser Augenform ein dicht hinter dem Ange gelegenes Ganghion ofticum annimmt und l. c. Fig. 3, f, ron der Biene abbildet, ron dem ich aber nichts habe erkemnen können.

\section{Einfacle Angen einiger Copepoden.}

lie Beobachtungen über einfache Augen einiger Gattungen der so formenreichen Ordnung der Copepoden, welche ich hier mitheilen will, stehen in einem so lockeren Zusammenhang mit den Hauptgesichtspunkten der ganzen rorliegenden Arbeit, rlass ich fast Bedenken trage. sie hier zur Sprache zu bringen. Es sind nur fragnentarische Bruchstücke. deren Ergänzung für mich allerdings weit hinausgeschoben erscheinen muss, und die nicht eimmal hinreichen, ein Urtheil ïber die gerade hier in's Unabsehbare gesteigerten Variationen des Sehorgans und deren mzweifellnaft rorhandene gesetzmässige Verknïpfung mor sich zu bilden. Mit lem Verzicht auf die Verwendung dieser Beobachtungen als triftige Argumente für das ganze Ziel der Arlueit soll

1) Auge der Gliederthiere. pag. 33.

2) Daselbst. pag. 36 . 
aber keineswegs anch gesagt sein. dass ich sie als werthlos ansehe. lch möchte im Gegentheil durch diese Notizen Andere auf ein sicher noch viele Früchte tragendes Feld anfmerksam machen, das trotz reichlicher Beobachtungen gerade für morphologische Studien über das Sehorgan noch mehr als eine blosse Aehrenlese in Anssicht stellt.

Eine Uebersicht des Formenkreises, immerhalb dessen sich die Sehorgane der Copepoden bewegen, geben die zahlreichen Arbeiten ron C. Clans, besonders descen fast durchweg auf eigenen Beobachtungen fussende, eine reiche Fundgrube hildende Hauptarbeit ${ }^{1}$ ). Von ilen dort besprochenen zahlreichen Augenformen, vom einfachen $x$-förmigen Pigmentfleck an bis zu den sonderbar complicirten Angen der Corycaeiden z. B. ist ein weiter Schritt; es schalten sich eine Anzahl ron merkwürligen, anscheinend ganz willkürlich gestalteten, und nicht in eine Reihe zu bringenden Organen dieser Art ein, deren gesetzliche Beziehmgen zn einander bis jetzt noch sehr mklar sind. Man wird deshalb aus neinen nachstehenden Mittheihngen, die sich gurarle auf die beiden Extreme dieser Reihe beziehen. anch keine Aufkliumg in diecem Simne erwarten dürfen; wohl aber dürften sie ausreichen, $\quad$ m zı zeigen, wie gering unsere Kenntnisse noch immer sind.

Meine Untersuchungen beschränken sich anf die Gattungen Calanella, als Repräisentant der Copeporlen mit $x$-förmigem Pignentfleck, und die Corycaeiden-Genera Sapphirina (fulgens u. a.), Corycaens spec., Copilia (denticulata) als extrene (iruppe. die ich in Neapel studirte.

1. Auge von Calanella mediterranea. - Das Ange dieses schönen, durch seine Grösse, Durchsichtigkeit nnd namentlich beim Weibchen anch durch seine Eleganz ansgezeichneten Copepoden ist, wie schon bemerkt. in die Reihe der einfachsten Formen des Sehorgans dieser Ordnung eingefügt worden, und liese Einfacheit findet ihren Ansdruck in der fast lakonischen Kürze der Beschreihung. die man dafür bereit hält. Ein x-förmiger Pignentfleck, mnit lichtbrechenden Kugch in den becherförnigen Seitenhälften rles Fleckes, allenfalls noch mit einer' dritten, mpanen língel von wechsehder Lage; das Ganze mit den centralen Nervensystem entweder durch directe Anflagermng, oder durch einen Sehnerv verbunden: danit diüfte wohl unsere ganze thatsächliche Kenntniss im Wesentlichen zusammengefasst sein, und mu noch erwïhnt werden. dass man vielfach in jenen durch ihre Lichtbrechung ausgezeichneten Krngeln Homologa der Krystallkegel des Facettenauges erkemnen wollte.

Indessen ist der Bau dieses Auges damit doch noch keineswegs erschöpft. Sicher ist das vorlänfig hlos für die uns hier beschäftigende Gattung Calanella, und anch an einem andern, leider nicht nïher bestimmten Copeporlen habe ich ganz den lier sich findenden analoge Verhältnisse des Banes - wenigstens in den allgememeren Umrissen - gesehen, ohne sie aber specieller verfolgen zu kïmnen. ITem num auch noeh inmer weitergehende Generalisationen darauf nicht zu gründen sind, so dürfte doch wohl eine nähere Prüfung auf die hier in Betracht kommenden Beziehnngen hin sicher der Gattung Calanella noch manche andere amreihen.

Das Stimange von Calanella gehört zu den vom Gehim entfernt liegenden ma mit ihm durch einen dentlichen Nervs opticus verhundenen. Ueber sein Aussehen in frischem Zustande gicbt die Ablildung von Claus (I. e. Taf. VII. Fig. 9) eine genügende Vorstellung ${ }^{2}$ ), und

1) C. Cla us. Die freilebenten Copepoten. Leipzig 1863. 4. (besonders pag. $4 t$ u. fr.)

2) Weniger zutreffend ist die Zuchmung, welche Leuckat (Arch, f. Natgesch. 1859. Taf. VI Fig. 12) von dem Ange seines ('alau u erythrochilus u. sp. giebt, der nach Cla us (Copepodenfauna ron Nizza. 1866. pag. 9) wahrscheinlich zu C'alanella mediterranea, sicher aber in die Gattung selhst gehört. 
selbst beträchtlich stärkere Vergrössermngen. als die, nach der jene Figur gezeichnet ist, lassen kaum mehr erkemnen. Clans zeichnet anch die am Gehim doppelt entspringenden, sich vor dem Ange zu einem einzigen Strang rereinigenden Sehnerven, von denen sich über das Ange hin ziehende Stirnnerven abzweigen, so correct, dass mir nichts hinzuzufügen bleibt.

Ganz anders aber sieht ein solches Ange ans, wenn man es der Einwirkung passender Reagentien unterwinft, und dann gewinnt man eine wesentlich andere Vorstellung von seinem Pan. Ich hale hesonders Osmiumsäme (in Dampfform) angewandt, ferner anch sehr viel die namentlich für pelagische Thiere so vorzïgliche Ḱleinenberg'sche Pikrinsäiure-Nischung; anch beide in der Art mit einander combinirt, dass die mit ersterer behandelten Thiere nachträglich noch in letztere geworfen wurden. Nach so erhaltenen, durch Isolation der Angen gewonnenen Präparaten wurden meine Zeichmungen (Fig. 36 Taf. V; Fig. 37, 38 Taf. II) cntworfen. Die Kleinenberg'sche Lösnng hat dabei noch das Angenehme, dass sie, wenn allein angewandt, das Pigment nach kurzer Einwirkung zerstört, so dass man der bei so zarten und winzigen Objecten immer bedenklichen Anwendung rler Salpetersinure enthoben ist.

In Fig. 36 Taf. $V$ ist ein Ange von Calanella, nach Anwendung von Osmimndämpfen allein, von oben, d. h. ron der Rückenfläche gesehen, dargestellt. Jede der beiden. in frischem Zustande homogen erscheinenden lichtbrechenden Ḱngeh lässt nun eine zellige Differenzirung erkennen, mit vou innen nach aussen verlaufenden Zelkontouren und Kermen. Dentlich sind in dieser Ansicht mur vier Zellen, eine fünfte erscheint nur angedentet ïber dem Pigment. - Dieses. intensiv tiefroth gefïr],t, bildet an der Berührmngsflïche der Kingeln zwei nur unvollstïndige, sie ungreifende Schalen; dler grösste Theil liegt auf der Bauchseite. ron der es nach oben durchschimnert, und nur hinten schlight es sich eine Strecke weit nach der obern Seite empor (Pg.). Wo der Opticus ( $N$. op.) in das Ange eintritt, springt am Hinterende noch eine halbkreisförmige, unter dem Nerren gelegene Pigmentplatte $\left(I y^{I}\right.$.) herror.

Noch dentlicher aber gewahren wir den eigenthümlichen Ban dieser Augen an den beiden andern Figuren. Fig. 37 mol 38 Taf. VI. Fig. 37 zeigt uns ein entfürbtes, vom Rücken ler gesehenes Ange; Fig. 38 ein solches ron der Banchseite ans, aber noch mit Pigment. Der Ban, den wir daraus erscliliesen. ist denmach folgender:

Das Ange ron Calanella besteht aus drei Theilen, zwei paarigen und einem rupaaren, medianen, der Banchseite angehörigen. Zu jedem der drei Theile gehört eine besondere Pigmentplatte, von denen wir nur noch der medianen zu erwähnen haben, die schildförmig, hinten breiter als rorn, sich mit ihrer gewölbten Seite in die Furche einfügt $\left(P g^{I}\right.$.), welche durch tie beiden paarigen Pigmentplatten $(P y$.) gebildet wird.

Zn jeder der Pigmentplatten gehört eine ganz bestimmte Anzahl rom dentlichen, in frischem Zustande bis zur. Unerkennbarkeit durchsichtigen und stark lichtbrechenden Zellen, die. rerschieden sonst in ihrer Form, alle ein conisch verjüngtes Ende gegen die Eintrittsstelle des Sehmerven wenden, welcher zwischen den Augenabtheilungen in rlas Auge eintritt. Zu jeder der paarigen Abtheilungen gehören acht Zellen (Fig. 36-38. I-VIII); fünf daron gehören der obern, drei der mtern Seite an. Znr mpaaren Abtheihung gehören zehn Zellen (Fig. 38). so dass also im Ganzen 26 Zellen in die Bildung des ganzen Auges eingehen. Die Constanz der Zahl wurde durch Lntersnchmg einer grössern Anzahl ron Thieren genan geprüft, nnd überall ergaben sich die Verhältnisse als ganz die gleichen.

Von den fünf Zellen, welche der Oberfläche jedes paarigen Abschnittes angehören, nimmt eine langgestreckte, im Umriss etwa dreieckige. den grössten Theil des Immemrandes ein (Fig. 37, I). Ton den andern rier sind zwei ror, zwei hinter iln gelagert und richten ihre Enden etwas 
convergirend nach aussen. Dasselbe Verhalten beobachten die drei Zellen der Banchseite (Fig. 38, $V I-V I I I)$.

Die unpare Angenabtheilung hat unter ihren zehn Zellen acht parige und zwei unpaare. Die parigen Zellen (Fig. 38, 3-6) mnstehen in einem Kreis clie eine der muaren, welche das Centrun der Rosette bildet (Fig. 38, 1); die andere gehört zwar denselben hreis an (?), liegt aber mehr ron der centralen Zelle abgerückt und nach rorn geschoben. In allen Zellen sind die Kerne mit grösster Dentlichkeit wahrunehmen, in keiner aber findet sich etwas, das mit cinem Stäbchen, wie wir es bisher kennen gelernt haben, irgend repgleichlsar wäre. In den beiden der Medianebene genäherten Zellen der obern Angenfl̈̈che habe ich zwar hänfig eigenthümliche, vor und hinter den herne gelegene Concretionen gesehen und auch gezeichnet; dieselben können aber wohl kaum etwas mit Stäbchenausscheidung zu thun haben, denn sowohl ihr Torkoumen, wie ihre Lagerung entbehrten zu sehr dex Regehnässigkeit.

Besonderes Interesse erregt aber das Terhalten des Nerven zu den Zellen. und ich habe in Figur 37 gezeichnet, was ich darüber beobachten komnte.

Der Nervus opticus (N. op.) tritt als ganz anselnlicher Strang von sehr deutlicher Faserung an das Ange, ror dem er eine leichte Einschn̈̈rung erleidet; jenseits derselben breitet er sich fïcherartig ans. Ich habe nun zwa nuit grosser Schwierigkeit, aber nichtsclestoweniger völlig sicher und zweifellos beobachten künnen, dass die Fasern des Sehnerren sich continuirlich in die inneren, zugespitzten Zellenenden fortsetzen. Diese Beobachtung wurle speciell an den mit $I$ und $I V$ bezeichneten Zellen gemacht. es kamn aber darnach kein Zweifel obwalten, dass dasselbe Terhalten anch für die übrigen zutıifft, an denen es wegen der Schwierigkeiten nicht constatirt werden konnte. Der Lebergang der Faser in die Zelle war ebensowenig durch eine scharfe Grenze bezeichnet, als man im Innern eine Fortsetzung der ersteren beobachten konnte. - Diese Thatsachen aber sind nichts weniger als leicht zu sehen, und erfordern ebensowohl sehr starke und scharfe Tergrïsserungen, als viele Geduld.

Der ganze Angencomplex ist von einer feinen Cuticula (ct.) nmgeben, die sich anf den Sehnerven fortsetzt. und sich nach rorn in conische Zipfel verlïngert. Die Frontalnerven (N. fr.), von denen schon Claus nachwies, dass sie mit den Ange selhst nichts zu thum haben, treten unter die Cuticula, zielıen damn unweit der äussern Ränder der parrigen Angenabtheilungen, und treten nach rorn wieder ans der Kapsel herans, ohne im Innern Fasern abzugeben, wenigstens keine an das Auge.

Die vorstebende Darstellung über den Zusammenhang der Nervenfasern mit den Zellen, aus denen der sog. "lichtbrechente Körper" zusammengesetzt ist, beweist, dass an eine Vergleichung dieses Gesammtkörpers sorrolıl als seiner einzelnen Zellen mit den Kirystallkegeln des Facettenanges, ja selbst schon nit den gleich zu beschreibenden der Angen der Corycaeiden nicht mehr zn denken ist. Die Krystallkegel sind äberall nur rein dioptrische Apparate, und stehen nirgends im Zusammenhang mit Terrenfasern, wie später noch ansfülnticher erörtert werden wird. - Dagegen entspricht der .. lichtbrechende Körper' einer wenn auch noch so unvollkommenen Retina. und die einzehen ihn zusammensetzenden Zellen sind functionell wie morphologisch mit den bisher behandelten Netzlıutzellen in die gleiche Linie zu stellen. Das Fehlen des Stäbchens zeigt freilich an, wie gering die Ausbildung, wie weit zurück, wenn ich so sagen darf, sie noch ist. Dass trotz dieser Tnrollkommenheit des Sehorganes die Thiere noch recht gute Lichtperceptionen haben, scheint mir ans-er Zweifel, wenn ich anch die Gewandtheit, mit der sie den Versnchen, sie mit der Glastölure zu fangen, zu entgehen wissen, keineswegs aussehliesslich auf Rechnung des Gesichtssimes allein, oder sellst nur in ljesonders hervorragender Weise, stellen möclıte. 
Es bedarf wohl keines besonderen Hinweises, dass die lier angewandte Bezeichnung les ganzen Sehapparates als Ange schlechthin im Gunde nicht passend ist. Es sind drei Angen vorhanden, zwei paarige und ein centrales unpaares, die hier in einen Complex rereinigt sind, wälneod sie bei zahlreichen andern Copepoden sich getrennt finden; und diese Deutung ist schon längst gemacht.

Beachtenswerth erscheint min, dass nach Leydig1) „rler paarige, braunröthliche Pigmentbecher (von Diaptomus [Cyclopsine] castor) eine dreilappige, nervöse, aus Ganglienmasse bestehende Grundlage habe". Die rou Zenker²) dem lichtbrechenden Körper zugeschriebene zellige Structur, die Ley dig bestimmt zurückweist, wäre doch wohl einer nähern Prüfrung noch werth.

2. Seitenangen einiger Corycaeiden. - "Um den ganzen überraschenden und fremdartigen Eindruck, den diese Gesichtswerkzenge auf den Beobachter machen, in seiner ganzen Grösse kennen zu lernen, bedarf es in der That der Untersnchmo eines derartigen Thieres." Diese Worte Lenckart's bezeichmen treffend die Empfindungen, die sicher Jeder gehabt lat, der sich mit diesen hochinteressanten Thieren und speciell mit deren Auge je befasst liat.

Znerst scheint Dana (1850) in einer mir nicht zugïnglichen Arleeit auf diese Eigenthümlichkeiten des Selıorgans anfmerksam gemacht zn haben, später folgten andere Beobachter, mnter denen ich besonders Gegenbaur, Lenckart, Claus und Haeckel zu nemnen habe, deren Arbeiten noch näher berïcksichtigt werden sollen. Trotzdem sind unsere Kenntnisse darüber von Vollständigkeit noch ziemlich weit entfernt, und ich hoffe deshalb, dass meine Beitrïge, die wenigstens in einigen Punkten etwas fördern, nicht unwillkommen sein werden.

Ich habe, wie gesagt, drei der Hanptgenera mer Händen gehabt, Sapphirina, Copilia und Corycaens. Meine Studien beziehen sich hauptsïchlich anf die erstgenannten beiden Gattungen, da mir von diesen das Naterial reichlicher zu Gebote stand, und ansserdem einige Schwierigkeiten, die der gedrungenere Bau und die geringere Durehisichtigkeit der letzteren bereiten, bei ihmen nicht vorhauden sinu. Ich habe aber doch Gelegenheit gehabt, mich zu ülserzengen, dass der Ban der Angen bei Corycaens nur durch sehr germge und untergeordnete Differenzen sich von dem jener Gattmgen untersheidet; Differenzen, die kaum über unbedentende Lage- und Formrerschiedenheiten hinausgehen.

Bekamntlich ist das so Characteristische dieser Angen eimnal ihre ungemeine Grüssen-. besonders Längenentrickelung, damn die weite ränmliche Trennung zwischen der der Cuticula angehörigen Linse mol ten zngehörigen der Perception dienenden Weichtheilen; endlich die besondere Ausbildung dieser letzteren, denen noch cin krystallkegelartiges Gebilde rorgelagert ist.

Wir wollen nun suchen, nähere Bekamntochaft mit diesen sonderbaren Angen zu machen; ich rerweise dabei auf die Figg. 39 A, 39 B, 40 Taf. IT, welche denn Seitenauge von Copilia denticulata, sowie Figg. 41-43 ders. Tafel, welche dem ron Sapphirina fulgens (す) gewidmet sind.

Was die Lage der Augen anbelangt, so ist zu bemerken. das bei Copilia die ron rothem Pigment muhüllten nervösen Endorgane bis in die Körpernitte gerïckt sind, während die zngelürigen Linsen an Vorderrande liegen; bei C'orycasus liegen jene sogar in der limtern Kürperhälfte, bei den Sapphininen aber in der rordem, ror dem Centralnervensystem. Bezüglich dieser allgemeinen topographischen Terhältnisse verweise ich auf die folgenden Abbildmgen: für Copilia auf Clans (l. e. Taf. XXY Fig. 14, copirt bei Gerstäcker [Bronn], Classen und Ordnungen etc. Arthro-

1) Leydig, Bemerkungen ïber den Bau der Cyclopiden. Areh. f. Natg. 1859. pag. 198.

2) Zenker, ebendas. 1854. pag. 93 . 
poden Taf. XIT Fig. 5), sowie auf die von Lenckart (Arch. f. Nat. 1859. Taf. VII Fig. 1). Die genamten Zeichnnngen geben ron der Lage des Sehorgans eine sehr gute Vorstellung, nur möchte ich dazu benerken, dass die Zeichung von Claus den "Pigmentkörper" zn wenig geknickt, den Winkel descelben etwas zn stmmpf und abgeruntlet vierdergiebt, während die von Leuckart (seine C. nicaeensis, anf welche sie sich bezieht, soll nach Clansi) mit C. denticulata identisch sein) eher in den entgegengesetzten Fehlex rerfält. wenigstens bezïglich der Schärfe der Unknickung. - Für die Gattung Corycaens rerweise ich anf Clans (1. c. Taf. XXIV Fig. 1 и. 3, Taf. XXV1ll Fig. 5, Taf. IX Fig. 1), Lenckart (1. c. Taf. II Fig. 9, copirt bei Gerstäcker I. c. Taf. XI, Fig. 24). Für Sapphirina endlich sind die Abbildungen Gegenbaur's (Müller's Arch. f. Anat. 1858. Taf. VI Fig. 1, 2 и. 4), sowie die von Clans (1. c. Taf. VIII Fig. 2, 3, 4. 5, 6, Taf. XXV Fig. 13) und Haeckel (Jenaische Zeitschift. I. 186t Taf. II Fig. 13, 17, 21, 26; Taf. III Fig. 40, 46, theilweise copirt bei Gerstäcker, 1. c. Taf. XIT Fig. 1 u. 1 c.) besonders hervorzuhehen.

Die Lage dex Linsen varït bei den verschiedenen Gattungen. ja selbst bei den Geschlechtern einer und derselben Art ziembich betrïchtlich. Bei Copilia liegen sie weit auseinander, an den äussern Ecken des breiten, fast geradlinig abgestntzten Tordertheils; bei Corycaeus rücken sie fast bis zur Berührung in der Medianebene aneurander; bei Sapphirina liegen sie entweder (bei den Weibchen) einander genäliert an Torderrande, oder auf der Banchseite (bei den Mämmchen). Die Linsen selbst bieten einige Eigenthümlichkeiten auffallender Art dar, die schon frïhern Beobachtern theilweise (s. u.) anfgestossen sind. Ich habe sie besonders an Copilia constatiren kömen, und rerweise rleshalb anf Fig. $39 \mathrm{~A} ; L^{I}$., $L^{I I}$. Die Linse ist nämlich nur zmm kleineren Theil ans der allgeneinen Leibescuticnla (Ct.) gebildet; nur der mit $L^{I}$. bezeichnete geht continuirlich an seinem ganzen Umfang in jene ïber. Er wölbt sich uhrglasförmig und in der Nitte nur wenig verdickt über den hinter ihn gelegenen grössem Theil $L^{I I}$. hinweg, und diesem fällt. trotz seiner geringeren Lichtbrechung gegenüber dem Cnticulartheil, hanptsächlich die Rolle zu, die Strahlen zu sammeln. Dieses imnere Segment bildet eine grosse, schön biconvex gewölbte, völlig durchsichtige und structurlose Linse, die rer innern Höhlung des änssern Segmentes sich einlagert, und dieselbe bis anf einen schmalen, spaltenförmigen Zwischenraum, den ich fast immer bemerkte, mo deshall, auch in meiner Zeichnung wiedergab, ausfüllt. - Seiner morphologischen Berlentung nach ist mir dieses Seginent unverständlich geblieben. Es hängt nirgends direct nur continuilich mit der Cuticula zusammen, sondern ist iln nur dicht angelagert; ebensowenig habe ich einen directen Zusammenhang mit der Hypodernis wahrzmehmen vermocht. Es ist mir ferner durch keinerlei Reagens oder Tinctionsmittel gelungen, Spuren einer Zusammensetzung ans Zellen daran nachznweisen. Es macht durchans den Eindruck, als wäre dieses Segment ein mit ganz weicher Gallerte prall erfülltes Säckchen, dessen Wandungen aber erst nach verschiedenen Manipulationen sich bestimnt als solche exkennen und nachweisen lassen. Behandelt man ein solches Thier nit sehr verdïmuter Osmiumsänre (ein Tropfen etwa anf ein mittleres Uhr' schälchen mit Seewasser), so fïben sich diese Segmente znerst tiefschwarz, lange bevor man an andern Organen etwas anders als eine ganz leicht brännlichgelbe Fürbung entdecken kann, und selbst lange, beror das Thier bewegungslos geworden ist. Fringt man nach dem Torle das Thier selı almälig in Weingeist (durch tropfenweisen Znsatz desselben), so entfärben sich die Linsen wieder mehr, schrumpfen aber änserst leicht in ein unkenntliches Faltengewirx, das von einer sehr zarten Membran her'ührt, znsammen; der lnhalt scheint in die Ungebung zu diffundiren 
mud die starke Lichtlorechmng geht verloren. Hat bei stärkerem Zusatz die Osmimnsïure mehr einwirken können, so erscheint die immere Nasse etwas krümelig, an Rande etwas blasig, anch fester: aber anch dann genügt die geringste Luvorsichtigkeit im Zusatz von I'eingeist, oder besonders von Glyccriu, um die Linse in Nin in's Lnkenntliche zusammensclmuren zu lassen.

Weniger leicht lassen sich diese Eigenthümlichkeiten bei den Linsen ron Sapphirina (Fig. 41, $L^{I I}$.) nachweisen. Ich habe nur Nännchen der Sapphirina falgens zu untersuchen Gelegenheit gehabt, und bei diesen ist die banchständige Lage, die bei der dünnen flachen Leibesgestaltmg die Gewinmmg von Profilansichten so schwierig macht, dafür sehr umgïnstig. Die Axe die linse steht ïbrigens nicht senkrecht auf der Leibesaxe, sondern neigt sich nach hinten, und in ihre Verlängerung fällt der Pigmentkörper, dessen hinteres Ende demuah etwas in die Höhe steht. - Trotzdem halte ich anch hier die Existenz emes solchen inneren Segmentes für sicher, da ganz genau dieselben Erscheinnngen wie die oben beschriebenen auftreten, und, wenn das innere Segment durch Quellung et.c. zu Grunde gegangen ist, dentlich die Contouren des äussern, der Cuticula angehörigen, sich erhalten.

Ueber das Verhalten der Linse bei Corycaens bin ich nicht im Stande, specielle Angaben mitzntheilen, da ich keine Aufzeiclmungen darüber gemacht habe; dass indessen auch hier die besagte Duplicität der Segmente sich findet, erimere ich mich ganz bestimm gesehen zu haben.

Bei Copilia inseriren sich in der ummittelbaren Umgebung der Linsenperipherie an der Cuticula eine Anzahl Fürlen (N. Fig. 39 A, 39 B, 40) die nach innen zu convergirend verlaufen, und durch ihren hinteren Tereinigungspunkt den weit hinter der Linse gelegenen zweiten Hauptbestandtheil des Anges markiren. Ganz dieselben Fäden beobachten wir anch an den Augen von Sapphirina (Fig. 41, 42 N.), nur haben sie hier ihr rorderes Ende nicht in der ummittelbaren Nachlsarschaft der Linse; ebenso fehleu sie anch bei Corycaeus nicht. Ueber die Bedentung dieser Fïden nachher; hier nur soviel. das wenigstens einige derselben sich bis zum centralen Nervensystem mit Sicherheit rerfolgen lassen, und sowohl deshalb, als anch wegen ihres Anssehens und der Art ihrer terminalen Insertion als Nerren in Anspruch genommen werden müssen.

Der zweite Hauptbestandtheil des Anges, an dessen Torderende diese Fïden sich scheinbar ganz imnig anlegen, ist der stabfümige Pigmentkürper, der vorn einen Krystallkegel oder -körper trägt ( $P g ., K \%$ in Fig. 39 B. 40-43).

Der Pigmentküryer ist bei Copilia und bei Corycaeus durch eine beträchtliche Längenentwickelung ansgezeichnet, worin beide der Sapphirina mm ein Bedentendes überlegen sind. Bei Copilia ist er vor der Mitte derart geknickt, dass sein kürzerer vorderer Schenkel annähernd der Längsaxe des Thieres parallel nach rom gegen die Linse gerichtet ist, wäluend der längere hintere unter einem Winkel ron ca. $100^{\circ}$ gegen den Nagen zu sanft geschweift hinzieht. Torn ziemlich dümn, schwillt er gegen die Nlitte hin allmälig an, um nach hinten sich wieder zu rexschmächtigen; er endigt quer abgestutzt, und an der Endfäche inserirt sich ein protoplasmatischer Faden, der im in semer Lage fixirt. Das Pigment ist intensir lraumroth, mit einem Stich in's Gelbliche, und lïsst nur wenig von den in seinem Imnern enthaltenen Axengebilfen durchschimmern.

Bei Sapplirina ist der Pigmentkörper, an lebenden Thiere ron oben gesehen, anscheinend gerade; an conservirten Exemplaren aber, wo durch den Druck des Deckglases die Angen leicht rm ihne Axe gedreht werden. kam man sich leicht überzergen, dass er ein wenig nach oben gebogen ist. Yon rom nach hinten verjüngt er sich schwach, ohme in seinem Terlanfe eine Anschwellung zn erzengen. Anch an ihm kömmen undentliche, rundliche und lïngliche, von dem etwas dunkleren Pigmente unhüllte Einschlüsse erkannt werden. 
Die Krystallkörper sind in frischem Zustande röllig durchsichtig mo schr stark lichtbrechend (Kk. rer Figg.). Bei Copilia sind sie länglich, kegelfömig, und an dem breitern der Linse zugewandten Ende halbkugelig abgerundet; bei Sapphirina dagegen etwas unregehässig eifömig. Das hintere Ende ist in dem Pigmente versteckt, das sich in verschiedenen Stellen des Imfanges ungleich weit über dieselben himanferstreckt. Bei Copilia erscheint sogar an der Innenseite des Krystallkörpers (bei $x$. Fig. 39 B) cine losgelöste Pigmentinsel als ein kleiner, spitzer Höcker. dessen Fürbung heller ist als die des iỉbrigen Pigmentes.

Differenzirungen irgend welcher Art sind sonst an dem ḱrystallkörper nicht zu erkemnen; namentlich fehlt jede Spur ron Längstheilung. die bei den Krystallkegehn der Facettenaugen sich immer findet.

Betrachten wir aber Krystallkörper von Augen. die mit Reagentien behandelt worden sind, so verïndert sich der Anblick sehr wesentlich. Für Copilia (Fig. 40 Taf. IT) gilt dies ganz besonders. nnd wir haben anf den ersten Anblick einige Nühe. das Bild res veränderten Krystallkörpers auf das des frischen zurïikzufẗihren. Unter dem Einfluss des Reagens in tlem gegebenen Falle wurde Pikrin-Salpetersiure in Anwendung gebracht. durch die allein das Pigment schon grossentheils zerstört wird) differenzirt sich der Krystallkërper in zwei Hälften der Quere nach, rou denen man vorher nichts zu erkennen vermochte. Nur die vordere Hälfte gelıört zum eigentlichen Krystallkörper, der, anstatt langconisch, nun eiförmig erscheint, umol hinten in eine kmze conische Spitze anslïnft; ansserdem ist er von emer dentlichen Hülle umschlossen. Er hat im Ganzen wenig von seiner frühern Lichtbrechung und Kilarheit cingebuisst, desto melı aber der lintere Theil, der vor der Einwirkung des Reagens sich in kemer Wreise rou ihm abhol,. Dieser Theil ist nun durch eine starke Granulirmg ansgezeichnet, und umfasst becherförmig das lintere Ente des ächten Krystallkörpers; nach hinten zn verschmälert er sich. und geht allnälig in die Substanz des Pigmentkïrpers über. Schwach angedentete Längsinien, sowie Kerne (K.), die in ihn eingestrent sind (es sind deren immer nur drei vorhanden), geben über seine zellige Znsammensetzung Auskunft, eine Zusammensetzung, die wir beim vorlem Abschnitt vergeblich suchen. Der pignentirte Hörker $(x$.) erweist sich anch als eine keineswegs oberflïchliche Anhangsbildmg, sondern als das Ende eines selbstïndigen Stranges, der limten unter der allgemeinen Pigmentschicht rerlïuft, nach rorn aher, durchsichtig und klar, larunter herrorliegt, und mit jener Pigmonthaube seitlich an die Oberfliche kommt. In dem äusersten Ende aber liegt ein kurzes, anschemend cylindrisches. stabfirmiges Gebilde eingesenkt, das schräg zur Axe des Pigmentkörpers geneigt ist. Ans ser dheh scinen Verlauf zeichnet sich dieser Strang vor den an den Krystallkörper tretenden auch noch durch seine viel gröhere Granulirmg ans.

Durch das Eintreten dieses Stranges mnter die pignentirte Oberfläche vind der immere Hohlram des Pigmentkörpers sehn verengert. In einiger Fntfernung rom Krystallkörper aber wird er ganz ansefüllt von stabartigen, stark lichtbrechenden. durdsiclitigen Gebilden, die, wie schon früher bemerkt, an frischen Augen, wemn auch nur sehr undentlich. doch schon erkembar durch das Pigment schimmern. Sie sind, vorn namentlich, seln dïm und dicht zusammengepackt, so dass ihne Zahl schwierig mit alsoluter Sicherheit zu bestimmen ist; sie endigen scharf begrenzt mit einer leichten Abrmdung nach vorn, und durchziehen den ganzen Pigmentkïrper bis an sein Hinterende.

In diesen Stäbshen (St.) haben wir mzweifelhaft die lichtpercipirenden Organe, und damit anch die Homologa der bisher beschiebenen gleichnamigen and gleichfunctionirenden Gebilde ror ums, und ron ihrer Anzahl hängt die Leistung ab, die wir den Ange zuschreiben. Diese Anzahl hier, bei Copilia, durch Zülılung genan zu bestimmen, ist num nicht geglückt; wenn ich es doch 
wage, dieselbe als höchst wahrscheinlich die gleiche wie bei der gleich zu besprechenden Sapphirina, zu bestimmen, so leitet mich nur die muthmassliche Analogie, mol ansserdem die Uebereinstimmung mit der Zahl der beobachteten Kerne. Wir haben bisher immer - und werden anch fernerhim anf das Gleiche stossen — die Stäbchen im Znsammenhang gefunden mit einer Zelle. In diesen Angen habe ich die zelligen Elemente nur erkemnen kömnen an den zwischen Stäbchen und Krystallkörper gelegenen Kernen, und diese möchte ich num als anch zn den Stäbchen. resp. deren Mutterzellen gehörig in Anspruch nehmen, und ılies $n$ m so eher, als der durch die leichten Trennungshimien an jener Stelle angedentete Verlanf dieser Zellen einer solchen Dentung nur günstig ist. Aller Wahrscheinlichkeit nach rerdankt der Krystallkörper übrigens auch diesen gleichen Zellen seine Entstehung, denn seine Zusammensetzung aus Zellen ist nicht nachzuweisen, und seine Lage zn den Zellen selbst spricht nur dafür.

Betrachten wir nun ebenfalls mit Reagentien behandelte Angen ron Sapphirina (Fig. 4?, 43 Taf. V1). so treten manche Verhältnisse dort dentlicher und unzweidentiger hervor, andere dagegen weniger klar und bestimmt. Fïg. 42 zeigt uns zwei freipräparirte Angen, nach Behandlung unit Pikrin-Schwefelsänre, und durch den absichtlich herbeigeführten Druck mit dem Deckglas etwas anseinandergequetscht; Fig. 43 ein mit Osmimnsämre behandeltes rechtes Ange, nicht gedrückt, ron oben bei viel stärkerer Vergrüsermug. An den Krystallkörpern vermissen wir die Hülle; bei den in Fig. 42 gezeichneten ist die innere oder hintere Begrenzung durch den Druck undentlich geworden. Ein Zexfallen des Krystallkürpers in der Art wie bei Copilia findet deshalb lier nicht statt, weil der entsprechende kernfiilnende Theil hier rom rordern Ende des Pigmentkörpers mmschlossen wird. Die Kerne sind hier sehr schwierig nachanweisen (Fig. 43, $\mathbf{K}$ ); wie ein Blick anf die genannte Abbildung zeigt, liegen sie aber ganz analog wie bei Copilia in den rordern, den Ḱrystallkörper' momschliessenden Enden von ebensoriel Zellen, die etwas mmegelmässige Formen haben. Dass diese drei Zellen zı den ren äbrigen Theil des Pigmentstabes erfüllenden drei Stïbchen die oben angedentete Beziehung haben. datïr ist auch hier der directe Nachweis mir nicht möglich gewesen.

Dass in den Pigmentkörpern von Sapphirina nur drei Stïbchen ron ammähernd gleicher Ansbildung sich finden, davon kamn man sich relativ leicht überzengen, und ich bewahre anser den gezeichneten noch eine Reihe von Präparaten auf, die in Bezng anf Ǩlarheit jenen darin nicht machstehen. Die Stïbchen sind etwas abgeflachte Prismen. vorn und linten wen abgeschnitten, stark lichtbrechend und völlig durchsichtig. Nit einer der schmalen Lüngsflüchen liegen sie der pigmentirten Wand an, und lier ist lanptsächlich eine stärkere Anhänfing der grannlirten Nasse, wahrscheinlich des hinteren Theils der Zellen, zu denen die Kierne gehüren, zu bemerken (Fig. 42). - Ausser den Stäbchen benerkt man aber hinter dem Krystallkörprer nocb einige andere, in ihrem optischen Terhalten mit jenen übereinstimmende Körper, die rom P'ignent eingeschlossen werden. Zunächst fällt ein solcher ron etwa halbkugeliger Gestalt anf (Fig. 41 bis $43, y$ ), welcher, vor den Stäbchen gelegen, dissen seine abgeflachte Seite zuwendet; ausserdem noch einige mehr seitlich gelegene (Fig. 42, 43, x) ron mregehmässiger Gestalt, mit deren Beschreibung ich mich nicht aufhalten will. Einer dieser Körper dürfte wohl d(m bei Copilia (Fig. 39 B, 40) mit $x$ bezeichneten, d. l. dem durchsichtigen Einschlnss im Pigmenthöcker. entsprechen, abèr wehcher? das weiss ich nicht zn sagen. Das bei Sapphirina mit y bezeichnete Gebilde scheint dort olme Tertreter za sein. - Dass jene Könper, die ich in den Figuren mit $x$ bezeichnete, in einer stumpfbuckeligen Torwölbung des Pigmentes nach der Banchseite lin gelegen sind, mag hier noch nachtrïglich erwähnt werden.

Der Eintritt der Nerri optici $(\boldsymbol{N}$. op.) in diese sonderbaren Pigmentliörper ist auch bei 
den beiden Gattungen, die hier specieller besprochen werden, etwas rerschieden. Bei Copilia (Fig. 39 B.) besteht er um aus sehr wenigen, zienlich langen Fasern, die etwa in der halben Länge des Pigmentköruers, also etwas hinter der Knickmng desselben, in die Spitze eines pigmentirten Vorspunges eintreten. Bei Sapplririna treten die Fasern dicht hinter dem Hinterende des Krystallkörpers in den Pignentkörper ein (rgl. bes. Fig. 41, 43, $N$. op.) Die Vereinigung der Fasem mit den Zellen und iln Verhalten zu den St:̈bchen konnte nicht emittelt werden.

lch wende mich num zur Besprechung der frïhern auf diese Augenform Bezug haljenden Arbeiten, soweit sie mir bekannt und zugänglich geworden sind, nnd werde dabei Gelegenheit haben, noch anf einige, bisher bei Seite geschobene Punkte näher einzugehen. Ich werde hier

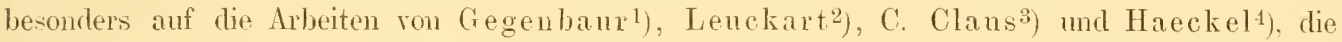
mehr oder weniger eingehend sich nit den Corycaeiden-Augen beschäftigt haben, eingehen miissen.

Zunächst möchte ich einen Irrthum berichtigen, der sich seit der Arbeit ron Gegenbaur eingeschlichen hat, und welcher sonderbarer Weise ron allen späteren Autoren übersehen worden zu sein scheint. Dieser Irrthum bezieht sich auf die Lage der Linsen beim Mämnchen von Sapphirina. Gegenbaur lïsst diese Linsen, oben anf dem Kopfloruststiucke" liegen (l. c. pag. 70). Bei Lenckart und Haeckel finde ich dariber keine Angaben; obschon letzterer ilnen relativen Abstand ron den Pignentkörpem als diagnostisches Kémzeichen benutzt. Claus aber sagt wieder von ilnen: ,dieselben liegen bein Nünnchen in der Regel auf der Rückenfläche des Kopfes etc." (Freileb. Copeporlen pag. 49). - lch habe schon oben die Lage der Linsen als eine ventrale bezeichnet. and man kann sich mit Leichtigkeit an jedem einigemassen gut conservirten Exemplar davon überzengen, dass sie derselben Körperseite angehören, welche anch die Extremitïten trägt.

Die Zusammensetzung der Linsen aus zwei Segmenten wurde zuerst von Lenckart an Corycaens beobachtet und anch auf Copilia und Sapphirina ïbertragen (l. c. pag. 251); Claus scheint sich, ohne die Angabe geradezu zu bestreiten, etwas zweifellaft ihr gegenüber zu verlalten (1. c. pag. 49), und glaubt riehmehr, dass die centralen Schichten die peripherischen an Dichtigkeit ülucrtreffen.

Zwischen Linse und Krystallkürper erstreckt sich nach Gegenbaur ein conisches Rohr, gefüllt mit einer Art Glaskörper ron gallertiger Beschaffenheit. Lenckart schliesst sich für Corycaeus dieser Deutmg an, nul auch Haeckel's schöne Zeichnungen von Sapphirina scheinen zu Grunsten ilieser Ansicht zn sprechen. Aber schon Claus komnte den Glaskörper nicht von der umgebonden Blutflüssigkeit unterscheirlen, und wenn er auch später wenigstens den Theil der Hülle des Glaskörpers, der dem Krystallkürper zunäichst gelegen ist, wahrgenommen. zu haben glaubt, so lassen doch neine eigenen Beobachtungen mir die Anwesenheit einer solchen Hülle selbst mit dieser Einschränkmy als selu zweifelhaft erscheinen.

$\left.{ }^{1}\right)$ Gegenbaur, Mitheilungen über die Organisation von Phyllosoma und Sapphirina. Müll. Arch. 1858 pag. 43. (Simnesorgane d. Sapphirina pag. 70.)

2) L e n ckart, Careinologisehes. Arch. f. Natg. 1859. pag. 247.

${ }^{3}$ ) C. Claus, Ueber das Auge der Sapphirinen und Pontellen. Müll. Arch. 1859. p. 269. Ferner in: Freilel. Copepoden etc.

4) II a ckel, Beiträge zur Kenntniss ler Corycaeiden. in: Jen. Zeitschft. etc. Vol. 1. 1864. p. 61. 
Ferner sollen nach Gegenbaur in der Scheirle des Glaskörpers vier Mnskeln longitudinal verlaufen, deren Contractionen, durch welche die Accomodation zu Stande konmt, er häufig gesehen hat. Clans aber erklïrt, nachdem er sich anfangs zustimnend geänssert hatte, in Folge erneuter Ĺntersuchmg wieder schwankend geworden zu sein. und hïlt demmach diese vermeintlichen Inskehn grüsstentheils für Nerven (1. c. pag. 50), deren Verlauf er theihweise genauer beschreibt. Muskeln sollen freilich ausserdeu anch noch sich finden; ob aber die durch sie veraulasste Bewegung als Accomodation, oder als ,eine wälrend der Schluckbewegung nothwendige Mitrerschiebung" aufanfassen sei. lïst er mentschierlen. Bei Copilia sollen nach ihm mehrere Muskehn sich an Pignentkörłer inseriren; die umfangreichste Grupe derselben kommt ron anssen und oben an denselben und besteht aus drei Fasern; andere kommen von innen, um theils den Selmerven zu begleiten, theils sich in der Nähe des Kirystallkörpers zn inseriren.

Es handelt sich hier $1 m$ die anch schon oben, aber nur flüchtig, erwälmten Füden, ïber deren Bedentung ich mich hier näher aussprechen muss. Diese Bedeutung ist nicht so leicht zu bestimmen, weil es melı. Schwierigkeiten hat, sich mit genügender Sicherheit über ihren Verlauf zu informiren. als man denken sollte. Was das Aussehen dieser Fürlen anbelangt, so sind sie sehr liass und protoplasmatisch. gleichdick in ihrer Erstreckmg, mol, wenigstens bei Copilia, zuweilen durch breite protoplasmatische Brücken nit eimander verbunden. An ihrer Insertion an der Cuticula lässt sich zuweilen eine Anschwellung mit einem Zellkern in Imem erkennen. Bei Copilia endigen die meisten Fäden in der Ungebung der Linse, bei Sapphirina aber in ziemlich weiter Entfermung von ihr. meist an dem lntegunente der Rückenseite. Bei ersterer Gattung lässt sich ron einigen. bei letzterer aber von den meisten der Lrsprung ans dem centralen Nervensystem nachweisen. und für diese kann dam die Deutmo um so weniger fraglich sein, als (bei Sapphirina) anssertem ilre Endigung theils in ganglï̈sen Simeszellen, theils in den einzelligen Drüsen, deren Kenmtniss wir vorziiglich Haeckel verdauken. ilne Natur als Nerven unzweifellaft darthut. Ich bin ïhrigens weit davon entfernt, allen diesen Füden die gleiche Rolle vindliciren zn wollen; im Gegentheil, ich möchte amehmen, dass mindestens einigen davon möglicherweise blos die Rolle der Fixation les sonst frei in der Leibeshöhle suspendirten Anges zukommt. Für die Dentung derselben als Muskeln habe ich aber keine Stütze auffinden kömnen; alle MIuskeln dieser Thice sind sowohl in frischem wie in durch Reagentien verändertem Zustand äusserst dentlich quergestreift, und nieses Criterium wirl durchaus an ihnen remnist. - Einen Mukel, der freilich nicht zu verkemnen ist, habe ich ebenfalls an dem Auge von Copilia aufgefumden (Fig. $39 \mathrm{~B}, \boldsymbol{M}$.), und dieser stimmt mit dem einen der vorhin nach Claus aufgeführten Züge überein; es ist aber der cinzige, den ich sicher als solchen erkemnen konnte, und in Bezug anf die andern weichen meine Ansichten von denen jenes Forschers wesentlich ab.

Gegenbanr fasste den Krystallkörper im Sime der damals eben zur Herrschaft gelangten Deutung des facettirten Arthopodenanges durch Leydig auf; er liess ilm continuirlich sich in das Lmmen der Pigmentscheide fortsetzen. und hielt ilm für den percipirenden Aprarat. Die scharfe Abgrenzung desselben aber nach hinten wurde ziemlich gleichzeitig ron Leuckart mo Claus erkannt. - Letzteren verdanken wir anch die einzigen bisher veröffentlichten Notizen über den Inhalt des Pigmentkörpers. Er sagt (Freileb. Copepoden pag. 52): „Bei Sapplirina besteht der in den Pigmentküper eintretende Nerv ans mu wenigen, ziemlich breiten Facern, die ich an äuscerst glïcklich erhaltenen, in Chromsïure und Glycerin aufbewahrten Präparaten in Innem des Pigmentkürpes in glänzende Stäbe mbiegen sehe. Der von Lenckart erwähnte Krystallstiel entspricht in seiner hintern Partie diesen glänzenden Nerrenstäben, die vordere Partie ist eine helle Substanz, in welcher ich bei Copilia Kerne eingebettet fand." 
Fragen wir num sowohl nach der norphologischen, wie nach der plyssiologischen Dentrung dieser Angenform. so funden wir nach beiden Seiten hin nur mimimale Beziehungen zu den bisher betrachteten. Min hat deshall, auch von jeher die Analogie ganz anderswo gesucht, und zwan beim Facettenange, dessen Einzelfactoren, wie in den nächsten Abschnitt zu zeigen sein wird, allerdings diese Vergleichmg bis zu einem gewissen Grade zulassen. Hier mag nur soviel bemerkt werden, dass in Hinsicht auf die Leistung die Vergleichung mit mehr Recht durchgeführt werten kamn, als in Rücksicht anf die morphologische Tebereinstimmung der einzehnen Theile. Naturgemäss müsste der hier als Krystallkörper bezeichnete dioptrische Aplarat rerglichen werden nit dem Krystallkegel des Facettenauges. Aber der letztere entstelit aus einer Anzahl (meist vier) discreter Zellen, die zu den pereipirenten Stäbchen keine Beziehungen haben; hier aber liegt einstweilen die Wihrscheinlichkeit noch so, dass die gleichen Zellen, welchen die Stäbchen zugehören, anch den Krystallkörper ansscheiden. Diese Terschiedenheit, wem sie auch noch nicht ganz ansgemacht ist, fordert doch zur Torsicht bei der Beurtheilnug anf. und darf nicht ignorirt werden.

Auf die Beurtheihug der Leistung des Organs hat diese Diflerenz alrer keinen Einfluss, und hier liegen eine Reihe ron Grïnden ror. dieselben für die gleiche zu halten, wie die des Einzelauges des facettinten. Freilich wird bei consequenter Durchführung dur Begriffe, die in dieser Hinsicht namentlich bezüglich der Leistung der Stäbchen nnd der Budeutung ihrer Zahl für die Sehchürfe in der Wissenschaft zur Zeit existiren, liese Leistmng zu einer minimalen heruntergedrückt. und die grosse Unvollkommenheit des pereipirenden Apparater, dessen anatomischer Bau die Annahme einer Bildpercention anschliesst, contrastirt seltsan nit dem sozusagen colossalen Anfwand ron Mitteln zur Erzengmug eines Bildes, wie sich dieser nanentlich im Ban der Linse auspricht. - Die Lntersuchnng des zusammengesetzten Auges wird mus noch mit den Gesichtspmkten, lie bei solchen Beurtheilungen massgebende sind, näher bekaunt machen.

\section{Abschnitt.}

\section{Vom zusammengesetzten Auge der Insecten und Crustaceen.}

Das zusammengesetzte oder facettirte Ange, dessen Ban ich hier darlegen werde, ist. trotz aller eingehenden Forschungen bisher noch immer eines der räthselhaftesten Organe in der ganzen Thierreihe geblieben. Das schliesst aber keneswegs aus. dass wir über eine relativ sehr betrïchtliche Summe ron Kemntnissen über dasselbe rerfügen, die zn einem dem Verstïndniss zugänglichen Ganzen zusammenzufasen elsen nur die Gesichtspunkte fehlen.

Dis Interesse, mit der die früheren Forrcher dieses Organ behandelt laben, äberhebt mich der Mühe, anf eine Peihe ron Thatsachen, die anf seine Begrenzung nach innen mo aussen, seme Gesammterscheimmg etc. Bezug haben. nïher einzugehen; ich kam mich begnïgen, hier auf die Werke mnd Abhandlungen von M. de Serresi), J. Müller, Will, M. Schultze und ganz besonders ron Leydig hinzuweisen, wo alles darauf Bezügliche sorgsam zusmmengestellt ist. Wohl aber möchte ich eine knuze Uebersicht der Architectur der innern

1) I. de Serres, Ueber die Augen der Insecten. Aus d. Franz. von J. F. D i effe n b a ch Berlin 1826. $8^{\circ}$.

Grenacher. Lntersuchungen üher das Sehorgan der Arthropoden. 
Weichtheile, wie sie sich nach meinen eigenen ITntersuchungen gestaltet, vorausschicken, theils weil die grosse [ebereinstimmmg im Ban clieses Organes bei Insecten md Crustaceen dies eher ermöglicht, als bei den Formen des Selıorganes, die ich als einfache Angen znsammengefasst habe; dam aber anch, weil es auf die ühersichtlichste Weise eine Torführung der fundamentalen Punkte - und es sind deren nicht wenige - gestattet, in denen ich von meinen Vorgängern abzuweichen genötligt lin. Anserdem mag diese Skizze anch gleich zm Orientimng iiber die von mir angewandte Ternninologie dienen, da ich mich reranlasst selıe, in Interesse einer schürferen Präcisirung der Begriffe einige der bisher am meisten üblichen Ausdrücke anfangeben, und mich dafür nener zu bedienen.

Wie schon benerkt. stimmen die Facettenangen der Insecten im Principe mit denen der Crustaceen vollkommen äberein. Dies schliesst jedoch keineswegs das Torkommen sehr zahlreicher Morlificationen, die oft einen ziemlich ansehnlichen Betrag erreichen, ans; aber es ist mir doch in der ganzen grossen Reihe der hier in Betracht gezogenen Thiere nur ein einziges Beispiel bekannt geworden, welches sich gänzlich ansserhalb des sonst allen gemeinsamen Schemas stellt.

Die gesammten Weichtheile des Facettenanges liegen bekamntlich ringsum eingeschlossen ron einer Chitinkapsel, die besonder's bei den unbeweglichen Insectenangen eine starke Entwickelung erreicht. Der durchsichtige. nach aussen gerichtete, mehr oder weniger sphärisch gewölbte Theil, die sog. Cornea, ist aus dem allgemeinen Integmente herrorgegangen, und meist aus den eiqentlichen Facetten gebildet, deren Zahl, Gestalt und Grad der linsenartigen Wölbung sehr beträchtlichen Tariationen unterworfen ist, die uns aber hier nicht interessiren. Die $\mathrm{Ab}$ grenzung nach imen. gegen das Sehganglion mo das übrige centrale Nerrensystem hin, ist ebenfalls von einer in simne der Comea und dieser parallel gewölbten, aher selm riel zarteren und ron Löcherı für den Durchtritt der Nervenfasem durchbohrten Membran gebildet. Zwischen diesen beiden Grenzmenbranen, und ringsum noch von einer mehr oder weniger starken Hülle abgegrenzt. liegen die zum Ange in engern simne gerechneten Weichtheile in Gestalt radiär angeordneter, nach ansen divergirender Stränge, ron denen je einer zn einer Corneafacette gehört.

Jeder Strang zerfillt in zwei Abschmitte. von denen der vordere, der Comea genäherte meist der kïrzere ist. Beide Abschnitte müssen wir morphologisch wie physiologisch ron einander getrennt halten. wie Glaskürper und Retina im Spimenange etwa. Gemeinsam ist beiden nur die Zusammensetzung aus mehreren Zellen oder Zellenderivaten, die sich dex Lïnge nach, und gewöhnlich in symmetrischer Gruppirung nu die Axe des Stranges, zusammenfïgen zu einer anscheinenden Einheit. Der Länge der betreffenden Abschnitte entepricht jeweils anch die der zelligen Elenente desselben, so mamigfach diese in rerschiedenen Höhen anch entrickelt sein mögen.

Wie leicht an erkennen, entsprechen die beiden Abschnitte des Stranges schon lïngst bekamnten und benamnten Gebilden: der änssere, der Cornea genäherte. den krystallkegel der Autoren, der imnere dem ... Tervenstab" (Leydig) oder "Sehstab* (M. Schultze). den man früher als einfache Opticusfaser auffaste. Ueber ren Werth und die Bedentung dieser beiden Hauptelemente mïssen wir uns zun̈chst klar zn werden suchen.

Der Krrystallkegel gilt bekanntlich nach der bisherigen Auffassmag als ein typisches, ansnahmslos jedem znsammengesetzten Ange znkommendes Gebilke. Dies ist er aber in Wahrheit nicht, dem trotz seiner sehr weiten Verbreitmo in Facettenange fehlt er doch seln vielen Formen durchans und zeitlebens, und bei denen, die ihn im fertigen Ange zeigen, ist er erst ein Product der Entwickelung. Wir finden überall zuerst linter der Comeafacette eine bestimnte Anzahl von Zellen, deren Function in erster Linie in der Ansscheidung der 
Facette selbst besteht. Sie haben in Allgemeinen zusammen die Gestalt eines mit der Spitze nach innen gerichteten Kegels; in weitaus den meisten Fällen beträgt ihre Anzahl vier (sïmmtliche Insecten, zahheiche Crustaceen); seltener nur zwei oder fünf (nur bei Crustaceen beobachtet).

Dies ist der Ausgangspunkt, das Embryonalstadium, das allen Insecten und Crustaceen mit fucettirten Augen (nit einer einzigen Ausnahme, soviel mir bekannt) zukommt. Die Augen der ansgebildeten Thiere aber sind scharf ron emander geschieden nach der Metanorphose, welcher jene Zellen sich unterwerfen.

Dei einer Crrupe persistiren diese Zellen in unveränlertem Znstande während des ganzen Lebens. Diese Gruppe findet blos unter den Insecten Vertreter (wenigstens keme ich bis jetzt noch keme Crustaceen, die sich darmter eimreihen liessen): unter diesen aber sehr zahlreiche. Es sind nämlich folgende hierher zu rechen: von den Coleoptera wohl alle ausser den Pentameren; von den Hemiptera die Unter-Ordnung der Heteroptera oder Wanzen; ron den Diptera wohl die überwiegende Nehrheit der Tipularidae orler der langfühlerigen Zweiflügler: ron den Orthoptera wenigstens die Forficulina oder Ohrwïmer.

Bei den andem Insecten, sowie bei den Crustaceen mit Facettenangen, existiren diese Zellen als solche nur relativ kurze Zeit vor völlig erreichter Entwickelung. Schon frühzeitig beginnt in ilunen die Ansscheilung eines mehr oder weniger festen, völlig durchsichtigen und meist. stark lichtbrechenden Gebildes, mit dessen Grössenzunahme die Zellenkörper selbst grösstentheils zı Grunde gehen. Gewöhulich erhalten sich nur die Keme, sowie Reste der Hülle. Die Zellenausscheidungen treten zusammen, mul hilken den sogenannten Krystallkegel, dessen Segmente an Anzall derjenigen der vorher seine Stelle eimehmenden Zellen entsprechen. Von dieser Regel sind mir nur einige wenige Ausnahmen bekannt geworlen: bei einigen Crustaceen werden wohI vier Zellen angelegt, aber uu zwei derselben betheiligen sich an der Bildung hes Krystallkegels, während die andern beiden die Corneafacette formiren.

Es finden sich übrigens nicht überall, wo die hinter den Facetten gelegenen Zellen ausser den Facetten sellst noch andern Ansscheidungen den Ursprung geben, Krystallkegel im ächten und waluen Simne des Viortes. So haben z. B. die Fliegen oder knufüllerigen Dipteren, soweit meine Untersuchungen reichen, keine ächten, typischen Krystallkegel anfuweisen, sondern die ihre Stelle vextretenden Nedien unterscheiclen sich ron ihnen in einigen wie nir scheint nicht unvesentlichen Punkten, so dass sie eine besondere Behandlung rechtfertigen.

Ich werte daher in Nachstehendem mach dem Torkonmen oder Fehlen, sowie nach der Ausbildung der Krystallkegel die Angen der Arthopoden in folgende Gruppen rertheilen:

1. Acone Angen. d. h. solehe, in welchen Frystallkegel nicht nachzureisen sind, sondern diese zeitlebens durch typische Zellen vertreten werden.

2. Pseudocone Augen, d. h. solche, bei welchen zwar ein besonderes kegeloümiges und lichtdurchlassendes Medium vorhanden ist, das aber nicht wit jenen Zellen, anch nicht mit den typischen Trystallkegehn morphologisch in die gleiche Linie gestellt werten kann.

3. Eucone Augen, mit ächten Krystallkegeh, wie sie bisher allen Facettenaugen zugeschrieben wurden.

Im Gegensatz zum "Rrystallkegel" wende ich in Folgendem das Wort "Krystallzellen" für die in den aconen Augen hinter den Facetten gelegenen Zellen an; und um den etwas schwerfilligen Ausdruck „unächter Krystallkegel” für die Gruppe der psendoconen Angen zu migehen, werde ich mich des Ansdrucks: "Pseudoconus" für das stellvertretende Gebilde des Krystallkegels bedienen. 
Wïhrend das erste oder rordere chen discutirte Glied eines Einzelstranges sowohl nach den Untersnchungen der Melızahl der früheren Forscher, als auch nach meinen eigenen, lediglich einen dioptriwchen Apparat rorstellt, und nichts nit der Unwandlung der Lichtbewegung in Nerrenerregmo zu thun lat, ist das hinter ihm gelegene zweite Glied, der Nerven- oder Sehstab der Autoren, der eigentlich nervöse, percipirende Theil des Ganzen. Dil von seiner richtigen Würdigung das morphologische wie das physiologische Verständniss des Facettenanges abhängt, so wird in der folgenden Einzelbeschreibung ein besonderes Crewicht auf ihn gelegt werden müssen.

Wem man bisher vom "Nervenstab" oder .Sehstab" sprach, so hat man hauptsächlich das im Innern befindliche, stark lichtbrechende, stabartige Axengebilde im Ange gehabt, dessen Nachweis in deu Angen der meisten Arthoporlen ohne besondere Schwierigkeit gelingt. Um dasselbe beobachtete man eine gewölnhlich intensiv pigmentirte Scheide; in der auch Kerne nachgewiesen wurlen. In Ganzen jedoch hat man der letzteren wenig Aufmerksamkeit geschenkt, und dem entsprechend war anch die Bedeutung, die man ihr zuschrieb, in jeder Hinsicht nur eine geringe. Dass hier ein fundamentaler und für die Deutung verhängnissroller lrrthum begangen wurde, wird aus dem ganzen Abschnitt, welcher der Darlegung meiner Befunde an zusammengesetzten Auge gewidmet ist, zur Evidenz herrorgehen.

Der ganze sog. „Sehstab" bestelit nümlich aus einer Anzahl der Länge nach aneinanderliegender Zellen, die selbst eine partielle Terwachsung mit einander eingehen können. Zu jeder dieser Zellen gehört eine durchsichtige Ausscheidung derselben, die wir hier, nach Analogie des einfachen Auges. mit dem Ausdruck .Stäbchen" bezeichnen kömnen, obschon diese Bezeichnung nicht immer der Form des Gebildes gerecht wird. Zuweilen, aber nur selten, ist dieses Stäbchen in das vordere oder ïussere Ende der zugehörigen Zelle eingesenkt, und dann sind die einzehnen Stïbchen, soviel ihrer rorhanden sind, ziemlich von einander isolirt; sonst aber treten dieselben meist als Sämme ihrer Zellen auf, welche rlie nach imnen, gegen die Axe des Ganzen, gerichtete Kante theils bilden, theils mehn oder weniger weit ïberziehen. Durch das Zusanmentreten der Stähchen sämntlicher Zellen, welches sich bis zu einer Verwachsung olune nachweisbare Trennungsflächen oder -Lininn steigern kann. entsteht damn jenes stark lichtbrechende axiale Gebilcle, das man hauptsächlich mit den Bezeichumgen Nervenstab orler Sehstab characterisiren wollte; die Zellen aber, donen die Emzelstïbchen oder Segmente des Sehstabes zugehören, fasste man als Scheide auf. In diese Zellen aber treten die Nerven des Optiens ein. und damit ist klar, dass ihre Bedeutung in Bezug anf das Sehen selbst eine weit grössere ist, als man cler rermeintlich dem Sarcolenm der Mnskelfaser, orter der Hülle der Nerrenfaser gleichwerthigen Scheide zuscluiel).

Gerade so, wie wir es vorhin bei dem dioptrischen Theil des einzehnen Stranges gesehen haben, ist anch hier wierler eine gewisse numerische Norm vorwaltend, die zwar oft modificirt erscheint, aber doch inmer mo immer wierlerkehrt, wm ziemlich mabhängig ron der zoologischen Classification sich erweist. Die Zahl der Zellen, die wir als die grundlegende ansehen kömnen, ist sieben, und es sind mir nur seltene Fïlle rorgekonmen, wo ich mehr, nïmlich deren acht, gezählt habe (bei Hymenopteren und Cicaden). Viel hänfiger sind Reductionen jener Zahl: fünf oder vier Zellen finden sich gar nicht selten, sowohl bei Insecten als bei Crustaceen. Weniger Zellen, lie in der Art znsammentreten, sind mir nicht rorgekommen.

Da, wie man sieht, neine Anffassmg des ...Nerven- oder, Sehstabes“ im Princip von der der Urheber jener Bezeichmmgen abweicht, so sehe ich mich reranlasst. un schon durch die Bezeichnung sellst dieser Verschiedenartigkeit der Deutung Ausduck zu geben, jene Namen zu verlassen, und nene dafür in Vorschlag zn bringen. Ich werde demnach fü̈r den ganzen Complex 
ron pereipirenden Zellen hinter dem Krystallkegel oder dessen Aequiralent von num an die Bezeichnung: „Retinula“ in Anwendmng bringen, dessen Berechtigung später, bei der Tergleichmng des einfachen mit dem zusammengesetzten Ange sich noch deutlicher heramsstellen wird. lch verstehe also darunter den Sehstab nebst der Hülle der früheren Autoren. In jenen zahlreichen Füllen aber, wo die zu den einzehnen Zellen gehörigen Stäbchen mer cinander zu einem anscheinend einheitlichen axialen Strang verschmelzen, werde ich den letzteren als „Rhabdom"1) bezeichnen, und rerstche also darunter den sog. Sehstab ohne seine Umbüllung.

Wenn ich hier schon die wichtigsten Modificationen, wnter welchen die Retimula und das Rhabdom vorkommen, zu skizziren versuche, so wären etwa folgende zu unterscheiden:

1. In einfachsten Falle sind die Zellen ziemlich gut von einander isolirt, und eine derselben, die hänfig durch eine stïrkere Entwickelung ansgezeichnet ist, steht in der Mitte des Ganzen, die sechs anderen palissadenartig darm. An ihrem rordem, der Lichtquelle entgegengerichteten Ende tragen sie je ein Stäbchen; die Nittelzelle in der Are, die ihre Umgebung bildenden entweder am axialen Rande oder doch demselben genïhert. Dieses Verhalten finden wir hei langfühlerigen Dipteren, Wanzen. vielen Käfern und den Forficuliden.

2. Eine weitere Art der Ansbildung besteht darin, dass sämmtliche sieben Zellen peripherisch nm die Axe gelagert sind, und keine derselben durch besondere Entwickelung eine Ausnalmestellung eimmimmt. Die Stähchensïmme derselben, die sich dann fast ihrer ganzen Ausdelmmg entlang erstrecken, sind dam sïmmtlich m einen gemeinschaftlichen Hohlranm angeorduet, also ant dex innern Fläche einer Rölıre, durch welche die Axe zielit, und lassen entweder noch Zwischenräume zwischen sich erkennen, oder berühren sich gegenseitig mit den damn abgeplatteten Seitenflïchen. - Dies Verhalten wude besonders bei Coleopteren und kurzfïllerigen Dipteren beobachtet, findet sich aber anch bei Crustaceen.

3. Eine fernere Abänderming besteht darin, dass die Stäbchensämme sämmtlicher Zellen der Retinula zu einem axialen, anscheinend cinfachen Strang (dem Rhabdom) verschmelzen, an dem man zuweilen auf Querschnitten noch Spuren der Tremnungslinien nachweisen kann. Hänfig fehlen anch diese, und man ist dam auf die Zühlıng der Zellen angewiesen, die auf Querschnitten rosettenartig m den axialen Strang angeordnet sind. Dies findet sich bei Hymenopteren, Orthopteren, Cicaden, Tagschmetterlingen und bei Crustaceen.

Es mag hier noch erwähnt werden, dass die beiden letzteren Arten der Anordnung sich anch finden können bei Retinulis von nur fünf oder vier Zellen.

4. Endlich modificirt sich der Zellencomplex der Retinula noch in der Art, dass nur an bestimmten Stellen der stark rerlängerten Zellen, gewölmlich an ihrer inneren oder linteren Hälfte, Stäbchensïmme zu Aushildnng kommen, die dam meist eine melu oder weniger starke Anschwellmg der Retimula verursachen. Der Uebergang zwischen der sauntragenden und saumlosen Region der Retinula ist dam bald schroff, bald allmälig. - Diese Form ist weit verbreitet: eine grosse Anzahl ron Käfern, wohl alle Schmetterlinge ansser den Tagfaltern, riele Nenropteren und ausserdem zahlreiche Crustaceen weisen sie anf. Anch hier findet sich häufig eine Reduction der Elemente bis anf vier herab: oft ist diese aber anch nur eine scheinbare, indem man wohl ganz deutlich sieben Zellen zählen kann, aber nur vier zugehörige Stäbchensämme des Rhabdoms, wie wir bei Crustaceen sehen werden.

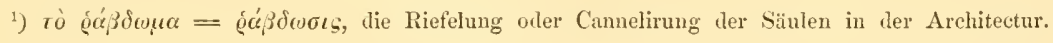


Damit dürften wohl rorläufig die ron mir beobachteten Hauptformen der Retinula genïgend characterisirt sein. Einige mehr untergeordnete Nodificationen werden im Laufe der Darstellung noch zur Sprache kommen, wie anch eine principiell rerschiedene, die sich bei Limulus findet, dessen Auge, obschon ein zusammengesetztes, einem ganz und gar abweichenden Typus folgt. der sich nicht anf die hier zu Gruncle gelegte Form zuruickführen lässt.

Nachdem wir hier in den dioptrischen und dem percipirenden Abschnitt, die jeweils zu einer Facette gehören, đlie wesentlichsten Bestandtheile des zusammengesetzten Auges flüchtig vorgeführt haben, bleibt ms noch ein dritter, norphologisch mehr motergeordneter, physiologisch dagegen nicht mwichtiger Factor zu berücksichtigen übrig, nämlich das Pigment.

Auch dieses zeigt hinsichtlich seimes Auftretens eine gewisse Constanz. Wir haben zunächst dreierlei Träger des Pigmentes zu iuterscheiden, nümlich: 1) die Zellen der Retinula; 2) die Pigmentzellen des Krystallkegels oder der ihn vertretenden Gebilde (Hauptpigmentzellen, Pigmentzellen 1. Ordnung), und 3) Pignentzellen 2. Ordnung, wie ich die in ilmer Anordnung weniger constanten bezeichnen will.

1. In weitaus den meisten Fällen sind die Zellen der Retinula durch und durch mit dmklem, körnigem Pigmente imprägnirt, selbstrerständlich mit Ansnahme des zugehörigen Stibchensammes, der immer röllig lilar und durchsichtig bleilst. Nur bei den vorlin unter 4. aufgezühlten Formen der Retmula ist cliese theilweise, orler selbst grösstentheils, frei rlavon, wenigstens bei Insecten; bei Crustaceen ist mir kein Beispiel daron hekamnt geworden.

2. Um die Krystallkegel. Krystallzellen und die sogenannten Pseudoconi fundet sich immer Pigment, wenn anch diese Gebilde nicht immer bis zur Unsichtbarkeit darin rersteckt liegen, sondern bald rom. bald hinten etwas durehscheinen. Bei den Insecten ist dieses Pigment sehr allgemein in zwei platten. zusammen eine tïten- oder trichterförmige Hülle un die genannten dioptrischen Apparate bildenden Zellen eingeschlossen, die liäufig anch nux das hinterste Ende derselben umfassen. Ich will nichit behaupten. dass unter den Insecten keine Ansnalmen rorkïmen, aber sicher siurl diese selten. und ich hahe deswegen jene Zellen als Hauptpigmentzellen zu bezeichmen rorgeschlagen. - Bei Crustaceen ist ebenfalls in der Tmgebung des Krystallkegels mehr oder weniger Pigment rorhanden, indes-en ist es mir nicht gelnngen. dort das Gebundensein desselben an solche Hawptpigmentzellen nachzaweisen.

3. Zwischen den Tuystallkegehn and teren Aequivalenten, wie auch zwischen den Retimuis finden sich die ron mir rorhin ah. Pignentzellen 2. Ordnung bezeichneten Gebilde. Sie sind bald nur kurz, und dann meist relatir dick; bald aber fadenförmig ansgezogen, mol lömnen damn piumentfreie Enrlen haben. Neist sind sie sehr zahlreich, und dann anscheinend regellos rertheilt; bei einigen Fliegen und Nachisschmetterlingen aber labe ich eine sehr gesetzmässige Lagerung und Anordnung bei constant bleibenden Zahlen derselben beobaciten können.

Ansserdem findet sich namentlich bei Crustaceen eine Forn ron Pigment. das rermuthlich anch an Zellen gejunden ist. obschon wir der Nachweis dieses Terhaltens nicht gelang. Dieses Pigment unterscheidet sich von dem bisher besprochenen durch seinen soznsagen erdigen Character. mol ist ebensowohl absolut modurchliissig für Licht, als auch mö̈lich in Salpetersïme. Ich funde es meist in der Umgebung des imnem Eudes der Retinula, und ron lier aus erstreckt es sich oft in Schleifen oder Arcaden nath ron bis in die Gegend der Krystallkegel. Nur selten findet sich ein älmliches, aber duch Salpetersäure zerstörbares Pigment auch bei Insecten (bei Tagschmetterlingen z. B.).

Ton ferneren, häufig auffallenden Bestandtheilen des Auges, wie z. B. den Tracheen bei 
Insecten, können wir hier $m$ so eher abshen, als sie mit ilem sohorgan als solchem direct vichts zu thum hahen, und ihr Vorkonmen nnd Terhalten änserst wechsehnd ist.

lis mag vielleicht auffallen, dass ich unter den essentiellen Butanitheilen des Facettenauges die von Leydig mit so grosser Bestimmtheit behaupteten Mnskelfasern nicht aufgeführt labe; ich muss deshalb wohl meine Stellung dazu etwas näher erörtern.

Bekanntlich hat Leydigl') in den zusammengesetzten Augen ron Insecten Fäden beschrieben, die balı innerhalb, bald ansserhalb der sog. Scheide des .Nervenstabes" der Länge nach verlaufend ihrem Tesen nach als feme quergestreifte, äuserlich pigmentirte Nuskelfibrillen aufgefasst werden mïssen. Bei Hymenopteren hat er sogar ilure Wirkmo unter den Mikroskop direct beobachten künnen, indem er die verschiedene Weite der .Pupillarringe" als Effect der Contraction dieser Mnskeln, die hier um den Krystallkegel noch ein irisartiges Geflecht bilden sollen, ansieht.

Leydig ist ler Einzige, der mit positiven Angaben darüber aufgetreten ist. freilich gleich mit so bestimmt formulirten. dass es nicht Wunder nehmen kann. wenn einnal seine Darstellung in den Lehrbüchern etc. allgemein Eingang gefmden hat, und dann andererseits kaum ein Zweifel. gexchweige dem offener Widerspruch sich geltend zu machen rersuchte. Schon Clapardè2) lässt indessen zwischen den Zeilen durchblicken, wie wenig seine eigenen L'ntersuchnngen die musknlös: Natur dieser Fäden zu stützen in Stande sind; M. Schultze. der sonst seine Beobachtungen gewiss nicht rozzenthalten pflegte, schweigt in sehr bezeichnender Weise völlig darïber. und einer der neuesten Beobachter, Steinlin ${ }^{3}$ ). spricht seme Verwmderung ïber die ihn erst nach Abschluss seiner eigenen [ntersuchungen hekannt gewordene Deutung dieser Fäden aus. da es ihm rorher „nicht von weitem in den Sinn kam. diese Gebilde für Juskelfiiden zu erklären ".

Neine eigenen Untersuchungen. die ich nach dieser Seite hin mit besonderer Sorgfalt an lebendem wie an gut conservirtem Naterial anstellte, machen es mir nicht mighlich. die Angaben von Leydig anzuerkennen. Ich kann in den von diesem Forscher beschriebenen und abgebildeten Fisern nichts anderes sehen, als fadenförmig verlïngerte Pigmentzellen, und da, wo diese vermeintlichen Nuskelfasem (bei Hymenopteren) sich mit dem irisartigen Pigmentgürtel vereinigen sollen. finde ich nu' die typi-chen beiden Hauptpigmentzellen, 'an denen die ersteren vorbeistreichen. Ebensowenig hat die Lntersuchung der Angen ron Dämmermgs- un Nachtschmetterlingen vermocht, meine Ansicht zu Gunsten der Leydig'schen Anschamngsweise zu indem.

Ich will num meine eigenen Unternclumgsesultate nitheilen. und dabei die Angen der Insecten und Crustaceen getrennt rorführen.

A. Zusammengesetzte $\operatorname{lugen}$ der Insecten.

\section{a. Leone Angen.}

Ich beginne die Darstellung meiner Intersuchungstesultate über den Bau des facettirten Anges mit der ron mir als acones Ange bezeichneten Form. und zwar zunïchst der Dipteren, soweit diese nicht zu den andern Abtheiłungen gehören. Es sind hier nur die langfühlerigen

1) Areh. f. Anat. etc. pag. 421, 421; Histologie pag. 255; Augre der Glietlerthiere pag. 11, 12; Taf. z. vergl. Anat., Erklïrung zu Tat. X.

2) Zeitschft. f. Zool. X. pag. 206.

3) Steinlin, Beiträge zur Anatomie der Retina. (Verhdlgn. der st. Gallischen natw. Ges. 1865-66. pag. 110 des Separatabdr.) 
Dipteren, die 'Tipuliden, zu berücksichtigen, denen wohl der Mehrzahl nach der nachfolgend beschriebene Grundcharacter des Auges zukommen dürfte, obschon z. B. die Euconie des Auges vou Corethra zur Torsicht hinsichtlich allzu rascher Generalisirung auffordert.

Ich habe von dieser Gruple der Dipteren drei Gattungen mntersucht, nämlich mehrere Species des Genus Tipula, dann Ctenophora flaveolata, und einige Arten von Culex. Ich gebe nur von den beiden ersten Gattungen Zeichnugen, da die Angen von Culex ziemlich mit denen ron Tipula übereinstimmen, und ansserdem zu kleine Dimensionen bicten, um sie gut und ïbersichtlich darstellen zu können.

1. Augen von Tipula spec. - Die Fignren 44 und 45 A-C Taf. III sollen den Bau des Anges dieser Gattung versimnlichen, und zwar stellt Fig. 44 einen Schnitt durch drei Facetten nebst den zugehörigen Weichtheilen, Fig. 45 aber Schnitte durch eine Retinula in drei rerschiedenen Höhen dar. Erstere Figm wurde nach einem Präparate entworfen, dessen Entfürbung unterbrochen wurde, als die Elemente durch das heller gewordene Pigment lindurch deutlich zu werden begamnen.

Die Corneafacetten (Lf. Fig. 44) exscheinen durch intensiv bram tingirte Zonen von einander getrennt, die von der imnern nach der änssern Oberfläche lin, allmïlig an Breite abnelmend, sich erstrecken. Die Wölbumg der einzehen Facetten ist nach aussen sehn bedentend, fast halbkugelig; mach imen sind sie dagegen sehr flach. Die Schichtung der Chitimmasse ist nicht zu rerkennen, und an der äussern Oberflïche markirt sich scharf eine dümne, ron der Masse sich abhebende Lamelle.

An die Innenfläche jeder Facette setzt sich ein kurzer und flacher. mit etwas einwärts geschweifter Mantelflïche rersehener Kegel an, lessen Spitze nach innen genichtet ist und sich im dahinter gelegenen Pigmente verliert. Dass dieser Kegel nicht mit dem Kirystallkegel zu identificiren ist, trotzdem er wie dieser aus vier Segmenten sich zusammensetzt. ergiebt sich daraus, dass jedes dieser Segmente in Imnern einen dentlichen Zellkern führt, der beim ächten Krystallkegel sich nie da fundet. Diese Zellen sind die ron nin so genamnten Kirystallzellen (Kz.), die Kerne sind lomolog den bekannten Semper'schen Kemen, wie sie Claparède (l. c.) genannt hat. die bekanntlich bei den enconen Angen als Ueberreste der die Krystallkegelsegmente bildenden Zellen zwischen Kegel und Comeafacette sich erhalten.

In dem $m$ die Spitze des Kegels dicht angehüuften Pigment erkemnt man zwei durchschimmernde Téene; diese gehören zn den Hanptpigmentzellen $\left(P_{y} I_{0}\right)$, deren Inhalt jene dichte Anhäufung rerursacht. Ausser diesen liegen der Imnenflïche der Cornea noch zahlreiche, kurzprismatische Pigmentzellen an, welche die Zwischenräume zwischen den Kégehn völlig erfüllen, und sich nach hinten verlieren. Dies sind die Pigmentzellen 2. Ordnung $\left(\mathrm{Pg}^{I I}\right.$.).

Die bishler besprochenen Elemente setzen, ohne dass solche nerröser Natur sich dazwischen fänden, die vordere der beiden Schichten zusammen, welche die Weichtheile des Anges bilden. Die weit dickere hintere Schicht ist ausschliesslich gebildet von den Retinulis (Rl.).

Un den Ban der Retimula zu verstehen. wird es nöthig, ausser den optischen Lïngsschnitten derselben in Fig. 44 anch die Querschnitte Fig. 45 in rerschiedenen Höhen zn Rathe zu ziehen. Zu jeder Retinula gehören sieben Zellen, die senkrecht auf der innern, das Ange abschliessenden Cuticula (ct.) anfsitzen (in den Randprortien des Auges sind sie freilich melu oder weniger stark dagegen geneigt), und als nach rorn etwas abgerundete Cylincler oder Prismen gegen jeden hrystalizellencomplex hinstreben. Von den Zellen der Retinula umstehen je sechs peripherische eine centrale, die jene an Grösse bedentend übertrifft. In allen lassen sich nach 
genügender Entfärbung die Kerne dentlich wahmehmen (n.); die Centralzelle besitzt einen grossen, kugeligen Kern, der ilır an Durchmesser niclit viel naclsteht, und der ziemlich nahe am Hinterende derselben gelegen ist. Die Kerne der Randzellen sind etwas abgeflacht und weiter nach vorn gerïckt. - Nach rorn convergiren die etwas abgeplatteten Randzellen gegen die Axe der Retinnla hin, entsprecheud der abgerundeten Znspitzung der Centralzelle.

Zn jeder dieser Zellen gehört ein Stäbchen (St., St $t^{I}$.), ron denen das zur Centralzelle gehörige $\left(S t^{T}\right.$ ) sich in einigen Punkten von den den Randzellen entsprechenden unterscheidet.

Die letzteren (St.) sind ungefähr von der halben Länge der zugehörigen Zellen, nach vorn, der Richtung der Zellen folgend, gegen die Axe hin zusammengeneigt und hier rimnenförmig ausgehöhlt (vgl. den Querschnitt Fig. 45 A Taf. VII), mit der Convexitüt gegen die Axe gerichtet. Hier liegen sie anch an der axialen Oberfläche der Zelle, so dass sie nur nach einer Seite hin ron der Zellsubstanz begrenzt werden. Teiter nach hinten werden sie dümmer, treten in das Innere der Zelle hinein, und die Rimne rerstreicht sich völlig (rgl. Fig. 45 B); mir ist auf allen derartigen Schnitten die stärkere Lichthrechung des axialen Randes aufgefallen. Das hinterste Ende ist röllig scharf begrenzt und läuft mit einer feinen Spitze ans.

Das zur centralen Zelle der Retinula gehörige Stïbchen (St. .) bildet einen einfachen langgezogenen Conus, und ist wie ein Nagel in die Axe der Zelle lineingetrieben, also ringsum ron der Zellensubstanz mongeben, wie besonders die Querschnitte (Fig. $45 \mathrm{~A}-\mathrm{C}$ ) ergeben. Es ist ziemlich gerarle, lïnger als die der peripherischen Zellen. und ragt sowohl nach rorn als nach hinten etwas über liese hinaus. In Fig. 44 scheint es, als ob ein hesonderes eiförmiges Körperchen sich zwischen das centrale Stäbchen mud die Krystallzellen einlagerte, was mich anfänglich auf den Crerlanken brachte, dasselbe möchte al ein etwas ahnorm gelegener rudimentärer Kirystallkegel aufufassen sein. Aber schon die Thatsache, dass dieses anscheinend selhständige Körperchen nicht ansnahmslos, ferner nicht immer in der gleichen frösse sich fand, liess den Verdacht an ein Kunstprodnct, hervorgebracht durch Tolnmenänderung bei der Erhärtung in Alcohol, anfkommen, und später rorgenommene Untersuchung sowohl frischer. als mit Osmimmsämre behandelter Augen, an denen ein solches Terhalten nie beobachtet werden konnte. erhob dies zur Gewissheit. Das Stäbchen scheint mit seinem vordern Ende den Hinterenden der Krystallzellen relativ fest anzuhängen; tritt num durch die Gerinnung in Alcohol eine Verkürzung ein, so bricht es meist quer durch. was wohl noch besonders dadurch erleichtert wirl. dass das Torderende frei ans der Zellensubstanz herrortritt.

An die imnere Seite der zarten, das Ange nach innen abschliessenden Cuticula (Fig. 44 ct.), welcher die Zellen der Retinula mit flacher Basis anfsitzen, treten die Nervenfasern nach ihrem Austritte aus dem Ganglion opticum heran. Die Scheiden mit den Kemen der relativ starken Fasern bilden einen mäsig dicken Ueberzug anf der hintem Seite der Cuticula; die Nerren selbst treten dnrch Oeffnumgen derselben hindnrch, um in's lnnere der Zellen einzudringen. Ich habe die Art and Weise. wie das geschieht, nur ein einziges Mal zu beobachten Gelegenheit gehalst. und an der Centralzelle der mittleren der drei gezeichneten Retinnlae darzustellen ressucht; es ist, wegen der Proceduren, welche zur Entfernung des Pigmentes unerlässlich sind, weit schwieriger zn exkemen, als man ron vornherein annehmen möchte. Das Ende der ziemlich dicken eintretenden Nerrenfaser rerbreitert sich leicht, zeigt hier eine Andeutung ron Lïngsstreifung, und hört ummittellıar linter der Eintrittsstelle anf, sichtbar zu sein; von einer Fortsetzung nach dem Stäbchen hin, an den Seiten des rorgelagerten, die Zelle fast in ganzen Querschnitte erfüllenden Kernes rorbei, komnte absolut nichts walıgenommen werden. 
2. Augen von Ctenophora flaveolata Mgn. - Bei Ctenophora, ron der ich einige Weingeistexemplare in sehr guter Erhaltung zu untersuchen Gelegenheit hatte, sind in allen wesentlichen Punkten die Augen nach dem gleichen Bau gestaltet, wie bei der vorigen Gattung, und die beobachteten Abweichmgen sind mur mutergenrdneter Natur. Die Figuren 46-48 Taf. VII zeigen sowohl die Uebereinstimmmg wie die Terschiedenheiten klar genug, um mich bei der Beschreibung kurz fassen zu können.

Fig. 46 entspricht der Fig. 44, mu ist sie einer mehr randständigen Partie des Ciesammtauges entnommen, was aus dem gebogenen Verlanfe der Zellen der Retinulae hervorgeht. Da hier die Pigmentanhäufung keine allzu dichte ist, so wurde auf Entfuirbung rerzichtet; in Fig. 47 dagegen ist der Zubelör einer Facette, melı ans den centralen Theilen des Auges, nach vollständiger Entfürbung mit Salpetersäure wiedergegeben.

Die Facetten (Lf.) sind ebenfalls durch dunkle Septa, die sich zu einem Netzwerk rereinigen (Fig. 48), ron einander getremnt; rom sind sie schwach convex, hinten dagegen leicht concar, beinahe plan. Das Terhalten der Krystallzellen ist, ahgesehen von der nach aussen convex gewölbten Mantelflïche, dasselbe wie bei Tipula, auch die Hauptpigmentzellen erfordern keinen besondern Hinweis. Der Unterschied liegt vorziiglich in der Retimula, besonders in dem Ueberwiegen des St:ïchens der Centralzelle ( $S t^{I}$.) über die der peripherischen (St.), die ron dem ersteren um das 3-, 4- bis melırfache übertroffen werden. An centralen Stäbchen zeigt sich bei Weingeistexemplaren gewöhmlich anch wieder das vordere Ende abgerissen, doch nicht ansnahmslos, wie Fig. 47 zeigt, die von demselben Ange stammt. Ferner liegt hier das centrale Stïbchen in einem weiten cylindrischen, nach hinten allmälig sich schliessenden Hohlram, in dessen Wandung, namentlich nach hinten hin, sich das Pignent besonders dicht anhäuft. Dasselbe ist anch bei den Randstäbchen, wenn auch in weit geringerem Naasse, der Fall. lch habe hier einfach von einer Höhlung un das Stäbchen gesprochen, bin aber dossen nicht völlig sicher geworden; es kam anch sein, dass der Anschein eines Hohlramns durch eine klare, schwach lichtbrechende Substanz zwischen Stäbchen und Zellkörper zu Stande kommt. Auch kann ich, falls erstere Vermuthung zutrifft, rem Einwand nicht entgegentreten. dass hier ein Kunstprorluct, entstanden durch eine starke Tolumsverringerung des Stäbchens bei der Erhärtung, vorliege; ich hatte nur Weingeistexemplare zur Verfügmg.

Die Kerne der Randzellen der Retinula liegen anch hier weiter nach vorn, als die der centralen; erstere mgeführ in der halben Länge; die letzteren liegen diclit vor dem stark pigmentirten Hinterende, sind ron oben geschen kreisrmud, von der Seite elliptisch, umcl erfüllen den Zellenquerschnitt fast vollständig.

Zn Fig. 48 ist zu benerken, dass dieselbe ein Stück eines Flächenschnittes, parallel einer Tangentialebene, darstellt. Links sind einige Reilıen von Facetten (Lf.) durclischuitten, so dass die dunkeh Maschen, welche die einzehen lichtdurchlassenden Facetten begrenzen, als geschlossenes Netz hervortreten; weiter nach rechts folgen die Krystallzellen (Kz.) und damn die Retimulae in verschiedenen Hölıen quer durchschnitten. Die Schnitte an meisten nach oben zeigen nur das centrale Stäbchen, dic ramdständigen sind unter dew Pigment der Hauptpigmentzellen verborgen; mehr in der Tiefe durchsehnitten, kommen anch die letzteren als Kranz un das centrale zum Torschein. - Eines weiteren Commentares bedünfen, wie ich glanbe, die Figuren nicht.

3. Augen von Notonecta glauca. - Die Augen der wanzenartigen Hemipteren schliessen sich ihrem Ban nach an natürlichsten an die eben beschriebenen von langfühlerigen Dipteren an. Ich beschrïnke mich bei der Darstellumg anf die genannte Art, die ich, weil sie 
mir znfällig am leichtesten zugänghich war, am eingehendsten notersucht habe. Ich habe übrigens ron Wasserwanzen noch ausserlem Nepa und Ranatra, von Landwanzen Pyrrhocoris, einige Pentatomen und Lygaens spec. anf den Angenban untersucht, bei allen aber bis anf untergeordnete Differenzen in Grösse etc. die Grumizüge des Banes so übereinstimmend gefunden, dass ich mich einer eingehenden berichterstattung über dieselben wohl für enthoben halten darf.

Dem Facettenange von Notonecta sind die Figg. 49-53 Taf. I'll gewidmet. Fig. 49 A zeigt eine Retinula mit den Krystallzellen, aber ohme zngehörige Facette, wie sie sich frisch ohne Zusatz eines Reagens oder einer Entfärbungsflüssigkeit präsentirt. Die W'eichtheile des Auges erweisen sich hier etwas resistenter gegen die Einwirkung ron Wasser, als man es sonst, ansser bei Fliegen, findet; sie ermöglichen demnach wenigstens bis zu einem gewissen Grafle ein Sturlimn lerselben in frischem Zustande, obschon, $n$ sie in ihrem ganzen Bau zu stuliren, noch mancherlei Manipulationen erforderlich sind.

Die Krystallzellen (Kz.) mit ihren dentlichen kugeligen Kernen sind ganz umschlossen von den beiden Hauptpigmentzellen, die eine becher- oder urnenförmige Hülle rm dieselben bilden (Fig. $49 \mathrm{~B}$ ), beim Prïpariren sich aber häufig von ihnen loslüsen, wie Fig. $49 \mathrm{~A}$ es zeigt. Uas Pigment in den erwïlnten Pigmentzellen bestrht ans ziemlich ansehnlichen, gleichgrossen Kïgelchen, die neist in regehmässigen Qnerreihen angeordnet sind. Die Beziehmugen dieser Zellen zn den Krystallzellen kïnnen am besten aus Figur j̃ ersehen werden, die einem entfüluten Prïparate entnommen ist. Die Retinula (Rt.) ist im Ganzen etwa kenlenförmig. und maclit einen weit mehr einheitlichen Eindrnck, als bei den rorbeschiebenen Dipteren. Sie ist in ilrer ganzen Lünge mässig pigmentirt, mit starken Anhäufungen ron Farbstoff an ilrem Vorter- und Hinterende, sowie an einer axialen Stelle hinter ihrer Mitte. In ganz frischem Zustande, ohne Zusatz irgend einer Flüsigkeit, oder bei gut crhärteten Angen liegen die Zellen derselben dieht aneinander wie in Fig. 51; bei Wasserzusatz aber weichen sie in der vordern Hälfte etwas anseinander (Fig. 49 A), so dass man wenigstens eine Strecke weit die im lunern eingeschlossenen Stäbchensïume (St.) erkennen kann, wie auch, dass das Pigment an der Grenzfläche zwischen dem Samm und dom Zellkörper besonders dicht angehiuuft ist. - Ansser den im lintern Drittel befindlichen Kernen (n.) beobachtet man noch zahlreiche grössere nnd kleinere unregelmässige Körper von starkem Lichtbrechungsvermögen, allem Anschein nach ein Fett.

Besonders instructir für die Zahl der Zellen der Retinula und die Beziehung der Zellen zu den Stäbchen sind Präparate wie Fig. 52, welche erhalten werden, wenn Angen nach 15 bis 20 Minuten langem Verweilen in Alcohol in Wasser zerzupft werden. Wenn durch Verletzung in vordern Theil der Zusammenhang fler Zellen gelockert wird, so weichen unter dem Einfluss der Qnellung, die noch nicht rerloren gegangen ist, nnd die namentlich stark die Stïbchensïume zu betreffen scheint, die Elemente anseinander, und sie biegen sich nach aussen um. Nur ein centrales Element bleibt ziemlich gerarle, weil der Widerstand, welcher der Verlïngerung des axialen Stäbchens entgegengestellt wird, ein allseitiger ist; das Stäbchen ist nüunlich, wie bei Tifula und Ctenophora, mitten in die zngehörige Zelle eingelagert. Nit Leiclitigkeit gelingt es, an solchen Prijaraten sich von der Identität der Zahlen wit den bei jenen Dipteren angegebenen zn überzeugen; ebenso, dass Stäbchen oder Stäbchensann und Zelle zusanmengehörige und fest mit einander vereinigute Gebilde sind, von denen die ersteren zu den letzteren sich morphologisch genan so verhalten. wie Cuticularbildung zur Zelle. - Anch der (entfärbte) Qnerschnitt durch drei ancinanderliegende Retimulae, welcher in Fig. 50 dargestellt ist, weist in nicht zn verkennender Treise darauf lin.

Die Länge der Stäbchensänme in Bezng anf die zugehörigen Zellen lässt sich an Präpa- 
raten wie Fig. $49 \AA, 51,52$ schwer bestimmen, weil selbst nach der Entfärbung noch so viel künnige Teberreste des Pigmentes übrig bleiben, dass die nach hinten sich betrüchtlich rerjüngenden Enden darunter unerkenmbar werden. Fig. 53 stellt nun ein Päparat dar, an welchem durch lange Einwirkmng der Salpetersänre die Zellenküruer durch Maceration völlig zerstört waren; sie zeigt, dass die Stäbchensämme der peripherischen Zellen, wie das axial eingesenkte Stübchen der centralen Zelle unter sich ziemlich gleichlang sind, aber anch an Länge den zugehörigen Zellen nicht viel nachstehen (die Fign ist nach der gleichen Tergrösserung wie Fig. 51 entworfen); ferner, dass sie nach linten in äusserster Feinheit anslaufen.

Wie sowohl Fig. 51, als der Querschnitt Fig. 50 zeigt, sind die Stäbchenbildungen einander sehr genähert, und bei Betrachtung mit schwachen Vergrössermngen kam man leicht schon den Complex derselben für em einheitliches Gebilde ansehen, das mit Längskanten rersehen ist. So hat Leydig den "Nervenstab " beschrieben, und gleichzeitig die ron mir bestätigte Beobachtung mitgetheilt $^{1}$ ), dass derselbe farblos ist in frischem Zustande. - Ausserdem liegen über das Ange der Wanzen noch Notizen ror von Müller²) und Will³), anf die ich einfach mnit der Bemerkung verweisen kamn, dass ron ihnen das Fehlen des ïchten Krystallkegels nicht erkannt worden ist.

4. Augen von Forficula. - Bei der Ordnung der Orthoptera finden sich nach meinen Untersuchungen acone Angen bei Forficula arricularia; die übrigen dürften wohl der überwiegenden Majorität nach in die Rubrik der Insecten mit eaconen Augen einzureihen sein.

Forficula (Fig. 54,55 Taf. V1I) besitzt nach aussen mäissig, nach innen stark parabolisch vorspringende Facetten $(L f$.$) , die sich durch starke Lichtbrechung anszeichnen. Die hinter ihnen$ gelegenen rier Krystallzellen $(\boldsymbol{K z}$.) haben eine etwas abweichende Gesammtform, indem sie eine Art von ziemlich dümner, der Facettenwölbung sich genan anschliessender Hülle bilelen, die sich in ein kurzes, axial gelegenes Spitzchen zwischen die Hauptpigmentzellen $\left(P g^{I}\right.$.) mnd gegen das Vorderende der Retinula fortsetzt. Die Hauptpigmentzellen sind seln ansehnlich, und ragen stark nach den Seiten him vor.

Die Retinula hat etwa die Gestalt einer umgekehrten Clampagnerflasche und ist sehr intensiv pigmentirt. Der Deutlichkeit wegen ist in Fig. 54 die eine Petinula in der Längsansicht, die andere in optischen Längsschnitt gezeichnet, und unter gleichzeitiger Zuhülfenalune der Querschnitte (Fig. 55) wird es leicht, sich ron der morphologischen Uebereinstimmung mit den bisher beschriebenen Augen zu überzengen; die Zellengrenzen sind freilich, weil sie nicht beobachtet wurden, auch nicht gezeichnet.

Das centrale Stäbchen $\left(S t^{I}\right.$.) übertrifft hier wieder an Länge die peripherischen; alle aber sind rom and hinten gleichdick und endigen nach beiden Seiten hin abgermulet. Das centrale ist ziemlich cylindrisch, und wieder in die Axe der zngehörigen Zelle eingesenkt, die randständigen bilden einzehn prismatische Cuticularsïmne, die sich zu einem sechsseitigen hohlen Prisma zusammenfügen, welches das Centralstïbchen umschliesst (Fig. 55). Diese Figur zeigt anch die Beziehung der Stäbchen zn den Zellen, die auf solchen Querschnitten als halbkreisförnige Figuren, welche den Seiten des Hexagons anfsitzen, erscheinen. - Die Kerne liegen hinter den Stäbchen. in Beginn der halsartigen Terengernng der Retinula. Unulüllt sind die Retinulae ron farlenartig

\footnotetext{
1) Arci.. f. Anat. etc. rag. 125.

2) J. M üller, Fortgesctzte Untersuchungen ete. Meckel's Arch, 1829. pag. 50.

3) Will, l. c. pag. 22 .
} 
verlängerten Pigmentzellen 2. Ordnung $\left(P g^{I I}\right.$.), deren Kerne theilweise in das Nireau der Schnitte in Fig. 55 fallen.

In dem grossen Heer der Coleoptera scheint, wie schon oben flïchtig angedentet wurde, die Aconie des Auges eine sehr weit verbreitete Erschemung zu sein. Wenn man aus den von mir angestellten Untersuchmgen schon einen sichern Schlnss ziehen könnte, so würden sich diese Insecten in zwei Reihen spalten, die der üblichen Unterabtheilung nach der Zahl der Tarsenglieder ziemlich entsprächen. Indessen sind die Untersuchurgen doch noch nicht völlig genügend; sie müssten Familie für Familie umfassen, und dazu fehlte mir die Gelegenheit. Indessen darf ich doch Jemerken, dass ich keinen Käfer von der Gruppe der Pentaneren (mit fünf Tarsengliedern) kemnen gelernt habe, der ächte Krystallkegel vermissen liesse; dagegen keinen aus den Gruppen der Heteromeren, Tetrameren und Trimeren, der solche besässe.

Ohne hier schon auf den Ban des enconen Käferauges einzugehen, werde ieh einige Repräsentanten des aconen Augenbanes, und zwar diejenigen, die ich am besten kennen lernen konnte (besonders auch hinsichtlich der Retinula) in Kiurze vorführen. Vielfach war ich wegen technischer Schwierigkeit genöthigt, auf das Studiun der letzteren zu verzichten, und musste mich mit der Constatirumg der Abwesenheit ächter Krystallkegel begnügen. - Die mehr oder weniger eingehend untersuchten Käferarten der genannten Gruppen sind die folgenden:

1. Coleoptera heteromera.

Fam. Melasonia

Tenebrio molitor.

"Vesicantia. . . . Meloë proscarabaeus.

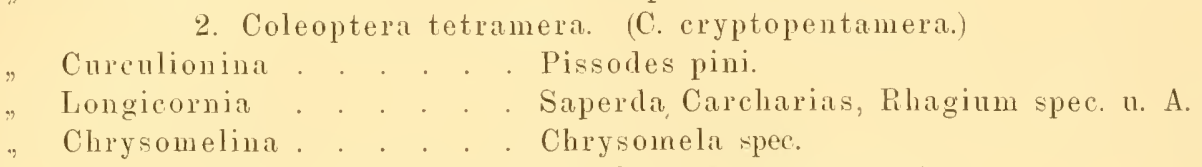

3. Coleoptera trimera (C. cryptotetramera.)

Coccinellidae. . . . Coccinella septempunctata.

Diese Aufzählıng. verglichen mit der grossen Anzahl der hierhergehörigen Gattungen und Arten, vermag natürlich nicht zu beweisen, dlass alle unter die genamten cruppen gehörigen Käfer acone Augen haben; ebenso wenig, wie die Aufzählung der par imtersuchten Arten aus der Gruppe der Pentamera das Vorkommen der aconen Augen bei dieser Gruppe anszuschliessen vermag. Aber da die Wahl der Tntersuchmosobjecte in beiden Fïllen eine sozusagen zufällige and rein durch äussere Unstände bedingte war, und die Resultate immer, je nach der Categorie, mit einander in der Hauptsache ïberemstimnten, so lïsst sich wenigstens die Wahrscheinlichkeit vorerst noch nicht bestreiten, dass die Charactere, die in der Bildung der Augen einerseits, in der Zahl der Tarsen andrerseits gegeben sind, nit emander vergesellschaftet sich finden.

lch inuss, wie schon bemerkt, hier von der Zusammensetzung der Retinula für die Mehrzahl der genannten Arten absehen; ich kann nur von Meloë, den beiden genannten Bockkäfern, und von Pissodes pini Erfalumgen mittheilen, die darin gipfeln, dass diese Käfer sowohl miter sich, als auch mit den vorher beschriebenen Insecten in Bezug auf Zahl und Anordnung der wesentlichsten Theile des Anges in Uebereinstimmnng stehen. Ich werde mich hier auf die Beschreibung des Auges von Meloë and Saperda bescluänken.

5. Auge von Meloë. - Meine Untersuchungen über das Auge von Meloë proscarabaeus sind leider nicht ganz so vollständig, wie die über die andern aconen Augen, da mir nur 
ailtere, in etwas zu schwachen Alcohol aufhewahte Exemplare zur Terfïgung standen. Sie genügen indessen für den Hauptzweck, die Abwesenheit des Krystallkegels und die Znsammensetzung der Retinula aus den bekamten sieben Elementen zu demonstrinen.

Die Facetten (vgl. Fig. 56 Taf. III $L$ f.) sind nach ansen selur wenig, nach innen aber ziemlich stark vorgewölbt; zwischen den imnern Torragungen sind die Zwischenrämme viel grösser, als bei den bisher betrachteten Formen, was auf cin gering entwickeltes Selwermögen hinweist, da anch die Retinulae weiter auseinandergerückt und deshalb sparsamer sind. Diesem Schluse legt die Beobachtung des lebenden, bekanntlich recht trïgen, Thieres kein Hinderniss in den Weg. Bei diesen grossen Interstitien zwischen den Retinulis laben die Pigmentzellen 2. Ordnung $\left(P^{I I}\right.$.) eine sehr bedentende numerische Entwickelnng erreicht. mol füllen jene ans. indem sie als feine Fäden von der Comea bis gegen die imere Grenz-Cuticula sich linerstrecken.

Der Complex der Krrystallzellen ( $K z$. ) sitzt in Forn einer Nütze der innem Facettenwölbung anf; ich habe freilich an meinem Materiale weder die Kerne, noch die Grenzlinien der Einzelzellen meln nachzuweisen vernocht, glaube aber doch meine Deutung aufrecht erhalten zn könuen, wenn auch nur fussend anf der Analogie. Ton ilmen zielıt ein ziemlich dicker Strang mach limten, gegen das centrale Stäbchen der Retinnla; er ist ron sehr richtem Pignent umgeben, das den wohl auch hier nicht fehlenden Hauptpigmentzellen angehören dürfte; anch diese labe ich nicht mehr sicher zu erkemen rermocht.

Weit besser hatten sich die kolbigen Retinulae (Rt.) conservirt. mil an ilmen konnte ich, bis anf die Kerne, ganz gut die Znsammensetzung erkennen (vgl. Figg. 56: 57 Taf. VII). Die sechs peripherischen Zellen tragen abgerundet vierkantige Stäbchen, die etwa $1 / 4-1 / 5$ ilner Länge einnehmen, mol am axialen Vorderende derselben gelegen sind. olme sich gegenseitig, wie bei Forficula, zu berühren (vgl. Fig. 57). Narh hinten endigen sie stmpf zngespitzt. Das Centralstäbchen, seiner Zelle axial eingepflanzt, rerschmälert sich nach hinten elsenfalls, und ist etwa doppelt so lang als seine peripleriwchen Nachbarn. Tom sah ich dasselbe gewöhnlich etwas weiter vorragen, und mit dem oben besprochenen Strang in Zusammenhang.

Erwälnt mag hier noch werden, dass schon .J. Müller ${ }^{1}$ ) bei M. majalis die krystallkegel nicht aufzufinden vermochte. mo in den starken innern Torragungen iler Facetten einen Ersatz dafür zu finden glaubte.

6. Auge von Saperda. - Genaner als bei Meloë habe ich das Auge ron Saperda Careharias (Figg. 58, 59 Taf. TI1) mtersuchen können.

Die Krürmmung der Facettenflichen ist beiderseits, innen wie anssen, beinahe die gleiche, mässig gewölbte, und die einzelnen Facettenantheile der selır dicken Cornea sind durch Zonen ron intensiv bramer Färloung ron einander geschierlen. Jeder Facette entspricht ein CorneaPrisma, das ungefälı doppelt so hoch als dick int ( $L f$. .).

Die Krystallzellen $(\boldsymbol{K} z$.) sind hier sehr deutlich erhalten, und bilden zusammen auch einen schalenförmigen Ueberzug äber die innere Comeawölbung; Kerne mut Zellgrenzen lassen sich sehr scharf unterscheiden. Der ron ilmen ausgehende, zwischen den beiden stark entwickelten Hauptpigmentzellen $\left(\mathrm{Pg}^{I}\right.$.) gegen die Retinula hinziehende Strang ist augenscheinlich von Fortsetzungen aller vier Zellen gebildet, worauf eine leichte Längsinie an rlemselben hindeutet.

An der gestreckt kollenfürmigen Retimula sind die peripherischen Stäbchen ebenso lang

1) J. M ï ller, Fortgesetzte Untersuchnngen ete. in M eckel's Arch. 1829. pag. 40. — Vgl. feruer dessen Physiologie Bd. II. 1810. pag. 309. 
und stark als das centrale; beide lassen sich bis in's hintere Drittel verfolgen, wo sie, immer dümmer werdend, sich der Beobachtnng allmälig entziehen. Dass die peripherischen durch gegenseitige Berïhrumg eine wenigstens im vordern Theil der Retinula geschlossene sechskantige Röhre bilden. ferner, dass das etwas plattgedrückte centrale Stäbchen im Imnern seiner Zelle eingelagert ist, das zeigen Querschnitte wie Fig. 59 zur Evidenz. - Die Kerne der Retinula-Zellen wenigstens der peripherischen, die der centralen lahe ich nicht gesehen - sind ziemlich weit nach rorn geschoben, mehr als bei den bisher besprochenen Formen, und liegen hier neben den Stailychen, statt linter ilmen.

Ganz elienso habe ich den Ban des Mnges von Rhagiun spec. gefunden, bis anf ganz montergeordnete Abweichungen.

Wie schon oben gelegentlich angeführt, hat Leydig ${ }^{1}$ ) das Ange eines exotischen Prionns mntersucht. und das Auffallende dabei gefunden, dass die Conea partiell, zwischen den Facetten, eine enorme Terdickung nach innen erführt, so dass die Retinnlae - die übrigens Leydig nicht specieller erkemnen komnte — in trichterförmige Höhlen eingeschlossen mul irolirt werden. Die morphologischen Consequenzen, zu denen Leydig dadurch geführt wurde, sind schon Eingangs, in rer listorischen LeJersicht, einer nähern Erörterung unterzogen worden.

Was die übrigen der oben genannten Käifer ambelangt, so will ich hier nur noch bemerken, dass bei Pissodes die Stäbchen der Retinula eine rerhältnissmässig berlentende Entwickelung erreichen. - Das Ange ron Tenebrio nolitor ist ron H. Landois und IT. Thelen ${ }^{2}$ ) anf seine Entwickehmg rormelmlich mersncht worden; die Aconie desselben wird aber nicht erwälnt.

Werfen wir noch cimmal einen flüchtigen Blick auf die hier vorgefülnten Thatsachen, so haben wir als characteristisch für die vorgefülrte Angenform zweierlei gefunden: 1) das Fehlen ächter Krystallkegel, an deren Stelle vier einfache kernhaltige Zellen sich finclen; 2) die Znsammencetzung der Retinula (des Seln- orler Nervenstabes) ans sieben einzelnen Zellen, zu denen ebensoviele Stibchen gehören. Da diese letzteren noch immer einen gewissen Grad von Selbständigkeit behampten, der wenigstens das centrale Stäbrhen nicht in die dichte Aneinanderlagermug, wie sie die peripherischen anfweisen können, eingehen lässt, also noch kein eigentliches Rhabrlom zn Stande kommt. so haben wir hier eine weniger ausgebildete Form des zusanmengesetzten Anges ror uns, die uns, wie wir sehen werden, für das Terständniss desselben werthvolles Naterial liefem wirl. Dabei wird sich ferner heramstellen, dass die Kenntniss dieser Angenform die merlässliche Toraussetzung nicht nur für die Zurückführung der einfachen und znsammengesetzten Angen auf einander, sondern anch für die Erklärung des Sehactes bei den letzteren bililet.

\section{b. Pseudocone Angen.}

Die von mir unter diesem Namen zusammengefasste Angenform findet sich nach meinen Erfahrungen, die der Natur der Dinge nach nur limitirte sein können, nur bei den ächten kurzfühlerigen Dipteren. Ich habe eine Reihe ron Formen - den Gattungen Tabanus, Haematopota, Sarcophaga, Syrphus und Musca angehörend - mtersucht, und, wem anch einzehe nehr orler weniger erhebliche Differenzen in Ban sich finden, doch bezüglich rer Hauptpunkte

1) Leydig, Arch. f. Anat. etc. 1855, pag. 421. Taf. XVI Fig. 29.

$\left.{ }^{2}\right)$ II. Landois und W. TheIen, Zur Entwickelungsgeschichte der facettirten Augen von Tenelrio molitor.

Ztschft. f. wiss. Zoologie. Bit. XVII. 1867. pag. 34 u. fi. Sehr dürftig! 
grosse Uebereinstimmmo erkannt. Ich werde mich deshalb anf einige wenige besonders eingehend studirte Formen beschräuken.

Ton den aconen und den enconen Angen muterscheidet sich das psendocone, wie ich es auffasse, durch folgende Charactere. Während beim aconen Ange die rier linter der Facette gelegenen und sie abscheidenden Zellen zeitlebens als solche nnverändert persistiren; beim enconen aber ansser der Facette noch den aus ebensoviel Segmenten, als Zellen rorhanden sind, bestehenden Krystallkegel aussonrlern, (und zwar erscheint jedes Segment ursprïnglich im Innern rler zugehörigen Zelle): scheiden die vier Krystallzellen beim psendoconen Auge eine reiche, halb oder ganz flüssige Substanz aus, die, zusammengelıalten durch trichterfürnnig gestaltete Hanptpigmentzellen, functionell dem Krystallkegel zu rergleichen ist. Sie ist aber vor den Zellen gelegen, durch deren Thätigkeit sie entstanden ist, zwischen denselben und der Facette; die Kerne jener Zellen, die man als Semper'sche bezeichnet, liegen demnach nicht, wie bei den andern zusammengesetzten Angen, der Facette stark genähert, sondern in einem oft recht erheblichen Abstand ron ihr abgerückt. Damit habe ich die hamptsächlichste Differenz zwischen der psendoconen und den andern Augenformen präcisint; die ïbrigen Modificationen treten daneben in den Hintergrimd.

1. Ange von Tabanus bovinus. - Das Ange von Tabanus ist in den Figuren 60 bis 62 Taf. T1I dargestellt; in Fig. 60, die einen Schnitt senkrecht anf die Cornea wiedergieht, aber nur den vordern Theil der W'eichtheile mufasst, ist der zu der einen Facette gehörige Antheil im Lïngsschnitt, der zn der andern gehörige in der oberfl̈̈chlichen Ansicht gezeichmet.

Die Convexität der Facetten ist nach anssen grösser als nach innen, obgleich anch hier noch merklich gewölbt; die einzelnen Facetten sind hier wieder durch tingirte Zonen ron einander isolirt, und ïberdies ron der äussern Oberfläche her noch durch schmale, nicht tief eindringende Spalten.

An die Seitentheile der immern Facettenfliche legen sich die nach aussen weit anseinanderveichenden Rä̈nder einer Röhre an, die sich nach hinten hin in cylindrischer Gestalt fortsetzt, so dass man sie etwa mit einem Speculum vergleichen könnte. Diese Röhre $\left(\operatorname{Pg}^{I}\right.$.) besteht ans zwei platten, gegen einander gerollten Zellen, deren Ründer mit einander rerwachsen sind. Sie sind mit dunkelm Pigment erfüllt, und übcrhaupt kein nenes Element, sondern nur die ms schon bekamnten Hauptpigmentzellen, die hier in etwas abweichender Form und Lagermo auftreten. Das hintere Drittel etwa des von ihnen gebildeten Rohres wird durch einen rorn eben abgeschmittenen. durchsichtigen, an den Seiten gewöllsten Pfropf $(K z$.) völlig erfïllt; dieser besteht aus vier dentlich ron einander abgegrenzten kernführenden Zellen, den mis anch schon genügend bekamten Krystallzellen (vgl. anch Fig. 61. Kz.). Die Pigmentrölure mmschliesst sie ganz dicht, schnürt sich, ihrem Unrisse folgend, hinter ilmen entsprechend ein, mo endigt an der hier anstossenden Retinula.

Zwischen der hinteren Facettenflïche und den Krystallzellen bleibt noch ein anselmlicher. seitlich von den Hauptpigmentzellen umschlossener Raum übrig. in welchem man den Krystallkegel zu finden glaubte, den die ïberwiegende Mehrzahl der Forscher auch den Fliegen zusprach. Indessen hat es doch seine Schwierigkeit, diesen Begriff anf den Inhalt des Hohlrammes einfach zu ïbertragen. Wo immer wir von .Krystallkegehn "sprechen, laben wir Gelilde im Auge, die, wem anch oft änsserst weich und zerfliesslich, sich durch den Besitz einer bestimmten gegebenen Form von einer beliebigen amorphen Flïssigkeit unterscheiden, und es gelingt uns durch Erhärtung inmer, mehr oder weniger gut diese Form zu conserviren und zu bestimmen. 
Hier versagen aber alle solchen Mittel ihre Dienste; es ist wir nie geglückt, in dieser Höhhng etwas emem Krystallkegel Aehnliches nachuweisen. und es machte duchans den Eindruck, als wïre sic mit einer Flïsigkeit erfüllt, die nur passir durch die sie einschliessenden Wände in Kegelform zusamnengehalten wird. Canz leichte granulöse Trühung durch Erhïrtungsflüssigkeiten. oder Erscheinmgen wie die bekamnten, ron Eiweisshüllen mmgebenen Wassertropfen. wie sie oft dem Mikroskopiker anfstossen. und die ich bei Untersuchung ganz frischer Angen anch hier erlielt, denten höchstens daranf hin. dass in der wässrigen Flüssigkeit Albminate gelöst enthalten sind, rerändern aber die Sachlage daduch nicht. Ich habe dechalb mich fïr berechtigt gehalten, das hier zur Beobachtung gekommene Verhalten ron den Fïllen, wo ächte Krystallkegel rorkoumen, abzutrennen, und diesen dioptrischen Apparat als "Psendoconns" besonders zu bezeichnen.

Tm den Psendoconns herum lagem sich noch die Pigmentzellen 2. Ordnung. Diese sind spindelförmig, ziemlich gestreekt, und biklen einen continuirlichen Beleg ïber die Hauptpigmentzellen (rgl. Fig. 60, 61, $\mathrm{Pr}^{I I}$.), was besonder's anf Querschnitten dentlich hervortritt. Vorn berïhren sie die Cornea, hinten erstrecken sie sich bis anf den Tordertheil der Retinula.

Die Petimula ist rom und hinten zierulich gleichdick und anch ron nahezn gleichem Ban. Durch eine Nasse ron kolbigen Tratheenenten (Tr.). die sich zwi-chen die einzelnen Retinulae drängen, wird die Form ilres Quershnittes (Fig. 62) bedingt; sie sind meist melu oder weniger abgermudete dreiseitige Prismen. Dass sie ebenfalls aus sieben Zellen zusammengesetzt sind, lïsst sich kamm ans den Zellengrenzen erschliessen, sellst wenn man äber selır gute Schnitte verfïgt, weil die Zetlen sehr innig unter einander rerwachsen, fiast versehnolzen sind. Nmr selten sieht man Spuren ron gegenseitiger Abgrenzung. Was indessen lier rermisst wird, wird ersetzt durch die Leichtigkeit, sich ïber die Zahl der Stäbchensiume zu orientiren. Die Retimnlazellen bilden zusammen ein Roln ron zienlich anselmlichem Lmmen (Fig. (62), das durch sieben vorspringeude Leisten rom kreismulem Querschnitte eingeengt wirt. Diese ziehen, ron der Seite gesehen, als stark lichtbrechende, gleichdicke Fïden (St.) ron rorn bis hinten, wo sie allmälig dïmer und blïsser verden, und ror dem hintersten Ende ganz verschwinden. Sie sind duch ansehmliche Zwischenräune ron einanter getrennt; rom aber, wo das Lumen der Retinula sich rerengert. convergiren sie, und treten an vordersten Ende in imigen Contact mit einander. Sie enden dort, an der Hinterseite der Liystallzellen, anf einen ganz klemen Gesamntquerschnitt zusamnengedrängt.

Diese Stähchensänme sind anch in frischem Zustande völlig farblos, und nie habe ich, sellbst bei Anwendung ron selur starken Vergrössermugen. Andentungen der sonst so oft rorkommenden Plättchenstnctur (M. Schultze) an ihmen walnnehnen kömen. Dies gilt ebenso für die andern genamnten Arten, wie anch die grosse Revistenz der Stäbchensïtune gegen Wasser für diese Geltung hat. Sie erhalten sich halbe, selbst ganze Stunden darin unverändert, anch wemn die ïbrigen Theile der Retinula schon längst durch Qnellung gelockert, zerbrückelt und zn Grunde gegangen sind.

Fast immer habe ich, wie auch in Fig. 62 angedentet wmde, ein Stäbchen besonders stark in das Lumen der Röhe rorspringen sehen; dasselbe sitzt dann am axialen Rande einer sehr dümen, zmm Zellenleib gehörigen Leinte anf. lch möchte dies ats eine Andentmng der ursprünglich axialen Lage der zugehörigen Zelle anffassen, die sich num der Peripherie eingefïgt hat; und dies $n m$ so eher, als ich hei Nusca vomitoria ganz sicher die ansgeprïgt axiale Lagermg tes einen Stïbchens beobachten konnte (rgl. weiter unten). 
Die Kerne der Zellen der Retinula liegen unweit rom Vorderende derselben, zienlich dicht bei einander.

2. Ange von Musca romitoria. - Bei der Schmeissfliege sind die Abweichungen ron dem eben geschilderten Ban nur untergeordneter Art; vgl. darüber Figg. 63-65 Taf. VIII.

Die Facetten sind blos anssen merklich convex, nach imnen fast völlig eben. Sie sind auf beiden Seiten durch schmale. spaltenartige Furchen ron einander abgegrenzt, von denen die der änssern Oberfläche entsprechenden zwar schmaler, aber weit tiefer sind, als die der Innenseite. In die letzteren sind die freien Vorderränder der die Psendoconi umhüllenden Hanptpigmentzellen soznsagen eingefalzt.

Der ron diesen Hauptpigmentzellen umsclilossene Ramm ist ein alogestumpfter Kegel mit rasch sich rerbreiternder Basis. In die wie bei Tabanus sich rerhaltenden Krystallzellen treten in eigenthümlicher Weise die Stäbchen der Retinula hinein. wor̈̈ber nachher das Nähere.

In Fig. 63 und 64 habe ich ein Verhalten dargestellt, das eher an die Anwesenheit ichter Krystallkegel erinnern könnte, als es sonst nach meinen Erfahrungen bei Fliegen der Fall ist. Nachdem ich mich lange rergeblich benüht hatte. über den Inhalt jenes kegelförmigen Hohlranus in s Klare zo kommen. führte mir der Zufall Exemplare ron M. vomitoria in die Iände, deren Angenban jene Figmen illustriren. Sie fanden sich unter ciner Anzalıl anderer, die im Torrath gefangen mo in Weingeist geworfen worden waren, und zeichneten sich ror den andern schon bei Betrachtmng mit blossen Ange dadurch ans, dass nach emiger Zeit die Angen das Pigment rerloren hatten und weis lich geworden waren, während die ïbrigen sich nicht verändert latten. Die Psendocuni dieser Angen - aber nur dieser — zeigten das abgebildete, gleich zu beschreibende Verhalten, und es ist mir nicht möglich, die Gründe dieser auffallenden Verschiedenheit anzugeben; möglich aber. dass sie mit den Alter der Thiere, d. I. mit der seit dem Verlassen der Puppenhülle verflossenen Zeit in Zusammenhang steht.

Wie dem anch sein nöge, in Algeneinen gilt für II. vomitoria das oben für Tabanus Ansgeführte. In den erwähnten specialfällen aber fanden sich im Innern jenes Holihanmes rier ganz zarte blasse Stränge. die ron den Krystallzellen nach der Corneafacette hinstrebten, und an beiden Enden sich fixirten (rgl. Figg. 63. 64. Ps. C.): an der Facette su fest. dass sie beim Losreissen derselben oft an ihr längen blieben. Da sie den Raum nicht entfernt ansfüllten, mod doch im Ganzen. besonders rom. seme Forn copinten, so war der Ëndruck der, als ob man hier anch nicht ein prïiexistirendes Gebilde ror sich hätte, sondern dine durch die Gerinnm sehr zusammengeschmmpte. ursüünglich den ganzen Paun erfüllende, änsserst weiche Gallerte. - Fig. 64 zeigt das Ausschen der Querschnitte dieser Strïnge.

Die Znsanmensetzung der Retinnla ist lie gleiche wie bei Tabanus, und ich wierlerhole nur. dass hier der Gegensatz von Centralstäbchen nnd peripherischen dentlicher ausgeprägt ist, als dort. Dies lässt sich besonders leicht an frischen Angen constatiren. Zerzupft man nämlich ein solches sorgfältig. so tindet man leicht unter den mmherschwimmenden Fragmenten der Retimula Stücke, die so gebogen sind, dass nan die Stäbchen an der Tmbiegungstelle im optischen Querschnitt ülrersieht, und damn ist immer eines in der Nitte der sechs übrigen gelegen, ohne aber sonst ansgezeiclmet zu sein.

Wie schon angeführt, treten bei II. romitoria die Vorderenden der Stäbchen zwischen die Krystallzellen hinein. Dabei erleiden sie einige Modificationen, welche in Fig. 65 nach einem frischen Präparat gezeichnet sind (bei $x$ ), ohne die umbüllenden Krystallzellen, die entfernt sind. Die frei rortretenden st:ibchenenden sind etwas rerdickt, rorn abgerundet, und riel 
reniger stark lichtbrechend als der ïbrige Faden. Aus der Mitte fles Bündels sah ich immer ein cinzehes Ende etwas unehr hervorragen, als die andern, nud ich remuthe darin das Centralstäbchen. - In der Figu 65 sind äbrigens, un Verwirrung zu verneirlen, nur fünf Stäbchen angegeben, und die Hülle, d. h. die Retinulazellen, im Zustande starker Quellung gezeichet.

Ton den Kernen der Retinula liegen sechs in vordern Drittel, wo sie lan gehärteten Augen) buckelartige Auftreibungen rerursachen; der siebente findet sich immer im lintern Drittel, und gehürt wohl zum Centralstiibchen.

Die Pigmentzellen 2. Orelnung sind moleich grösser, aber spasamer als bei Tabanus. Es siml. wenn ich nicht irre, un jede Retinnla deren vier gelagert, aber so, dass jede zu zwei benachbarten Retinulae gehört (rergl. Fig. 63, $P g^{I I}$.). Sie sind kugelig mit einem rordern und einen hintern Auslïufer.

3. Auge von Sarcophaga carnaria. Dieses weist nur sehr mberleutende Abweichungen ron den beschriebenen auf, die einer eingchenden Darstellung nicht bedürfen. - Fig. 66 Taf. Tlll ist einem frischen Auge entnommen; man erkennt deutlich die Grenzen der (in ihren natürlichen Farben wiedergegebenen) Hauptpignentzellen $\left(P_{y}{ }^{I}\right.$.) und deren Kerne; den Ort. wo die Krystallzellen (Kz) liegen ete. - In Fig. 67 Taf. IIII habe ich eine Zeichnung gegeben. welche die Stäbchenendigung an Borlen des Psendoconus-Trichters rerdentlichen soll. Die Ansicht ist ron der Conneaseite her, nach Entfernung der Facette, und die sieben hellen. ron dunklem Pignent umgebenen Punkte1), welche bei tieferer Emstellung in Hintergrund sich heransheben, sind die Endigungen der Stäbchen. Anssertem rerdienen die Pignentzellen 2. Ordnung noch eine Erwähnmng. Sie sind kolbenförmig, langgezogen, purpurroth gefürbt, und in einer eigenthümlich äconomischen Teise $11 n$ die Retinulae angeordnet. Fig. 68 Taf. V11I, die einen Querschnitt dureh diese Pigmentzellen wiedergiebt, lehrt. dass jeweils zwölf solcher zu einer Retinula gehören, dass aber jede einzehne Zelle gleichzeitig zu zwei Retinulae gelört. was durch die altemirende Anordnung drei- uml vierkantiger /ellen erreicht wird.

Jch kann danit meine eigenen Mittheilungen über das Fliegenauge abschliessen, und nun dazu äbergehen, meine Resultate mit dencn, die frühere Intersncher darüber veröffentlicht laben, zu vergleichen.

Nachten J. Mïller anfünglich in seinem Hauptwerke (Tgl. Physiol. des Gesichtsinnes) das allgemeine, ausnahmslose Torkommen ron Krystallkegehn in Facettenange rertheidigt hatte. sih er sich durch die sprïtere Wiederaufnalune semer Lntersuchnngen doch genöthigt. einige Einschränkungen zu machen, und zwar ausser der schon angefühnten für Mcloë auch für Fliegen²) (M. domestica. carnaria), bei denen er niemals solche durchsichtige Kegel aufgefunden hat. - Willa) dagegen glaubt sowohl bei M. domestica als bei Tabanus borinus die Kegel gesehen zu haben, wenn auch nur mit Schwierigkeit, da sie sehr klein und mit Pignent bedeckt sind.

Dass es gerade Fliegen waren, an ilenen Gottsche (1. s. c.) sein der Müller'schen Theorie so gefihrliches Experinent machte. und wie wenig gerade diese gecignet sint. für eine Betheiligung der Krystallkegel an der Bilderzengung herangezogen zu werden. darauf labe ich schon früher (hist. Ielersicht) lingerriesen. lch denke, nach meiner jetzt gegebenen

\footnotetext{
1) St teinlin (1. c. pag. s6) giebt nur rier an.

2) J. Mï $11 \mathrm{er}$, Fortges. Untersuch. etc. 1. c. pag. 51.

3) l. c. pag. 26 .
} 
Darstellung der Constitution des ,Krystallkegels" wird man wohl zugeben. dass diese die Manipolationen, die Gottrelıe mit ilmen rornahm, umnöglich äberdanern. und einen irgendwie in Betracht konnenden Einfluss anf die Bildentstelung ebensowenig ausüben komnten.

Auch den neveren und ganz andere techniwche Hülf-mittel in Anweminng bringenden Untersuchem - Leydig. Steinlin. M. Schnltze - scheint kein Lnterschied zwischen der Bildung rler Krystallkegel bei Fliegen und den ïbrigen Insecten anfgefallen zu sein. Er wird wohl als sehn weich beschrieben, aber das ist Alles. Die verünterten Lagebeziehungen des Psendoconus zu den sog. Sempre'schen Kernen scheinen anch ihnen entgangen zu sein; sowohl Leydig (Arch. f. Anat. 185ว, p. 426) als Max Sehultze (1. c. pag. 22) haben sie zwar gesehen; aber ersterer spricht nur von , vier in's Krenz gestellten Kïgelchen. die das Licht stark brechen". während letzterer sie dem, Sehstab" zutheilt, und in dem Vorkommen derselben eine Eigenthimlichkeit der Fliegen erblickt.

Aus der neuesten Zeit kommt mir eine Arbeit ron Ciacciol) zu Gesicht, deren Resultate sich am meisten den ron mir mitgetheilten auschliessen. Er sagt darüber (1. c. pag. 315): „En ce qui tonche ì la capsule particulière, en forme de dochette (d. h. den ans den beiden Hanptpignentzellen gebildeten Trichter), elle envelope le batomet ì son extrémité antérieure, et s’attache entièrement ì ce demier rar la partie smpérienre de son fond. Il est ntile dajonter que cette capsule est formée d'une menbrane très délicate. homogène ef éla-tique et qu'elle ne renferme, dins son intérieur, a ucun corps on cône crystallin, comme l'ont prétendn la plupart des observatems. On trome, seulement, dans la partie terminale du bitonnet, un flnide très limpide qui sert, à un moment domé, à maintenir la capsule distendue et à en conserver la partie terminale en son rapport avec la pupille et arec la facette sons-jacente de la cornée."

Wenn es noch nöthig sein sollte, die Homologie der von mir lier als kirystallzellen bezeichmeten Elenente mit den gleichnamigen fräher beschriebenen. fermer mit jenen des enconen Anges, deren Korne als Semper'sche hezeichnet werden, zu erweisen. so kömnen liefür die be-

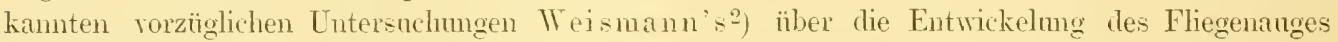
herangezogen werden. Nach desen Beobachtungen liegen anfïnglich die vier Kerne dicht unter der zur Cornea werdenden Cuticula, und werden erst duch die Entwickelung des , Krystallkegels" (dessen Anlage er z̈brigens wegen der frühzeitigen Pigmentablagerme nicht rerfolgt hat, und dessen sonstige Eigenthümlichkeiten ihn auch entgangen zu sein scheinen) von clieser abgerlüngt. - Mit Unrecht bestreitet übrigens Weismann die Angaben von Claparède, der Schmetterlinge und Ameisen untersucht hat, dass diese vier Kerne zu elonsoviel Zellen gehören, und seine Behauptung, dass sie ,zu keiner Zeit vier Zellen angehören, sondern immer nur einer einzigen ". hat nux den thatsächlichen Hintergrund, dass bei seinem Nlaterial ganz ansmahnsweise der Fall vorliegt, dass die Zellgrenzen fehlen. Auch ich habe sie bei Insca romitoria nicht erkemen können, dafür aber reichen andern Insecten lïsst mich der Dentung ron Claparède beitreten.

Anch die Retimula lat ihre Geschichte, und ror Allem ist zu notiren, dass ich bei keinem einzigen der frühern Forscher die Zahl der Stäbchen, oder. wie man sie meist namte, der

1) M. G. V. Ciaceio. De l'oeil des Diplères. Lebersetzg. ans: Mem. Acad. Bologna, in: Journal de Zoologie p. Gervais. Vol. V. 1876. pag. 312.

$\left.{ }^{2}\right)$ A. Weismann. Die nachemulyonale Entwickelung der Muscilen etc. Ztschtt. f. wiss. Zool. Bd. XIV. 1864. pag. 280 u. ff. 
Nervenfïden, völlig richtig angegeben gefunden habe. _ . Müller spricht einfach von Faser'n des Schnerven, wenn or die Rutinula meint; Will lässt den "Nervenfarlen" aus einer hellen immern Röhre und einer selu weiten Scheile bestehen, und anch Leydig hat in seiner ersten Arbeit noch nicht erkannt, dass der "Nervenstab", dem er anch eine weite Scheide vindicirt. aus discreten Fäilen besteht. Weismann erkannte diese, zeichnet anch ganz correct sichen (l. c. Taf. XXTI Fig. 55), spricht in Text aber von sieben lis acht. und meint, es schienen anfünglich nur vier zu sein.

Steinlin ${ }^{1}$ ) spricht nur von vier Fürlen, die er ..Jei Fliegen mol Trespen" gesehen haben will - bezüglich beider sicher ein Irrthm. - Genau dasselbe gilt von M. Schultze's so bestimmt ausgespochener Behauptung, er habe bei Fliegen acht solcher Fürlen gezühlt. Dic Fliegen spielen bei ihm darbrch eine besondere Rolle, dass sie zu den wenigen Insecten gehören, bei denen er eine grössere Anzalıl feinster Nerrenendigungen dicht hinter den Krystallkegel machweisen zu künnen glanbte (l. c. pag. 2-2). Diese feinen Fasem sollten sich wieder in Bündel, wahrscheinlich vier. gruppiren, und etwas divergirend verlaufen. - Für mich ist kein Zweifel, dass 11. Schultze hier die modificirten St:̈bchenenden gesehen, aber nach Zahl mo Bedeutung rerkannt hat. ( Tol. seine Figg. 24-26 Taf. II. 1. c. von Syrphus).

Ciaccio zählt fünf odler siehen solcher Fäılen, die ilnem Aussehen nach mit denen des Nervus opticus äbereinstimmen und durch eine homogene Sulstanz zusammengehalten werden sollen; er lässt sie mmittelbar hinter der Facette endigen, was ein zienlich derber Irrthm ist.

Wie ich aus einem Citat ron Milne Edwards²) ersehe, hat Künckel in seiner mir nicht zu Ciesicht gekommenen Mlonographie der Tolucellen eimen axialen Faden, aus der Retimula in den Kirystallkegel (Psendoconus) eintretend, als Nervenendigung in Ansproch genommen. lch glaube mich der Nühe überhoben, dem etwas linzuzufügen.

Man könnte vielleicht geneigt sein, ans den schwankenden Zahlenangaben der genamnten Autoren den Schluss zu ziehen, dass die Zahlenrerhältnise sellst fluctuirende und unbeständige seien. Nach meinen selır zahlieichen Beobachtungen ist dies aber nicht richtig. Ich habe immer die gleiche Zahl gefunden, und die Richtigkeit wird wohl auch durch die schon beim aconen Ange mitgetheilten, und bein ewconen noch weiter anzngebenden Zahlenverhältnisse gestützt. Die verschiedenen Augaben finclen ihre Erklärung schon in der Schwierigkeit, auf blossen Lïngsansichten sicher zı zälılen.

Dit zahlreichen kleineren Controversen gegenüber den Darstellungen meiner Torgänger zu erörtern, lohnt nicht der Mühe.

\section{c. Eucone Augen.}

Die enconen Augen, alle liejenigen umfassend, bei denen hinter den Facetten ächite, typische Krystallkegel gelegen sind, haben bisher Modell stehen müssen für die zusammengesetzten Augen der lnseeten und Crustaceen überhaupt. Der Grund dürfte wohl hauptsïchlich darin zu suchen sein, dass in diese Categorie die grössten und meist auch an leichtesten zur Untersuchung sich darbietenden Insecten, wie z. B. sümntliche Schmetterlinge, die grösseren, d. h. die pentaneren Kïfer, die Heuschrecken, Libellen etc. etc. gehören. Und in der That, sieht man nach,

1) Steinlin, Beiträge zur Anatomie der Retina. Verhdlgn. d. St. Gall. Nat. Ges. 1865/66. pag. 82 des Sep.-Abd.

$\left.{ }^{2}\right)$ H. Milne Edwards, Leçons sur la Physiologie et l'Anatomie comparée ete. Tome XII. $1^{\text {ère }}$ part. 1876. pag. 249 . 
an welchem Lntersuchung-materiale die Forscher ilse Sturlien gemacht haben, so überwiegen die hierhergehörigen husecten so bedeutend, dass man sich nicht wundern kann, dass die hier sich findenden Terhältniss ohe Weiteres als Nonn angesehen, und schliesslich anch nicht hierhergehr̈rige Augenformen. wenn der Znfall auf solche fïhrte, eingereiht wurden, und das Tremnende nicht zor Beachtung kim.

Die zahlreichen und gerade hiefür besonders ansgieligen Vorarbeiten erleichtern mir neine Anfgabe insofern, als ich mich über manche Formverhältnisse kurz fassen kam. Besonders gilt dies von den krystallkegeln. sowie von der Configuration der Retinula im Allgemeinen, wo es äberflüssig wäre. das sehon längst und wiederholt Gesagte noch einmal vorzufiiluren. Dagegen muss dic Zusammensetzung der Retinula besonders betont werden, und ich berlaure blos. dass die grosen technischen Schwierigkeiten es nir nicht ermöglicht laben, die urspüngliche Absicht in mehr zufriedenstellender Weise zn realisiren. Tollkommen befriedigende Pesultate habe ich nur relativ wenige aufzuweisen, aber ich denke, sie genügen vorlänfig, dasjenige, was ich als Hamptsache anselie. manfechthar zu machen. nämlich den Nachweis einer ihrem Wesen nach unveränderlichen, nur durch secundäre Dodificationen in zahlreichen Variationen auftretenden Normalstructur.

Hier treten hauptsïldich jene mannigfachen, Eingangs schon erwähnten Differenzirungen der Retinula in rom und hinten rerschierlene Abschnitte auf; lier ist ferner statt der isolirten Einzelstäbchen das aus ihrer Vershmelzung hervorgegangene Rhabdom rorherrschend; hier endlich varïren die Zahlen der Elenente. welche die Retinula bilden, zwisehen vier nurl acht, obschon anch die typische Zahı sicben noch immer als der Ansgangspunkt angesehen werden muss.

1. Ange rou Corethra plumieornis. - Das Auge von Corethra (Figg. 69, 70 Taf. VIII), sehliesst sich hinsichtlich de- Banes seiner Retinula entschieden mehr an die früher besprochenen Augenformen, besonder's an das acone Ange an. Während die ansgebildeten Krystallkegel (K\%) es scharf von jenen zu tremnen nöthigen. Corethra niunt dadurch eine eigenthüuliche Stellung muter ihren Terwandten ein, bei denen doch wohl das acone Ange das herrschende sein dürtte.

Ich habe für meine Lntersuchungen nur Larven und Pupen benutzt, keine Imagines, was aber irrelevant ist, da das zusammengesetzte Ange schon bei der Larre ansgebildet ist mol mrerändert durch das Puppenstadium hindurehgeht.

Ton den beiden lirystallkogeln nebst Zubehör in Fig. 69 ist der mit 1 bezeiclmete dargestellt nach einem Platinchlorid-Chromsïmre-Prïparat. der mit \& bezeichnete nach Erhärtmo in Alcohol. beide mit nachfolgender Entfïrbung. Fig. 70 zeigt Qnerschnitte durch die Retinula.

Die Comea (der Larren) ist, wie Leydig (s. mut.) angielot, facettenlos. Die dahinter gelegenen Krystallkegel ( $\mathrm{K} / \mathrm{i}$ ) sind regelmässig lirnförmig, linten mit abgermdetem Ende, und umgeben von einer, wenigstens nach der Erhärtung ziembich abstehenden, relatir starken Hülle ( $\kappa z$.). Die Längslinien der Krystallkegel sind, wie Ansichten von oben oder unten belehren, auch hier nur der Ansdruck der bei den Insecten nach unsern bisherigen Erfalumgen allgemein rorkommenden Viertheilung derselben. Tor dem Krystallkegel, der Innentliche der Hülle anliegend, finden sich rier dentliche abgeplattete sog. Semper'sche Keme, Kerne der Krystallzellen, die als Antterzellen der hrystallkegelsegnente vorher diese stelle eimnahmen. nud als deren Leberrest noch ansserdem die Hïlle $n$ m den Kegel anzusehen ist. - Die neben dem Vorderende der Kegelhällen gelegenen Kerne gehören wohl zu den Pigmentzellen 2. Ordnung.

An ihrem Hinterende geht die Hülle in einen kurzen, feinen, von zwei sehr kleinen Haupt- 
pignentzellen $\left(P_{g} I_{\text {. }}\right.$ ) umschlossenen Strang über. der auf die Retinula zuführt. - Die letztere besteht, wie der Qnerschnitt erweist (Fig. 70) ebenfalls aus sieben Zellen, von denen wieder eine centrale mit ihrem zugehörigen Stäbchen den sechs peripherischen entgegengesetzt ist. Die Zellen moreifen den Krystallkegel noch eine beträchtliche Strecke weit nach rorn; nach linten sind sie etwas verschmälert. - Die Stäbchen (St.) sind weit kürzer als die Zellen. kuz cylindrisch und an beiden Enden abgerundet. In dem Platinchlorid-Prïparat (Fig. 69. 1) sind die Stäbchen vorn mit einander im Contact, wie verlöthet, und divergilen nach hinten, so dass das Ganze etwa wie ein viehwzehger Backenzahm aussieht; in Weingeistpräparat sind die Stäbchen von einander isolirt mul parallel gelagert. Bemerkt mag noch werden, dass an exsterem dic Stïbchen, soweit sie getrennt sint. eine zwar feine, aber doch deutliche Streifung zeigten.

Ueber die Augen von Corethra liegen, abgesehen ron ïlteren Beolnachinngen von R. Wagner ${ }^{1}$ ) nud Leydig ${ }^{2}$ ). besomlers die werthrollen Tntersuchungen ron A. Weismann ${ }^{3}$ ) ror. Diesem letzteren Forscher sind aber doch die Retimnlie entgangen, und die Entstelımg des Krystallkegels glaubt er auf eine einzige Zelle zurückfülıren zu können, wozu neine obigen Beobachtungen allerilings schlecht stimmen.

2. Argen von Bienen und Hornissen. - Soweit ich die Ordnung der Hymenopteren iibersehen kamn. gehören alle zu den Insecten mit enconen Angen. Ich habe allerdings nur vereinzelte Formen, theils eingehender, theils nur oberfäichlich untersncht (Biene, Wrespe, llornisse, Crabro cribrarius, Ameisen mul einge Ichneumoniden); bei allen aber dentiche, wenn anch immer weiche und leicht zerstörlare Krystallkegel gefunden.

An meisten hat mich bei den Hymenopteren die Thatsache der Vermehrung der die Retinula zusammensetzenden Elemente auf acht interessirt, von der ich allerdings nicht anzugeben im Stande bin, ob sie allgemein. oder nur auf wenige beschränkt vorkommt. Ich konnte sie nu bei Bienen (Figg. 71, 72. Taf. VIIl) und besonders dentlich bei Hornissen (Fig. 73 Taf. V111) mit Bestimmtheit constatiren, es wird wohl aber nicht fehlgegriffen sein, wenn man diese Eigenthümlichkeit nicht blos auf die genannten Arten beshrïnkt sein lässt. bei denen sie zufällig vegen der Grösse sicher unterschieden werden kimn.

Bei den Hymenopteren (vgl. Fig. 71, von der Honighiene) ist die Retinula (Rt.) in ihren ganzen Lünge fast gleichliek, und nur nach imen mmerklich sich rerjüngend, cannelirt (Fig. 72) und pigmentirt. Wer Krystallkegel ( $K k_{\text {. }}$ ) ist weich und ron schwacher Lichtlorechung; in der Abbildung ist die Schattirung der Deutlichkeit wegen übertriehen. Die Trennungsflächen der einzelnen Segmente desselben sind sehr schwer wahzunehmen. desto leichter die Semper"schen Kerne (n) trotz ihrer geringen Grösse. Besonders gut entwickelt sind die beiden Categorien ron Pigmentzellen; beide zeichen sich durch relativ grosse Keme ans $\left(P g^{I}, P_{1 y^{I T}}\right.$.). -

Aus dem Innem der Retinula schimmert ein axialer Stab (Tom., Firg. 71) durch, der dieselbe von vom bis hinten, gleichnäsig an Stäke nach immen abnehmend. durchzieht. Torn endet er abgerundet in einer geringen Entfernung rom Hinterende des Krystalliegels. so dass jeder Gedanke an einen ummittelbaren Uebergang der beiden in einander widerlegt wird. Anf Qnerschnitten (Fig. 72, von der Biene; Fig. 73, von der Hornisse) erscheint er als hell aus dem

1) Archiv f. Anat. u. Physiol. 1835. pag. 313. Anmerkg.

$\left.{ }^{2}\right)$ Fr. Leydig, Anatomisches mu Histologisehes äber die Larve ron Corethra plumicornis. in: Ztsehft. f. wiss. Zool. Vol. I1I. 1851. pag. 435. (Alıge pag. 442).

${ }^{3}$ ) A. Weismann, Die Metamorplose ron Corethra plumieornis, ebendas. Vol. XVI. 1866. pag. 45. 
Pigment heranslewchtendes, stark lichtbrechendes Centrun einer achtstrahligen Rosette, deren einzehe Rarlien altemirend lïnger und kürzer sind, no dass der Gesammtumuiss etwa rhombisch wird. Jeder einzehe Rarlus entspricht einer Zelle cler Retinula, der axiale Stab alser kamn nur aus der innigen Terwachsung aller zu den Zellen gehörigen Stäbchensümme in eine Einheit, ein Rhabdom, hervorgegangen sem. Diese Terschmelzung ist eine so imnige, dass es nir selbst auf den besten Schnitten, sowie nit Zuhülfenalme der stärksten Vergrössermngen, nicht gelmgen ist, mehr als ganz mbestimmte, möglicherweise rein zufällige Spuren der Trennmgsflächen zu erkennen. - Nicht entfürbte Querschnitte zeigen die Rhabdome als seln regelnässig vertheilte lielle Punkte auf tiefschwarzem Grunde.

Ueber die älteren Darstellungen des Baues dieser Augen ist nicht riel zu bemerken, und ich kamn mich begnügen, daranf linzureisen, dass ich die Leydig'schen Angaben über die speciell lier besprochene rermeintliche Musculatur schon früher, rlie Steinlin'schen aber, ,ler sie mit den Fliegen zugleich behandelt, gelegentlich der Besprechung dieser letzteren berührt habe.

3. Arge von Cicada grossa (\%). - Die Hemiptera homoptera, die in umserer Fama ansschliesslich durch kleine, wenig zu Querschnitten duch die Retimulae sich qualificirende Formen repräsentirt sind, schliessen sich bezüglich ihres Angenbanes in bemerkenswerther Weise an die Hymenopteren an, und merscheiden sich ron ihren sonst systematisch ihmen so nahe gestellten Terwandten, den Hemiptera heteroptera, dadurch selm beträchtlich. Ich habe nur die unter obigen Namen in der liesigen Sammlung befindliche Art näher untersuchen können, die Anwesenheit des Krystallkegels alser auch an einer noch unentwickelten, au Fuchsien schmarotzenden Aphrophora constatirt. die sonst zu Untersuchungen über die Petinula sich wenig eignete. Bei beiden Fornen fand ich die Frystallkegel selur wohl entwickelt. lang flaschenfürmig ansgezogen, aber von schwachen Lichtbrechumgsvermögen. Ton der langen, camelirten Retinula der Cicada grossa habe ich (Fig. 74, a, 6 Taf. TIII) zrei Querschnitte viedergegeben; der eine (a) ron dem Krystallkegelende, der andre $(b)$ melr ans der Nitte; und zwar olme rorlierige Entfübmg gezeichnet. Lei beiden ist die Znsammensetzung ans acht Elementen ganz evident, und das im Centrum gelegene Pilabdon untersheidet sich ron dem bei Hymenopteren beschriebenen nur durch die Anvesenheit eines in der Axe desselben verlanfenden Längsanales, der oben zienlich eng ist, weiter nach linten sich etwas erweitert, wobei gleiclizeitig anf der Aussenflüche des Rlabdomes den einzelnen Zellen entsprechende rippenartige leichte Torsprünge (Fig. 74, b) anftreten. Anch lier sind keine dentlichen Trennmgsinien der einzelnen Zellenantheile am Rhabdom melur nachzuweisen.

Auf die Angaben Will's (1. (. pag. 23) ïber Cicada orni erlaube ich mir einfach limzuweisen.

4. Ange von Periplaneta mul Gryllotalpa. - - Die genamnten ron mir mtersuchten Orthopteren-Genera gehören bezüglich des Verhaltens des Krystalliegels ebenfalls zu den enconen Formen, unterscheiden sich aber bezüglich dex Anzahl der Elenente, aus denen die Retimula hervorgeht, sehr wesentlich von den eben beschriebenen daduch, dass nicht eine Vermelnung. sondern eine Reduction dersellsen anf vier hier vorkonmt.

Figg. 75 und 76 Taf. VIIl gehören zu Pexiplaneta orientalis; letztere $(1-4)$ zeigt Quersclmitte durch die Retinula in rerschiedenen Höhen, $m$ das Verhalten des Rhabdomes zu demonstriren. 
Die Comea (Lf.) bestelit ans zwei deutlich ron einander getremnten Lagen; die innere, etwas dickere, ist durch ein ron innen her nach aussen eimhingendes Netz von scharf auslaufenden Furchen sozusagen in ebensoriele Prismen gesondert. als Facetten rorhanden sind. Die ïnssere Facettenwälbung ist kaun merklich und bleilst weit hinter der inneren zurïk. Der bauchigeiförmige, vorn ziemlich oben abgeschnittene Krystallkegel steht in eigenthümlicher Weise mit der Retinula md dem Phabdom in Beziehung. Die Retinula nämlich weicht an ihrem rordern Ende becherförmig auseinander, und daran participirt auch das Rhabrom, das sich in vier Stränge theilt. In die Höllung senkt sich der hintere Theil des Krystallkegels ein, so dass er davon umfasst wird, wie etwa eine Blumenkione ron den Kelchblïtten. Weiter nach innen treten diese zusammen, um einen ziemlich drehrunden Stab zu bilden, der hinten scharf begrenzt und leicht abgerundet endigt (Fig. 75, Rm.). - Die Querschitte zeigen dentlich genug die Zusammensetzung aus nur vier Einzelstïbchen, denen wohl sicher ebensoviele Zellen zugehören. Der erste derselben (Fig. 76,1$)$ geht noch durch den hrystallkegel, unter dem herror die divergrirenden Enden des Phabulomes durchschimmern. Der zweite Schnitt (Fig. 76. 2) zeigt das Rhabdom etwa in der Gegend. wo die Dirergenz beginnt; das Rhabdom hat einen ungefïlı quadratischen Querschitt und imen noch ein sehr deutliches Lmmen. Auf den weiteren Schnitten 3 nnd 4 zeigt sich das Rhabdom rund, das Lumen ist im ersteren norh kenntlich. im letzteren aber rerschwmen, doch sind die Trennungshinien noch iiberall nachweisbar. - Zu den Abbildungen benerke ich noch, dass die Hanptpigmentzellen in dem zu Grunde gelegten Präparate zu sehr zerstört waren. um wiedergegeben rerlen zu kömmen. und dass mir die Kerne der Retinula nicht zu Gesicht gekommen sind.

Das Auge ron Gryllotalpa bedarf nach dem Angeführten kciner besondem Besprechung melı (vgl. Fig. 77 Taf. VIII). Ich will blos bemerken, dass die beilen dargestellten krystallkegel ans den grössten Extremen ausgesncht sind, welche das Präparat darbot. Der rechterseits dargestellte dürfte dem frischm Zustande am nächsten kommen. während der linke sehr berleutende Shlumplung zeigt. - Die Theilung les Rhabdoms ist lier mu rudimentär. so das nur die äusserste Spitze des Krystallkegels sich in dic Vertiefung am Vorderende desselhen einsenkt. Die Kerne der Retinula $(n$.) sind sehr deutlich; man kamn mit Leichtigkeit deren vier zählen. welehe Zahl auch den Theilstücken des Rhabdoms auf Querschnitten, welche fast durchaus mit Fig. 76. 4 äberemstimmen, entspricht.

Ich habe noch eine Reihe anderer Orthopteren (Locusta, Acrilium etc.) untersucht, aber ohne dass es mir gelungen wïre. wesentlich Teues daran zu finden. Die Längsansichten gaben über die Zahl der Elemente der Petinula keinen Aufschluss, mul mit Querschnitten war ich nicht gliicklicher.

Ton früheren Beobarhtungen sind ror Allem die von Leydig hervorzuheben. der gerade an Orthopteren (Nantis, Schizodactyla) den unmittelbaren Znsanmenhang mol Lebergang olme Grenze zwischen Frystallkegel und Nersenstab beschieb,1), und darauf seine Folgermgen aiber die Bedeutung des ersteren aufbaute. Ferner hat Leyrlig an den hírystallkegehn ron Acridium Beobachtungen gemacht, die ihm genügend schienen, der ron Claparède vertretenen Genese derselben gegenïber Opposition zu erheben. In den einzehen segmenten dersellen hat Leydig einen runden kernartigen Fleck wahrgenommen (vgl. Arch. f. Lnat. etc., l. c. Taf. XVII, Fig. 27) und glaubt nun, dass die Segmente einfache Zellen wäien, ams denen der Krystallkegel bestehe. Was ich selbst rom Auge von Acridium kemnen gelernt habe, lïsst mich dieser Auf-

1) Arch. f. Anat. etc. pag. 422. - Auge der Gliederthiere pag. 22. 
fassung, die, wemn sie richtig wäre, diese Gattung unter die Fubrik der Insecten mit aconen Angen eimeihen wiirle, nicht beitreten.

5. Auge von Necrophorns. - Welche Verbreitung die lier geschilderte Form des anconen Auges mit einfachem Phabdom bei der grossen Ordnung der Kïfer hat, bin ich nicht in Stande anzugeben. Ich muss nich hier auf ein einziges Beispiel beschränken. und noch dazu anf eines, dessen Ban in gevisser Beziehung berechtigte, ihn hier die Aufnahme zu versagen, mm es in der Alstheilung der pseudoconen Augen unterzubringen. Dies in mancher Beziehming interessante Ange gehört der Gattung Neerophorus. Todtengräher, an (rgl. Figg. $78-80$ Taf. VIII).

In erster Linic ist das Ange ansgezeielmet durch den rudimentären Character seiner Kinstallkegel. Hinter den rom glatten, hinten schwach convex rorspringenten Corneafacetten liegen, von fadenfürmigen Pigmentzellen $\left(P y^{I T}\right.$.) nmgeben, lange znckerhntförnige liegel, deren spitzen von den Hamptpignentzellen mmschlosen werien. Diese Kegel zerfallen in vier Segmente, die aber kernfühnend sind, and die Kerne sind etwa in ihrer Mitte gelegen (Fig. 78, bei n.); sie sind demuach nicht mit den Krystallkegehn, sondern mit den Kiystallzellen identisch. Indessen sind anch die Krystallkegel nicht mvertreten; sie bestehen aus vier nicht nit einander in Contact stehenden, nahezn prismatischen Stücken, welche dicht an die Cornea anstossen, und je zu einer der Krystallzellen gehören, rgl. Fig. $78,79 \mathrm{~K} \%$.). Sie sind ron schwaeher Liehthrechung, dreikantig, und hinten abgerundet; ilne Lünge beträgt etwa ${ }^{1}$ s der zngehörigen Zellen, cher weniger als mehr.

Die Retimula ist wenig pigmentirt, rom mehr, nach linten aber vicl schwächer; im Ganzen ist sie cylindrish mit regelmässig abgemuleter Camelirmg, (rgl. besonder's die Querschnitte Fig. 80). Das Rhahdon lïst sich anch olme rorlurgehende Entfïrbme recht gut als ein gleichmässig die Retinula ron rom bis hinten dmehsetzender Stab erkemen (Rm. Fig. Ts). Querschnitte zeigen hier mit einer in Ganzen seltenen Dentliclikeit sowohl die Znsammensetznng der Retinula ans sieben Zellen, als anch den Autbau des Fhabloms aus ebensorielen, zu den einzehen Zellen gehörigen Segmenten (rgl. Fig. S0).

Dass dieses Ange nur bedingmgsweise in die gegenwärtig behandelte Gruppe der enconen gehört, geht ans der Beschreibung hervor. Nlit den psendoconen Augen hat es ror Allem die relative Lage der semper'schen Korne zu der Luscheidung (hier dem liegelframente) gemein, die bei heiden linter derseben liegen. Sonst aber ist das Kegelfragment keineswegs so flüssig nnd formlos, wie dort, und insofern dïnte die Eimreilung hier wohl gehilligt werden.

Dieser Beschreibmg sicher erkannter Augen mit gleichmissig entwickelter Retinula füge ich noch einige wenige Bemerkmugen über andere, ebenfalls hierhergehörige an, bei denen es mir nicht gelungen ist, dentlich und unzweidentig die Zusammensetzung der Retinnla ibrem numerischen Verhïlnisse nach zu bestimmen.

In erster Rieilue neme ich die Tagfalter, ron denen ich an mehreren Gattungen (Pieris, mehrere Arten Tanessa, Lycaena etc.) Aufschluss zu gevinnen suchte. Im Allgeneinen zeichnen sich diese Thiere dmeh sehr kleine hrystallkegel ans, die oft (bei Lycaena z. B.) so winzig sind, dass man scharf anfachten muss. $m$ sie nicht zu übersehen, trotzdem sie von grosser Resistenz und starker Lichtbrechung sind. - Auf den Querschitten der Retmulae lïsst sich wohl eine mehr oder weniger dentliche Cannelirmg ilner Nantelfliche nachweisen, dieselbe ist jedoch so wenig sicher ausgeprägt, dass ich ein bestimmtes Urtheil über die Zahl der zu iluem Anfbau beitragenden Zellen daranf him abzugeben ansser Stande bin. Ebensowenig befriedigent sind die Biller, die ich anf solchen Schnitten rom Rhabdom erhalten komnte, besonders, 
da es morer der Procedur der Entfürbung oft sehr leirlet. Die Aneinanderlagerung der Zellen ist lier eine selur dichte und innige.

Dasselbe gilt ron den rerschedenen Formen der Libellen (Aeschna. Libellula. Agrion). die ich näher untersuchte. Hier sind besmolers die überans zahlreichen. in das Innere des Auges eindringenden Tracheen störend, welehe die Retinulae in vielkantige Stäbe umformen. ohne dasm aber die Zahl dieser Kanten irgend welchen sicheren Schluss anf die Zellenzahl erlaubte. Inf Querschnitten durch solche Retinulae hat nan eine Nenge sehr umregelmissig stemfürmiger Figuren ror sich, deren Strahlen ron verschiedener Lünge und anffallend schwankender Zahl sind.

Bezüglich beider genamten Gruppen ist es mir leider nicht möglich. die älteren harstellungen (vgl. besonders die ron II. Schultze l. с.) in der bisherigen Weise zu ergäinzen. Darüber jedoch, dass anch diese noch widerstrebenden Formen sich auch noch als in das Schema sich einfügend herausstellen werden. kam wohl kam ein Zweifel olswalten. Ich glanbe, dass hier wohl ebenfalls die normale Zallu durch Reduction rerringert ist - wenigstens bei Libellen -; bei den Tagschmetterlingen sind die Eindrücke, die ich erhalten habe, so widerprechent. dass ich mich ausser Stancle frklïren muss. anch mu eine bestimnte Termuthung zu äusern.

Ein wesentlich anderes Ausehen als die bisher behandelten Retinulat bieten diejenigen dar, bei welehen die Staibchenausscheidnng nur in einem Theil ihrer Erstreckung ror sich geht. Dieser Theil ist nach den ITntersuchungen meiner Vorgïnger sowohl, als nach meinen eigenen, immer der immere. an weitesten von dem Kirystallkegel abgelegene, und zeichnet sich gewölmlich durch eine masige cylindrische oder spindelfömige Gestalt ror dem dam meist farlenartig rerdümnten vordern Theil ans. Dieser farlenatige Theil kann num seinerseits entweder unmittellyar in die ebenfills fadenartig rerdiunt ihm entgegenkommende Scheide des Kryatalliegels ohne wahmehmbare Grenze ïbergehen, oder an rordersten Ende wieder eine mehr orler weniger ausgeprägte kolbenförmige Anschwellung tragen, in welcher dann die Kene der Retinulazellen zu suchen sind. - Ueber die anch hier nicht fehlenden Variationen in den Zahlenverhältnisen werden die nachbeschriebenen Beispiele Auskunft geben.

6. Ange ron Melolontha. - leh wälle als erstes Beispiel das Auge des Maikäfers, den ich als Repräisentanten der grossen Fanilie der Lamellicornia an eingehendsten zu untersuchen Gelegenheit latte (Figg. 81, 82 Taf. TIII).

Fig. 81 zeigt drei Augenabtheilungen rom Maikïfer, die eine mit erhaltenem Pigment. ،lie beiden andem nach Zerstïmug desselben dargestellt; ron diesen letzteren zeigt die nittlere den Krystallkegel in optischen Längschnitt, die rechts gelegene die einfache Ansicht desselben.

Die Cornea ist mach anssen nur schr wenig. nach imnen aber dafür um so mehr. und anscheinend parabolisch gewölbt. Dieser Wöllang schliessen sich die Krystalliegel ganz dicht, beinalıe bis zur Berïhrung an. und zwar mit ilnen entsprechend concas ansgehöhlten vordern Flächen. Wir haben ilemnach eines des bekanntlich nicht allzu zahlleich vertretenen Beispiele vor 1 ms, wo die sonst meist gewölbte Basalflüche des Krystallkegels rertieft erscheint. - Die Semper'schen Kerne (vgl. die mittlere Facette) liegen seitlich neben den papillenartig vortretenden immern Facettenwölbmgen. - Die Scheide der Krystallkegel inserirt sich rom am basalen Unfang dieser Wölbungen und setzt sich hinter dem lirystallkegel. deswen Tmrisen sie sonst genau sich anschliesst, noch in eme langauslaufende Spitze fort, die mit dem Vorderende der Retinula ( $\mathrm{T}^{I}$.) zusammentrifft. Die Abbildung erspart nir wohl eine näluere Bechreibung des Krystallkegels; ich will blos anführen, dass er sehr resistent mo stark lichtbrechend ist. - 
Die Zwischenü̈mme zwischen den Kegeh werden durch massenhafte fadenförnnige, nur in ilurer vordern Hiilfte pignentirte Pignentzellen 2. Orinung ansgefüllt, deren Verlüngerungen sich bis zur hintern Anschwellumg der Retinula erstrecken, und deren Kerne sehr deutlich sind $\left(P y^{I I}\right.$.). Die Hauntuigmentzellen ( $I^{\prime} y^{I}$.) umfax-en die hintere Spitze der Kórystallkegelliüle.

Ton den drei Abschnitten der Retinula ist der mittlere, fadenartige, der längste, das kolbige Torderende $\left(\boldsymbol{I}^{I}\right.$.) der kürzeste. Das letztere geht in den Mitteltheil ganz allmälig über, mol ebenso dieser in den hinteren Hanptabshnitt. Nur dieser träigt an semem innersten Ende rine dichte Anhäufung ron Pigment, sonst ist die ganze Retinula frei davon, und genügend dureh die rorgelagerten Pigmentmassen vor tlem Eintritt seitlichen Lichtes geschützt. Die bei Längsansichten erkembaren Structureigenthümlichkeiten der Retinula sind auf den vordern mo hintern Abrhnitt beschränkt; der mittlere Faden ist anschemend homogen. Der vordere Abschnitt zeigt deutlich Längsfurchen und eingelagerte Zellkerne: der hintere erscheint durch stärker lichtbrechende homogene glänzende Kanten, die am vordern und hintern Ende desselben leicht conrergirend sich verheren. besonders ausgezeichnet. Bei tieferer Einstellung treten sie in die Tiefe zurück und nähern sich gleichzeitig einander' bei sehr starken Vergrösserungen erkennt man an ihnen zwischen den Haupteontouren noch eine feine und zarte Mittellinic, was anf eine Zusammensetzung derselben linweist.

Querschitte durch diesen Theil dex Retinula (Fig. 82 Taf. VIIl) remögen allein, den Ban der-

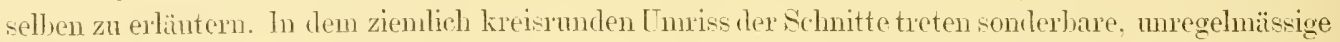
Strahlenfiguren hervor, bei denen allen die Zahl der Radien die gleiche, nänlich sieben, ist. Die stark lichtbrechenden Strahlen heben sich durch ilue Duchsichtigkeit sehr deutlich von dem trïb granulirten Grunde der Hauptmasse der Retinula ab; jerler derselben erreicht die Peripherie, wohneh er in der Längsansicht als Kante oder Rippe erscheint. Ferner int jeder durch eine zarte Linie halbirt, die sich continuirlich, an innern Ende des Strahles sich theilend, auf die beiden nïchst henachbarten fortsetzt. Kurz, wir haben ws hier wieder nit den schon zur Genüge bekannten Cuticularsämmen. als welche wir die Stäbchenbihlungen anffassen müssen, zu thm, die uns freilich hier in einer sehr cigenthümlichen Gestalt und Anordnung entgegentreten — sie übcrziehen nämlich die innern Flächen der meist dreikantig prismatischen Retinulazellen rollstiindig. nnd die einander zugewandten Lanellen treten in innigen Contact. nm ein Rhabdom zu bilden, das main, nach Analogie der Stengelbildnng bei vielen Pflanzen, als ein geflügeltes bezeichuen könnte. mul das in jen'n Stemfiguren seinen Anslınck findet.

Meist zeigt eine der Retinulazellen insofem eine von der der iibrigen sich mnterscheidende, melur centrale Lagerung, als diese betreffende mit allen andern sechs in Berühumg steht, während gewöhnlich jede dirser letzteren nn von den beilen seitlichen unnittelbaren Nachbarn und von jener mehr centralen begrenzt wird. In der (nit Hülfe der Camera lacidia entworfenen) Fig. 82 ist dies Verhalten in fünf der sieben dargestellten Qnerschnitte der Fall, die beiden andern bemeisen, dass jene Anordnung höchstens Pegel. aber nicht Gesetz ist. Es erimnert dies an das hall) central gelegene Stäbchen bei Tabanus (vgl. ob.). - Gegen das Vorderende der Retinulaanschwellung him nimnt die Lichtbrechung des Rhabdoms so berleutend ab, dass man es nicht leicht rerfolgen kimm. und in der fadendümen Fortsetzung nach rom lïsst sich ebensowenig mehr etwas davon benerken, als in der vordern Anschwellung. Kerne finden sich in keinem andern Theil der Retinnla, als in dieser vorlern Anschwellung, und sie sind demnach mit Sicherheit als die zn den sielsen Retinulazellen gelø̈rigen anzuswechen.

Aelmlich wie bei Melolontha sind die Retinulae ron Cetonia und Geotrupes gebant, so weit ich ohne eingehentere Lntersuchungen ein Urtheil abgeben kann. Doch habe ich bei 
letzterer Gattung Gelegenleeit gehabt, mich ron der Uebereinstimmung der Zahlenverhältnisse nit denen, die rom Naikïfer beschrieben wurden, zu überzeugen. - Bei Geotrupes hat Schultze (1. c. pag. 20) im Innern der kolbenförnigen vordern Anschwelhung noch angeblich vier stark lichthechende und quergestreifte (also ans Stibchensubstanz bestehende) und anscheinend in zarte Fibrillen gegen den Krystallkegel auslaufende Gebilde beschrieben.

7. Auge von Dytiscus (Cybister). - Das Auge von Dytiscus (Tntergattung Cybister) demselben Typus an, zeigt aber nicht mbeträchtliche Modificationen hinsichtlich der numerischen gelïrt Terhältnisse (rgl. Figg. 8:3, 84, 85 Taf. V11I).

Die Retinula (in Fig. 83 olme Cornea und lírstallkegel dargestellt) unterscheidet sich lauptsächlich in folgenden Punkten von der des Maikïfers. Zucrst tritt uns entgegen, dass das Rhablon nicht auf die hintere Anschwellung allein beschränkt ist, sondern sich erkennbar duch den fadenartigen Terbindungsstrang nach rorn zur vordern Anschwellung fortsetzt, und dort eine ziemlich ansehnliche kolbenförmige Masse ( $R m^{I}$.) bildet (rgl. auch die dbbildmgen bei M. Schultze, 1. c. Taf. II Figg. 1-4; anch (laparède hat 1. c. Taf. Xll Figg. 2 u. 3 gnte Bilder gegeben). Dann aber zeigt uns der hintere Abschnitt, dass das in ihm enthaltene Rhabdom ein riel conpacteres und ander's beschaffenes sein müsse, als das bei Melolontha.

In Fig. $8 t$ labe ich durch diese Region gesclmittene Retinulae abgebildet, die, neben Fig. 8: gelıalten. den zwischen beiden Fornen obwaltenden Tnterschied klar genug hervortreten lassen. Die Retinulat sind hier rierkantige Prismen ron rechteckigem Querselnitt; die Kanten sind abgerundet, die Flächen melr orler weniger rimenartig ausgehöhlt. Auch hier treten uns deutliche Abgrenzungshinien entgegen. welche zu den ansstrahlenden Radien des Rhabdoms in engster Deziehung stehen; aber es sind deren nur rier vorhanden, statt sieben, wie dort. Jede Seite des Vierecks gehört zu einer Zelle; die Querschnitte der zu den breiteren Seiten gehörigen Zellen treffen in der Nitte in einer gerarlen Linie aufeinander; die: zu den kurzen Seiten gehörigen Zellen kommen nicht mit cinander in Contact. Da anch hier wicker die nach innen gerichteten Flächen der Zellen mit der ausgeschiedenen Stäbchenmasse ïberzogen sind. so entstehen die merkwürdigen Figmen, welche die Abljildung wiedergiebt. Es ist so ziemlich ein Ding der Unmöglichkeit, (wie aus der Art mu Teise des mikroskopischen Sehens wohl erklärlich ist), aus den Längsansichten allein sich eine zutreffende Vorstellung von der wirklichen Anordnung des Rhabdoms inı Innern der Fetinula zu bilden.

Ganz anders rerhält sich das Phabdom in der rordern Anceluwellung, von der ich in Fig. 85 eine Abbildung des Querschnittes gebe. Tn C'entrum befindet rich das schon erwähnte. conisch nach linten sich verjüngende, mit der limtern Anschwellung in Verbindung stehende axiale Gebilke $\left(R m^{2}\right.$ ) , an dem ich eine Theilumg nicht zu erkemen rermochte. Tm dasselbe hermu grungiren sich wie die Blätter einer Rosette die Querschnitte ron Zellen, und wenn ich nicht selur irre, sind es deren sechs, von deren Kernen nur einzelne in die Schmittebene fielen. Jedenfalls aber sind es lier mehr, als hinten zur Beolsachtung komnen. wo die Zülılung eine ungleich leichtere, weniger dem lrutlum preisgegebene ist.

Telche Erklärung soll man num für ein solches Terhalten geben? Ich glaube, dass hier ron den als Tom anzusehenden sieben Zellen der Retinula nur vier vollständig entwickelt sind. und Stäbchensïume tragen, die drei anderu aber unvollständig zurückgebildet erscheinen. Vielleicht tragen diese - oder doch wenigstens zwei daron - anch zum Aufbau des in der vordern Anschwellung gelegenen Rhabdomabschnittes bei: - ich sage zwei daron, denn, wemn meine oben gegebene Darstellung richtig ist, so luätten wir immer noch die siebente Zelle erst zu suchen. 
biese aber kömnte recht gnt rertreten, resp. angerlentet sein durch einen Zellkern, welcher hinter den llinterende des Haupttheiles des Plıabdons in der grossen Anschwellnng (hei $n$, Fig. 83) gelegen ist. Man mag diese Erklürung vielleicht für etwas zu sehr gekünstelt halten. Indessen werden spaiter noch mitzntheilende Beobachtungen, die ich bei Crustaceen (Decapoden) machte, mol die ganz analoge partielle Rednctionen meines Dafürhaltens als einziges Erklärmgsmittel anzmmelmon nüthigen. der hier angegebenen Erklärmng als eine niclit zn rerachtende Stütze dienen kömen. Da ausirdem sich immer nehr die Siebenzahl der Retinulaelemente als Regel herausstelit, so ist meiner Ansicht nach die Frage an sich gar nicht unherechtigt, was in den Fällen, wo nur vier derselben nachzureisen sind, ans dem Rest geworden ist, mul elsensowenig a priori die Vermuthung, dass in einzelnen Fällen die abortiven Zellen sich, wem anch nur in mutergeordneter Weise, noch erhalten und an dem Antban der Retinula betheiligen kïmnen.

Anhangsweise füge ich hier noch einige wenige Bemerkmngen ïber die Retinnla von Carabus anratus hinzu, muter Terweismng auf Fig. 86, welche einige Querselnitte durch diese in verschiedenem Nivean zeigt. Die Terwandtschaft der Lanfkäfer mit den Schwimmkäfern findet anch in Auge ihren Ausdruck, obschon hier eine Längsdifferenzirung ${ }^{1}$ ) nicht iiberall. md namentlich nicht in der ansgeprägten Form wie bei jenen rorzukommen scheint. Häufig beschränkt sie sich anf das Rhabdom allein, das in scinem hintern Theil eine mehr oder weniger narkirte spindelfümige Anschwellung anfweist. Dass daselbe ans nur vier Stäbchensïmnen herrorgeht, dürfte durch die Fignr 86 genïgend erwiesen sein, welche mo allerdings ïber die Zahl der Retinulazollen keinen Aufschluss gewährt.

8. Auge ron Phryganea. - Ton Phryganea grandis, deren Stemma schom früher beschrieben wurde, habe ich anch das Facettenauge untersucht, und die Figg. 87, 88 und 89 Taf. IX geben die Resnltate der Hauptsache nach wieder.

Die sehr langen mol schlanken. Haschenfümigen Krystallkegel (Fig. 87, K\%.) sind ziemlich resistent, stark lichtbrechend, linten selur sclanf zugespitzt, und ron ciner ziemlich festen Hülle muschlossen, die sich noch eine ansehnliche Strecke weit unter stcts abmehmenter Dicke nach linten lim fortsetzt. Die llanptpigmentzellen sind mir entgangen, fellen aber wohl kaum; die Pignentzellen zweiter Ordnung ( $P g^{I 1}$.) sind lang fadenfümig mol maswenlaft angehänft.

Die Fetinula (Rt.) ist in Ganzen wenig pigmentirt; nu die rordere Hälte zeigt wenig gehüuftes, das Hinterende aber rine kurze Strecke massig angesammeltes Pigment. Ton den drei Facetten. welche in Figur 87 dargestellt sind, zeigt eine das Bild. wie es sich olme Pigmentzerstörung darbietet, die beiden andern nach Anwendung ron Salpetersänre. - Wie die Fign zeigt, betrifft die Differenzirung der Länge nach nur das Rhablon ( $\mathrm{km}$.); die Retinula selbst in Ganzen ist rom. in der litte nul hinten zienlich gleichlick. Ersteres aber bildet in der hinteren Hälfte einen starken, rundlich prismatischen Stab, mit sehr schwach angedenteter Znsammensetzung ans Segmenten; derselbe rerjüngt sich vorn ziemlich plötzlich in einen dümen Farlen, der sich der Endigung der Krystallkecolhülle nähert, und dahei von linten nach vorn stetig an Lichtbrechung abnimnt. Nach hinten hin ist das Rhabdom deutlich und scharf abgerundet.

Ton den heiden Figg. 88 und 89 zeigt die arstere die Beschaffenheit der Retinula in der Region der hintern Anschrellung as Phabdons, die letztere aber in der vorderen Hiilfte ilurer Erstreckung. - Das Rhabrlon füllt in sciner V'erdickung den ganzen Unfang der Rectinula fast vïllig ans: von den Zellen, welche letztere zusammensetzen, ist lier wenig oder nichts mehr zu

1) Nach Leyalg und M. Schultze besonders dentlich bei Procrustes ansgebildet. 
erkemen, mol mu die scharfen Aussencontomen heben sich sehr deutlich ab. Das Rhabdom selhst, von sehr nnregehüissigem Querschnitt, lïsst dagegen, wenn auch nu mit Mühe, gewahren, dass in seine Bildung wierler die gewöhnliche Zahl von Segmenten dingehen; es sind aber weniger scharfe und gut begrenzte Tremungslinien, durch welche die Abgrenzung erfolgt, als richmehr radiine Streifen ron anderer, geringerer Lichtbrechmg, die in den als seichte Rillen anf der Oberfläche erscheinenden Tertiefungen endigen. In der vordern Hälfte ist lie Retimula mit mregehmïssigen, scharf vorspringenden Kanten versehen. so dass der Querschitt ein sehr unregelmïssiges. oft fast zerissen ansehendes Polygon darstellt (vgl. Fig. 89). Ton dem hellen Centrum eines jerlen solchen Querschnittes gehen aber dentlich sieben Radien ans, welche denselben in ebensoriele Dreicke theilen; lie in diesen enthaltenen Kerne, welche anch auf Längsansichten leicht anfzufinden sind, lassen über die Dentung des Pildes im bisherigen Sinne keinen Zweifel zu. Hervorzuheben ist noch, dass nicht alle Zellen der Retinula gleichmässig pigmentirt sind, sondern die Ablagerung desselhen sich auf einzehe beschrïnkt; ferner, dass auch hier, wie bei Dytiscus, linter dem Rhabdom sich noch ein einzehner Zellenkern (bei $n^{I}$ Fig. 87) findet, der möglicher-, ja wahrscheinlicherweise, trotz seiner so ganz amlerm Lage verglichen mit der der andern Kerne, einer der Zellen der Retinula angehört.

9. Ange ron Liparis salicis mol anderer Nacht- und Diimmerungsalter. Die Angen dex genannten Art. die diese lierorzngung nur dem zufilligen [rmstande rerdankt, dass sie nir eine Zeit lang in sehr reichlicher Weise zur Verfügmg stand, mögen Morlell stehen für die Angen rler Dämmerungs- unı Nachitfalter überhaupt. Neine Torgänger anf diesem Gebiete sowohl wie ich solbst haben eine ganze Reihe ron Reprïsentunten der verschedenen grössern und kleinern Familien, die in die genannten Énterabtheilngen der Ordnung der Lepidoptera gehören. untersncht, mo nach allem, was ich über diese Angen weiss. schemen sie simmolich nach ein und demselben schema gebaut zu sein, was ja natiurlich nntergeordnete Modificationen in keiner Weise ansschliesst.

Ich selbst habe mich seln abgemüht, die Nethode der Querschnitte durch die Retimula, resp. durch die Rhabdone, anch für diese Thiere so fruchthingend zu machen. wie es mir für andere meist gehmgen ist, aber leider mit wenig Glïck. So wenig Schwierigkeiten der Anfertigung tadelloser Schnitte als solcher in Wege stehen. so vele ergeben sich für die Erhärtung besonders der Rhabdone, deren Zusammensetzung zu studiren jene gemacht werden, und is ist, nach neinen so vielfach variirten Erfalıungen zu urtheilen, ein seltenes (riück, wem man auf solchen Schnitten einmal meln als blusse schattenhafte, eine bestimnte mol sichere Zühlnng nielit gestattende Andentungen der Rhabdomsegmente erkemen kam. Es ist in Gegensatz zu dieser wirklich nicht gering anzuschlagenden Schwierigkeit als ein ganz besonder's günstiger [Tnstand zu betrachten, dass bei sehr zahlreichen hierhergehörenrlen schmetterlingen wenigstens durelr die Lage der Zellenkeme der Retimula, die das Zühlen derselben erleichtert, ein gewisser Ersatz geboten und dadurch wenigstens die Zahl der Elenente festzustellen ermöglicht wird. Nach unsem frühem Erfalıngen (bei Dytiscus) sowohl. als nach noch spïter, bei den Crustaceen mitzutheilenden, liegt darin allerdings noch keine absolute Garantie, dass anch die Zahl der Elemente, in welche das Rhabrlom zerfïllt. damit übereinstimmt; aber ich hoffe, dorch die anznfülırenden Beispiele wenigstens die Wahrschemlichkeit dieser Tebereinstimmmg begründen zu kömen, auf die Gefahr hin, zukünftig bei beseren Nethoden munerische Correctionen mir gefallen lassen zu müssen.

Ich kamn mich bei Besprechung dieser Augenform un so eher auf eine geringe Anzahl von Beispielen beschänken, als dieselbe von jeher zu den berorzugten gehörte, und demmach 
zn den an relativ besten bekannten - bis cben auf das cigentliche Punctum saliens, die Zusammensetzung und Dentmug der Retinula und des Rhabdoms — zählt. Ton neueren Forsehern laben besonders Leydig, noch mehr fast M. Sclnultze, zn ilner liemntniss beigetragen, mnd die von ilnen gelieferten Abbildungen sind als die besten darüber existirenden zn bezeichen ${ }^{1}$ ).

Soweit meine eigenen Erfahrungen reichen, unt ich die der früheren Forscher zu beurtheilen im Stande bin, hahen die Schmetterlinge der genannten Grupren, also das Gros der (rdnung üherhaupt, sowohl nach Consistenz als nach Form fast vïllig überemstimmende Krystalllegel; ferner sine hinten rerdickte Retinnla, die nach rorn in einen Faden anslïnft. der ohne Grenze, aber auch ohne eine vordere Anschwellung zn bildem, mit der ihm entgegen kommenden Hülle des Krystallkegels rerschnilzt. Enflich mag noch erwähnt werden, dass oft die Hanptpigmentzellen eine sehr geringe, die Pigmentzellen 2. Ordnung aber dafür eine sehr ansehnliche Entwickelung zejgen.

In Fig. 90 Taf. IX habe ich eine Retimula nebst zugehörigem Krystallkegel, sowie zwei der Pigmentzellen 2. Ordnung von L. salicis abgel,ildet. Der stark lichtbrechende, ron einer ziemlich dicken Hïlle mschlossene Krystallkegel hat hier, wie überall bei den Terwandten, etwa die Form einer Langgranate der modernen Artillerie, d. h. er ist seiner Hamptmasse nach cylindrisch, an seinem Hinterende alogermulet. (Vgl. anch Fig. 93 Taf. IX ron Triphaena promba.) An Hinterende mnschliesst die Hülle. die bei Liparis da sich etwas rerdickt, die Spitze des Krystallkegels nicht, sondern lässt sozusagen eine Oeffumg, durch welche der Inhalt zwischen ihr und dem Krystallkegel ohne jede walunehmbare Grenze mit der als zarter Faden herantretenden Retinula sich rereinigt. Wenn man die mogefälre Erstreckmg der Hülle nach derjenigen bentheilen darf, welche die Contonrverdickung, die an der Retinula nicht wahrnehmbar ist, eimmumnt. so ist sie bei Tripbaena pronuba (Fig. 93) grösser als bei Liparis und der Mehrzahl der hierher gehörigen Schmetterlinge. Hier nämlich rerengert sie sich hinter dem Krystallkegel, dessen Umriss etwa entsprechend, conisch, un damn abermals sich leicht zu erreitern, und bildet so eine schwach eifömige Anschwellung, die ilrerseits direct in die Retinula übergeht. In dieser Erweitermg erkamte ich noch ein entsprechend geformtes, seitlich und hinten scharf hegrenztes, auch durch eine selı leicht angedentete Längslinie als segmentirt characterisirtes Gebilde, dessen vordere Grenze ganz molentlich mol rerschrommen wrr. An Lichthrechung stand es hinter dem Krystall-

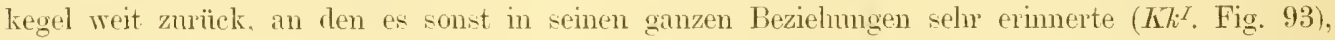
und ich glanhe anch in der That, in imm ein dem Krystallkegel rerwandtes Element zn erkennen.

Was die Retimnla anbetrifft, so variut sie etwas je nach der relativen Länge der Anschwellung zn dem farlenatigen vordern Theil — aber immer nur innerhalb mässiger Grenzen — und ferner je nach der Lage der Kierne. - Bei Liparis liegen diese in der rordern Hälfte (bei $n$ Fig. 90), ebenso bei Euprepia Caja, Zerene grossnlariata. Triphaena pronuba (Fig. 93) mol zahlreichen andern; bald sind sie dicht auf einen Haufen gedrängt, so dass der' Faden an dieser Stelle eine Anftreibung erleidet (wobei in Imern desselben häufig eine axiale Längslinie als Andeutung der Zusammensetzmng desselben erkannt werden kamn); bald aber einzeln hinter einander liegend. Immer aber sind sie leicht und olme Mühe zähllbar, besonders, wemn sie durch Imbilition mit Farbstoffen recht dentlich gemacht worden sind, md immer habe ich deren sieben gefmnden. Bei den Schwärmernn n. a. liegen die Kerne mehr nach hinten, meist da, wo der Retinnlafaden in die Anschwellung äbergeht, und dann bietet die sichere, jeden Zweifel

1) Besonders hervorzulieben sind die hierauf sieh beziehenden Figuren Leydig's in seinen, ,Tafeln zur vergl. Anatomie" ('Tat: X). 
ansschliessende Zählung derselben wegen ilures dichten Aneinanderüickens mehr Schwierigkeit, als in den oligen Fällen. Indessen habe ich doch auch bei sphinx convolvuli mit Sicherheit, weniger klar bei Hacroglosia deren sieben gezälylt. und glanbe deshalb, die Angabe ron II. Schultze, der ihre Zahl zwischen vier und acht schwanken lïsst, auf jenen Numerus berichtigeu zu diüren.

Die Anschwellung der Retinula erimnert mngemein an jene des Iaiküfers, namentlich lassen sich auch hier leicht die durch das Phabdom rerursachten Andentungen änsecrer Kanten walnnehmen (Fig. 90, Rm.). (Ton den büschelförnig dic Retinula-Anschwellung mmkleidenden Tracheen, die sich hier so oft finden, habe ich nu den hinteren Theil [Tr.] angegeben.) Einen Qnersclnitt durch eine Anzahl Retinulae, welche dir Glierlerung des Rhabdoms deutlich zeigen, stellt die Fig. 91 dar. Die Retinula erscheint ilerzufolge cylindrisch, und das im Innern jeder einzelnen als siebenstrahliger. ziemlich regelmäsiger Stern auftretende Rhabdom bedarf wohl keines besonderen Commentares mehr. Ganz in der gleichen Weise, wenn auch nicht völlig so klar, gelang es nir anch. das Rhabdom von Euprepia Caja als aus sieben Theilen znsammengesetzt zu erkemmen, und bei Cossus ligniperda wenigstens zu sehen. dass es bestimnt melur als vier Segmente sind, wem auch eine absolut sichere Zïhlung hier nicht roöglich war.

In etwas anderer Art weist die Fig. 9t Taf. IX. die einer leider nicht nïher bestimmten Noctuide entnommen ist ${ }^{1}$ ), auf die rominirende Siebenzall hin. Die Retinulae, deren Querschnitte dort wiedergegehen sind, sind dentlich siebenkantig. nicht cylindrisch, wie bei Lipari. und ein Schnitt durch dieselhen bietet ein ïnserst zierliches Bild; die einzelnen u. a. ziemlich stark vortretenden Ripren greifen fast nach Art ron Kammräderv in einander ein. Tom Rhabdon selbst war nichts zu erkenneu, aber das Bild beweist doch wohl die Tebereinstimnung auch dieses Falles mit der gefundenen Regel dentlich und klar genug. Hinzugefügt mag übrigens noch werden, dass bei dieser Form die Zählung der Keme das gewöhnliche Resultat ergab.

In Fig. 90 sind die Hauptpigmentzellen, was hier nicht selten passirt, bei der Isolation losgeblättert. Die Pigmentzellen 2. Ordnung $\left(P y^{I I}\right.$.) sind hier besonders stark entwickelt; sie bilden lange. dicht nit Pigment erfüllte, an beiden Enden zugespitzt auslaufende Cylunder, deren Anordnung um den fadenfirmigen Theil dor Retimula Fig. 92 Taf. IX, einem Querschnitte entnommen, klar macht. Man erkennt, dass jede der sechs Zellen. die zu einem Farlen gehören, gleichzeitig zwei Systemen zugetheilt ist, wie wir es ähnlich schon früher (bei Sarcophaga. Fig. (68 Taf. VIII) gefunden baben. wo sich zwölf Zellen analog anordnen.

Tas ich sonst noch über das Terhalten dieser Zellen bei andern hierher gehörigen Schmetterlingen zu sagen weiss, beschränkt sich auf sehr wenig. Nicht ïberall sind sie in ihrer ganzen Länge pigmentirt, es können sowohl die linteren, als auch beide Enden frei davon bleiben; wie überhapt hier wohl. nebst der Lage der Kierne. die hauptwächlichsten; aber an sich völlig mutergeordneten Verschiedenheiten zwischen den einzelnen Augenformen sich finden dürften.

Auf eine specielle Discussion der Abweichungen von den frühern Darstellungen über den Ban dieser Angen, wie sie sich nach meiner Auffassung derselben naturgemïss ergeben, einzugehen. diurte kaum einen Werth hahen und der Nühe lohnen; um so weniger. als wohl eine Reihe ron einzehen Angaben, namentlich ron M. Schultze, eben ausschliesslich nur für das specielle Naterial, an dem sie gewonnen wurden, Geltung haben dürfte. Bekanntlich lat dieser Forscher gerade hier seine relatir reichste Ernte gehalten: abgesehen ron der Plättchen-

1) Die Exemplare kamen ganz abgestaubt in meine Hände. 
structur dos sehstalos", also unseres Rhabdoms, hat ex bei den Dänumerungs- und Nachtfaltern mit besonderer Sorgfalt die mmittelbar an den Krystallkegel anstossende Partie der Retinula untersucht. und bei einer Reihe ron Formen Differenzirungen beschrichen, die er als eigentliche femste Nervenendigungen, wie sie seiner Ansicht nach als plysiologisches Postulat sich ergeben mussten, in Anspruch nahn. Dass ich die ron M. Schultze beschriehenen Structurverhältnisse nicht einfach negire, möchte ich hier bei dieser Gelegenheit ebensowohl hervorheben, wie dass ich sie für durchaus untergeordneter und nebensächlicher Natur ansehe, und nicht in Stande bin, für eine Erklärung im simne jenes Forschers irgendwelche Stïtze zu liefrm. Der Gegensatz zwischen msern beidereitigen Auffassungen ist. wie man sieht. principieller Natur: M. Schultze sieht darin den Schwerpunkt seiner Untersuchungen, dass es ihm bei einer Anzahl ron Formen geglückt ist, die auf den Krystallkegel folgende Partie der Retinula durch künstliche Mittel in feinere Fïden aufzulösen, denen ex dam olme weitere Lmstände die bisher substratlose Perceptionsfähigkeit zuschreilst. Für meinen Standpunkt dagegen ist es wesentlich, dass erstens jene feimere Zertheilung an frischen Präparate nicht wahmehmbar ist, und zweitens, dass die Substanz, der ich die Fülingkeit der Lichtperception zuschreibe. in linteren. dicken Theil der Retinula als Rhabdom angehüuft ist, und wohl kaum sich über diesen hinans erstreckt; höchstens geschieht dies in einer Weise, die das Resultat, wie ich es ans dem ganzen Befunde ziehen werde, nicht 211 alteriren im Stande ist.

Neben dieser Terschiedenheit der Auffassung treten die andern Differenzen sehr zurück. M. Schultze spricht wie Leydig rom rierkantigen oder riertheiligen Nervenstal); bei Sphinx convolvuli will er deren acht gezählt laben (I. c. pag. 18). Wie wenig diese Zülılungen sowohl der einzehen Stïbchen des Rhabdoms, als die schon oben erwälnten der Kerne mich in meinem rorhin ausgesprochenen Urtheil ïber die vorausichtlich auch hier durchgängig zu Grunde liegende Zahl beirren können. Iratzche ich wohl kamm noch auszuführen; elsensowenig. dass dies Misstranen gegen die früheren Zahlenangaben nicht gegen die von N. Schultze allein gerichtet ist, sondern atch gegen alle andern.

\section{B. Zusammengesetzte Augen der Crustaceen.}

\section{a. Typische Crustaceen.}

Wie schon in der Einleitmo $z n$ dem Abschitt ïber das zusammengesetzte Ange im Allgemeinen lremerkt worden ist, haben wir in dem Facettenauge der Crustaceen ein Organ ron (im Princip) identischen Bat mit den desselben Organs bei den Insecten zu erkennen. Dieser Satz gilt jecloch nicht für alle Thiere mit Facettenaugen, die wir gewöhnlich in zoologischen Hand- mo Lehrbüchern der Classe der Crustaceen einverleibt finden; wir sind genöthigt, die bekanntlich auch in andem anatonischen Beziehmgen sich ganz eigenartig verhaltende Cruppe der Poecilopoda oder Xiphosma. mit der Gattung Limulus. daron anszuschliessen. Das zusammengesetzte Auge dieser Thiere ist völlig alweichend ron dem Schema gelont. mit dessen Wandelungen in die rerschierlenen Gestalten wir uns bisher beschüftigt haben, und es noch ferner zu thun haben werden; ich scheide deshalb jene Angenform rorlänfig noch aus, um sie an geeigneter Stelle für sich allein zu behandeh.

Unterabtheilungen, denen enteprechend, welche ich bei den Insectenaugen in Anwendung brachte, un die Lebersicht über die Einzelformen zu erleichtem, sind hier, wie auch schon frïher bemerkt, nicht anf der gleichen Grmalage dmehzuführen, da acone und psendocone 
Argen mir bei den ächten Crustaceen nicht bekannt geworden sind. Ich werde demnach die Gruppirung in Allgemeinen mehr nach systematischen Verwandtschaftsterhültnissen folgen lassen, ohne mich aber streng an die hergebrachte Reihenfolge zu binden.

1. Ange von Porcellio scaber. - Das Auge ron Poreellio scaber, dem die Figg. 95-98 Taf. IX gewidmet sind, mag als Nodell für das Sehorgan der Isopoden dienen. In der Art und Weise der Aushildung. welche das Auge bei der genannten Gattung zeigt, ist dasselbe als eine sehr extreme Form aufzutassen; das andere Extrem fundet sich, wie wir sehen werden, bei Angehörigen derselben Ordnung der Arthrostraca. nämlich bei den Hyperiden.

Das Auge der Kellerasseln unter die zusammengesetzten zu zählen, und nicht nuter die in etwas grös-erer Anzahl ausgebildeten einfachen, wie es fü̈her meist geschah, bedarf einer gewissen Rechtfertigung. welche ich den nachstehenden Thatsachen zu führen überlasse. Bei der lietrachtung solcher Augen von anssen. oder bei nicht völlig genügender anatomischer Untersuchung machen sie allerdings, wie ich gerne zugeben will, weit mehr den Eindruck von gehäuften einfachen Angen; aber das Gegentheil ergielst sich bald ron sellst.

Es sind bei der zn Crmole gelegten Art ea. 20 Facetten rorhanden, oder einige darüber. Dieselben stehen in solcher Entfernung von emander, dass sie völlig kreisförnnig sich entwickeln kömnen. und wich nicht zu Vicr-oder Sechsecken. wie sonst meistens, gegenseitig abplatten. Dass die Linsen der Facetten biconvex sind. ergiebt eimmal die optische Prüfung derselben in der Flächenansicht bein Zurückschrauben des Tubus, wobei das Bild des Fensterkrouzes oder derartiges anftritt; noch besser aber der Querschnitt an entkalkten Köpfen. Die innere Conrexitüt der Linsen, die in den ron mir gegebenen Zeichnungen keine Berücksichtigung fanden, passt in die rordere Concavitit der Ireichtheile des Auges, wie ich sie auf Fig. 96 gegeben habe, genan hinein.

Diese Weichtheile sind. ron iler Seite gesehen, dargestellt in Fig. 95 und 96 ; erstere zeigt ein Einzelauge ohne roransgegangene Zerstörung des Pigmentes. wälrend letzterer ein entfïrhtes Präparat zn Crmnde gelegt ist. Bei keiner von beiden haben aber lie massenhaft zwischen den einzelnen Facetten anf der Immenflïche angeordneten Pigmentzellen - relatir kleine. unregelmïsig rerthilte. pigmentirte Hypodermiszellen - Berücksichtigung gefunden; diese sind dagegen in der Fig. 97 (Facetten son imen) dargestellt. - Die imnern Weichtheile bilden zusammen ein etwa mnenförniges Ganzes, das sich den Rändem der Linse mit seiner vordern Begrenzung anlegt, und ausserdem dieselbe an ihrer immern Fläche überzieht. Nit Leichtigkeit erkennt man (in darin liegendes kngeliges Gebilde ron starker Lichtbrechnng, wïhrend das Pignent das Iebrige völlig einlüllt mid rerdeckt.

Beginnen wir mit den dicht an die Linse sich anschliessenden Theilen, so ist zuerst tler ITeberzug derselhen zu besprechen. Derselbe besteht aus zwei flïchenhaft ausgebreiteten, je hall.kreisförmig gestalteten pigmentirten Zellen ron mäisiger Dicke (Fig. 96, 97, Z.), deren Kerne nach der Entfiurbung sehr deutlich sind (Fig. 96 und $97 n^{I}$.). Nur die Nitte ist pigmentfrei, und hier sind diese Zellen in näherer Terbindung mit den an sie stossenden kugeligen.

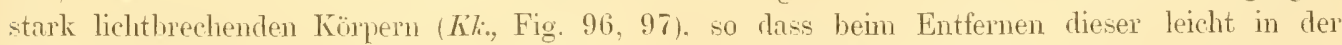
Nitte ein Loch in dem Leberzug entsteht. Dies ist wiedergegeben in einer der drei Facetten der Fig. 97, in welcher das Centrum der beiden andern Facetten noch durch die anhaftenden Körper verleckt wird.

Der lichtbrechende Körper ist ein abnorm gestalteter Krystallkegel. Er ist hier kngelfürmig, von vorn nach hinten etwas abgeplattet. und besteht aus zwei dentlich zu erkennenden Halbkugehn, deren Berïlırungsfläche senkrecht auf der Ebene der Comeafacette steht; auch fällt 
die Trennumgsinie dex beilen hinter der Facette gelegenen Zellen (Z.) in clie gleiche Ebene (Fig. 97). Der Kíystallkegel, wie wir ilm nm richtig bezeichnen wollen (so wenig er anch kegelfömuig gestaltet, uncl so mpassend demnach der Austruck für iln anch ist), ist in frischem Zustande, wie anch nach Erhärtung in Alcohol, völlig durchsichtig und klar, ron starkem Lichtbrechungsvermögen; die Undurchsichtigkeit dessellsen in Fig. 96 rührt von der Erhärtung des Auges, dem clie Figur entnommen wurde, in Chromsiume her, durch welche er trüje und granulirt wird. - Er ist ron einer ebenfalls leicht nachzuweisenden, ans zwei Zellen bestehenden Hülle umgeben, die sich semer Oberflïche in einem geringen Abstande anpasst; die Tremmngsflïche der beiden Zellen (der Nutterzellen der Segmente) stimnt ïberein mit der der Krystallkegellälften. Zwei in ihmen, rom gegen ،lie Comea zu gelegene Semper'sche Kerne (Fig. 96, $n^{I I}$.) sind ebenfalls nicht schwer nachumeisen. Die urnenfümige pigmentirte Masse ist die Retinula, die hier insofern abweichend gestaltet ist, als sie nach rorn, durch dn-einanderweichen ihrer Elemente, einen Hohlramn zur Anfnalme des Krystallkegels bildet; hinter dem letzteren ist sie compact, und enthält das kurze, dicke Rhabdom. Ton diesem ist olme rorherige Entfärbung nichts zu erkennen, weshalb es anch allen früherm Antoren entgangen ist; an entfürbten Angen erkennt man dasselbe als eine stark lichtbrechende. mit breiter Ansatzstelle an der Hinterseite des Krystallkegels sich anlegenile, ans mehreren longitudinalen Stücken bestehende Masse, die hinten scharf abgeschnitten und ziemlich gerade endigt (vgl. Fig. 96, Rm.) Teber die Zahıl der Retimnlazellen und der Theilstäbchen des Phabdoms geben an besten Ansichten des Auges ron hinten, wie Fig. 98 eine solche darstellt. Aufschluss; hier ist der Focus tief eingestellt. 1 m die optischen Querschnitte der Stïbchenantheile des Fhabdoms zu zeigen. - Die ïnssere Rosette (Fl.) entsuricht den Retinulazellen, deren Zahl sich mit Sicherheit als sieben bestimmen lïsst; im lmern derselben leuchtet ein ebenfalls siebenstrahliger Stern herror, dessen einzelne, im Umiss etwa lanzettliche Strahlen wieder durch eine feine Linie halbint werden. Das Zusammenstossen der Radien des Rhabdoms im Centrum ist mir immer etwas unklar geblieben, da dort lie Lichtbrechung geringer ist, als in den änssern Theilen; aber hervorheben möchte ich wenigstens, dass die Hallumungslinie der Pilabdomstrahlen nicht zusammenfïlt mit der Tremungslinie zwischen je zwei Retimulazellen, wie man wohl, nach Analogie mit den ron mir oben beschriebenen Retinulae von Melolontha, Dytiscus, Lipraris ete. rermuthen kümnte. Jedes Einzelstäbchen ist in len keilfürmig zugeschärften axialen Rand der zugehörigen Retimulazelle eingesenkt, und besteht ans zwei aneinanderliegenden Elïttern, wofür wir beim znsammengesetzten Ange kem Beispiel weiter anfznweisen haben; die einzige Analogie dafür dürfte wohl beim Spimnenange zu snchen sein. Die Keme der Retinnlazellen ( $n$. Figg. 96. 98) sind selu gross, oval, mul nicht leicht zu übersehen. Nach hinten rerschmälem sich die Zellen in Nervenfasern (N. Fig. 96), auf welche sich (Fig. 95) das Pigment noch eine kurze Strecke weit fortsetzt.

Soviel über den Ban dieses Organs, das in sehr vielen Beziehmnen ganz eigenartig sich zu den andern Formen des zusanmengesetzten Anges rerhält, und es sellst nach näherer Einsicht in den Ban desselben nicht leicht macht, dasselbe nit Sicherheit hier einzmeihen. Neiner Ansicht nach kann aber doch die Anwesenheit eines zweitheiligen Krystallkegels, sowie einer siebentheiligen, ein ans ebensoviel Segmenten bestehendes Rhabdom bildenden Retinula nur zu Gumsten der Stellnug bei den znsammengesetzten Angen in's Gewicht fallen.

Was nun die Angen der Isopoden in historischer Beziehme betrifft, so können wir für unsern Zweck von den älteren Beobachtungen absehen. - Bei (ymothoa hat Nlüller ${ }^{1}$ ) die innere

1) 1. s. c. in : Meckel's Arch. ete. 1829, pag. 42. 
Convexität ‘ler Cornealinse irrigerweise fïr eine sellständige Bildung angesehen; die Krystallkegel, deren Bedentung ihm freilich nicht klar wurde, hat er richtig beobachtet. Gleich allen andem Beobachtern betonte er mehr die Beziehungen dieser Augenform zu dem Stemna, als zum Facettenange.

Anch aus der viel neneren Arbeit rou Lereboullet') über die Landisseln (Cloportides) ist nicht viel Anfschluss über den Ban des Anges zu holen. Er giebt (1. c. Taf. X. Figg. 181, 182) ein par hübsche Zeichnugen einzeher Augen, beschreibt den Krystallkegel als "petit cristallin" linter der Comealinse; ror dem Krystallkegel erwähnt er anch die Pignentlage, die nur eine kleine pupillenartige Oeffnnng frei lïsst etc. etc.

Leydig ${ }^{2}$ ) hat sich mit dem Ange der Assehn eingehencler beschäftigt, ohne aher wesentlichen Aufschlnss erhalten zu haben. Nach semer Ansicht ist rlie Cornealinse imnen concav, was sicher unrichtig ist; auch die Darstellıng des Banes des Krystallkegels (seines ,zweitheiligen lichtbrechencen Körpers") leirlet an einigen Mängeln. Er soll nämlich ans zwei in der Quere liegenten Kngehn bestehen, und ansserdem kalkhaltig sein, welch letzteres er aber blos ans seinem starken Lichthrechnugsvermögen, sowie seinen Verhalten beim Zerdruicken erschliesst. Was das erstere anbelangt, so verweise ich auf meine Darstellung, die sich leicht controlliren lïsst; hinsichtlich des Kalkgehaltes habe ich vergebens rersucht. Anhaltspmkte für jene Behauptung durch Zusatz von Säuren zu den isolirten Krystallkegehn wälnend der Beobachtung unter dem Mikroskop zu gewinnen, und muss sie für nicht zutreffend erklären. Anch die Darstellung der Nervenendigung, - "Stäbchen, die in ilner Form an die Nervenstifte des "Ohres" der Insecten gemahnen" wie er sie 1. c. Fig. 8 (an den linken der drei gezeichneten Angen) wiedergiebt, beweist, dass er etwas ganz Anderes für die wirklichen Stäbehen gehalten hat; mir scheint es, nach eigenen Präparaten zu urtheilen, als wenn ron der Cuticula losgelöste Pigmentzellen, deren Kerne oft stark hervortreten, lier eine Rolle gespielt hiiiten.

Ton sonstigen neueren Beobachtungen ïber die Angen verwandter Thiere sind nir nur noch die von G. O. Sars33) an Asellus aquaticus bekannt geworden. Der Verfasser lat leider nur mit seln schwachen Vergrösserungen untersucht, und manche Einzelheit ist ihm deswegen entgangen. Ich hebe nur lıervor, dass ron den vier Augen, auf welche diese Thiere reducirt sind, drei emen zweitheiligen, eins aber einen dreitheiligen Krystallkegel — wie der Verfasser in Uebereinstimmung mit der hier gegebenen Darstellung die betr. Kugehn nennt - luben sollen.

2. Augen ron Gamuarus locusta und Talitrus saltator. - Ton Amphipoden ans der Crupe der Crevettina (Familien der Gammaridae und der Orchestidae) habe ich die obigen Arten anf den Ban ihrer Angen mutersncht; leider aber ist es mir nicht geglïckt, entscheidende Qnersehnitte duch die Retinula zn machen, und ich muss deshalb meme Mittheilungen dariber als noch der Ergünzmng bedürftige, keineswegs erschöpfende bezeichnen.

Bei den Augen dieser Thriere ist man bekanntlich nicht im Stande, für sie den Ansdruck "facetturte" in dem allgemein ïblichen Sinne anfrecht zu erhalten. Wie Fig. 99 Taf. IX ron Gammarns locusta zeigt, zieht die Cornea ganz gleichmïssig über die inneren Augentheile hinweg, ohne Facetten, resp. Jesondere Linsen zu bilden.

1) Lereboullet, Múmoire sur les Crustacés de la famille des Cloporticles etc. (Mem. Soc. Hist. nat. de Strassbourg) 1853. pag. 113 (des Separatabdrucks).

$\left.{ }^{2}\right)$ Ange der Gliederthiere. pag. 40 u. ff.; 'Taf. zur vergl. Auat. Taf. VI. Fig. 8.

$\left.{ }^{3}\right)$ G. O. Sars, Histoire naturelle des Crustacés d'eau douce de Norrège. 1re Lirraison. Cluristiania 1867. - pag. 110-112. Taf. VIII, Figg. $11-14$. 
Diese imeren Argentheile stelien, was die Zusammensetzung des Krystallkegels anhelangt, im engsten Zusammenhang mit den Augen der Isopoden; sie entfernen wich aber, soviel ich wenigsteus aus meinen (ungenügenden) Beobachtungen schliessen darf, ron ihnen durch den Ban ihres Rhabdoms und ihrer Retinula.

In den Figg. 99, 100 and 101 Taf. IX habe ich meine Beolyachtungen ïber das Auge ron G. locusta, in Figg. 102 und 103 rerselben Taf. die äber das Auge ron Talitrus im Pilde zusammengefasst.

Die Krystallkegel von G. locusta sind gestreekt eifümig, vom abgermdet, linten etwas ahgestntyt, aber meist nicht mit gerader Flïche. Die Grösse und Gestalt derselben ist in rin und demselben Ange, je nach ihrer Lage, mancherlei Schwankumgen mterworfen; am regelmässigsten und typischsten finde ich immer die in der Nitte des Auges gelegenen anisgebildet. wïlurend die randständigen nicht blos kleiner, sondern auch mregehnässiger in ihren Formen werden. hïnfig sogar geradezu den Eundruck ron verkrüppelten machen. Dass die Kegel ans nur zwei Segmenten zusammengesetzt sind, ist sehr leicht zu constatien; ebensowenig Schwierigkeit bietet es, sich zu überzengen, dass sic, wie bei Porcellio. von den Resten der zwei Mntterzellen muschlossen werden, in denen sich noch rom die Kerne (Fig. 100, n.) erhalten. Thr hinteres Drittel etwa ist von dichtem. nach rom allmïlig sich lichtendem Pigmente unhüllt, das anch hier zn den, den Kegel eine Strecke weit becherförmig umschliessenden Zellen der Retimula gehört.

Etwas anders sind die Kegel bei Talitrus geformt. wie die Figg. 102 A, B and 103 beweisen mögen. Diese nähern sich schon mehr den bei den Iyperiden rorkomuenten Kégelformen, zu denen sie gerrissermassen len Tebergang verunitteln. Sie sind bei unserer Art gestreckt conisch und rom mit ebener Eniläiche abgeschnitten. Bei den mehr central gelegenen, die kürzer sind, strht diese Endflïche annähernd senkrecht zm Lüngsaxe des líegels; bei den lïnger werdenden randstïndigen entsprechend schief. Um den linteren Theil des Kegels bildet das Retinulapigment eine etwas angeschwollene Anhäufung, die nach rom plützlich viel lichter wird. - Die Hüllen der Kegel bleiben bei der Isolation meist an der Comea haften, so dass man sie. wie die dargestellten. fast immer olme sie zu sehen bekoumt.

Die Zalıl der Zcllen, aus denen die Retinula sich zusammensetzt, ist mir mit Sicherheit zu bestimmen nicht gelungen, wie schon bemerkt. Es ist zwar sehr leicht, Bilder zu erhalten, wie Fig. 100 eines zeigt, wo die Zahl der pigmentirten Auslänfer der Petimula nach imnen lin mindestens als auf melır als vier sich belaufend erkannt werden kann; aber die allein beweisenden und jeden Zweifel röllig ausschliessenden guten Qucrschnitte sind mir nicht geglückt. - Bei Talitrus (Fig. 102 A, li) seheint liese Zahl geringer zu sein, als bei Gammarus.

Ich habe hinsichtlich rer Wiedergalue entfïrbter Präparate mich auf eine Retinula von Talitrus (Fig. 103) beschrïnkt. Die Ausbreitung der Retinula nach rorn äber den Krystallkegel, sowie die Einlagerming der Kierne ihrer Einzelzellen neben den Hinterende des letzteren bediufen blos der Erwälmmg. Das Plabdom ist ein vorn schwach verdickter. nach liunten hin sich leicht rerjüngender Stab, dessen Querschittsform man allerdings an Längsschitten sich nicht wohl zu construiren im Stande ist. Er schmiegt sich mit seinem Vorderende ganz dicht an das ebene, odler gar etwas concave Hinterende des Krystallkegels an, und man gewalnt leicht an ihm eine feine Längslinie als Andeutung seiner Znsammensetzung, und ebenso gar nicht selten dentliche Querstreifung (Plätchenstructur). Ganz älılich sehen analoge Präparate von G. locusta ans, nur ist bei diesem die Verschmïchtignng des Rhabdoms nach 
innen eine riel raschere und bedentendere, das Vorderende desselben ein relativ breiteres, seine Nasse aber eine geringere.

Als ein vielleicht aushelfender Ersatz für die fehlemlen Qnerschnitte lïsst sich allenfalts die Ansiclit eines Krystallkegels rom hinten ansehen, welche Fig. 101 (von G. locusta) zeigt. An solchen prägt sich gar nicht selten recht dentlich die Ansatzstelle des Fhabdoms aus in Gestalt eines Krenzes, dessen Arme der Länge nach durch eine feine Linie hallont werden. Nach solchen Bildern zu schliessen, hesteht das Phabdom aus vier der Lünge nach rechtwinklig gebogenen, unter sich zusammentretenden Einzelstäbchen, wobei nur die Frage noch eine offene bleibt, ob die zur Retinula gehörigen Zellen sich in der gleichen Zahl vorfinden, orler ob es deren melir sind.

Yon neueren barstellungen des Augenbaues nnserer Thiere ${ }^{1}$ ) ist mir nur eine einzige. von G. O. Sars herü̈luende, anf Gammarus negleetus sich beziehende bekamnt geworien (1. c. pag. 61). Er gieht eine in Ganzen recht zutreffende Schilderung, und hat, trotz der relativ geringen Vergrösserma. die er in Anwendma Jrachte, doch eine Reihe von Dingen, z. B. das Phabrlom, ganz richtig erkannt und abgebildet. (Taf. VI Figg. 6, 8). Ich" nuss blos seine Angabe, dass der Krystallkegel ans rier Segmenten bestehe, als eine entschierlen irrige bezeichnen.

3. Auge von Hyperia galba und ron Phronima sedentaria. - Ton Hyperidenangen, die durch ihre oft ungehenerliche Grösse ebensowohl, als durch eine Reihe ron sonstigen Bildungseigenthümlichkeiten öfters die Autmerksamkeit der Forscher auf sich gelenkt haben, habe ich die der genamnten beiden Arten nüher zn mutrsuchen Gelegenheit gehabt. Ich kann mur von der erstgenannten Form Abbildungen geben ${ }^{2}$ ) (Figg. 104-106 Taf. X); diese genügen aber für mnsem Zweck $14 n$ so elier, als der Bau des Auges bei Phronima im Princine ganz der gleiche ist.

Hyperia galba gehört nicht eimmal wer diejenigen Hyperiden, die hinsichtlich ilnex Augenbildung an meisten herrorragen, mo doch ist der Unterschiced zwischen ibr und ren Gammariden darin ein sehr ansehnlicher. - Die Cornea ist ebenfalls linsenlos mol zieht sich gleichlick äber die Augen lim; die bei der Betrachtung von oben benerkbare Felderung ist nnr anf Rechmung der unter iln gelegenen Weichtheile zu sclureiben.

In Fig. 104 habe ich einen Krystallkegel nebst zugehöriger Retinula dargestellt, und zwar einen der Randpratie des Anges angehörigen, was sich aus der schräg abgestutzten Vorderfläche. mit der er der Cornea anliegt, erkennen lässt. Die mehr in Centrum gelegenen Kegel sind anch hier wieder kürzer, und zwar wm einen oft sehr ansehnlichen Betrag, und ebenso, wie bei Talitrus, mit senkrecht zur Axe stehender Endfläche versehen. - Alle sind selur in die Länge gezogen, gegen ilı hinteres Ende hin ansserordentlich dünn, vor diesen Ende aber schwellen sie noch einmal leicht an, um mit einer mehr oder weniger dentlichen geraden winzigen Flïche dicht vor dem Phabdom zu endigen. Gleich denen der Amphipoden mod Isoporlen sind sie in ilner ganzen Erstreckung gleichmässig mol stark lichtbrechend.

Auffallend ist die starke Entwickelung, welche die ihre Bildung reranlassenden Mutterzellen ihrer Segmente erreichen und beibehalten (Figg. 104, 105 Mz.). Dieselben ungeben den Kegel in Gestalt einer weiten, in Querfaltem (bei Tremgeistexemplaren) gelegten Hülle, die den grössten Theil desselben, von der Cornea ausgehend, überzieht. Nach linten zu legt die Hülle

1) Ton iilteren rgl. bes.: J. Mïller, in seinen Fortges. Untersuchgn. etc. 1. s. c. pag. 58.

${ }^{2}$ ) Ich habe leider s. Z, in Neapel versäumt, meine Präparate von Phrou ima gleich zu zeichnen; und ungliicklicherweise sind sie, wie andere werthrolle Präparate, das Opfer der Rülekreise geworden. 
sich in zwci flügelartig abstehende Launellen zusammen, wie besonders auf Qnerschnitten ersichtlich ist (Fig. 105). Dass diese Hülle mit dem Krystallkegel beiderseits an den Nühten, in denen die beiden Segmente zusiummentreffen. rerbmelen ist, erkennt man auf solchen Schnitten anch besonders leicht. - Bei der geringen Schwierigkeit, die Anzahl der Kégelsegmente als nur zwei zu bestimmen, ist es fast zu rerwundern, dass die Beobachter bis vor wenigen Jaluen allgemein vier Segmente angaben. Entoprechend der Segmentzahl sind zwischen der Basis der Kegel und der Comea auch mu zwei sog. Semper'sche Kerne rorhanden, die in ihrer mächtigen Entwickelung derjenigen der zugehörigen Zcllen entsprechen.

Die Kegel sind röllig pigmentfiei, und nur mit ihrer imnersten Spitze senken sie sich eine kurze Strecke weit in das Pigment der Retinulae ein. Dieser Farbstoff ist, beilünfig bemerkt. so wenig resistent, dass el bei der Conservirung der Thiere in Alcohol sehr bald rollkommen ausbleicht.

Die Retinula (R7.) ist im Allgemeinen spindelförmig, und etwas hinter dem von ihrem vordern Ende umschlossenen Hinterenrle des Krystallkegels an umfingreichsten. Wie die Querschmitte durch dieselbe ergeben (vgl. Fig. 106, a-c) läisst sich sehr leicht und zweifellos ihre Zusammensetzung aus fünf Zellen constatiren, die rorn $(a)$ eine nur sehr wenig ausgesprochene Cammelirung bilden, hinten aber $(c)$ in ebensoviele abstehende Flügel auslanfen. - Die Kerne der Retmulazellen liegen weit nach rorn gerïckt (n. Fig. 104).

Das ron der Retinula umschlogsene Rhabdour ( $R m$.) ist ebenfalls spindelförmig. vorn gerade abgeschnitten, nach hinten ziemlich spitz anslanfend. In Innern ist ein deutlicher Canal, besonders an den dickeren Stellen, ïusserlich aber meist noch eine feine und zarte Querstreifung kenntlich. Dass die Zahl seiner componirenden Stïbchen derjenigen der Retimula-Zellen entspriclit, ergiebt sich besonders ans den Querschuitten durch seine vorderen, stärkeren Partien; gegen das Hinterende zu rerschwinden ebensowohl die radiären Theilungslinien der Segmente. als anch die Hölılung (Fig. 106, c).

Ich habe hier noch kleiner, spindelfönuiger Zellen zo erwälmen, die, an Torderende der Retinula begimmend, sich eine kuzze Strecke weit am Krystallkegel in die Höhe ziehen (Fig. 104. Z). Ich glaube deren je zwei gezählt zu haben. bin aber meiner Sache nicht völlig sicher. Ihre Bedentung ist mir unbekamnt geblieben; sollten sie etwa die abortir gewordenen Zellen sein, welche rer Retinula noch fehlen zur Errcichung der typischen Siebenzahl?

Dieser Augenform schliesst sich imnig die ron Phronima sedentaria an, die ich in Neapel näher untersuclit habe. Bekamntlich ist lier jedes Auge, ebenso wie das zugehörigc Ganglion opticum. in zwei selu ungleich entwickelte Hälften getheilt, von denen die cine, mit ganz mgehenerlich entwickelten Krystallkegeln, die ron oben, die andere aber. mit sehr viel kïzeren und schwächeren Kegehn. die ron der Seite herkommenden Lichteindrücke percipirt. Die Kiegel der erstgenamnten Hälfte haben etwa die Form von selı langen und schlanken Stecknadeh, mol kömen in Anbetracht der geringen Körperdimensionen des Thieres. dem sie angehören, sicher den Anspruch darauf erheben. die relativ längsten ihrer Categorie in ganzen Gebiete der Arthropoden zu sem; ja, sie rangiren selbst unter den absoht grössten, da ihre Lünge bis auf $4,5 \mathrm{~mm}$ (nach A. Pagenstecher, s. u.) steigen kamn. - Beide Kegelformen bestehen ebenfalls nur ans je zwei Segmenten.

Es ist mir auch hier geglückt, lie Retinula näher zu untersuchen, und die Befunde stimmen, natürlich von Einzellseiten abgesehen. völlig überein mit den von Hyperia gallı mitgetheilten; namentlich habe ich anch hier mich mit voller Sicherheit (auf Querschmitten) von der Fünfzähligkeit sowolıl der Retimula als anch des Rhabdomes überzengen künnen. 
Die starke Entwickelnng des Anges der Hyperiden ist schon seit lange bekannt, aber eme gewisse Rolle in der Discussion einiger der Haupt- md Principienfragen, mit welchen es die Untersuchung des Arthropodenauges zu thm hat, scheinen sie erst seit der Mittheilung Gegenbaur's ${ }^{1}$ ) zu spielen, der an einer nicht näher bestimmten Form sich iiberzengt zu haben glaubte, dass die Krystallkegel ohme irgend welches Nittelglied direct dem Gehirne aufsitzen, demmach im Sinne Leydig's gedentet werden müssen. Ueber die Zahl der Segmente des Krystallkegels erhalten wir von Gegenbaur keinen Aufschlrss; es scheint ihm überhaupt, was bei der Untersuclumg frischer, lebender Hyperiden leicht passiren kann, die Zusammensetzmo entgangen zu sein. - Gegenbanx hat übrigens sicher die Retimulae oder Sehstäbe übersehen, die als Vermittler zwischen Gehirn und Krystallkegel anch hier vorhanden gewesen sein müssen; nur dadurch erklärt sich die Verwerthung semer Beobachtung zu Gunsten der Leydig'schen Anffassung.

Der gleiche Irrthum ist auch Claparède ${ }^{2}$ ) widerfahren, der freilich die Angen dieser Thiere (Hyperia Latreillei - msere vorhin besprochene H. galba - und zwei TyphisArten) nur aus fertigen, ron C. Semper erhaltenen Präparaten kemnen gelernt hatte; und der gleiche Irrthum hatte auch die gleichen Folgen, die sich ebenfalls in einer Anerkenunng der sonst nur mit einem gewissen Widerstreben angenomnenen Auffassung Leyrlig's änsserten. Er sagt: „Diese und ̈̈hmliche Torkommnisse sprechen sehr dafür, dass Leydig, wenigstens für gewisse Fülle, nicht Unrecht hatte, als er clen Krrystallkegel für ein nervöses Gebilde erklärte" etc, etc. - Sonst wäre noch zu bemerken, dass Claparède der Zusammensetzung des Kegels gedenkt, aber ihn aus rier Stïcken bestehen lässt.

In einer ausführlichen Arbeit über Phronima hat A. Pagenstecher'3) anch die Angen dieses Thieres zum Gegenstand einer eingehenden Erörterung gemacht. Er unterscheidet in den beiden Hälften eines jeden Anges die .Stäbchen” (Krystallkegel), umd rlahinter gelegene, von Pigment umhüllte "cylindrische Elemente" (unsere Retimulae oder die Sehstäbe), leren scharfe Tremung ron den ersteren, die jeden Gerlanken einer ununterbrochenen Continuität ausschliesst, ihm nicht entging (1. c. pag. 32). Wie sowohl aus der Beschreibung als aus den Figuren hervorgeht, hat er seine Studien über das Auge hauptsächlich an conservirten Exemplaren von zweifellafter Güte genacht; er hat zwar die Zusammensetzung des Krystallkegels ans zwei Hälfteu gesehen, aber die Bedentung dieser Znsammensetzung so selr rerkannt, dass er darin die Andentung einer Vermehrung derselben durch Längstheilung zu erblicken glaubte (l. c. lag. 32, 33). - Für weitere Einzelheiten semer Darstellung verweise ich anf die Arbeit selbst.

Auch M. Schultze hat eine nicht näher bestimmte Hyperide auf den Ban ihrer Augen mitersucht. und sowohl die scharfe Abgrenzming der Kegel ron dem Rhabdom, als auch die Querstreifung des letzteren beobachtet (1. c. Taf. I. Fig 9; im Texte an rerschieclenen Stellen, aber nur gelegentlich erwähnt). In Bezug auf die abweichende Zusammensetzung des Krystallkegels scheint es ihm nicht besser ergangen zu sem, als seinen Torgängern.

Clans $\left.{ }^{4}\right)$ scheint der erste gewesen zu sein, dem das Ungewöhnliche im Ban des Hyperidenanges anffiel, mol der anf die Zweitheilmg des Lirystallkegels aufmerksain machte. Er

1) C. Gegeubaur, Zur Kenntniss der Krystallstäbehen im Krustenthierauge. in: Miall. Areh. f. Anat. ete. 1858. pag. 82-81. Taf. IV Fig. 6 .

2) Cl a parède. 1. s. c. pag. 211. Taf. X1V Figg. 27. 28.

$\left.{ }^{3}\right)$ A. Pagensteeher, Phronima sedentaria. Ein Beitrag zur Anatomie und Physiologie dieses Krebses: in Arch. f. Natgesch. 27. Jahry. 1861. Bd. I. pag. 15. Taf. I-III.

$\left.{ }^{4}\right)$ C. Clans, Untersuchungen iiber deu Bau und die Verwandtschaft der Hyperilen. in: Göttinger Nachrichten ete. 1871 . pag. 149 u. $\mathrm{ft}$ :

Grenacher, Untersuchungen über das Sehorgan der Arthropoden. 
sagt (ron Oxycephalus. 1. e. lag. 151): „Ueber den feineren Bau des grossen mächtig entwickelten Anges, zu dessen Studium die Hyperiden ansserordentlich günstig sind. mag hier nur kurz bemerkt werden, dass ich mit II. Schultze in der scharfen Abgrenzung der Krystallkegel ron den Nervenstïben volliommen übereinstimme. Gewölmlich setzen vier Nervenelemente einen Stab znsammen. Während sich der lange Krystallkegel stets ans nu' zwei Längssegmenten zusammensetzt, und demgenäss auch nur zwei Semper'sche Kerne vorhanden sind." Und anch neuerdings ist er nochmals1) auf die erwähnte Eigenthümlichkeit der Zusammensetzung des Krrystallkegels zurüickgekonmen. - Leider ist die Notiz über die „gewöhnliche" Zusammensetzung des Selistabes, des Rlabdoms, ans vier Nervenelementen etwas aphoristisch, und namentlieh darans nicht zu erschliessen, ob die Zahlenangabe auf Querschnitte oder auf blosse Längsansichten basirt ist. Ich habe nm zwar noch keinen Oxycephaliden zu untersuchen Gelegenheit gehabt, glaube aber doch bis auf Treiteres jene Zahl vier mit einem Fragezeichen versehen zn müssen, da die geringe Verlässlichkeit solcher nicht durch Querschnitte gewonnenen Zählungsresultate, wie sehon oft herrorgehoben, mir nur zo wohl bekannt ist. Selbstrerständlich soll dimit aber nicht die Iöglichkeit, sondem nur die Wahrscheinlichkeit eines viertheiligen Phabdoms in $A b-$ rede gestellt werden.

4. Augen ron Branchipus nnd Apus, nebst Bemerknngen über die Augen anderex Phyllopoden. - Aus der Ordnung der Phyllopoden habe ich mich mit der Untersuchung mehrerer, verselifedenen Gruppen angehöriger Gattungen abgegeben; die besten und am meisten zufriedenstellenden Rosultate, besonders auch hissichtlich der Zusammensetzung der Retinula, habe ich an den beiden genannten Genera erhalten, welche in die Unterordnung der Branchiopoda gehören. Da meine Beobachtumgen hinsichtlich der Angen der andem Lnterordumg, der Cladoceren, nicht ron gleicher Voll-tändigkeit sind, so will ich das Venige, was mir dariber zu bemerken bleibt, an die Besprechung der Sehorgane der rorhin genamten Gattungen anknüpfen.

Beiden Gattmoen kommen im Wesenthichen übereinstimmend gebante Angen zu, so gross anch die Unterschiede in der Ansljildung der einzelnen Angentheile für den ersten Anblick erscheinen mögen. Sie weichen beide ron den bisher besprochenen Crustaceenformen durch die Tierzahl der Krystallkegelsegmente ab, stimmen aber mit den Hyperiden in der Zahl der Retinula-Elemente ïberein.

In Fig. 107 Taf. $\mathrm{X}$ sind die Antheile zweier Facetten ron Branchipus stagnalis; in Fig. 108 Tat. X Qnersehnitte dureh sechs Retimulae desselben Thieres, ferner in Fig. 109 Taf. X zwei Krystallkegel nebst Zubehör von Apus eancriformis wiedergegeben²).

Bei Branchipus finde ich die Cornea insofern in einzelne Facetten getheilt, als dieselbe ïber jedem Krystallkegel sich in leichter Wölbung erhebt. Die Innenflache ist aber fast in demselben Grade vertieft, als die Wölbung nach anssen convex rortritt. so dass ron einer Linsenwirkung kamm die Rede sein kann. Noch weniger bei Apus, wo die Comea ganz gleichmässig eben sich über das Ange linzieht.

An den erhürteten Krystallkegeln von Branchipus fält ein Terhalten auf, das wir in etwas anderer, noch mehr herrortretender Weise später besonder's bei den Decapoden wieder finden werden. Es exhalten sich nämlich die Zellen, welchen die Krystallkegel-Segmente ilne

1) C. Claus. Zur Kíenntniss des Batues und der Organisation der Polyphemiden. Denkseluriften d. Wien. Akad. Math.-nat. Cl. Bd. 37. 157\%. pag. 9 des Siep.-Abd.

$\left.{ }^{2}\right)$ Ich bin für the freundliche Ueberlassung des Materiales Ilem Dr. F. C. Noll in Frankfurt a/M. zu Danke verpflichtet. 
Entstehung rerdinken, und zwar nicht nur als einfache, für sich optisch wirkungslose Hüllmembranen $u m$ den Kegel, sondern als Haupttheil des Ganzen der Masse nach, und obendrein unter erheblicher I Tmwandlmng ihrer Substanz. Die eigentlichen Ansscheidungsprodncte dieser Zellen, die Lirstallkegel, sind als zwar scharf umschriebene und bestimmt geformte, aber an Unfang relatir geringe Gebilde etwas zurïckgedrängt. So entspricht also das ganze, zwischen Cornea mol Retimula resp. Rhal)dom gelegene ovale, nach hinten hin spitz auslanfende Gebilde ( $1 L_{z,}$, Fig. 107) zunächst den Mutterzellen des Krystallkegels (es sind natürlich morplologisch die gleichen Elemente, die beim aconen Insectenange als Krystallzellen bezeichnet wurden). und erst in diesem Complexe tritt der eigentliche ellipsoidische, vorn mo hinten abgerundete, chenfalls riertheilige Krystallkegel $(K h$.) auf. Ich bin leider nicht in der Lage gewesen. die Thiere in frischem Zustande untersuchen zu können, sondem musste mich auf schon ziemlich alte Weingeistexemplare beschränken. Aus den vorhandenen Beschreibmugen des frischen Auges geht aber hervor, dass die bei conservirten Thieren so anffallenden Differenzen in Aussehen und besonders in der Lichtbrechung der kegelförmigen Gebilde im Leben nicht zur Geltung kommen, sondern das Ganze, ähnlich wie bei den Decapoden. homogen mod stark lichtbrechend erscheint. - Pei Spiritusexemplaren bleibt der eigentliche Krystallkegel ganz klar und durchsichtig, ron starker Lichtbrechung, md grenzt sich wie ein scharf und bestimmt contourirter fiern von der völlig anders aussehenden Trmgebung als. Die Mntterzellen erscheinen dann nämlich grösstentheils grob granulirt, und nur dex inmerste zngespitzte Theil ( $K k^{I}$. Fig. 107) bleibt klar und zeigt dasselbe Lichtbrechungsvermügen. wie der ellipsoidische Körper im Innern. Dieser hintere Theil erscheint in seiner vondern hegrenzmg selrr unbestimnt und umegelmiissig ausgezarkt, wie die Figur zeigt; ex steht aber im Zusammenhang mit einer diinnen Schicht, die, ron ihm ansgehend, scharf alıgegrenzt die Oberfläche des Ganzen membranartig ïberzieht. - Ich will noch linzufïgen, dass es mir nicht mehr gelungen ist, an den alten mir zur Terfügung stehenden Exemplaren die Kéne der Zellen (die Semper'schen Kerne) nachzuweisen.

Ganz rerschieden sehen die ebenfalls deutlich riertheiligen liegel von Apus (Fig. 109, K\%.) aus, mol doch ist der Ban im Grunde fast der gleiche. Der Unterschied besteht nur darin, rlass der ïchte Krystallkegel den vorher von scinen rier Bildungszellen erfüllten Ram nach erreichter Entwickelung fast völlig einnimmt, so dass nur ein geringer Zwischenraum zwischen seiner Oberflärhe und der ihn mulü̈lenden Membran übrig bleibt. Vor den eigentlichen Kegeh, aber noch innerhalb der Hüllmembram labe ich noch die abgeflachten Semper'schen Kerne nachzureisen vermocht.

Bei den Augen beider Gattungen sind die Retinulae in ilırer Länge gleichnässig entwickelt, mol umgreifen eine Strecke weit das Hinterende der Kéel. Wie weit, kam ich so genan nicht angeben, da der Erhaltungszmstand meines Materiales die vordere Grenze (besonders bei Branchipus) festzustellen nicht gestattete. Dass die Retinula ans fünf Zellen besteht, zeigt der Querschnitt durch dieselben bei Branchipus (Fig. 108); bei Apus bin ich nicht so glücklich gewesen, brauchbare Querschnitte zu erhalten, konnte dafür aber un so sicherer die Zahl der hier recht ansehnlichen Kerne der Retinulazellen feststellen. und diese weisen anf dieselbe Zusammensetzung hin. Bei Apus liegen diese Kerne dicht ror dem innern Ende der Retinula (n. Fig. 109); bei Branchipus habe ich sie. wenn auch nur undentlich, in rordern Ende, etwa im Nivean des Endes des Phabdoms, walngenommen (Fig. 107, n).

Bei Branchipus ist das Rhabdom (Rm.) beinahe von derselben Länge wie die Retinnla, bei Apus aber viel kürzer; bei beiden läuft es nach linten in eine spitze aus. Diese Zuspitzung geschieht aber bei Apus so rasch, tass man das Rhablom als conisch gegenüber dem von Branchipus, das eher cylindrisch ist, bezeichen muss. Bei Branchipus stösst dasselbe 
nach rom an die ilmm entgegenkommende Spitze des Complexes der Krystallkegelzellen, bei $A_{p}$ ns fïgt es sich an den linteren etwas mregehnässig gestalteten Pol des Kegels selbst an. Bei beiden habe ich deutliche Längslinien als Andentung des Hervorgehens ans Einzelstäbehen gesehen; bei den Quersehnitten dmeh die Retimulae von Branchipus labe ich mich musonst bemüht, die als homogene Centra der fünfstrahligen Retinularosette anftretenden winzigen Rhabdomquerselmitte in ilure Einzelbestandtheile zu zerlegen.

Ueber das Ange ron Branchipus hat Burmeister ${ }^{1}$ ) wohl zuerst nähere Nachricht mitgetheilt; es ist ron seiner Darstellming nur hervoruheben, dass er den eigentlichen oroiden Krystallkegel als Linse vom in einem becherförmigen Glaskörper (Krystallkegel) liegend dentete. Leydigr ${ }^{2}$. der die Angen später, und wie es scheint nm an frischen Exemplaren studirte, konnte die ron Burmeister herrorgehobene Scheidnng in eine Linse und den Kegel nicht erkennen, obschon ilm die Sondermng in eine innere festere und eine corticale weichere Schicht nicht entging. Später hat Fr. Spangenberga ${ }^{3}$ die Beziehrmg der Limse zum Krystallkegel oder Glaskörper wieder ähnlich wie Bnrmeister beschieben, md auch einige Bemerkungen über den Sehstab beigefügt.

Weniger noch scheint das Ange ron Apns berücksichtigt worden zn sein. Ansser den älteren Beobachtmgen ron J. Nïller ${ }^{4}$ ) (ron den noch viel älteren Schäffer's [1756] n. A. ganz alozisehen), mol ron Zaddach5), die sich hanptsïchlich anf die Beschreibnung der facettenlosen Cornea, sowie der Form der Krystallkegel beschränken, scheint sich Niemand mit dem Bau dieses Organes specieller befast zu luben.

In Anschluss an diese beiden Gattungen mögen hier noch einige Bemerkungen über den Augenban jener im Systeme nahe gestellten Thiere eine Stelle finden.

In die nähere Verwandtschaft mit Branchipus mo $A_{p} n$ s bringt man bekanntlich anch die Familie der Estheridae. Anch diese besitzen zusammengesetzte Angen mit Krystallkegeln, denen man früher, wie äberhanpt einem jeden Arthropoden mit Facettenangen, die als Norm geltende Zahl ron vier Segmenten zuschrieb. Nun hat aber nenerdings Lenz ${ }^{6}$ ) an Estheria californica sowohl wie an E. tetracera den Nachweis geführt, dass die Krystallkegel derselben aus fünf Segmenten gebililet sind, und ich bin dureh die freundliche Termittelung ron Seiten des Entdeckers in den Stand gesetzt, die Beobachtung zu bestätigen. Leider aber nicht hinsichtlich der Znsammensetzung der Retimula mi des Rhabdones zn erweitern, denn die Ǩleinheit der Angen, noch meln aber der zu schlechte Erhaltumgszustand des mir zur Verfügung gestellten Materiales erlanbten ein nüheres Eingehen nicht mehr. Soviel ich gesehen habe, erscheint das Rhabdom recht kmz and zart (nur ca. ${ }^{2} / 3$ der Länge der Krystalliegel erreichend, die birnförmig oder langeiförmig gestaltet sind), und nach hinten zu rasch verjïngt; ansserdem momschlossen ron den intensiv dunkeln Petimulazellen.

1) H. Burme ister, Ueber den Bau der Augen bei Branchipus paludosus (Chirocephalus Prev.) in: Mï 11 e r's Arelı, ete. 1835. jag. 529 und 613 .

${ }^{2}$ ) Fr. Leydig, Ueber Artemia salina und Branchipus stagnalis. Beitr. zur anat. Kenntn. d. Thiere. in: Ztschft. f. wiss. Zool. III. 1851. pag. 280.

3) Fr. Spangenberg, Zur Kenntniss ron Branelipus stagnalis. Ebenilas. Śupplem. zu Bu. XXV, pag. 1.

4) J. M $\mathrm{ïll}$ er. Fortgesetzte Untersuehungen etc. - l. s e. pag. 54.

$\left.{ }^{5}\right) \mathrm{Zaddaeh}$. De $\Lambda$ podis eancriformis anatome et historia evolutionis. Bonnae 18 11 . pag. 45.

$\left.{ }^{6}\right)$ H. Lenz, Estheria ealifornica Paek, in: Areh. f. Natgeseh. 187\%, pag. 24. (Auch Rostocker Inauguraldissertation.) 
In die gleiche Ordnung der Phyllopoda bringt man bekanntlich auch die Cladoceren, deren Auge schon gar häufig untersucht und beschrieben worden ist; besonders eingehend ron Leydig1), der" zuerst die Anwesenheit eines "Nervenstabes" hinter den segmentinten Krystallkegehn der zusammengesetzten Angen dieser interessanten Thiere constatirte. Seither sind die Cladoceren in zahlreichen trefflichen Arbeiten belandelt worden, alier im Verlıältniss zu der Summe von Kenntnissen, welche wir von den meisten andern Organsystemen besitzen, lassen die über das Auge noch Manches zu wiunschen ïbrig. Wir laben bis jetzt nur Einblick in die Zusammensetzung des Krystallkegels einiger Arten; die der Retinula und des ron ihr umschlossenen Rhabdons zu bestimmen ist bis jetzt noch nicht gelungen. - Die Kenntniss der wahren Segmentzahl der Krystallkegel ist aber auch erst den Studien der letzten Jahre zu rerlanken. da man früher eben anch hier die iiberall roransgesetzten vier Theilstïcke gefunden haben wollte; so z. B. Weismann ${ }^{2}$ ) bei Leptodora. Claus ${ }^{3}$ ) bei Sida und Daplinia. Letzterer will anch bei diesen Gattungen eine riertheilige Sonderung des "Nervenstabes" beobachtet laben. Nun hat schon lange Leydig ron Bythotrephes longimanns (l. c. pag. 24ó) erwälint, llass bei diesen Thier die krystallkegel ans fünf deutlichen Segmenten zusammengesetzt seien. Später bringt Spangenberg ${ }^{4}$ ) lie gleiche Beobachtung für Daphniden, Claus5) für Polyphemus und Evadne, und macht denselben Bau auch für Podon walı'scheinlich. (Letzteren beiden Gattungen hatte er übrigens bei einer früheren Gelegenheit ${ }^{6}$ ) die Znsammensetzung des Krystallkegels aus Segmenten abgesprochen.)

Mir selbst sind diese Zahlenverhältnisse schon seit längerer Zeit ans eigenen Untersuchungen bekannt geworden. Ich fand die Fünftheiligkeit des Krrystallkegels der Cladoceren zuerst nur mit Nühe an wenig günstigem Nateriale (Daphnia longispina, D. pulex), mul habe spaiter in Neapel an einem in Auftrieb sich zuweilen vorfindenden Porlon. wo die Augen dafür ungleich günstiger gestaltet sind, ganz die gleiche Beobachtung gemacht, aber bis jetzt nuich vergeblich bemiilit, auch die percipirenden Angenelemente einer derartigen numerischen Analyse zu unterwerfen.

5. Auge von Mysis. - Ton der kleinen Gruppe der Schizoproden unter den Podophthalmen habe ich die Angen ron Mysis (M. vulgaris, flexuosa) ziemlich eingehend sturirt, und auf diese Gattung beziehen sich die Figg. 110-116 Taf. X. Ich halte das Studium des Auges der Arten dieses Genus in melur als einer Hinsicht für ein selır interessantes, nicht allein für den Sehapparat im engeren Simne, sondern noch weit mehr für die zugehörigen mud sich dicht daran anschliessenden Apparate des centralen Nerrensystens, die man schlechthin als Ganglion opticum bezeichnet. Obgleich ich im Verlaufe meiuer Lntersuchungen im Wesentlichen immer den gleichen Theilen hinter dem zusammengesetzten Auge begegnet bin, ist es mir doch

1) Leydig. Naturgeschichte der Daphniden (Crustacea Cladocera). Tübingen 1860. pag. 36 и. ff.

2) A. Weismann, Ueber Bau und Lebenserscheinungen von Leptodora hyalina Lilljeb. in: Ztschft. f. Zool. XXIV. 1871. pag. 349 .

$\left.{ }^{3}\right)$ C. Claus, Zur Kenntniss der Organisation und des feineren Banes der Daphniden nnd verwandter Cladoceren. Ebendas. Vol. XXVII. 1876. pag. 362 .

4) F. Spangenberg, Ueber den Bau und die Entwiekelung der Daphnien. in: Göttinger Nachrichten ete. 1876 . pag. 517 .

5) C. Claus, Zur Kenntuiss des Banes und der Organisation der Polyphemiden, Abhdlgn. Wiener Akad. Math. nat. Cl. XXXVII. pag. 8 des Sep.-Abd.

6) C. Claus, Ueber Evadne mediterranea n. sp. und polyphemoïles Lekt. in: Würzbg. Natw. Ztsehft. d. III. 1862. pag. 238 . 
bei keinem (1)ject so leicht geworden, die Aufeinanderfolge, den Zusammenhang, Ban, überhaupt die ganze nugealnnte Complication dieser kleinen Centralorgane für das Auge so zu rerfolgen wie hier, und ich habe deshalb, trotzdem es meiner unnittelbaren Aufgabe an sich ferner lag, doch der Versuchung nicht widerstehen können, in den Figg. 110 unl 116 einige Einzelheiten, die sich darauf beziehen, wierlerzugeben.

Ich habe in Fig. 110 eimen Schnitt durch den ganzen Augenstiel nebst Auge ron Mysis rulgaris abgebildet, ta bekanntlich the Mysideen hinsichtlich der Insertion der Augen mit den ïbrigen Podophthalmen übereinstimmen. - Die Comea des Anges ist leicht facettirt. die einzelnen Facetten sind rund, nach ansen sclwach rorspringend. inmen aber leicht concav. so dass dadurch die Linsenwirkung wieder etwas paralysirt wird (vgl. bes. Fig. 111, Lf.). Bei Flächenansichten (Fig. 112) erscheinen unter den Facetten vier Semper'scle Kerne, von denen zwei näher an die Facette, flie beiden andern melır in die Tiefe gerückt sind. Die eigentliche Bedentung der Zellcontouren 1 m dieselben lässt sich nu schwer enträthseh; sie erweckt den Eindruck. als ob zwei Zellen mit den einander zugewandten. zngeschärften Rändern übereinandergeschoben wälen. - Hervorzuheben sind noch kleine, dreitheilige spitze Dömchen (Fig. 111. 112 d.), die in regehnässiger Vertheilung un die Facetten gruppirt nach imen vortreten.

Die Krystallkegel (K7., Fig. 110, 111) sind in frischem Zustande ziemlich weich und quellbar; ihre Gestalt wäre etwa nit der einer ziemlich schlanken Flasche zu rergleichen. Ich habe es keineswegs leicht gefumden, üher die Zahl ihrer Segmente in's Klare zu kommen. da sie namentlich in den rerschieflenen von mir in Anwendung gebrachten Erhärtungsmitteln sich sehr gut exhielten, und die Trenumgsflïchen zwischen den einzelnen Segmenten nur seln zart angedentet raschienen. Was nir aber die reifen Thiere so schwierig machten. erleichterten mir Embryonen. deren Krystallkegel erst im Werden begriffen waren (Fig. 113). Bei diesen unschliessen die Intterzellen der Krystallkegel ein Kngeliges. ans zwei Hälften hestehendes Tröpfehen ron starkem Lichthrechungstermögen. das unter den Einfluss des zur Erhärtung verwandten Alcohols geronnen und dabei etras geschrmpft ist ( $K$ \%. Fig. 113), so dass der rorher ron ihm eingenommene Ramm nun als eine helle Spläre um dasselbe erscheint und scharf nach aussen abgegrenzt ist. In den Augen ron noch jüngeren Embryonen bilitet jede Iälfte eine Kugel für sich, und diese ist ron der Berührungsfläche der zwei Zellen, in denen sie entstehen. mehr abgerïckt in's Imere; die gegenseitige dnnäluerung und Berïhrung unter gegenseitiger Abplattung ist erst ein Resultat der Entwickelung. - Wir haben demnach in dieser Beobachtung den Beweis, dass die numerische Znsammensetzung des Kiystallkegels hier. bei Mysis. dieselbe ist wie bei den Amphipoden und Isopoden. und sich sclarf miterscheidet ron der der andern Podoplithalmen.

ITm den Krystallkegel lässt sich eine feine Hülle erkennen. die sich an seinem Imnenende in eimen langen, gleichlicken. völlig durchsichtigen Strang fortsetzt, der sich bis zu dem rordern Ende des tief in das Imnere der Retinula zurïckgezogenen Rhabdoms continuirlich erstreckt, und ron den Retinulazellen umgeben ist. Auf dem Schnitte Fig. 110 zeigen die dunkler gehaltenen Streifen jene Stränge an, die wegen inres etwas stärkeren Lichtbrechungsrermögens sich ziemlich deutlich aus alen umgebenden Elementen abheben. bis sie in rem den Grund des Auges bildenden Pigment sich dem Blicke entziehen. Wenn man num freilich frägt, ob diese Stränge zu den Krystallkegelliüllen, oder vielleicht zu den Retinulis resp. den Rhabdomen gehören, so ist die Entscheidung toch keine so einfache. Ich habe mich. wie rorstehend zn ersehen für die Deutung im ersteren Sinne entschieden, trotzdem man vielleicht rersucht sein könnte, hier einen dem bei Liparis mr andern Insecten geschilderten analogen Fall zu sehen. 
Mich hat zn dieser Dentung in erster Linie die Thatsache lostinmt, dass hier nicht, wie bei jenen Insecten, die Kerne der Retinula im lnnern dieses Stranges. der dort dentlich eine fadenförmig verdümte Retinula repräsentirt, gelegen sind, somlern daneben; dass wir also in dem Strange selbst eine Fortsetzung des Rhabdoms zu sehen hätten, wogegen aber wieder die starke Differenz in Lichtbrechmostermögen (rgl. Fig. 114 ron M. flexuosa), ebenso die scharfe Grenze zwischen beiden, und ansserdem noch gegen die Rictimulazellen hin spricht. Dilher meine Dentung dieses Stranges als einer mgewöhnlich verlängerten, über die Norm linaus sich erstreckenden Kegelhülle — eine Deutung, deren mögliche Lnsstossmg ich mir ïbrigens keineswegs rerliehle.

Die grosse Längenentwickehmg der Retinula fällt $u$ so mehr auf, wenn man die geringe Dimension des Rlubiloms damit rergleicht. Der Antheil der Retinulaelemente an Anflan des Gesamntanges kamn am Besten an Schnitten wie Fig. 110 überchen werden, in welchen der gesammte Ramm zwischen den lintern Enden der Krystallkegel und der lintern Grenze des immeren Pigmentgiirtels ron den Retinulis eingenommen wird, und die Rlabdome nicht eimnal välig die vordere Grenze derselben Pigmentzone erreichen. Anch das Pigment selbst ist nicht seln stark entwickelt; ron seiner im Augenhintergrund gelegenen Hautanhänfung zieht es an den seitlichen Grenzen derselben, an den Rändern des Gesammtanges, nach anssen gegen die Oberfläche lin empor, un mit einer dümnen änssern Pigmentschale, in welche die Hinterenden der Krystallkegel cingesenkt erscheinen. zu verschmelzen.

Leider kann ich über die numerische Znsammensetzung der Retimula bei diesen Crustaceen keine genügende Anskunft geben. und Alles, was ich darïber in Erfahrung bringen konnte, beschänkt sich auf folgendes Wenige. Dic Retinulazellen sind als solche erst vom rordern Ende der dicken, massigen, dicht aneinanderliegenden Blobilone (Fig. 114) an zu erkennen als zarte, blasse. anscheinend cylindrische Elemente, die an ihrem vorlem Lnde, dicht linter dem innem Krystallkegelende, die länglichen grossen kerne tragen, die in ihrer Gesammtheit eine dunkle diese Region markirende Zone bilden. Ans der Zahl der Kierne, die je einen rom Krystallkegel ausgehenden Strang mmlüllen, die der Retinulazellen zu er-chliesen, ist mir nicht gelungen. Ich glaube nur, dass die Zahl der Kerne meln als vier ist, d. h. mehr als das Fhabdom Segmente hat; kann aber niclit sicher angeben, wieviel.

Die Rlabdome (Fig. 114 Rm.) sind kurze, relativ dicke, alogerundet vierseitige Pyramiden, deren Seitenflïchen ctwas gewölbt, deren spitzen nach hinten, resp. innen, und deren eben abgeschnittene basen gegen die Krystallkegel hin gerichtet sind. Anch sie sind stark lichtbrechend nnd erhalten sich in Weingeist mel andern conservirenden Medien zienlich gut, so dass man meist noch die Plättchenstructur mit Leichtigkeit daran erkemen kann. An ihrem Torderende inserirt sich mit trompetenartig verbreiterter Fläche der schon besprochene Strang (st., Fig. 114); das scharf abgegrenzte, mäsig spitze Hinterende ist meist wenig kenntlich, weil sich mu dasselbe Züge eines eigenen. nit den Nervenfasem des Opticus linter der imnern Cuticula aufsteigenden erdigen Pigmentes legen. die leider durch Salpetersäure nicht zu entfernen sind; indessen kann man sich leicht durch Zerzupfen den Anblick isolinter Rhabdome rerschaffen. Ueber die Zahl ilner Segmente geben (unerschnitte, wie der in Fig. 115 abgebildete, genügende mol jedenfalls sichere Anskunft; diese Zahl betrïgt hier vier. Die Quersclmitte der Rhabdome erscheinen meist annähernd quadratisch mit abgermoleten Ecken. nnd die Theilungsebenen der Segmente, die relatir leicht zu erkennen sind (sie markiren sich anch sehr scharf anf der Oberfläche [Fig. 114]), halbiren die Seiten des Tiereckes. - Die Plättchen des Rhabdoms, das beilänfig bemerkt in frischem Zustande auch jene schon so oft erwähnte rothe Färbung zeigt, 
sind in je zwei benachbarten Segmenten so gestellt, dass sie mit einander alterniren; die Segmentgrenze erscheint dabei, wegen des gegenseitigen Uebergreifens, als eine Zickzacklinie, wie in Fig. 114 angedentet worden ist.

Wegen des Interesses, das die nerrösen Angencentren als solche beanspruchen kömnen, möchte ich bei dieser Gelegenheit noch einige Bemerkungen über dieselben mittheilen, ım die Figg. 110 und 116, welche einige der wichtigsten Terhältnisse ihrer Anordnung rersinnlichen, näher zn erläntem. Diese Nittheilungen rerzichten auf den Anspruch der Vollständigkeit, da sie nur nebenher gewomnen wroten, und es vorliufig nicht in meiner Absicht lag, die Grenzen meiner speciellen Untersuchungen anch noch über diese dem Perceptionsapparat in engern Simne nicht mehr angehörigen Nervencentra anszudehnen.

Wie die Fig. 110 zeigt, sind in dem Angenstiel nicht weniger als vier discrete gangliöse Centren $\left(G .-G^{I I I}\right.$.) eingeschlossen, die muter sich durch eine sehr grosse Anzahl feiner Nervenfasem in Terbindnng stehen. Drei ron diesen Ganglien $\left(G^{I} .-G^{I I I}\right.$.) sind massig, das vierte $(G$. $)$ aber, welches dem eigentlichen Sehorgan am nächsten gelegen ist, zeigt eine mehr flüchenhafte Entwickelmng. und ist dabei mit seinem Centrum so rorgewölbt, dass es gegen das Auge hin eine Art ron papillenförmiger Vorragung bildet. Ringsum sind die Ganglien von der Cuticula des Angenstieles abgetrennt durch eime massenhafte Anhäufung anscheinend freier Zellenkerne, die an rielen Stellen eine eigenthümliche reihenfürmige. d. h. in Schichten auftretende Anordumg zeigen. Ich sage "freie Zellenkerne“, weil es mir nicht gelnngen ist, an imen einen mzweifelhaft dazu gehörenden Zellkörper nachzuweisen (rgh. Fig. 116, $K m^{I}$., $K m^{I I}$.). Diese Kernanhänfung um also bis anf Weiteres ihre Natur so zu bezeichnen - erstreckt sich vor der ersten gangliösen Masse $(G$.$) in emen ihr entsprechend gebogenen, in zwei Schichten getheilten Gewölbe$ $\left(K m^{I}\right.$., $K m^{I I}$. Figg. 110, 116) quer durch den ganzen Augenstiel.

Ich möchte besonders die Aufmerksamkeit anf den Verlauf der Nerrenfasem, sowie auf einzelne Punkte des Baues der Ganglien selbst lenken. Znerst rom Faserverlanf.

Die Nerven, welche rom eigentlichen Sehorgan durch die immere Cuticula durchtretend nach linten convergiren, sind an ihrem peripherischen Ende merklich dicker und derber als an ilurem centralen (N. Figg. 110, 116), mol werden noch eine Strecke weit ron Pigmentkörnchen begleitet. Die Gesammtmasse aller Fasem wird durch eine Anzahl unter sich parallel rerlaufender bogenförmiger Capillaren ( $C_{p}$. Fig. 110) in Blïtter al)getheilt, die auf Qnerschnitten ein sehr zierliches Bild geben. - Dam treten die Fasem, schon sehr fein geworden, durch die erste Schicht der Kerne hindurch ( $K m^{I}$. Fig. 116), mm dam, bündelweise gruplirt $\left(N^{I}\right.$. Fig. 116), nach Durchsetzung der zweiten Kernlage $\left(\kappa m^{I I}\right.$.) sich in der ersten gangliösen Masse $(G$.) zn rerlieren. Der Theil der Nerrenfasem, der in rer Fig. 116 mit $N^{I}$. bezeichnet ist (zwischen den beiden Kemlagen), zeichnet sich durch eine ganz ansserordentliche Feinheit ans, und man muss schon sehr starke Vergrösserungen anwenden, um sie überhanpt dentlich zu sehen.

Im Imern des ersten Ganglion $(G$.) entzieht sich der Verlanf der Fasern der Beobachtung. Hinter demselben aber erscheinen sie wieder, um sich hier einer möglichst rollständigen Krenzung zu unterwerfen ( $N^{11}$. Fig. 110, 116), der Art, dass die rom insserten rechten Rande des ersten Ganglion (G.) kommenden Fasern zum änssersten linken Rand des zweiten Ganglion (GI. Fig. 110) treten, und mugekehnt, und nur die in der Axe des Angenstiels gelegenen ziemlich gerade durchtreten.

Auch im zweiten Ganglion $\left(G^{I}\right.$.) ist der Verlauf der Fasem mol ihr Verhalten im Imern unbekannt. Aber an seiner hintern Fliiche kommen sie wieder zum Torschein, um ganz in der eben beschriebenen Weise einer abermaligen Kreuzung zn miterliegen ( $N^{T I I}$. Fig. 110), im Terlauf 
ron diesem zum dritten Ganglion $\left(G^{I I}\right.$.). Nach dem abermaligen Heraustreten aus diesem erfolgt eine nochmalige, aber, wie es scheint, nicht so streng geregelte, vielleicht nur partielle Kreuzung (bei $N^{I I I I}$. Fig. 110); lierauf treten die Fasern ein in das vierte Ganglion $\left(G^{I I I}\right.$.), wo sie wenigstens in ihren gröbern Zügen noch im Innern rerfolgt werden können, und treten endlich ans diesem in das Innere des Cephalothorax zum eigentlichen Centrahnerrensystem, wohin ich sie zu rerfolgen unterliess.

Ueber die Structur der Ganglien selbst will ich mich auf folgende Bemerkungen besclüinken.

Das erste derselben (Fig. 110, 116, G.) zeigt eine dentliche Differenzirung in zwei Schichten, umd wiederum jede Schicht in eine grössere \uzahl anscheinend prismatischer Unterabtheilungen. Man kümnte rersucht sein, diese Unterabtheilungen für Zellen zu lalten; ich labe nich jedoch unsoust bemüht, die nöthigen Eigenschaften ron Zellen an ilmen aufzufinden.

Das zweite Ganglion (Fig. 110, $G^{I}$.) besteht ebenfalls aus melreren Schichten, von denen namentlich eine wierler doppeltheilige, viel hellere, weniger granulirte als etwas Besonderes ror den übrigen herrortritt. Der Terlauf dieser Schichten ist gewölbt; die in der Figur angegebene, senkrecht zu der Ebene der Schichten rerlaufende Streifung, _ die man sich übrigens viel feiner: und zarter, als die Figur sie zeigt, zu denken hat. - steht wzweifellaft in encsten Znsammenhang mit den Durchtritt der Nerrenfasern; es ist aber mmöglich, über die Frage der Continnität der Fasern, überhaunt ihres nähern Terhaltens sich ein sicheres Urtheil zu billen. In ähnlicher Wrise, aber weniger deutlich, zeigt auch das dritte Ganglion (Fig. 110, $G^{1 I}$.) sich ans meluern Schichten zusammengesetzt, die von einer bestinunten Faserstreifung durehkrenzt irerden; weniger ist mir dies am vierten $\left(G_{r}^{I I}\right.$.) entgegrngetreten, das ich übrigens nicht genaner studirt habe.

Auffallend war mir, und ist mir noch, die anffallend geringe Betheiligung nachweisbar zellig gefornter Elemente an dem Infban dieser Centren. Man sollte doch wohl erwarten, in diesen relativ volnminösen Nassen Nervensubstanz wenigstens lier und da Ganglienzellen in grösseren oder kleineren Ansamulungen, oder auch durch das Ganze zerstrent, anzutreffen. Ich kann zwal das Torhandensein von zelligen Elementen im Imern der Ganglien nicht völlig in Alrede stellen. aber diese sind so selten, sie treten so sehr neben ier . Pumktsubstanz" (wie bekamntlich Leydig die granulirte Grundsulstanz besonders im Gehin ron Arthropoden genannt hat) zurück, dass eimmal der Zweitel auftaucht, ol nir es hice äberhaupt mit Ganglienzellen zu thm haben, und wemn, ob diese hier nicht eine secumdäre Rolle spielen neben eben jener „Punktsubstanz". - Eine andere Frage taucht noch auf, wenn man den Ceberfnss an Zellkernen in der munittelbarsten Unogelıng der Ganglien in Tergleich zieht mit der übergrossen Dürftigkeit an solchen im Innem der Ganglien selbst. Gehören am Ende jene so massenhaft angehäuften Kerne zu den Ganglien, in der Art etwa, dass die Zellkörper derselhen zur Bildung dieser Ganglien zusammentreten, sie sellost aber nach aussen geschoben, gewissermassen beseitigt werden. wie etwa bei den oben beschriebenen Vorderandangen ron Salticus die lieme der Retinazellen?

Die einzelnen, hier nur ganz skizzenhaft ron mir mitgetheilten Thatsachen, mögen sie num den complicirten Faserverlauf der Nerven, orler die feinere Structur der gangliösen Centren betreffen, sind für nich in morphologischem wie in physiologischem Sinne ebensoviele Räthsel, deren Lösung zu snchen ich Anderen ïberlassen muss. Der Zweck nemer rorstehenden Darstellung war aber nu, auf Mysis, als anf ein in vieler Beziehnng seln günstiges Object für Denjenigen, der sich mit solchen Problemen zn befassen Lnst und - Muth hat, hinzuweisen. 
Ton frühern Darstellungen des Banes der Augen ron Mysis ist mir nur selur wenig bekannt geworden, da mir eine Reihe von Arbeiten, namentlich skandinavischer und englischer Forscher über diese Gruple von Crustaceen. die möglicherweise ebenfalls anatomische Untersuchungen enthalten, unzngänglich geblieben sind.

Ueber das Mysis-Auge finde ich einige Bemerkungen bei Frey und Lenckart'1), wo che Form der Krystallkegel beschrieben mol von den Facetten mitgetheilt wird, dass sie rumd erscheinen. Zwischen ihnen und den Krystallkegeh glauben die Terfasser noch einen .zweiten dioptrischen Kürper", eine Krystalllinse, beobachtet zu haben, die in ihrem Inuern mehrere rundliche Körper, fast wie Zellen, beherbergt. Dies dürfte vielleicht die erste Erwähmung der später von Claparède benannten Semper'schen Keme - denn dies sind mzweifelhaft jene kngeligen Gebilde, welche die Antoren erwiilmen - in der. Literatur sein.

Ungleich eingehender sind die Beobaclitungen über das Ange ron Mysis oculata, var. relicta, die wir G. O. Sars²) rerdanken, und die sich nicht allein auf das eigentliche Ange beschränken, sondern auch auf die Ganglien in Augenstiel elstrecken. Er besclneilbt die Cornea und die Krystallkegel, wie oben geschehen, nur scheint el diese für viertheilig zu halten, und ausserden Vacnolenbildung in seiner Substanz, wie sie miter dem Einfluss von Reagentien wohl hänfig bemerkt werden, für normale Torkommnisse anzusehen (l. c. pag. 33). Noch besser hat Sars das Rhabrlom erkannt, beschrieben unr alggebilçet, und anch die freilich selrr ausgeprägte Plättchenstructur ist ilm nicht entgangen.

Ton seiner Darstellung des Bates der Ganglien im Angenstiel will iclı nur soviel hervorheben, dass seine sehr zutreffende Schilderung sich neln auf das heschrïnkt, was man bei schwïcherer Vergrössernng am lebenden Thier ron ansen erkennen kann. Sars hat zwar anch Schnitte untersucht, aber es ist ihm doch Janches entgangen, obschon er die schichtenartige Aufeinanderfolge der Lagen in den Ganglien, sowie die feine fibrilläre Streifung in der Richtung der Axe gesehen hat. Wenn er ron Ganglienzellen spricht, die er geselıen haben will, (1. c. prag. 32: , ce n'est quaux points de rúmion des segments [i. e. der einzchen Ganglien] qu’il se trouve des cellules ganglionnaires distinctes"), so bin ich leider nicht in der Lage. diese so bestimmt ausgesprochene liehauptung unterstïtzen zn können. Die wegen ilurer üfteren Wiederholung so merkwürdige Faserkreuzung des Selmerren scheint ihm nicht aufgefallen zu sein. -

6. Auge von Palaemon squilla, nebst Bemerkungen über die Augen anderer Decapoden. - Das Decapodenauge ist, wie allbekannt, trotz der Schwierigkeit, welche es der Untersuchnng nach der techischen Seite hin lietet, doch schon vielfach Gegenstand eingehender Studien gewesen. Hier ist es nicht allein die Retinnla, sondern auch in einem kaum geringeren Maasse der Krystallkegel, wekher der anatomischen Erforschung Hindernisse in den Weg legt. -

Ich bin nicht in iler Lage, zn der Summe von Thatsachen, welche wir den frïhern Autoren auf diesem Gebiete rerdanken, einen besonders grossen Zuwachs - im quantitativen Simne in Aussicht zn stellen. Ich musste mich anf die Untersnchung einiger weniger Formen einschrünken, und will als Schema den ron mir am genauesten mtersuchten Palaemon wïhlen, von dem ich sowohl frische; als auch mit verschiedenen Flüssigkeiten behandelte Angen studiren konnte. - Auf eine Reihe ron Thatsachen, welche sich am Decapodenange beobachten lassen,

1) Frey und Leuekart, Beiträge zur Kenntniss wirbelloser Thiere, mit besonderer Berïeksichtigung der Fauna des norldeutschen Meeres. Braunschweig 1847. pag. 113.

2) 1. s. e. pag. 31 u. ff. 
ist es kaum nüthig nüher einzugehın, da von den nenern Untersuchungen namentlich die von M. Schultze (l. e.) sich mit ganz hesonderer Sorgfalt hieriber verbreiten.

Hinter den leicht hiconvexen Facetten (Lf. Fig. 117 Taf. XI) erheben sich die langgestreckten Weichtheile, die man schlechthin als Krystallkegel zu bezeichnen fflegt — ein langgezogen pyramidaler. in frischem Zustande sehr weicher. glasartig durchsichtiger Körper, der aber, nach der Erhärtung weit deutlicher als frisch. in scinen resschiedenen Theilen doch ein wesentlich verschiertenes Aussehen darbietet. Wir sind dieser Heterogeneitit schon oben (bei Branchipus) hegegnet; hier aber. wie bei den Decaporlen überlıupt, ist sie eine nngleich mehr ausgeprägte, und scheint ron allgemeiner Verbreitung imnerhalb der Ordnung zu sein. — An exhärteten Palaemonaugen zeigt dieser ganze "Krystallkegel" folgende Abschnitte. Zunärhst an (Jer Facette liegt eine dünne Lage ron grober Granulirung. die durch den Besitz von Zellkernen (n. Fig. 117) wohl am ehesten Anspruch erheben darf, für dem ursprünglichen Zustand am nächsten kommendes Protoplasma angesehen zu werlen. Ton diesem kleinen Abschnitt grenzt sich scharf der vicl dichter granulirte Hauptheil des Kégels ab, mo in diesen sind an mehreren bestimmten Stellen Einlagerungen von bedeutend stärkerem Lichthrechungsvermögen, die anch nach der Erhärtung klar und durchsichtig bleiben. eingebettet. Die erste derseblyen befinclet sich ganz rom (bei KkT. Fig. 117), und besteht aus vier flachen Stücken. die sich hä̈fig kaum berïhren. Die dann folgende zweite ist die wichtigsto $(K k)$. (ine abgekürzte, ebenfalls ans vier Segmenten bestehente Pyramide bilitend (rgl. auch Figg. 119 Taf. XI, wo dieser Theil für sich allem in schnäger Ansicht dargestellt ist. mu seine Form und Zusammensetzung besser deutlich zu machen). Die Iritte Finligermng endlich bildet eine Art ron Corticalzone num dun linteren stark rerschnïlerten Theil des Kegels $\left(K_{i} I_{*}\right)$, und entrpricht ebenso der mit $K l_{i}^{I}$. bezeichneten Partie bei Branchipus Fig. 107. wie die in beiden Figuren mit K/. bezeichneten Abschnitte als einanter gleichwerthig anzusehen sind.

Dieser Alschnitt K\%, den man auch häufig mit dem auf einer irrigen Toranssetzmng fussenden Tamen . Linse" bezeichen hört, ist meines Erachtens allein der Tertreter dessen, was wir lisher als Krystallkegel im engem Sinne aufgefast haben. Ich habe schon oben angedeutet. dass ich in dem liegelfümigen Gesamunteomplex linter der Facette weniger das Homologon des Krystallkegels, als vielmeln seiner Mutterzellen erkennen müchte. die (bei Palaemon) nur in anem kleinen 'Theil, in der nächsten Ungebung der Semper'schen Keme, sich relativ unrerändert erhalten. inı weitaus grössten Theil aber sich wesentlieh modificiren, olne doch ganz das Aussehen uxd die Eigenschaften des Krystallkegels anzunelmen; dies geschieht nur von relatir geringen Bruchtheilen der Gesammtnasse, und diese stücke $(K \%)$ stmmen dam allein in jeder Bezielung mit den lirystallkegeln anderer Artliropoden überein.

Die fein ausgezogene Spitze dieser Pyramide durchsetzt, bevor sie in Contact mit der Retinula tritt. zuerst eine in Form eines Holilcylinders sie umhïllende Pigmentmasse (I'y. Fig. 117), um sich dann in das Torderende der Retimula eine Strecke weit einzusenken. - Die Retinula (Fl.) ist im Ganzen prismatisch. nach imen nur wenig rerjüngt, und limten mit ansgeprïgteren Kanten versehen als rorn; ihre Pigmentirung ist namentlich der Nantelflüche entlang eine besonder's intensive, nul ebenso ist das Rhabdom $(R m$.) an seiner Grenzfläche von emer dichten Pigmentanhäufung bedeckt. Mit Leichtigkeit kann man sich üher die Lage, weit schwieriger aber über die Zahil der Kierne orientiren ( $n^{I}$. Fig. 117), die ziemlich zusammengedrängt unweit rom Torderende ler Retinula sich finden.

Die Zusammensetzung der Retinula und des ron ihr umschlossenen Rhabdoms ist eine höchst eigenthümliche, wie die Querschnitte Fig. 118 A, und B Taf. XI zeigen. Erstere 
Figur zcigt einen Schmitt durch vier Retinulae etwas hinter inrer Mitte, letztere ist ganz diclut ror den Hinterende gewomen. mul die Versehiedenheit besteht lanptsïchlich in der grösseren Lockerung und Individnalisirung der Zellen mach hinten him. Auf solehen Schnitten durch die Mitte erseheint der Querschnitt durch das Rhabdom als ein Quadrat, so dass also hier der "Sehstal, : wirklich vierkantig ist, was man frülier so allgemein behauptet hat, und wir dorh nur in seltenen Fällen bestätigen konnten. Das Rhabdom erscheint durch Theilumgsebenen, welche die Seiten des Qnadrates halbiren. in vier Segmente zerfüllt; aber um dieses vierkantige und viertheilige Phabdon gruphren sich nicht vier. wie man wohl erwarten sollte, sondern sieben Zellen, deren Anordnung eine sehr eigenthümliche ist. Iuf drei Seiten des Quadrates rertheilen sich nïnlich sedıs der Zellenquerschnitte in der Art, dass die Crenzlinie je zweier Zellen in der Verlïngenng der Grenzlimie zwischen zwei Rlablomsegmenten liegt (vgl. Fig. $118 \mathrm{~A}$ ); der vierten Seite des Quadrates alier liegt nu eine einzige Retinulazelle an, die dam anch eine enteprechend grössere Breite und Masse anfweist. - Nach hinten lin gleichen sich diese Grössendifferenzen unter den einzelnen Retinulazellen aus; die Zellenkërper platten sich ron der Seite her ab, und berühren das anch rundlich gewordene Phabdom nur mit einem Rande, während der andere fügelfömig mach anssen hervortritt. - Wie die Figm 117 zeigt, ist das Rhabdon spindelförmig angeschrollen, doch so, dass die grïsste Dicke linter der Mitte liegt.

Gegenüber den hier mitgetheilten Thatsachen haben wir uns nun nach einer Erklïrng mmznsehen, und meines Erachtens diurfte der nachstehende Tersuch einer solchen für's Erste vielleicht gen̈̈gen. Wir finden dio uns bekannten sichen Retinulazellen, und nur vier dazngehörige

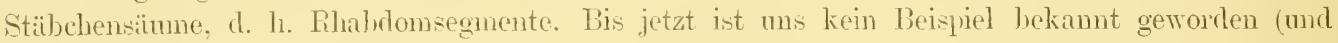
es ist anch a priori in hohem Grade nualuscheinlich). dass zum Aufbau eines einzelnen solehen Sammes melu als eluenfalls eine einzige Zelle beitrüge; es liegt folghich anch in umerm Falle keine Teranlassmg vor, andere Amnalunen zu machen. Wir mürsen also, lis wir etwa durch Thatsachen anders belehrt werden, dam festhalten. dass hier vou den sieben Retimulazellen nur vier zur Ausscheidung ihrer Staihchensä̈me gelangt sind, die drei andern aber nicht. Welche der Zellen das aber sind, das lïsst sich nicht bestmmen: das Einzige. was man allenfalls mit einem gewissen Rechte annehmen kann. wiine. dass wohl die gröste, die nit zwei Rhabdomsegmenten in Berülnung ist. wahrsheinlich gerade deswegen nicht mber die bei der Bildung derselben betheiligten gehört.

An den Rhabdom ist die Plïttchenstructur änsserst dentlich, mnd fast immer fand ich die lellen und dunkeln alternirenden Plittchen in den aneinanderstossenden Segmenten so aufeinandertreffend, dass dem hellen Streif des einen Segmentes ein iunkler des anderu enteruach. Dass anch hier das Rhabdom nach rom sich scharf von dem Hinterende the Krystallkegels absetzt, branche ich wohl nicht mehr besonders hervorzuheben; leicht zu beobachten ist es gerade nicht, da die Lichtbrechung des Rhabuloms nach rorn hin abnimmt.

Ton hinten her. dureh die das Ange ron den Sehganglien abtremnente Cuticnla, dringen nebst den Sehnerrenfasem noch Streifen eines opaekn, in Salpetersüure sich nicht lösenden Pigmentes $\left(I^{\prime} y^{\prime}\right.$.) in das Ange ein; es breitet sich theils in mregelmässig zerrissenen Aesten $1 m$ das hintere Ende der Retinnlae aus, theils zieht es in Streifen viel weiter nach vorn, um etwa in der halben Lïnge der Krystallkegel rielfach gebogene. nnter einander zusammenhängende Areaden zu bilden.

Soriel über die Angen ron Palaenon. Die mehr aphoristischen Bemerkungen über die Angen einiger wenigen andern von min nntersuchten Decapoden mögen im Anschluss hieran ibre stelle finden. 
Zumächst möge les Auges der nahe verwandten Gattumg Crangon (C. vulgaris) gedacht werden; es genügt wohl die Denurkung. dass. wie es bei der Terwandtwelaft zu erwarten i-t, kein besonders berrortretender Untersched zwischen ilm und len Auge ron Palaemon existirt.

Der Natur der Dinge nach gehört der Flusskrebs (Astacus fluviatilis) zn ten am meisten nnd zngleich am eingehendsten auf ilnen Angenbau nutersuchten Decapoden, wofür besonders die Arbeiten ron Fr. Leydig. M. Schultze u. A. Belege liefern. Ich selbst bin nicht in der Lage. nene Thatsaclen ron besonderer Bedentung rorführen zu kömnen. Ich habe zwar Querschinite dureh die Retinula und das Rlabdon angefertigt. nnd mich daran überzeugen kömnen, dass das letztere ebenfalls viertheilig, auf den Querschitte aber ziemlich rundlich ist. Weniger glücklich aber war ich linsichtlich der genanen, jeden Zweifel beseitigenden Zahlenbestimmung der Retinulaelemente; ich habe indessen doch alle Ursache. auch hier die Zilhl derselben als identiseh mit der bei Palaemon gefundenen anzmehmen, weil die im Torderende des Rhabdomes gelegenen Kerne, deren es melır als rier, höchst wahrscheinlich sieben sind, entschicden genug darauf hinweisen.

Bestimntere Angaben lassen sich aber für Portunus Maenas unachen, ron dem ich aine Retimula in Querschnitt in Fig. 120 Taf. XI abljilde. Das stabfümnige Rhabrlom ist hier sehr dünn unıl schliank, vierkantig; sein Quersehnitt war aber zu klein. Iun daran noch die Zusammensetzung aus vier Segmenten. die nach den Forstehenden wohl kam bezreifelt werden kam, thatsïchlich nachweisen zu können. Tm diesen Fhabdonquerschnitt hermu grupuren sich aber in Gestalt einer fosette mrorkennbar mu ganz deutlich zälılbar mnsere bekannten sieben Retinnlazellen. - Ich will bei dieser Gelegenheit auch auf den Querschnitt eines Krystallkegels unseres Krebses in Fig. 121 Taf. XI linweisen, dessen Verhalten mir auch nicht das allgemeine zu sein scheint. Hier sind nämlich die Segmente desselben in zwei Paare getheilt; nu die Segmente des einen Pares bertihren sich in der Mitte mit breitcr Flïele; die des andern Pares werden darluch weit auseinandergehalten.

Auch die ron mir untersuchte Gattung siquilla liefert ein Beispiel ganz derselben - dem Wesen nach - Zusammensetzung. wie Fig. 122 Taf. XI wohl genügend darthun wird. - Die einzehen Retinulae sind (bei Teingeistex(mplaren) durch ein sonderbares, ans kürzeren und längeren, stark lichtbrechenden Stäbchen bestehendes Gewebe ron einander getrent. das sich massenhaft zwischen ilınen anlä̈uft. Der Sclmitt zeigt eimmal, dass das viertheilige Rlabelon seiner Länge nach mit vier Hohlkehlen rersehen ist, so dass der Querschnitt desselben kreuzförnig erscheint; dam alser, dass ron den sieben das fhabdom umgebenden fietinulazellen wieder eine die sechs andern an Grösse iihertrifft. - Die Retinulazellen stehen anscheinend mit dem Rlabodom nicht in näheren Contact: ich bin aber, da cler Erlaaltungszustand des ron mir benutzten Nateriales Nanches zu wünschen übrig liess, nicht in der Lage, das genauere Verhalten und die näheren Beziehnngen der stärker granulirten Substanz zwischen den eigentlichen Retinnlazellen und dem Rhabdome selbst anzugeben.

Damit laben meine Untersuchungen über das Auge der Decapoden ein Ende. Wie man sieht. erstrecken sie sich nu über sehr renig Formen. Indessen glaube ich, dass die unverkennbare Lebereinstimmung der Resultate unter sicl, gewomnen an rein zufällig lierausgegriffenen, systematisch weit ron einauder entfernten Fonnen, Berechtigung genug bietet, jene Uebereinstimmung nicht als eine zufïllige zu betrachten, sondern in ilu den Ausdruck eines sicherhich sehr weit rerbreiteten Terhaltens zu erkemnen, dessen Awsdehnung ïber den ganzen hier in Betracht kommenden Formenkreis zu bestimmen, Sache späterer Untersuchung sein mag. -

Ich will num noch einige wenige Worte der historischen Entwickelung unserer Kenntnisse 
son Decaporlenange widmen, halte es jerloch für unsern Zweck für überflüssig, die einzelnen Ansichten, wie sie in den citirten Abhandlungen niedergelegt wnrten, einer nähern Besprechung zu nuterzichen.

Bekanntlich reicht die Kenntniss einzelner Theile des Decapodenanges, namentlich der Krystallkegel, ziemlich weit zurück. indem schon Swammerdam, Leenwenhoek. Cavolini n. A. dieselben erwähnen. Da aber die Erörterung solcher historischer Facta cimen zum mindesten mur sehr berlingten Werth beanspruchen kamn. so ziehe ich vor, mit einem raschen Schritt uns in weit morlemere Zeiten hineinzurrersetzen.

Es danerte noch längere Zeit nach den ersten Publicationen T. Müller's, der die Retinula überall, unil so auch hier, als einfache Nerrenfaser in Anspruch nalım, bis man zu der Erkemutniss eincr grösseren Complication derselben kam. Will1) hat ron dem bei Krebsen doch meist recht ansehmlich entwickelten Rhabdom wenig genng erkannt; er spricht ron der "Schcide" und der in ilu eingeschlossenen "Röhre" in der uns genügend bei ihm bekannten Weise. — Der erste For'scher, dem der sonderbare Ban des .Nervenfadens" auffiel (beim Flnsskrebs) war wieder" Joh. Müller2); später gab Gottsche (l. c.) eine der Walnheit näher kommende Darstellung davon, die dam besonder's in den Schilderungen von Leydig eine wesentliche Bereicherung und rorlänfigen Abschlnss fond. Die nenesten und ansführlichsten [Tntersnchnngen sind die schon so oft citirten ron 11. Schultze (l. c.), aber weder dieser noch einer iter rorher genamnten Forscher hat gerade die Dinge, auf die ich meine Aufmerksankeit ganz speciell gerichtet habe, besonders in's Auge gefasst, und vor Allem hat Keiner die Bedentung des Rhabdoms - namentlich nicht in morphologischem sime - erkannt. Ebensowenig sind. wenn überhaupt je mumerische Angaben in den bezïglichen Arbeiten sich finden - z. B. üher die Kieme in ler Retinula diese für nnsern Zreck branchbar. - Man gestatte mir. noch einige Abhandlungen zu citiren, die zwar olme besonderen Einfluss blieben, aber immerhin eine oder die andere beachtenswerthe Angabe bringen: Nilne Edwards ${ }^{3}$ ), Steinlin ${ }^{4}$ (der einige sehr sonderbare Ansicliten äussert, z. l3., tlass bei gewisen Kirebsen die Krystallkegel mit melneren Retinnlae in Verbindung ständen etc.), Lémoine5), E. T. Newton ${ }^{6}$ ) ete. etc. - die specieller zu analysiren, und deren Riesultate mit den meinigen zu vergleichen meiner Ansicht nach lieinen Zweck lat.

\section{b. Augen ron Limnlıs.}

Hinsichtlich des Banes seiner zusammengesetzten Angen steht Limulus den vorhin als "typische Crustaccen" aufgeführten so schroff gegenüber, dass eine scharfe Trenumg sich wohl anch ron diesem Standpunkte ans rechtfertigen lïst. Seine Stellung im System ist bekanntlich in der nenern Zeit anf Grund nen aufgenommener anatomischer und embryologischer Forschungen mehrfach kritisch gejü̈ft worden, mo die merkwürdigen Thatsachen, zu denen uns diese

1) Will. l. s. c. lag. 12 11. 11 .

2) Joh. Mïller, im Areh, f. Anat. n. Physiol. 1843. [rag. 351. Anmkg. - Joh. Mïlle r erkennt im Innern des Nervenfułons ..einen gewundenen Schlaueh von durehsichtig blassröthlicher Färbung * - wohl die erste Erwälhnung des in der neuesten Zeit zu so grosser Bedeutung gelangten .,Sehpurpurs" bei Arthropoden.

3) Milne Edwards. Hist. nat. des Crustaeis. Tome 1. pag. $11 f \mathrm{u}$. fr.

4) Ste inlin, l. e. pag. 75 u. ff.; ferner in: M. Schultze s Arch. f. mikr. Anat. Vol. IV. pag. 10.

5) Lémoine, Anatomie de leerevisse. Ann. seiene, nat. Zool. V. Sér. Vol. IX. 1868. pag. 185 u. ff:

$\left.{ }^{6}\right)$ E. T. Newton. The strueture of the Eye of the Lobster. Quart. Journ. Miki. Se. 1873. New Ser. Vol. Xlll. pag. 325-343. 
Forschungen verholfen haben. liessen mich mit einer gewissen Syanumg rler Gelegenheit entgegensehen, das Auge einer nähern Prüfung zu unterwerfen. Wenn ich anch anf nancherlei Eigenthümlichkeiten und Abreichnngen von dem bei den übrigen Chustacen Beolachteten gefasst war, so wagte ich doch kemeswegs, an einen ganz nenen, völlig von lem der übrigen Arthopoden abweichenden Typus des Facettenanges zu denken.

Ein solcher aber findet sich hier in der That. Das zusammengesetzte Auge von Limulus hat mit den miter sich ïbereinstimmenden Facettenaugen der andern Crustaceen und Insecten weiter nichts gemein, als die Thatsache, dass es eben ein zusammengesetztes ist. In Uebrigen aber ist es eine jenen völlig fremde Bildung, und weder die bei diesen beobachteten mmerischen, noch die topographischen Gesetze haben für dasselbe irgend welche Geltumg. Die nachfolgende Darstellımg wird den Beweis dafïr zu exbringen haben.

Leider war das mir zur Verfügmo stehende Material nicht geeignet, über alle bei einer anatomischen Lntersuchung in Frage kommenden Punkte nach jeder Richtmo hin genïgenden Aufschluss zu geben. Es waren theils ältere Weingeistexemplare, die ich vom Musenm Godeffroy acquirirte; theils auch frischgestobene Thiere, welche Herr Dr. Bolau in Hamburg, dem ich dafür sehr zn Danke rerpflichtet bin, mir zn senden die Güte hatte, die aber, während der ersten warmen Sommertage befördert, schon merklich in Fäuhniss ïbergegangen hei mir eintrafen. Ich mus deshalb manche Frage noch ganz offen lassen, andere kam ich nur wter gewisser Reserve beantworten. Trotzilem aber bleibt von dem sicher Beobachteten nocls so viel, mm das oben in Alkgemeinen ansgesprochene Lrtheil äber die Bezichung dieser Angenform zu denen der andern Crustaceen und lnsecten zu begründen.

Die beiden grossen umbeweglichen zusammengesetzten Angen von Limulus haben bekamntlich einen etwa nieren- oder bohnenförnigen Lmriss, mel liegen weit getremnt sowohl unter sich, als anch von den anser ihnen noch rorhandenen zwei einfachen Angen, dio der Medianebene genähert in vorderen Theil des Cephahothorax gefmulen werden. Die zusammengesetzten Angen, die ich allein untersucht habe, sind eingeschlossen in eine dicke Chitinkapsel, deren äussere Wand die Facettenzeichmung trägt und lichtdurchlässig ist, deren innere aber, an Stärke der äusseren kaum etwas nachgelend, aus einer eigenthümlich schwammigen, von Canälen durchsetzten, leicht schneidbaren Chitinmasse gebildet ist. Beile Chitinlamellen gehen an der Peripherie des Anges continuirlich in einander und in das allgemeine Integmnent über; der von ihmen abgeschü̈rte Hohhaum zur Aufnalme des Anges - das ilm ühnigens lange nicht ansfüllt - hat etwa die Gestalt einer mmegelmässigen plan- oder schwach concav-conrexen Linse, wobei die Convexitiit der Corneaseite entspricht. Der Opticus tritt in eine Anzahl starker Aeste getheilt an die innere Lamelle etwa in deren Nitte heran, und duchsetzt sie, 1 m zum eigentlichen Auge hindurchutieten.

Die zun eigentlichen Sehorgan gehörigen Weichtheile bilden nur eine relativ dünne Rindenschicht unter der Conea, und machen sich durch ihre intensiv schwarze Pigmentinung leicht bemerklich. Der bei weiten gröste Theil der Angenkammer ist ron einem eigenthiunlichen maschigen Gewebe erfüllt, dessen Natur zn bestimmen, wenigstens nit Sicherheit, mir mein Material nicht mehr gestattete; es mag genügen, wenn ich hier anführe, dass ich, ausser den in bestimmten Richtungen duch dasselbe ziehenden und sich entsprechend der Angenausbreitung immer mehr theilenden und verzweigenden Nervensträngen, keine nervösen Elemente mehr darin zu erkennen im Stande war, also las Ganze auch nicht als eine Art von Ganglion opticum betrachten kam. Die Pigmentzone verlüuft auf Schnitten senkrecht zur Cornea in Zickzacklinien, entsprechend den Torsprüngen der Cornea, welche je ein Einzelange anzeigen. 
Ine Cornea (Fig. 123 Taf. XI) ist anf ilner äussern Oberflïche fast glatt. auf ihrer imnern dagegen durch regehü̈sig rertheilte Hücker fast tachelig zu nemen. Ausser der im Algemeinen sehr deutlichen feineren Schichtnng, wetche sie mit einer so grossen Anzahl analoger Chitinbildmgen gemein hat, hahe ich an ihr noch drei gräbere Lagen erkemsen können, ron denen die äussere die dünnste, die innere aber die dickste ist (vgl. Fig. 123, 1, 2, 3). An der Bildung der den Einzelangen entsprechenten Torsprünge sind alle drei Schichten betheiligt, aber in selır rugleichem Grade; am wengsten wieder die änsere Lage. an meisten die imerste. Die erstgenannte (Fig. 123. 1) zeigt sich auf Schnitten in Allgemeinen von parallelen Flächen begrenzt. nur an den Stellen, welche einem nach innen sich erhebenden Kegel entsprechen. erscheint sie schwach linsenförmig rerdickt. mnd so scheint nur die innere Begrenzmgsfläche zu sem, durch deren Erhelıug diese Terdickung zu Stande kommt. Die zweite, dickere und gröber geschichtete Lage (Fig. 123. 2) erhebt sich ïber jenen Stellen, wo die erste sich schwach rerdickt zeigt, schon weit stärker. so dass sie nach imnen, gegen die dritte Lage lim. starke. mässig zugespitzte Kegel lildet. Die Hauptsache aber fällt der immersten Lage (Fï. 123. 3) zn. Diese ïbertrifft an Mächtigkeit die beiden ersten znsammen $u m$ das Doppelte und meln. und ihre Schichtung int ebenfalls eine riel ansgeprägtere und dentlichere. 1hre innere Grenzfläche erhebt sich in steilen, an der Spitze meln ofler reniger geradflühig abgestutzten Kegeh. die gewissemassen mur die Spitzen ron riel massigeren banchigen Kegeh sind, welphe mit dem grösten Theil ihres hörpers in der inneren Comealage eingeschlosien bleiben. mol von dieser gebildet rerden. Es könnte fast den Eindruck machen, als ob diese Kegel etwas dor Cornea an sich Fremeles. nur ron ihr bei ihrem snecessiven Dickenwachsthm nach innen allmälig Ln- um sogar Leberwachsenes wären; sie erscheinen nämlich seitlich scharf abgegrenzt. mel heben sich überhaunt in ihrer gesammten Ausdehnumg von der Masse. in welche sie eingelagert erschemen. dentlich als. Indessen kann doch daron keine Rede sein. dem die Schichtumg setzt sich, wie man bei stärkerer Vergrösserung mit Leichtigkeit sieht. continurich von den Zwischenränuen zwischen den Kegeln auf diese selbst fort. und die anscheinende Tnterbrechng ist nur eine. allerdings nicht unbedentende, Teränderung in der Lichtbrechung, linsichtlich deren die Kégelsubstanz, besonders in ihrem Manteltheil, die benachbarten Theile der Grundsulstanz um ein Bedentendes iibertrifft. (Es mag wohl nicht überflüssig sein zu benterken. dass die Zeichnmg hinsichtlich der Regelmässigkeit der schichtung linter der Natur betrüchtlich zurückhleils.)

Olme mich vorläufig anf eime nähere Begründung einzulassen. will ich die Kegel einfach als etwa ungerwilnlich gestaltete Cornealinsen ansehen, und nit den entspredienden Facetten der Angen der andern Arthropoden als ilentisch behandeh. So mgewöhnlich sich nun anch das Aussehen derselben prïsentirt, so ist doch tarin kein Grond gegeben. sie als etwas ganz Besonderes zu betrachten. Tohl aber gilt dies für die dahinter gelergenen Weichtheile, wie die Sclilderung dieser ergeben wird.

In Fig. 12t Taf. XI habe ich einen Längsschnitt durch ein Einzelange (in stärkerer Tergrösserung als die Cornea gezeichnet) wiedergegeben, nud in den Figg. 125 und 126 derselben Taf. Querschnitte durch ein solches in rerschiedenen Höhen. und ebenfalls in relschiedenen Vaassstäben. In diesen Fignten sehen wir ms rergeblich nach den mo bekamten Bestandtheilen des zusammengesetzten Auges mn, welche wir bisher ne völlig rermisten.

Die Einzelangen stellen ïber und über prigmentirte Kegel dar. welche auf ihrer nach rorn gegen die Cornea hin gerichteten Basis eine trichterförmige Vertiefung besitzen, in welche je einer der Corneakegel mit seinem inneren freien Ende sich so einfügt, dass er sie röllig ausfült. An die Mantelfäche des Kegels stossen eine Mase cylindrischer Pigmentzellen (I'g. Fig. 124), deren 
Schicht sich ron Einzelange zu Einzelange fortsetzt; in den lnterstitien sind sie relativ kurz, an dem Angenkörper selbst aber rerlängern sie sich nach hinten, nnd scheinen sich nit ihren farlenförmigen Enden mm die nüchtigen noch zu besprechenden Retimulazellen herumzuziehen, um sich endlich zu verlieren. Diese Pigmentzellenlage hat da, wo die Corneakegel abgestutzt endigen, Lücken. nnd ich habe zwischen diesen Enden und den Vorderflächen der Retinulazellen keine zelligen Elemente mehr nachweisen können.

Der wichtigste Theil eines Einzelanges ist die Retinula (Rl. Figg. 124-126), die hier eine andere Gestalt hat, als in den bisher besprochenen Fällen. Thre Gesammtform lässt sich etwa mit der einer geschälten Orange vergleichen, da sie, wie diese, in Allgemeinen sphäroidal, rorn nud hinten abgeplattet, nnd durch ihre Zusammensetzung ans Segmenten mit meridional rerlaufenden seichten Furchen rersehen ist. Die Zahl der einzelnen je einer Zelle entsprechenden Segmente habe ich, da die Grenzen derselben häufig verwischt erscheinen, nicht genau bestimmen kömnen, ebensowenig. ob die bisherige Constanz auch lier obwaltet. Ich schïtze sie anf ca. 14-16. Jedes Segment ist an seiner zugeschärften axialen Kante mit rlem Cuticularüberzuge, den wir als eine so häufig vorkommende Form der StäbchenJildnng kennen gelernt haben, und welcher an den seitlichen Grenzflächen etwa das imnere Drittel bekleidet, bedeckt, und soriel ich sehen komnte erstrecken sich diese Ueberzüge anf den beiden einander zugekehten Seiten. zweier benachbarten Segmente gleichweit. Anf diese Weise entstehen dann anf Querschnitten. jene zweitheiligen, zarten, von einem gememsamen Mittelpunkt ausgehenden Strahlen, die in einer grösseren, dunkelpigmentirten Rosette gelegen sind, wie sie ms Fig. 125, die etwa der Mitte einer Retinula entnommen ist. zeigt. Ein analoges Bild, mit der Camera lncida nach einer viel stärkeren Tergrösserrmg entworfen. stellt Fig. 126 vor; das Prïparat stammt rom änssersten Hinterende einer Retinula. und es ist möglich, dass die relativ geringe Anzahl von Strahlen dadurch ihre Erklärung findet. cliss einige der Segmente von Schnitte schon nicht mehr getroffen wurden. - Etwa in der Nitte tragen die Retmulazellen einen ziemlich grossen blïschenförmigen Kern. dessen Nachweisnng übrigens an meinem Nateriale nicht olne Schwierigkeit war.

Der mehr axiale Theil der Segmente der Retinula schien mir noch mach vorn, gegen die conischen Corneavoragungen him, sich fortznsetzen in Gestalt von zarten, pinselförmig getheilten. Fasern, wie sie in Fig. $12 \pm$ dargestellt sind. Sie füllen also die oben erwähnte Lücke, welche die Pigmentzellen hier lassen, wenigstens theilweise ans. Ich muss aber bekennen, dass es mir nicht gelang, den Znsammenhang dieser Fasern mit den Retinulazellen röllig sicher festzustellen.

Dafür aber war der Uabergang der Zellen der Retinula nach linten in Nervenfasern m so deutlicher zn verfolgen. Ton diesen letzteren tritt eine Anzahl zu jedern Einzelange; sie divergiren hinter ilun, und ich habe melrfach recht dentlich den Eintritt einer Faser in den axialen Theil einer Retimnlazelle verfolgen künnen. - Hinter der Retinula, zwischen und um die Fasern hermm, scheinen noch schwach contourirte kleine Zellen angehäuft zu sein, jedoch bin ich anch hierin nicht sicher, da die Entfärbung den ohmehin nicht besonders günstigen Znstand meines Nateriales nicht rerbesserte.

Damit kann ich meine in so rielen Punkten wenig befriedigende sachliche Darstellung zum Abschluss bringen.

Nun bleibt noch übrig: die Stellung dieser eigenthümlichen Form von zusammengesetzten Angen näher zn bestimmen durch die Tergleichnng derselben mit den anrlern Formen.

Schon oben habe ich mich für die Identificirung der Hornhautkegel von Limulis mit. den Cornealinsen der andern Arthroporlen ausgesprochen, nud muss dies hier nun zu rechtfertigen versuchen.

Grenacher, Lntersuchungen üluer das Sehorgan der Arthropouen. 
Wir rerdanken besonders den Untersuchungen ron Leydig und M. Schultze die Kenntniss einiger Formen des zusammengesetzten Auges, die mit dem hier beschriebenen hinsichtlich des Banes der Cornea anscheinend zusammenfallen. Wir wissen nämlich, dass bei gewissen Käfern - bei Arten der Gattung Cantharis (Telephorus). bei Lampyris, Elater noctilncus - Krystallkegel sich zwar finden, aber nicht als isolirbare Gebilde; sie sitzen im Gegentheil mit ilurer Vorderflüche der lnnenseite der Cornea fest an, sind mit iln verwachsen, so dass selbst jede Spur einer Grenze zwischen beiden in Wegfall konmen kann. Anch bei diesen Thieren erscheint dann die Innenseite der Cornea mit Stacheln besetzt, die oft eine relativ recht ansehnliche Länge haben kömnen. Nan könnte nun leicht in Tersuchung kommen, hier bei Limulus das gleiche Terhalten vorauszusetzen und die Erscheinmo der Corneahöcker anf eine Verwachsung der Krystallkegel mit der zugehörigen Facette zurückzuführen.

Die nähere Prüfung der in diesem und in jenen Fällen zu berücksichtigenden Nomente spricht aber nicht zin Gunsten einer solchen Analogie. Tersuchen wir es, aus dem anatomischen Befund uns ein Bild des Torgangs der Corneabildung bei Limulns zu machen, so werden wir kamm unhin können, ilm uns in folgender Weise zu denken. Die gesammte Cornea wird ausgeschieden durch die pigmentirten ihr dicht anliegenden Zellen, und natürlich entstehen die einzelnen Schichten derselben in der Reihenfolge, wie sie ron aussen nach innen auf einander kommen. Znerst also die äussere Lage, welche durch stärkere Ansscheidung an den Stellen, unter welchen je ein Einzelange sich findet, eine schwache linsenartige Verdickung erhält. Dann die mittlere Lage, in welcher diese Verdickmng schon zu einem niedrigen, mässig zngespitzten Kegel vergrössert wirt. Endlich folgt damn die dicke innere Lage, bei deren Abscheidung die schon angelegten Kegel inmer melr zunehmen, ohne aber jemals ansser Comex mit der interstitiellen Corneasubstanz zu treten.

Ein im Wesentlichen anderes Bild ergiebt aber die Genese bei den oben genannten Käfern, deren Krystallkegel mit der Comea rerwachsen sind. Ich selbst habe nur eine einzige der oljen genannten Gattungen (Telephorus), und diese nicht eimnal entrickehmgsgeschichtlich studirt. Nichtsdestoweniger ist der Torgang mit voller Sicherheit auch ans dem fertigen Organe zu erschliessen, und ich erlaube mir, eine ron mir ausgefülnte Zeichnmng, die sich anf die genannte Gattung bezieht, in Fig. 127 hier zur Vergleichung beizufïgen. Hier ist, wie im Facettenauge der Insecten im Allgememen, der Krystallkegel $(K k$.) ron der Linsenfacette $(L f$.) durch einen weiten Zwischemram getrennt; eine angenscheinlich erst nach Bildung beider ausgeschiedene Chitinmasse $(x$.) hat jedoch verursacht, dass die beiden, denselben zelligen Elementen ihre Entstehung verdankenden Bildmgen zu einem unbeweglichen und untrembaren Ganzen verbunden worden sind. Darin aber ist auf das Bestimmiteste ansecesprochen, dass das Terhalten bei Limulus nicht verglichen werden kamn mit dem bei Telephorus, und sicherlich wird dasselbe anch für die andern genamnten Gattungen Geltung haben. Ich glaube aber vor Allem, dass nach dem vorstehend Ausgeführten es wohl kamm Widerspruch erregen wird, wem ich sage: bei Limulus sind die Kegel nur eigenthümlich modificirte Colnealinsen; Homologa der Krystallkegel sind in ilmen nicht zu erblicken.

Wem wir in den Corneazapfen aber nicht die Homologa der Krystallkegel ror uns haben, so sind sie hier ïberhaupt micht anfzufinden, denn in den dahinter gelegenen Weichtheilen ist ms nichts begegnet, was wir mit ihnen, oder anch mit ihren Tertretern im aconen Insectenange, den Ḱrystallzellen, vergleichen kömnten. Dazn konmen nun noch die Retinula mit ihrem ebenfalls ganz mngewölnhlichen Bau. Wenn sie anch in einzehen Punkten, besonders hinsichtlich der allgemeinen Anordnung ihrer Elemente (Lüngsstellnng derselben in der Richtmng des einfallenden 
Lichtes, seitliche axiale Anfügung der Stäbchensäume, Zusammentreten der letzteren zu einer Art von Rhabdom) einiges mit der Retinula der andern Arthropoden Uebereinstimmende aufweist, so ist sie doch ilurch die den letzteren so gänzlich fremden Zahlenverhïltnisse scharf von ihnen getrennt.

Fassen wir diese beiden Punkte in's Ange, so sind wir genöthigt, das zusammengesetzte Ange ron Limulns, wie es ja auch schon her geschehen ist, aus der Reihe der übrigen zusammengesetzten Augen als etwas Fremdes, Incommensurables, auszuschliessen und für sich zu behandeh. Ich rermag wenigstens keinen emzigen Anhaltspmkt für emen genetischen Zusammenhang dieses Auges mit den übrigen aufufinden. und eine Zurückführung des cinen auf das andere wird immer an dem Widerspruch eines so wichtigen Elementes, wie der Krystallkegel und sein Substitut ist, scheitern müssen. Es ist zwar, genan in demselben Sinne, wie die andern auch, ein zusammengesetztes Ange, und insofern hinsichtlich seiner Totalitit in gewisser Bezichung jenen gleichwerthig; aber die Einzelelemente, aus denen es sich aufbaut, haben nichts mit jeuen gemein, sind nicht ron ihnen ableitbar, und müssen nothwendig einen andern Ursprung haben. Wir haben demmach hier ein interessantes Beispiel genetischer Processe, die nach Habitus und Function zn einem überemstimmenden Endresultat gefüht laben, obschon ilire Ausgangspunkte aller Wahrscheinlichkeit nach recht weit auseinander liegen.

Wenn wir uns sonit genöthigt sehen, eine andere als blos physiologische Terwandtschaft des Anges ron Limulus mit ien ïbrigen Facettenaugen der Crustaceen und Insecten in Abrede zu stellen. so int damit die Sache noch nicht erledigt. dem es erhel,t sich sofort cine weitere Frage darnach, ol dicse Augenform ganz unvermittelt und eigenartig für sich bestehe. Iclı bin allerdings rorlänfig noch nicht im Stande, eine bestimmte Antwort auf diese Frage zu geben; vielleicht ist es mir aber gestattet, Termutlnngen, die sich mir anfgedrüngt haben, natürlich minter allen in solchen Füllen gebotenen Reserven, kuzen Ausdruck zu geben.

Es giebt bekanntlich wenig Thiere, deren systematische Stellung eine so unsichere ist, wie gerade Limulus nelst seinen nähern oder entfernteren Verwandten, und eine Reihe ron nenern Untersuchmgen hinsichtlich seiner Anatomie und Entwickelungsgeschichte hat nur dazu beigetragen, zu zeigen, wie schwierig haltbar die ihm bisher eingeräumte Stelle ist. Man hat auf eine Reihe ron Punkten hinwcisen kömnen, in denen die Poecilopoden mit den sonst ihrern gesammtbiologischen Terhalten nach weit von ihnen abstehenden Arachniden Verwandtschaft zeigen, und rorgeschlagen, aus ihnen eine zwischen Arachniden und Crustaceen zu stellende Classe zn bilden. Es ist hier naturlich nicht der Ort. zu der Frage der Berechtigung einer solchen, durch Abwiegung aller morphologischen lnstanzen zu motirirenden Veränderung der Stellung im System Position zu nehmen: sicher ist aber, dass wir damit für die uns lier beschäftigende Frage keinen Gewinn erziclen, denn auch bei den Arachniden suchen wir bis jetzt vergeblich nach Anklïngen an diese so selu isolirte Angenform.

Dagegen aber halte ich es nicht nur für möglich, sondern sogar für wahrschemlich, dass sich in dieser Hinsicht verwaudtschaftliche Beziehungen nicht blos zufïlliger Art ergeben zu einer Arthopodenclasse, mit der sonst die Poecilopoden in Verbindung zu bringen kamn Veranlassung vorliegt. lch meine damit die Myriapoden. Leider sind aber meine scl!on lange auch für diese Classe begonnenen Angenuntersuchungen wegen Mangel an brauchbarem Material noch zu unvollständig. $\mathbf{m}$ zu einer sichem Begründung dieser Ansicht auszureichen. Auch bei diesen Thieren finden sich bekamtlich neben einfachen auch facettirte Augen - bei Scutigera (Cermatia) z. B. - aber keine von beiden Formen weist auf die entsprechenden bei den Sjinnen oder Insecten verbreiteten hin, sie sind vielmehr ganz eigenartigen Banes. Irohl aber wurde 
ich durch eine Reihe von Zügen überrascht, die sie mit dem Auge von Limulus gemeinsam zu haben scheinen, die aber hier schon anseinanderzusetzen rerfrïht wäre. Sollte diese hier nur rermuthungsweise geäusserte Cebereinstimmung im Augenbau sich bei näherer Lutersuchung als eine thatsächliche erweisen, so kïme damit noch ein weiterer Factor hinzu, un die Lnterbringung der Poecilopoden im Systeme zn erschweren, und diesen Thieren den Character der anachronistischen Mittelformen aufzudrücken.

Was nun entlich die früheren Untersuchungen über das Ange dieser Thiere anbelangt, so ist mir nicht viel davon bekamnt geworden.

Zuerst scheint André1) sich damit befasst und den Zusammenhang zwischen Cornea und Kegeln beobachtet zu haben. Mir ist die Arbeit nur durch Citate von J. Nü̈ller und van der Hoeven (s. u.) bekannt geworden, und ich habe demnach kein Urtheil über ihren Werth.

Spaiter hat J. van der Hoeven ${ }^{2}$ ) in semer Monographie der Poecilopoden anch das Auge untersucht unu daron eine kurze Darstellung gegeben, die des Nenen wenig genug bietet. Er heht die bernsteinfarbige Cornea, wnd die ihr anhaftenden gleichfarbigen Kegel, gegen deren Hinterende sich die Fasern des Sehnerven begeben, hervor. Den Sehnerv lässt er irrigerweise ganz und mgetheilt durch eine Oeffumg der das Auge nach innen begrenzenden Chitimplatte durchtreten, was später $O$ wen $^{3}$ ) berichtigte.

Aus einer ganz kïrzlich erschienenen Darstellung des Banes dieser Organe ron Gerstäcker4) will ich hervorheben, dass dieser Forscher (nach Untersuchung eines jungen, $4_{12}^{1}{ }^{\mathrm{cm}}$ langen Exemplares von L. polyphemus) über die Vertheilung der Hornhautkegel einige eigenthümliche Angaben bringt. Er sagt (1. c. pag. 1102): „Bei weiten am dichtesten stehen diese Zapfen längs des Torder- und des an ihn angrenzenden Theiles des Tnnemrandes und hier sind sie zugleich am längsten, schmalsten und sich zumeist der Cylinderform annähernd. Am Aussen- und Hinterrand stehen sie selhr riel sperriger, und haben sie ein stumpf und dick conisches, zum Theil selbst warzen- oder zitzenförmiges Ansehen. Toch unregehnässiger erscheinen sie über die Nitte hin, wo sie häufig durch grössere (fache) Zwischenräume geschieden und mit kleinen bläschenfïrmigen Erhebungen untermischt sint. Eine, wiewohl keineswegs regelnässige, radiäre Anordnung ist an diesen Kegehn in Bereich rles rordern Drittheils der Cornea wahrmuchmen; sehr viel undentlicher zeigt sich dieselbe an hintern Ende, röllig geschwunden an der lnnenseite. Alle Tiegel convergiren mit ihrer Spitze gegen einen hinter der Cornea liegenden gemeinsamen Mittelpunkt, so dass die an Vorderrande entspringenden ilem Auge des Beschauers in der Lüngsrichtumg, die aus der Nitte herrorgehenden ihn senkrecht (mit der Spitze) entgegentreten." Dies sind des Verfassers eigene Worte; ich labe ihmen blos hinzuzufügen, dass mir an meinem, aus erwachsenen Exemplaren bestehenten Intersuchmgsmateriale derartige [nregehnäsigkeiten in der Tertheilumg der Kegel nicht aufgefallen sind; sollten es vielleicht Abweichungen sein. die sich blos an Jugendformen fiuden?

Von der weiteren Beschreibung, welche Gerstäcker liefert. mag lier blos noch hervorgehoben werden, dass er msere Retinula zwar auch gesehen, jedoch ihrem Bane nach nicht

1) André, A microscopie deseription of the eye of the Monvenlus polyphemus. Phil. Trans. 1782. Vol. 72.

$\left.{ }^{2}\right)$ J. ran der Hoeven, Recherches sur llistoire naturelle et l'anatomie des Limules. Leyde, 1838 . avec 7 pl. Fol. - pag. 23.

$\left.{ }^{3}\right)$ R. O we n, Lectures on the comparative anatomy und physiology of the Invertebrate Animals. London, 1843. jag. 174 .

$\left.{ }^{4}\right)$ A. Gerstäcker, (Bronn's Classen etc. Tol. Y.) Arthropoda. pag. 1101 (in Lief. 23 und 24). 
erkannt hat. Er spricht von einer, sich in der Richtung nach hinten an die Spitze der Kégel anschliessenden gelblich gefïrbten weichen Masse, in welche rie zahlieichen aus dem Nervus opticus hervorgehenden Nervenfasern ausstrahlen"; ferner: "Vermuthlich correspondirt die Zahl dieser einzelnen Sehnervenfasem mit derjenigen der Corneakegel, deren Spitze sich je eine zuwenrlet, ohne noch ihrerseits ein lichtbrechendes Medium in Form eines Krystallkürpers zu bilden." Meine eigenen Beobachtungen reranlassen mich, eine Uebereinstimmung der Zalıl der zu jedem Einzelauge tretenden Nervenfasern mit der Zahl der Retinulazellen für wahrscheinlich zu halten.

Das ist Alles, was mir von frülern Untersuchungen des Limulus-Auges bekannt geworden ist.

Einige sich auf die morphologische Auffassung desselben beziehende Bemerkungen verden iu folgenden Abschnitte noch ihre Stelle finden. 


\section{Folgerungent.}

In den mmmehr ansfïhrlich mitgetheilten thatsächlichen Resultaten habe ich ein Material zusammengetragen, das sich in mehr als einer Beziehung ron dem durch meine Torgänger auf diesem Gebiete erworbenen merscheidet. Ich habe in der listorischen Lebersicht über die neuere Entwickehng moseres Themas zu zeigen rersucht, zu welchen Consequenzen jene Forscher nach ihren Untersuchungen kommen mussten, und dass diese Consequenzen, ảbgesêhen von den gar nicht selten vorkommenden inneren Widersprïchen, durch ihre Unverträglichkeit unter sich auf der einen, durch die Nothwendigkeit, ad hoc creirte Hypothesen zu Hülfe zu rufen, auf der andern-Seite ihren Credit beeinträichtigt sahen. Es fehlte ihnen eben das, was im Grossen wie im Kéleinen in der Naturwissenschaft bei Verallgemeinermgen jeder Art sich ron rornherein als ein Argument von fast mwiderstehlicher Kraft erweist - jene fast als selbstrerstïndlich erscheinencle Einfachheit, welche wie eine alsebraische Fornel die zahlreichen Einzelfülle im knappsten Ausdruck umschliesst, und zur umfassenden Beherrschung der Thatsachen nicht jeden Moment zn "wemn" und ,aber" greifen muss.

Ich selbst bin sehr weit ron dem Glauben entfernt, meinerseits mun ein solches unfassendstes Resumé ziehen zu können. Dazu stehen deun doch eine Nenge, selbst von hier mitgetheilten Thatsachen in zu geringer Vermittehung unter sich da, ganz abgeseluen ron jenen, welclıe erst die Zukunft zu erforschen haben wird.

Aber es sind wenigstens drei Fragen, die in mehr oder weniger genïgender Wrise vielleicht einer Lösung durch das ron mir zu Tage geförderte Material entgegengefülnt worden sind; zwei daron, wie ich glaube, so sicher, als nach dem dermaligen Zustande miserer WTissenschaft mur möglich ist, während die dritte allerdings sich auf einge Torbehalte wird gefasst machen inüssen. 7wei dieser Fragen schlagen in das Gebiet der Morphologie ein, die dritte aber ist die am eifrigsten discutirte, die nümlich über den Vorgang des Sehens in dem Facettenange. Eine ron den ersten und diese dritte glaube ich sicher entscheiden zn kömnen, während die noch restirende, um mehr zu sein, als blosse Hypothese. wohl noch der Lnterstiitzung einiger auf anderem Gebiete geworbenen Hülfstrupen sich bedürftig zeigen wird. Keine der Fragen ist neu. jede ist schon von linger Zeit her anfgeworfen, jede schon oft genug zu beantworten versucht worden. Dass anch die Antworten schon oft genug in demselben Sinne ausgefallen sind, wie hier, ist nicht zu bestreiten, ist aber auch kein Wunder, wemn die Alternative nm zwischen ja und nein gestellt ist. Num macht aber weniger die Bestimmtheit einer Behanptung, als ihre Begründung ihre Glaubwïrdigkeit ans, trotz aller Bei-piele des Gegentheils in der nenern Zoologie. Und hinsichtlich der Begrïndung glaube ich Einiges gewomen zu haben.

Wenn wir an ein und demselben Einzelwesen zweierlei Organe neben einander entdecken. die notorisch derselben Function — wenn anch rielleicht mit unwesentlichen Nodificationen - 
dienen, und wir dabei die Beobachtung einer weit auseinandergehenden Verschiedenheit in Bau dieser Organe machen. die uns nicht durch die Einsicht in eben jene secundären Modificationen genïgend erklärt wird, so wird dieser Lmstand, der zn unserer gewölnhlichen Erfahrung sich in einen starken Gegensatz stellt, dem Beobachter genug Stoff zum Nachdeuken geben. Derartige Beispiele sind äusserst selten, und vor Allcm selten ist die Grösse rles Gegensatzes, in welchem in unserm Falle die beiden Organe, die wir hier im Sinne haben, nämlich die am Kopfe unzähliger Insecten-Imagines gleichzeitig und in nächster Nühe rorhandenen einfachen und zusammengesetzten Augen, zu einander stehen ${ }^{1}$ ). Dieser auffallende Contrast erklärt uns auch die Verschiedenheit in dem Ausdruck der morphologischen Beziehnngen, die man, wie in rler historischen Uebersicht angeführt. zwischen ihnen aufrichtete: während der Eine jede morphologische Beziehnug zwischen den beiden Formen längnet, und nichts weiter anerkemen will, als dass beide Augen sind, vergleicht ein Anderer das einfache Ange dem Facettenauge in toto, wälnrend der Dritte in der Einzelfacette der letzteren den dem Stemma homologen Antheil erkannt haben will. Demnach. haben wir die erste Frage so zu stellen:

..Lassen sich zwischen dem Stemma und dem Facettenauge der Insecten (und Crustaceen) morphologische Beziehungen nachweisen? Und wenn. - welche Theile des einen sind denen des andern im Sinne der lientigen Morphologie zu vergleichen?"

Da es sich aber nicht allein um das Stemma der Insecten-Imagines, sonderin ebensowohl nm gleich orler: ähnlich geformte Sehorgane auch bei anderu Arthropoden handelt, so wird schon dadurch naturgenäss die Frage eine weitere und mehr umfassende. Wenn wir nun gar, was uns ja nicht verwehrt werden kamn, über die Grenzen des Arthropodentypus hinausschreiten, jemseits deren wir rengstens im Allgemeinen ähmliche Formen ron Angen antreffen, so stellt sich ms ein weiteres Problem dir, das aber. weil es so weit tum sich greift, viel schwieriger und nur sehr vorsichtig zu behandeln ist. Die Frage kömnen wir dann so formuliren:

"Welche Beziehungen haben die verschiedenen Formen des Selorgans der Arthropoden zu denen der andern Thiertypen? Lässt sich, abgesehen von der allgemeinen Function der Lichtperception, etwa auch eine allen Formen ron Angen gemeinsame morphologische Grundlage nachweisen?"

Und endlich drittens: Das Sehen mit dem Facettenange gieht noch innmer zu vielen Discussionen in entgegengesetztem Simne Veranlassung, soweit es den Modns, die Mechanik anbelangt. Es ilarf deshalb wohl anch gestattet werden, auf Grund eirer Reihe nener Unter'suchungen die Frage einer abermaligen Discussion zu unterwerfen, un zu versuchen, Klarheit und Sicherheit in dem so schwierigen Gebiete zu erzielen. Die Frage selbst aber formuliren wir so:

"Ist der zu je einer Facette gehörige Antheil eines zusaminengesetzten Arthroportenanges als ein selbständig functionirendes, zur Bildperception befähigtes Einzelinge aufzufassen, oder ist sein Leistungswerth nur vergleichbar mit dem einer Perceptionseinheit. eines Stäbchens?"

Der Beantwortung (lieser drei Fragen, wenn auch in anderer Reihenfolge, sollen die folgenden drei Ahschnitte gewidnet sein.

1) Solche Beispiele liefern ferner noch die Gattung Euphausia mit ihren bauehständigen einfaehen Angen neben den kopfständigen ficettirten (rgl. Cla us. Ueber einige Sehizopoden und andere Malacostraken Messina's. Ztsehft. f. Zool. 1863. Tol. XIII. pag. 422). Leider war während meines Aufenthaltes in Neapel die Ausbeute an En phausia zn gering. um eingehendere Studien über ihre Banchangen zu machen. - Ferner hat neuerdings C. S emper (Uel)er Schneekenangen rom Wirbelthiertypus etc. Arch. f. mikr. Anat. 1877. Vol. XIV. pag. 11t; spüter in einer ausfülırlichen Monographie [s, u.]) einen hierher gehörigen Full von On ehidium beschrieben. Ton diesem letzteren später. 


\section{Abschnitt.}

\section{Das Stemma und das zusammengesetzte Auge.}

So lange man das Vorkommen ron Krystallkegeln als mit dem Begriff eines facettirten Arthropodenanges intrembar verbunden betrachtete, musste nothwendig der Yersuch der Zurückfülırung beicler Angenformen anf einander auf Schwierigkeiten stossen, welche sicherlich durch die Unsicherheit, das Schwankende in der Deutung derselben hinsichtlich ilırer pliysiologischen Rolle nicht verringert wurden. Man hatte bekanntlich versucht. dirse Elemente, deren Bedeutung und Wichtigkeit für das Zustandekommen des Sehvorgangs schon aus ihrer anschemend ausnahmslosen Verbreitung hervorzugehen schien, auch im einfachen Ange nachzuweisen, und wäre dies geglückt, so wäre damit sicher eine Brücke für die morphologische Zurückführung beider Augenformen auf emander geschlagen gewesen; leider liess jedoch die Beweisfülırmg noch gar Nanches zu wünschen ïbrig.

Sehen wir nun zu, wie sich die Sache gestaltet, nachdem der Nachweis gefülurt worden ist, dass eine ungeahnt grosse Anzahl von Insecten sich ohne Krystallkegel behelfen muss. Es wurde gezeigt, dass an dessen Stelle sich immer ein Complex ron rier. Zellen befindet, die functionell (abgesehen von ihrer geringeren Lichtbrechungsfähigkeit) wohl diesellse Polle zu spielen vermögen, welche bei den andern dem Krrystallkegel zukommt. Zunächst sind wir noch in keiner Weise berechtigt, sie mit den Krystallkegeh morphologisch zusammenzustellen; wir müssen vorher diese letzteren noch einer nähern Prüfung unterwerfen.

$\mathrm{Zn}$ diesem Zwecke wollen wir die Entwickelungsgeschichte des Krystallkegels, wie sie uns ron Claparède ${ }^{1}$ ) dargestellt worden ist, noch einmal zu Rathe ziehen. Claparède hat Schmetterlinge und Aneisen, also Insecten mit euconen Angen, zu seinen Untersuchungen benutzt; die sonst so trefflichen Untersuchungen ron Weismann, an Dipteren angestellt, kommen hier nicht in Betracht. da diese Thiere, wie wir wissen. psendocone Augen haben.

Claparède hat num den Nachweis geführt, dass in der Pupje ursprünglich an der Stelle des Krystallkegels sich ein Complex von vier Zellen findet, die mit einander einen „globnlösen Klumpen" bilden. Diese Zellen scheiden gemeinsam die zu ihnen gehörige Facette der Cornea aus, und ausserdem tritt später in jeder derselben ein durchsichtiges Kügelchen auf, das sich allmälig vergrössert, bis schliesslich alle vier Krïgelchen mit emander in Terbindung treten, um zusammen den Krystallkegel herzustellen.

Jch selbst habe mich bis jetzt zwar nicht mit Entwickelungsgeschichte des Auges planmässig beschäftigt, doch sind mir wenigstens ein paar Beobachtungen, die ich gelegentlich machte, beweisend genug fïr die Richtigkeit rler Claparède'schen Darstellung.

Ich habe Embryonen von Mysis und ron Porcellio, also von Crustaceen, unter Angen gehabt, und hier verläuft der Process (al)gesehen natürlich ron den hier anderen Zahlenverhältnissen) genan in der oben geschilderten Weise (rgl. ob. pag. 118 für Mysis). In lyeiden Fällen bildet die Anlage des Krystallkegels zunïchst ein Par kleiner Kügelchen, die tief im Innern der zugehörigen Zellen eingesenkt an völlig farblose Fetttröpfchen erimnern; später treten sie zusammen, und jedes derselben bildet sich zu einer Hälfte des Krystallkegels um. Bei rliesen Crustaceen sowohl wie bei den Insecten bleibt ron den ursprünglichen Mutterzellen schliesslich

1) 1. e. (Ztsehft. f. wiss. Zool. Bd. X, jag. 191 u. ff.) 
venig genug mehr übrig; meistens persistiren die sog. Sempèr'schen Kerne. und man wird wohl auch die Hülle der Kegel anf die ursprünglichen Zellmembranen zurückfüluren dürfen.

Diese Thatsachen liefern uns einen meiner Ansicht nach manfechtbaren Beweis dafür, dass die Krystalliegel erst eine secundïre Bildung simd, hervorgegangen aus der primären, dem Complex der Krystallzellen, die bei einer grossen Anzahl ron lnsecten sich beständig in dieser Form erhalten. Wh nehme auch keinen Anstoss daran, wenn nan jene hinsichtlich ihrer Genese als ,eine Art ron imnerer Cuticularbildung" (Claparède) auffast; man darf dabei nur nicht allzu streng an der eigentlichen Bedentung des Wortes kleben bleiben. - Jedenfills aber berechtigt uns das hier vorgelegte Material zu tlem Versuch, den Anknüpfungspunkt an das Stemma im aconen Ange zu suchen.

Niclıt geringere Schwierigkeiten als der Krystallkegel bereitete der räthselhafte Bau des ..Seh"- oder "Norvenstahes", suweit die früheren Lntersuchungen Aufschluss darüber zu geben rermochten. Invernittelt stand dieser anscheinend nicht minder wichtige Bestandtheil des Facettenanges für sich da, und wim komnte weder seinen stärker lichtbrechenden Axenstab — unser Rirabdon, — noch seine "Hülle" mit den Kernen — die Körper mserer Petinulazellen in morphologischen Sime vollgültig verwerthen. Aber ebensowenig im physiologirchen; denn ich brauche nur anf Leydig, der in Krystallkegel das percipirende Element, auf II. Schultze, rler diese in feinsten Fäserchen hinter rem Krystallkegel und ror dem .. Selıstal," sah, hinzuweisen, um das Schwankende und Ln-ichere in ihrer Dentung zu illustriren.

Ich habe nun aber mit Formen der Retinula - nm uns jetzt wieder dieses Ausdrucks zu bedienen - bekannt genacht. die eine sichere Bestimmung in morphologischer wie physiologischer Hinsicht ermöglichen. lch habe zeigen kömnen. dass die Retinnla mit iłrem Rhabdom, wie sie in den Angen der bisher am meisten untersuchten Insecten sich findet, als eine obenfalls abgeleitete Bilrung antzufassen ist, herrorgegangen aus ler Coalescenz einer Jestimnten Anzahl ron Einzelelementen, die sich ilnerseits wieder in typischen Anordungs- md Structurverhältnissen bei emer andern grossen Scrie ron Insecten danemd ohne Terschmelzung und selbstïndig erhalten. Lis sind, un es lier kurz zn recapituliren, diese Elemente Zellen, die nach vorn hin, anch seitlich an vordern Theil, je ein Stäbchen ansscheiden, die nach limten mit einer Nervenfaser in Connex stehen, und deren grundlegende Zahl sieben sowohl Rednctionen auf fünf und vier, als anch in scltenen Fällen Erweiterung anf acht erfiihrt.

Was ist num hier das Prinäre, was diss Secmdäre? Auch ohne Rücksicht auf andere als blos in der Retinula selbst gelegene L'mstïnde glaube ich nicht, dass das Lrtheil hierüber einen Schwanken unterworfen sein kam; wohl Jecher wirl die Retinula mit unverschmolzenen Elementen für das Primäre halten. Tritt an einem Organe eines Thieres eine bestimmte Anzahl von cliscreten Elementen auf, clie unter sich gleichwerthig sind; finden wir an einer andern Thierforn lesselben Organisationsplanes diese Elemente durch Integration, wie H. Spencer sagt, zu einer höhern Einheit rersclunolzen, so führt man, wie die Erfahrung zeigt, nie den ersten Zustand auf den letzteren zurück, sondern immer mngekehrt. Nan denke an clie Frage iiber die Gliedmassen und Segmente bei den Arthropolen z. B., bei welcher doch unstreitig als der Heteronomie rorhergehend die Homonomie rorausgesetzt wird, - und an die in mancher Beziehnng allerdings etwas differirende über die Wirbeltheorie des Schüdels, wo Niemand die Wirbel vom Schädel, sondern leder diesen ron jenen ersteren ableiten wird.

Hierzu kommt aber noch ein ferneres Argument. Lässt man das vorlin für den Krystallkegel als eine secundäre Bildung Ausgeführte gelten. so beeinflusst dies anch die Deutung der Phabdome führenden Retimulae wenigstens in gewissem Simne. Ich kann auf die im beschreibenden 
Theile gegebenen Thatsachen hinweisen, aus denen hervorgeht, dass ïberall da, wo der dem Krystallkegel roraufgehende mimäre Zustand der bleibende ist - beim aconen Ange — auch die Selbständigkeit der Retinnlaelennente cine relativ grosse ist. Der gewissermassen archaistische Character des aconen Auges ist demmach nicht nur durch die Alwesenheit jener nemem Bildung. des Krystallkegels, allein ausgesprochen, sondern auch durch die noch nicht rollzogene Verschmelzmng der Retinulazellen. Auch dies berechtigt mich, bei einer Vergleichung der zusammengesetzten unit den einfachen Augen hinsichtlich ihrer empfindendeu Alparate beim aconen Ange Anknïpfungspunkte zu suchen.

Alles weist uns sonit auf diese aconen Augen hin. Sehen wir nun zo, was diese mit den Stemma Gemeinsames haben. Wenn ich unter dem. Stemma ganz im Allgemeinen auch das Spinnenange mit eimbegreife, so wird das, bei der völligen Lebereinstimmmng des letzteren mit dem einfachen Insectenange in morphologischer Hinsicht, nicht befremden. Wohl aber sehe ich mich genüthigt, für jetzt wenigstens die von mir beschriebenen Larvenaugen. sowie diejenigen der Copeporlen ansser Betracht zu kassen. Wemn auch von gewissen Gesichtspmeten ans betrachtet die ersteren in letzter Instanz wohl mit dem Stemma und dem Facettenange znsammengestellt werden künnen, was für die Copepodenangen noch nicht erlanlut ist. so gehört dies doch noch nicht hierher, mol für die hier zu erörternden Beziehungen fehlen uns die Mittel und Wege gänzlich.

Für die Tergleichung des Stenma mit dem Facettenange stehen uns num zwei Wege offen. Wir können eimmal, mit Leydig, sehen. ob eine Zurückfülurung des Stemma auf das Facettenange in toto durchführbar ist. oder ob. nit der Mehrzalıl der übrigen Autoren, das erstere init der Einzelfacette nebst Zubehör in eine Linie zu stellen ist, mol wir werchen uns wohl vorbehalten dürfen, derjenigen Tergleichung den Torzug einzü̈umen, die nicht nur die morphologischen Schwierigkeiten aus dem Wege rämmt, sondern auch, was freilich dem Simne nach fast damit identisch ist. uns eincu Blick anf die Gence dieser Organe in Simne der Descendenztheorie eröffnet.

Für eine Tergleichno des Stemma mit dem ganzen Facettenauge erwachsen aber gleich beim Beginne Anstösse. Wir finden zwar in letzterem dieselben Elemente wieder, die das erstere zusammensetzen: rorn eine Cornea, linter dieser eine Zellenlage als Matrix für sie, und endlich wieder hinter dieser eine aus den percipirenden Elementen gebildete Zcllenschicht. Während aber im Facettenauge alle diese Elemente durch Gruppenbildung ein fremdartiges Gewand erhalten, die Comea diesen Gruppen entsprechend in kleine "Corneules", wie die Franzosen sie nemmen, parcellirt, jede der Gruppen ferner ron rom bis hinten durch Pigment ans:-er Terbindung mit ihren Nachbarn gesetzt ist, fehlt dies Alles bein Stemma gänzlich. Ferner lïsst uns der Prüfstein für die Richtigkeit der unorphologischen Verglcichung, die Denkbarkeit einer Abhängigkeit der beiden Formen ron einander in Simne der Descendenz. vollends im Stiche; dem es erfordert nur kurze Ueberlegung, um einzusehen, dass man ohne lens ex machima, oder ohne die doch essentielle Function des Organs als Sehorgan für grosse Zeiträume wälnend der Lmwandlung röllig preiszugeben, kurz, ohme merlaubte Hülfsmittel, nicht im Stande ist, das eine vom andern abzuleiten.

Leichter wird die Aufgabe aber auf dem andern Wege, nämlich auf dem der Zurückführung des Stemma auf den zu einer Facette gehörigen Bruchtheil eines znsammengesetzten Auges. Fassen wir das Wesentliche eines Insectenstemma oder eines Spinnenanges, ohne Rücksicht zu nelmen auf die kleinen secundären Nodificationen, wie sie uns bei verschiedenen Gattungen und Arten entgegentreten, zusammen, so finden wir ïberall:

1. eine mehr oder weniger linsenförmig gewölbte Cornea;

2. eine hinter dieser gelegene durchsichtige Zellenschicht, welcher die Cornea ibre Entstehung verdankt; 
3. eine hinter dieser Zellenschicht gelegene, ebenfalls aus Zellen gebildete Retina, deren Elemente vorn ein Stäbchen eingesenkt tragen, linten mit einer Nervenfaser in Verbindung stehen;

4. Pigmentzellen, welche das Ganze an seiner Peripherie ringfönnig gegen seitlich einfallendes Licht schïtzen.

Diese ans einer Reilie ron Einzelfällen gewomnene Abstraction des Banes der hier in Frage kommenden Form des einfachen Anges passt aber buchstäblich auf den Facettenantheil des aconen zusammengesetzten Auges. Auch hier ist rorn die Cornea von rarirender Wölbung, hinter ihr die sie abscheidende durchsichtige Zellenschicht (Krystallzellen), hinter dieser ferner die Lage der Retinaelemente (hier als Retimula) rorhanden, und auf die Elemente der letzteren passt das rorhin Gesagte ebenfalls - abgesehen von der geringfügigen Abweichung, dass die Stäbchen häufig seitlich an Vorderende der Zellen anfsitzen _-, und endlich ist auch die Anordnung der Pigmentzellen dieselbe. Sorreit es also auf die merlässliche Tebereinstimmung in der Anordnung der Angenelemente, den Banplan, ankommt, so ist in dieser Hinsicht gewiss alles Erforderliche geleistet; dagegen ergeben sich Tnterschiede in den Verhältnissen der Zahlen rer Augenelenente, sowie der Form einiger derselben. Was die Zählenverhältnisse anbelangt, so stellen sich diese aber sowohl beim einfachen, als anch, wenngleich innerhalb engerer Grenzen, bein zusammengesetzten Ange als schwankende dar. (zwei- bis fünftheilige Krystallkegel, vierbis achttheilige Retinulae), sodass wohl nichts in Wege steht, aucl lier ron ihnen geradeso abznsehen, wie wir es in vielen andern Füllen zu thun gezwungen sind. Noch weniger aber dürften die untergeordneten Differenzen in dex Gestalt. die besonder's in der nach hinten conischen Form der Krystallzellen gegenüber der mehr prismatischen der Elemente des „Glaskörpers" im Stemma ilıren Ansdruck findet, zu besagen liaben; um so weniger, als, wie wir sehen werden, diese Formumänderung mit der Modification der Function in imnigsten Zusammenhange steht.

Wenn demmach morphologisch das Stemna der Einzelfacette in aconen Ange entspricht, so wird, nach den früher Angeführten. dasselbe anch für das pseudocone und das eucone Ange Geltung haben müssen, da wir in diesen nu anders, resp. weiter differenzirte Formen vor ms haben, bei denen die Teiterbihtung sich nicht nur anf die limter der Cornea gelegenen Zellen (durch Ausscheidung des Pseudoconus und des Trystallkegels) beschünkt, sondern auch sich anf die Retimulazellen, welche unter sich in innigeren Contact treten, und deren Stäbchen zu cinem axialen Rhabdom verwachsen kümen etc. ctc., crstreckt. - So werden demn alle Formen vom Stemma an ifurch das acone und pseudocone, Jis zo den complicirtesten Fornen des euconen Aages ier Insecten und Crustaceen - Limulus selbstrerständlich iumer ausgenommen - zu einem übersichtlichen Gesammtbilde rereinigt.

Wemn wir eimmal dies Restultat erhalten haben, so fällt es auch nicht schwer, dasselbe im Sinne der Descendenz zu verwenden. Freilich glaube ich, dass der Gerlanke der Ableitung der einen fertigen Angenform ron der andern, wie wir sie an msern leutigen Arthropoden kennen, nicht aufkommen kamn. Das Stemma, wie es die Insecten jetzt zeigen. ist. un ein Bild zu gebrauchen, nicht als Mutter, sondern als Schwester des Facettenanges aufunfassen, und beide führen auf einen Ausgangspunkt zurïck, rer sich nur lyypothetisch feststellen lïsst. Befolgen wir den in der nenern Zeit so viel — vielleicht allzuriel - betretenen Weg, die muthmassliche Urform verschiedener. jetzt stark differirender Organe ans deren anatumischen Eigenthümlichkeiten und Terwandtschaften zu reconstruiren, so würde der Ansgangspunkt nicht weit von dem Einzelange des aconen Anges - etwa der Tipnliden z. B. - gelegen scin; nicht geradezn in ihm. aber in einer nur $u$ ein Geringes daron unterschiedenen Form. Diese Form aber brauchte sich 
ron der erwähnten nur durch die nach hinten nicht conisch verjüngten Krystallzcllen, sowie die unter sich gleichen Retimnlazellen und Stäbchen zu mnterscheiden. mu als Ansgangspmlit für das Stemma nach der einen Seite, für das zusammengesetzte nach der andern dienen zn können. Es stelit ms frei, mit dieser einzigen Angenform die vermuthlichen Urahnen unserer jetzigen Arthroporlen anszurüsten, und im Lanfe der Zeit. T'mwandlungen daran anftreten zn lassen, deren Trsachen wir nicht kemnen, deren Pesultate wir aber in der bekannten Differenzirmg jener beiden Hauptformen des Sehorganes ror ms haben. Termehrung der Einzelelemente des Urauges führt nus zum Stemma; Termehrnng der Zahl der Einzelangen, nähere Aggregirmg derselben muter leichter Umformug ler Elemente dagegen leitet nus zum. Facettenauge hinüber.

Indessen hat diese Art und Teise. uns die Sache zurecht żu legen. auch wieder ihre Schattenseiten, die bei näherer Betrachtung nicht entgehen können. Denn eimmal participiren miter den hier in Frage kommenden Arthropoden die Spinnen mit den Insecten an den Besitz eines dem Bau nach bei beilen Classen vällig identischen einfachen Auges. die Crustaceen aber mit den Insecten an rem Besitz eines nicht minder morphologisch identischen Facettenanges. Sehen wir nun vorlüufig ab von den Argunenten, welche man in der letzten Zeit zn Gunsten einer gesonderten Abstammmng der Crustaceen geltend gemacht lat. wud setzen wir den Fall, ihre Zurückführmg mit Insecten mo Spinnen (von Myriapoden wollen wir hier nicht reden) auf denselben Stamm mnterliege keinem Zweifel. Demnach müsste dam, bei der morphologischen Zurückführbarkeit der Angen anf einander. jenem supponirten gemeinsanen Trahnen, dem alle drei Classen ihren Ursprung in letzter Instanz rerdanken, anch der Besitz jener indifferenten Tramgen zngeschrieben werden, mor die descendirenden Stämme hätten sich in der Weise in die Modification getheilt, dass den Spinnen nur die Entwickelung zum Stemma, den Crustaceen nur die zum Facettenange da bei ilmen kein stemma. wie bei den beiden andern Classen, sich zu finden scheint), zufiel, während bei den Insecten beide es zn einer relativ hohen dushildungsstufe brachten.

Nmn finden wir bei beiden Clasken mit Facettenangen. Insecten mol Crustaceen. diese so eigenartig unl specifisch eingerichtet. und dabei so sehr mter sich übereinstimmend, dass man der Versuchmng nicht leicht widerstehen kamn, anzmehmen. dass diese Organe als gewichtiges Bindeglied zwischen den beiden, sonst so rerschiedenen Classen dienen und in den wesentlichsten Grundzïgen ihrer Form und Ansbildung schon vorhanden gewesen sein müssen, bevor diese Stïmme ilure gesonderten Wege einschlngen; jeder der Stämne erhielt dieses alte Erbtheil, $m$ es nur unwesentlich zu modifiriren. Zu rlieser alten Erbschaft aber gehörte anch rer hrystallkegel, denn sein Torkommen in beiden Classen. sowie die Tebereinstimmung in Ban mnd Entstehmo legen diese weitergehende Folgermng nahe genug. Bei der monophyletischen Auffassmgsweise des Facettenanges drängt sich uns aber die Frage anf: wie konmt es denn. dass ein Organ von der Bedentung des Krystallkegels wienler verloren gehen konnte bei jener grossen Anzahl von lnsecten. deren Augen wir als acone bezeichnet haben?

Es ist klar. dass diese Frage anch nicht ans der Luft geschafft wird, wemn wir von der olmehin stark bestrittenen Stammesverwandtschaft der Insecten und Crustaceen abselren, damit also schon der polyphyletischen Entstehmnsweise des Facettenanges - wohlverstanden. bis zu fast identischen Endresnltaten — die Thüre öfnen. Gegen die monophyletische Abstammung der einzelnen Insectenordnungen ist meines Wissens noch kein ernstlicher Widerspruch erhoben wortlen; wir hätten also hier freie Hand, deren gemeinsane Ansgangsform wieder mit krystallkegelhaltigen Facettenangen anszustatten. Aber das Facit bleilst das gleiche: entweder haben eine Menge ron Formen ein durch Zuchtwahl entstandenes, für das Sehen mit dem Facettenange 
vorzüglielı geschicktes Organ wieder eingebüsst; oder dascelbe ist nicht rererbt. sondern polyphyletisch imerhalh der Ordnmgen der Insecten entstanden. Tie eigenthümlich in diesen räthselhaften Beziehmngen einzelne der Insectenordnungen sich stellen, wie z. B. die Coleopteren, bei denen arone und encone, die Dipteren, bei denen acone, pseudocone und rereinzelt encone Angen anftreten etc., brancht hier nicht weiter ansgeführt zn werden.

Die Alternative, ror welche wir gestellt sind, ist eine eigenthümliche. Die monophyletische Anffasming der Insectenclasse - m bei dieser stehen zu bleiben — fordert das Anfgeben, den nach erlangtem Besitz erst eingetretenen Verhst eimer Bildung. die. wenn wir ans der beständigen Anwesenheit derselben in den Organen höchster Leistungsfühigkeit cinen Rürkschluss ziehen dürfen. gerade für diese Leistungsfïlhigkeit als eine besonders günstige Vorbedingmg gelten muss. Ich kann mich, ich gestehe es offen, um sehr schwer dazu entschliessen, dies testimonimm pampertatis der natürlichen Zïchtung auszustellen, die doch sonst so mgemein hanshälterisch mit ihren Enungenschaften verfïlurt; und dies trotz aller Lehre ron den rudimentïren Organen, für welche doch immer eine Compensation nach dieser oder jener Seite gewälıt wird. - Demnoch, glaube ich, werden zur Zeit wohl mehr Forscher sich finden lassen, die sich in dieser Hinsicht zu Concessionen bereit erklïren, als zn solchen nach der andern Seite hin. Denn wollen wir der monophyletischen Auffassung nicht jenes Verlustconto eröffnen, so bleibt uns keine Wahl, als zur polyphyletischen zn greifen. Lassen wir diese aber auch nm für ein einziges Organ gelten, so sehe ich nicht ein, was hindern sollte, sie tür die ganzen Organismen in Anwendmg zu bringen, und lice scheint mir der Einsatz zn gross.

Es ist natürlich schon erlaubt, Tersnche zu machen, mn ans diesem Dilemma zu kommen. Ëmen solchen möchte ich hier mittheilen, trotzdem ich mir sagen muss, dass er noch lange nicht ansreicht. alle Schwierigkeiten ans dem Wege zu räumen. Tielleicht sind Andere auf diesem oder auch einem andern Wege glücklicher als ich.

Ich fusse dabei auf einer Veränderung der Auffassung der Beziehungen, welche zwischen Krystallkegel und Corneafacette obwalten. Beide verdanken, wie uns die Beobachtung lehrt, ihren Trsprung denselben zelligen Elementen des Anges. Beide zeigen bezïglich ihres Banes gewisse Verschiedenheiten, von denen die am meisten in die Augen fallende Differenz die der Consistenz ist: die Facette ist immer fest und derb, oft genug ganz aussergewöhnlich hart mud dick, während der Krystallkegel meist weich, oft halbfliissig und dadurch schwer isolirbar erscheint. Es frägt sich num, ol man berechtigt ist, anf diese und andere I nterschiede physicalischer oder chemischer Art soviel Gewicht zu legen, m Facette und Tirystallkegel als in jedem Sinne ganz rerschiedene Dinge aufzufassen. Ich mïchte dies keineswegs umbedingt bejahen, wenigstens nicht in dem angedentren Simne, welcher mur anf das Tesen der Substanzen, aus denen sie bestehen, Bezug nimmt. Ich glaube. dass auch das Material, aus welchem die Krystallkegel bestehen, dem Chitin der Facette seln nahe steht, trołz seiner oft so geringen Consolidirung. Diese Wesensihnlichkeit scheint mir eine Stütze zu erhalten in den schon erwïhnten Fällen, wo. wie bei Telephorus. Lampyris und Elater noctilucus. die Kegel mit den Facetten so imig verwaclısen könmen, dass man sellsst rergebens nach emer Grenze zwischen beiden sich mmsielit. Giebt man aber dies zn, so wäre es vielleicht anch möglich, die Anffassung des Krystallkegels in morphologischer Bezichung etwas anders zn fassen, und in ilm hlos ein losgelöstes Stück Facette, die äbergross gewordene, und dann ron der Hauptmasse losgetrennte innere Convexität der Comealinse etwa zn erblicken. Dass dieses abgetrennte und selbstïndig gewordene Stück seine Natur in vielen wesentlichen Punkten, namentlich hinsichtlich seiner Consistenz, änderte gegenüber der immerhin einen Theil des Integumentes bildenden Facette, würle wohl kaum wundern können. obschon eine Reihe von imnern Chitmbildmgen sich hierin den oberflïchlich 
gelegenen ähnlich verhält. Damm würden ms auch die acomen Angen in einem ctwas andern Lichte erscheinen; wir würden dam in ilmen nicht Augen, welche die hrystallkegel veroren laben, sondern nur solche zu erblicken haben, in welchen sie mit der Facette immer untrembar rerschmolzen hleiben, und überhaupt ilıer Mlasse nach so geringfügig angelegt werden, dass sie keine, oder dloch nur eine geringe Vorragming nach imnen hervormfen. Nathematisch ansgedrückt: wir hätteı dam den Kirystallkegel nicht $=0$, sondem als unendlich klein zu setzen, was für die Praxis, d. h. für die Beobachtung, natürlicl völlig gleichwerthig wëre, aber nicht für die theoretische Anffissung der ganzen Frage. Das Fehlen des Krystallkegels würde dam nicht mehr völlig so störend sein, da es sich mehr um eine hochgradige Abschwächung der Ansbildumg handeln würde.

Wie schon bemerkt, bin ich selbst durchans nicht der Ansicht. hiermit der ganzen Frage die Spitze abgebrochen zu haben. Es ist nu ein Tothbehelf. den ich biete. und ich bin ausser Stande, weun man etwa den Torwurf der Soplistik gegen die ganze Betrachtungsweise erheben wollte, dagegen żn opponiren.

Doch, wie man sich auch zn diesen Seiten des Problems stellen möge: Eines scheint mir nicht erschüttert werden zu kömnen, nümlich der geführte Nachweis der Ueberemstimmumg des einfachen und des facettirten Anges in Bezug auf ihre homologen Bestandtheile.

Das Auge ron Limulus, um auch über dieses noch ein paar Itorte hinzuzufügen, bietet uns ein ganz eridentes Beispiel einer Schemhomologie. Auf den ersten Anblick überrascht uns sicher die üussere Aehnlichkeit mit den Facettenaugen der andern Arthropoden nicht im Geringsten; dem wir setzen stillschweigend rorans, dass anch der architectonische Bau derselbe sem miisse. Nun zeigt sich aber bei nïlerer Betrachtmng das directe Gegentheil. dem wir finden keinerlei Anklänge an jene Structmr. als solche rein äusserlicher Art. Hier geben wir willig eine separate Entstehung, mabhängig von den ander'u Facettenaugen der Crustaceen und Insecten, zu, mud nach den dort gewonnenen Erfahrungen werden wir diese Entstehmg ehenfalls auf eine einfache Angenform, die durch massenlıfte Anhäufung und ent-grechende Umbilınng ilner Einzelbestandtheile sie veranlasst. zurïckzuführen geneigt sein. Aber auch dieses einfache Auge wird schon den Kím des Gegensatzes gegenüber den andern aufweicen mürsen.

Dasselhe wird ron den Fällen gelten nüssen. Welche wir aus der Classe der Myriapoden kennen; ich meine ron den Facettenange der Scutigera. Thatsächliches kann ich darüber nur das berichten, dass es zwrr ein zusammengesetztes. aber mit dem der Insecten und Crustaceen ebenso wenig anf morphologischer Basis vergleiclibares ist, als das ron Limulus. Es wird späterer Untersuchmg noch anheim gestellt werden müssen, die Lücken in der Beobachtung und der Terwerthmg der Funde auszufüllen.

\section{Abschnitt.}

\section{Der Sehrorgang im Facettenauge.}

An zweiter Stelle tritt an uns die Frage heran, wie wir die im speciellen be-chreibenden Theile mitgetheilten Thatsachen benutzen können, um den so oft discutirten Vorgang des Sehens im Facettenauge festzustellen. Wie abuängig das Resultat dieser Frage ron der Sicherstellung der Bedeutung der einzehnen Augenbestandtheile in morphologischer und physiologischer Hinsicht ist, haben wir schon aus der historischen Uebersicht erkennen können, wo es unumgünglich war, 
auch auf die thatsïchlichen Befunde rer Vorgänger anf diesen Gebiete zuweilen näher einzugehen, un deren Deutung rerstehen zu kömnen. Soweit ich die Sache übersehen kamu, bleibt uns zur Zeit als allein zum sichern Ziel führender Weg nur der übrig, anf den uns die morphologische Forschung hinwexist; aber auch dieser führt ms nicht direct zum Ziel, sonelern es ist nöthig. die Tragweite und lnterpretationsfahihgeit jeder einzelnen Thatsiche genan zu erwägen, und nach der Prüfung aller das Facit ans ihnen zu ziehen.

Die Entscheirhng wird uns daduch wengstens erleichtert, als es sich hier nur um die Wahl zwischen zwei Modis handelt, und ein dritter so gut wie gänzlich ansgeschlossen bleiben muss; wenigstens gilt diese Einschränkung so lange, als wir ms zur Erklürung des Sehroroanges auf thatsiichliche Grundlagen stïtzen wollen.

Die beiden sich gegenïberstehenden Ansichten sind schon Eingangs dieser Arbeit characterisirt, und die Bedingungen, unter denen sie anf Geltung Anspruch erheben kömnen, hervorgehoben worden. Die exste, ältcre, ist die Müllor"sche, Theorie vom mnsivischen Sehen"; die andere kimnte man als ., Bildchentheorie. ihr in Kürze gegenüberstellen, mnd diese fusst auf der Auffissmg des Sehrorgangs, wekhe sich durch das Gottsche'sche Experiment eine so weitgehende Anerkemming rerschafft hat.

Win erimnern ms, dass die Amnahme der Müller'schen Theorie eine mabweisliche ist, sobalıl dargetlan werden kamn, dass linter jeder Corneafacette sich nur ein einziges Perceptionselement findet, wie es ja auch der Auffassung ilues Lrhebers, der je eine "Nerrenfiser" an je einen Krystallkegel herantreten liess, ent-pricht.

In Gegensatz dazu wirl die Bildchentheorie dam das Feld behaupten, wenn da, wo das bildchen projicirt wird, eine als Retina zu bezeichnende Tielheit von percipirenden Nervenendorganen nachgewiesen werden kann.

Was man in den rerschiedenen Formen des Arthropodenanges als Elemente, welche der Perception des Lichtes dienen, d. l. der Imwandlung der Aetherwellenbewegnng in Nervenerregung, anzmsehen hat, das dürfte durch mueine Untersuchungen wohl munmelur definitiv festgestellt worden sein. In allen einigermassen ansgelildeten Sehoiganen der gesanmten thierischen Reihe finden wir Gebilde ciner ganz specifischeu Art, die Stäbchen (ganz allgemein gesprochen). welche wir als die percipirenden Endorgane zn betrachten gelernt haben. Auch in den einfachen Arthropodenangen. besonders den Stemma der Insecten und Spinnen haben wir diese Stïbchen nachweisen können, und die principielle Lebereinstimmmg nit denen der äbrigen Thiere ist eine so grosse, dass wir ihnen auch die gleiche Bedeutung vindiciren mï̈sen; also namentlich auch die rler Lichtperception, und dies mn so mehr, als wir vergeblich hier nach andern Netzhantelementen uns umsehen, die wir dafür in Anspruch nehmen könnten ${ }^{1}$ ).

Demnach ist der Ort, die Region, wo sich die Stäbchen befinden, bestimmend für den Ont. wo wir die Perception hin zu rerlegen haben. Bei der anerkannten Uebereinstimmmng der Projection eines mngekelnten Bildchens auf die Retma eines Spinnenanges z. B. rerglichen unit den Wirbeltherange wroten wir also anch hier annehmen nüssen, dass nur die Objecte der

1) Bekanntlich giebt es noch immer - allerdings sehr vereinzelte — Forseher (W. Kra use z. B.), welche diese Function der Stäbehen für das Wirbelthierange in Abrede stellen wollen. Hier dürfte sich aber der Nutzen des Studiums der vergleichenden Anatomie auch für den mensuhlichen Anatomen gerale recht evident zeigen; das einzig constante Element der entwickelteren Augen sind eben u u r die Stïbchen. und diese fast immer (bei Evertebraten) in einer Anordnung, dass an eine katoptrisehe Bedentung derselben nicht zu denken ist. 
Anssenwelt deutlich gesehen werden kömen, deren Strahlen auf der stïbchentragenden Region der Retina zur Tereinigung kommen. Lm Objecte verschiedener Distanzen mit gleicher Dentlichkeit sehen. 1. h. ihre Bilıler mit gleicher Schürfe auf die Retina projiciren zu künnen, besitzt das Vertebratenange bekamntlich einen Einstellungs- oder Accomorlations-Apparat, der den einfachen Arthropodenangen abgeht. Vielleicht findet er hier einen theilweisen Ersatz in der relatiren Längenentwickelung der Stäbchen, so dass etwa entferntere Objecte, deren Bilker auf den vorderen, der Linse zugewandten Enden der Stäbchen zur Tereinigung kommen, unehr auf diese Enden einwirken, nälıere Objecte dagegen. die meln in der Tiefe der Retma projicirt werden, erst an den hinteren Enden der Stïbchen den Reiz anslisen - aber das sind nur Termuthungen, denen man gewiss mit Recht entgegenhalten kamn, dass das die Stäbchen meist bis zu ilnem Torderende cinhüllende Pigment einer Bildprojection auch in mu geringer Entfernung linter den rordern Stïbchenenden schon ein bedenkliches Veto entgegenstellen muss.

Aber wie dem mun anch sei, für den llamptpunkt, anf den es uns hier ankommt, ist dies rein nebensïchlich, und wir haben hier nur hervorzuheben, dass wir bein Selnact die physiologische Lichtwirkmg auf die Weichtheile des Anges innerhalb einer Zone fixirt haben, deren vordere Grenze durch eine die Stäbehenvorderenden in sich fassende Fläche, deren lintere Grenze durch eine andere Flïche, in welcher die hintern Stäbchenenden liegen, bestimnt ist. Mit andern Worten: der Lichtstralıl kann den adaequaten Nervenreiz nur da auslüsen, wo das Stäbchen sich befindet.

Nun habe ich aber durch meine Lntersuchnngen das Recht erhalten, rom Stemma aus weiter zu gehen zum zusammengesetzten Ange. Haben wir dort das Stäbchen als Grenzgebilde zwischen dem objectiven Lichtstrahl und der suljectiven Reizempfindung lestgestellt, so mü̈ssen wir ganz dieselbe Rolle seinem nurplologischen Aequiralente auch hier zutheilen. Wir haben demnach im aconen Auge ron Tipula and Ctenophora die Lichtperception gebunden an die sieben Stäbchen, von denen bei letzterer Gattung beconder's (rgl. Figg. 46 - 48 Taf. VIl) das centrale die peripherischen an Lünge berlentend übertriflt, so dass wir für dieses eine viel tiefere Zone, innerhalb deren die Perception vor sich gehen kam, zugeben uüssen, als für die peripherischen Stäbchen. Aehnlich ist es bei Forficula (Fig. 54 Taf. VII), Meloë (Fig. 56 Taf. VTl), während bei Notonecta (Fig. 49 u. ff. Taf. V1l) sowie bei den Bockkäfem (Fig. 58 Taf. VIl) die Differenz im Ganzen nicht berlentender ist, als bei Tipula.

Gehen wir num ïber zu jenen Facettenaugen, bei welchen die Emzelstibchen zn einem axialen Phabdon zusammengetreten sind, so müs-en wir die Fähigkeit der Lichtperception anf dieses localisiren. Bleiben wir zunïchst bei jenen stehen, bei denen das Rhabdom die Retinula ihrer ganzen Lïnge nach durchzieht. wie bei den Orthopteren, Hymenopteren, Tagschmetterlingen, vielen Käfern und Crustaceen, so haben wir eine Ansbreitung der lichtempfindenden Schicht, dic ganz eigenthïmlich contrastirt mit der Torstellung, die wir geröhnlich ïber eine solche uns zu bilden pllegen. Ihre Flïchenaushreitung ist nümlich auf cin Ninimum reducirt, anf den Querschnitt des Rhabdoms nämlich; dafïr aber erreicht sie eine sehr bedeutende Tiefe, welche der Lïnge desselben entspricht, und es steht Nichts im Vege, die Unwandlung des Lichts in Nervenerregung in der ganzen Lünge des Rhabrloms vor sich gehen zu lassen.

Nun existirt aber noch em weiterer Modus der Ansbildung, nämlich der bei den Dämmelungs- und Nachtfaltern, vielen Kiffern mo andern Insecten, sowie bei Crustaceen sich findende, wo die zum Rhabdom zusammentretenden Einzelstäbchen nu im innern. rom Krystallkegel abgewandten Theile der Putiunla zur Ausbildmg kommen. Nun lässt sich ja allerdings nicht mit 
ahsoluter Sicherheit behaupten, dass die Stälychensubstanz ïberall in dem rordern, meist fadendünnen Theile der Retimnla, ror' der Rhabdomanschwellung, völlig fehle. Indessen lıalte ich es cinstweilen für höclist wahrscheinlich, dass sie in den allemeisten Füllen auf die Anschwollung selbst beschü̈nkt ist, und damn haben wir demn auch die Licht empfintende Stelle ebenda, und nur da zu suchen. Darans ergiebt sich weiter ein sehr bedteutsames, von uns spüter zu rerwerthendes Factum, nämbch die grosse Entfermung der empfindenten Substanzen ron den als dioptrische bezeiclmeten IIcdien.

Damit haben wir den einen Gegenstand mserer Untersuchumg. den Ort, in welchen wir den ersten pliysiologischen Trorgang bein Sehen zu verlegen haben, erschüpft, und wenden ıms nun zu einem andern.

Die Grösse des Sehfeliles, das einem Einzelauge zukommt, ist ebenfalls von Bedentung für unsere Untersuchung. Diese bestimnt sich, ganz allgemein gesprochen, für das Stemma, ron dem wir wieder ansgehen, duch das Verhältniss des Kugelsegmentes, welches mosaikartig mit den lichtempfundenden Elementen besetzt ist. zur Grösse der gesammten sphürischen Flïthe, von der eben jene Retina ein Abschnitt ist. Wir kömen auch einfach abgekürzt sagen, durch die Grösse des Deffnungswinkels der Retina. md meinen danit einen Wrinkel, dessen Scheitel im optischen Nlittelpunkt der Linse liegt, dessen Schenkel lie Retina an zwei diametral entgegengesetzten Punkten ilırer Peripherie berühren. - Es ist nu mzweilellıft, dass wir dieses Terhältniss ohne weiłeren Anstand auch benutzen dürfen zur Bestimmung der Grösse les Schfeldes beim Einzelange des Facettenauges, und zwar zunächst wieder des aconen. Hier ergiebt sich num gleich eine beträchtliche Terringerung desselben, rerglichen mit den des Stemma, und diese rülurt hier zmäichst her von der Abnahme des absolnten Durchmessers der Pietina. wobei wir noch absehen ron der Wirkung des Pigmentes. die wir s]äter zu discntiren haben werden. Terfolgen wir num wieder, wie rorhin geschehen. das Facettenange in der gleichen Reilınfolge, so treffen wir auf eine stete mul schliesslich sehr beträchtliche Abnahme des Selifeldes des Einzelanges, und diese Reduction geschieht nicht blos durch Dnahme des Durdmesser's der Gesammtheit der Perceptionselenente, wie wir sie bei der Bildung des einfachen Rhabdoms finden, sondern anch durch Vergrösserung des Abstandes der Fläche, welche durch die Schenkel des Winkels gestreift wird, rom Scheitehomkte des Winkels selbst. Dies ist ganz besonders der Fall bei jenen Augen. in welchen die Rhabromanschwellung in den innern Theilen der Retimula gelegen ist.

Wir haben damit ein zweites Factum von Pelang festgestellt, nümlich dass das Selnfeld der Finzelfacette immer kleiner wird. je weiter sich das Auge bezüglich seines Banes von dem Stemma entfernt, je typisclıer und vollkommener es die Charactere des Facettenauges ausgebildet zeigt.

Ein fernerer Punkt, den wir noch zu berücksichtigen haben, ist die Sehschürfe der Angen. Diese genan zu bestimmen hat natülich hier seine Schwierigkeiten, die wohl kamn zu überwinden sein dürften; für viele Fälle, wo nur die allergröbsten Schattirungen zu berücksichtigen sinr, bietet uns das Verhalten des lebenden Thieres in seiner Lmgelıung Anhaltspunkte, die lehreich genug sind. - Indessen legt uns schon der anatomische Ban mancher Angen darauf bezügliche Folgermngen nahe genug. So kömnen wir uns z. B. gewisse Rückschlüsse auf die Sehschürfe des Spinnenanges erlauben. wenn wir die Vertheilung, resp. die Distanz der percipirenden Elemente von einander bei rersehiedenen Formen vergleichen. Denn es bedarf wohl keiner besondern Rechtfertigung, wenn man es für wahrscheinlich erklärt, dass, ceteris paribus, ein Grenachex, Untersuchungen üluer das Sehorgan der Arthropoclen. 
Ange, welches auf der gleichen Retinafläche eine grosse Anzahl kleiner und feiner Stäbchen trägt, schärfer zn mnterscheiden befähigt sein wird, als ein anderes, welches jene Fläche mit sparsaneren und dem entsprechend massigeren Stäbchen garnirt zeigt. So wird also, $n$ m ein concretes Beispiel anzuführen, das rordere Dorsalange ron Epeira (Fig. 18 Taf. II) in dieser Hinsicht dem hinteren überlegen sein, demn die Zahl cler Stïbchen, welche bei ersterem sich in rlas Gesichtsfeld zu theilen halien, ist eine mugleich grössere, als die des hintern Auges; in Bezug auf die Grösse des Gesichtsfeldes ist dagegen das hintere Auge gegenüber dem vordern etwas im Vortheil.

Tragen wir diese Betrachtmosweise über anf das Facettenange, d. h., wie immer anf den zu einer Facette gelıörigen Antheil desselben, so tritt uns hier die Thatsache der Constanz der Stäbchenzahl in einer Retinnla etwas befremdlich entgegen, da dureh sie die cmpirischen Beobachtungen über die Sehschärfe der Thiere, so roh jene anch noch sein mögen, keinerlei Erklärung -finden. Wie wir gesehen haben, sund die Alweichnngen von der als Norm anzusehenden Zahl sieben in weitans der Mehrzalil der Fälle Reductionen anf fünf (Crustaceen) oder vier (Insecten und Crustaceen), und nur in wenigen Beispielen (Hymenopteren und Cicaden) dürften wir aus der Zähhnng der Retimulazellen den Schhıss auf eine Termehrung der zugehörigen Stäbchen auf acht ziehen. Nun verkleinert sich zwar im Allgemeinen auch das Selffeld bedeutend, und besonders gilt dies ron jenen, bei welchen in einer linteren Retinnla-Anschwellung nur vier Stäbchen des Rhabdoms nachgewiesen wurden. Tergleichen wir aber z. B. das Auge von Dytiscus, das nur vier, und das ron Melolontha, das sieben Stäbchen hier aufweist (Figg. 81-84 Taf. ITlI), so liesse sich doch meines Erachtens num schwierig behaupten, dass der darin sich anssprechende Unterschied in der Sehschürfe zu Gumsten des Maiküfers etwa dadurch wieder compensint würde, dass bei Dytiscus die vier Stäbchen sich anch in ein entsprechend kleineres Gesichtsfeld zu theilen hätten; hierzu dürfte die Differenz kamm gross genug sein. Aber dabei wissen wir doch, dass Dytiscus ein gewandter, beweglicher Räuber ist, der dmchans den Emdmck macht, als ob sein Sehvermögen besser entwickelt wïre, als das des Naikäfers. Es würde nicht schwierig sein, noch eine Reihe von solchen Beispielen vorzuführen, die alle darthun können, dass die Differenzen im Sehrermögen grësser sind, als es nach der Zahl der Perceptionselemente im Einzelauge des facettirten den Anschein hat.

Vielleicht dürfen wir aber hier eine andere Beobachtung registriren, die sich uns aufdrängt. Wem anch nicht durchgïngig, so doch wenigstens im Allgememen weisen diejenigen Arthroporlen mit Facettenaugen, deren Sehvermögen wir als ein unter ihresgleichen besonders hoch entwickeltes ansehen, die grösste Concentration der percipirenden Elemente, eine typische Rhablombildung anf, und wie imnig die Terschmelzmng der Einzelstäbchen, wie täuschend die Simulirung ciner anscheinend einheitlichen Bildung sein kann, haben wir früher gesehen. - Als besonderes Beispiel abweichender Bildung führe ich hier die Fliegen mit psendoconen Augen an, deren Sehvermögen wohl Niemand bezweifehn wird, deren Stäbchen aber discret bleiben, und nur im vordersten Ende der Retinula sich dicht aneinander lagern (vgl. oben).

Damit hätten wir einige Terhältnisse einer nähern Prüfung unterworfen, deren Resultate uns dienen sollen, die Wahl zwischen den beiden Theorien über das Sehen mit dem Facettenange zu treffen.

Wie ich schon melnfach ausgesprochen habe, wäre eine Wahl überhaupt überflüssig, wemm unsere Untersuchmen mas die Richtigkeit der Ansicht J. Nüller's über die Anwesenheit mur eines einzigen Perceptionselementes (.Nerrenfaser" ) hinter jeder Facette ergeben hätte. Da lies aber nicht der Fall ist, wir im Gegentheil eine zwar kleine und bestimmte, aber immerhin mehrfache Zahl kemnen gelernt haben, so sind wir genöthigt zı prüfen: 1) ob diese Veränderung der 
thatsïchlichen Grundlage die Theorie Nïller's mhaltbar zu machen in Stande ist, und 2) ob dieselbe rermag, zn Gunsten der Anwesenheit emer Retina, als nothwendiger Voranssetzung der Bildchentheorie, zu sprechen.

Hier aber sind wir genöthigt, zuerst das Bildchen selbst und seine Bedleutung einer eingehenderen Erörterung zu unterzichen.

Bei der Beweiskraft, welche man dem schon so erwähnten Versuche Gottsche's beigelegt hat, und häufig genug noch immer beilegt, darf es billig Wunder nelmen, dass eine nähere Prüfung sowohl des thatsächlichen Verhaltens - namentlich auch bei andern Angenformen, als den rom Urheber des Tersuches benntzten Fliegenangen - als anch eine kritische Würdigung der Bedingmuen, unter denen es von jener Beweiskraft sein kann, so gut wie gar nicht von Seiten Jener stattgefunden hat, die sich eingehender m die anatomische Erforschnng des Arthroporlenauges gekümmert haben. Erst die nenere Zeit hat einige Versuche aufzuweisen, das früher Tersïmmte nachzulolen, und es sind besonders die Arbeiten ron Fr. Boll (1. s. c.) und aus nenester Zeit die ron S. Exner1) namhaft zu machen. Der Inhalt der ersteren ist, soweit er sich anf unser Thema bezieht, schon oben einer eingehenderen Analyse unterzogen worden; die letztere, die mir erst bekannt geworden ist, nachdem meine Publication über das Arthropodenange in den „Klinischen Nonatsblättern f. Augenlieilkunde“ schon erschienen war, soll hier noch behandelt werden.

Ich brauche hier nicht in extenso die Geschichte der Beobachtungen über das Bildchen zu wiederholen. Es genügt, lier nochmals hervorzuheben, dass Gottsche den Naclıweis führen zu kömnen glaubte, dass es hinter dem Krystallkegel anftrete, und demnach zu einer Modification, oder gar zum Umsturz der llüller'schen Theorie führen müsse. Um aber dies wirklich zu leisten, müsste das Bildchen einer Reihe von Bedingıngen genügen. Wenn nämlich der Sehvorgang von ilm abhängig ist, so muss es erstens überall, in allen Facettenangen, sich finden; es muss zweitens in allen diesen Angen dahin projicirt werden, wo es als Bild auf die percipirenden Organe cinzuwirken im Stande ist, und es darf sich ihm nichts in den Weg legen, was seine flïchenhafte Ausbreitung hindern kömnte; und endlich inuss es da, wo es entsteht, eine in seiner Ebene sich ausbreitende, von einer Tielzalıl percipirender Elemente gebildete Netzhant zn seiner Anfnahme rorfinden. Wir wollen num sehen, ob und wie diese Bedingungen in der Natur erfüllt sind.

Das Zustandekommen eines umgekehrten Bildchens hinter den brechenden Nedien wird überall abhängig sein ron der sphärischen Begrenzung derselben, wodurch sie als Linsen zu wirken in Stande sind. Dieser Bedingnng ist nun allerdings in weitans den meisten Fällen genügt, und es ist dann die Comea, deren Convexität in den verschiedensten Grarlen ansgebildet erscheint. Es ist aber in kemer Weise anszuschliessen, dass anch der Krystallkegel, wenn die Cornea ron parallelen Flächen begrenzt ist, durch eine convexe Vorderfäche zur Bilderzengiug Teranlassung geben kann, wie z. B. bei Apns (Fig. 109 Taf. X), Branchipus (Fig. 107 Taf. X), (wo jedenfalls die ganz mbedentende Convexitüt der Cornea zuriicktritt neben der des Krystallkegels), bei Gammarus (Fig. 99 Taf. 1X), sowie ferner anch bei Phronima. wo die kolbigen Enden der langen Krystallkegel nelır oder weniger stark conrex erscheinen.

Dancben aber finden wir, wem anch nur rereinzelt, Beispiele, bei denen nicht einzusehen ist, wie ein Bildchen projicirt werden kam, da alle pliysikalischen Pedingnngen hierfür fehlen.

1) S. Exner, Ueber das Sehen von Bewegungen und the Theorie des zusammengesctzten Auges. Mit 1 Taf. (Separat-Abd. aus den Sitzungs-Ber. Wien. Akad. III. Abth. Bd. LxxII. Juliheft 1875.) 
Ich weise besonders auf die Gattung ITyperia him, bei welcher werler die facettenlose Cornea, nock anch die mit gerader Flïche an sie anstossenden Kirystallkegel im Stande sind. eine linsenlafte Wirkmg in dem geforderten Sime auszü̈ben.

Nun gielot es aber noch eine andere Categorie ron Fällen, in denen es zur Entstehung eines Bildchens nicht kommt, und es ist Exmer's ${ }^{1}$ ) Verdienst, zuerst darauf aufmerksam gemacht zu haben. Er hat Tersuche angestellt wit Lampyris. die, wie wir oben schon erwähnt haben, zu den Insecten gehürt, bei welchen Cornea mol Krystallkegel untrennbar rerwachsen sind, und hat dabei gefunden, dass man, auch wemn alles Pigment sorgfältig entfernt ist, nie ein Bildchen himter den Kiegeln erhält. sondern dars die gesammte Cornea schwarz und ron lenchtenden, den Krystallkegeh entsprechenden Punkten durchsiet erscheint. die beim Einstellen des Focns nach der Höhe oder Tiefe in Zerstrenungskreise auseinandergehen.

So spärlich diese Beispiele auch sind gegenüber der grossen Zahl derer, in welchen die Lnmöglichkeit einer Bildchenentstehung noch nicht in dieser Weise dargethan wurde. so sprechen sie für sich doch schon dentlich genng ans, dass das postulirte allgememe Torkommen des Bildchens, wenn es wirklich die ihm rindicirte Polle spielen soll, in der That nicht stattfindet.

Die zweite Bedingung rerlangt, dass das Bildchen da projicirt wird, wo wir die percipirenden Elemente erkannt laben, also jedenfalls linter dem Krystallkegel. Das war eben das Bestechende an dem Gottsche schen Experimente, dass dadurch anscheinend der Nachweis geführt wurde. dass das ron der Comealinse erzengte Bildchen, imalterint durch den Krysiallkegel, hinter dem letzteren, da, wo man die empfindende Region linverlegen muste. zu Stande kommt. Wir wollen hier noch eimmal auf das schon oben erwälmte Experiment zuräckkommen. Tie wenig sowohl das Naterial - Fliegen - mit dem Crottsche experimentirte, als auch seine Nethode geeignet sind, den Antheil und Einfluss des Krystallkegels bei der Entstehung des Bildchens zu illustriren. darauf wurde schon wiederholt hingewiesen und gezeigt, dass der .Psendoconns". wie ich ihn genannt labe, rermöge seiner Constitution nothwendig zerstürt werden und ausfliessen mmste. so dass wir im Grunde nur das alte Experiment ron Leeuwenhoek. Baker, Brants etc. ror ms haben. Ind dies Experiment ist weiter nichts als die Demonstration des a priori nicht zn bezweifelnden Satzes, dass die Cornealinsen optisch denselben Einfluss auf die durehtretenden Lichtstrahlen ansüben, wie Glaslinsen.

lch habe den Versuch mit weniger zweifelhaftem Nateriale wiederholt, und nit dem besten, der Bildchentheorie aber nicht gerale gïnstigen Erfolg. Tch bediente mich dazu verschieclener Dämmerung- und Nachtfalter, wie sie nir in Neingeistexemplaren gerade zugänglich waren; die Erhaltungsmetlode ist in diesen Falle insofern gleichgültig. als bekanntlich bei einigermaassen resistenten Krystallkegehn. wie sie ja diese Thiere besitzen. weder die Krystallkegel ${ }^{2}$, und noch weniger selbstrerständlich die Comealinsen, welche das Bildchen exzengen, durch den Alcohol rerändert werden. Beide bleiben ebenso klar und durchsichtig wie rorher. Schneidet man num ein scheibchen eines solchen Anges mit scharfem Nesser ab, und legt es so auf den Objectträger. dass die anhaftenden Kriystallkegel ihre Spitzen dem Ange znwenden, zerstört dann durch möglichst vorsichtige Anwentung ron Saljetersïme das Pigment, so lässt sich in ausgezeichneter Teise das Gottsche'sche Experiment wiederholen. Stellt man auf die Kirystall-

1) 1. e. pag. 26 .

2) Soriel ieh urtheilen kann, scheint durch die Wirkung des Alcohols anch der Brechungsexponent der Krystallkegel nicht merkbar verändert zu werlen. Dies bedürfte selustrerständlich für genaue Bestinmungen noeh einer nähern Controle. 
kegel ein, deren Axe in die optische Axe des Mikroskops fällt, so sieht man da. wo man das Bildchen doch mindestens erwarten müsste, hinter oder an den Spitzen der Kegel, Nichts ron einem solchen; geht man aber immor mehr in die Tiefe, so tritt es zuerst umdeutlich, allmälig immer schärfer and klarer werdend, hervor, und es ist endlich so bestimmt und scharf in den Tmrissen, dass man mit voller Deutlichkeit die Form eincr Staamarlel, die man zwischen Spiegel und Objecttisch lim- und herfülnt, erkemnen kann. Aber, wie gesagt, es ist in Innern des Kegels gelegen, und hier befinden sich keinerlei Perceptionselemente. Wie tief aber in Innern, das komnte ich, da mir geeignete Vorrichtungen zum Iessen fehlten, nicht näher bestimmen; es ist für unsem Zweck übrigens anch nur von secundärer Bedentung. - Ich branche wohl kaum anzufülıen, dass lier der Planspiegel in Anwendung kommen muss.

Nun lagen aber die Präparate bei diesen Tersuchen in Flüssigkeiten, welche andere Brechmosverhältnisse bieten, als die nomalen Medien rles Anges oder seine ITmgelung. Also z. B. statt der Luft, welche die Aussenseite der Cornealinsen berïhrt, war diese letztere bespült von Wasser orker von sehr verdïnntem Glycerin (1:10), demach Flüssigkeiten von riel stïrkerem Brechungsexponenten; und ebenso war die Angenflïssigkeit dadurch ersetzt. Dies ist natürlich von grossen Einfluss auf den Ort der Projection des Bildchens; aber es ergiebt sich, dass, wenn die Vorderfläche der Cornea an Luft grenzt, statt von Wasser oder verdümten Glycerin ungelsen zu sein, dies das Bilichen weiter gegen die Cornea hin verschicbt, also noch weiter von dem Orte entfernt, auf den es eigentlich fallen müiste, un wirksan zu sein. - Ferner habe ich bei dem Tersnche die Staamadel, als den bilderzengenden Gegenstand, zwischen Spiegel und Objecttisch, also selı nahe an die lichtbrechenden Augenmedicn, gebracht; Bildchen weiter entfernt gelegener Gegenstände aber müssten nach den bekannten optischen Gesetzen ebenfalls weiter nach vorn, gegen rie Cornealinse hin, rücken, und demnach anch weiter von jener Stelle hinweg. an der sie allein wirksam sein kömten.

So evident anch für die Augen ron Dämmermugs- und Nachtfaltern die Beweiskraft dieses Experimentes sein mag, so bin ich doch gerne zn dem Zugeständniss bereit, dass es nicht ausreicht, um eine alle Einzelfülle unschliessende Generalisation daraufhin zu bilchen. Anfechtbar ist auch z. 13. die Anwendung der Salpetersäure, deren man zur Zurstörung des Pignentes bedarf; es liisst sich nicht pasitiv nachweicen, dass sie ohne jede Wirkung anf die Krystallkegel hinsichtlich des Brechungsindex derselben sei, und dieser Einfluss kann sich selı' wohl füllbar unchen. Tch weiss aber keine Möglichkeit, solche Versuche an frischen Angen ohne Hinzuziehnng derartig eingreifender Substanzen zu machen, und ich glaube vor Allen. dass die so gewonnenen Resultate so lange iluren Werth behalten, als sie nicht zu quantitativen Bestimnungen benutzt werden. Die Beweiskiaft lieschünkt sich claher darauf, dass nicht nothwendig alle Krystallkegel das Zustandekommen eines Bilkhens hinderu. dass aber fïr gewisse Krystallkegelformen wenigstens dies Bildchen im Innem derselben, vor ilurer Spitze, entsteht. Nun haben aber factisch nicht alle Kegel der Cornea zugewandte Flächen, welche so günstige Bedingungen darbieten.

Zn diesen scheint Hydrophilns zu gehören, der ron Exner zu seinen hübschen Lntersnchungen benutzt wurde. Dieser Forscher verfolgte die uns hier beschäftigende Frage mit ganz andem Mitteln: er suchte durch Messing und Rechnung die optischen Constanten zu bestimmen. Ueber seme Resultate nachher; hier mag mu angefülut sein, dass dieselben mindestens ebensowenig wie meine eigenen mitgetheilten zu ganz allgemein gültigen Schlüssen berechtigen, da er sich auf die gename einzige Form beschränkte. Er konmt nämlich zu dem Schlusse, dass bei den Insecten die Krystallkegel das Zustandekommen des von der Cornealinse entworfenen Bildes hindern, was: wie wir oben gesehen haben, sicher nicht anf allgemeine Gültigkeit Anspruch 
erheben kann. Umgekehrt beweist das Beispiel ron Hydrophilus, dass der Schluss auf Allgemeingültigkeit, den man ans meinen Tersuchen zu ziehen geneigt sein möchte, auch nicht zulässig ist.

Ich kann Exner nicht auf seinem ganzen Gang folgen, sondern muss mich auf einige wenige Hauptpunkte seiner Deduction beschränken.

Exurer beschäftigt sich zuerst mit dem ron der Coneafacette allein entworfenen Bilde, olne auf den Einfuss, den der Krystallkegel auf den Strahlengang ausïhen kamn. Rücksicht zu nehmen. Er wirft die Frage auf, ob sich dies Bildchen, - trotz der Schönheit desselben, die er ausdrücklich hervorhebt - als Netzhautbild verwenden lasse, aber nur um sie dahin zu beantworten, dass uns keine Thatsachen das Recht geben, sie zu bejahen (1ag. 16 ı. 17, 1. c.). Er findet es sehr wahrscheinlich, dass die einzehnen Antheile des Bildes in sehr verschiedenen Ebenen liegen, d. h. dass einzelne Punkte eines so abgebildeten Gegenstandes auf einer Ebene noch ein dentliches Bild lieferı, auf welcher andere Punkte desselben Gegenstandes nur starke Zerstreumgskreise entwerfen. Aus eirem Tersuche, den er näher beschreibt, folgert er weiter, dass ., die lichtempfindliche Schicht eimer Netzhaut, welche die Détails an dem Bildchen wahmehmen soll, die wir an demselben erkemen, die Dicke eines menschlichen Blutkürperchens kamm überschreiten dürfte" (1. c. pag. 19), eine Torstellung, deren Schwierigkeit er mit Recht betont.

Dann aber berücksichtigt er auch den Einfluss, den der Krystallkegel auf das Bildchen ausüben muss. Gleich mir verwirft er das Experiment, das Gottsche angestellt hat, und kommt äberhaupt zu dem Resultat, dass noch Niemand das Bild, das am Grunde des optischen Apparates des Facettenanges an der Stelle, wo die percipirenden Endorgane liegen, entstehen soll, gesehen habe. Er versuchte zunächst, das Experiment in ler herkömmlichen Weise an frischem Materiale ron Hydrophilus zu wiederholen, aber ohne Erfolg, da er das den Krystallkegeln anhaftende Pigment mechanisch abzustreifen versuchte, aber dabei stets die Krystallkegel mit entfernte (pag. 20, 1. c.).

Demnach versuchte er es auf einem andern 1 rege, die Lage des Bildchens zu bestimmen. Durch Messung wie durch Rechumg wurde zunächst festgestellt, wo das Bildchen der Corneafacette allein sich entwerfen müsse, und dam der Einfluss des Kirystallkegels in Rücksicht gebracht, dessen nicht mit Sicherheit festzusteilender Brechungsexponent als mindestens dem der Comea gleich angesetzt wurde. Lnter dieser Torausetzung aber ergiebt sich eine Vereinigmg der Lichtstrahlen zu einem Bildchen erst in einer Entfernung von ca. 3 mm hinter der Cornea (rgl. pag. 20-25, 1. c.), also reit hinter der Grenze des Anges im Ganzen.

Im Krystallkegel selbst kann hier ron Biflerzengung nicht die Rede sein ${ }^{1}$ ); alser. selbst wenn es noch dazu küme. so wäre bei der nach hinten vollkommenen Zuspitzung der Krystallkegel anch gar kein Raum für die Entfaltung desselben vorhanden (1. c. pag. 24).

Nlit dieser letzten Bemerkmng aber kommen wir anf einen andern Punkt, den wir zu priifen haben, nämlich auf den: hat das Bildchen, selbst wem es hinter dem Krystallkegel nach Naassgabe der optischen Constanten projicirt werden solite, hier anch den nöthigen Raum? Stcllt sich seiner Projection gerade da nichts in den Weg?

Sehr bald ergiebt sich bei emer Prüfung auf diesen Gesichtspumkt lin, dass es lamit misslich genug aussieht. In weitaus der Mehrzahl der Fälle läuft der Krystallkegel oder sein

1) Auch ich habe, naeh Kenntniss der Exner'schen Arbeit, den Versuch mit Ilydrophilus nach meiner Methode gemacht, aber mit negativem Erfolg. Ich muss aber hinzufügen, dass das mir zu Gebote stehende Material Manches zu wünschen übrig liess hinsichtlich seiner Erhaltung. 
Stellvertreter, wie wir wissen, nach linten mehr oder weniger spitz aus, und wir suchen rergeblich nach einer Projectionsfäche für das Bildchen, das doch selbstrerständlich nicht dimensionslos gedacht werden kann. Wenn dies nun schon bedenklich ist für jene Fülle, in denen die als Perceptionselemente erkannten Einzelstäbchen der Retinula orler das Phabdom sich mehr oder weniger imnig an das Hinterende des Krystallkegels anfügen. so wird dieser Wirlerspruch zwischen dem Postulat und dem thatsächlichen anatomischen Befund geradezn mnlösbar in allen jenen Fällen, wo zwischen dem Hinterende des Krystallkegels und dem Torderende des Perceptionsapparates sich eine fadendïnne Finschaltung befindet, die, wie in einer Reihe von Figuren dargestellt worden ist, oft eine recht ansehnliche Länge erreichen kann. In allen solchen Fällen ist eine Vereinigung der duch die Cornea eintretenden Lichtstrahlen zu einem Bilde im Nireau der empfindenden Endorgane, selbst wenn sie nach Maassgabe der Krümmungsradien und Brechungsindices der durchlassenden Medien gerade hier zu Stande kommen müsste, ein Ding der Unmöglichkeit, und der auch schon, wenn auch in anderm Sinne anfgetauchte Gedanke, dass das weiter vorn entstandene Bildchen durch jene Terbindungsstrecke als solches weiter nach imen geleitet werden sollte, wie etwa ein Tonstük dmech einen Metalldralit, ist eine solche Ungehenerlichkeit in Sime der Physik, dass jedes Wort zu ilner Widerlegung überflüssig ist. Fallt es num schion innerlıalb der durchsichtigen Angentheile an Ramm für die Entfaltung eines Bildchens. so ist natürlich ansserhalb, neben denselljen, noch weniger Platz dafür. Dies verhindern vor Allem die Pigmentzellen, und namentlich scheint es eine Aufgabe der' beiden von mir als Hauptpigmentzellen besonders hervorgehobenen Gebilde dieser Art zu sein, welche, wie wir ms ans der speciellen Darstellnng her noch erimnern, entweder die Krystallkegelspitze, oder jenen durchsichtigen Terbindumgsfaden zwischen iln und der Retinula mehr oder weniger dicht umhällen, und die Ausbreitung des ron rom eintretenden Lichtes auf eine gewisse minimale Grenze einschränken.

Das bisher Besprochene kann, wie leicht zu ersehen, nicht dazu dienen, die dem Bildchen vindicirte Bedeutung in meinen Angen zu befestigen oder gar zn erhölıen. Die dargelegten Umstände können im Gegentheil schon für sich allein ansreichen, dieselbe auf's Tiefste zu untergraben. Als Beleg dafür fülıre ich Boll mol Exner an, die, ohne in die Anatomie der Perceptionsorgane des Facettenanges eingedrungen zu sein, schon allein auf das Verhalten des Bildchens hin sich genötligt sehen, wieder auf die Müller'sche Theorie zurückzugehen.

Aber wir müssen noch weiter gehen, nümlich sehen, wie eben diese Perceptionsorgane sich dazu verlıalten, also prüfen, wie die letzte der oben gestellten Forderungen erfüllt ist. Diese verlangt, dass eine Tielheit von Nerrenendigungen zur Aufnahme des Bildchens sich nachweisen lasse, also eine Retina, und wir wollen zunächst lier völlig ron dem eben ausführlicher erörterten Umstaude absehen, dass das Bildchen nicht nothwendig dahin projicirt wird, wo die von uns als Perceptionsorgane erkamnten anatomischen Elemente liegen.

Was wir als eine Retina bezeichnen wollen, ist eigentlich kaum zu definiren; die Anwendung dieses Wortes ist lediglich eine conrentionelle, und hängt ab ron der Zahl der percipirenden Organe, oder ist, genaner gesagt, vielmelu bedingt durch die grosse Anzahl derselben. Wie viele Elemente nun noch genügen, um die Anwendung jenes Ausdruckes zu rechtfertigen - diese Frage hat eine Jedenkliche Aelmlichkeit mit jener berufenen Sophistenfrage, wie viel Haare der Mensch noch wenigstens haben müsse, um nicht neln Kahllkopf zu heissen. Jedenfalls glaube ich es vertreten zu kömen, dass ich durch Einfülırung der Bezeichnung "Retinula" sowoll der in der geringen Anzahl der Perceptionselemente bernhenden Differenz, als auch der sonst nachweisluaren morphologischen Uelsereinstimmung dieser Elemente mit denen 
einer ächten Retina Ausrlpuck gab. Unsere Retinula ist clemuach als eine seln reducirte Retina mit durchschnittlich sieben percipirenden Elementen aufzufassen. und es frägt sich num, wie wir uns die Wirkmng dieser, namentlich in Beziehnng anf das Bild, das wir vorläufig anf sie projicirt annehmen, denken sollen.

Der günstigste Fall wïre angenscheinlich der, welcher sich uns in den meisten aconen, femer den psendoconen Angen darbietet. wo nümlich die einzehnen Perceptionselemente isolirt sind, wie wir es in den Angen der hühern Thiere zu sehen gewöhnt sind. Aber anch hier muss es olme Weiteres einlencliten, dass sieben Elemente. selbst wenn jedes für sich einen Findrnck leiten sollte, mü̈glich ansreichen könncu, dem Scnsorim die Torstellung anch nur des allereinfachsten Objectes, dlessen Bild anf sie projicirt wird, zu ïbermitteh. Und anch die Menge der gleichzeitig entworfenen Bilder dep benachbarten Facetten würde in keiner Weise Ersatz für das ïnserst Invollkommene der Finzelleistung liefern kümnen, was wohl nicht mehr einer besondern Ansfïlnung bedürftig erscheint. - Immerhin lässt sich bei dieser Form der Retinula wenigstens freilich auch nur unter der Toraussetzung, dass das Bild auf die Einzelstäbchen fällt — der Gedanke rechtfertigen, dass jedes dieser Einzelstäbchen, wegen seiner relativ grossen Selbständigkeit gegenüber den benachbarten, für sich einen discreten Eindruck erhalten, und anch zur Empfindung gelangen lassen kömne, und das ist eine fundanentale Bedingmug. Aber, dürfen wir mun fragen, wie steht es demu num hierin bei den höher entwickelten Formen des Facettenanges, als welche wir nach dem früher Ausgeführten jene anzusehen haben, bei welchen die Einzelstäbchen zu einem Rhabdom zusammentreten? Schen wir anch völlig darüber hiureg, dass gerade unter diesen sich relativ hïnfig Angen funden, bei denen die Zahl der zur Perception bestimmten Elemente auf fünf oder vier reducirt ist, demnach der oben betonte Einwand sich hier verstäkt geltend machen muss, - welche ungemein feine Bildprojection wïre hier nothwendig. mu zu erreichen, dass bei dem oft so minimalen Qnerschnitte des mehrtheiligen Rlabdoms ein Einzelfactor des Bildchens nur einem Einzelstibchen zngefülnt und nicht durch gleichzeitige Einwirkung auf ein benachbartes dessen Function illusorisch genacht wird? Sicher wird der Gedanke an eine Bildperception durch diese Rhabdoubildung noch um ein Beträichtliches erschwert.

Wir haben lierbei mu noch angenommen, dass ïberhaupt eine so geringe Anzahl von Perceptionseinheiten nocl ausreiche, bei gehöriger Projection mindestens zwei in der Aussenwelt (objectiv) getrennte Pildpunkte anch noch als solche fïr die Enpfindmg (subjectiv) auseinanderizulalten. Dass es bei den Arthropoden nicht so sein soll, dürfte sich wohl schwer mit Bestimntheit erreisen lassen. Indessen liegen doch aus der physiologischen Optik (fles menschlichen Anges) einige Thatsachen vor, die mus zum minclesten berechtigen, die dagegen sich anfdrängenden Zweifel anszuspiechen.

Mir liegt die Absicht ferne. himsichtlich dieses Gegenstandes, nannentlich was die früheren Controrersen darüber anbelangt. in's Einzelne einzngehen. Ich möchte nur auf eines der nenern Werke ïber physiologische Optik, anf die treffliche Bearbeitung derselben dureh Aubert in dem nenen grossen Handbuch der Angenheilkunde ron Graefe und Saemisch ${ }^{1}$ ) hinweisen.

Nach den Angaben Anbert's. auf welche ich mich hier beziehen möchte, gehört, um einander sehr genïlierte, aber noch räunlich getrennte Punkte. resp. Objecte, als ron einander getrennte zu erkennen, dazu eine Winkeldistanz von $50-70^{\prime \prime}$, je nach Farbe und Belenchtung, wiilnerer die rutsprechende Winkeldistanz zweier Perceptionselemente der Retina von einander etwa 10“ beträgt; mit andern Worten: m zwei Punkte noch als gesonderte zu erkennen, genügt

1) Bd. 2. Theil 2 (rgl. besonders pag. 584). 
es nicht, dass ihre Bilder noch auf zwei nebeneinanderstehende Stäbchen fallen, sondern es müssen mehrere nicht afficirte zwischen den beilen gereizten liegen.

Hat dieser am menschlichen Auge gewomnene Erfahrungssatz allgemeine Geltung, so ist an eine, wenn anch noch so einfache Rildperception in keiner der Formen des Facettenanges zu denken. Aber anch olme anf einer solchen, zum mindesten unbewiesenen, also sehr fragwïrdigen Generalisation zu fussen, lässt sich ron andern Erwägnngen ans mit Sicherheit das Gleiche belaupten. Nehmen wir irgend einen Retinulaqnerschnitt, etwa Fig. 82 (von Melolontha), oder Fig. 8t Taf. TIII (von Dytiscus), und denken uns daranf möglichst einfache Fignren, etwa einen Kreis, dann ein Quadrat, durch die optisch vollkommen gedachten dioptrischen Nedien projicirt. Ein jeder Plıabdomantheil (jedes Eimzelstïbchen einer Retimulazelle) wïrde durch den auf ihn entfallenden Bildantheil entsprechend gereizt werden, aber in keiner Weise kömnen wir uns denken, dass dadurch ein Urtheil z̈lser die Form des den Reiz erzengenden Objectes, ob Kŕreis, ob Quadrat, ermöglicht würde, denn das Einzelstäl,chen reagirt auf den Eindrnck ganz einerlei, gleichgültig, ob dieser Eindruck ron dem Fragment eines Kireises oder eines Quadrates erregt vird. Bei der so überans imnigen Annäherung der Stäbchenantheile des Rhabdoms in diesen und verwandten Angenformen muss es auch in hohem Grade zweifelhaft erscheinen, ob überhaupt ein Stäbchen für sich reizmngsfïhig ist, ohne das benachloarte mit hineinznziehen.

Bis jetzt war es unsere Aufgabe, die Torgïnge, welche bei der Annahme der Bildchentheorie als unerlässliche, als ganz nothwendige postulirt werden mussten, einer Prüfung, und zwar einer jeden einzeln für sich, zn unterziehen. Wie wir gesehen haben, fiel diese analytische Art der Prüfung ungïnstig genug für sie ans. Recapituliren wir das Ganze noch einmal in aller Küurze, so haben wir Folgendes als Resultat gefunden.

In vereinzelten Füllen kann von einer Bilderzengung weren Mangel an entsprechend sphürisch gekrümmten lichthrechenden Medien keine Rede sein. In anderen Fällen aber wäre höchstens, nach der Natur dieser Medien, die Annahme einer Bilderzengung weit hinter dem Gesammtange zulïssig. Wieiler in anderen hat das Experiment die Entstehung eines Bildes, trotz der Anwesentıeit der Krystallkegel. lewiesen, aber dieses Bild liegt ebenfalls nicht da, wo allem eine Wirknng, vergleichbar der im Tertebratenange, denklor wïre, sondern riel weiter nach vorn. Einer wirksamen Projection dieses Bildes weiter nach linten stellt sich aber die hanptsächlich durch impenetrables Pigment verursachte Beschränkung des Qnerschnittes entgegen, zu der sich in sehr zahlreichen Fällen noch das oft sehr beträchtliche Zurücktreten rler percipirenden Elemente von den brechenden Meilien gesellt. In allen Füllen ohne Ansnahne aber wïrde auch die schürfste Bildprojection anf die Perceptionsfläche effectlos sein wegen der Insufficienz dieser letzteren; denn wir haben gesehen, dass man, sowohl was die Zahl, als anch was die Art der Zusammensetzung ilner Elemente anbelangt, kanm Grund hat, ihre Wirkung qualitativ viel höher anzuschlagen, als die einer Perceptionscinheit (eines einzelnen Stäbchens).

Ich glanlse, all das An- und Ansgeführte clürfte genügen, die Bildchentheorie, wie wir sie der Iï̈rze wegen genamnt haben, definitiv zu Grabe zı geleiten.

Nun müssen wir aber auch versuchen, ans der bisher blos negirenden fíritik herauszutreten, und zu sehen, wie wir uns den Gang der Lichtstrahlen sowie deren Einwirkung, zu denken haben.

Wir künnen dies am leichtesten und einfachsten für jene Fülle durchfülıren, welche für die Bilkchentheorie am schwierigsten zı erklären sind; nämlich für jene enconen Augen mit hinterer Rhabdonnanschwellnng, ror der sich ein dïmner Faden befindet, also etwa für die Angen per Nachtschmetterlinge, der Naikiffer etc. etc. Wir haben noch zndem für einige dieser Angen 
den Vortheil voraus, dass wir über den Ort, wo das Bild zu Stande kommt, durch das Experiment unterrichtet sind.

Betrachten wir ein solches Einzelange, so wissen wir gleich, welche Strahlen sicher dahin gelangen, wo sie physiologisch wirksam werten können, d. h. in's Phabrlom. Es ist angenscheinlich in dieser günstigen Lage ein dïnnes Strahlenbüschel, welches die optische Axe emeinschliesst, und dieser Axe parallel den ganzen Facettenantheil von vorn bis hinten durchsetzt. Der Querschnitt eines solchen Strahlenbüschels wird durch zwei Factoren bestimmt: einmal durch die Krrümmung der brechenden Nedien, dann aber durch das Pigment und die dümen Verbindungsfäden. Bei sehr zugespitzten Krystallkegeln, wie bei Phryganea z. B. (vgl. Fig. 87 Taf. 1X) wird diese Verschmächtigung des Strahlenbüschels naturgemiiss eine sehr betrüchtliche sein mïssen, da ja nur diejenigen Strahlen geradlinig, d. h. ungebrochen, durchtreten können, für welche die Ein- nnd Anstrittsflächen als parallel angesehen werden kömnen, was sich für die Spitze des Krystallkegels wohl nur auf einen minimalen Theil beschränken wird.

So einfach der Gang für die axial einfallenden Lichtstrahlen ist, so schwierig scheint es mir, denselben für die in einiger Distanz ron der Axe einfallenden Strahlen zu bestimmen. Diese werden mehr oder weniger gebrochen werden, tund je weiter entfernt sie von der Axe einfallen, um so mehr wird ihre Richtung veränlert. llır Terlauf wird sie nothwendig an die Mantelfäche des Krystallkegels führen, und dort wird der Winkel, unter welchem sie auffallen, bestimmend sem dafür, ob sie melir oder weniger rollstündig reflectirt, oder, nach aussen durchtretend, ron dem umgebenden Pigmente absorl,irt werden. Je nach der Configuration des Krystallkegels lïsst sich sehr wohl zugeben, dass durch (ein- oder melımalige) Reflexion solche Strahlen schliesslich anch noch auf das Rhabdom. und damit zur physiologischen Verwerthung gelangen; zu Gunsten der Bildchentheorie können sie aber tmmöglich rerwerthet werden.

Neiner Ansicht nach wird unter allen Lmstïnden dem schmalen, ungebrochen durchgehenden axialen Strahlenluischel die Hauptbedentmig zufallen. Diese Strahlen kommen aber, der Natur der Dinge nach, ạns der directen Terlängerung der Axe des Einzelanges her; da die Einzelaugen, bei ihrer radialen Anordnung nm einen hinter ilmen gelegenen Nittelpunkt, unter sich klemere oder grössere Winkel bilden, so erhält jedes sein Licht für sich, und ein solches von einem bestimmten Punkte ansgehendes Axenbïschel kann nur ein einziges der zahlreichen Einzelangen aus dem gesammen Facettencouplex afficiren.

Diese Affection wird aber ihrer Art nach bestimmt durch die Qualität nnd Quantität des Lichtes, durch die Farbe also and durch die Intensitït desseblben, wie wir uns ungefähr die Vorgänge anch in der menschlichen Retina zurechtzulegen pflegen. Wie ich zu zeigen versuchte, ist die Amahme, dass die axialen Stralilen ihrer Zusanmensetzung und Herkunft nach wieder gesondert auf die Einzelstäbchen einwirken künnten. ron nur mininaler Wahrscheinlichkeit, und daraus würde dann folgen, dass die kleinsten Theile des Gesamurtgesichtsfeldes nur ihrem allgemeinen Lichtcharacter nach, ohne weitere Sonderung, zur Perception gelangen, und das Rhabdom, obschon morphologisch einer Nehrheit ron Stibchen gleichwerthig. dennoch physiologisch nur einem solchen als Eimlieit rerglichen werden muss.

Ist dies zugegeben, so ist eine weitere Folgerung cbenfalls nicht abzuweisen. Da, wie erwähnt, die Einzelangen radiär divergirend nach anssen gerichtet sind, so müssen die in sie fallenden axialen Strahlen convergirend dew hinter den ersteren gelegenen Centrum zustreben. Demnach müssen diejenigen Stellen des Gesammtanges, in welchen die dem entsprechenden Lichtcharacter zngehörigen Erregnngen zu Stande kommen, nothwendig zu einander dieselbe Lage im Raume haben, wie die Stellen der Anssenwelt, ron denen jene Strahlen ausgehen. Es 
existirt also ein bestimmter Gegensatz zu dem Ange der Wirbelthiere sowohl, als zu dem Stemma der Arthropoden, wo die Erregungsstellen das ungekehrte Vorzeichen derjenigen Stellen in der Aussenwelt haben. von welchen die Erregung ansgeht. Diese Relation der Lage der Perceptionsstellen zu derjenigen der lichtanssendenden Punkte hat man andenten wollen mit dem Ausdrucke des "aufrechten Bildes" im Facettenange; einem Ausdrucke, der trotz seiner Klarheit, wem man sich die fundamentalen Anschaumgen eimmal zo eigen gemacht hat, doch nicht vor Missverständnissen lat schützen können, namentlich damn nicht, wemn es auf die Erörterung der Bedeutung des dioptrischen Bildchens ankam.

Die beiden zuletzt angeführten Erwägungen haben uns aber vollständig auf den Boden der Müller'schen Theorie geführt, während die frühere Prüfung, die wir über das Bildchen sowolıl, als über die zu seiner erentuellen Aufnahme geschickten Organe angestellt haben, nur dazu dienen konnten, die Basis der mit il» rivalisirenden Bildchentlieorie zu untergraben. Den unversöhnlichen Gegensatz beider Auffassungen kömen wir aber noch in folgender Weise formuliren.

Die Bildchentheorie muss nothwendig eine gewisse Tollkommenheit des Einzelanges, sowoll in seinem Projections-, als auch besonders in seinem Perceptionsapparat, voraussetzen, und ihre Anerkennmg steht demnach in einem Verluältniss der Abhängigkeit vom anatomischen Nachweis dieser Vollkommenheit. Im directesten Gegensatze dazu fusst die Müller'sche Theorie auf der Unzulängliclıeit des Einzelauges gegenüber der Summe von Reizen, welche ein Bildchen zur Perception beanspruchen muss, und, wie in diesen Zeilen schon oft genug betont, sie würde über jede Discussion himans sicher stehen, wenn die Reduction der Retina sich bis auf ein einziges Element vollzöge. Zu Gunsten welcher der beiden concurirenden Theorien unsere anatomischen Untersuchungen sprechen, haben wir gesehen.

Dies betrifft aber nur das Einzelange aus der Gesammtsumme, die ja auf mehrere Tausende sich belaufen kann. Lassen win nun die Summirung dieser Einzelangen zu dem vollständigen Organe vor sich gehen, und prüfen wir dann den Gesammteffect, so ergeben sich wieder nicht zu unterschätzende Vortheile zn Gunsten der Müller'schen Theorie. Eine Anhänfung ron vielen Tausenden an sich relativ vollkommener, zur Bildperception befähigter Augen wäre für uns unverständlich. Hier würde Nïller's Einwand vollkommen zu Recht bestehen, wenn er nämlich herrorhebt, dass dann jeder einzelne Theil des dem Gesammtange zukommenden Sehfeldes für sich ungekeht werden nnüsste ${ }^{i}$ ), was eine Orientirung im Raume, wenn nicht geradezu numöglich, doch für unsern Terstand mzugünglich erscheinen lassen würde. Der anscheinende Tortheil. Welchen die Tollkommenheit des Emzelanges bei dieser Auffassung darböte, ginge demmach für uns völlig wieder verloren. - Ganz anders bei der Rolle, welche die Müller'sche Theorie dem Einzelange zuspricht: die Unvollkommenheit des Einzelauges wird ausgeglichen durch die Summirung derselben; jedes individuelle Ange tritt zurück, geht unter in der Gesammtheit aller, und diese Gesamntheit erhebt sich dadurch zu einem einheitlichen Organ, dessen Leistungen sicher zu den bedentenderen unter den verwandten Organen in der Thierreihe gehören.

Die hier erörterte Verschiedenheit in der Art und Weise der Leistung beim einfachen Arthropodenauge auf der einen, dem zusammengesetzten Auge auf der andern Seite scheint aber eine so principielle zu sem, dass sie sich nicht mit der im vorigen Abschnitt ansfülnrlich erörterten unorphologischen Uebereinstimmung in Einklang bringen lässt. Der Widerspruch ist aber nu ein scheinbarer, der olme Schwierigkeit durch folgende einfache Ueberlegung beseitigt werden kamn.

1) Arch. f. Anat. u. Physiol. 1835. pag. 614. 
Wir haben als Ausgangspunkt für die beiden divergenten Angenformen eine hypothetische Urform zu construiren versucht, anf welche beirle sich morphologisch zurückführen lassen. Wir haben dieser Urfor'm des Auges einen möglichst indifferenten Bau gegeben, wie es die ganze Art und Weise der morphologischen Vergleichung mit sich brachte, und namentlich nussten wir die Zahl der in seine Bildung eingehenden Elemente — sowohl des Projections-, als anch des Perceptionsapparates - imerhalb gevisser Grenzen einschrïnken. Dabei ergiebt sich freilich für jenes hypothetische Urange eine sehr geringe Leistungsfïhigkeit, die sicher nicht bis zum dentlichen Sehen heranreichte. Diese Leistungsfähigkeit erhöhte sich aber im Laufe der Zeiten und zwar auf zwei Wegen, die nach diametral entgegengesetzten Richtungen hinführten. Die eine derselben leitete unter Ausbildung immer besserer Linsen und unter immer zunehmender Vermehrung der Perceptionselemente zum Stemma, das seine höchste Ansbildung bei den allein daranf angeviesenen Arachnoideen findet. Die andere Pichtung aber drïngte die Entwickehng des Einzelanges immer mehr zurück, compensirte aber entsprechend diesen Rückschritt durch die Massenhaftigkeit, in welcher sie diese Angen neben einander, in bestimmter Richtung und Anordnung, anhïnfte; durch leichte Umwandlung in der Form, und unțer Mitwirking des Pigmentes gestalteten sich die brechenden Nedien statt zum Sammeln, wie beim Stemma, num zum Isoliren des von einem bestimmten Punkte ausstrahlenden Lichtes $1 \mathrm{~m}$, das für eine gegebene Zeiteinheit nur anf ein einziges, ilm gerade zngerichtetes Rhabdom einzuwirken im Stande ist. Aber die Tausende solcher combinirten Perceptionsorgane, symmetrisch angeordnet und unter sich in gleichmässiger Wukeldistanz radiär vom Centrum einer Kngel nach deren Oberflïche, jenseits welcher das Gesammtsehfeld liegt, ansstrahlend, sind schliesslich im Stande, dassclbe zu leisten, wie die ebenfalls sehr zahlreich vorhandenen, auf einer concaren Retina angeordneten Stäbchen eines Stemma. Möglicher, ja selbst wahrscheinlicher Weise existirt hinsichtlich der Lichtstärke ein Unterschied zwischen beiden, und zwar zu Gunsten des Stemma, da hier die gesammte Menge des auf die Cornealinse fallenden Lichtes durch die Linsenwirkmng anf die einzelnen Stäbchen concentrint wird, wilıend von der durchschnittlich viel kleineren Facette wahrscheinlich ein grosser Theil, der peripherischen Strahlen namentlich, so gehrochen wird, dass sie schliesslich vom Pigment absorbirt werden. Indessen liesse sich wohl die Frage aufwerfen, ob nicht die im Allgemeinen ihrer Masse nach recht ansehnlichen Rhabdome eben durch ihre Masse, sowie durch ihre Zusammensetzung aus mehreren Einheiten, die doch wohl wieder jede für sich mit einer Nervenfaser in Verbindung stehen werden, diesen Nachtheil auszugleichen im Stande sind. Indessen dürfte es wohl noch lange danern, bis sich daranf eine bestimmte Antwort geben lïsst.

Damit können wir dieses Capitel abschliessen. Es sind nur noch ein paar Bemerkungen, die ich hier anzufïgen habe, welche sich auf die Sehorgane der Corycaeiden, sowie des Limulus beziehen.

Man wird es vollkommen begreiflich finden, dass ich nach dem oben über die Leistung des einzelnen Facettenantheils aus dem Gesammtange Gesagten auch dem sonst hinsichtlich seines Projectionsapparates so complicirten Ange der Corycaeiden keinen höliern physiologischen Werth beilegen kamn, als einer jener Einheiten. Die beste Bildprojection wird nicht in Stande sein, mit Hülfe ron nur drei percipirenden Elementen riel mehr zu erreichen, als eine allgemeine Lichtempfindung mit ihren gradweisen Abstufungen ron Dunkel und Hell. In dieser Hinsicht wird man, wie ich glaube, jene Augen getrost mit den Einheiten in einem Facettenange in dieselbe Linie stellen kömnen, selbst wemn, was immerhin nicht mmöglich ist, durch die Kenntniss der Genese jener Augen ihre morphologische Stellung zu diesen etwas verschoben werden sollte.

Ferner bedarf es wohl keiner besonderen Ausführung, dass das Endresultat dieses Capitels, 
wornach ein zusammengesetztes Auge nur nach dem von .J. Mïller formulirten Nodus eine Gesichtswahrnehmung remitteln kam, anch für das Ange von Limulns Geltung haben muss, obschon dieses seinem morpliologischen Aufbar nach als ganz rerschieden ron den andern Augen sich erweist. Ein Blick anf das im Querschnitt sternförmige Rhabdom wird wohl kaum den Gedanken aufkommen lassen, dass hier eine Bildwahmehmung im Einzelange anzunelmen sei, selbst wenn die dioptrischen Apparate noch ungleich besser zur Bildprojection geschickt wären, als sie es in der That sind.

\section{Abschnitt.}

\section{Das Retinaelement im thierischen Auge.}

Es bleibt uns nun zum Schlusse noch ïl)rig, das Arthropodenange nach einer andern Seite lin zu betrachten, nämlich nach seinen Beziehungen zu den verschiedenartigen Angenformen, welche uns die Thierreihe darbietet. Derartige vergleichende Betrachtungen füllen in der ältern Literatur einen nicht mansehnlichen Ramn, und die Ansdrücke wie "Glaskörper", "Chorioidea", "Iris", "Cornea" u. a. m., ron denen auch wir licr einige wegen ihres erworbenen Bürgerrechtes beibehalten laben, sprechen an und für sich deutlich genug über den Mlodus der Tergleichung, den man frülıer nicht blos für zulässig, sondern für geboten lrielt.

In diesen Sinne soll hier die bealssichtigte Tergleichnng nicht durchgeführt werden, und es bedarf hentzntage keines Wortes der Rechtfertigung für diese ablehnende Haltung. Denn es ergiebt sich auf den ersten näher auf das Wesen der Dinge gerichteten Blick, dass die Augenformen der grossen Thierkreise, wögen sie anch bei allgemeinerer Betrachtung noch so sehr ïbereinstimmen linsichtlich der Anordnung der einzelnen Elemente, doch für sich so bestimmten Gestaltungsgesetzen folgen, dass das Suchen etwa nach einer gemeinsamen Grundform des Auges für alle Thiere, sowie die Rednction rerschiedener Angenformen - z. B. der Arthropoden und Weichthiere oder Wirbelthiere - auf einander, eine undankbare, weil resnltatlose Arbeit wäre.

Immerlin aber ergeben sich gewisse Momente bei dem eingehenderen Studium der Morphologie des Sehorganes, die weiter zn verfolgen wohl der Mühe verlohnen möchte. Es kann aber nicht meine Aufgabe sein, alle hier möglicherweise in Frage kommenden Gesichtspunkte in die Discussion hineinzuziehen: manche erlerligen sich fast von selbst, während für andere wieder erst die nöthige empirische Basis durch die Forschung zo gewinnen ist. Dannit ergiebt sich das von mir beanspruchte Recht der Beschüinkung auf eine kurze, skizzenhaft gehaltene Uebersicht aus der Natur der Sache.

Von allen Bestandtheilen des Auges der Arthropoden, von dem wir hier wieder ansgehen wollen, und das wir nun in einer ziemlichen Anzalıl von Modificationen kennen gelernt haben, ist es allein las Retinaelement, das wir hier in speciellerer ITeise vergleichend betrachten können. Nm das Retinaelement, d. h. die Einlıeit, durch deren Anhäufnng und Combination wir eine Retina oder Retimula zn Stande kommen selıen, zeigt nach seinem anatomischen Ban sowohl, wie anch nach seiner Genese Beziehungen zu den entsprechemlen Elementen in den Angen anderer Thierformen, die zu Fragen herausfordern. Ob diese Fragen überhaupt, und in welchem Sinne sie beantwortet werden können, darüber mögen die Ansichten weit anseinander gehen; es mag uns hier wenigstens rerstattet sein, auf die Punkte hinzuweisen, die für eine sichere und bestimmte Beantwortung festgestellt werden mïssen, wo sie es noch nicht sind. 
Betrachten wir noch eimmal die Retimaelemente der Arthropoden, wie wir sie kennen gelernt haben, im flüchtigen Rückblick, und sehen wir ron allen secundären Nodificationen ab, die in den rerschiedenen Einzelformen des Auges ilıre äussere Gestalt, ihre Grösse etc. etc. beeinflusst habeu, so können wir nach den vorliegenden Untersuchungen als Abstraction aus der Gesammtsumme unserer Erfahrungen den Satz formuliren: das Retinaelement bestelit aus einer Zelle, die nach derjenigen Seite hin, von welcher das Licht einfällt, mit einem Stäbchen, nach der entgegengesetzten Seite aber mit einer Nervenfaser des Opticus in Verbindung steht. Das Stäbchen ist nicht selbständig, sondern ein ron der Zelle abhängiges, von ihr nach Art einer Cuticularbildung ausgeschiedenes Prorkct; für einen directen Zusammenhang zwischen ilnn und der Nervenfaser (d. h. mit Ausschliessung der Vermittelung durch die Zelle) fellen bisher noch alle Indicien.

Diese Characteristik passt auf alle in dieser Arbeit behandelten Formen des Arthropodenauges, mit Ausnalme ron zweien: das Ange des Copepoden Calanella (Figg. 36-38 Taf. V, IT), sowie das Stemma ron Phryganea (Fig. 35 Taf. V). Dadurch aber dürfen wir uns, wie ich gtaube, nicht anfechten lassen. Das Retinaelement ist schon eine recht complicirte Bildung in morphologischer Beziehnng, und der Sitz nicht minder compticirter Torgänge in Hinsicht auf seine Function. Die beirlen genannten Formen haben als gemeinsames Moment das Fehlen der Stäbchen, während der Zusammenlıang der Retinazelle mit der Nervenfaser unzweifelhaft ist. Aber dies Noment bringt die beiden Augen blos scheinbar zusammen: meiner Ansicht nach können wir in der erstgenannten Form wohl eine noch unentwickelte, in der zweiten aber eine vielleicht zurückgebildete erblicken. - Sichcr aber passt auf alle übrigen die angegebene Definition.

Retinaelementes.

Der zweite Punkt, auf den es wesentlich ankommt, betrifft die Herkunft des

Was diese anbelangt, so haben wir anch einige Beispiele kennen gelernt, die uns in einer Weise, die kaum etwas zu wünschen übrig lïsst, diese Abstammung klarlegen; nur schade, dass sich so renige andere anfügen lassen. Mit den ersteren meine ich die Augen der Schwimmkäferlarven (Figg. 1-10 Taf. I), die ms so evident als möglich nicht nu die Abhängigkeit des Retinaelementes, sondern anch aller übrigen Augentheile ron dem Integument, der Hyрodernis mit Cuticula, erkemnen lassen. Damit ist aber für diese Thiere auch zugleich die Abstammung des Retinaclementes rom ersten, äussem embryonalen Keimblatt, dem Ectorlerm. gegeben.

Nicht so günstig steht es mit den iübrigen Formen von Larrenaugen, somie der einfachen Angen der Spinnen und Insectenimagines. Nenn anch über die Herkunft einzelner Augentheile, ïber die Abstammung derselben ron der Hypodermis, namentlich bei den erstgenamnten beiden Categorien, kein Zweifel obwalten kamn, so ist doch hier die Retma in den von mir untersuchten Zuständen ausser aller Continuität mit ilı mol jenen Angentheilen, und der erforderliche strenge Nachweis dieses jedenfalls höchst walurscheinlichen urspïünglichen Zusammenhanges ist erst noch zu führen.

Ganz andere Schwierigkeiten aber erwachsen uns für das zusammengesetzte Auge, rorzügłich für das der Dipteren (Musciden), deren Entrickelungsgeschichte ms durch A. Weismann's ${ }^{1}$ ) beriihmte Cntersuchungen als eine so sonderl)are und räthselhafte erscheinen muss.

Hier ist es besonders die Entwickelung des lntegumentes (nebst seinen Anhängen) des Torderköryer's der Imago, mit welcher die Entrickelung des Facettenanges auf's Imigste verknüpft

1) Ztsehft. f. wiss. Zool. Bd. XIV. pag. $221-328$; vgl. bes. pag. 280 u. ff. 
ist, die uns fremdartig berïht. Dasselbe geht bekanntlich aus Bildungselementen hervor. die weit entfernt liegen von der Körperoberflïche, ans den sog. "lmaginalscheiben ", die, angcheftet an die Hüillen von Tracheen oder Nerven, sich frühzeitig anlegen und ausbilden. Die sog. „Augenscheiben" speciell bilden sich als Appendices der Hülle eines Nerven, und aus ilnnen gehen alle Bestandtheile der fertigen Augen, die dioptrischen sowohl wie die percipirenden, auf eine Weise hervor, die hier im Einzelnen anseinanderzusetzen keine Veranlassung vorliegt. Ob man nun den Unstand, dass in diesem Falle die Anlage von einem Nerren ansgeht, in anderen Fällen aber die Imaginalscheiben, die zu Integumentbildungen werden, an Tracheen suspendirt sind, geltend machen kann zu Gunsten einer tiefer liegenden Heterologie zwischen beiden Categorien — darüher lässt sich wenig disputiren. Mir scheint dieser anscheinend eine Trennung herbeifülnrenrle Ứnstand mit nur germgem Gervicht versehen zu sein. Anders aber steht die Frage, wie diese Imaginalscheiben sich himsichtlich ihrer Zugehörigkeit zu den Embryonalanlagen verhalten; ich glaube, wir thun gut, die Entscheidung hierïber vorläufig noch in suspenso zu lassen, trotzdem auch hier die Wahrscheinlichkeit eine nicht geringe ist, dass in letzter Instanz das Ectoderm den Ausgangspunkt für Alles bildet.

Nir scheint vor Allem das Verhalten ron Corethra, nach den Untersuchumgen desselben trefflichen Fonschers'1), zu Gunsten dieser Wahrscheinlichkeit zu sprechen. Wir finden hier, wie schon oben angefühnt worden. das zusammengesetzte Ange schon in der Larve fertig ausgebildet, und hier gelit es ans der Larvenhypodernis, also aus dem Ectoderm, hersor, ohne jede Vermittelung eines an die Imaginalscheiben erimnernden Torstadiums. Dass diese aber, wemn anch in anderer Weise - namentlich anch rerschieden von denen der Musciden hinsichtlich ihres zeitlichen Auftretens - sich bei Corethra am Aufbau des Thorax betheiligen, und hier nachweisbar von der Larrenhypodermis ausgehen, ist sicher geeignet, als Basis für jene Vermuthung zu dienen.

Genan genommen haben wir durch diese Fälle wenigstens das Eine in den allgemeinern Umrissen ziemlich sichergestellt: die Entwickelung des Anges geht - wie mehr oder weniger positiv nachgewiesen worden ist — aus denselben Elementen vor sich, ans denen die Hypodermis der Imago sich aufbant. Wie sich aber diese Imaginallypodermis hinsichtlich ihrer Abstammung von dem ätssem Kreimblatt verhält, bleibt zwar für eine Reihe einzeher Fälle erst festzustellen; im Ganzen aber darf der Gedanke an eine directe Ableitung derselben rom Ectoderm anch in den complicirteren Fällen noch keineswegs anfgegeben werden.

Diese beiden Gesichtspunkte: allgemeine morphologische Beschaffenheit des Retinaelementes, dam Stellung desselben zu den Keinblïttern, also vornehmlich zu dem äussern, sollen nun hier in einer kurzen Uebersicht ïber die in der Thierreihe vorkommenden wichtigsten Augenformen, sorreit sie nälier bekannt sind, berücksichtigt werden. Ich habe aber keineswegs die Absicht, mich in die Unmasse von anatomischen Detailangaben, die in der Literatur aufgespeichert sind, irgend tiefer einzulassen, um so weniger, als es für den in's Auge gefassten Zweck genügt, aus den rerschiedenen Gruppen einen oder den andern Pepräsentanten heranszugreifen; ich werde dabei besonders solche zu bevorzugen mir erlauben, über welche mir eigene Erfahrungen zu Gebote stehen, oder ïber welche wenigstens nenere und zuverlüssige Mittheilungen vorliegen.

Damit ergiebt sich schon, dass wir von den Protozoen abzusehen haben. Erst für die Coelenteraten, und anch bei diesen erst für einige wenige, haben wir durch ganz nenerdings veröffentlichte genanere Intersnchungen den Bau einiger schon seit längerer Zeit als Angen

1) A. Weismann, Die Metamorphose von Corethra plumicornis. Ztschft. f. wiss. Zool. Bd. XVI. 1866. pag. $45-127$; rgl. bes. pag. $60-65,112-121$. 
in Anspruch genommener Pigmentflecke soweit kennen gelemt, dass wir ihnen diese Bezeichnung mit vollem Rechte gcben dürfen. Ich meine hier die Gattungen Lizzia und Oceania, deren Ocellen von O. und R. Hertwig ${ }^{1}$ ) untersucht, ferner Charybdea, deren Angenban ms von Clans ${ }^{2}$ ) mitgetheilt worden ist.

Von den genannten Gattnngen besitzen die erste und die dritte lichtbrechende Körper (Linsen), die der zweiten fehlen. Die dahinter gelegenen Weichtheile enthalten unter ihren zelligen Elementen, neben Pigment- und Ganglienzellen, anch sog. „Sehzellen", die mit momsem Retinazellen im Wesentlichen als identisch anzusehen sind, und mit einem relativ zarten Fortsatz an dem einen, dem Licht zugewandten Ende, mit einer Nerrenfiser an dem andern versehen sind. Ob der genannte Fortsatz schon morphologisch als Stäbchen in unseru Sinne anfzufassen ist, orler nicht, muss noch dahingestellt bleiben. Sicher ist aber die Abstammung der Angenelemente vom Ectoderm, dem sie angehören.

Anch bei der Gruppe đer Echinodermen können wir von Angen sprechen, obschon anch hier nn wenige, nïnlich nur die Asteriden, nns mit solchen entgegentreten, in denen Retinaelemente nachgewiesen worden sind.

Ich verweise hiefür auf eine der nenesten Darstellnngen des Asteridenanges, die von IV. Lange ${ }^{3}$ ) gegebene, bei dem anch die Angaben seiner Vorgänger auf diesem Gebiete zusammengestellt sind. Nach seiner Schilderung ist das Seestemange, d.h. das ron Asteracanthion rubens, auf das er sich beschränkt, in toto nichts als eine kegelförmige Einstiilpung der Epidermis, ein rein epitheliales Gebilde; die das Ange znsammensetzenden Elemente gehen nnmittelbar ans den daneben gelegenen Epidermiszellen hervor. Was aber für uns besondere Bedentung hat: sie tragen an ihrem änssern, dein Lichte zngewandten Enile ein kurzes Sehstäbchen, dessen wahrscheinliche Natur als Cuticularbildung der Verfasser noch ansdrücklich hervorhebt. - Für die specielleren Angabẻn über diese Zellen, ihr Pigment etc. muss anf das Original selbst verwiesen werden.

Auch über die Herknnft dieses Anges in letzter Instanz sind wir genügend unterrichtet, obschon meines Wissens sich noch Niemand mit der Entwickelung des Anges selbst beschäftigt hat. Indessen lässt sich am reifen Thiere die morphologische Zugehörigkeit des Auges zur Epidermis nicht verkennen, und diese letztere stammt, wie wir besonders durch E. Metschnikoff's Untersuchungen ${ }^{4}$ ) wissen, direct ab von der Epidermis der Echinodermenlarve, geht also bei allen den complicirten Vorgängen der Metamorphose in geraler Linie zurück anf das Ectoderm in seiner ursprïnglichen Anlage.

Ungleich mehr Formen sind in dem grossen, vielgestaltigen Kreise der Würmer mit Augen ansgerüstet, und doch wäre es schwierig zu behaupten, dass unsere Kenntnisse des Banes dieser Organe hier über das Gröbste hinansgingen. Es sind im Grunde nur ein paar Anneliden, deren Sehorgane eingehender studirt worden sind, nnd von diesen allein die Alciopiden soweit,

1) O. und R. Hertwig, Das Nervensystem und die Sinuesorgane der Medusen. Leipzig 1878. $4^{\circ}$. vgl. bes. pag. 100-103, sowie Taf. VIII.

2) C. Claus, Untersuchungen über Charybdea marsupialis. Wien 1878. (Sep. Abd. aus d. Arb. d. zool. Inst. Wien. Heft 2) - pag. 27-39; Taf. V.

3) Wichard Lange, Beitrag zur Anatomie und Histiologie der Asterien und Ophiuren, in: G egenbaur's Morphol. Jahrbuch Bd. II. 1876. pag. 242-286; rgl. bes. pag. 257-264.

4) E. Metschnik off, Studien über die Entwiekelung der Echinodermen und Nemertinen. Mém. Acad. St. Pétersb. 1869. VII. Sér. Tom. XIV, Nr. 8. 
mm sie mit einiger Sicherheit interpretiren zu können, wobei wir freilich noch von den fundannentalsten Torgängen der Entwickelungsgeschichte des Anges völlig abzusehen haben.

Die Angen der Alciopiden haben ron jeher die Aufuerksamkeit der Forscher wegen ilner hohen Ausbildung in besonderem Grade anf sich gelenkt, wie die älteren und neneren Abhandlungen darüber beweisen. Für msern Zweck ist es dmchins genügend, anf die trefflichen Publicationen hinzuweisen, welche Greeff ${ }^{1}$ ), der neneste der Antoren darüber, unlïngst reröffentlicht hat, und deren hierher bezügliche thatsächliche Resultate ich nach eigenen zienlich eingehenden Untersuchungen im Wesentlichen völlig bestätigen kamn.

Das grosse, sphäroidale, rorn mit einer schönen Linse ausgerüstete Auge dieser Thiere hat eine ansgezeichnet entwickelte Retina von frappirender Einfachheit des Banes. Sie besteht nur aus einer einzigen Zellenlage, einer einfachen Sclicht langgezogener, radiïr zum Augenmittelpunkt gestellter Retinazellen - Greeff giebt ihr den etwas schwerfälligen Namen einer "kernhaltigen Sünlenschicht" - ; diesen Zellen sitzen nach rom, gegen die Linse hin, stark entwickelte St:̈bchen anf, und nach imen gehen sie in die Fasern des Opticus ïber. An rer Basis der Stäbchen findet sich eine dichte Pigmentanhänfung, die aber, wie ich übereinstimmend mit Greeff gefunden habe, kein besonderes Stratum bildet, sondern ans den Retiuazellen sellsst differenzirt erscheint. Die Stäbchen selbst bestehen aus zwei rimnenfürmigen Hälften, ganz ähnlich denen, die wir oben von einer Reihe von Spimmen kennen gelernt haben, und diese schliessen in ihrem ITohhram eine Terlängerung der Retinazelle ein. Greeff will ausserden noch einen in Innem der Stäbchen axial rerlanfenden feinen Faden beobachtet haben, den or als eine Nervenfaser auffasst; das Stïbchen selbst soll nach ilnn blos zur Stütze für diese Faser dienen.

Wir haben hier ein ganz ansgezeichnetes Schema des Retinaelementes, wie es oben priicisirt worden ist, ror uns, wenigstens soweit es seinen anatomischen Ban betrifft. lch habe diesen nu im allgemeinsten Umriss gegelıen, olme mich anf die vielen Einzelheiten einzulassen, welche Greeff l. c. sehr ansfïhrlich mittheilt; aber anch, olme nich an des Letzteren Dentung zu binden, die mir in manchen Punkten verfehlt erscheint. So verstehe ich z. B. nicht, was Greeff veranlassen kann, die Retinazellen, d. h. seine "kerntragenden Sünlen", als bipolare Ganglienzellen anfzufassen (1. c. 1. 110), und ebensowenig, welche Gründe ihn bestimmen, die Rolle der Stäbchen so hermuterzudrücken. um ans ihnen blos eine stützende Hülle für ein Füdchen zu machen, dessen Natur als Nervenfaser doch zum mindesten änsserst problematisch und noch sehr der nähern Prüfung bedürftig ist. - Was den ersteren Punkt, nämlich die Natur der Retinazellen, anbelangt, so bewegen mich Gründe allgemeiner Natur, ilun einen andern als den von Greeff supponirten Character zuzuschreilien. Obschon wir ron den sperielleren Torgïngen der Angenbildung der Alciopiden zur Zeit noch Nichts kennen (die par Bemerkumgen von Claparède und Panceri reichen hier lange nicht ans), so kann es doch für eine fast als sicher anzusehende Erklürmg betrachtet werden, dass die Petina sich rom Integmmente ans - entweder durch einfache Einstülpung, orler durch Verdickung desselben mit darauf folgender Abspaltung — gebildet hat. Die ganze Anordnung der Augentheile lässt keinen andem Schlnss aufkommen. Aber ans diesen Epidermiszellen, die ihren ursprünglichen Platz verkassen haben, m zu den wichtigsten

1) R. Greeff, Ueber das Ange der Alciopilen. Ein Beitrag zu Kenntniss đes Baues der Retina. Marburg 1876. Mit 2 Taf. - Ferner: Untersuchungen über die Alciopiden. Nora Acta Acut. Leop. Carol. etc. Vol. XXXIX, Nr. 2. 1876. - Vgl. bes. pag. 92-112.

Grenacher, Untersuchungen. über das Sehorgan der Arthropoden. 
Bestandtheilen eines Sinnesorgans zu werden, werden dadurch noch keine Ganglienzellen, um so weniger; als sie ihren epithelialen Character; den eines Nenroepithels, nur umbedentend modificirt sich bewahren.

Es ist in hohem Grade wahrscheinlich, dass das hier in dieser Familie so nngemein hoch entwickelte Sehorgan nur eine ungewühnliche Ausbillung eines Angentypus ist, der sich, natiurlich im allgemeineren Grundschema, bei der Classe der Anneliden einer weiten Verbreitumg erfreut. Eine Reihe ron Beobachtungen wenigstens, die mir für Nereiden und Heteronereiden aus dem Golfe ron Neapel zu Gebote stehen, lässt mich dies annehmen.

Unter den Anneliden sind noch die Hirudineen. die Blutegel, als Besitzer ganz eigenartiger Sehorgane bekannt. Dieselben sind bekamntlich besonders eingehend von Leydig1), und in nenerer Zeit von Ranke $\mathrm{e}^{2}$ ) untersucht worden, und Letzterer hat aus der ïusseren Partie des Auges kleine kugelige Zellen bescluieben, die gegen die Oberfläche lin mit einem feinen stähchenförmigen Fortsatz versehen sein: nach imnen aber mit Nerven zusammenhängen sollen. — Ich muss die thatsïchliche Puchtigkeit dieser Angaben vorläufig auf sich beruhen lassen; sicher aber sclieint mir, dass uns das Auge des Blutegels für msere Zwecke noch keinen Nutzen zu gewïhren vermag. -

Günstiger, als für die Angen der Würmer, steht es um unsere Kenntniss des Banes und - wenigstens in einer Reihe von Fällen - auch um die der Entwickelung der Sehorgane bei den Mollusken. Hier haben wir wenigstens für die wichtigsten der typischen Abtheilungen anatomische Darstellungen, theilweise ron hervorragender Bedeutung. die ums für die Gesichtspunkte, ron denen wir die Sachlage auffassen, reichliches Material an die Hand geben.

Begimnen wir mit den Lamellibranchiaten, so möchte ich allerdings kaum glauben, dass bei diesen Thieren Alles, was in der Literatur darüber als Ange gedentet worlen ist, anch in der That dahin zu rechnen sei ${ }^{3}$ ). Indessen kommen unter diesen zum mindesten recht ziveifelhaften Sehorganen anch Augen ror wie die ron Pecten und Spondylus, und über diese so hochorganisirten Sinneswerlizenge kam hinsichtlich ilıer Function keine Meinungsrerschiedenheit obwalten.

Das Auge von Pecten kemnen wir besonder's aus del mustergültigen Darstellung von V. Hensen ${ }^{4}$, und wir dürfen Angesichts dieser ron Enwähnung der ältern Beobachtungen Umgang nehmen. Ich selbst habe über diese Augenform eingehende Thntersuchungen angestellt, und kann jener Schilderung nur bis in 's Einzelne beipflichten ${ }^{5}$ ). Ich habe mehrere Arten untersucht, und im Wesentlichen überall das Gleiche gefunden; anch bei Spondylus stimmt nach meinen Untersuchungen der Ban bis in's Einzelne damit überein.

Dies Ange hat bekanntlich durch zwrei besondere Eigenthümbichkeiten die Aufmerksamkeit der Forscher auf sich zu lenken vermocht. Zuerst nämlich durch die Thatsache, dass hier die Stäbchen. wie bei den Tertebraten. rom Centrum des Auges abgewandt sind, ilr freies Ende also

1) Fr. Leydig: im Areh. f. Anat. und Physiol. 1861. pag. 588-605; ferner: Taf. zur vergl. Anat. 1864. I-II.

2) J. Ranke, Beiträge zur Lehre von den Uebergangs-Sinnesorganen. Ztschft. f. wiss. Zool. Bd. XXV. 1875. pag. 118 ; vgl. bes. pay. 152 u. ff.

$\left.{ }^{3}\right)$ Vgl. darïber die Zusammenstellung in Bronn, Classen unil Ordnungen ete. Vol. III. 1. pag. 399-402.

4) V. Hensen, Ueber das Auge einiger Ceplalopoden, in: Ztschft. f. wiss. Zool. Bd. XV. 1865. pag. $155-242$, vgl. bes, pag. 220 u. ff.

5) Nur die etwas schematisirte Uebersichtsfigur (Taf. XXI, Fig. 95) lässt Einiges zu wünschen übrig, besonders hinsichtlich der Linse und deren Ungebung. 
in der Peripherie des Bulbus liegt. Dann aber durch das andere, noch merkwïrdigere Factum, dass der Nervas opticus, kurz yor seiner Ankunft an Bulbus, sich in zwei annähernd gleichstarke Aeste theilt, von denen der eine sich direct zu den Stälschenzellen, der andere aber zu einer zwischen Linse und eigentlicher Retina gelegenen Zellenschicht wendet, mm dann von dieser aus wieder in feinsten Fasern an die Stäbchen der Retinazellen heranzntreten 1).

Wir haben uns jedoch hier nur mit den Retinaelementen als solchen zu beschäftigen, und hier liegen die Terhältnisse kaum ninder klar vor, als bei den Aleiopiden. Anch bei Pecten und Spondylus finden wir als Grundlage des ganzen Perceptionsapparates Zellen, die an dem einen Ende, das allerdings diesmal vom Lichte abgewandt ist, ein Stäbchen hervorbilden, an dem andern aber sich in eine Norrenfaser fortsetzen. - Die Thatsache, der wir hier zun ersten Male begegnen, dass ansser diesen Nervenfasem noch andere in imnige Beziehung zn den Stäbchen treten, ist sicherlich eine selır wichtige, aber kaum bis jetzt schon eme mit völliger Sicherheit zu interpretirende; da ihre Bedentung aber ansschliesslicls auf dem physiologischen Gebiete liegt, so wird man es begreiflich finden, wenn lier ron einer Discnssion derselben abgesehen wird.

Entschieden ungünstig aber steht es um unsere Kenntniss der Entwickelung des PectenAuges, ron der wir gar nichts wissen. Bei der eigenthümlichen Anordnung der gesammten Angentheile ist es nicht eimmal möglich, anf Gr'md gewisser, an sich wahrscheinlicher Voranssetzungen sich emen provisorisch functionirenden Modus für diesen Vorgang zurechtzulegen, den in Wirklichkeit zu beobachten wohl die vielen Schwierigkeiten noch lünger limansschieben dürften.

Ein besonderes Interesse rerknïpt sich mit dieser Entwickelungsgeschichte durch den zn erwartenden Anfschlnss ïber die oben angegebene, wie bei den Vertebraten ungekchrte Lage der Stäbchen zur Richtung des Lichteinfalls, die wir für die Wirbelthiere num zu erklären im Stande sind, die Erklärtmg aber nicht anf Pecten ühertragen kïnnen.

Bis ror Kinzem war das Ange von Pecten das einzige, das einen solchen anscheinenden Anschluss an das Wirbelthierange darbot; jetzt aber theilt es sich in denselben mit sonderbaren Sehorganen. die bei Schnecken rorkommen. Wir wollen mit diesen die Aufzählung der den Gasteropoden zukonmenden Sehwerkzenge begimmen.

Semper2) gebührt das Terdienst, mus mit dieser eigenthümlichen Angenform bekamnt gemacht zu haben. Sie findet sich bei einer Anzahl ron Arten der Gattung Onchidinm in wechsehnder Zahl auf dem Rücken derselben. Sie besitzen eine aus wenigen Zellen gebildete Linse, und hinter dieser - wenigstens bei den ansugebildeteren Formen — eine flächenhaft ansgebreitete Retina. in welcher eine centrale Oeffinung zum Durchtritt des Nervus opticus sich findet. Dieser tritt ganz ähnlich wie bei den Vertebraten durch die Retima zwischen diese und die Limse; hier strahlen seine Fasem radiür anseinander, um sich zu den imem, d. h. rordern Enden der Retinazellen zu begeben. Die äussern, d. h. hintern Enden der Retimazellen zeigen bei den gut ausgebildeten Angen einiger Arten deutliche, in ihre Substanz eingelagerte Stäbchen, rie an Pigment anstossen.

Nicht nur über den Ban, sondern anch über die Entwickelumg bringt Semper Nit-

1) Ieh verdanke es ier fremulliehen Autmerksamkeit von Herrn Prof. 11 ensen, mit dem ich einige Wochen in der zool. Station in Neapel zu verweilen das Glijck hatte, dass ich in diese so schwierig nachauweisenden Verhältnisse einen nähern Einblick erhielt. Herr Prof. Hensen zeigte mir eine Anzahl frisch angefertigter Präparate, die gar

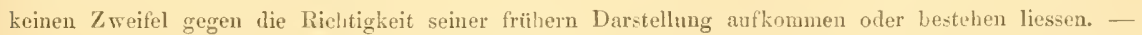

2) C. Semper. Ueber Sehneckenangen rom Wirhelthiertypus ete, in: Areh. nikr. Anat. Vol. XIV. 1877. pag. 118-122. - Ausfïhrlich: Ueber Sehorgane vom Typus der Wirbelthieraugen anf dem Rücken von Schneeken. Wiesbaden $187 \%$. $4^{0}$. wit 5 Tafeln. 
theilungen; er hält die Abstammung dieser Angen von der Epidermis für ebenso wahrscheinlich, wie cine eventuelle Neubildung derselben. Ich citire sein Resumé mit seimen eigenen Worten: „An der Spitze einer Papille entsteht durch Wucherming der Epidermis zuerst eine orler mehrere Driisenzellen, diese werden durch weitere Wuchertung und Ausbildung eines Blasenzellhanfens zur Seite geschoben; der letztere wandelt sich in den unregehü̈ssig gestalteten Angenpfropf um, welcher durch Umlagerung von Pigment und Verbindung mit dem Sehmerv zu einem ganz gleichartigen Augenbulbus wird; die innerhalb derselben liegenden Zellen des früheren Augenpfropfens bilden sich _ .... direct $\mathbf{m}$ zu den Linsenzellen, Retinafaserschicht und Stäbchenzellenlage" etc. etc.

Ob diese Darstelhnng dem Sachverhalt entspricht, ist eine weitere Frage. Ich gestehe, dass mir die ganze Darstellung noch nicht den Eindruck hinterlassen hat, den der Terfasser derselben, nach den krïftigen Ausdrücken zu urtheilen, mit denen er jedem Skeptiker ron rorn herein entgegentritt, zu erwarten sich berechtigt glaubt. Ich kann noch nicht ersehen, wie nach dem angegebenen Entwickelnngsmodus die Stäbchen zu ihrer Umkehrung kommen, und das ist für mich ein wesentliches Moment. - Es mag ïbrigens bier noch beigefügt werden, dass bei Onchidium anch am Kopfe noch Angen vorkommen, diese zeigen aber den normalen Ban der Schneckenangen.

Diese normalen Formen kenmen wir besonders gut ans den Darstellungen Hensen's ${ }^{1}$ ) und Anderer, und ich kam mich 1 m so eher auf die ganz kurze Erwähnung beschränken, dass anch hier die Retinazelle den von ums bisher überall aufgeführten Ban in ansgeprägter Weise darbietet, d. h. ein nach vorn, gegen die Lichtquelle gerichtetes Stäbchen anfweist, md nach innen mit einer Nervenfaser in Verbindung tritt. Ueber die Bedentung anderer, zwischen diese Retinazellen eingelagerter Elemente haben wir zu discntiren lier keine Teranlassung. - Ferner sind wir hier im Stande, die Abstammung der Retinaelemente ron dem Integiment als mit völliger Sicherheit erwiesen zu betrachten.

Die so auffallend entwickelten Angen der Heteropoden lassen sich himsichtlich der allgememen inorphologischen Grundzüge ilures Banes leicht auf deu Typus des Gasteropodenauges zmrïckführen, so selır sie diese anch hinsichtlich der speciellen Ansarbeitung dieses Planes übertreffen. Anch bei ihmen finden wir das Retmaelement in der gleichen Weise wieder, und wenn wir von einer Reihe specieller Modificationen secundiirer Natur absehen, so besteht es aus denselben integrirenden Bestandtheilen, mit denen wir es bisher zu thun hatten. Es nuag genügen, zum Belege hierfün auf die Untersuchungen ron M. Schultze $\mathrm{e}^{2}$ hinzureisen, vor Allem auf dic characteristische Tafel II semer unten erwähnten Arbeit.

Dies führt ums zu den Cephalopoden, deren Sehorgane hinsichtlich der Complication ihres Banes nicht nur unter den Erertebraten auf höchster Stufe stehen, sondern auch nicht wenigen Angen von Wirbeithieren, besonders anch functionell, überlegen sein dürften. Wie anch bei diesen Angen das Retinaelement der gleichen Formenreihe, die wir nun so vielfach kennen gelernt haben, sich cinfügt, darïber vermögen uns die trefflichen Arbeiten ron V. Hensen ${ }^{3}$ ), M. Schultzet) n. A. eridentes Beweismaterial an die Hand zn geben. Hinsichtlich der Genese des Cephalopordenanges. die darthut, dass anch hier die Retina durch dinecte Ectodermein-

1) 1. c. pag. 217; ferner: Teber den Bau des Schneckenauges und über die Entwiekelung der Augentheile in der Thierreilıe. Areh. mikr. Anat. Vol. II. 1866. pag. 399-129.

$\left.{ }^{2}\right)$ M. Schultze, Die Stibehen in der Retina der Cephalopoden und Heteropoden. Arch. f. mikr. Anat. Tol. V. 1869. pag. 1 n. ff. Taf. I, II.

${ }^{3}$ ) I. s. e. (Ztschft. f. W. Zool.)

4) 1. s. c. 
stülpung entsteht, darf ich vielleicht auf lie von mir selbst veröffentlichten Untersuchungen hinweisen ${ }^{1}$ ).

Bei den Cephaloporden treffen wir aber znerst auf eine Complication der Retina, welcher wir bis dahin noch nicht begegnet sind. Bei allen bisher besprochenen Thiergruppen bestand die Netzhant meln oder weniger dentlich ans einer einzigen Zellenlage, deren Elemente meist, wenu auch nicht immer, einen durchweg gleichartigen, sicher aber immer einen epithelialen Character haben. Hier aber lagern sich hinter die die Netzlrat nach vorn aloschliessende epitheliale Schicht noch eine Anzahl anderer Strata an, deren Elemente in jeder Beziehung, in morphologischer wie in physiologischer, wesentlich ron denen abweichen, die jene zusammensetzen. Diese Complication des Baues, welche die Retina der Cephalopoden mit derjenigen der Wirbelthiere theilt, hat nicht wenig rlazu beigetragen (besonders, weil diese Augen die Forscher sehr früh beschüftigten), das Terstïndniss ressen, was begrifflich zu einer Retina erforderlich ist, zurückzudrüngen, indem man umilkï̈rlich der Tersuchung unterlag. mebr darin zu erłlicken, als der Natur der Dinge nach in Wirklichkeit darin liegt. Die Genese dieser rerschiedenen Schichten, deren anatomische Lienntniss wir hauptsïchlich Hensen in seiner meisterhaften Arbeit über das Cejhlılopodenauge (1. s. c.) verdanken, ist noch nicht genügend aufgeklürt; für unsere Zwecke aber reicht die wohl beglauhigte That-ache aus, dass die Retina ursprünglich eine einfache Zellenlage ist, auf deren Vorderseite, gegen das Licht lim, die Stäbehen hervorsprossen; ferner die Thatsache, dass bei Nautilus, dessen ganzes Auge auf dem embryonalen Stadim verbleibt (es kommt bekanntlich lier nicht eimnal zum Terschlnss der Ectodermeinstülpung, die zum Auge wird), auch darin der embryonale Character sich zeitlebens erhält, dass die Retina nicht jene Schichten zeist. -

Welche geringen Anhalt-qunkte eine Tergleichung der Retina der Wirbelthiere mit den verschiedenen Retinaformen bei Evertebraten in morplrologischer Hinsicht bis in die neneste Zeit hinein - trotz der fast unübersehbaren Literatur über die erstere - darbot, ist eine zu bekannte Thatsache, als dass es nüthig wäre, lange dabei zu verweilen. An Versuchen hat es zwar nicht gefehlt; aber diese komten schon deswegen keine genügenden Resultate liefern, weil man theils auf rein secundäre Mlomente, wie die rerschiedene Lage der Stiibchen zur Lichtquelle, besonderes Gewicht legte, und theils, weil man als Maassstab die inenschliche Netzhaut verwandte, und auf diese die der Evertebraten zuriekführen wollte, statt richtiger den Versuch in umgekehrter Reihenfolge zu machen. Ihies hatte zunïchst den Erfolg, dass man der Versuchung, die den hühern Thieren eigenthümlichen complicirten Structurerhältnisse auch auf die nierlern zu übertragen, nicht genug widerstand, und auch die Geschichte der Kienntnisse des Arthropodenanges weiss daron zn erzïhlen. So musste aber natürlich die ganze Fragestellung verschoben werden.

Erst in der neneren Zeit hat man hinsichtlich der morphologischen Auffassung der Wirluelthierretina beträchtliche Fortschnitte aufzuweisen, die uns hier näher berülnen, als die rein histologischen, die so oft danit repwechselt werden. Unter diese ist ganz besonders zu rechnen die Einsicht, dass die Retina ans zwei Lnterabtheilnugen besteht, die anch morphologisch scharf auneiranderzuhalten sind. Die eine derselben, die sog. Neuroepithelschicht, unfasst die Stäbchen- und Zapfenschicht, die sog. üussere Kürnerschicht, nebst der Nembrana limitans externa;

1) H. Grenacher: Zur Entwickelungsgeschichte der Cephalopoden. in: Ztsehft. f. wiss. Zool. Bd. XXIr. 1874. pag. $419-499$. 
die andere aber, die sog. (iehirnschicht1). umfasst den ganzen ïbrigen Complex (äussere und innere granulirte, innere Körner-, Ganglienzellen-, Nervenfaserschicht nebst Membrana limitans interna), je nach Naassgabe seinel Auslithlung in der Wirbelthierreihe.

Gehen wir nun ron den Evertebraten ans, so ist für uns blos die Nenroepithelschicht ron Pelang, ansser wenn wir die Cephalopodenretina besonders accentuiren wollen. Nur in ihr finden wir die entsprechenden morphologischen Elenente wieder, welche bei den Evertebraten vorkonmen, hier aber zu allermeist die Retina ganz allein bilden; die sog. "Gehirnschicht" aber können wir, wemn denn eimmal durchaus verglichen sein muss, noch am passendsten mit einem flächenhaft ausgebreiteten. mit der eigentlichen percipirenden Retina in imnigstem Comnex stehenden Ganglion opticum in Parallele stellen.

Im Gebiete der Neuroepithelschicht aber finden wir die ms lier beschäftigenden Elemente wieder in den sog. „äussern Körnem" nebst den damit in Verbindung stehenden Stälschen und Zapfen; erstere bilden den Haupttheil der Retina-, oder, wie man sie hier auch genannt hat, Sehzellen, letztere die zu ihnen gehörigen Cuticularbildungen. Darüber dürfte nun kaum mehr ein Zweifel obwalten kömnen. Die genannten Beziehungen wuden bekanntlich, schon vor langen Jahren, durch Kölliker²), wenn auch nu dem damaligen Standpunkte der Gewebelehre entsprechend. ansgefülırt, aber später reniger im Ange behalten, als sie es rerdienen.

Wenn nun so an der morphologischen Lebereinstimmung dieser zelligen Elenente mit den entsprechenden der Evertebraten nicht zu zweifeln ist, und wohl ebensowenig an iler functionellen, so ergiebt eine Prüfung ihrer Genese anch hier die gleichen Resultate, wie dort. Nur mit einem einzigen gewichtigen Unterschiede. Bekanntlich entwickelt sich bei den Vertebraten die Retina (incl. Pigmentschicht) ron centralen Nerrensysteme ans, was wir bei Evertebraten, soweit Untersuchungen darither reiclien. nicht gefunden haben. und lierin liegt die Differenz. Aber das centrale Nerrensystem geht seinerseits wieder rom ersten Keimblatte aus, und damit stellt sich die Uebereinstimmmg wieder lier. IVie dieser ganze Entwickelungsgang die relative Lage der Stibchen zur Lichtquelle, die den älteren Autoren so Vieles zu rathen aufgal, auflklärt, lat II. Schultze ${ }^{3}$ ) flïchtig angerlentet; ich sellst habe dann später Teranlassung gefunden, ausführlicher darüber zu sprechen ${ }^{4}$ ). und habe zugleich ansgeführt, dass anch darin die Ascidienlarven mit den Wibelthieren übereinstimmen. Nach neneren Untersuchungen ${ }^{5}$ ) fügt sich auch das unpare, rudimentïre Sehorgan ron Amplioxus hinsichtlich seiner allgemeinen Topographie in das Tertebratenschema ungezwmgen ein, obschon hier von Retina im eigentlichen Simne keine Rede sein kam.

Damit können wir nun unsere Tebersicht abschliessen, und sehen, was wir als Gewimn derselben zu rerzeichnen haben. Dies wird sich in wenig Worten zusammenfassen lassen. Mir haben ïberall als lichtempfindende Elemente solche gefumden, die wir nach ihren wichtigsten norphologischen Eigenschaften als fast völlig ïbereinstimmend bezeichnen dürfen, da keine

$\left.{ }^{1}\right)$ Vgl. bes. die Darstellung der Retina, welche $S \mathrm{ehwalbe}$ in lem Handbueh der ges. Angenheilkunde von Gra fe und $\mathrm{Saem}$ is eh gegeben hat. (Vol. I. pag. 354-457).

2) Kölliker, Mikroskopische Anatomie. II. 2. 1852. pag. 730.

3) M. Sehultze, Art. Retina in Stricker's Gewebelehre. II. pag. 10 I1.

4) 1I. Grenather, Zur Entwickelungseschichte der Cephalopoden etc. Ztschft. f. wiss. Zool. Tol. XXIV. 1871. pag. 187. (Icls darf wohl lier bemerken, dass mir damals die rorhin citirte Bemerkung M. Sehultze's entgangen war). Zn den gleichen Resultaten sind auch nenerdings O. und R. II e r 1 wig (Nervensystem etc. der Medusen. pag. 173. 174) gekommen, ohne, wie es scheint, meine fröheren Ausführungen darïber zu kennen.

5) W. Mïler, Ueber die Stammesentwickelung des Sehorgans der Wirbelthiere. Festgabe ete. Leipzig, 187 . 
Differenzen derselben zwischen den einzelnen zoologischen Typen nachweisbar sind, die grösser wären, als die immerhalb der Typen zwischen den Retinaelementen der Clasien oder Ordnungen vorkommenden. - Was die Herkunft dieser Elemente von den Embryonalanlagen anbelangt, so ist die Auskunft darüber stellenweise noch beclanerlich lückenhaft; aber noch keine einzige Thatsache hat eine Ahleitung derselben von rinem andern als dem exsten Keimblatte ergeben, und da lie überwiegende Wahrscheinlichkeit für eine gesetzmässige Zurückführung der Perceptionsorgane auf jenes Keimblatt spricht, so dürfen wir wohl mit ziemlicher Ruhe dem Ergebnisse weiterer Lntersuchnngen ạch über jene noch unaufgeklärten Fälle entgegenschen.

Setzen wir num als streng bewiesen roraus, was es ja freilich noch nicht ist, dass das morphologisch äbereinstimmende Retinaelement bei allen den Thieren, welche durch Differenzirung ron Keimblïttern sich entwickeln, sich auf das äussere derselben zurïckführen lasse, so würde der Gedanke sich fast von selber anfdrüngen, diese Ueberemstimmung auch in phylogenetischer Beziehung zu verwerthen. In der That wiirde dam anf ein Alter des Retinaelementes hingewiesen werden, das dasjenige enes jeden zoologischen Typus bedeutend übertrüife; Anhänger der Gastraeatheorie würden sich für hefugt halten, das Anftreten ron bestimmt configurirten lichtpercipirenden Zellen schon auf die Gastraea zurïckzutühren, und ron diesen Sehzellen dann, den Typen gemäss, die so rielfach rerschiedenen Selırgane der Thiere sich anfbanen lassen.

Dieser Tersuch würde aber sehr bald anf Hindernise stossen, die schwer zu überspringen oder zu umgehen sein dürften. Ich meine damit besonders die so verschiedenartige Lagerung der fertigen Sehorgane bei den rerschiedtnen 'Tlierformen; wir haben bei Pecten und Spondylus Angen allein am Mantehand (bei andern Muscheln sollen solche an den Siphonen sich finden), bei Enphansia banchständige Angen neben nomal beschaffenen kopfständigen, bei Onchidinm rückenständige accessorische Sehorgane neben kopfständigen typischen kemen gelernt u. s. f. u.s.f. - kurz eine Peihe von Einzeltä̈len, wo Thiere sich von ilnen nächsten Terwandten durch den Besitz abnorm gelegener Selwrerkzenge unterscheiden. Die lsolintheit solcher Einzelfälle läss' den Geanken an eine Vererlung ron Alters her nicht aufkommen. Dem, liegt auch kein Grumd ror, bei der hypothetischen Gastraea - wenn man eine solche als Ausgangspunkt der höhern Thiertypen anerkemnen will — eme Localisirmg der lichtenpfindlichen Elemente in ilnem Substrat, dem Ectodernn, anzunehmen, so fehlt doch nach der anderm Seite hin die Möglichkeit, nachiden eimmal die Localisirung sich in der oralen (Kopf-) Region vollzogen hat, anders gelegene accessorische Sehorgane mit den kopfständigen in einen genetischen Zusammenhang zu bringen. Sowenig ich Bedenken tragen kamn, die typischen Sehwerkzenge der cephalophoren Nollusken, der Arthropoden, Vertebraten und zahlleicher Würmer auf eine einzige Ausgangsform für jede dieser Abtheilungen zurückzufülıren, so seln würde es mich frenen, wenn es gelänge, diese verschiedenartigen Formen noch weiter zurückzuverfolgen, und noch fester mit einander zu rerknïpfen. In diesem Kreise aber haben jene abnormen Angen keinen Raum; es bleibt nichts übrig; als sie, mabhïngig von den bereits bestehenden normalen Angen, für sich entstehen zu lassen - eine Concession, die anch Semper ${ }^{1}$ ) für die Rückenangen von Onchidium schon gemacht und ausführlich discutirt liat. ${ }^{2}$ )

1) 1. s. e. pag. 33 u. fi:

2) Auf die nämliche Frage kommen anch O. und R. Hertwig (1. s. c. pag. 173), die ebenso die Mantelrandaugen ron Pecten. sowie die Gehörorgane von Mysis und der Heuschrecken anführen. Sie versuchen aneh eine Erklärung zu geben, indem sie die Entstehung dieser alonorm gelegenen Sinnesorgane durch die Zurüickfuhrung derselben auf überall in kler Haut verbreitete indifferente Sinneszellen unserm Verständniss näher zu bringen gliuben. - Gegen die 
Man überselıe aber dabei nicht, dass mit dieser Concession ein Kieil in die ganze Art und Weise des Argumentirens hineingetrjeben worden ist. Denn was gielst uns dann ein Pecht, wemn wir der Anpassung die Fähigkeit zuschreiben, morphologisch nicht ron dem durch Vererbung Entstandenen zu Trennendes herrorzubringen, andererseits wieder rliese norphologische Uebereinstimnung zu Schlüssen für elen diese Vererbung zu verwerthen? Namentlich in Fällen, wo die Dinge nicht so klar liegen, wie in unserm? -

Mlit dieser Frage können wir schliessen. Wir laben schon ohnehin den Boden der Thatsachen hinter uns gelassen, und eine Discussion der Principien, welche gegenwärtig in unserer Wissenschaft - nicht immer zn ihrem Heil - mit einer früher moeahnten Lebhaftigkeit befehdet und rertheirligt werden, kamn nicht in unserem Plane liegen: Es galt hier blos, auf ferne, am Horizonte aufdïmmernde Umrisse hinzureisen. auf die wir durch unsern Curs getrieben wurden, und die in's Auge zu fassen nicht gut zu ungehen war. Nügen sie sich als feste Klippen und Gebirge - oder mögen sie sich als eitel Donst und Wolken erweisen, wer kamn das roraussagen?

\section{Nachtrïglicher Zusatz.}

In einem erst nach Abgang des Manuscriptes rorliegender Arbeit in die Druckerei erschienenen Anfsatz kommt O. Schmidt') zu dem Schlusse, dass schon in vielen Fällen aus der Form der Krystallkegel die Unzulässigkeit der Bildchentheorie, nicht minder aber auch der Ansicht der Allgemeingültigkeit der Müller'schen Theorie rom musivischen Sehen, wie sie Exner und ich vertreten, gefolgert werden müsse. Die Regelmässigkeit der Form der Krystallkegel, als nothwendige Voraussetzung der letzteren, sei durchaus nicht ïberall vorhanden; bei einer Anzahl ron Formen, besonders Crustaceen (Phronima, Palaemou, Astacus, Palinurus etc.) umel Insecten (Dytiscus) kïmen Kergel ron gebogenem Verlauf, un'egelmässig gestalteten Endflächen etc. etc. vor, die nothwendig das Zustandekommen einer Wahmehmung auf dem durch die musivische Theorie formulirten Wege ausschlössen.

lch will mich, obschon ich die anatomischen Befunde O. Schmidt's auf Grund meiner mehrjährigen Erfahrungen anf diesem Gebiete, rle mich gründlich mit den Schrierigkeiten der technischen Behandlung (namentlich der Crustaceen) bekannt gemacht haben, nicht als völlig über jeden Zweifel erhaben anzusehen im Stande bin, doch hier nicht anf eine ausführlichie Discussion aller einzehen Punkte, die mir mehr oder weniger anfechthar erscheinen, einlassen, sondern einfach seine Darstellung acceptirend prïfen, ob daraus die Berechtigung folgert, für solche irreguläre Formen den Boden der II üller'schen Theorie, die für regulïre Krystallkegel auch O. Schmidt nicht beanstandet, zn rerlassen. Ich memerseits muss die Frage verneinen.

Annahme soleher inlifferenter. Sinneszellen ïlerhanpt lïsst sich meiner Ansicht nach nichts einwenden; wohl aber seheint mir die mit ilırer Hülfe versuchte Erklärung verfehlt. Sollten bei den Heusehreeken z. B., als die so nahe rerwandten Gattungen Acridium und Loeusta sich ron einaniler oder ron einem gemeinsanen Stamme trennten, ihre späteren Gehörorgane noch nicht tiber das Stadium indifterenter Sinneszellen hinausgekommen gewesen sein? Und die anderu Sinnesorgane dersellen Thiere?

1) O. Scltmiılt, Die Form fler hirystallkegel im Arthroporlenauge. in: Ztschft. f. wiss. Zool. - Suppl. zu Vol. XXX. 1878. pag. 1-12. Taf. I. 
Leider hat O. Schmidt bei seiner Untersuchung dem Rhabdom so ganz und gar keine Aufmerksamkeit geschenkt, und demgemäss die Rolle, die dasselbe als Hauptinstanz in jeder Beziehmg bei dieser Frage spielt, allein dem Krystallkegel ïbertragen, der in seinen Fällen wohl der Bildchentheorie rerhängnissvoll werden kamn, bei der Discussion über die musivische Theorie sich aber durchans nicht ron gleicher Bedentung erweist.

In der Geradaxigkeit der lichtbrechenden Medien, also besonders des Frystallkegels, den Punkt zu erblicken, wit dem die Mïller'sche Theorie steht oder fällt, liegt meines Erachtens durchaus nicht im Wesen der Theorie. Wenn O. Schmidt vielleicht auf einen auch von ihm citirten Passus aus meiner zweiten Mitheilung (Klin. Monatsbl. für Augenheilkunde etc. pag. 39), in dem ich ron den centralen Strahlen als den einzigen spreche, die geradlinig und mgebrochen durchtreten und das Rhabdom erreichen, besonderes Gewicht legt, so darf ich dies vielleicht dahin erlüutern, dass für gerade Krystallkegel, die ich nach meinen Erfahrungen als Regel ansehen und demmach auch behandeh muss, die centralen geradlinigen Strahlen eben die einzigen sind, die zur Wirkung gelangen. Krümmen wir num ein solches System stetig und gleichnässig, so sehe ich nicht ein, dass damit auch gleich das Princip aufgegeben zu werden brancht, sofern nur durch immere Reflexion (sei es im Kirystallkegel, sci es in einer fadenförmigen Verlïngerung der Retinula vor dem Rhabdom) dem axialen Strahlenbüschel die Möglichkeit benommen ist, aus dem System auszutreten, sondem dasselbe genöthigt ist, das Rhabdom zu durchistralilen.

Einen zweiten Einwand erhebt O. Schmidt speciell für Plronima, bei der die Absorption seitlich in die Kiegel eintretenrler Strahlen nicht rorkomme. Durch Pigment, das nur ganz hinten an den Krystallkegeh sich findet, allerdings nicht; indessen schreilst Schmidt, und ganz mit Recht, den vordem gewölbten Enden eine Linsenwirkung zи, und damit haben wir doch wieder den Gegensatz ron axialen Strahlen, die ungebrochen durchtreten, und ron mehr oder weniger gebrochenen, ausserhalb der Axe einfallenden, die doch nach der Vereinigung zum Bilde ihren Weg gegen die Mantelfliche des Krystallkegels fortsetzen, und dort je nach Maassgabe des Auffallswinkels aus demselben anstreten kümen. Wenn O. Schnirlt etwa aus dem pag. 7 1. c. beschriebenen Tersuch mit Glasstäben, denen die Form solcher Krrystallkegel gegeben wurde, die er als rorzügliche Lichtleiter beschreibt, und ron denen er sagt: „genan so, wie diese Glasstäbe, mïisen sich die Krystallkegel der Phronima verhalten" - ctwa die Beweiskraft desselben urgiren sollte, so möchte ich doch an den bedeutenden Unterschied hinsichtlich des Einflusses auf die innere Reflexion — demm $u m$ diese dreht es sich - zwischen Glasstäben, umgeben von Luft einerseits. und Krystallkegeln, ungeben und durchtränkt von Wasser andrerseits hinweisen. In letzterem Falle sind bekamntlich die Bedingungen für den Austritt schief auf die Grenzflïche fallender Strahlen malcich gïnstiger, als in ersterem. (Mir scheint überhaupt, beilünfig bemerkt, O. Sehmidt dem Unstande, dass bei den Crustaceen Wasser das die Angen umspülende Medium ist, nicht überall genügend Rechmung getragen zu haben.) Indessen mögen immerhin noch genug der selur schräg auffallenden Strablen zum Rhabdom geleitet werden; dam tritt cben der Fall, der oben pag. 154 erwähnt wurde, ein, olme dass memer Ansicht nach die musivische Perception aufgegeben zu werden braucht.

L'ebcrhaupt darf meines Erachtens auch aus dem Eintritt von Lichtbïscheln oder Lichtkegeln, die 0. Schmirt speciell für Phronima behauptet (1. c. pag. 6), in das einzelne Ange des facettirten noch nicht die Unhaltbarkeit des musivischen Sehens für diesen speciellen Fall gefolgert werden. Diese Lichtbüschel entsprechen den Eimzelbestandtheilen des Gesammtsehfeldes, den "Differentialen" desselben, wie ich sie frïher anch genamt lnbe; verbreitern sie sich, so nimmt 
eben dies "Differential“ an Grösse zn, und damit rlie Sehschärfe ab, wie umgekehrt die Verschmälerung derselben, unter Voranssetzung des dichtern Aneinanderrïckens der Einzelangen, eine Steigerung der Selıschärfe theoretisch bedingt. Werden die Lichtbïschel, die in den Krystallkegel eintreten können, so divergirend nach anssen, dass sie sich mit ihren Mantelstrahlen in einem grösseren oder kleineren Abstande rom Auge krenzen, können also, mit andern Worten, Theile des Sehfeldes, die jenseits dieses Abstandes gelegen sind, in mehr als nmr eines der Einzelangen Strahlen senden, so wird allerdings jenseits dieser Grenze die Sondermg der Lichtqualitäten völlig anfhören, die diesseits derselben noch in einem gewissen Grade besteht, das Thier also neben geringer Selıschärfe auch noch eine geringe Sehweite haben. Der ganze, wenn anch noch so mangelhafte Sehact wird aber, wie ans der Natur des Rhabdoms als höchstwahrscheinlicher Perceptionseinheit folgert, trotzdem anf musivischem Wege ror sich gehen.

Auf die andern, von 0 . Schmidt für das Decapodenauge betonten Irregularitäten, die vor allem die mregehmässigen Grenzflächen der verschierlenen Bestandtheile des sog. Krystallkegels betreffen, (den ich im beschreibenden Theil meiner Arbeit als modificirte Mntterzelle mit verschiedenen Einlagerungen auffasse), branche ich $1 \mathrm{~m}$ so weniger einzugehen, als dieselben im frischen, lebenden Ange wegen der dam wohl allermeist geringen oder gar nicht vorhandenen Differenzen der Brechmngsindices kaum von nennenswerthem Einflnsse sein kömen. Diese Differenzen treten freilich nach Erhärtung der Angen nm so dentlicher herror.

Nur noch ein parr allgemeinere Bemerkmngen bei dieser Gelegenheit.

Wenn O. Schmidt (1. c. pag. 2) sagt, dass die bekannte Arbeit von MI. Schultze über unsern Gegenstand unter einer ,anthropomorphischen Ansclianung" gelitten habe, so muss dieser Vorwurf oder Tadel, wenn es einer sem soll, anch mene Arbeit, und in weit höherm Grade, treffen. Wemm dagegen ich selbst an jener Schrift etwas anszusetzen habe, so ist es das gerade Gegentheil: hätte M. Schultze die Summe ron Erfalmungen über die Natur des Stäbchens, die ilm von den Vertebraten wie Evertebraten zux Verfügung standen, bei seiner Untersuchumg des Artliropodenanges mitsprechen lassen, statt sich auf die Jagd nach den "physiologisch postulirten" feinsten Nervenfasern zu begeben: sollte ihm da die Lösmmg des Problems vorenthalten geblieben sein? Anch bei O. Schmidt sähe ich emige Concessionen an den "Anthropomorphismus" lieber, als die vermuthungsweise eingeführte Beziehmng der Krystallkegel-Krümnnmgen zn einem durchans hypothetischen "Raumsinn", ron dem wir doch absolut nichts wissen. - Dagegen nnterschreibe ich gern und willig, wenn auch wahrscheinlich in einem etwas andern Simne, als der des Terfassers ist, O. Schmidt's Satz (1. c. pag. 11): wenn der Krystallkegel nicht nur rortrefflich Licht leitet, sondern anch die Perception von Lichtstärke und Farbenschattirmgen vermittelt, „so sind wir allerdings wieder bei einer besondern Species von einfachem Ange angelangt". Diesem Nachweise ist ja der grösste Theil meines Bnches gewidmet.

$\mathrm{Ob}$ es mir nun gelmgen ist, den geehrten Gegner von einem blos bedingten Anlänger der musivischen Theorie zn einem unbedingten Vertreter derselben umzuwandeln, trotz einiger Irregnlaritäten, auf die wir im Bereiche der organischen Schöpfmng ja immer gefasst sein müssen - das weiss ich nicht. Hoffentlich aber ist es mir - und nicht nur durch diesen Znsatz — gelungen, ihn wenigstens zn überzengen, dass wohl katum der Krystallkegel mit seinem Formenreichthmm ein gïnstiger Angriffspunkt anf dieselbe ist; hat sie überhampt Gefahren zu befïrchten, so liegen diese für sie viel tiefer, im Rhabdom; denu darin liegt eben ibr Wesen. dass sie nicht, wie ihre Rivalin, eine Projections-, sondern eine Perceptionstheorie ist. 


\section{Erklärung der Abbildungen.}

\section{Bedentung einiger öfters wiederkehrenden Buchstaben.}

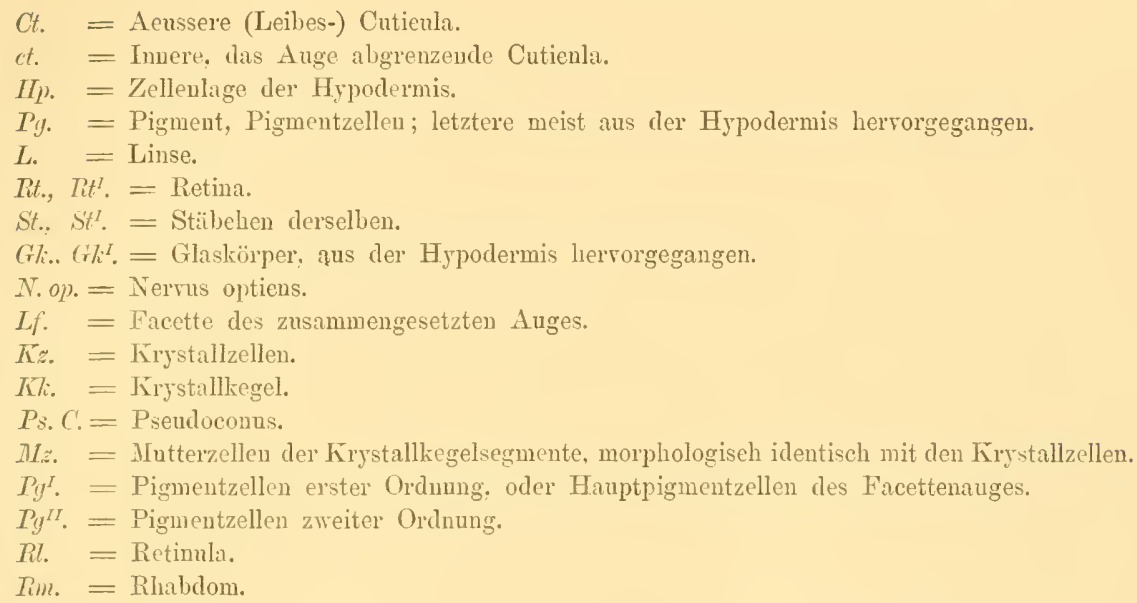

\section{Erklärung der Figuren.}

NB. Die eingeklammerten Buchstaben und römisehen Zahlen beleuten die Combination der Z eiss'sehen Objeetive und Oculare. mit denen die darauf folgende Vergrösserung erzielt wurde. - Die Behandlung des Präparats ist meist ebenfalls in Abkïirung angegeben, z. B. Plat. chl., Chroms., Ac. uitr. heisst: das Auge wurde in Platinchlorid und Chromsïure erhärtet, der Schnitt mit Salpetersïnre entfïrbt, etc. ete. — Die Zahlen am Encle geben einige Dimensionen in Millimeter.

\section{Tafel I.}

Fig. 1. Durehschnitt, dnrch ein Ange einer jungen, ca. $3 \mathrm{~cm}$ langen Dytiscuslarve (E. II. 350). Plat. ehl., Chroms., Ae. nitr. - Man erkennt das Hervorgehen sämmtlieher Augenweiehtheile (Pigment, Glaskörper, Retina) aus modifieirteu Hypoderuiszellen.

Durchmesser des Anges (quer) $=0,12 \mathrm{~mm}$.

$$
" \quad \text { der Linse . . . }=0,045 ",
$$

Dicke .. . . . . $=0.021$,

Länge der Stäbehen . . $\cdot=0,018$ " 
Fig. 2. Drei Retinazellen nebst Stäbchen aus dem Auge einer fast völlig ansgebildeten D y tis cus larre (Imm. 2, II. 590). Plat. chl., Chroms. Ac. nitr.

Lä̈nge der Stäbchen ca. $=0,026 \mathrm{~mm}$.

Fig. 3. Eines der in die Quere rerlängerten Angen einer D ytisc us larre, scliräg durchschnitten (Vergr. ca. 130fach). Alcoh., Ac. nitr. - Bei dieser Schnittfülnung ist die Linse nicht getroffen.

Querdurchmesser des Auges ca. 0,33 $\mathrm{mm}$.

Fig. 4. Eines der grossen Scheitelangen einer noch jungen, ca, 10-12 mm langen Larre von A cilius sulc a tus im Längsschnitt (E. II. 350). Plat. chl., Chroms., Ac. nitr. - Die Hauptmasse des Anges hinter der Linse wird gebildet ron dem Glaskörper, der aus grosen, theils mehr gerade, theils gebogen verlanfenden, der Hypodermis angelı̈̈rigen Zellen gebildet wird. Die dicke consex-concare Retina whd duch eine tiefe Querspalte $\left(S_{p}\right.$.) in zwei Hälften getheilt; die Wïnde der letzteren sind mit riesigen Stäbchen $\left(S t^{I}\right.$.) garnirt, welche weit grösser sind, als die auf der Vorderflïche der ïbrigen Retina befindlichen.

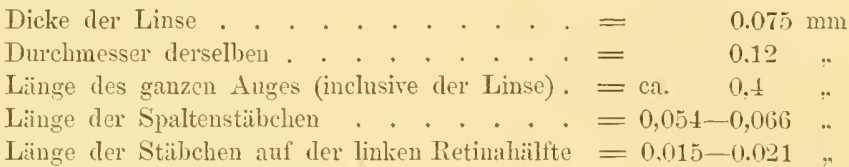

Fig. 5. Ansicht der inneren, resp. Iantelenden der Glaskïrperzellen desselben Anges; man erkennt darin die Kerne. die vor der Entfärbung von Pigment umliullt sind.

Fig. 6. Die colossalen Stäbchen der Retinaspalte desselben Thieres, gesehen von ihrer dem Spaltenlumen abgewandten Seite; man glaubt auscheinend parweise einander genäherte Stäbchen zu sehen. die aber bei tieferer Focaleinstellung einander nüher rücken und schliesslich zusammenfliessen (Imm. 3. II. 1030).

Fig. 7. Dieselben, auf einem Schnitte schief zur Spalte gesehen (E. II. 350). Alcoh., Ac. nitr. - IIan sieht nach der Tiefe hin ihre palissadenförmige Stellung neben einander; ihre rimnenfürmige Gestalt ist so nicht zn erkemen.

Fig. 8. Dieselben; von einem Ange, das nach kurzem Verweilen des Thieres in Alcohol in Wasser zerzupft wurde (Imm. 2. Ш. 590). - Die dem Beschauer zugewandte Seite ist die. welche gegen das Lumen der Spalte gerichtet ist; das dichte, schwarze. die Stäbchen ron unten herauf ledeckende Pigment erfiillt die Spalte theilweise. Nach unten gehen die mit gelhen Tropfen und braunrothen Pigmentkïrnchen erfïllten Retinazellen in die Nerrenfasern des Opticus ïber.

Fig. 9. A, B, C; Fragmente kleinerer Stiihchen, ebendalıer; etwas rerändert (Imm. 2. II. 590).

Fig. 10. Eines der nach der Unterseite gerichteten Augen einer Acilius-Larre, nach rorhergegangener Erhärtung in Clromsäure unvollständig mit Ac. nitr. entfïrbt (E. П. 350).

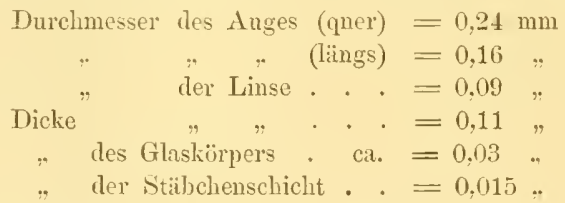

Fig. 11. Flächenansicht der Stäbchenschicht von einem solchen Acilins-Auge (Imm. 2. III. 800). - Die Stäbchens:ïume der einzelnen Retinazellen, auf solchen Ansichten nicht auseinanderzulhalten, bilden ein rundlich-polygonales Maschenwerk, aus dessen Tiefe das Pigment durchscheint.

\section{Tafel II.}

Fig. 12. Durchsehnitt durch ein Ange einer Larve ron Semblis (Sialis) spec. (E. II. 350). - Alcoh., Ac. nitr. - Hinter der grossen Linse liegt ein querdwchschnittenes Gebilde, das mit dem Krystallkegel des Facettenauges morphologisch vergleichbar erscheint $(K k)$; hinter diesem die Retina, aus zwei Schichten von Zellen bestehend, ron denen aber lier blos eine zu sehen ist. Jede Zelle trägt rorn einen Stäbcheniiberzng. 


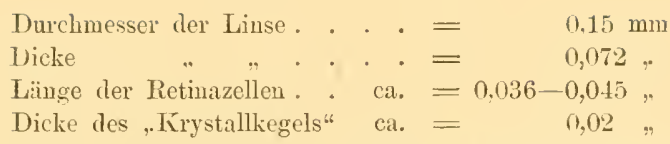

Fig. 13. A, B. Zwei solcher "Krystallkegel* von der Flïche gesehen, um ilre Zusammensetzung aus acht Segmenten zu zeigen; der in B dargestellte ist zersprengt, und das eine der abgesprengten Segmente hat eine abnorme Bildung.

Fig. 14. Retina und „Krystallkegel“ eines Auges einer Semlilis-Larve isolirt und von imnen (hinten) gesehen (Imm. 2. II. 590). Ale., Ac. nitr. - Ian erkennt die beiden Zellenlagen, aus denen die Retina besteht; durch das Zusammentreten der Seitentheile der Stäbchen, welche zu den Retinazellen gehören, entstehen die strahligen Figuren (St.). $\quad H$. = Hïlle aus dem „.Krystallkegel“.

$$
\begin{aligned}
& \text { Lïnge des ". Krystallkegels" }=0.085 \mathrm{~mm} \\
& \text { Breite " } "=0.078 \%
\end{aligned}
$$

Fig. 15. Schnitt durch ein Auge von Pla langinm opilio, frontal gerichtet (DD. II. 235). Plat. chl., Chroms., Ac. nitr. - Der Pfeil neben der Figur giebt die Richtung der Medianebene des Thieres an. Glaskörper und Retina sind etwas gedrïckt und aus ilırer Lage verscholsen. Der continuirliche Uebergang der Hypodermiszellen in Pigmentzellen und Glaskörperelemente ist dentlich.

$\begin{aligned} \text { Durchmesser der Linse . . } & =0,15 \mathrm{~mm} \\ \text { Dicke ." . . } & =0,15 \% \\ \text { Länge der Glaskörperzellen } & =0,051-0,12 \% \\ \text { " " Retinazellen . . } & =0,12-0.15 \% \\ \text { " Stäbchen . . } & =0,021-0.04 \% \\ \text { Durchmesser der Retina . } & =0.27 \%\end{aligned}$

Fig. 16. Torderenden von drei Retinazellen mit (kurzen) Stäbchen ron Phalanginm opilio (Imm. 2. II. 590). Alc., Ac. nitr. - Man erkennt die Hïlle der Stäbchen und deren Längstheilung.

Fig. 17. Querschnitt durch drei Stäbchen desselben Thieres; gleiche Tergrösserung wie vorhin. - Plat. chl., Chroms., Acid. nitr. - Hiille der Stäbchen, sowie Zusammensetzung derselben aus drei Stïcken sind dentlich.

Fig. 18. Lïngsschmitt durel ein rorderes (A) und ein hinteres (B) Dorsalauge ron Epeira diadema (DI. II. 235). Alc., Ac. nitr. - Zur Demonstration des Dimorphismus der Retinaelemente, die bei dem vordern Auge (A) die Stäbchen an ihrem Linsenende, die $K$ me an ilnem Opticusfaserende tragen, wïhrend sie bei dem hintern Auge (B) die Keme ror den massigen Stäbchen aufweisen. K. Kerne der Retinazellen im vordern, $\boldsymbol{K}^{I}$. im hintern Ange; St. Stäbchen im vordern. St . im hintern Auge. M. quergestreifte IInskelfisern, welche, vom Integument entspringend, das vordere Auge anscheinend schleifenförmig tragen; sie fehlen dem hintern Auge. $M^{I}$. Querschnitte dieser Muskelfasern (am linken Rand der Zeichung des vordern Anges).

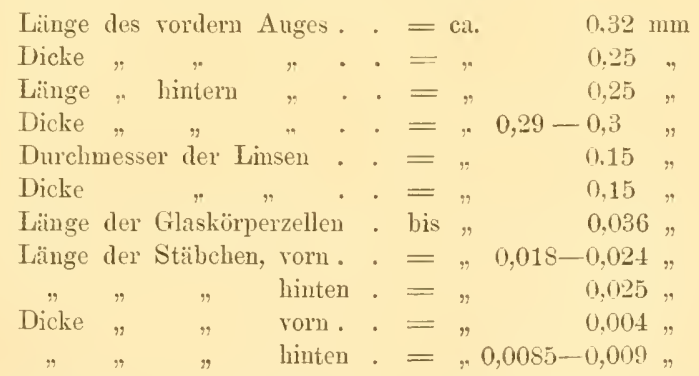

Fig. 19. Vier Stïbchen aus dem vordern Rückenauge ron Epeira diadema (Imm. 2. II. 590). Man erkennt ilne Zweitheiligkeit, sowie die zarte, auf die Seitenränder beschränkte Querstreifung. Gk. Hinterende der Glaskörperzellen, scharf abgesetzt, mit Kernen. 
Fig. 20. Vier Retinazellen nebst den eingeschlossenen Stäbchen aus dem hintern Rückenauge dessellben Thieres, bei gleicher Tergrösserung wie Fig. 19, besonder's, um die relative Lagerung der Stäbchen zu den Zellkernen, die For'm und Halbirung der ersteren zu zeigen.

Fig. 21. Eine Anzahl Stäbchen aus dem hintern Rüickenange rou Epeira diadema im Querschnitt, um ihre Zusammensetzung zu zeigen (Imm. 2. II. 590). - Sowohl in Fig. 21 als in Fig. 20 (das Stäbchen links) sind die Theilungshuien, der Deutlichkeit wegen, markirter angegeben, als der Natur entspricht.

\section{Tafel III.}

Fig. 22. Längsschnitt durch zwei Angen von Lycosa spec., parallel der Medianebene (Vergr. ca. 140). Alc. Ac. nitr. - Der Schnitt entspricht dem in Fig. 18 von Epeira gezeichneten, liegt nur umigekehrt. A demnach rorderes, B hinteres Auge; ersteres ist riel kleiner als das letztere, entspricht aber hinsichtlich der relativen Lage der Kerne $(\boldsymbol{I}$. $)$ zu den Stälschen. sowie hinsichtlich der Mnsculatur dem mit A bezeichneten in Fig. 18, sowie anch B dem dort mit dem gleichen Buchstaben bezeichneten. - Die Kerne sind mit Haematoxylin tingirt.

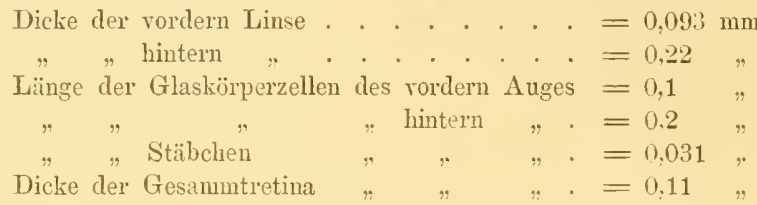

Fig. 23. Stück der Retina welst den angrenzenden Hinterenden der Glaskörperzellen eines hintern Auges von Lycosa spec. (E. II. 350). Alc. - Pigment noch erhalten, Haematoxylinfürbung. Zur Demonstration der relatiren Lage der Retinazellenkerne $\left(K^{I}\right.$. $)$ zu den Stäbchen $\left(S t^{I}\right.$.), welche im Pigment rersteckt liegen. Die Zeichnung ist den peripherischen Theilen der Retina entnommen.

Fig. 24. Anordnung der Stïbchen auf der Retina eines der Augen des hintersten Pares ron Lycosa spec. (DD. II. 235). Die Stïbchen, die hier nicht einzeln gezeichnet sind, erscheinen auf Flächenansichten der Retina in einer solchen Schlangenlinie neben einander angeorduet.

Fig. 25. Lüngsschnitt durch eines der äussern Vorderrandaugen ron Salticus spec. (DD. II, 235). Alc., Ac. nitr.; Tinction durch langsam gelöstes Angenpigment. Die Kerne der Retinazellen (K.) bilden eine ringförmige Anhäufung um das Ange; mit ilren zugehörigen Retinazellen stehen sie nur durch die feinen Fäden $(F$.$) , welche zwischen Glaskörper und Retina eine ansehnliche Lage bilden, im$ Zusammenhang. - Die mit Gf. (?) bezeichneten, in rerästelten Ziggen aus dem Opticns in die Retina eintretenden Zellkerne gehören rermuthlich zu einem in das Auge eintretenden Blutgefïss.

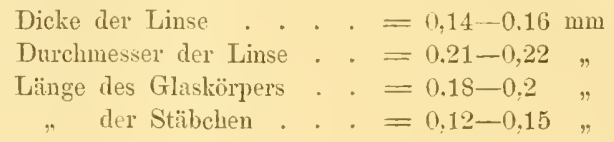

\section{Tafel IY.}

Fig. 26. Stïck eines Schnittes quer durch ein solches Ange (Fig. 25. Taf. III), schräg, ettra in der Richtung des Pfeiles in Fig. 25 gefiiln't (E. II. 350). Alc. - Man erkennt aus dem Querschnitt der Stäbchen (St.) ihre Zusammeusetzung aus zwei Hälften, ferner die Fïden, welche zu der pigmentirten Zone der Retinazellkerne $(\boldsymbol{K}$.) verlaufen, und unter ihnen durchscheinend die hintern Enden der Glaskörperzellen.

Fig. 27. Ein Auge des hintersten Paares ron demselben Thiere (DD. II. 235). Alc.. Ac. nitr. - Der Bau des Anges ist der gleiche, wie in Fig. 25, abgesehen von dem Ueberwiegen des Querdurchmessers.

Fig. 28. Inneres Torderrandauge desselben Thieres im Lüngsschnitt (CC. II. 145). Alc., Ac. nitr. - Das Auge ist durch die ungehenre Entwickelung des Glaskörpers in Cylinderform rerlingert; die Elemente des hintern Theils dieses letzteren $\left(G h^{I}\right.$.) selien aus wie ein regetabilisches Zellgewebe. - Das Pigment in den peripherischen Zellenenden des Glaskörpers ist noch als erhalten gezeichnet. Die Retina 
zeigt rorn eine centrale trichterförmige Vertiefung, ror den Stäbchen eine anscheinend aus Fäden gebildete Schicht $(F)$, und die Kerne derselben befinden sich hinter den Stäbchen. Diese sind in der Mitte der Retina besonders lang und sehr fein.

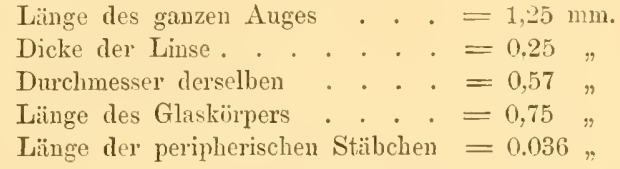

Fig. 29. Schnitt durch ein Auge ron Pulex canis, frontal (E. II. 350). Alc. - Das pigmentfreie Auge ist ron einer dunkel tingirten Chitinkapsel $\left(C t^{I}\right.$.) umbïllt, an welche sich Muskeln ansetzen. Im Innern derselben sind die Elemente des Glaskörpers $(G k$.), sowie Andentungen der Stäbchen (St.) vor der Opticusausbreitung $(R t$.$) zu erkemnen. T i$. $=$ Tracheen $; I I .=$ Muskeln.

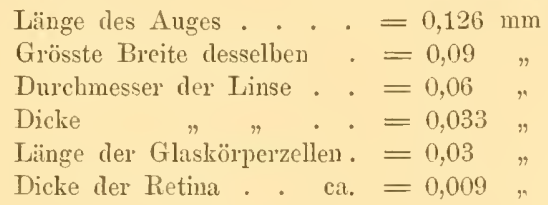

\section{Tafel $\mathrm{V}$.}

Fig. 30. Stemma ron Musca vomitoria im Längsschnitt (E. II. 350). Alc., Ac, nitr. - Die einzelnen Bestandtheile des Auges sind noch alle dentlich zu erkennen. Das Stemun sowohl, wie der Sehnerv, sind umgeben von Zellen des Fettkörpers $(F \%$.), zwischen denen Tracheen (Tr.) verlaufen.

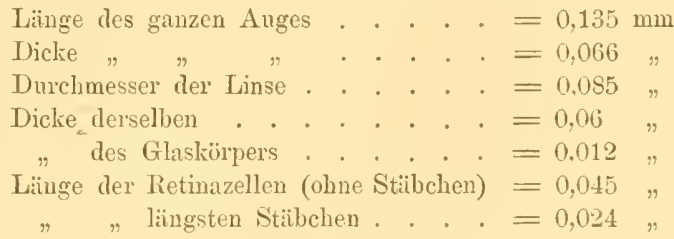

Fig. 31. Stemma von Tespa communis im Lüngsschnitt (DD. II. 235). Alc., Ac. nitr. - Die Linse ist in ihrer innern Hälfte stark durch das Schneiden zerklïftet. Zwischen sie und die Retina schiebt sich die sebr diunne, in der Darstellung hier etwas schematisirt gehaltene Schicht der Glaskörperzellen (Gl.) ein.

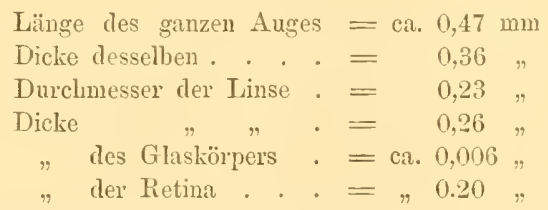

Fig. 32. Torderenden einiger Retinazellen desselben Anges (Imm. 2. II. 590), um die plattenförnigen, zweitheiligen Staibchen zu zeigen. Stäbchen bei den mit a bezeichneten Retinazellen im Profil, bei den mit $b$ bezeichneten von der Flïche gesehen.

Fig. 33. Dieselben Elemente im Querschnitt, bei gleicher Vergrösserung.

Durchmesser der Retinazellen ca. 0,005-0,008 mm.

Fig. 34. Schnitt durch ein Stemma von Crabro cribrarius (CC. II. 145). Pikrinschwefelsäure, Alc., Ac. nitr., Haematoxylin. - Retina sowohl wie Glaskörper, dessen Elemente hier ebenfalls änsserst klein sind, haben sich von der Linse losgelöst; letztere ist durch eine tiefe, ringförmig verlaufende Furche in ihrer Aequatorialgegend in zwei Hülften getheilt. (L., $L^{I}$.) 


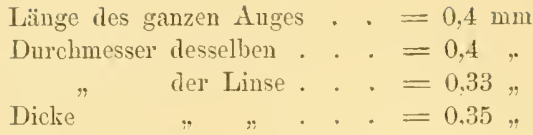

Fig. 35. Stemma von Phryganea graudis, im Längsschnitt (DD. II. 235), - Alc., Haematoxylin. Der Schnitt ist melı durch die Seitentheile des Auges gelegt; die imnere Wölbung der Linse ist bedeckt mit den epithelartigen Elementen des Glaskörpers. - Die Retinazellen sind o lı ne Stäbchen und ohne Pigment, sie tragen die Kerne vorn.

Fig. 36. Auge ron Calanella mediterranea, 웅, jur, ron oben (Imm, 2. II. 590). Osmiumdampf. Man sieht nur die pararigen Theile, die nach oben und anssen gerichtet sind; von den dazu gehörigen Pigmentplatten kommt nur der nach oben geschlagene hintere Innemrand $\left(P_{y}\right.$.) zur deutlichen $\mathrm{A}$ sicht. $P g^{I}$. = Pigmentplatte des untern, mpaaren Theils. - Die Zellen der paarigen Theile sind hier, wie in den folgenden Figuren, mit denselben römischen Zahlen (I-VIII) bezeichnet. $-N$. fr. $=$ Nerven, welche durch die Hülle des Anges hindurch nach der Stirn treten.

\section{Tafel VI.}

Fig. 37. Ange von Calanella mediterranea. ausgebildetes Weibchen, ron oben (Tmm. 2. II. 590; einige Details mit Imm. 3. I. 760). - Pikrinschwefelsäure. Pigment zerstört, wodurch die einzelnen Zellen in ihrer Lage, sowie auch in ihrem Zusammenliang mit den Nervenfasern dentlich werden. $x$. = wahrscheinlich ein Kern, der zur Matrix der Cutienla des Anges gehört.

\section{Länge des Auges $=0,06 \mathrm{~mm}$}

Breite , $\because=0.078$.

Fig. 38. Ange ron Calanella mediterranea, Q, jur., rom der Banchseite (Imm. 2. II. 590). Osmiumdampf, - Die Zellen des unpaaren, unteren Theiles sind hier mit arabischen Zahlen (1-6) bezeichnet; die römischen s. ob. Fig. 36. $P y$. $=$ Pigmentplatten der parrigen Theile; $P y^{I}$. = Pigmentplatte des unpaaren Theiles.

Fig. 39. A. Linse des rechten Seitenauges ron Copilia denticulata, ron unten gesehen, frisch (DD. II. 235). $L^{T}$. = Linsenantheil der Cuticula; $L^{I I}$. = dahinter gelegene, weit stïrkere Gallertlinse. $A t .=$ Antenuen; $N .=$ Nerren unbekaunter Bedeutung, welche zur Cuticula treteu.

$$
\begin{array}{ll}
\text { Durchmesser der Linse } & =0,22-0,24 \mathrm{~mm} \\
\text { Dicke derselben . . . } & =0.12 \%
\end{array}
$$

Fig. 39. B. Das eigentliche Ange, der sog. .:Pigmentkör'per” nebst „Krystallkörper" desselben Thieres ron derselben Seite; der Ramnersparniss wegen für sich gezeichnet. mit Anslassung der laugen Nerren $(N-N)$, die sich rom Kúrystallkürper (Kk.) nach der Peripherie der Linse hin erstrecken. $x$ kleine, dem Krrystallkörper seitlicl anhaftende Pigmentanhäufung. $M$. einziger deutlich quergestreifter Muskel des Auges, seitlich zum Integumente tretend.

Ganze Lïnge des Pigmentkürpers, im Bogen gemessen . . = ca. $0.4 \mathrm{~mm}$

Entfernung des Krystallkörper's, vom Hinterrande der Linse $=\ldots 0.9-1.0$,

Fig. 40. Krystallkörper mol vorderer Theil des Pigmentkörpers desselben Thieres, reclite Seite, ron oben (Trm. 2. II. 590). Pilirinsalpetersäure. $-x$ (vgl, Fig. 39, B) zeigt einen schräggestellten, lichtbrechenden Körper im Imnern. K. die drei Kerne vor dem Torderende der Stäbchen St.

$$
\begin{aligned}
& \text { Lüuge des Krystallkörpers }=0,066 \mathrm{~mm} \\
& \text { Breite . " }=0.042 \text {, } \\
& \text { Dicke des Pigmentlkörpers }=0,012-0,015 \text { " }
\end{aligned}
$$

Fig. 41. Linkes Auge ron Sapplirina fulgens, ron oben. frisch (DD. II. 235). L $L^{I I}$. Linse, d. h. inmerer, gallertartiger Theil derselben (wie in Fig. 39, A). MLt. unpaares medianes Auge. - Am Pigmentkörper sieht man die Stäbchen (St.): sowie, ror diesen, einen rundlichen lichtbrechenden Kü̈rper (y) durchschimmern. Bedeutung der uibrigen Buclstaben wie in den vorhergehenden Figuren.

Durchmesser der Linse $=$ ca. $0,075 \mathrm{~mm}$.

Fig. 42. Seitenaugen von Sapphirina, freipräparirt, etwas gedrückt (E. II. 350). Osmiums., Alc. - Die Krystallkörper" sind besonders stark gedrïckt, so dass sie Falten anf ihrer Fläche zeigen; auch die 
Pigmentkürper sind comprimirt, wodurch, besonders in dem reclits gelegenen Auge, die im Innern derselben gelegenen St:̈bchen (St.) sehr deutlich hervortreten. $x$ lichtbrechende Körper, die in einer dem Krystallkörper seitlich ansitzenden Pigmentinsel liegen, welch letztere bei der Ansicht Fig. 41 nicht sichtbar ist. $y$ wie in Fig. 41.

$$
\begin{gathered}
\text { Lüinge des ganzen Auges. } \cdot=\text { ca. } 0,18-0,22 \mathrm{~mm} \\
" \text { " Pigmentkörpers : }=" 0,075-0,09 "
\end{gathered}
$$

Fig. 43. Rechtes Auge ron Sapphirina, ron oben, Tordertheil (Imm. 2. II. 590). Osmiuns., Alc. Bedeutung der Buchstahen wie vorhin; ct. Cuticula des Pigmentlïrpers; $K$. die drei Kerne, welche vor den Stäbchen gelegen sind, wie in Fig. 40.

\section{Tafel VII.}

Fig. 44. Stiick eines senkrechten Schnittes durch das zusammengesetzte Ange ron Tipula spec., drei Einzelaugen darstellend (Imm. 2. II. 590). Alc., Ac. nitr., Entfïrbung vicht vollständig. Hinter jeder Comeafacette (Lf.) liegen vier Krystallzellen (Kr.), von denen nur zwei dargestellt werden; der lintere, rexengte Theil derselben wird von zwei Hauptpigmentzellen $\left(\mathrm{Pg}^{\mathrm{I}}\right.$.) umschlossen. - An diese schliesst sich die Retimula (Til.) an, aus sieben Zellen (sechs peripherischen, einer centralen) bestehend, ron denen nur je drei gezeichnet sind. Zu jeder dersellen gehört ein Stïbchen (St., St $t^{I}$.). Die centralen Stäbchen $\left(S t^{I}\right.$.) sind rom quer durchgebrochen, das vordere Stiick hängt mit den Krrstallzellen zusammen. - P $y^{\prime \prime}$. Nelsenpigmentzellen. Pigmentzellen zweiter Ordnung. - n. Kerne der Retimulazellen. ct. imere zarte Cuticula, durch welche die Faseru des Opticus treten.

$$
\begin{array}{lll}
\text { Durchmesser einer Facette . . }= & 0,027 \mathrm{~mm} \\
\text { Dicke } & =0,025 " \\
\text { Lünge eines centralen "Stäbchens } & =0,028-0.03 "
\end{array}
$$

Fig. 45. Durchschnitte durch drei Retinulae, in verschiedenen Höhen, um das Verhalten der Stïhchen zu den Retinulazellen, sowie die Zahlenverhältnisse der letzteren zu zeigen (Imm. 2. II. 590). Alc.. Ac. nitr. A. Schnitt aus dem vordersten Theil, B. aus der Nitte, C. durch das hinterste Ende des centralen Stïbchens.

Fig. 46. Senkrechter Schnitt durch drei Facetten ron Ctenophora flareolata, eine vierte ist gestreift (F. II. 550). Alc., ohne Pigmentzerstörung. Der Schnitt ist dem Randtheile des Gesammtanges entnommen. Berlentung der Buchstaben wie oben in Fig. 4.

$$
\begin{aligned}
& \text { Durchmesser einer Fitcette . . . }=0,027 \mathrm{~mm} \\
& \text { Dicke } \quad \text { " . . . }=0,015 \quad \text {. } \\
& \text { Lü̈nge eines centralen Stiibchens }=0,05 \text { " } \\
& \text { " peripherischen " . }=0,012 \text { " }
\end{aligned}
$$

Fig. 47. Einzelauge desselben Thieres, aus der Mlitte des Gesammtanges, mit Ac. nitr. entfïrbt (Imm. 2. II. 590). Es wurden zwar die peripherischen Stäbchen, aber nur zwei der zu ilmeu gehörigen Retinulazellen wiedergegeben.

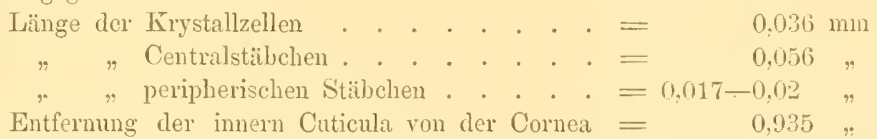

Fig. 4s. Flïchenschnitt durch das Auge desselben Thieres, olne Entfärlsung (F. II. 550). Links sind die Corneafacetten im Querschuitt, umgeben ron intensiv tingirten Säumen; bei $K z$. treten die vier Krystallzellen auf; weiter mach rechts zuerst die centralen Stibchen allein, herrortretend aus den Hauptpigmentzellen; dazu ihnen kommen endlich noch die peripherischen.

Fig. 49. A. B. Eine Retinula nelsst Krystallzellen aus dem Auge ron Notonecta glauca (E. II. 350). Frisch. Bei B der aus den zugehörigen Hauptpigmentzellen gebildete Becher, welcher die Krrystallzellen umgiebt. - Die Retinulazellen sind durch Quellung etras anseinander gewrichen, und man erkemnt sowohl das centrale $\left(S t^{\prime}\right.$.) als die peripherischen Stiilschen (St.) eine Strecke weit.

$$
\begin{aligned}
& \text { Ganze Lünge der Retinuli = ca. } 0,25 \mathrm{~mm} \\
& \text { Länge der Krystallzellen . }=0,042 \%
\end{aligned}
$$


Fig. 50. Qnerschnitt durch drei Retimulae desselben Thieres (E. II. 350). Ale., Ac. nitr. in mässiger Einwirkung, so dass das Pigment nicht röllig zerstört ist. - Py ${ }^{I I}$. fadenförmige Pigmentzellen zweiter Orduung in Querschnitt. - Der Schnitt geht durch den rordern Theil der Retinulae.

Fig. 51. Eine Retinula nebst Krystallzellen ron demselben Thier (E. II. 350). Alc., Ac. nitr. - Im hintern Theile der Retinula sind stark lichtbrechende Körner eingelagert, zwischen denen die Kierneder Retinulazellen durchschimmern.

Fig. 52. Eine Retinula desselben Thieres, nach kurzem Verweilen in Alc. in Wasser gebracht, wodurch die einzelnen Retinulazellen rorn auseinandertreten. Dieselbe Vergr. - Pigment noch erhalten. $S t^{I}$. centrales Stäbchen.

Fig. 53. Die einzelnen Stïbchen desselben Thieres nach längerer, intensirer Maceration mit Ac. nitr. freigelegt. Gleiche Vergr.

Fig. 54. Zwei Einzelaugen von Forficula auricularia (E. II. 350). Alc., Ac. nitr. - In der Retimula links sind die Stäbchen in der Lüngsansicht, in der rechts gelegenen aber im optischen Längsschnitt gezeichnet.

\begin{tabular}{|c|c|c|}
\hline Durchmesser der Facette. & $=$ & 0,033 \\
\hline Dicke & $=$ & 0,033 \\
\hline Lä̈nge der centralen Stäbchen . & $=$ & 0,04 \\
\hline icke des Gesammtauges". & & \\
\hline
\end{tabular}

Fig. 55. Querschnitt durch zwei Retinulae desselben Thieres. um die Zusammenfügung der peripherischen Stälschen zu zeigen. - Gleiche Vergr. wie rorhin. Die Kerne um die Retinulae gelı̈ren zu Pigmentzellen zweiter Ordnung.

$$
\text { Durchmesser einer Retimula }=0.024 \mathrm{~mm} \text {. }
$$

Fig. 56. Zwei Einzelaugen aus dem Facettenange ron Heloë proscarabaeus (Imm. 2. II. 590). Alc., Ac. nitr. - Linke Retinula mit Lüngsansicht, rechte mit optischem Lüngsschnitt der Stäbehen. Die Krystallzellen sowohl wie die Hamptpigmentzellen sind wegen mangelhafter Erhaltung des Exemplars nicht mehr speciell nachzuweisen.

Fig. 57. Querschnitt durch eine Retinula desselben Thieres, dieselbe Vergrösserung und Behandlung.

Fig. 58. Eine Facette nebst Retinula aus dem Auge von Saperda Carcharias (E. II. 350). Alc., Ac. nitr. - Retinula im optischen Längsschnitt. Die Stïbchen endigen nach hinten obne scharfe Abgrenzung.

\begin{tabular}{|c|c|c|c|c|}
\hline \multicolumn{5}{|c|}{$15 \mathrm{~mm}$} \\
\hline Dicke & & & $=$ & 0,096 \\
\hline Länge der Krystallzellen & & zur Retimula & $=$ & 0.021 \\
\hline Länge der Retinula. & . . & . . . . & & $-0.1 t$ \\
\hline Durchmesser derselben & . & . & & 0,024 \\
\hline Lü̈nge der Stäbchen . & & . . & $=$ & 0,075 \\
\hline
\end{tabular}

Fig. 59. Drei Retinulae aus dem Auge desselben Thieres im Querschnitt, dicht hinter dem Vorderende. Gleiche Vergr.

Fig. 60. Zwei Facetten nebst den vordern Enden der Retinulae von Tabanus bovinus, als Typus eines psendoconen Auges; links in der Längsansicht, rechts im optischen Lüngsschnitt (Imm. 2. II. 590). Alc., Ac. nitr. - Hinter den Linsen der Cornea erblickt man den Raum des Psendoconus (Ps. C.), eingeschlossen von den beiden Hauptpigmentzellen $\left(P_{y^{l}}{ }^{\mathrm{V}}\right.$ ), und nach hiuten begrenzt ron den vier Kúrystallzellen (Kz.). Zwischen den Retinulae liegen zahlreiche Tracheenblasen (Ti.).

Durchmesser der Facette . . . . . = $=0.054 \mathrm{~mm}$

Dicke $\quad " . . . . .=0,05 t$,

Entfermung der Retinula ron der Cornea $=0.06$,

Durchmesser der Retinula . . . . = $=0,027 "$

Fig. 61. Querschnitt durch einen Psendoconus aus dem Ange desselben Thieres (Imm. 2. II. 590). Gleiche Behandlung. $P g^{I}$. Hamptpigmentzellen; $P_{g^{I l}}$. Pigmentzellen zweiter Ordnung. Kz. Krystallzellen. 
Fig. 62. Zwei Retinulae desselben Thieres, im Qucrschnitt (Imm. 2. IT. 590). Alo, Ac. nitr. - Die Retinulae sind ron den Trachecu ( $T T$. ) eingeengt; die Zellen der exsteren sind um undeutlich von einander gesondert. Zu jeller gehört ein Stäbchen; eines ron den sieben tritt mehr als die übrigen in's Lumen des vou den Zellen gebildeten Rohres vor, und spielt so gewissermassen die Rolle eines Centralstäbchens.

\section{Tafel VIII.}

Fig. 63. Zwei Facetten nebst Zubehör aus dem Auge rou Musca vomitoria (Tmm. 2. II. 590). Alc. In den comschen, von den Hauptpigmentzellen umschlossenen Hohlrüumen sind die sehr zarten Reste der Pseudoconi (Ps. C.) noch zu erkennen. - Bei $x$. die Terlängerung der Torderenden der Stäbchen zwischen die Krystallzellen hinein. - Pg ${ }^{I I}$. kugelige Pigmentzellen zweiter Ordnung mit Auslïufern.

$$
\begin{aligned}
& \text { Durchmesser der Facette. . . . . }=0,03 \mathrm{~mm} \\
& \text { Dicke " " . . . . . =0.018" } \\
& \text { Länge cles Psendoconus . . . . . . }=0,036 \text { " } \\
& \text { Entfermung der Retimla ron der Cornea }=0,042 \text { " }
\end{aligned}
$$

Fig. 64. Querschnitt durch den Pseudoconus desselben Auges (Imm. 2. IT. 590), um die rier im Innern des selben gelegenen Strïnge zu zeigen ( $P$ s. C.).

Fig. 65. Vorderende einer Retimula von II usca vomitoria, frisch, in Wasser (Tmm. 2. TH. 590). Zellenkörper der Retinula durch Quellung veräindert. Um die Torderenden der Stäbchen $(x$.$) zu zeigen,$ welche sich (vgl. Fig. 63, x.) zwischen die Krystallzellen einfïgen.

Fig. 66. Pseudoconus und Tortertheil einer Retinula von Sareophaga carnaria (E. II. 350). Frisch in Jodserum. Um die Pigmentvertheilung zu zeigen. An den Hauptpigmentzellen (Py ${ }^{\prime}$.) erkennt man eine der trenuenden Nähte, sowie die Kerne; ferner schimmern die Krystallzellen hindurch.

Fig. 67. Nach Entfernumg der Corneafacette sieht man in die Tiete eines Pseucloconus desselben Thieres hinein (E. IT. 350). Frisch. - In der Tiefe des Hintergrundes erkenut man die Torderenden der Stäbchen dicht aneinand rgedrï̈gt.

Fig. 68. Querschnitt durch die kenlenförmigen rothen Pigmentzellen zweiter Ordnung desselben Thieres, in ihrer natïrlichen Anordnung un die Retimlae (die nicht gezeichnet sind). (E. II. 350.)

Fig. 69. Zwei encone Einzelaugen aus dem Ficettenange von Corethra plumicornis (Larve), olne die zugehörige Cornea (E. II. 350). Dis rechts gelegene (1) wach Einwirkmng von Plat. chlor. und Chroms. . das links gelegene (2) mach Erhärtung in Alc.. beide mit Ac. nitr. entfärbt. n. sog. „S emper'sche Kerne“, d. I. Kerne der Mutterzellen der Krystallkegelsegmente.

$\begin{array}{rlr}\text { Lïnge der Krystallkegel } & = & 0.02 \mathrm{~mm} \\ \text { Dicke " } & = & 0,012 ~ ", \\ \text { Lïnge der Stäbchen . . } & =0.012-0,015 \%,\end{array}$

Fig. 70. Quersehnitt durch drei Retinulae desselben Thieres, ebeufalls ron der Larre (Imm. 2. II. 590). Um die Zahl und Anordnung der Stïbchen zu zeigen.

Fig. 71. Tordertheil zweier Einzelaugen aus dem Facettenange ron Apis mellifica (Imm. 2. Il. 590). Alc., Kali cansticum. 2 . Semper'sche Kierne. Rm., Rhabdom, aus den vereinigten Stäbchen der Retinula gebilclet. - Schattirmg der Krystallkegel etwas zu stark ansgefalleu, cla sie nur schwach lichtbrechend sind.

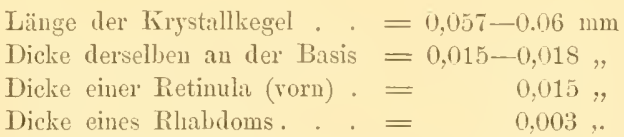

Fig. 72. Querschnitt durch eine Anzahl Retinulae desselben Thieres, um Form und Anordunng der Retinulazellen. deren hier acht vorhanden sind, un das Rhabdom zu zeigen. An letzterem ist eine Theilung in Stäbchen nicht zu erkennen (Imm. 2. II. 590).

Fig. 73. Ebensolche Querschuitte ron Tespa erabro (Tmm. 2. II. 590). Alc., Ac. nitr. - Dicht hinter dem Krystallkegel entnommen. Hier ist die aus acht Zellen besteliende Retinula, um das anscheinend einfache Rhabdom gelagert, noch deutlicher zu erkennen. 


$$
\begin{array}{cc}
\text { Durchnesser einer Retinula }= & 0,02 \mathrm{~mm} \\
., \quad \text { eines Rlabdoms } & =0,0018-0,002 . .
\end{array}
$$

Fig. 74. Retinnlaquerschnitte ron Cicada grossa (?) (Imm. 2. II. 590). Alc. — a. dicht linter dem Krystallkegel; b. näher an der Nitte. - Die Retinula ist hier ebenfalls dentlich achttheilig.

Durchmesser der Retiuula $=0,025 \mathrm{~mm}$.

Fig. 75. Zwei Einzelangen aus dem facettirten von Periplaneta orientalis (E. II. 350). Alc., Ac. nitr. - Das Rhabdom (Pm.) weicht hier nach vorn in vier Theile auseinander, welche die Spitze des Krystallkegels zwischen sich aufnehmen. Die Hamptpigmentzellen kamen nicht zur Beobachtmug.

Durchmesser einer Facette . . . $=0,03 \mathrm{~mm}$

Dicke einer Facette . . . . . $=0.036$,

Lïnge des Krystallkegels . . . . =0.036 .,

Durchmesser des Rhabdoms (unten) $=0,009$,.

Fig. 76. Querschmitte durch den Krystallkegel (1) und Retinula nebst Rhabdom (2-4) in rerschiedenen Höhen, von demselben Thier (E. II. 350). In (1) sieht man bei Rm. die vier divergirenden Blaitter des Rhabdoms durch den Frystallkegel himlurchschimmern.

Fig. 77. Zwei Einzelangen aus dem zusammengesetzten von Gryllotalpa (E. II. 350). Alc., Ac. nitr. Das viertheilige Rhabdom ist ebenfalls, aber in weit geringerem Maasse, gespalten; der Krystallkegel links ist in stark geschrumpftem Zustancle dargestellt, n. Kerne der Retinulazellen.

Fig. 78. Aus dem Auge von Necroph or us. vorderer Theil der Retinulae, Kiystalliegel etc. (Imm. 2. II. 590). Alc. - Die vordern, glatten Flächen der Corneafacette sind nicht mit gezeiclınet. Die Krystallkegel (K7:) sind kurz; ihre Segmente sind vou einander isolirt, und stecken in ilnen sehr grossen Mntterzellen $\left(K_{z}\right)$. - Die Retinulae sind im optischen Längsschnitte dargestellt.

$$
\begin{aligned}
& \text { Dicke der Facetten . . . . . . . = } 0,07 \mathrm{~mm} \\
& \text { Liinge der Retinula . . . . . . . }=\text { ca. } 0,2 \text { " } \\
& \text {.. } \quad \text { Mntterzellen der Krystallkegel }=0,039-0.04 \text {.. } \\
& \text {., ., Krystallkegelsegmente . . . = } 0,012 \text {, }
\end{aligned}
$$

Fig. 79. Querschnitt durch drei Krystallkegel desselben Thieres (Imm. 2. II. 590).

Fig. 80. Querschnitt durch drei Retimlae desselben Thieres (Tmm. 2. II. 590). Sowolıl Retinula als Rhabdom zeigt deutlich die Zusammensetzung aus sieben Stücken.

Fig. 81. Drei Einzelangen aus dem zusammengesetzten von Melolontha vulgaris (E. II. 350). Ale., Ac. nitr, - Das eine (linke) dersellyen ist dargestellt, wie es sich mit seinem Pigment ror der Entfärbung prïsentirt, die beiden andern nach derselben. Bei dem mittleren ist der Krystallkegel im optischen Lüngsschnitt, bei dem rechten aber in der Lüngsansicht wiedergegeben. Thre Hülle verlïngert sich stark nach linten; die Retinula zeigt zwei durch einen fadenartig verdiinnten Strang verbundene Anschwellungen $\left(R l ., R l^{I}\right.$.). von denen nur die hintere die Camnelirung des Rhabcloms $(R m$.$) , die vordere aber die Ḱerne der Retimulazellen erkennen lässt.$

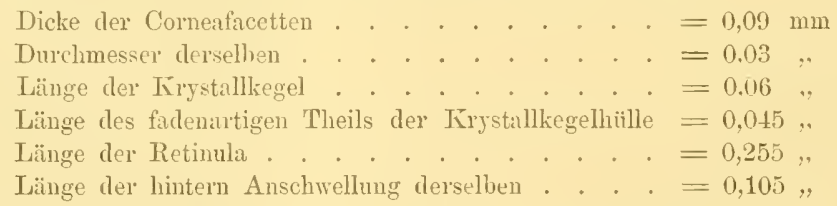

Fig. 82. Querschmitt durch sieben Retinulae desselben Fäfers, um die Entstehmng der Cannelirung derselben durch das siebenfach geflügelte Rliabdom zu zeigen (Imm. 2. IT. 590).

Durchmesser der Retinula $=0,017 \mathrm{~mm}$.

Fig. s3. Eine Retiuula von Dytiscus $\left(\mathrm{Cy}^{\mathrm{l}} \mathrm{b}\right.$ ister), ohne zugehörigen Kurystallkegel etc. (E. II. 350). Osm.. Alc., Ac. nitr. - In der vordern Anschwellung ebenfalls ein lichtbrechendes Axengebilde, das mit dem in der lintern Anschwellıng befindlichen durclı einen feinen Farlen zusammenhängt. n. Kén hinter dem Hinterende des Rhabdoms.

Länge del Retimula . . . . = $=$ ca. 0,45 $\mathrm{mm}$

Länge der hintern Anschwellung $=0,12$, 
Fig. 84. Querschnitte dureh acht Retinulae (lintere Anschwellung) desselben Käfers, nm die Viertheiligkeit und die specielle Configuration des Rhabloms zu zeigen (Imm. 2. II. 590). Alc.

$$
\begin{array}{ll}
\text { Grössere Dimension . } & =0.022 \mathrm{~mm} \\
\text { kleinere }, & =0.017,
\end{array}
$$

Fig. 85. Querschnitt durch die vordere Anschwellung der Retinula desselben Thieres, um die anscheinend sechs Zellen um das axiale Gebilde zu zeigen ( $\mathrm{mmm}$. 2. II. 590).

Fig. 86. Eimige Querschnitte durch Retinulae ron Carabus a u ratus in verschiedenen Hölien (Imm. 3. II. 1030). Alc., Ac. nitr.

$$
\begin{gathered}
\text { Durclimesser der Retinula }=\text { ca. } 0.0137 \mathrm{~mm} \\
. . \quad \text { des Rhabdoms }=, 0,005 \quad,
\end{gathered}
$$

\section{Tafel IX.}

Fig. 87. Drei Einzelangen aus dem zusammengesetzten Auge ron Phryganea grandis (E. II. 350). Alc., Ac. nitr. - Das linke vor der Entfürbung gezeichnet. Die Retinula ist iiberall zientich gleichdick, das RhaJdom zeigt in der hintern Hälfte der ersteren eine starke Anschwellung. Die Hanptpigmentzellen wurlen nicht erkannt. Im Vordertheil der Tetinula liegen Kerne (n.), auch hinter dem Rhabdom wurlen noch solche beobachtet $\left(n^{I}\right.$.).

Durclimesser der Cormeafacette . $=0.03 \mathrm{~mm}$
Dicke der Corneafacette . - . $=0,02.4$,
Lünge der Krystallkegel . . . $=0.08$.,
Länge der Rhabdomanschwellung $=0,063 .$,

Fig. 88. Qnerschnitte dweh einige Retinulae desselben Thieres in der Gegend (ler Rhabdomanschwellung (Imm. 2. II. 590). Alc. - Man erkennt die Siebentheilung des Rlıabloms.

Durchmesser des Rhabloms = ca. 0,011 mm.

Fig. 89. Querschnitte durch dieselben, aber weiter nach rorn, in der Region der Zellkerne; gleiche Vergr. Die siebenfache Zusammensetzung der Retinuli ist deutlich; anch die ungleiche Vertheilung des Pigmentes.

$$
\text { Durchmessey der Retinula }=0,016 \mathrm{~mm} \text {. }
$$

Fig. 90. Retiunla nebst Krystallkegel ron Lipar is salicis (E. II. 350). Frisch in wässeriger Lösung vou Ac. oxal. zexzupit. - Die Hülle des Kiystallkegels geht anscheinend contimuirlich in deu fudenartigen 'Theil der Retinula über' bei n. liegen in diesem dentlich zïhlbar sieben Kerne. Von den stark entwickelten Pigmentzelleu zweiter Ordinug $\left(P g^{I I}\right.$.) sind zwei dargestellt. Die cannelirte Anschwellung des Rhabioms ist ron sehr feinen Tracheen eingeliuillt, ron denen die hintern Enden gezeichnet wurden $(T \%$.

$$
\begin{aligned}
& \text { Länge des Krystallkegels . . . . . = } 0,054 \mathrm{~mm} \\
& \text { Länge der Retimla . . . . . . . . = ea. } 0.1 \text {.. } \\
& \text { Länge der Anschwellung des Rhaludoms }=\text {, } 0,135 \text {.. }
\end{aligned}
$$

Fig. 91. Qnerschnitt durch einige Retinulae desselben Schmetterlings (Imm. 2. II. 590). Alc. - Die Strahlen des Rhabdomquerschnittes sind deutlicher gezeichnet, als sie im Präparate selbst erscheinen.

$$
\text { Durchmesser der Retinuli }=0,01 \mathrm{~mm} \text {. }
$$

Fig. 92. Querschnitt durch den fadenatigen Theil der Retinula desselben Thieres, um die Anordnumg dex Pigmentzellen um denselhen zu zeigen (E. II. 350).

Fig. 93. Vorderer Theil der Retinula nebst Krystallkegel ron Triphaena pronuba (E. II. 350). Nach kurzer Einwirkung ron Alcolol zerzupft. Hinter dem Krystallkegel befiudet sich noch in einer Erweiterung eine stärker lichtbrechende Einlagerung $\left(K k^{I}\right.$.). In dem Retinnlafaden lassen sich ebenfalls leicht (bei $\varkappa$.) sieben Kerne zühlen.

Fig. 94. Querschnitt durch eine Anzahl Retinulae einer Noctu a spec. (Imm. 2. II. 590). Nach Einwirkmg von Oxalsäure. Weder das Rhabdom, noch die Grenzen der Retumlazellen sind zu exkennen, aber die constante Siebenstrahligkeit der Querschnitte dentet auf entsprechende Zusammensetzung. 
Fig. 95. Ein isolirtes Einzelauge von Poreellio scaber (olme Facette dargestellt) (E. II. 350). Alc. Pigment noch erhalten; ans seiner vordern Partie ragt der sphäroidale Tirystallkegel hervor.

Fig. 96. Ein ebensolches Auge (F. II. 550). Chroms., Ac. nitr. - Der Krystallkegel. durch die Chromsäure opak geworden, zeigt seine Znsammensetzung ans zwei Hälften, sowie die iln umgebende Hiille; die Kerne der letzteren liegen bei $n^{I I}$. $Z$ ist die nur aus zwei Zellen bestehende, die Facette imen iiberziehende Lage, $n^{l}$. die zugehörigen Kerne. - Die nach vorn ïber den Krystallkegel ïbergreifenden, stark pigmentirten Retinulazellen haben ihre Kerne bei $n$. $-N_{\text {., Nervus opticus. Das }}$ Rhabdom (Rm.) liegt dem Krystallkegel mit seinem Vorderende dicht an.

Querdurelımesser des Trirstallkegels $=0,045-0,54 \mathrm{~mm}$

L:inge des Rhabdoms . . . . . =0,027-0,036 ..

Fig. 97. Facetten desselben Thieres ron imen gesehen, zwei davon mit noch anhaftenden Kirystallkegeln, von der dritten ist er losgerissen (E. II. 350). Alc., Ac. nitr. - Z., wie in voriger Figur; $x^{I}$. ebenso. Pg., pigmentirte Hypodermiszellen zwischen den Einzelaugen.

Fig. 99. Optischer Querschnitt durch eine Retinula desselben Thieres (F. II. 550). Alc., Kali caust. Man erkennt die sieben Retinulazellen, sowie das siebentheilige Rhabdom.

Fig. 99. Schnitt durch ein Ange von Gammarus locusta (CC. II. 145). Alc., Ac. nitr. - Der Schnitt ist parallel der Lüngsaxe des Thieres und senkrecht auf die Lüngsaxe des Gesammtauges gefïhrt. - Unter der facettenlosen Cornea liegen die Krystallkegel ron verschiedener Grösse, nach innen im Connex mit den Retinulie.

$$
\begin{aligned}
& \text { Dicke der Cuticula . . . . . . . . = }=0,02 \mathrm{~mm} \\
& \text { Durchschmittliche Länge der Krystallkegel }=\text { ca. 0,105 .. } \\
& \text { Dicke derselben . . . = } 0,06 \text {, }
\end{aligned}
$$

Fig. 100. Ein Krystallkegel rou clemselben Thier, mit anhängender Retinula. noch mit Pigment. An ersterem noch die Hïlle mit den S e mper' schen Kiernen (n.) sichtbar (E. II. 350).

Fig. 101. Ein Krystallkegel desselhen Thieres, frei präparirt, ron hinten gesehen (E. II. 350). Die krenzförmige Ansatzstelle des Rhabdoms an seiner Spitze weist auf Tiertheiligkeit desselben hin.

Fig. 102. A, B. Zwei Krystallkegel mit noch pigmentirten Retinulae von Talitrus saltator (E. II. 350). Alc. - A. stammt ans der Mitte, B. rom Rande des Gesammtanges, letzteres mit schräger Endfläche.

Fig. 103. Krystallkegel und Retimula desselben Thieres, bei gleicher Tergrösserung, mit Ac. nitr. entfärbt; man erkemnt das stabfürmige Rhabdom mit feiner Querstreifung im Innern der Retinula. n. Zellkerne der letzteren.

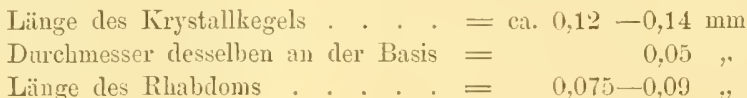

\section{Tafel $\mathbf{X}$.}

Fig. 104. Krystallkegel mit Retinula ans dem Ange ron Hyperia galba (H. Latreillei). (E. II. 350.) Alc. Ac. nitr. - Der Krystallkegel, aus den peripherischen Theilen des Auges. ist von einer weiten Hïlle (ㄱz.) umgeben, deren Kerne rorn bei $n^{I}$. gelegen sind. $Z$., besondere Zellen um das Hinterende des Krystallkegels. Das fein quergestreifte Rhabdom hat in seinem Imern einen deutlichen Canal.

Lünge des Krystallkegels hier $=0,5-0,6 \mathrm{~mm}$ (sonst anch weit darüber),

Durchmesser desselben . . . = ea. 0,03,

Länge des Rlabdoms . . . = .. 0,16,

Fig. 105. a., b. Qnerschnitte durch den Krystallkegel desselben Thieres in verschiedenen Höhen, nm das Verhalten desselben zu seiner Hiille ( $1 I z$ ) zu zeigen.

Fig. 106. a., b., c. Quersclnitte durch die Retiunla desselben Thieres in drei rerschiedenen Gegenden (a. oben, b. Mitte, c. unten). (Imm. II. 590.) An allen ist die Znsammensetzung der Retinula aus fiunf Zellen, an den beiden ersteren auch die des Rhabdoms aus elsensoviel Stäbchen, sowie der centrale Canal desselben zu erkennen. 
Durehmesser cler Retinula, oben (a.) . . . $=0,015-0,018 \mathrm{~mm}$
,
des Rhabcloms, in der Nitte (b.) $=$
(),009

Fig. 107. Zwei Einzelaugen von Branchipus stagnalis (E. II, 350). Alc., Ac. nitr. - In den grossen Zellen ( $M z$.), welche den eifümigen Krystallkegel $(K \hbar$.) ausscheiden und mmschliessen, waren die Semper'schen Kerme nicht mehr zu erkemen; an ihrem innern Ende zeigen sie stark lichtbrechende Partien $\left(K k^{\prime}\right.$.), mit denen sie etwas in die Retimulae sich einsenken. Die Gestalt der Vorderenden dieser letzteren wegen mangelhaften Erhaltungsznstandes nicht speciell ausgeführt.

Länge der Hiille $u$ die Krystallkegel $=0,075 \mathrm{~mm}$

.. . Krystalliegel . . . . . =0,03-0,033.,

Durchmesser der Krystallkegel . . . =0,018-0,021 ,

Länge des Rhabdoms . . . . . . =0.12-0.15 ,

Dicke der Retinula (hinten) . . . . = 0,021 ,

" des Rhabloms . . . . . = 0.002 ",

Fig, 108. Einige Retiuulae ron demselben Krels, im Querschnitt (E. II. 350). Alc., Ac. nitr. - Die Retinulae erweisen sich ebenfalls als ftinftheilig.

Fig. 109. Zwei Einzelaugen aus dem zusammengesetzten ron A pus cancriformis (E. II. 350). Ale., Ac. nitr. - Hinter der glatten Cornea liegen die Kiystallkegel, vor welchen sich, innerhalb der sie umgebenden Hälle, noch die Semper'schen Kerne erkennen lassen $\left(n^{I}\right.$.). - In den Retinulae lassen sich mit Bestimmtheit fünf Kerue (n.) zählen.

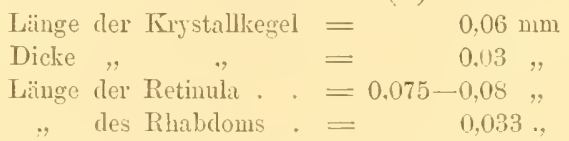

Fig. 110. Schnitt durch einen Augenstiel nebst Auge von Mysis vulgaris (CC. II. 145). Alc. - Hinter den Corneafacetten erkennt man die ilmen anlaftenten Semper'schen K(rne (u.), hinter den Kirystallkegeln die grossen dicht geläuften Kerne der Retinulazellen $\left(n^{T}\right.$.). Hinter dem die Rhabriome einhïllenden, das Auge nach innen begrenzenden Pigmentgïrtel erkennt man die Ausstrahlung

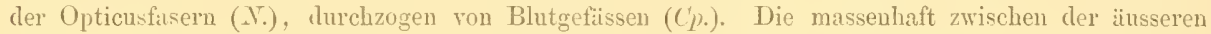
Cuticula und den Ganglien gelegenen Kerne ( $K m$.$) bilden vor dem ersten Gauglion (G.) eine$ doppelte Lage $\left(\kappa m^{I} ., K m^{I I}\right.$.), zwischen denen die Fasern des Opticus als äusserst feine Fäclen ( $N^{\prime}$.) zum Torschein kommen. Zwischen den einzelnen Ganglien (G., $G^{I} . . G_{T}^{I I} ., G^{I I I}$.) beobachtet man mehr oler weniger regelmässige Kr reuzungen der Opticusfasern $\left(N^{\prime \prime}, N^{\prime \prime} ., N^{I I I}\right.$.) M., Muskeln zur Bewegung des Augenstiels.

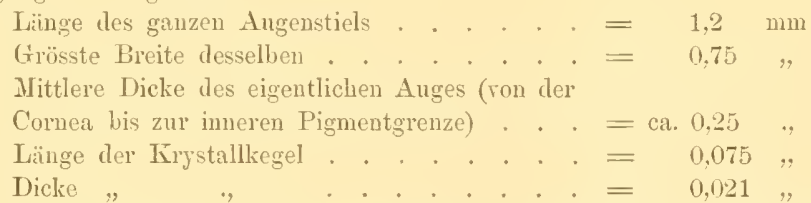

Fig. 111. Ein Krystallkegel nebst zugehöriger Corneafacette ron demselben Thiere (E. II. 350). Alc., Ac. nitr. - l., spitzenförmige Torragung der Cuticula nach innen. st., wahluscheinliche Verlängerung der Mutterzelle des Krisstallkegels zum Rhabdom lin.

Fig. 112. Ansicht der Cornea desselben Krebses yon innen, bei gleicher Tergrösserung. - d., wie in Fig. 110.

Fig. 113. Anlage des Krystallkegels bei einem ca. 3,5 mm langen Embryo desselben Thieres (E. II. 350). Alc., Ac. nitr.

Länge des ganzen Complexes $=0,043 \mathrm{~mm}$
Durchmesser des Krystallkegels $=0,008$.,

Fig. 114. Zmei Rhabdome von IIysis flexuosa (Imm. 2. II. 590). Alc. - st., wie in Fig. 111. - Die mit dentlicher Plättchenstructur versehenen Rhabdome verlieren sich nach innen in einem graugelben, erdigen Pigment.

Lünge eines Rhabdoms $=0,025 \mathrm{~mm}$

Dicke eines solchen, vorm $=0,008$, 
Fig. 115. Querschuitt durch vier Rhabdome der gleichen Art, bei derselben Vergrösscrung, um die Viertheiligkeit derselben zu zeigen.

Fig. 116. Ein kleines Stiick aus dem in Fig. 110 dargestellten Präparat, ron der vorderen Wölbung der ersten gangliösen Hasse (G.) (Imm. 2. II. 590). Bedeutung der Buchstaben wic in Fig. 110. Auch in der Nerrenkreuzung $N^{I I}$. sind Blutcapillaren kenntlich $\left(C_{L^{\prime}}\right.$.).

Durchmesser der Kerne $\left(K m{ }^{I}\right.$. $)=0.005 \mathrm{~mm}$

Dicke der Schicht $G$. . . . = 0,025 ..

\section{Tinfel XI.}

Fig. 117. Zwei Einzelangen rou Palaemon squilla (E. II. 350). Alc.; das linke davon vor, das rechte nach der Entfïrbuug mit Ac. nitr. dargestellt. n., die dicht hinter der Facette liegenden Semper'schen Kerne; hinter diesen die vorderste Ausscheidung stark lichtbrechender Masse $\left(K k^{l}.\right)$ in den Krystallkegel-Mutterzellen; am lintern Ende der letzteren die hinterste $\left(K l^{I I}\right.$.) in Gestalt eimes Hohlkegels. Der eigentliche Krystallkegel (K/.) liegt in der Mitte. Die Retinula umschliesst das spindelförmige, quergestreifte Rhabdom $(R m$.$) . sowie die an ihrem Vorderende$ gelegenen Kerme $\left(n^{I}\right)$. Tor ihr liegt eine starke Pigmentanhäufung $\left(P_{y}.\right)$, welche den hintern Theil der Krrystallkegel-Mutterzellen umschliesst. Vom Opticus her treten Streifen dunkeln, erdigen Pigmentes $\left(Y_{g}{ }^{f}\right.$.) ein, welche zrischen den Kirystallkegeln arcadenartige Schleiten bilden.

\begin{tabular}{|c|c|c|}
\hline Durchmesser einer Facette. & $=$ & $0,0.12$ \\
\hline Dicke $\quad, \quad$, $\quad$. & $=$ & 0,02 \\
\hline Distanz rou der Facette bis $K 7$. & $=$ & 0,075 \\
\hline Lünge des Krystallkegels $K /$ : . & $=$ & 0,075 \\
\hline Tou Kk. bis zur Retinula. & $=$ & 0.15 \\
\hline Lüinge der Retinnla . . & $=$ & 0.12 \\
\hline , des Rhabdoms & & 0.09 \\
\hline
\end{tabular}

Fig. 118. A, B. Durchschnitte durch Retinulae desselben Thieres (Imm. 2. II. 590). Alc., Ac. nitr. A. etwa aus der Mitte, B. rom lintern Ende der Retinula. Man erkennt bei erstern die Viertheiligkeit des in der Mitte liegenden Rhabdoms (Rm.), sowie die Siebenzahl der dasselbe umschliessenden Retimulazellen.

$$
\begin{array}{ccc}
\text { Durclimesser einer Retinula } . & 0,024 \mathrm{~mm} \\
, " & \text { eines Rhabdoms }=\text { cat. } 0,01-0,012, .
\end{array}
$$

Fig. 119. Der Krystallkegel (K/.) desselben Thieres. freiprïparirt (E. 11. 350). Alc. - Um seine Gestalt und Zusammensetzung zu zeigen.

Fig. 120. Querschnitt durch eine Retinnla von Portun us Ma enas (Imm. 2. II. 590). Alc., Ac. nitr. Um das dünuc, vierkantige Rhabdom, dessen Zusammensetzung nicht zu erkemnen ist, gruppiren sich wieder sieben Retinulazellen.

$$
\text { Durchmesser der Retinula }=0,025 \mathrm{~mm} \text {. }
$$

Fig. 121. Querschmitt durch den Krystallkegel desselben Thieres (Imm. 2. II. 590).

$$
\text { Durchmesser dessellsen = ca. } 0,029 \mathrm{~mm} \text {. }
$$

Fig. 122. Querschnitt durch eine Retinula von Squilla mantis (E. II. 350). Alc. Ac. nitr. - Der Schnitt zeigt wieder, wie bei Fig. 118, ein riertheiliges Rhaldom umgeben von sieben Retinulazellen.

Fig. 123. Durchschnitt durch die Comea ron Limulus polyph emus (BB. II. 100). - Um die Schichtung derselben, sowie das Terhalten der Corneakegel zu zeigen. 1., 2., 3. schürfer von einander al)gesetzte Schichten, die ihrerseits wieder ans mehr oder weniger feinen Lamellen bestehen; aus der letzten hauptsïchlich gehen die Comeakegel hervor.

Dicke der Gesammtcornea, bis zur Kegelspitze . = ca. 0,82 mm

Höhe der Kegel, ron der Schicht 2 an gemessen $=$ " $0, \overline{\mathbf{7}}$,

Dicke derselben imnerhalb der Schicht $3 . .=0.23-0.26$,

Breite der Endtliiche derselben . . . . . = , 0,065 ,

Fig. 12t. Längsschnitt durch ein Einzelauge von Limulus, olne Cornea (DD. II. 235). Alc., Ac. nitr. Der nach rorn offene Trichter umschliesst in situ den freien Theil eincs Corneakegels, welcher ihn 
völlig ausfiullt. Gebildet wird der Trichter von Pigmentzellen $(P y$.$) , von denen sich besonders die$ innem stark nach linten verlüngern. In dem Innern der massigen, kưzen Retinula (Rl.) erkennt man undentlich einige Stäbchensïume, welche zn den Zellen derselben gehörend eine Art von Rhabdom bilden.

Lünge des ganzen Anges. . . . . . = ca. 0,56-0,62 $\mathrm{mm}$

Durchmesser der vordern Trichteröffnıng $=0,33$,.

Länge der Retinula . . . . . . . . = 0,17-0,18 ,

Fig. 125. Querschnitt durch eine Retinula desselben Thieres (DD. II. 235). Alc., Ac. nitr. - Die zallreichen Retinulazellen umschliessen in ihrem Innern ein strahliges Rhabdom; die Strahlen entsprechen nach Zahl und Auordnung den nicht überall dentlichen Grenzflächen der kugelförmigen Retimulazellen.

Fig. 126. Querschnitt durch eine andere Retinula desselben Thieres. dicht ror ihrem hintern Ende (Imm. 2. II. 590). Alc., Ac. nitr. - Um das Verhalten der Stübchensäume zu ihren Zellen, sowie das Znstandekommen der sternförmigen Figur in Fig. 125 zu zeigen.

Fig. 127. Zwei Facetten mebst Krystallkegeln ron Cantharis fusca (Telephorus f.), zur Vergleichung mit den Corneakegeh ron Limulus polyphemus (Fig. 123). x., Masse, welche den Krystallkegel Kl: mit der Cornea verkittet. 



\section{Inhaltsübersicht.}

Vol'wort.

Pag.

Historisch-kritische Uebersicht seit Joh. M üller”s: „Zur vergleichenden Physiologie des Gesichtssinues“ 1 Bemerkungen ïber Methode und Technik . . . . . . . . . . . . . . . . . . . . . 22

I. Untersuchungen . . . . . . . . . . . . . . . . . . . . . . . . . . . 26

1. Abschnitt. Tom Stemma . . . . . . . . . . . . . . . . . . 26

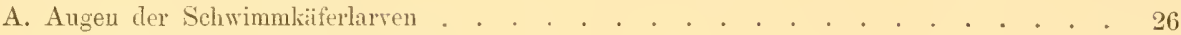

1. Augen der Dytiseus-Larren. . . . . . . . . . . . . . . . . . . 26

2. Augen der Larven ron Acilius suleatus . . . . . . . . . . . . . . . 30

- Angen ron Semblis- (Sialis-) Larven . . . . . . . . . . . . . . 37

B. Augen einiger Arachniden . . . . . . . . . . . . . . . . . . . . . . 39

1. Auge ron Plialanginm . . . . . . . . . . . . . . . . . . . . . . . . 4 40

2. Augen von Epeira. . . . . . . . . . . . . . . . . . . . . . 43

3. Augen ron Lycosa . . . . . . . . . . . . . . . . . . . . . . . . 4 47

4. Augen ron Salticus . . . . . . . . . . . . . . . . . . . . . . 49

C. Einfache Angen einiger Insecten . . . . . . . . . . . . . . . . . . . . 57

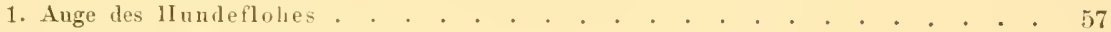

2. Stemma ron Musca romitoria. . . . . . . . . . . . . . . . . . . 58

3. Stemmata ron Tespa communis und ron Crabro cribrarius . . . . . . . . 59

4. Stemma ron Pliryganea grandis. . . . . . . . . . . . . . . . . 60

D. Einfache Augen einger Copepoden . . . . . . . . . . . . . . . . . . 62

1. Ange von Calanella mediterranea. . . . . . . . . . . . . . . 63

2. Seitenaugen einiger Coryeaeiden . . . . . . . . . . . . . . . . 66

2. Abschnitt. Tom zusammengesetzten Ange der Insecten und Crustaceen . . . 73

A. Zusammengesetzte Augen der Insecten . . . . . . . . . . . . . . . . . 79

a. Acone Angen . . . . . . . . . . . . . . . . . . . . . . . . 79

1. Auge ron Tipula spee. . . . . . . . . . . . . . . . . . . . . 80

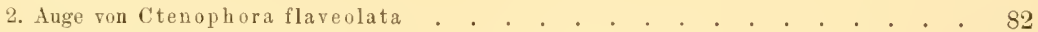

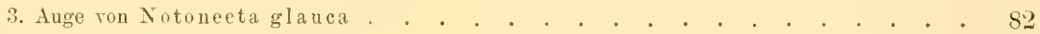

4. Ange von Forfieula. . . . . . . . . . . . . . . . . . . . . . . 84

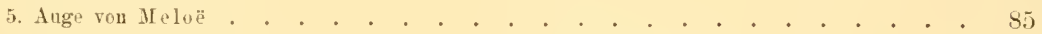

6. Ange ron Saperda . . . . . . . . . . . . . . . . . . . . . . . . 86

๖. Psendocone Argen . . . . . . . . . . . . . . . . . . . . . . 87

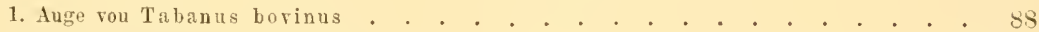

2. Auge von Musca vomitoria . . . . . . . . . . . . . . . . 9 90

3. Auge ron Sareophaga earnaria . . . . . . . . . . . . . . 91 
c. Encone Augen . . . . . . . . . . . . . . . . . . 993 93

1. Auge von Corethra plumieornis . . . . . . . . . . . . . . . . . 94

2. Augen der Bieve und Hornisse . . . . . . . . . . . . . . . . . 95

3. Ange ron Cieada grossa (?) . . . . . . . . . . . . . . . . . . . . . . 96 96

4. Augen ron Periplaneta und Gryllotalpa . . . . . . . . . . . . . . 96

5. Ange ron Necroplorus . . . . . . . . . . . . . . . . . . . 97

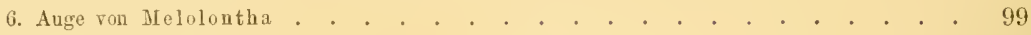

7. Ange von Dytiseus . . . . . . . . . . . . . . . . . . . . . 101

8. Auge von Phryganea . . . . . . . . . . . . . . . . . . 102

9. Auge ron Liparis salicis und anilerer Nacht- und Dänmerungsfalter . . . . . . 103

B. Zusammengesetzte Augen der Crustaceen . . . . . . . . . . . . . . . . 106

a. Typische Crustaceen . . . . . . . . . . . . . . . . . . . . 106

1. Auge fon Porcellio seaber . . . . . . . . . . . . . . . . 107

2. Angen ron Gammarus loeusta nnd Talitrus saltator . . . . . . . . . 109

3. Augen von Hyperia galba und Phrouima sedentaria . . . . . . . . . . 111

4. Augen ron Branchipus uni Apus, nebst Bemerkungen über die Augen anderer Phyllopoden . . . . . . . . . . . . . . . . . . . . . . . . . . . . . . . . 11

5. Auge von Mysis . . . . . . . . . . . . . . . . . . . . . . 117

6. Ange von Palaemon squilla, nebst Bemerkungen über die Augen anderer Decapoden . 122

b. Augen ron Limulus . . . . . . . . . . . . . . . . . . . 126

II. Folgerungen . . . . . . . . . . . . . . . . . . . . . . . . . 134

1. Abschnitt. Das Stemma und das zusammengesetzte Ange . . . . . . . 136

2. Abschnitt. Der Sehvorgang im Facettenange . . . . . . . . . . . 142

3. Abschnitt. Das Retinaelement im thierischen Auge . . . . . . . . . . 157

Nachträglicher Zusatz . . . . . . . . . . . . . . . 168

Erklïrung der Abbildungen . . . . . . . . . . . . . . . . . . . . . . 171 


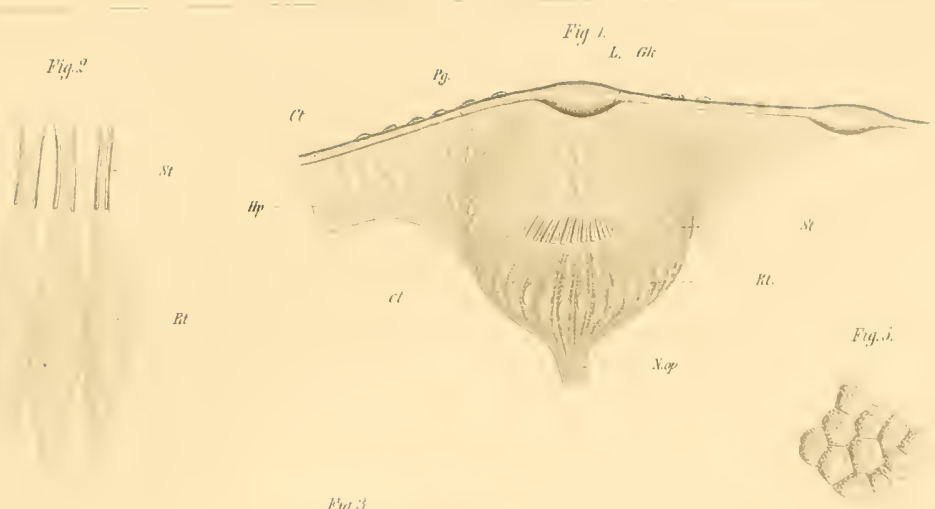

Fing 6
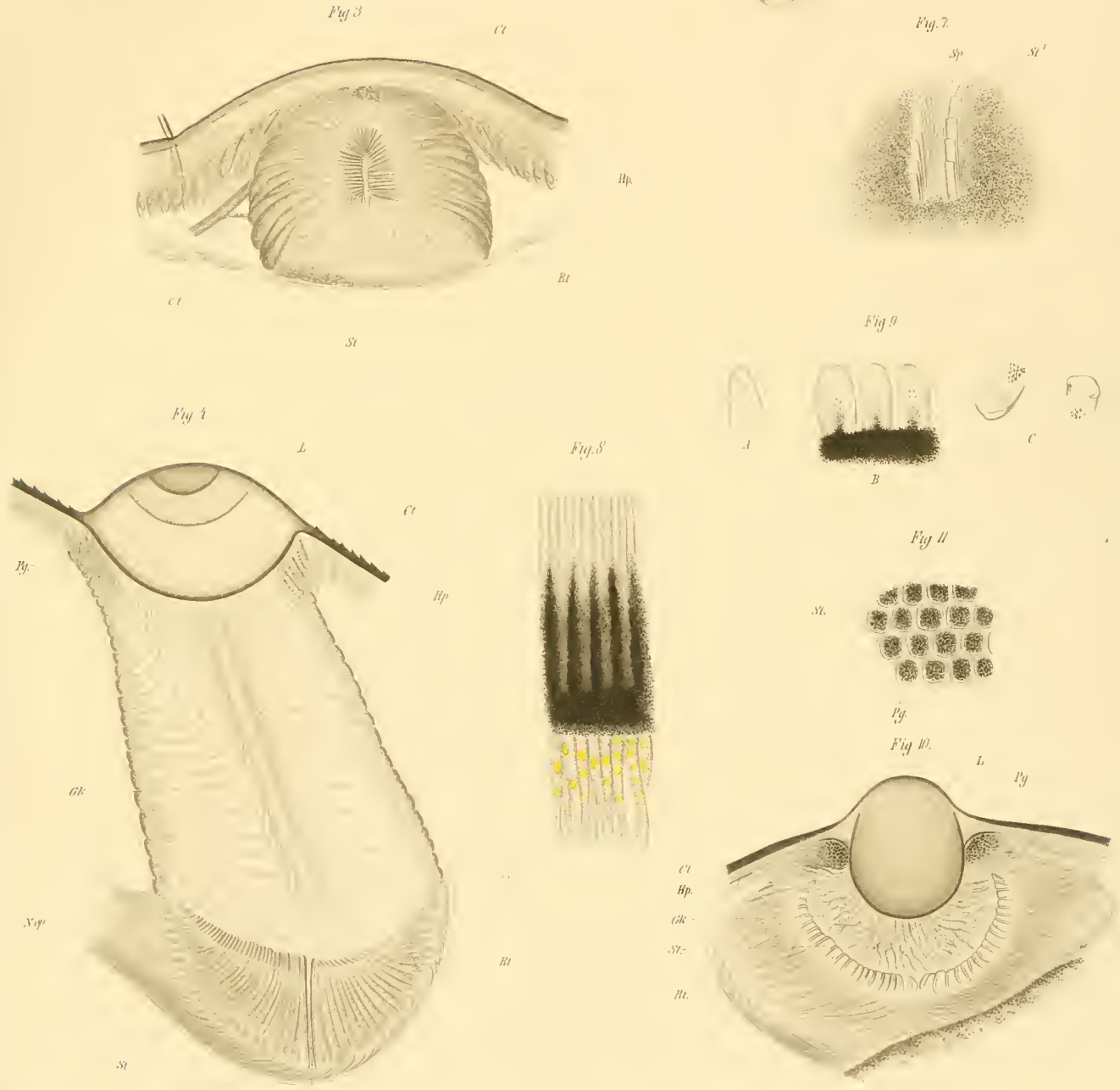

kig in.

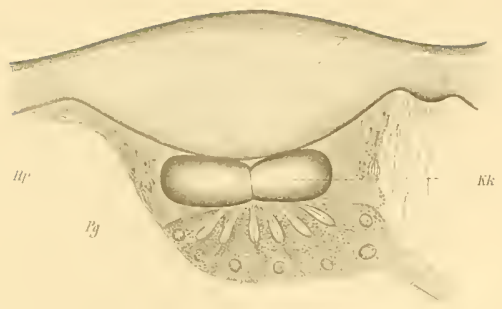

Fing lis

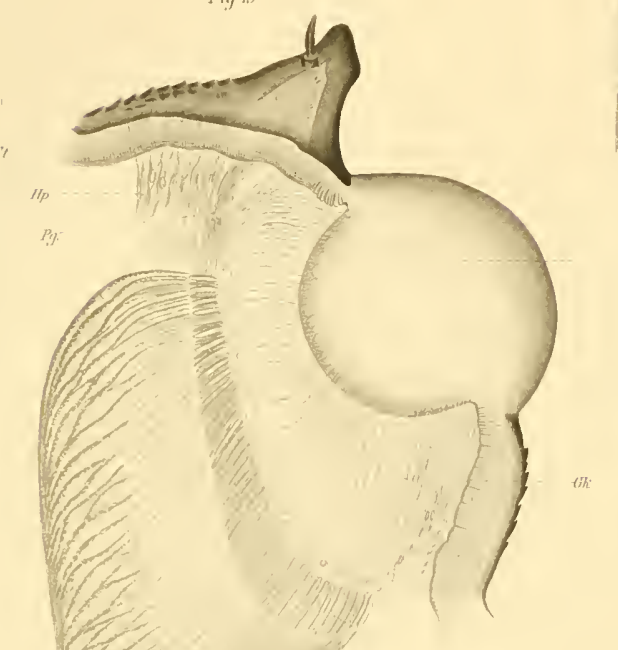

Fut 16

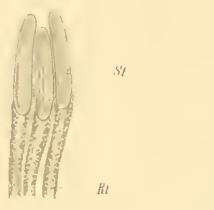

Figit

${ }^{2}{ }^{0}$

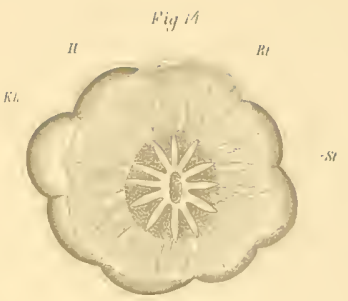

Fig. I.

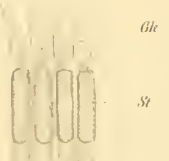

Fig.

Fig. $\%$.
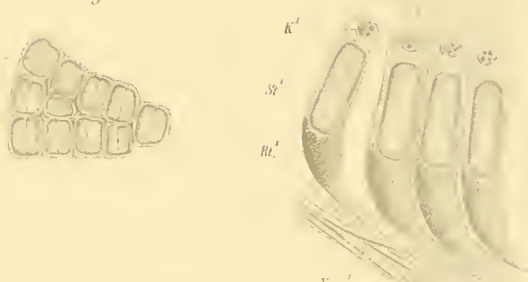
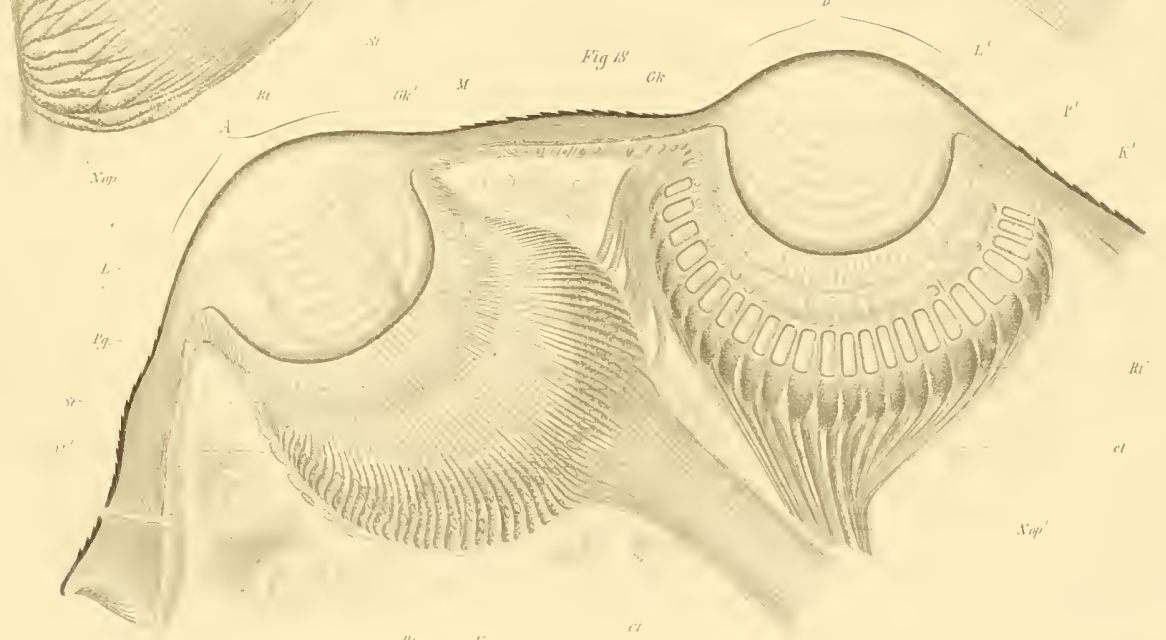

(I) HI 



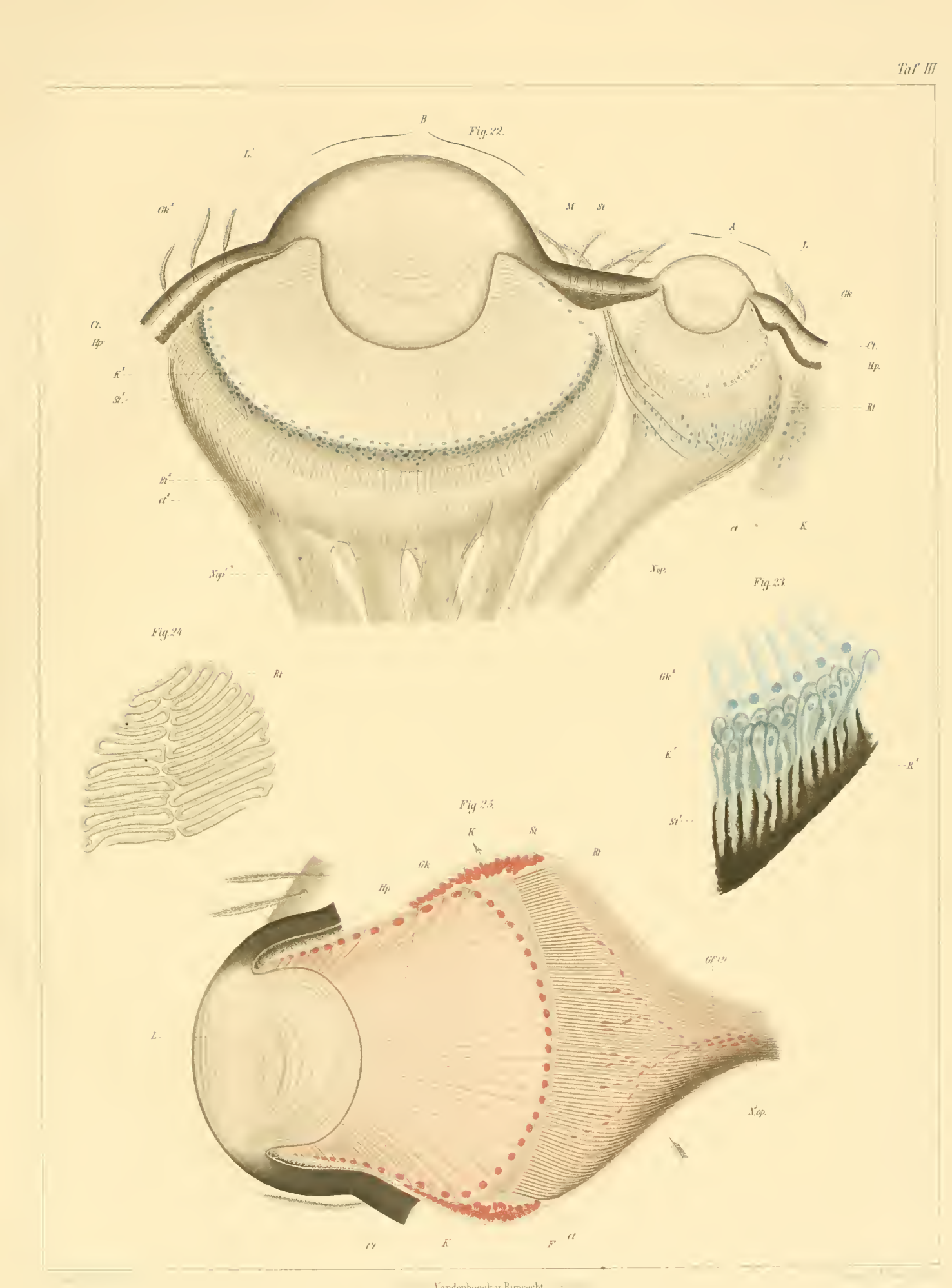



Frig. "s

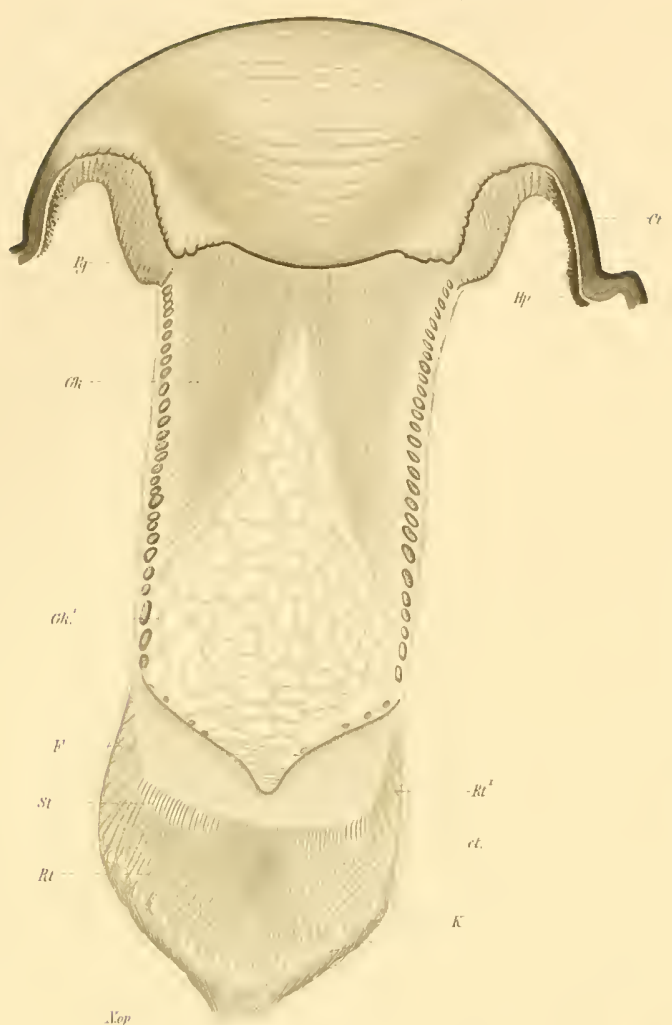

$f^{\prime} l y ? ?$

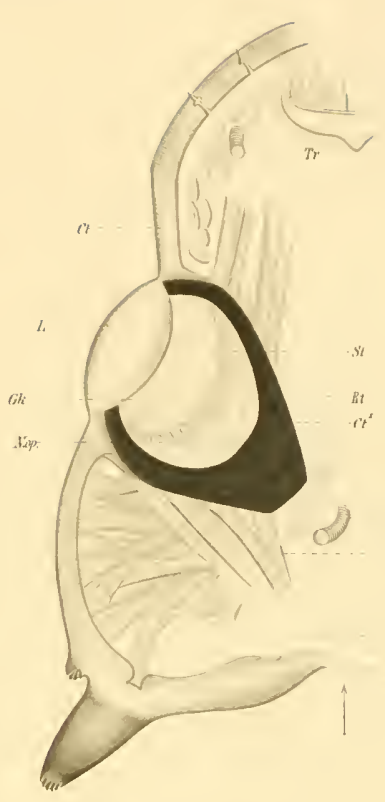

Fig. $2 \pi$

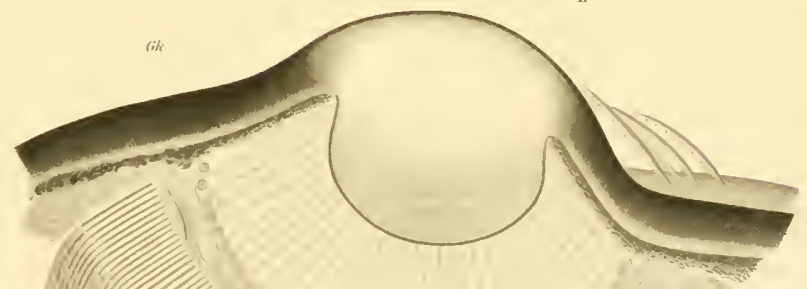





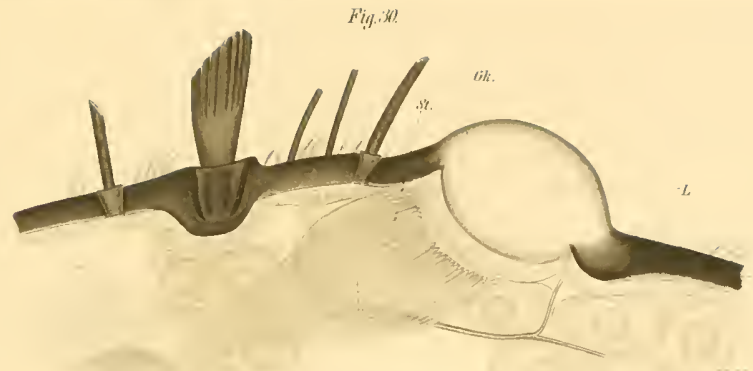

Hig. $3: 2$
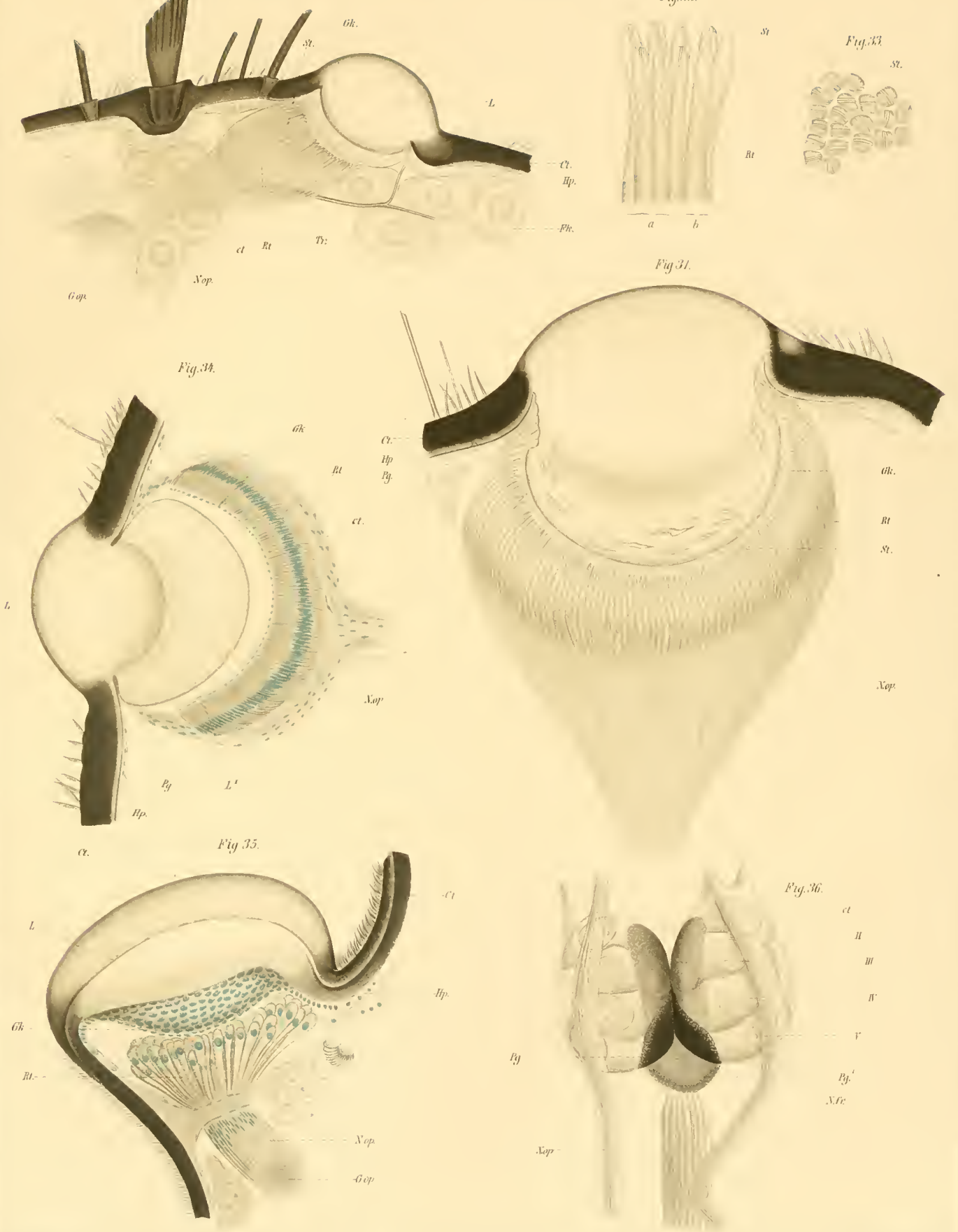



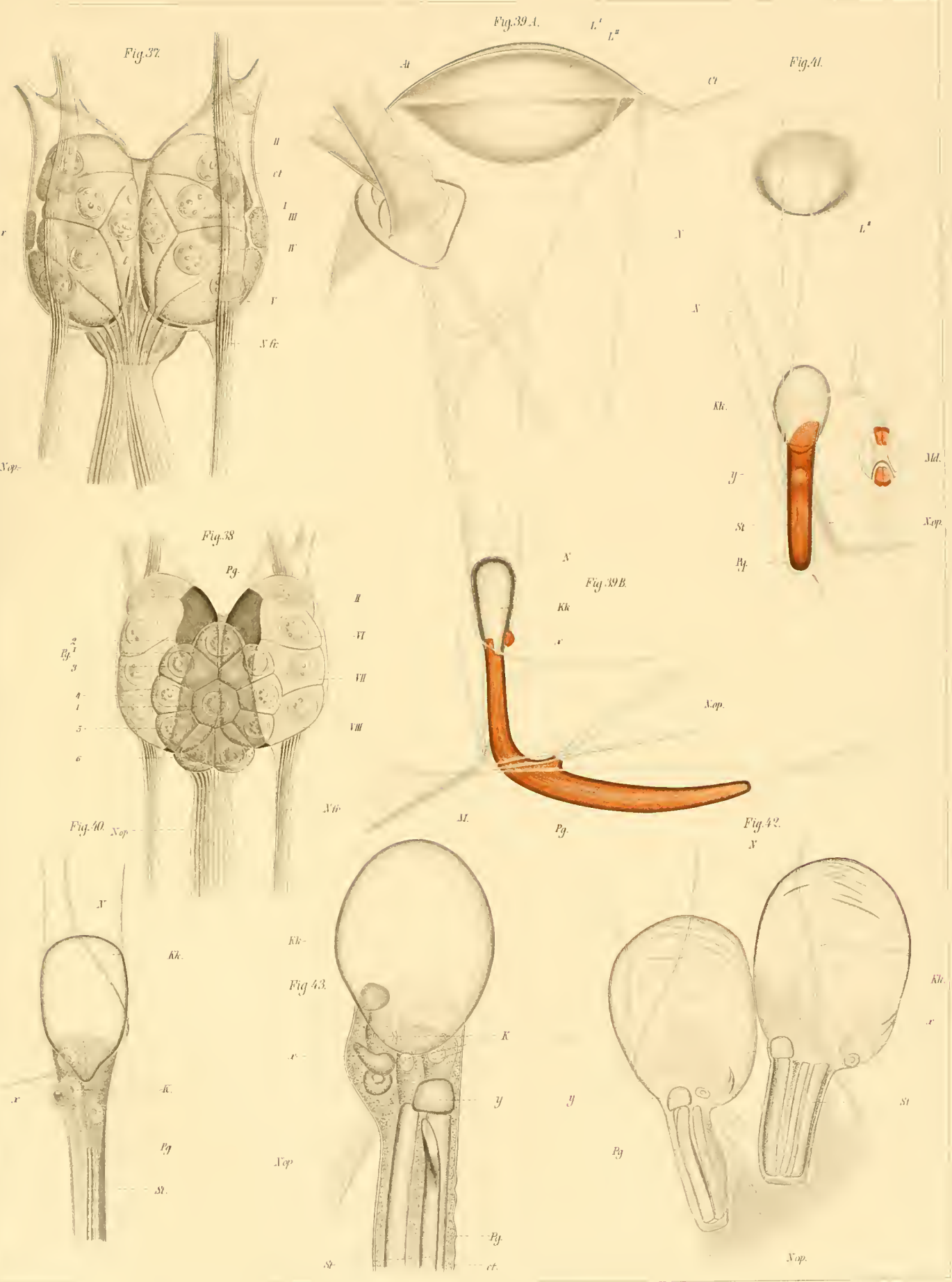



ligg. 14

111 He for of cor a oxiph
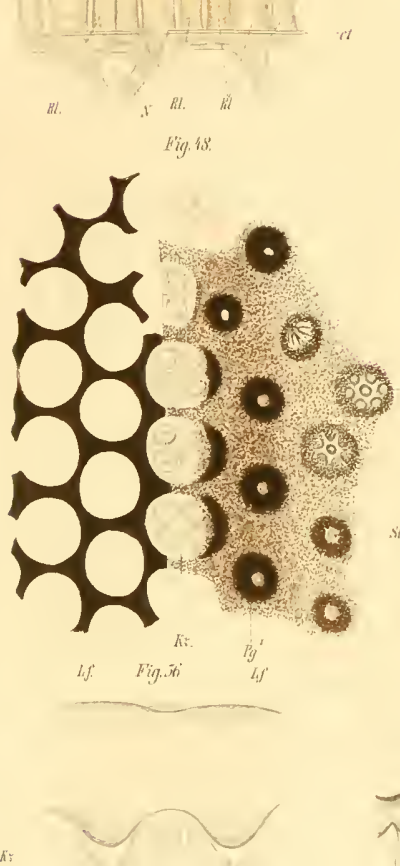

(f) $)$

joำ

F(y J)

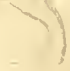

1.f. Fig.
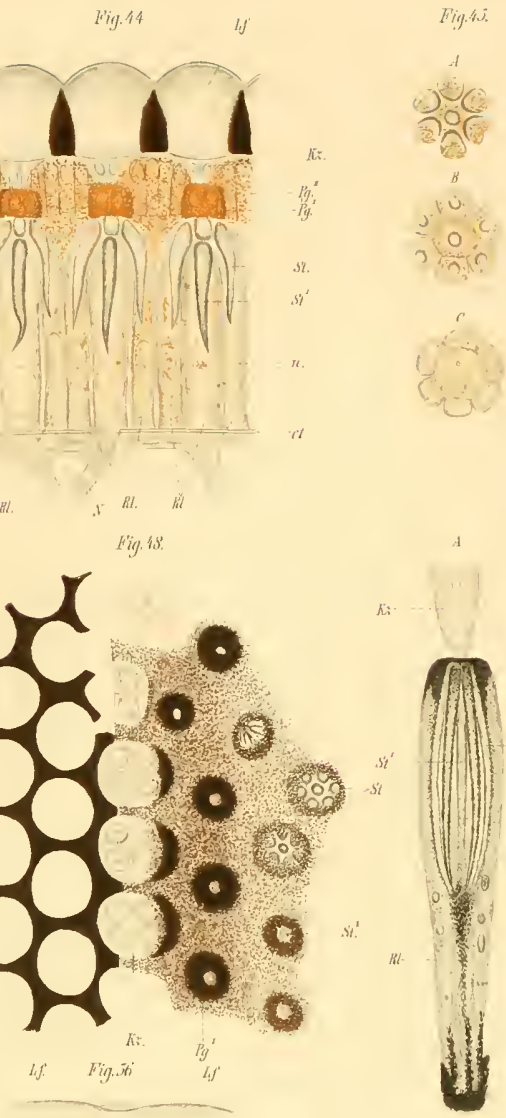

Fing 40

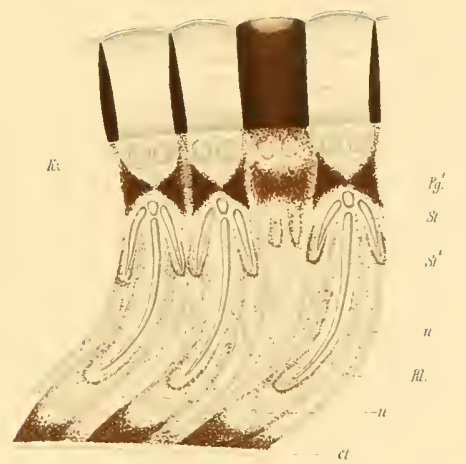

Fin. 4.4

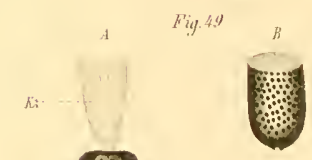

Fig. vil

$\therefore 80^{\circ}$
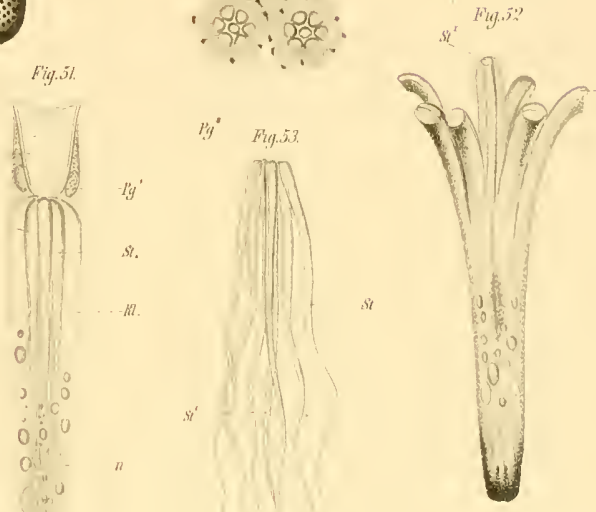

Fig. 34
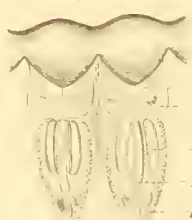

Fig. 6.
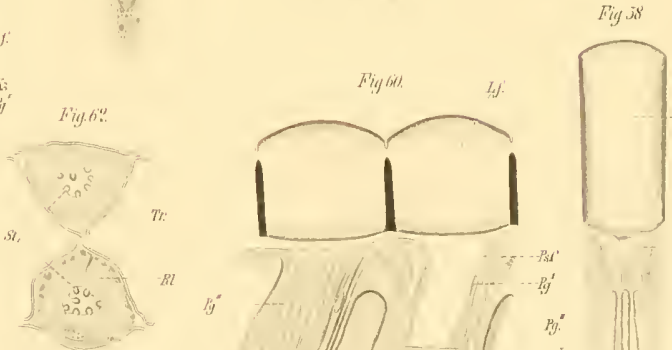

Pig:
Fig. 15
(oㅏ
(10)

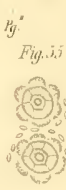

Fiy, 5,y

(b) $B$
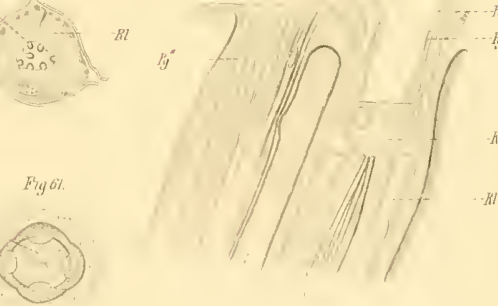

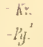




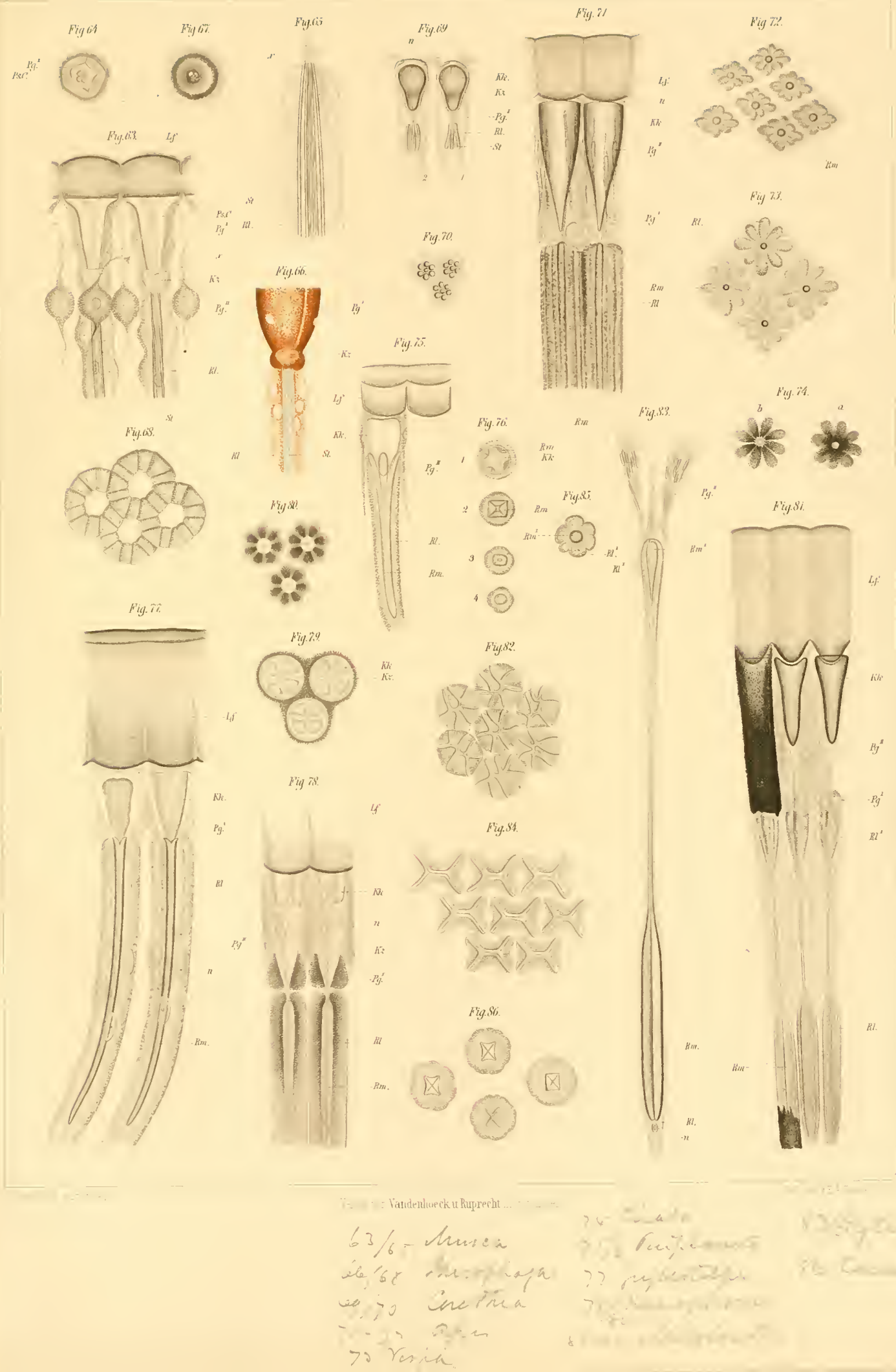

Fizy. 47.

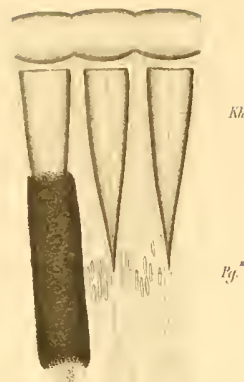

1.

Fig. ...
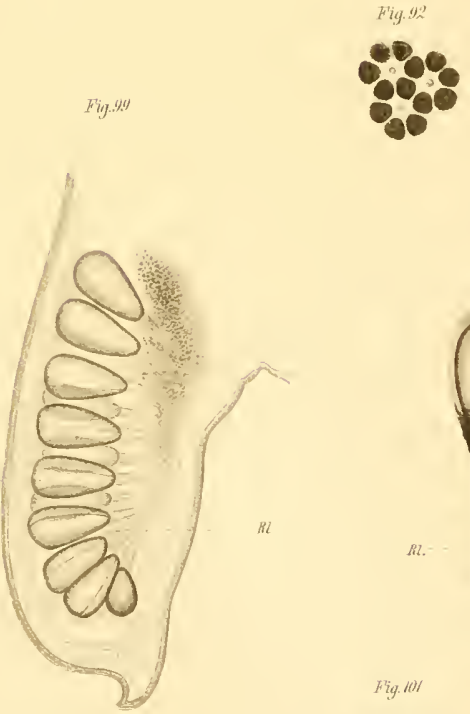
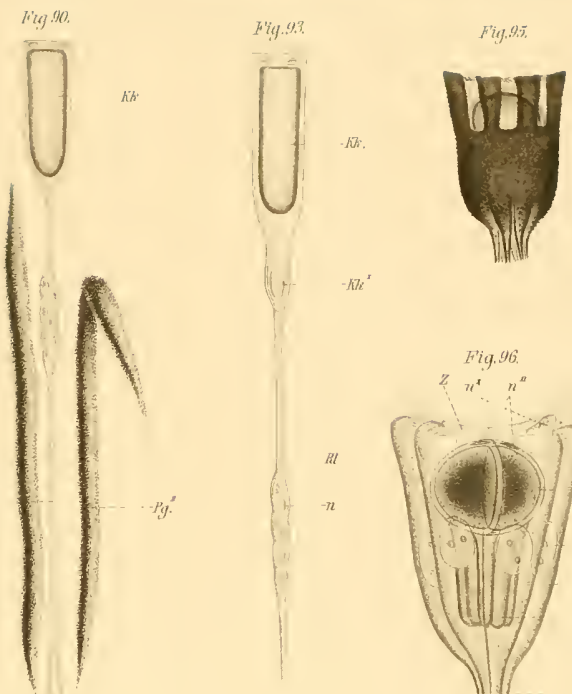

$-\pi i^{x}$

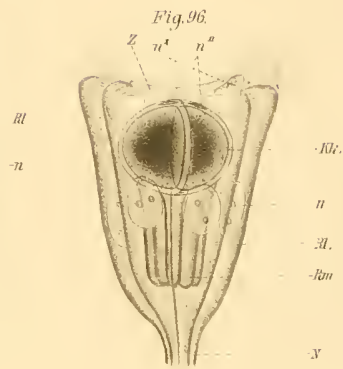

Fig. 9 .
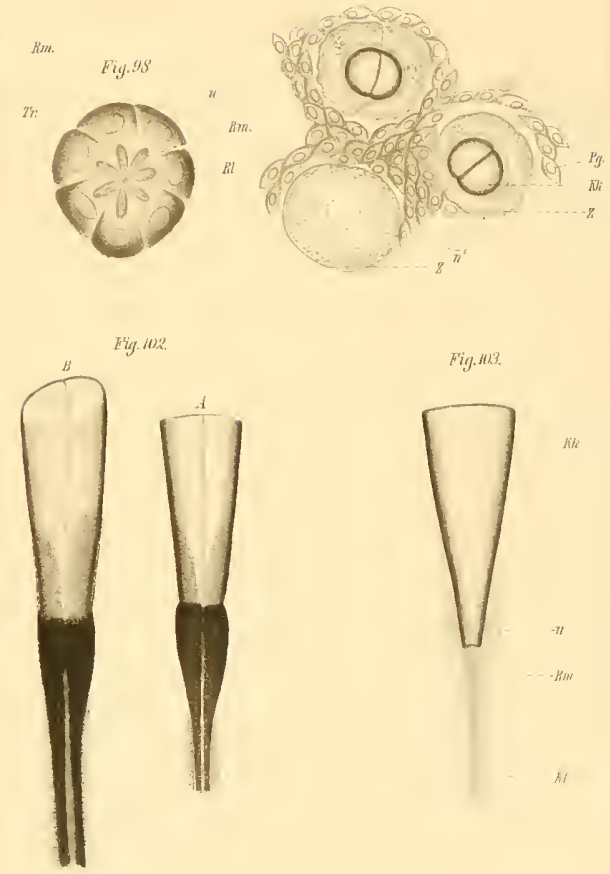

Fig. WB.

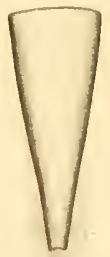

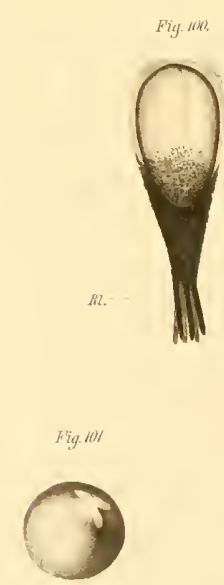



Fity. (1)\%.

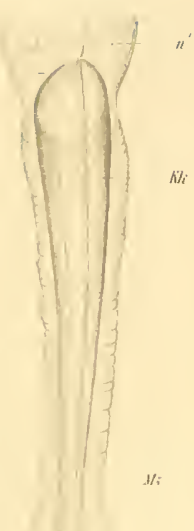

Hi $\quad 0_{0}^{\circ}$

(Q)

Fily. Hs

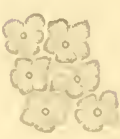

Fig. W

Fily lli

$$
\text { Frig / } 12 x
$$

$\theta \Theta N^{N}{ }^{N}$

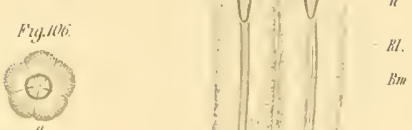

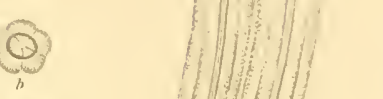

Fiy. II:?
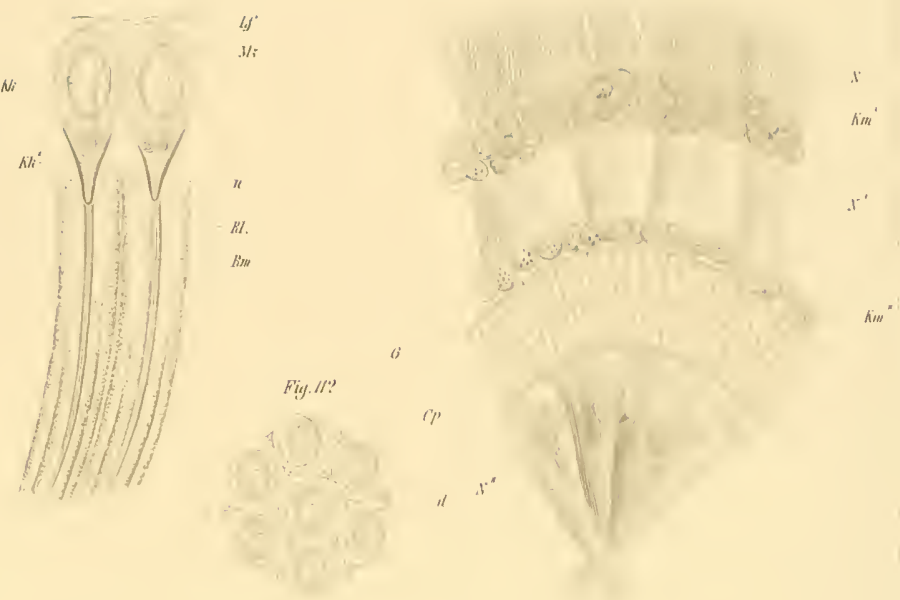
ins"

Fing 11.

Fig 11
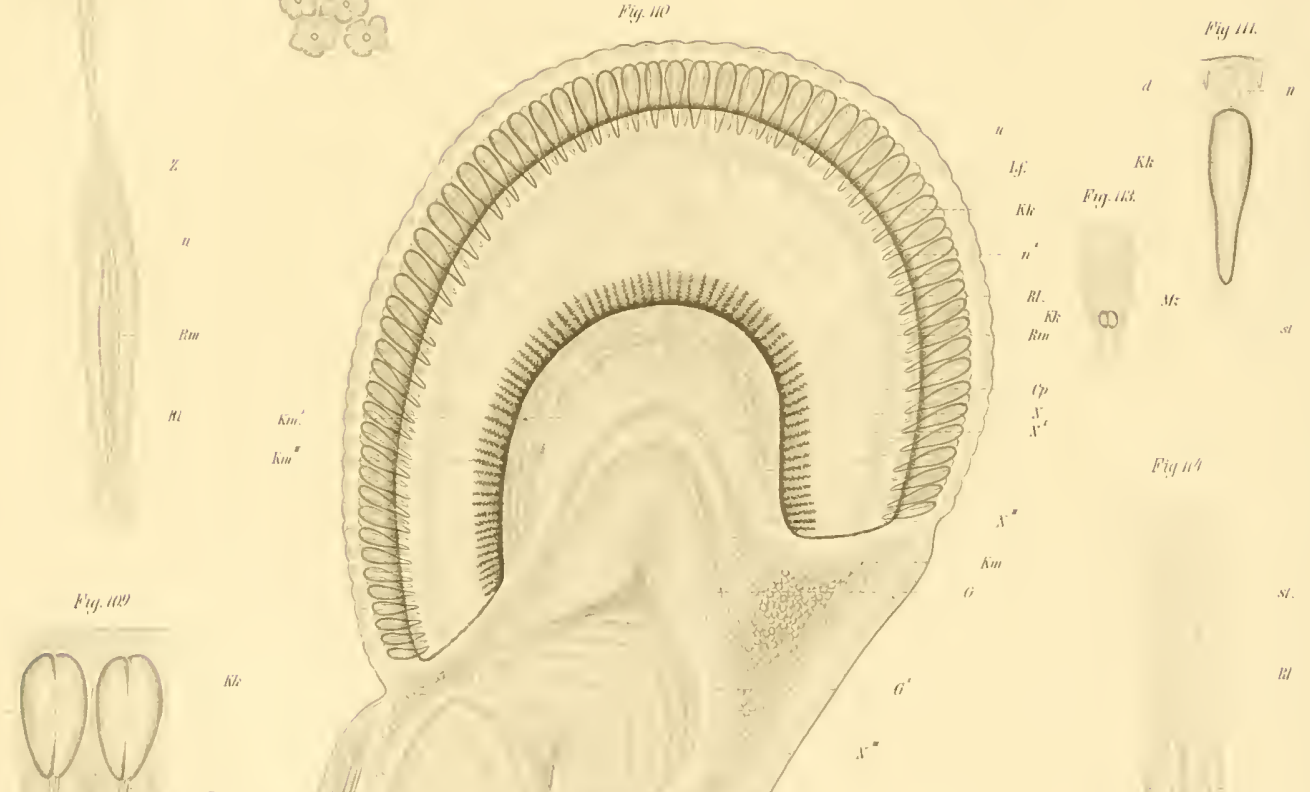

Tandentisack u Rummbi
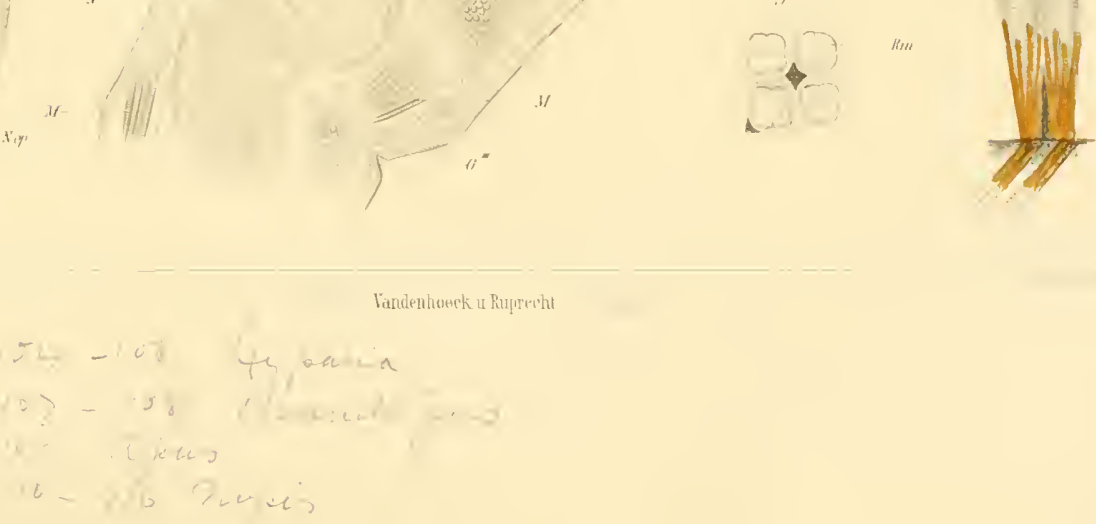

$F^{\prime} y, i$
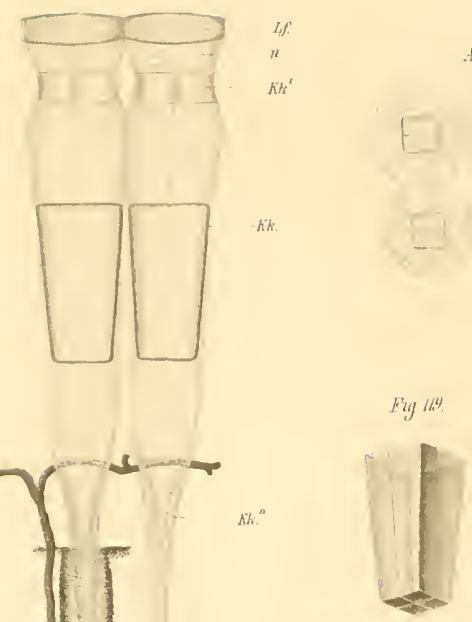

$R t$

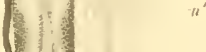

F,

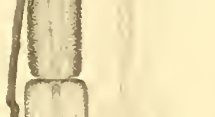

1

1

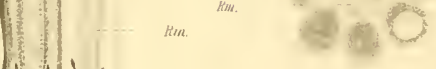

(1) 14,4

$P^{\prime}$

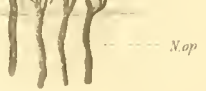

fing I"6

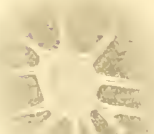

Fig. li:?

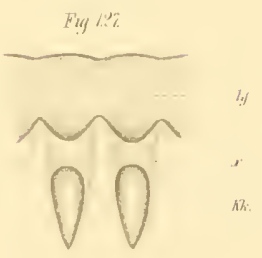

Fig. $/ 1 \%$

Fing $1: ?$

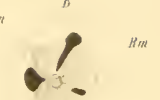

fing $\left(x^{\prime \prime \prime}\right.$

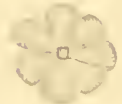

Fig.

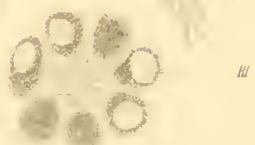

Fig. $1 \% 1$

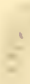

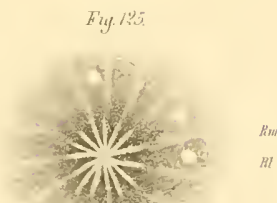

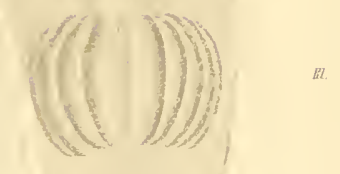








